Aleta-Amirée von Holzen

\title{
Maskierte Helden
}

Zur Doppelidentität in Pulp-Novels und Superheldencomics
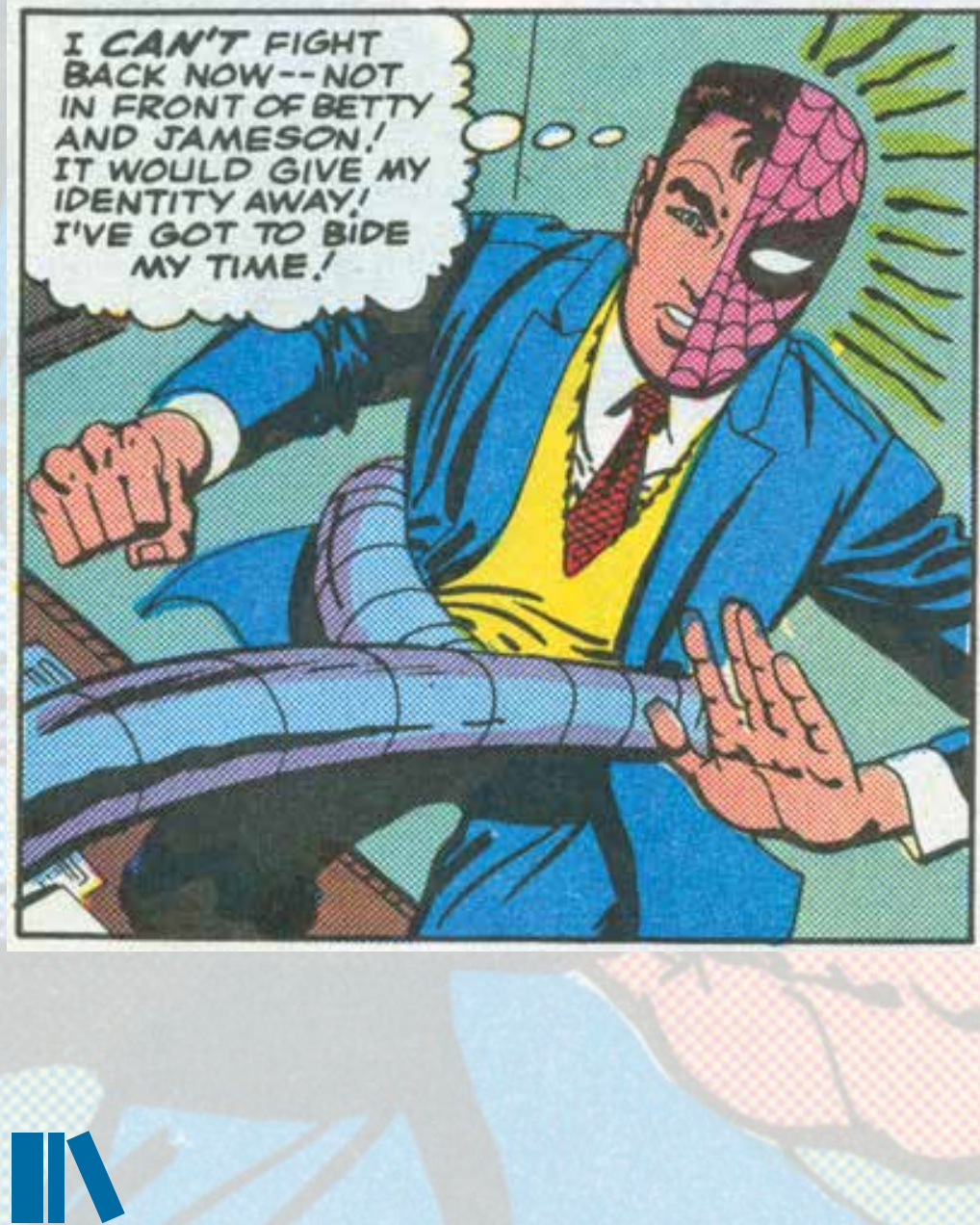

CHRONOS 
Populäre Literaturen und Medien I 3

Herausgegeben von Ingrid Tomkowiak 
Aleta-Amirée von Holzen

\section{Maskierte Helden}

Zur Doppelidentität in Pulp-Novels und Superheldencomics 
Publiziert mit Unterstützung des Schweizerischen Nationalfonds zur Förderung der wissenschaftlichen Forschung.

Die vorliegende Arbeit wurde von der Philosophischen Fakultät der Universität Zürich im Frühjahrssemester 201 8 auf Antrag von Prof. Dr. Ingrid Tomkowiak und Prof. Dr. Klaus Müller-Wille als Dissertation angenommen.

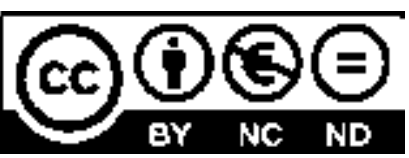

Weitere Informationen zum Verlagsprogramm:

www.chronos-verlag.ch

Umschlagbild: Steve Ditko (Zeichner), Stan Lee (Autor) et al.: «Unmasked by Dr. Octopus», in: Spider-Man Classics Vol. I, No. I 3, April 1994, S. 5 (Nachdruck aus: The Amazing Spider-Man I 2, Mai i 964). (C) Marvel Comics

(C) 2019 Chronos Verlag, Zürich

Print: ISBN 978-3-0340-I 508-0

E-Book (PDF): DOI I0.33057/chronos. I 508 


\section{Inhalt}

$\begin{array}{ll}\text { Einleitung } & 7\end{array}$

$\begin{array}{ll}\text { Maskerade und Geheimnis } & 17\end{array}$

Verbergen und Zeigen - Enthüllung durch Verhüllung I8

Geheimnisbedrohung und -bewahrung: Narrative Koordinaten

der Doppelidentität 30

Masken, Rollen, Identitäten $\quad \mathbf{4 5}$

«Die ganze Welt ist eine Bühne» - die metaphorische Maske 49

Interaktion und Identität, Konformität und Einzigartigkeit $\quad 56$

Interpretationsansätze zur Doppelidentität (der Mann aus Stahl und der unscheinbare Reporter) $\quad 67$

Die zivile Identität als Identifikationshilfe für den Leser $\quad 70$

Der Superheld als Organization Man $\quad 77$

$\begin{array}{ll}\text { Die Frage nach der wahren Identität } & 83\end{array}$

Doppelidentität und Männlichkeitsbilder $\quad 94$

C. G. Jungs Schatten 99

Die maskierten Helden in den Pulp-Novels $\quad 105$

Mit Mantel, Degen und Maske $\quad$ I I 3

Scarlet Pimpernel/Percy Blakeney $\quad$ I I 3

$\begin{array}{ll}\text { Zorro/Diego Vega } & \text { I } 22\end{array}$

$\begin{array}{ll}\text { The Whirlwind/Pedro Garza } & \text { I } 34\end{array}$

Gentleman-Gauner in Grau, Rot und Violett $\quad$ I38

$\begin{array}{ll}\text { Jimmie Dale/The Gray Seal } & \text { I } 38\end{array}$

The Man in Purple/Richard Staegal und The Crimson
Clown/Delton Prouse

Maskierte Verbrechensbekämpfer in der Metropole I $\quad$ I 4

The Shadow und die Schatten der modernen Grossstadt I 54

The Phantom Detective/Richard Curtis Van Loan,

The Spider/Richard Wentworth, The Black Bat/Tony Quinn und

The Green Ghost/George Chance $\quad$ I 70

Maskierte Pulp-Helden und Comic-Superhelden (Zwischenfazit) I95 
Die maskierten Superhelden im Golden Age der Comic-Hefte

Die Verweigerung der Identitätskrise: The Owl/Nick Terry,

The Black Hood/Kip Burland und The Black Terror/Bob Benton

205

Marginal Men? Das geteilte Selbst, der Zeitgeist und die Superhelden

236

Spider-Man/Peter Parker und das proteische Selbst

249

Das proteische Selbst

254

Peter Parker - Spider-Man: «Odd Combinations»

258

Krisen, Bestätigung, Balance

267

Daredevil/Matt Murdock und die stigmatisierten Identitäten

283

Stigma - Passing - Closet

Karussell der Identitäten: Daredevil und Matt (und Mike) Murdock

292

Das offene Geheimnis: «I am (not) Daredevil»

310

Thunderbolts: Mögliche Selbste zwischen Gut und Böse

Possible Selves

Vom Schein zum Sein

Die fortwährende Auseinandersetzung mit möglichen Identitäten

Wie aus Bruce Wayne immer wieder Batman wird -

der multiple Dunkle Ritter und die narrative Identität

Multiplizität durch Serialität: Batmen

Das Streben nach Einheit und Einzigartigkeit: Es kann nur einen geben

Fazit 


\section{Einleitung}

We shall have a noble sport tonight [...];

this masquerade is a most glorious invention.

Palamede in John Drydens Marriage à la Mode, I673

"Let's just say, I could write a bell of a paper on a grown man who dresses like a flying rodent.» "Bats aren't rodents, Dr. Meridian."

Chase Meridian und Batman in Batman Forever (Regie: Joel Schumacher), I995, 5:19-5:27

Verkleidungen und Maskierungen verleihen vielen Abenteuerhandlungen eine zusätzliche Attraktivität. Maskenepisoden können die Spannung steigern, spassige Momente bieten, heimliche Freuden bescheren oder unheimliches Unheil ankünden, bevor die dazugehörige Demaskierung (im Idealfall) in eine Überraschung mündet und für Staunen sorgt. Der Reiz des Maskenmotivs besteht stets in einem Spiel mit dem Sein und Schein von Identität(en). Ein 〈Ausbruch aus dem Alltag> lässt sich üblicherweise mit dem Aufsetzen einer gegenständlichen Maske verbinden, wogegen man in der metaphorischen Rede von Maske meist gerade auf das Aufrechterhalten einer sozialen Rolle, also eher den Alltag, Bezug nimmt.

Gleich beide Formen der Maskerade zu einer Lebensart erhebt der fiktionale Figurentypus des maskierten Helden. Maskierte Helden und Heldinnen ${ }^{1}$ erschaffen sich durch das Tragen einer Maske eine zweite Identität, in der sie ihre Heldentaten vor den Augen der Öffentlichkeit vollbringen, während sie ihr ‘wahres〉 Können in ihrem sozialen Umfeld sorgfältig verbergen bzw. sich sogar als heldenuntauglich inszenieren, um eine <zivile> Identität aufrechtzuerhalten. ${ }^{2}$ Die Maskerade ist bei diesen Figuren keine temporäre Angelegenheit, sie stellt vielmehr einen durch den ständigen Wechsel zwischen zwei (oder mehr) Identitäten geprägten Dauerzustand dar. Geschichten um maskierte Helden schöpfen

I Der Lesefreundlichkeit und Sprachökonomie zuliebe beschränke ich mich in dieser Arbeit auf die Nennung von männlichen Formen, ausdrücklich sind Frauen dabei stets mitgemeint. Obwohl die männlichen maskierten Helden klar in der Überzahl sind, gilt dies insbesondere für den Begriff <maskierter Held).

2 Meyer (20I I, I36) formuliert dies als Charakteristikum des «klassische[n] Superhelden». 
aus der langen Tradition von Maskenmotiven - kehrte doch schon Odysseus von seinen Irrfahrten als Bettler verkleidet heim nach Ithaka. Als populärer Figurentypus präsentiert sich der maskierte Held aber als eine Erscheinung des 20. und 2I. Jahrhunderts. ${ }^{3}$

Unter der Bezeichnung ‘populärer Figurentypus> verstehe ich ein abstraktes Erzählmodell, das aus der Menge einzelner Figuren gespeist wird, die wiederum als Aktualisierungen des Modells gelten können. Solche Typen populärer Figuren erscheinen teils als genreprägende oder genreverkörpernde Figuren (wie der Archäologenabenteurer oder der Cowboy), können teils aber auch davon losgelöst auftreten (wie etwa die Diva oder die Femme fatale). ${ }^{4}$ Gängige Genre- und Subgenrebezeichnungen basieren unter anderem häufig auf der raumzeitlichen Situierung des erzählten Geschehens (zum Beispiel Western, Steampunk) und/oder einer bestimmten Thematik (zum Beispiel Kriminalliteratur, «Romantasy»).5 Hingegen lassen sich populäre Figurentypen als figurenbasierte Erzählstrukturen oder Motive verstehen, die solche üblichen Genretypologien kreuzen und ergänzen. ${ }^{6}$ Literarische Figuren können dabei ähnliche Funktionen wie Genrekonventionen erfüllen, wie Anz erklärt: «Das «Gelingen literarischer Kommunikation über Figuren und im Medium von Figurendarstellungen setzt voraus, dass Autoren die Schemata, die ihre Adressaten bei der Wahrnehmung bestimmter figurenbezogener Informationen aktivieren, partiell kennen bzw. vermuten, dass die Adressaten ähnliche Schemata verinnerlicht haben [...].» Und geradezu passend für den maskierten Helden fügt er an: «Das ist Voraussetzung auch für solche Texte, die solche Schemata thematisieren und sie zur Basis literarisch überaus beliebter Spiele mit sozialen Rollen und personalen Identitäten machen.» ${ }^{7}$ Auf der Ebene inhaltlicher Textkategorien stellen solche Figurentypen wohl eine Art von Motiven dar, die allerdings entgegen den häufig zitierten Motivdefinitionen kaum als «kleinste bedeutungsvolle Einheit» ${ }^{8}$ zu fassen wären. ${ }^{9}$ In der Regel

3 Verschiedene Vorläufer aus der Zeit vor 1900 kommen im Kapitel zu den Pulp-Novels zur Sprache.

4 Das Handbuch Populäre Kulturen beispielsweise versammelt einige solcher Figurentypen unter der nicht näher spezifizierten Bezeichnung «Medien- und Genrefiguren» (Hügel 2003, 2I).

5 Zum Genrebegriff vgl. Müller 2003.

6 Vgl. dazu die Erläuterungen zu literarischen Figuren von Anz 2007, I 26, wenn auch ohne konkreten Bezug zu maskierten Helden. Mit Bezug auf Motive als kulturelle Verständigungshilfen schreiben Ähnliches etwa Daemmrich/Daemmrich 1987, XIf., oder Wulff 20I 2, I6.

7 Anz 2007, I 26.

8 So formuliert etwa Doering 2007 (meine Hervorhebung).

9 Etwas weiter fasst das Motiv etwa die bekannte Definition von Frenzel $(1978,29)$ als «eine kleinere stoffliche Einheit, die zwar noch nicht den ganzen Plot [...] umfasst, aber doch bereits ein inhaltliches, situationsmässiges Element und damit einen Handlungsansatz darstellt». Eine genauere Beschreibung der hier erwähnten populären Figurentypen als Motive wäre ebenso wie 
eng mit auf sie abgestimmten weiteren Motiven, Topoi und Erzählschemata verknüpft, weisen solche Figurentypen oft Verschränkungen mit bestimmten diskursiven Kontexten auf. ${ }^{10}$ Diese können in den konkreten Umsetzungen bloss latent vorhanden sein, nebenbei mitschwingen oder explizit thematisiert werden.

Vor diesem Hintergrund steht die Hauptthese dieser Arbeit: Aufgrund der besonderen Konstruktion des Protagonisten - der Doppelidentität mittels Maske und damit der Vorspiegelung zweier Personen, wo nur eine ist - äussern sich in Erzählungen um maskierte Helden Identitätsvorstellungen des 20. und 2 I. Jahrhunderts. Hinter der vordergründigen Konzentration auf Action transportieren die entsprechenden populärliterarischen Texte $^{\mathrm{II}}$ diese weiter; sie partizipieren, wenn auch vielleicht eher indirekt, an der Etablierung, Verbreitung und Diskussion von Identitätsvorstellungen. Der Maskerade kommt dafür eine zentrale Funktion zu: Sie hinterfragt Identitätskategorien bzw. -kategorisierungen und kann gleichermassen der Identitätskonstruktion wie deren Dekonstruktion dienen.

Als Grundlage meiner Analysen dienen soziologische und sozialpsychologische Identitätstheorien. Der Einbezug dieser Theorien erfüllt in dieser Arbeit zwei Zwecke: Als populäre Unterhaltungsmedien thematisieren Pulp-Novels und Superheldencomics, wie bereits angedeutet, Fragen über und Vorstellungen zu Identität(en) - gerade im Vergleich zu einer wissenschaftlichen Diskussionspraxis - nur indirekt (und ohne etwa Begriffe zu differenzieren oder Konzepte explizit und ausführlich zu beschreiben). Die verwendeten Theorien sollen daher zum einen als Analysewerkzeuge helfen, um die Interpretation dieser Quellen zu schärfen. Zum andern belegen sie zumindest ausschnitthaft, in welche Richtungen das Denken über Identität im 20. Jahrhundert erfolgt ist ${ }^{12}-$ sie stellen

eine allfällige Differenzierung von weniger stark mit einem «Handlungsansatz» verknüpften Typen wie dem Sonderling - den etwa Frenzel (ebd., 30) als Motiv «menschlicher Typen» und Doering (2007) als «Typen-Motiv» erwähnen - allerdings noch zu leisten. Erschwerenderweise prägt den Motivbegriff nach wie vor eine gewisse Schwammigkeit. Vgl. dazu als einen neueren (filmwissenschaftlichen) Beitrag Wulff 20 2, der etwa im «Gesamtkomplex «Zigeuner im Film» einen Stoffkreis sieht, wobei sich Motive wie die Zigeunerprinzessin durch Kondensierung, Komprimierung und Kombination aus «vorgefundene[n]» Stoffen entwickeln (ebd., I4).

Wenn man etwa auch den verrückten Wissenschaftler (Mad Scientist) als populären Figurentypus sieht, besteht eines seiner diskursiven «Erzählknäuel` darin, die Gefahren von Wissenschaft und Fortschrittsglauben in Kombination mit Übereifer oder Hochmut zu thematisieren.

I I Um Missverständnisse auszuschliessen: Ich gehe von einem weiten Textbegriff aus, der nicht nur schriftliterarische Texte, sondern auch Comics, Filme, Videogames etc. umfasst.

I 2 Identität ist allerdings nicht messbar, womit zu erklären sein dürfte, dass in den beigezogenen wissenschaftlichen Disziplinen eine Tendenz zu beobachten ist, Identität dem Denken mithilfe von Metaphern zugänglich zu machen. 
daher die unverzichtbaren Pfeiler dar, um die hier zu untersuchende These zu untermauern.

Da die Maskerade auf Interaktion beruht, erschien es für diese Untersuchung am gewinnbringendsten, Identitätstheorien zu referieren, welche Identität als Phänomen der Interaktion begreifen. Aus diesem Grund kommen hier vor allem soziologische und sozialpsychologische Identitätstheorien zur Sprache, nicht aber psychoanalytische Ansätze. ${ }^{13}$ Zentral sind dabei in einem ersten Schritt Identitätstheorien, die sich der Maske als Metapher bedienen. Insbesondere Erving Goffmans Beschreibung des Individuums als Darsteller in zwischenmenschlichen Interaktionen (in The Presentation of Self in Everyday Life, mit deutschem Titel Wir alle spielen Theater, I959) bietet zahlreiche Anknüpfungspunkte für das Konzept des maskierten Helden.

$\mathrm{Da}$ aber im 20. Jahrhundert die Kategorie Identität vielfältiger Revision unterzogen wurde, ${ }^{14}$ konnte es nicht das Ziel sein, nur auf eine bestimmte Identitätstheorie zu fokussieren. Deshalb werden für die Einzelanalysen maskierter Helden verschiedene weitere Identitätskonzepte herangezogen. Im 20. Jahrhundert wurde dabei die Vorstellung eines fixen, einheitlichen Selbst - je nach Standpunkt - verworfen, überholt oder nur ergänzt durch oft als (post-)modern etikettierte Identitätskonzepte, welche Identität als multipel und prozesshaft denken. Der Frage, wie sich die maskierten Helden in diesem Spannungsfeld positionieren, wird in dieser Arbeit nachgegangen.

Denn die Doppelidentität und damit das Ausleben von zwei (oder mehreren) verschiedenen sozialen Rollen bietet Gelegenheit für das narrative Bespielen verschiedener Identitätsaspekte in Interaktion, seien dies kontrastierende Rollenerwartungen, Identitätskrisen und -bestätigungen, Herausforderungen wie das Alles-unter-einen-Hut-Kriegen, emotionale Zerreissproben und heimliche Triumphe, die sich nur den eingeweihten Figuren und den Lesern erschliessen. $\mathrm{Zu}$ weilen treten diese Elemente nur am Rande auf, zuweilen erhalten sie aber auch narrativen «Eventcharakter».

Inwiefern das diesbezügliche Potenzial des maskierten Helden in der jeweiligen narrativen Umsetzung ausgeschöpft wird, ist unterschiedlich und hängt vor

I 3 Eine Ausnahme bildet ein kurzer Überblick zu C. G. Jungs Konzept des Schattens im Kapitel über die bestehenden Interpretationsansätze zur Doppelidentität.

I 4 Identität wurde vor allem ab dem 20. Jahrhundert vermehrt zum Gegenstand öffentlicher und spezifischer (wissenschaftlicher) Diskurse. Obwohl es in der Philosophie eine lange Tradition gibt, über Identität nachzudenken, hat dazu wohl nicht zuletzt die um die Wende vom I9. zum 20. Jahrhundert erfolgte Institutionalisierung von Psychologie und Soziologie als akademische Wissenschaften beigetragen, die sich ja der Erforschung der menschlichen Psyche, des Verhältnisses zu sich selber und zu anderen widmeten bzw. widmen. 
allem davon ab, wie viel Entfaltungsraum der zivilen Identität und der Relation zwischen dieser und der heldischen Identität eingeräumt wird. Da es sich bei maskierten Helden in der Regel um serielle Charaktere handelt, kann dies im Lauf der Zeit sehr verschieden gehandhabt werden - einerseits kann die Doppelidentität eines Helden gänzlich in den Hintergrund gerückt sein oder werden oder sogar verschwinden (wenn sich der Protagonist öffentlich zu seiner Heldenidentität bekennt), andererseits können «brachliegende> Doppelidentitäten narrativ wiederbelebt werden.

Der maskierte Held manifestiert sich zweifellos am häufigsten in der Gestalt von Superhelden. Im Superhelden-Kontext wird die Doppelidentität häufig mit der Bezeichnung secret identity erfasst, die von den Comics selbst verwendet wird und Teil des Fanjargons ist. Secret identity wird oft mit ziviler Identität gleichgesetzt, dies führt aber zu einer inhaltlichen Verwirrung, da nicht eine der beiden Identitäten - die zivile oder die heldische - geheim ist, sondern die Einheit zwischen diesen beiden Hälften (worauf ich im Kapitel zu Maskerade und Identität zurückkomme). ${ }^{\text {Is }}$ Deshalb und weil die Comics in ihrer Verwendung von secret identity schwanken (gemeint ist von beiden möglichen Standpunkten aus die jeweils andere Hälfte), ziehe ich die Bezeichnung zivile Identität vor.

Die enge Verbindung von Superheld und Doppelidentität betont etwa Richard Harrison, wenn er anhand von Superman vorschlägt, ein Genre secret identity fiction zu denken: «[...] Clark Kent isn't the secret identity in a heroic fiction that stars Superman - Superman is the hero in a secret identity fiction that stars Clark Kent. If we can think of the superhero comic as a genre defined by something other than the fantastic powers of its protagonists, it's as a literature of the secret identity [...].» ${ }^{16}$ Obwohl es zwischen Super- und maskierten Helden eine grosse Schnittmenge gibt, ${ }^{17}$ sind die beiden Konzepte nicht deckungsgleich. ${ }^{18}$ Denn zum einen gibt es viele Superhelden ohne Maske (wie die Fantastic Four oder einige der X-Men des Marvel-Verlags), zum andern ist der maskierte

Is Vgl. Morris 2008, 254, sowie Harrison in Easton/Harrison 2010, 277, 339.

I6 Harrison in Easton/Harrison 2010, 277 (Hervorhebung im Original). Allerdings gäbe es unter der Bezeichnung secret identity fiction noch weitere Verwandte des maskierten Helden zu betrachten - von Spionen/Agenten über Gentleman-Gauner bis zu «zweigesichtigen〉 fantastischen Figuren wie Vampiren, Werwölfen oder Feen (je nach Umsetzung), Stars (z. B. in der TV-Serie Hannab Montana, 2006-20 I I), digitalen Identitäten (Avataren) und nicht zuletzt Crossdressing- und Racial-Passing-Figuren.

I7 So beobachten etwa auch Söll/Weltzien (2003, 298), «dass das Genre der Superhelden durchaus unscharf begrenzt ist und zahlreiche Übergänge zu andern Gattungen bietet», "wenn das Motiv der Maskerade als leitendes Kriterium der Definition dient».

I 8 Ein weiterer Begriff, der sich nur schwer vom maskierten Helden trennen lässt, ist «Masked Avenger», den etwa die Encyclopedia of Fantasy für die hier besprochenen Figuren wählt (Westfahl I997, 629). 
Held einer jener Figurentypen, die nicht an eine bestimmte Situierung gebunden sind. Tatsächlich wird der Figurentypus im Mantel-und-Degen-Roman und im Krimi (im weitesten Sinn) etabliert, bevor er mit den Superheldencomics in fantastische Gefilde rückte. Der maskierte Held ist nach wie vor ohne Weiteres in anderen Situierungen denkbar, wobei hier zumindest die maskierten Westernhelden, wie The Lone Ranger oder The Masked Rider, zu nennen sind. ${ }^{19}$

Trotz aller Veränderungen im Lauf der Zeit zeigt der Figurentypus des maskierten Helden eine erstaunliche Konstanz. Da ein Nebenziel dieser Arbeit ist, die Genese des maskierten Helden nachzuzeichnen, wird den Superheldenvorläufern in den Pulp-Novels - den US-Groschenromanen der i93oer- und i940erJahre - einige Aufmerksamkeit geschenkt. Dies erscheint umso nötiger, weil die Pulp-Novels ausserhalb des Science-Fiction-Bereichs relativ wenig wissenschaftliche Aufmerksamkeit erhalten haben. So werden namentlich The Scarlet Pimpernel, Zorro und Jimmie Dale, die den maskierten Helden <einführen>, gesondert betrachtet, bevor dieser durch die zahlreichen Umsetzungen in den Pulp-Thrillern und Krimis vor allem als Detektiv erst zu einem Figurentypus wird. In der Analyse der Pulps beschränke ich mich darauf, die Charaktere mit Goffmans Konzept des Darstellers abzugleichen, verzichte aber auf den Einbezug einer zusätzlichen Identitätstheorie. Stattdessen erfolgt in Bezug auf The Shadow eine Kontextualisierung mit New York als idealtypischer grossstädtischer Metropole.

Für die Analysekapitel war aufgrund der Fülle des vorhandenen Materials letztlich eine Beschränkung auf eine vergleichsweise kleine Anzahl von maskierten Helden nötig. Dabei war mir eine Kombination von sehr erfolgreichen und entsprechend bekannten mit weniger berühmten oder in Vergessenheit geratenen Charakteren ein Anliegen. Die Auswahl der konkreten Beispiele gleitet gewissermassen durch einen Flaschenhals: Für die Pulps und die Golden-Age-Comics habe ich mehr in die Breite gelesen, da viele Figuren dieser Quellengruppen relativ kurzlebige Gestalten waren. Ab dem Silver Age der Superheldencomics (ab I956) habe ich mehr Wert auf den Zeitfaktor gelegt und auf vier ausgewählte, aber langlebigere Beispiele fokussiert.

I9 Da deren Doppelidentität meist als eher leeres Motiv erscheint, werden sie hier von der Betrachtung ausgeschlossen. Am vielversprechendsten wäre diesbezüglich noch The Masked Rider (1934-I953 als Titelheld von Masked Rider Western (Magazine) einer der langlebigsten Pulp-Helden überhaupt), der in Zivil als Wayne Morgan auftritt, was freilich ein Deckname ist; seine ‘angestammte> Identität bleibt unbekannt. Wie The Lone Ranger und Tonto reitet aber auch The Masked Rider mit seinem Begleiter Blue Hawk in jedem Abenteuer an einen neuen Ort, sodass das Tragen einer Maske, um nicht erkannt zu werden, wenig zwingend scheint. $\mathrm{Zu}$ den maskierten Helden in Western-Pulps vgl. Carr 1989, Dinan 1983, 36-46, und DeForest 2004, I 50-I 56. 
Der Aufbau dieser Untersuchung gestaltet sich wie folgt: In den nächsten beiden Kapiteln wird das theoretische Fundament gelegt. Dazu werden zunächst die narrativen 〈Koordinaten〉 des maskierten Helden abgesteckt, aufbauend auf (gegenständlicher) Maskerade und Geheimnis als Formen sozialer Interaktion. Das Kapitel Masken, Rollen, Identitäten befasst sich mit Identitätsvorstellungen, die von der Metapher der Maske Gebrauch machen. Zum einen fallen hier drei Schlaglichter auf historische philosophische Ansätze, zum andern werden Goffmans Theatermetapher bzw. sein Akteur/Darsteller erläutert. Im anschliessenden Kapitel erfolgt am Beispiel von Superman/Clark Kent eine Auseinandersetzung mit bisherigen Forschungsansätzen zur superheldischen Doppelidentität. Im darauffolgenden Analyseteil werden in den Kapiteln zu den maskierten Helden in Pulp-Novels und im Golden Age der Superheldencomics jeweils mehrere Figuren in den Blick genommen. Zum einen wird die Entwicklung des maskierten Helden im Medium der Pulp-Novel ausführlich verfolgt. Zum andern wird die Darstellung im Golden Age der Superheldencomics näher betrachtet, wobei diese schliesslich in Bezug zu bestehenden Interpretationen zu den Entstehungshintergründen der Superhelden und, damit verknüpft, zu Robert Ezra Parks Konzept des marginal man gesetzt werden.

Die folgenden vier Kapitel stellen das Herzstück dieser Arbeit dar und bieten jeweils auf eine bestimmte Identitätstheorie und einen bestimmten Charakter fokussierte Einzelanalysen über relativ lange Zeiträume hinweg. Spider-Man/ Peter Parker wird anhand des protean self analysiert, Daredevil/Matt Murdock im Rahmen von stigmatisierten Identitäten interpretiert, die Thunderbolts werden mit den possible selves gelesen, und Batman/Bruce Wayne wird als Verkörperung narrativer Identität betrachtet. Schliesslich präsentiert ein Fazit übergreifende Resultate der einzelnen Analysen.

Die einzelnen Kapitel sind jeweils so aufgebaut, dass zu Beginn ein mehr oder weniger kurzer 〈Vorspann> in die Produktions- und Publikationskontexte des untersuchten Materials einführt. Auch wenn visuelle Aspekte bzw. Bild-TextRelationen in den folgenden Erläuterungen weitgehend ausgeblendet werden mussten, um den Fokus auf das gewählte Thema nicht zu zerstreuen, sollen die zahlreichen Abbildungen einen Eindruck der Umsetzung in Text und Bild vermitteln. 


\section{Anmerkungen zur Verfügbarkeit des Primärmaterials und zur Zitierweise}

Diese Arbeit befasst sich mit Pulp-Novels und Comic-Heften - beides sind Formen populärer Lesestoffe, die früher klar im Hinblick auf Vergänglichkeit publiziert wurden. Erst nachdem die Pulps in den I950er-Jahren fast ganz aus den Kiosken verschwunden waren und sich nochmals fast zwei Jahrzehnte später Comic-Shops zu etablieren begonnen hatten, erfolgte hier ein Umdenken. Aufgrund verschiedener Besonderheiten widerstreben Pulps und Comics den üblichen akademischen Zitier- und Bibliografiersystemen. Daher sind hier einige Erläuterungen zu meiner Zitierweise nötig.

$\mathrm{Da}$ es sich bei den Pulp-Novels und den frühen Comics um serielle, fliessbandmässig> produzierte Werke handelt, ist oft nur schon die Benennung der Autorschaft ein Problem: In den Pulps war es gängig, Pseudonyme und house names zu verwenden. Dasselbe gilt für Golden-Age-Comics, dort weisen Geschichten manchmal gar keine Verfasserangabe auf, oder es wird nur ein Name angegeben, obwohl es sich oft um kollaborativ verfasste Werke handelt. Da nicht alle Pseudonyme so offensichtlich sind wie die Verfasserangabe von The Ray $\left(\right.$ E. Lectron $\left.{ }^{20}\right)$, ist in einzelnen Fällen unklar, ob es sich um ein Pseudonym oder einen authentischen Namen handelt. Die Forschung und freiwillige Archivare bzw. Fans haben hier schon sehr viel geleistet, Hunderte Pseudonyme aufgelöst und Werke zugeordnet (zum Beispiel in der Grand Comics Database). Dennoch bleiben einige Identifizierungen spekulativ. Aus diesem Grund habe ich jeweils den gedruckten Namen als Verweis angegeben; ist klar, wer hinter dem Pseudonym steckt, wird dies im Text oder in Klammern genannt. ${ }^{21}$ Im Lauf der Jahre wurde es in den Comics üblich, alle Beteiligten aufzuführen - Autor (writer), Zeichner (penciller), Tuscher (inker), Koloristen, Letterer etc. Da dies erstens jede Bibliografie sprengte und zweitens die Kreativteams theoretisch bei jedem Heft wechseln können, erfolgen in der Bibliografie Sammeleinträge nach Hefttitel. Die Verfasser zitierter Werke werden in den Fussnoten aufgeführt, wobei die Angaben auf Autor, Zeichner und Inker (falls vorhanden) beschränkt werden. Zur Zitierweise der Comics ist anzumerken, dass Comics prinzipiell nur Kapitale verwenden, was hier nicht übernommen wird; die Fettschreibung betonter Stellen wird durch Kursivdruck ersetzt.

20 The Ray alias Reporter Happy Terrill erschien in Smash Comics I4-40 (1940-1943, Quality Comics). Hinter «E. Lectron» verbargen sich u. a. die Zeichner Lou Fine und Reed Crandall.

2 I Sind Zuordnungen auch in einschlägigen Verzeichnissen wie der Grand Comics Database als unsicher gekennzeichnet, stehen sie in eckigen Klammern. 
Eine weitere Herausforderung ergibt sich daraus, dass viele der hier besprochenen Produkte nur schwer in Originalausgaben erhältlich sind. So muss man sich (wie bei vielen anderen Quellen) auf Neuausgaben und Sammelbände verlassen, von welchen die meisten keine Faksimiles sind. Eine Geschichte kann so in verschiedenen Ausgaben zugänglich sein: Der Verlag DC etwa publizierte eine ledergebundene Golden Age Archives-Reihe (Faksimilenachdrucke der gesamten Hefte) ebenso wie die erschwinglichere Chronicles-Reihe (jede Geschichte von zum Beispiel Batman in der publizierten Reihenfolge); Konkurrent Marvel produzierte schwarz-weiss gehaltene Essential-Bände und opulentere Marvel Masterworks- bzw. Omnibus-Ausgaben. Heute werden ausserdem digitale Ausgaben immer wichtiger. So konnten einzelne Pulps nur in digitaler Form aufgetrieben werden, obwohl insbesondere der Verlag Altus Press mit Pulp-Sammelbänden in den letzten Jahren die Sache um einiges einfacher gemacht hat. Für die Golden-Age-Comics habe ich auf das Digital Comics Museum zurückgegriffen, für das zahlreiche private Sammler ihre Bestände von inzwischen gemeinfreien Heften gescannt und so zugänglich gemacht haben. Wer aber mehr als nur die ersten paar Geschichten eines DC- oder Marvel-Superhelden lesen will, muss ebenfalls auf das Internet zurückgreifen, wo die beiden Verlage ihre Bestände nach und nach zugänglich machen. Allerdings wird hier meist das ursprüngliche Impressum mit neuen Angaben (mit angepasstem Copyright-Jahr) überdeckt, sodass die ursprünglichen Publikationsdaten wie die Jahreszahlen nicht mehr ersichtlich sind. ${ }^{22}$

Unter diesen Umständen habe ich es für besser befunden, in den Fussnoten wie in der Bibliografie auf die Angaben zu den von mir konkret verwendeten Varianten zu verzichten und stattdessen alle Informationen zur Wiederauffindung der zitierten Stellen in verschiedenen Ausgaben aufzuführen. ${ }^{23}$ Bei den Pulps ergänze ich dazu insbesondere die Kapitelnummer. Bei den Comics nenne ich jeweils den Innentitel der Geschichte (und nicht den Covertitel).

In Bezug auf digitale Ausgaben verlieren zudem Seitenzahlen ihren Sinn. Hinzu kommt, dass auch neuere Comic-Hefte und als Graphic Novels verkaufte Sammelbände, wohl aus künstlerischen Gründen, auf Seitenzahlen verzichten. Weist

22 Ich werde jeweils die sogenannten cover dates angeben; dazu muss man wissen, dass Comics und Pulps schon ein bis zwei Monate vor dem aufgedruckten Monat distribuiert wurden bzw. werden.

23 Tatsächlich gibt es bei verschiedenen Neuauflagen mitunter Unterschiede - so entspricht der Nachdruck der allerersten Batman-Story in Batman in the Forties (2004) wohl eher der Originalversion als die Variante in Batman Chronicles I (2005), die klar retuschiert wurde (die Tuschlinien wurden verbessert und die Panels neu koloriert). Für meine Arbeit sind solche Unterschiede jedoch unbedeutend. 
ein von mir benutzter Comic keine Seitenzahlen auf, werden auch keine angegeben, da es sich jeweils um Geschichten von wenigen Seiten Umfang handelt. Im Zweifelsfall bezieht sich die Seitenzahl auf die Paginierung der einzelnen Geschichte und nicht auf jene einer Sammelausgabe - in Einzelfällen (den frühesten Superman-Comics) handelt es sich dabei um die Panelnummerierung. Bei den Pulps habe ich die Seiten der von mir benutzten Nachdrucke angegeben. In digitalen Ausgaben lassen sich Zitate wohl problemlos per Wortsuche auffinden, aber die Angabe soll ja auch überprüfbar sein, wenn man eine materielle Ausgabe zur Hand hat. - Die Sekundärliteratur dagegen habe ich auf übliche Weise zitiert und bibliografiert. 


\section{Maskerade und Geheimnis}

The mask only covers the face, not the heart. Mike Grell: Batman - Masque, 1996

"Why don't you just give up?»

"Because I know your secret. I know whose face is behind that mask."

"We all wear masks, Spider-Man. But which one is real?

The one that hides your face, or the one that is yourface?»

Spider-Man und Green Goblin in

The Spectacular Spider-Man (SoI Eog), 2008

Jede Sache hat zwei Seiten. Aber erst wenn $d u$ erkennst, dass es drei sind, hast $d u$ sie verstanden. Schülerspruch

Wie der Name sagt, definiert sich der maskierte Held als narratives Modell, als Figurentyp, über einen bestimmten Gegenstand, die Maske - genauer über deren Gebrauch, das Tragen einer Maske. ${ }^{\mathrm{I}}$ Da darin einige wiederkehrende Motive und narrative Elemente wurzeln, die sich um die Figur des maskierten Helden winden, sind zunächst einige grundlegende Aspekte der Maske und Maskerade (des Agierens mit einer Maske) zu erläutern, die in einem engen Zusammenhang mit dem Geheimnis stehen.

«Eine Maske tragen» - diese Formulierung kann sich genauso gut auf eine gegenständliche Form beziehen wie nur metaphorisch gemeint sein. Maskierte Helden kennzeichnet, dass sie Ersteres tun und Letzteres nicht lassen. Tragen sie in der öffentlichen Heldenrolle eine dingliche Maske, kommt in ihrem Alltag, in dem sie ihr Heldentum geheimhalten, die metaphorische Variante zum Zug. Obschon in der folgenden theoretischen Annäherung an die Maske die gegenständliche Form als Ausgangspunkt dient, lassen sich die beiden Formen, so klar man sie unterscheiden zu können meint, oft nicht scharf trennen. Wie man es auch dreht und wendet: Die Maske hat stets zwei Seiten, wie Richard Weihe in

I Einige Inhalte dieses Kapitels habe ich bereits in zwei früheren Aufsätzen dargelegt (von Holzen 20I I und 20I2a). 
seiner umfassenden Theorie der Maske als Form betont. ${ }^{2}$ Die Maske des maskierten Helden - diese pleonastische Formulierung ist zuweilen nicht zu umgehen - stellt zwar in gewisser Weise eine Masken-Sonderform dar, doch treffen auf sie durchaus Merkmale anderer Maskenarten zu. ${ }^{3}$

\section{Verbergen und Zeigen - Enthüllung durch Verhüllung}

Die Maske verbirgt nicht irgendetwas, sondern das individuelle menschliche Gesicht $^{4}$, gewissermassen das primäre Identifikationsmerkmal, das die Unverwechselbarkeit eines Menschen und damit auch dessen Wiedererkennbarkeit garantiert (Phänomene wie Zwillinge und von Auge nicht erkennbare Identifikatoren wie Fingerabdrücke oder DNA einmal ausgenommen). Als Gesichtsabdeckung verbirgt die Maske also die Identität ihres Trägers und spiegelt manchmal eine andere vor.' Maskerade hängt daher stets mit Identität bzw. deren Verschleierung zusammen. Wenn Reinhard Olschanski pointiert erklärt, die Maske sei «das Ding gewordene Geheimnis» ${ }^{6}$, lässt sich dies spezifizieren als Geheimnis um Identität. So betont auch Werner Mezger in Bezug auf Karnevalsmasken: «Das entscheidende Faszinosum der Maskierung war und ist das Spiel mit der Identität.»

2 Weihe 2004, I3, 44 .

3 In der einschlägigen Literatur finden sich verschiedene Maskentypologisierungen (vgl. Weihe 2004, 27I). Olschanski (200I) etwa diskutiert Schreckmasken, «Masken der Gefahr» (Arbeits-/ Schutzmasken) und «Masken der Gewalt», wobei die Heldenmaske Züge aller dieser trägt. Für diese weniger von Bedeutung sind u. a. Totenmasken (dazu ebd., 80-84; Weihe 2004, 20f.) und <ethnografische), auch schamanistische Masken (dazu z. B. Ebeling I987, 9-59). Die mir bekannten theoretischen Beschäftigungen mit Masken (v. a. aus Philosophie, Soziologie, Ethnologie, Volkskunde, Literaturwissenschaften, Theaterwissenschaft, Kunstgeschichte) haben sich bisher nicht mit der spezifischen, bis vor wenigen Jahren nur im Fiktionalen existierenden Heldenmaske, um die es hier geht, befasst. Hingegen stützen sich die Comic- bzw. Filmanalysen von Brownie/Graydon 2016 unter dem Fokus Kostüm-Kleidung-Mode und Sitz 2015 für Superheldenfilme auch auf allgemeine Ansätze zur Maskerade.

4 Zur Relation von Maske und Gesicht vgl. Weihe 2004, bes. I7, 49-76, Olschanski 200 I, ferner Sitz 2015, 2 I 8.

5 Weihe 2004, I8.

6 Olschanski 200I, 45. Schon Caillois (I982 (I958), I48) sprach von der Maske als «Zeichen des Geheimnisses».

7 Mezger 2000, I 25. (Mezger bezieht hier Stellung gegen oft wieder-, jedoch überholte Erklärungsversuche von Karneval und Fasnacht als Überbleibsel heidnischer Glaubensvorstellungen, etwa «Wotans Wildem Heer».) Dazu befand bereits Caillois (I982 (I958), 30): «Das Vergnügen [der spielerischen Maske] besteht darin, dass man ein anderer ist oder für einen anderen gehalten wird.» 
Durch das Verbergen der Identität, das die prinzipielle Austauschbarkeit des Maskenträgers beinhaltet, schafft die Maske Uneindeutigkeit: Wer unter bzw. hinter der Maske steckt, ist für den Nichteingeweihten ungewiss - ganz so wie beim Geheimnis der Nichteingeweihte, der allerdings von dessen Existenz weiss, nie sicher sein kann, was dessen Inhalt alles umfasst und ob es ihn nicht doch betrifft. ${ }^{8}$ Wer seine Umwelt dergestalt «erheblich zu verunsichern» vermag, «gewinnt dadurch eine nicht zu unterschätzende Macht über sie», schreibt Mezger. ${ }^{9}$ Ein Maskierter unterwirft sich a priori nicht der Macht anderer, denn durch die Anonymität entzieht er sich der Rechtfertigung und der Belangbarkeit für sein Handeln. So behält der Masken- und damit Geheimnisträger für sein Gegenüber - selbst bei etablierten maskierten Heldenidentitäten - stets einen Rest an Unberechenbarkeit. ${ }^{\text {IO }}$

Ihre Funktion erhält die Maske als Gegenstand erst, wenn sie von jemandem getragen wird. ${ }^{\text {II }}$ Abgesehen von reinen Arbeits- und Schutzmasken, bedürfen Maske und Maskenträger laut Weihe eines Publikums als dritter Komponente, um das der Maske inhärente Dreiecksverhältnis zu vervollständigen. Die Maske erhält ihren Sinn so erst in der Interaktion; Maskerade bedeutet - stärker noch als Kleidung im Allgemeinen - stets einen performativen Akt. ${ }^{{ }^{2}}$ Einerseits ist der Zweck der Maske das Verbergen, andererseits ist ihr zugleich die Funktion des Zeigens von etwas immanent, wie Weihe ausführt. Zumindest zeigt sie, dass sie etwas verbirgt, und impliziert, dass es ein «Dahinter» gibt. ${ }^{13}$ Für ihren Träger hat die Maske in erster Linie eine Schutzfunktion. Doch wie Olschanski für die von ihm so genannten «Masken der Gewalt» erläutert, antizipiert die Schutzstrategie mögliche Aktionen des Gegners und signalisiert gerade dadurch eigene Angriffsflächen, besonders verwundbare Stellen. ${ }^{\mathrm{I}}$

Dies lässt sich auf das Geheimnis des maskierten Helden übertragen: Die Maske schützt und exponiert die Doppelidentität ihres heldischen Trägers gleichermassen, da sie durch das Verbergen geradezu ausstellt, dass diese existiert, wie etwa

8 Schirrmeister 2004, I I und 32.

9 Mezger 2000, I 25. Grundlage dieser «Macht» ist Wissen, vgl. Schirrmeister (2004, 2): «Das zu wissen, von dem der andere nichts weiss, erzeugt wissende Überlegenheit, [...] Handlungsvorteile und Macht.»

Io Vgl. Weihe 2004, 47: «Die Ungewissheit des Betrachters bei der Konfrontation mit dem Undurchdringlichen und der Ambivalenz der Maske ist ihr eigentliches Kapital.»

I I Ebd., I 4. Weihe geht von den ursprünglich gegenständlichen Masken des antiken Theaters bzw. allgemein Masken als Kommunikationsmitteln aus.

I2 Weihe 2004, 60.

I 3 Ebd., I7. Vgl. auch Olschanski 200I, 46; Ebeling 1987, I73.

I4 Olschanski 200I, 75. Als «Masken der Gewalt» fasst Olschanski Masken, die «Teil einer Auseinandersetzung mit andern» sind (ebd.); als konkrete Beispiele (des «modernen Kriegs») nennt er Gas- oder Strahlungsmasken. 
Thomas Nehrlich für die Superhelden erläutert: «Anders als die Larve des gemeinen Kriminellen hat die Maske des Superhelden keine Täuschungs-, sondern im Gegensatz eine indexikalische Funktion: als Hinweis auf beide Rollen seiner Identität. Dadurch werden Maske und Wesen des Superhelden untrennbar.» ${ }^{\text {is }}$ Die Schutzfunktion wird in den Geschichten um maskierte Helden am häufigsten als Erklärung für die Notwendigkeit der Maske bzw. des Geheimnisses um die Doppelidentität geboten: Würde der Held als sozial integrierte Person auftreten, würde er durch die Bedrohung seines Umfelds erpressbar (etwa indem er zu Inaktivität oder zu Handlangerdiensten für den Schurken gezwungen würde, um Schaden von seinen Freunden abzuwenden). ${ }^{16} \mathrm{Um}$ nur das wohl bis heute eindrucksvollste tragische Beispiel zu nennen: In The Amazing Spider-Man I I (1973) wird Peter Parkers Geliebte Gwen Stacy vom Green Goblin entführt, weil dieser weiss, dass Peter Parker Spider-Man ist - durch die Androhung ihres Todes will er SpiderMan zwingen, sich von ihm töten zu lassen. Die Aktion führt trotz Spider-Mans verzweifeltem Rettungsversuch zu Gwens schockierendem Tod. ${ }^{17}$ Die Doppelidentität des Helden zu kennen, scheint häufig ein Machtfaktor zu sein, was allerdings im Lauf der Geschichten oft wieder ausgehebelt wird.

Je nach Ausgestaltung deckt die Maske das Gesicht in unterschiedlichem Ausmass ab, von der Vollmaske über die Halbmaske bis zur nur gerade die Augenpartie bedeckenden Dominomaske. Nur in seltenen Fällen tragen maskierte Helden Schutzmasken im eigentlichen Sinne - solche Ausnahmen stellen etwa die Golden-Age-Figuren The Sandman/Wesley Dodds mit seiner Gasmaske (ab 1939 in Adventure Comics) und The Human Bomb/Roy Lincoln (in Police Comics I-58, I94I-1946) mit seinem Bombenschutzanzug ${ }^{18}$ dar. Wenn die Protagonisten der hier betrachteten Werke nur einen ‘Hauch von Maske〉 tragen, ist es in den einzelnen Geschichten reine Konvention, dass sie nicht erkannt werden. Solche Masken, wie sie etwa The Black Terror, The Green Arrow, The Huntress und nach Robins Vorbild viele Sidekicks verwenden, werden zum blossen äusseren Zeichen der Nichterkennbarkeit, ohne dass sie diese tatsächlich gewährleisten würden. ${ }^{19} \mathrm{Da}$ maskierte Helden anscheinend niemals Hautunreinheiten,

Is Nehrlich 2013, I27; vgl. Brownie/Graydon 2016, I.

I6 Etwas kurzsichtig argumentiert etwa Fingeroth $(2008,52)$ unter Verweis auf die Polizeiuniform, diese Erklärung sei hanebüchen; Brownie/Graydon (2016,39) dagegen sehen darin die moralische Rechtfertigung der Heldenmaskerade. Allerdings haben viele Superhelden ohne Doppelidentität dieses Problem nicht.

I7 The Night Gwen Stacy Died (Gerry Conway, Gil Kane, John Romita et al.), in: The Amazing Spider-Man I 2 I, Juni 1973.

I 8 Roy Lincolns Anzug schützt nicht nur seine Identität, sondern auch seinen Körper vor den Effekten seiner Superkraft, da alles, was er mit blossen Händen berührt, explodiert.

I9 Vgl. Fingeroth 2008, 58, zur zeichnerischen Umsetzung Nehrlich 2013, I 24 f. 
Sommersprossen, signifikante Kinnformen geschweige denn eine individuelle Iris haben, muss Samuel Taylor Coleridges oft zitierte willing suspension of disbelief $^{2 \circ}$ wiederholt ihre Wirkung entfalten; Roger Caillois schilderte einen ähnlichen «Kontrakt» zwischen dem Maskenträger und dem Zuschauer als einer Art Komplizen als Grundlage jeden Maskenspiels. ${ }^{21}$

Aufgrund dieser lange Zeit unverbrüchlichen narrativen Gesetzmässigkeit scheint es hier müssig, diese Grade der Maskierung zu unterscheiden. ${ }^{22}$ Während in den Pulp-Novels die Maske häufiger das einzige extravagante Kleidungsstück des Helden war, ist sie bei den Superhelden üblicherweise Teil eines Kostüms, sodass Maske und Kostüm in diesem Buch als Einheit aufgefasst werden. Denn wie Weihe festhält: «Doch im Sinne eines pars pro toto meint die Maske nicht nur das Objekt, der Begriff impliziert auch die Accessoires dieses anderen $<\mathrm{Ge}$ sichts', das Kostüm, eine andere Haltung, ein anderes Gehabe.»²3

Das heldische Outfit ist in der Regel von etwas inspiriert, was mit den Kräften, der Motivation oder dem Handeln des Protagonisten eng verbunden ist. Das Kostüm bringt sozusagen die ihn bezeichnende Eigenschaft in ikonisch einprägsamer Weise auf den Punkt. Besonders bei tierischen Namensgebern gibt es oft totemistische Anklänge. Unter dem Gesichtspunkt der Zeichenhaftigkeit könnte man aufgrund ihrer Namen bzw. Kostüme den meisten Helden unterstellen, dass sie letztlich als wandelnde Metaphern interpretierbar sind. Doch im Gegensatz zu zeitlich begrenzten Verkleidungen für gesellschaftliche Anlässe wie Maskenball, Karneval oder Halloween soll das Heldenkostüm keineswegs vorgeben, jemand oder etwas anderes zu sein ${ }^{24}$ - vielmehr verweist es letztlich auf sich selbst. ${ }^{25}$ Dies verdeutlichen insbesondere auch die das Kostüm schmückenden Embleme. Seien es Bruce Waynes Fledermausmantel und -signet, Barry

$20 \mathrm{Vgl}$. dazu z. B. Spiegel 2007, 5of.

2 I Caillois I982, 3 If., dazu auch Mahler 1995, i 18.

22 Vgl. aber Weihe 2004, 220: «Nur die Ganzmaske kann als soziale und politische Metapher die Vorstellung einer doppelten Fassade vermitteln, die Halbmaske ist ein [...] markantes Symbol für die paradoxe Doppelnatur der Persona.» Caillois (I982 (I958), I48) spricht von der Halbmaske als «abstrakter Maske», sie sei «Attribut des galanten Festes und der Verschwörung» und «Symbol der amourösen oder politischen Intrige». Auch die Halbmaske steht somit in einem ordnungsunterwandernden Kontext und ist von daher prinzipiell suspekt.

23 Weihe 2004, I7. Eine allgemeine Differenzierung von Maske und Kostüm bietet Deger (2000, I87f.); unter dem Fokus des Kostüms statt der Maske setzen sich Brownie/Graydon 2016 mit den Superhelden auseinander.

24 Genau genommen transportieren etwa Karnevalsmaskeraden durch den klaren Spielcharakter meist ebenfalls keine andere Identität, sondern werden als Verkleidung (sei es als Piratin, Prinz oder Panda) wahrgenommen. Anders ausgedrückt, sagt das Karnevalskostüm in der Regel: «Ich bin X, die sich als Y verkleidet hat», das Superheldenkostüm sagt: «Ich bin der Held Z, der einen Bezug zu Y hat.»

25 Vgl. Brownie/Graydon 2016, 29; Söll/Weltzien 2003, 3 I I. 
Allens Blitz-Zeichen oder Peter Parkers Kostüm mit Spinnensymbolen - sie stehen nicht für irgendeine Fledermaus, ein Gewitter oder Spinnen im Allgemeinen, sondern für den spezifischen Helden: Batman, den dunklen Ritter und Rächer von Gotham City, Central Citys roten Tempobolzen The Flash und New Yorks Spider-Man, den netten Netzschwinger von nebenan. Zusätzlich markiert der bestimmte Artikel die Einzigartigkeit des Helden: The Flame zum Beispiel ist ja nicht irgendeine, sondern die eine, ganz bestimmte «Flamme». Bei einigen weniger bekannten und eher kurzlebigen Gestalten der I940er-Jahre bezeichnete sogar die Maske an sich den Helden, so etwa beim Pulp-Helden The Crimson Mask (1940-1945) und bei den Comicfiguren The Green Mask (ab I939 unter anderem in Mystery Men Comics), Miss Masque (ab 1946 unter anderem in Exciting Comics) oder - gleich aufs Minimum reduziert - The Mask (ebenfalls in Exciting Comics I-20, 1940-1942). In neueren Superheldencomics werden maskierte Helden (und Schurken) oft schlicht als costumes oder masks bezeichnet, so prominent in Alan Moores und Dave Gibbons' Watchmen (1986).

Gewiss lässt sich die (gegenständliche) Maske als eine Art Eintrittskarte in eine andere, dem Alltag enthobene Welt verstehen. So erklärt Olschanski für seine Kategorie der Arbeitsmaske, dass diese «das Vordringen in eine [...] Exterritorialität»», die für Menschen nicht ohne Weiteres zugänglich ist, ermöglicht und insofern auch einen Machtzuwachs verkörpert. ${ }^{26}$ Allgemeiner bemerkt Weihe: «[Die Maske] signalisiert den Auftritt in einer künstlichen [...], einer hergestellten, zeichenhaften Welt. Das Aufsetzen der Maske bedeutet auch die Anerkennung der Regeln dieser veränderten Welt.» ${ }^{27}$ Aus der Perspektive des Spiels Caillois zufolge ist mimicry ja eine der vier Grundformen des Spiels - kann man die Maske, den Trikots von Mannschaftsspielern nicht unähnlich, auch als Signal für die Teilnahme am Spiel sehen. Hier lässt sich etwa Caillois' Beschreibung der mit Halbmaske versehenen Gäste galanter Feste (vor allem des i 8. und I9. Jahrhunderts) hinzuziehen:

Es sind nicht nur zwei Unbekannte, die sich auf dem Ball begegnen [...]; es sind zwei Wesen, die das Zeichen des Geheimnisses tragen und die durch ein schweigendes, heimliches Versprechen [...] verbunden sind. Die Maske befreit sie offensichtlich von dem Zwang, den ihnen die Gesellschaft auferlegt. [...] [D]ie Maske [stellt] traditionsgemäss das Mittel und beinahe die manifeste Entscheidung dar [...], die Schwellen des Erlaubten zu überschreiten. ${ }^{28}$

26 Olschanski 200 I, 70.

27 Weihe 2004, I8.

28 Caillois 1982 (1958), I48. 
Hier ist allerdings einzuschränken, dass ihre Gewandung die maskierten Helden zwar von der Erwartung alltäglicher Verantwortlichkeiten befreit ${ }^{29}$ und sie sich eine bestimmte Handlungsfreiheit nehmen, ihre Handlungsweise aber einem (manchmal sehr weit ausgelegten) Tugendkatalog unterwerfen müssen, um als Helden zu gelten - Maske und Kostüm bedeuten für die Protagonisten ebenso eine Verpflichtung. ${ }^{30}$ Für die maskierten Helden bedeutet der Wechsel zwischen ihren beiden Identitäten in gewisser Weise einen Welten- oder zumindest einen Milieuwechsel von einer durch (vermeintliche) Gewöhnlichkeit geprägten Alltagswelt in eine actionreiche Welt der Verbrechensbekämpfung, in der es Unschuldige und manchmal die Welt vor Bösewichten und allerlei Katastrophen zu retten gilt. ${ }^{3 \mathrm{I}}$ Die Maske scheint hier zugleich die Funktionen einer Grenze wie einer Brücke zu übernehmen, ${ }^{32}$ indem sie eine äusserliche, vermeintliche Trennung des Helden in zwei Identitäten zu bewerkstelligen vermag, während das quasi hinter ihr verborgene Wissen um die Doppelidentität für die Eingeweihten (inklusive der Leser) die Verbindung dazwischen schafft.

Es ist klar, dass die Maske bzw. das Kostüm so nach aussen den Anspruch des Protagonisten auf seine Zugehörigkeit zur distinkten Gruppe der vermummten Helden, kurz: seinen Heldenstatus, zum Ausdruck bringt. ${ }^{33}$ Insofern schafft das Kostüm des Helden eine Parallele zu staatlich berufenen Ordnungshütern, wie Änne Söll und Friedrich Weltzien für die filmische Version von Spider-Man (2002, Regie: Sam Raimi) erklären: «Damit wird die Maskerade gewissermassen zum Zeichen eines Dienstzustandes, so wie die Uniform aus einem Durchschnittsmenschen einen Polizisten mit Sonderrechten und -befugnissen macht. [Sie] lizensiert ihren Träger und ermächtigt ihn zur Anwendung von legitimer Gewalt.» ${ }^{34}$ Tatsächlich benennen die maskierten Helden ihre Einsätze immer wieder als eine Arbeit («This is a job for Batman») und sprechen von ihrem Kostüm entsprechend als «working clothes». Da der Protagonist sein Kostüm als individuelles Einzelstück meist selbst entwirft und herstellt, betonen Söll/

29 Brownie/Graydon 2016, 36.

30 Vgl. ebd., 34-37.

3 I Vgl. Inchausti i 983,68 , der in den beiden Welten die «two poles of human experience» sieht. Zur Raumsemantik von Superheldencomics vgl. das Modell von Ditschke/Anhut 2009, dazu Meyer 2011, I36.

32 Vgl. Tseëlon 200I, 20. Zur Maske als Mittel zur Grenzüberschreitung vgl. Napier 1986, I 7.

33 Zum Superheldenzeichen/-kostüm als Marke vgl. Söll/Weltzien 2003, 309.

34 Ebd., 307f., ähnlich Brownie/Graydon 2016, 36f. Während Olschanski (2001, 77) sagt: «Jede Uniformierung ist Maskierung», sah Caillois (1982 (1958), I 50) die Uniform als Ersatz und Gegenteil der «Rauschmaske» in «zivilisierten Gesellschaften». Hier lässt sich argumentieren, dass die maskierten Helden dies kombinieren: Sie handeln in der Regel als Individuen und Einzelkämpfer, dienen mit ihren Aktionen aber dem Erhalt bzw. der Wiederherstellung der Ordnung. 
Weltzien, ist es Zeichen der «Selbstermächtigung seines Trägers».35 Maske und Kostüm des Helden stellen zugleich Uniform und Unikat dar und dienen gerade nicht der Identitätsverschleierung, sondern verkünden sowohl die Einzigartigkeit des Protagonisten wie sein Heldentum - zumindest für die Leser. ${ }^{36}$

Wie Barbara Brownie und Danny Graydon in ihrer Studie zum Superheldenkostüm erörtern, ist ein solches darum «more commonly associated with professional responsibilities than with personal identity» ${ }^{37}$, da es im Gegensatz zur täglich ändernden Alltagskleidung eine über weite Strecken unveränderliche Bekleidung darstellt. In der Auffälligkeit der bunten Kostüme sehen Brownie/Graydon einen vertrauenerweckenden Effekt - was der Maske als Attribut des Uneigentlichen und Unbestimmbaren, das Unbehagen auslöst, widerspricht. Für Brownie/Graydon kommunizieren die grellen Heldenanzüge eine «honesty of intention»; sie seien so "noticeable that the wearer would be unable to commit criminal or dishonest acts without being identified by witnesses» $3^{8}$. Mit andern Worten scheint das Kostüm dem Helden jene Belangbarkeit zu verleihen, die die Maske als solche ja verweigern soll. Für die gezeichneten Figuren der Comics ist anzumerken, dass gerade nicht das eigentliche Gesicht des Protagonisten die Wiedererkennbarkeit garantiert, sondern das «Maskengesicht ${ }^{39}$, denn während dieses die Individualität der Figur proklamiert, können Darstellungen des Helden in Zivil, wenn man sie isoliert betrachtet und kaum Kenntnisse der verschiedenen Zeichnungsstile hat, durchaus mehreren Charakteren zugeordnet werden. Dem Argument von Brownie/Graydon lassen sich dennoch zwei Punkte entgegenhalten: Zum einen kann die Auffälligkeit des Kostüms auch zur Ablenkung vom Gesicht oder identifizierbaren körperlichen Merkmalen dienen, wie zahlreiche Doppelgängerplots belegen. Zum andern widersprechen dieser Beobachtung die ebenso knalligen Kostüme vieler Superschurken, obschon man für diese in Anspruch nehmen kann, dass sie oft ein gewisser Drang auszeichnet, ihre Untaten nicht ungesehen, sondern aufsehenerregend $\mathrm{zu}$ begehen.

Während der Protagonist für die Leser üblicherweise klar als Held zu erkennen ist, kann er intradiegetisch in einigen Fällen durchaus als Krimineller wahrgenommen werden (wollen) oder einen schwankenden Heldenstatus aufweisen. Bei den Superhelden gehört es inzwischen zum guten Ton jeder Heldenbiografie, mindestens einmal die Seite gewechselt zu haben - innerhalb der erzählten

35 Söll/Weltzien 2003, 308; vgl. auch Nehrlich 201 3, I 26.

36 Vgl. Brownie/Graydon 2016, 25, Reynolds i994, 26.

37 Brownie/Graydon 2016, I2. Die Autoren denken hier freilich vor allem an Superman, der ja keine Maske trägt.

38 Ebd., 20.

39 Vgl. Sitz 2015, 217. 
Welt ist ein wichtiger Faktor bei der Frage nach Held oder Bösewicht oft die gesellschaftlich-öffentliche Wahrnehmung, die nicht selten als höchst wankelmütig dargestellt wird. Schurke wie Held eint der Anspruch, einen Teil der sozialen, gesellschaftlichen und staatlichen Regeln für sich selbst auszuhebeln, der eine als Ver-brecher, der andere als Paragon der Selbstjustiz, der sich um polizeiliche Protokolle der Verbrechensbekämpfung nicht kümmert.

Mit dem Aufkommen der Superschurken - die erst mit den Jahren die Superheldencomics zu bevölkern begannen - verliert die Verbindung von Maske und Held die vermeintliche Exklusivität, wie Scott Bukatman für die Superhelden bemerkt: «[...] the mask becomes less a sign of ethical status than a morally indeterminate superness. $\gg^{\star 0}$ Die Aussage zeigt, wie sehr im Feld der Superheldencomics die Maske als Attribut der Heldenfiguren etabliert ist, denn in der historischen Entwicklung dürfte es sich wohl gerade andersherum verhalten: Der maskierte Held leiht sich die Maske vom Räuber bzw. vom Kriminellen und wertet diese durch seine Taten um. Gerade in den sehr frühen Beispielen maskierter Helden gibt es einige Protagonisten, die durchaus unter den Topos Verbrecher als Held bzw. Gentleman-Gauner fallen und dem Motiv des edlen Räubers nahestehen. Dies lässt sich etwa für Frank L. Packards Safeknacker Jimmie Dale/The Gray Seal (ab i9i4) oder Johnston McCulleys Delton Prouse/The Crimson Clown (ab 1926) behaupten (mehr dazu im Pulp-Kapitel). In einigen weiteren Beispielen hält der Protagonist bewusst die Täuschung aufrecht, selbst ein Verbrecher zu sein, um diesen damit umso besser das Handwerk legen zu können. Das bekannteste Beispiel dafür ist wohl The Green Hornet, der ab 1936 in Radiohörspielen auftrat und dessen Strategie diverse Comic-Helden übernahmen. ${ }^{4 \mathrm{I}} \mathrm{Wie}$ schnell aber maskierte Figuren offenbar ohne Umwege als Helden akzeptiert wurden, zeigt die Tatsache, dass es schon bald maskierte Helden gab, die ohne Weiteres mit der Polizei oder ähnlichen Stellen zusammenarbeiten oder in deren Auftrag tätig sind. Beispiele dafür sind The Green Ghost/George Chance in den Pulps oder The Shield/Joe Higgins (ab I940 in Pep Comics) und The Woman in Red/Peggy Allen (ab 1940 in Thrilling Comics), wobei die beiden Comicbeispiele keine nennenswerte, das heisst narrativ produktive, plotrelevante zivile Identität aufweisen.

40 Bukatman 2003, 214, vgl. Reynolds 1994, 26. Auch Fingeroth (2008, 51) bemerkt, dass die Maske allgemein als «bestower of power» wie «disguiser of identity» erkannt werde (wobei er hier v. a. «ethnografische> Masken meint). Zur Superschurken- im Vergleich zur Heldenmaske am Beispiel des Films Spider-Man (2002, Regie: Sam Raimi) vgl. Söll/Weltzien 2003, 304, und Meyer 2003, 523-525.

4I Zum Green Hornet und seiner multimedialen Karriere vgl. ausführlich Grams/Salomonson 2010. 
Indem die Maske des maskierten Helden den Status ihres Trägers - seine Identität als Held - proklamiert, entschärft sie zumindest für die Leser die heikle Konnotation der Maske als Mittel der Täuschung. Doch so individuell die Maske eines Protagonisten auch sein mag: Weil sie doch die Austauschbarkeit bzw. Beliebigkeit des Maskenträgers ermöglicht, beinhaltet sie für die Zuschauer (also «Mitfiguren` wie Leser) trotz allem das Potenzial zur Täuschung. Ein Trägerwechsel kommt bei maskierten Helden allenfalls im Rahmen eines Generationenwechsels vor - als wohl frühestes Beispiel hat sich etwa Lee Falks seit 1936 als Zeitungsstrip publiziertes Phantom über 400 Jahre den Ruf der Unsterblichkeit erworben, indem die Maske stets im Geheimen vom Vater auf den Sohn überging. Auch dann, wenn ein Protagonist seine Maske kurzfristig einem Ersatzträger überlässt, wird immerhin die Heldenfunktion mehr oder weniger stabil ausgeführt. Das Gegenteil tritt indes ein, wenn sich ein Antagonist der Maske bemächtigt und als Doppelgänger die Identität des Protagonisten vortäuscht. Durch die Uneindeutigkeit der Maske als solcher bleibt darum selbst die Heldenmaske stets etwas suspekt, womit die Geschichten um maskierte Helden in vielfältiger Weise immer wieder spielen.

Die negative Konnotation der Maske, die bis heute für Täuschung ${ }^{42}$ und Heuchelei stehen und als Symbol für Falschheit ${ }^{43}$ gelten kann, blickt dabei auf eine lange Geschichte zurück. Wie Weihe erläutert, wurde die Maske namentlich in der christlichen Tradition als Gegensatz zum Gesicht positioniert, das in dieser Dichotomie als nackt und aufrichtig besetzt wurde. Die Maske aufzusetzen, bedeutet dann den Beginn einer Täuschung, sie abzunehmen, die Enthüllung der Wahrheit bzw. den «Wegfall der Täuschung». ${ }^{44}$ Da die Täuschung eng mit dem Teufel in Verbindung gebracht wurde, konnte die Maskerade nur negativ gewertet werden: «From medieval times onward, the prevalent interpretation of the mask focuses on its role as an evil disguise»45, erklärt A. David Napier. In dieser Tradition beinhaltet die Maske Julika Funk zufolge eine «identitätsgefährdende Uneigentlichkeit» und damit auch «moralische Subversivität».46

42 Vgl. dazu Daemmrich/Daemmrich $(1987,303)$ : «Die christliche Tradition verurteilt das Verschweigen der Wahrheit und jede Form der Täuschung [...], die dem eigenen Vorteil dient»; sie bemerken aber, dass Täuschungsvermögen bzw. List bei Heldenfiguren als «Ausdruck von Mut und Klugheit» seit jeher Bewunderung hervorgerufen habe (ebd.). Wimmer/Schäfer 2000, 9f., vgl. Brownie/Graydon 2016, $38 \mathrm{f}$.

44 Weihe 2004, 70. Die «Maskerade als Verhüllung», so Funk (1995, I 8f.), bedeutet indes, das hinter der Maske Verborgene «erst mit den Attributen der Eigentlichkeit und des Essentiellen» zu versehen, während «die Verhüllung zum einzig Zugänglichen und Sichtbaren [wird], das Uneigentliche wird zum Modus der (Re-)Präsentation».

45 Napier 1986, I I.

46 Funk 1995, I9. Funk sieht diese Konnotationen ab dem späten I8. Jahrhundert belegt, doch 
Die Maske zieht einen grossen Teil ihrer Spannung aus den binären Oppositionen, ohne die sie lange nicht denkbar zu sein schien und die eine klare moralische Wertung hatten: auf der einen Seite Wahrheit und Natürlichkeit bzw. Aufrichtigkeit des Gesichts, auf der andern Lüge und Künstlichkeit bzw. Täuschung der Maske. ${ }^{47}$ Damit verbindet sich überdies das Spannungsfeld von simulatio (was ich zu sein vorgebe) und dissimulatio (was ich nicht zu sein vorgebe). ${ }^{8}$ Die Maskerade steht somit nicht nur in einer «Dialektik von Enthüllung und Verhüllung» ${ }^{49}$, sondern spielt stets auch mit der Dualität von Sein und Schein.

Denn dem Verständnis der Maske als Inbegriff der Täuschung gegenüber steht eine alte Weisheit von Karnevalsbegeisterten, wie sie etwa Mezger formuliert: «[...] dass es nicht etwa der Fastnachtstrubel, sondern der Alltag ist, in dem wir uns verstellen und manchen falschen Schein erwecken, dass wir tagein, tagaus mehr oder weniger perfekte Masken tragen, und dass wir unser wahres Gesicht vielleicht nur einmal im Jahr für ein paar Stunden hinter der Narrenmaske zeigen.» ${ }^{50}$ Die (gegenständliche) Maskerade ist hier nicht die Täuschung, sondern enthüllt vielmehr «die Wahrheit. Diese Umkehrung bringt Efrat Tseëlon auf den Punkt: «The paradox of the masquerade appears to be that it presents truth in the shape of deception.» ${ }^{\text {s }}$

Es ist dabei wohl eine Frage der philosophisch-soziologischen Perspektive auf das Verhältnis von Individuum und Gesellschaft, ob man - in Bezug auf das Beispiel der Karnevalsmasken - Ausschweifung und Enthemmung als das swahre Wesen oder das ‘wahre Gesicht > des Individuums werten will (oder soll). ${ }^{52} \mathrm{Je}$ denfalls geht mit dieser Auffassung ein Verständnis des alltäglichen Lebens - des Einfügens in und des Angepasstseins an eine Gesellschaft - als Unterdrückung des «wahren Selbst einher. Hier wird die gegenständliche Maske zum Gegensatz der metaphorischen Maske(rade), auf die ich im nächsten Kapitel näher eingehe.

passt die Feststellung nahtlos in die christliche Traditionslinie, die Weihe (2004, 37, 205-208) diskutiert. Für Schauspielermasken zeichnet Baumbach (2000, I38) eine ähnliche Entwicklung nach, situiert die <Verteufelung a aber auf nach 1795 .

47 Bettinger/Funk 1995, 9, Funk 1995, I 8, Weihe 2004, 69, 71.

48 Vgl. von Matt 2006, 29.

49 Hettlage 2000, I7 I. Weihe (2004, I 3) verwendet die Formulierung «Dialektik des Zeigens und Verhüllens». Bemerkenswerterweise sagt Schirrmeister (2004, 78) vom Geheimnis dasselbe: In ihm «vereinigt sich die Dialektik von Verbergen und Enthüllen».

50 Mezger 2000, I3 I.

5 I Tseëlon 200I, 5 .

52 Auf einer nur leicht abgewandelten Auffassung der Maskerade fusst als nur ein Beispiel etwa die durchaus zu kritisierende Analyse von Superhelden mit Tierkostümen von Brownie/ Graydon $(2016,83 \mathrm{f}$.): «[...] the mask allows him to be who he really is; to revert to a primal, unsocialized, and arguably 〈pure, animal version of himself» - obschon der Held nie gänzlich zum Tier werde, sondern stets ein hybrides Zwischenwesen bleibe. 
Dieser Topos der Maskerade - gerade in der Verhüllung <die Wahrheit zu enthüllen - dürfte darauf beruhen, dass die Maske Freiräume und Handlungsmöglichkeiten schafft, die sonst nicht gegeben sind (Stichwort Narrenfreiheit). Um dies in den Worten Petra Degers zusammenzufassen: «Gerade (echte) Masken stellen einen wesentlichen Entkopplungsmechanismus für die Gültigkeit sozialstruktureller Merkmale dar. Hinter einer Maske sind viele Verhaltensweisen legitim, die sonst illegitim wären. Masken können Individuen für kurze Zeit einen völlig anderen Status verleihen [...].» ${ }^{33}$

Für die maskierten Helden ist diese Umkehrung nur schon deshalb relevant, weil das Anziehen der Maske aus diesem Blickwinkel zur Demaskierung wird (Abb. I). ${ }^{4}$ In geradezu ikonischer Weise scheinen die Superheldencomics diese Umkehrung der Maskerade in jenen Szenen vorzuführen, in welchen die Protagonisten bloss ihre Kleidungsstücke abzustreifen brauchen, um als Held im darunterliegenden Kostüm <enthüllt > und aktionsbereit dazustehen - in ihrer, so scheint es, <wahren Gestalt>. s Diese Interpretation der Doppelidentität soll hier jedoch keineswegs als allgemeingültig vertreten werden. Denn die Maske bietet ebenso einer vom Gegensatz wahr - falsch losgelösten Deutungsweise von Identität eine Grundlage.

Der christlichen Denktradition der Maske ging, wie Weihe ausführlich darlegt, in der Antike ein anderes Verständnis von Maske und Gesicht voraus: In der Antike bezeichnete das griechische Wort prósopon sowohl die Maske (ursprünglich des Schauspielers) als auch das Gesicht; dem vergleichbar meinte das lateinische persona sowohl eine Theaterfigur wie eine Zivilperson. ${ }^{56}$ Maske und Gesicht/Person bildeten eine, wie Weihe es nennt, "prosopische Einheit», in der sich zwei unterschiedene Dinge als Einheit denken lassen. ${ }^{57}$ Ausgehend von der Maske als Form, kommt Weihe zu seinem «Theorem der Maske», das dieser pro-

53 Deger 2000, 205. Zur Maskerade als Befreiung von Status/Regeln vgl. Weihe 2004, I8, Olschanski 200 I, 90, Mezger 2000, I 30, Mahler I995, I I 9 . Ähnliches schreibt Schirrmeister (2004, 77) zum Geheimnis, wobei man das Wort «Geheimnis〉 mit 〈Anonymität austauschen könnte: «Das Geheimnis erlaubt und ermöglicht folglich ein Loslösen von der Rolle, es schenkt insofern ein Stück Freiheit und Autonomie über das eigene Handeln und befreit von Rechtfertigungen.»

54 Trotz Parallelen lässt sich die Helden- nicht mit der Karnevalsmaske gleichsetzen, die oft durch ein Demaskierungsritual zeitlich beschränkt getragen wird, während der maskierte Held einen dauernden Wechsel vollzieht.

55 Vgl. Kniep 200I, I43 (bzw. identisch Kniep 2009, 33): «Legt der Held die Maske ab, bleibt er als solcher unerkannt, setzt er sie aber auf, tritt er als derjenige in Erscheinung, der er in Wahrheit ist.»

56 Weihe 2004, 26-28. Zu den Etymologien vgl. auch Napier 1986, 8, und Baumbach 2000, I42.

57 Weihe 2004, 37; 102. Weihe sieht die prosopische Einheit als Denkfigur vor allem da als «Verständnishilfe», wo nicht mehr scharf zwischen Gesicht und Maske unterschieden werden kann (ebd.). 


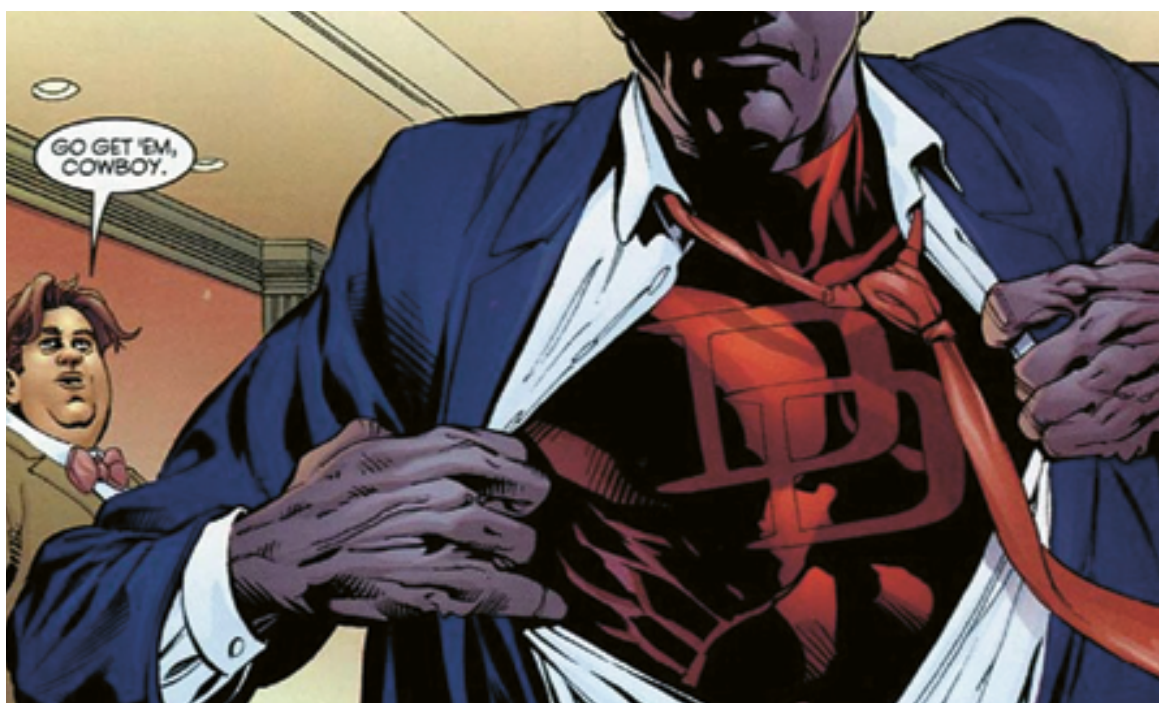

Abb. I: Der ikonisch gewordene Enthüllungsmoment des Helden, hier in der Variante von Matt Murdock alias Daredevil. Dagegen wird in den Comics deutlich seltener visualisiert, wie sich der Held, komplementär zum Hemd-Aufreissen, die Maske überstülpt (oder die Schuhe wechselt). Playing to the Camera, Part IV: Making Offers (Bob Gale, Dave Ross, Mark Pennington et al.), in: Daredevil 23 (Volume 2), November $200 \mathrm{I}$. (C) Marvel Comics

sopischen Einheit entspricht: Als Form besitzt die Maske eine Innen- und eine Aussenseite (konkav und konvex), zugleich aber ist sie auch das Dazwischen (und somit ein Drittes) - sie «trennt die beiden Seiten [...], aber sie verbindet sie auch» ${ }^{8}$. Die Maske als «Denkfigur» beschreibt Weihe darum als «die Paradoxie [...] einer Einheit des Unterschiedenen» `9. Anders ausgedrückt: Die Maske verkörpert die paradoxe Gleichzeitigkeit von einem Entweder-oder mit einem Sowohl-als-auch. ${ }^{60}$

58 Ebd., 35; 46. In diese Richtung, unter einem verschobenen Gesichtspunkt, denkt auch Olschanski (200I, 47): «Entscheidend ist dabei, wie im gleichzeitigen Verhüllen und Darstellen des Gesichts sowohl eine Zweiheit «Mensch und Maske» als auch eine Einheit dieser Glieder erfahrbar wird.»

59 Weihe $200435,47$.

60 Ebd., 47. 
Das Oszillieren der Maskerade zwischen Dichotomien einerseits (wahr - falsch) und paradoxen Verbindungen andererseits macht die Maske zu einer komplexen Angelegenheit. Tseëlon fasst diese Aspekte wie folgt zusammen:

Masquerade unsettles and disrupts the fantasy of coherent, unitary, stable, mutually exclusive divisions. It replaces clarity with ambiguity, certainty with reflexivity, and phantasmatic constructions of containment and closure with constructions that in reality are more messy, diverse, impure and imperfect. The masquerade, in short, provides a paradigmatic challenge $[\ldots]$ to dualistic differences between essence and appearance. ${ }^{61}$

Die Maskerade dient zum einen der Selbstdarstellung und damit der Selbstdefinition - also der Identitätskonstruktion. Zum andern stellt sie Identität(en) infrage und bedeutet stets eine Herausforderung von Identitätskategorien, wie Tseëlon weiter betont, was implizit auch die Möglichkeit eines Selbstverlusts enthält. Entsprechend bietet die Maskerade in Bezug auf Identität grundsätzlich zwei Interpretationsmöglichkeiten: «One assumes the authenticity of the self (that the mask - sometimes - covers). The other approach maintains that through a multitude of authentic manifestations the mask reveals the multiplicity of our identities.» ${ }^{62}$ Auch hier lässt sich die Maske nicht auf eine Seite festnageln, vielmehr erweist sich die der Maske eingeschriebene Zweiheit als ein Sprungbrett zur Vielheit, als deren Gegensatz sie zunächst erscheint. Mehr noch als bei der gegenständlichen Maske kommt dies wohl bei der metaphorischen Maske des Alltags zum Tragen, deren Faden ich im Kapitel zu Rollen, Masken, Identitäten wieder aufnehmen werde, in welchem es den Blick auf rollengestützte Identitätstheorien zu erweitern gilt.

\section{Geheimnisbedrohung und -bewahrung: Narrative Koordinaten der Doppelidentität}

Das eingangs erwähnte Dreiecksverhältnis der Maske findet eine Parallele in der Grundkonstellation des Geheimnisses, wie es bereits Georg Simmel in seiner Soziologie (1908) konzeptualisiert hatte. Denn auch dieses wäre, so erklärt Claudia Schirrmeister in seiner Nachfolge, in totaler Isolation sinnlos: Ein Geheimnis kann nur existieren, wenn es neben dem Geheimnisinhalt und dem Geheimnisträger auch Nichteingeweihte gibt. ${ }^{63}$ Entsprechend lässt sich auch das Geheim-

6I Tseëlon 200I, 3.

62 Ebd., 25; vgl. 200I, 4.

63 Schirrmeister 2004, 33; so auch Nedelmann I995, I; Spitznagel I998, 29. 
nis, kurz als «rigideste Form der bewussten Verhinderung von Wissen in der Interaktion ${ }^{64}$ definiert, als Kommunikationsform verstehen, ist doch dessen Konstruktion «reines Informationsmanagement», bei dem sich der Geheimhaltende stets überlegen muss, ob und wie er was kommunizieren kann, will oder muss, um bestimmte Geheimnisinhalte verborgen zu halten. ${ }^{65}$

Da das Geheimnis eine "grundsätzlich labile Interaktionsform» ${ }^{66}$ darstellt, verwundert es nicht, dass der Doppelidentität eine gewisse Spannung geradezu inhärent ist und sie bei den meisten maskierten Helden auf der Ebene der narrativen Strategien und Plots regelmässig in Gefahr gerät, entdeckt zu werden. Schon Simmel hielt fest: «Das Geheimnis enthält eine Spannung, die im Augenblick der Offenbarung ihre Lösung findet. ${ }^{67}$ Für die maskierten Helden wie für alle Geheimnisse gibt es zwei Möglichkeiten der Enthüllung: Selbst- oder Fremdentlarvung. ${ }^{68}$ Beide können zufällig oder geplanterweise und unterschiedlich weitreichend erfolgen. Handelt es sich nur um eine oder wenige Personen, können diese allenfalls zu Mitwissern werden, handelt es sich hingegen um die Öffentlichkeit, ist das Geheimnis am Ende (jedenfalls theoretisch, praktisch sieht dies in Maskierte-HeldenErzählungen anders aus, worauf ich weiter unten zurückkomme).

Alfred Spitznagel weist darauf hin, dass Geheimnisse im Allgemeinen eine «Verlaufsstruktur» haben, wobei er als zwei Stationen dieser Struktur mit «Entscheidung» und «Lüftung» nur den Anfangs- und den (implizit stets drohenden) Endpunkt erwähnt. ${ }^{69}$ Das Geheimnis aber erscheint auch als Grundbaustein des narrativen Modells der literarischen Intrige, wie sie Peter von Matt charakterisiert hat, der als ihr «Handlungsgerüst» drei Phasen benennt: «Planung, Durchführung und Anagnorisis». ${ }^{\circ}$ Der Schlusspunkt erhält dabei eine besondere Bedeutung: «Aller Spannungsaufbau geschieht über die erwartete, die erhoffte, die gefürchtete Anagnorisis. Sie ist das Phantasiebild am Horizont, das die Lektüre begleitet von dem Moment an, wo der Plan ausgedacht wird.» ${ }^{71}$ Selbstverständlich liegt die Spannung in Geschichten um maskierte Helden selten allein in der

64 Schirrmeister 2004, I.

65 Ebd., 55; auch 59 f.

66 Nedelmann I995, I0; vgl. auch Schirrmeister 2004, 79.

67 Simmel I908, 274.

68 von Matt 2006, 322.

69 Spitznagel $1998,32$.

70 von Matt 2006, г2 г. Vgl. ebd., I36f.: «Wie immer man sie fassen will, gewiss ist, dass der unveränderliche Kern einer universalen Ästhetik der Anagnorisis im Ereignis des beseitigten Unwissens, des zerrissenen Schleiers, der fallenden Maske liegt. [...] Der Kern liegt in der Wahrheit als plötzlichem Ereignis. Wahrheit kann nur Ereignis sein, wo sie vorher fehlt [...], [also] unter der Voraussetzung eines vorgängigen Geheimnisses.»

7I Ebd., I21. 
doppelten Identität, denn den Hauptakzent setzt klar die Auseinandersetzung mit einem Gegner. Nimmt das Geheimnis des maskierten Helden im Plot eine Rolle ein, gilt jedoch, was Hans J. Wulff für Geschichten mit Mehrfachidentitäten im Film erklärt: Die Spannung der Handlung basiert dann auf der «Doppelfrage», ob der Held seine Aufgabe löst und ob er dabei sein Geheimnis wahren kann..$^{72}$ Oft bedeutet es eine zusätzliche Herausforderung für das heldische Handeln, sich nicht selbst zu verraten oder entlarvt zu werden.

Erzählerisch kommt die Intrigenstruktur in den Handlungssträngen um die Doppelidentität zum Zug, wenn sich der Held von geplanten Enthüllungsversuchen bedroht sieht, und seinerseits sozusagen eine Gegenintrige - die laut von Matt demselben Bauprinzip folgt, aber «oft zeitlich versetzt» ${ }^{73}$ ist - starten muss, um die Entdeckungspläne seiner Gegenspieler (die hier pikanterweise auch seine Freunde sein können) zu verhindern. Wie bereits Simmel bemerkte: «Die Absicht des Verbergens nimmt aber eine ganz andre Intensität an, sobald ihr die Absicht der Entschleierung gegenübersteht.»74 Um (nur) ein konkretes Beispiel zu nennen, findet sich dies geradezu klassisch direkt in jener frühen Batman-Geschichte, in der die Reporterin Vicky Vale zum ersten Mal auftritt (I948): Wegen einer Kinnverletzung schöpft Vicky Vale Verdacht und will nun beweisen, dass Bruce Wayne Batman ist. Trickreich versetzt sie einen von Batmans Handschuhen - als Intrigenrequisit - mit fluoreszierendem Pulver (Abb. 2a). Doch als die Überführung, die Anagnorisis, bevorstehen sollte, hat Bruce zwei leuchtende Hände statt nur einer, weil er Vicky einen fluoreszierenden Blumenstrauss gekauft hat (Abb. 2b). Wie er erst im Nachhinein Robin und den Lesern enthüllt, war er Vickys Vorhaben eher zufällig auf die Schliche gekommen und konnte durch seine Gegenaktion die Entdeckung vermeiden. Die Geschichte schliesst bezeichnenderweise mit einem Erzählerkommentar, der das folgende jahrelange Spiel um das Geheimnis zwischen diesen beiden Charakteren ankündigt: «Well, it looks as if there's a battle of wits ahead! Will Batman win the next time?»75 Abgesehen von klar auf eine versuchte Entlarvung hin aufgebauten Storylines, ist auch die Maskerade des maskierten Helden als eine Art Intrige - allerdings eine ohne konkretes Ziel (bzw. mit sich selbst, das heisst der Wahrung des Ge-

72 Wulff 2007 , I 52 .

73 von Matt 2006, I2 I.

74 Simmel 1908, 272. Ähnliches halten Daemmrich/Daemmrich $(1987,303)$ für die Täuschung und deren narrative Möglichkeiten generell fest: «Jede Art der Täuschung bewegt die Handlung voran, stellt Spannungsbögen her, ermöglicht die Ausarbeitung von konfliktgeladenen Situationen und stützt den Figurenaufbau der Handlungsträger durch die Verwerfung verschlagener Pläne der Gegenspieler.»

75 The Scoop of the Century (Bill Finger, Bob Kane, Lew Sayre Schwartz et al.), in: Batman 49, Oktober-November 1948, I 2. 

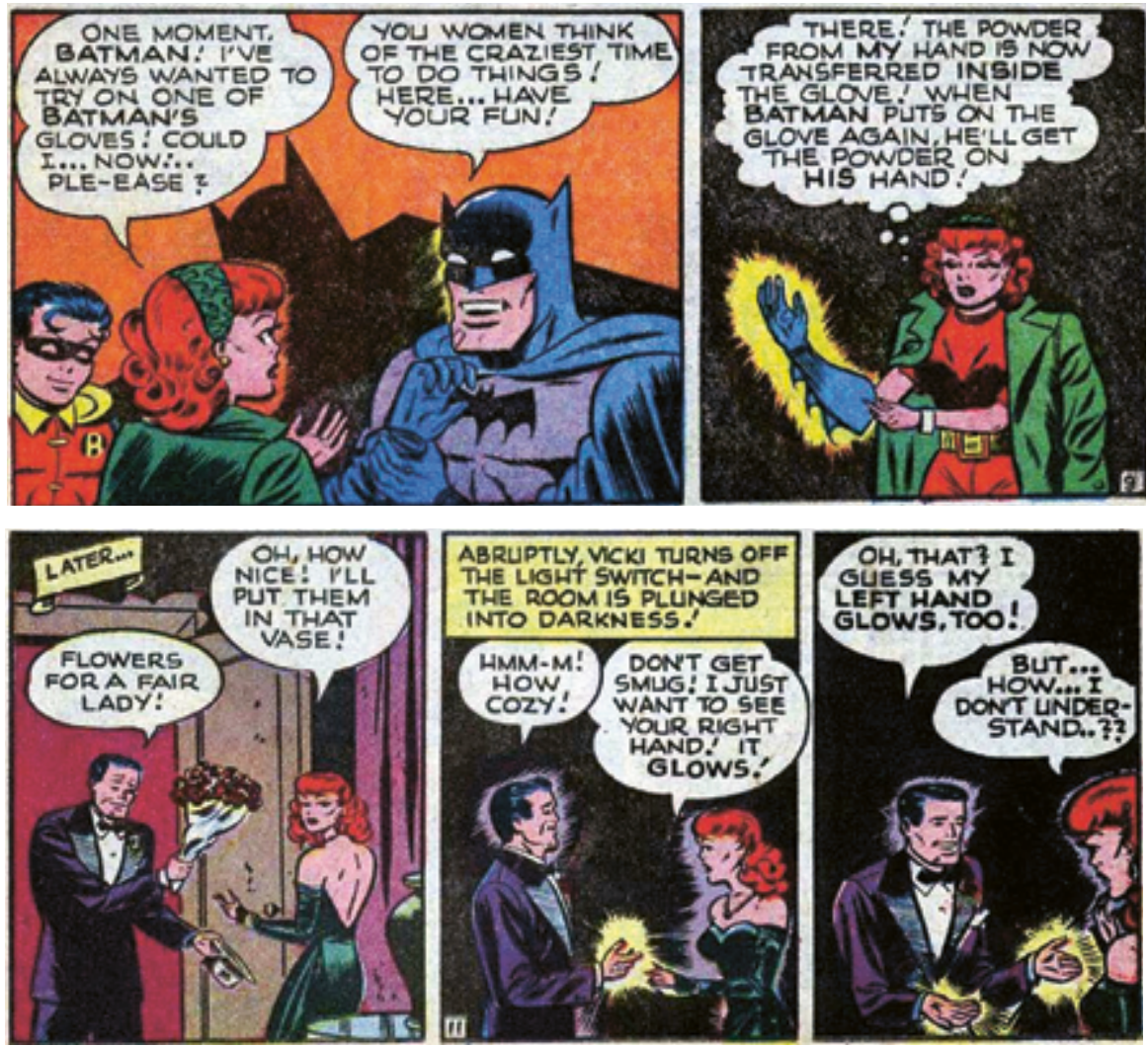

Abb. $2 \mathrm{a}$ und 2b: Vicky Vales Intrige und Bruce Waynes/Batmans verhinderte Anagnorisis - wobei er Vicky erst noch neckisch einen Moment glauben lässt, ihr Trick hätte Erfolg gehabt. The Scoop of the Century (Bill Finger, Bob Kane, Lew Sayre Schwartz et al.), in: Batman 49, Oktober-November 1948, 9 und I I. (C) DC Comics

heimnisses, als Ziel) - interpretierbar. Bei vielen Helden liesse sich in der OriginStory (oder wenigstens einem Teil davon, dem Ergreifen des Kostüms) die Planungsszene und im Heldenleben die Durchführung erkennen. Jedenfalls trifft von Matts Beschreibung des Intriganten ohne Weiteres auf den maskierten Helden zu: Er lebt stets «auf der Schwelle der Anagnorisis» ${ }^{6}$. Ständig muss er sich 
vor der Entdeckung hüten: «Immer wieder zieht sich das Netz um ihn zusammen, scheinbar ausweglos, und doch entwischt er jedesmal, oft sogar auf eine seltsam unglaubhafte Weise.»77 In dieser Unglaubhaftigkeit, die bei den maskierten Helden sozusagen zum Standardmodell gehört und die man aufgrund der Serialität nur als zwar nötigen, aber letztlich «billigen Trick» werten könnte, sieht von Matt beileibe keine Schwäche der Erzählung: «Die [...] Unwahrscheinlichkeit, die eigentlich ein Kunstfehler sein müsste, gewinnt eine erzählerische Funktion, sie steigert den Geheimnischarakter.» ${ }^{8}$

Die Erzählungen von maskierten Helden loten diese Geheimnisspannung immer wieder aus: Die Anagnorisis existiert üblicherweise nur als Gefahr, nicht aber als Tatsache. Gerade das Umgehen der Anagnorisis kann, so erläutert von Matt weiter, eine ähnliche Wirkung wie diese entfalten: «Nicht die Anagnorisis ist hier das dramatische Ereignis, sondern ihr Ausbleiben, der Nichtvollzug.»79 Schliesslich kann einmal erlangtes Wissen nicht ‘zurückgegeben> oder ‘abgelehnt> werden; wie Schirrmeister bemerkt, kann es allenfalls durch Vergessen wieder zu Nichtwissen werden. ${ }^{80}$ Die Konstanz der Doppelidentität ist ohne Frage in der Serialität der Geschichten über maskierte Helden begründet. Als serielle Produkte sind diese selbstredend der Variation wie der Überbietung verpflichtet. So kommt immer wieder vor, dass die Doppelidentität eines Protagonisten (in diversen Abstufungen) offenbart wird. Im Lauf der Jahre haben viele Helden - so die Comic-Helden The Black Hood I946, The Atom 1984 oder Iron Man $2002-$ teils freiwillig, teils gezwungenermassen ihr Geheimnis, aber nicht ihr Heldentum, an den Nagel gehängt, was eine Änderung des Erzählschemas bedeutet. Bei den oft über lange Zeiträume erzählten Abenteuern maskierter Heldenfiguren hängt die Sprengkraft> einer Identitätsaufdeckung oft davon ab, als wie permanent sie sich erweist. Geradezu berüchtigt sind die zahlreichen erzählerischen ‘Winkelzüge〉, um die Enthüllung in vielen Fällen zurückzunehmen, das heisst folgenlos bleiben zu lassen. ${ }^{8 \mathrm{I}}$ (Manchmal entschliessen sich die Autoren auch zu

77 Ebd., I 24. Von Matt bemerkt zudem (ebd.): «Dieses Leben am Abgrund der Entdeckung [...] ist kein Running gag [sic] der Erzählerin, sondern ein Kunstakt hohen Ranges.» Konkret bezieht von Matt diese Aussage auf Patricia Highsmiths The Talented Mr. Ripley (1955). Bemerkenswerterweise hat Patricia Highsmith in jungen Jahren (um 1945) (Superhelden-)Comics, unter anderem Black-Terror-Storys, getextet, was über Jerry Bails' Who's Who im Comic (http://www. bailsprojects.com/whoswho.aspx) hinaus wohl erst mit Joan Schenkars Highsmith-Biografie The Talented Miss Highsmith. The Secret Life and Serious Art of Patricia Highsmith (2009) bekannt wurde.

78 von Matt 2006, I25.

79 Ebd., I 26. Dies ist bei von Matt auf Max Frischs Mein Name sei Gantenbein von 1964 gemünzt.

80 Schirrmeister 2004,4 .

8 I Vor allem die (fantastischen) Superheldencomics bieten zahlreiche Strategien, um die Offenbarung ungeschehen zu machen: Die erzählte Geschichte erweist sich als Traum oder Zeitreise, 
einem erzählerischen Gewaltakt, dem Neustart (reboot) einer Serie, bei dem die Doppelidentität wieder eingeführt werden kann.) Offenbarungsszenen können so die (zeitweilige) Abkehr von der Konvention bedeuten, aber auch eine letztlich die Konvention bestätigende Episode bleiben.

Mit Blick auf seine beiden Identitäten hegt der maskierte Held zwei verschiedene Geheimnistypen. Beim «einfachen Geheimnis» ist zwar dessen Inhalt verborgen, doch ist bekannt, dass es ein Geheimnis gibt. Im Unterschied dazu bleibt beim «reflexiven Geheimnis» auch dessen blosse Existenz geheim; hier darf der Nichteingeweihte von seinem Nichtwissen nichts erfahren, wobei es sich sozusagen um eine «doppelte Verheimlichung» (des Geheimnisses an sich wie des Geheimnisinhalts) handelt. ${ }^{82}$ In seiner zivilen Identität übt sich der Held in reflexiver Geheimhaltung. Da die Devise der metaphorischen Maske <bloss nicht (als heldenhaft) auffallen> lautet, steht sie hier erneut im Kontrast zur extravaganten maskierten Erscheinung des Helden. Die maskierte Heldenidentität (wie gesagt offenbart die Maske stets, dass sie etwas verbirgt) entspricht offensichtlich einem <einfachen Geheimnis`. Den Betrachtenden präsentiert sich die Maske hier als Rätsel ${ }^{8_{3}}$ und fordert so die Neugier und Forschungslust heraus, die in den Geschichten vor allem Journalisten, love interests (die erwähnte Vicky Vale vereinigt diese beiden Rollen sogar) und Schurken packt. Maskierte Helden sind so in mehrfachem Sinn intriguing.

Während die maskierten Helden ihre Doppelidentität verbergen, ist ihre Heldentätigkeit bemerkenswerterweise häufig dem Aufdecken von Verantwortlichkeiten gewidmet, sind doch die meisten ihrer Geschichten dem Krimi bzw. dem Thriller zuzuordnen. Insbesondere dort, wo (im weitesten Sinn) menschliche Unholde ihr Unwesen treiben, agieren die maskierten Helden als Ermittelnde und sind teilweise explizit als Detektive tätig (als Paradebeispiele für maskierte Meisterdetektive sind Batman und aus den Pulps The Phantom Detective zu nennen). Obschon die maskierten Helden selbst nur verhüllt agieren, ist Enthüllung ihr Geschäft. ${ }^{8}{ }^{8}$ Zuweilen zeigt sich dies sogar noch deutlicher im Beruf, den der Protagonist in Zivil ausübt. Obwohl es im Lauf der Jahre doch zu eini-

oder die Figur, die das Geheimnis erfahren hat, hält ihre Erkenntnis schliesslich für eine Wahnvorstellung oder doch (durch futuristische Technik oder Maskenspiele) für einen Irrtum, bekommt Amnesie, wird hypnotisiert oder stirbt usw. usf.

82 Schirrmeister 2004, 55-57, 63. Schirrmeister übernimmt dieses Begriffspaar von Sievers (1974, 80-87), Nedelmann (1995, 4f.) etwa spricht von «absoluten» und «relativen» Geheimnissen. Vgl. auch Olschanski 200I, 44.

83 Vgl. Tseëlon 200I, 30; Brownie/Graydon 2016, 30.

84 Vgl. Nedelmann 1995, 9, die allgemein weiter bemerkt (ebd.): «Je grösser die Professionalität der Enthüller [Journalisten, Detektive, Spione, Fahndungsbeamte oder Geheimdienstler], desto grösser die Anreize, Geheimhaltung zu professionalisieren und umgekehrt.» 
ger Varianz gekommen ist, ist die Mehrheit der Protagonisten in vier Berufsfeldern tätig, von denen drei eine starke Affinität zum Nachforschen und Rätsellösen haben: Abgesehen von den berufslosen Millionären sind dies (Technik- oder Natur-)Wissenschaften, Journalismus - wobei oft dessen investigative und sensationalistische Seiten betont werden - sowie im weiteren Sinne die Staatsgewalt, konkret Polizisten, Anwälte, Agenten etc. ${ }^{85}$ Arbeitet der Held an einem Ort, wo er an für ihn relevante Informationen kommt, muss er nicht darauf warten, bis er in seiner zivilen Identität zufällig an eine Aufgabe heranläuft, oder regelmässig durch die Stadt patrouillieren und hoffen, zur rechten Zeit am rechten Ort zu sein. Da ihm als kostümiertem Helden der Zugang zu gewissen Institutionen verweigert sein kann, erweist sich die zivile Identität oft als essenziell für die Informationsbeschaffung - schliesslich bleibt der beste Held nutzlos, wenn er nicht weiss, wo seine Hilfe gebraucht wird. ${ }^{86}$ Dies wird selbst in einem Beispiel mit einer eher seltenen zivilen 〈Karriere〉 deutlich: Johnston McCulleys eigene Zorro-Imitation Pedro Garza alias El Torbellino (The Whirlwind, 1933/34) arbeitet als Handlanger in einem Wirtshaus. Da dieses jedoch ein ergiebiger Umschlagplatz von Informationen ist, erweist sich dieser Arbeitsplatz durchaus als strategisch gut gewählt.

Mehr noch als die dingliche Maske bedeutet die metaphorische Maske eine Anpassung an die Umwelt bzw. die Erwartungen der anderen an das Rollenverhalten des Protagonisten, was eine sorgfältige «Antizipation fremder Erwartungserwartungen ${ }^{87}$ erfordert, wie Schirrmeister formuliert. Die eigene Kommunikation und das eigene Handeln sind in der Interaktion mit andern

$85 \mathrm{Zu}$ den Millionären zählen etwa Bruce Wayne/Batman, Oliver Queen/Green Arrow oder Danny Rand/Iron Fist. Polizisten sind u. a. Dan Garrett/The Blue Beetle (I) und Kip Burland/ The Black Hood, Anwälte Matt Murdock/Daredevil und Helena Wayne/The Huntress (I), zu den Wissenschaftlern und Tüftlern gehören z. B. Ray Palmer/The Atom und Ted Kord/The Blue Beetle (II). Die Berufsfelder sind freilich nicht exklusiv, Barry Allen/The Flash (II) etwa ist Polizeilaborant, Tony Stark/Iron Man zugleich Milliardär und Erfinder.

86 Vgl. Thurtle/Mitchell 2007, 279-28I. Sie sehen in der Doppelidentität einen Reflex auf zwei Formen von Information, die sich ergänzen (im Beispiel der Zeitung einerseits die Anzeigen und Unterhaltungssparten, andererseits die 〈harten〉 News): «In one form - usually the humanized alter ego [gemeint ist die zivile Identität] - a superhero plugs into an industrialized society's informational flows in order to gain knowledge beyond his or her own embodied experience.» Paradebeispiel dafür ist Superman: «Kent gathers information about the world as it is, while Superman embodies the potential for using this information in previously unforeseen ways. A similar dynamic characterizes Spider-Man and his alter-ego [...]. This functional division of abilities in comic books should not be construed as a mind/body split. It is more accurate and productive to understand this division as a representation of the distinction between information understood as affective/pragmatic on the one hand, and information understood as message on the other.»

87 Schirrmeister 2004, 59. 
stets unter Kontrolle zu halten. Dies erfordert in unerwarteten Situationen mitunter grosse Flexibilität und Geistesgegenwart: «Um den anderen in seinem [...] Nicht-Wissen und Nicht-Ahnen zu bestätigen, muss der reflexiv Geheimhaltende eine beständig hohe Aufmerksamkeit und eine nahezu perfekte Selbststeuerung [aufbringen], die nur durch ein gewisses Mass an Kaltblütigkeit zu erreichen ist $[\ldots]$ - muss er doch in prekären Situationen unauffälliges Normalverhalten demonstrieren [...].» ${ }^{88}$ Brownie/Graydon, die in den Alltagskleidern ebenso eine Verkleidung sehen wie im Heldenkostüm - während dieses für dressing up steht, erfüllen jene die Funktion des dressing down-, betonen diesbezüglich, dass das ¿Zivilkostüm〉 darum in mancherlei Hinsicht eine effektivere Verkleidung sein muss als sein Gegenstück: «[It] must present such a convincing replica of normality that no one questions its authenticity.» ${ }^{89}$ Burkard Sievers weist darauf hin, dass insbesondere die Lügen des reflexiv Geheimhaltenden «eine permanente Expansionstendenz» haben; denn damit die «ersten Lügen» nicht auffliegen, kommen zusätzlich «Stützlügen» zum Einsatz. ${ }^{\circ}$ Geradezu toposhaft müssen die Protagonisten immer wieder (mehr oder weniger fadenscheinige) Ausreden erfinden, um etwa Absenzen bei wichtigen Terminen oder Ereignissen zu erklären.

Während die gegenständliche Maske eine Trennung in zwei Identitäten des Helden vorgibt, sind diese für den Helden selbst und damit für die stets eingeweihten Leser über ein Netz von Bezügen verbunden. Der maskierte Held ist so in vielen Momenten ein heimlicher Held. Dies wird etwa in jenen Szenen offenbar, in denen der Protagonist andere Leute über sein Alter Ego sprechen hört, wo er sich also inkognito in einer Gruppe aufhält. Laut Wilhelm Stok bedeutet das Inkognito die «Verheimlichung sozialer Identität»" : "Man ist faktisch anwesend und doch sozial nicht da.» ${ }^{92}$ Wie Schirrmeister anfügt, bestehen dabei «Sinn und Zweck [...] natürlich im Nicht-Wissen der anderen um die Existenz einer solchen Tarnung»; es handelt sich in gewisser Weise um eine Extremform der «reflexiven Geheimhaltung».93 In solchen Momenten kann der Protagonist über sich als einen Dritten sprechen - und kann je nachdem eine andere Haltung gegenüber «sich selbst` vertreten, als Fan, Befürworter oder Kritiker seiner selbst

88 Ebd., vgl. Brownie/Graydon 20I6, 3 I.

89 Brownie/Graydon 20I6, 71. Dazu Sievers (1974, 91) allgemein für das Geheimnis: «Die Strategie der Täuschung zwingt ferner zu einer peinlich genauen Wahrung der Normalität.»

90 Sievers 1974, 90, auch Schirrmeister 2004, 6r.

9I Schirrmeister 2004, 58.

92 Wilhelm Stok: Geheimnis, Lüge und Missverständnis. Eine beziehungswissenschaftliche Untersuchung. München, Leipzig 1929 (Ergänzungsheft II zu den Kölner Vierteljahresheften für Soziologie), 5 , zit. n. Schirrmeister 2004, 58. Ebd. 
auftreten. Beispielsweise echauffiert sich der ruheliebende Diego Vega über diesen impertinenten Zorro, der so viel Aufruhr veranstaltet: «The highwayman [Zorro]? Been here? By the saints! It is as much as a man can endure.» ${ }^{94}$

In Bezug auf Karnevalsmasken beschreibt Mezger den Reiz einer solchen Situation wie folgt: «Als Unerkannter hat er [der Maskierte] nämlich die einzigartige Möglichkeit, mit seinem nicht verkleideten Gegenüber einmal über sich selbst wie über einen abwesenden Dritten zu sprechen, um dabei [...] die Inkongruenzen zwischen Selbst- und Fremdeinschätzung der eigenen Person hautnah zu erfahren: die Maske als Medium von Illusion und Desillusionierung zugleich.»95 Der Protagonist kann so zu sonst ungehörtem Lob kommen, aber ebenso verurteilt werden, ohne dass er sich verteidigen könnte, weil er sein Wissen, ‘wie es wirklich war/ist>, bei Missverständnissen und Ungerechtigkeiten nicht preisgeben darf. Die Maskerade kann für ihren Träger die Möglichkeit ebenso wie den Zwang zum heimlichen Heldentum bedeuten. Diese Augenblicke werden manchmal implizit, oft sogar explizit als «If they only knew>-Momente etikettiert, die der Held und die Leser teilen, während der Rest der fiktionalen Welt aussen vor bzw. unwissend bleibt (Abb. 3). Solche Momente werden auffallend oft am Ende einer Einzelstory positioniert, wo sie als Schlussgag oder bittersüsse Schlussnote fungieren.

Im Prinzip haben Birgitta Nedelmann zufolge Mitwisser von Geheimnissen stets zwei Handlungsoptionen: Sie können das Geheimnis entweder bewahren oder offenlegen bzw. verraten - und damit ihre Verbindung zueinander stärken oder aber trüben und sogar zerstören. ${ }^{96}$ Dies gilt in erster Linie für den Geheimnisträger selbst, der so in gewisser Weise stets über die Macht der Selbstzerstörung verfügt. ${ }^{97}$ In den <If they only knew>-Momenten wird sozusagen die stille Überlegenheit des Helden, die Macht des Schweigens, aktualisiert. Als Kehrseite der Medaille könnte man freilich auch von der Ohnmacht des Helden, sein Schweigen zu brechen, sprechen. Als Selbstaufgabe gegenüber seinem Heldentum und seinem Geheimnis lässt es sich etwa werten, wenn der Held aus Rücksicht auf seine Doppelidentität auf eine Liebesbeziehung verzichtet.

Dass die beiden Identitäten des Helden stets in einem Kontrast zueinander stehen, erklärt sich hieraus mit Blick auf die spezifische Konzeption der Figur geradezu von selbst - wären Helden- und zivile Identität deckungsgleich, wäre die Maskerade überflüssig. Aus der Kontrastierung der beiden Identitäten ergibt sich dagegen die Möglichkeit, die beiden Seiten des Helden von anderen Figu-

94 McCulley I998 (I924), I70, vgl. z. B. auch I 24 f.

95 Mezger 2001, I30.

96 Nedelmann 1995, 6, vgl. Schirrmeister 2004, $85-87$.

97 Simmel 1908, 275, vgl. Nedelmann I995 sowie Schirrmeister 2004, 79-85. 


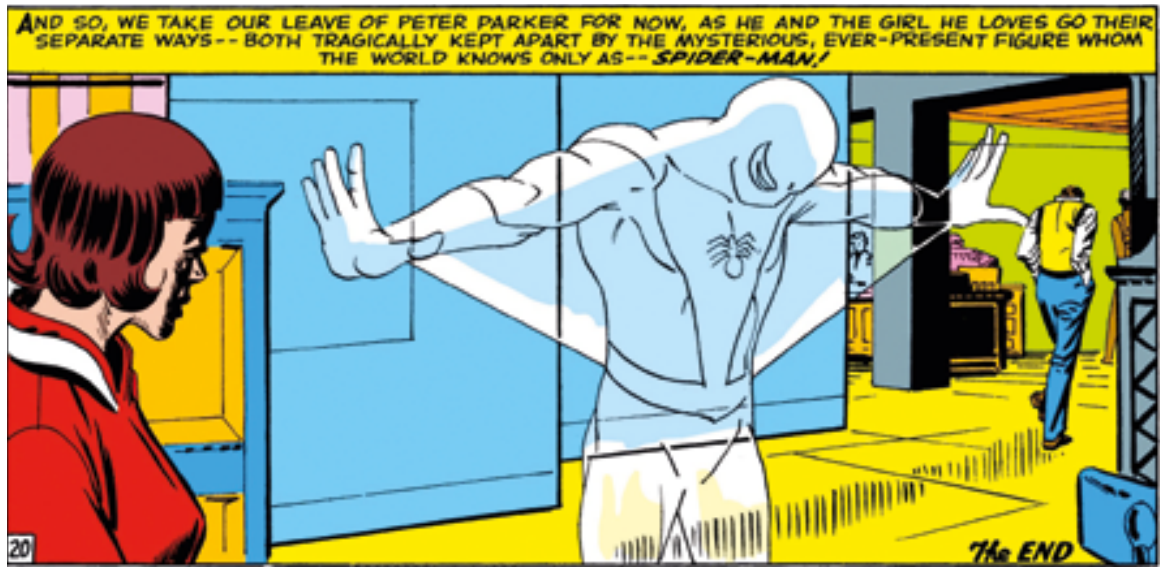

Abb. 3: Ein fast schon klassischer schmerzlicher If they only knew >-Moment von Spider-Man: Nur Peter und die Leser wissen um den wahren Grund für das Ende von Peters Liebesbeziehung zu Betty und ihre Heirat mit einem anderen Mann - gleichsam als trennender Geist steht Spider-Man zwischen den Liebenden. "The Claws of the Cat!» (Stan Lee, Steve Ditko et al.), in: The Amazing Spider-Man 30, November 1965, 20. (C) Marvel Comics

ren unterschiedlich bewerten zu lassen. Durch die vermeintliche «dullness» des Helden in seiner zivilen Erscheinung wird laut Brownie/Graydon die Tatsache der dualen Identität ebenso zu einem Spektakel, wie es sozusagen die heldische Seite des Protagonisten für sich allein (also das Agieren mit Superkräften) darstellt, die Brownie/Graydon als ein «spectacle of otherness» fassen. $9^{8}$ Was für ein Spektrum der Spagat zwischen seinen beiden Seiten für den maskierten Helden bedeuten kann, lässt sich mit einer Aussage Schirrmeisters zur Geheimhaltung zusammenfassen: «Geheimhaltung ermöglicht gute und schlechte Überraschungen, erzeugt negative und positive Spannung, verhindert und provoziert Konflikte, zerstört Beziehungen und hält sie zusammen, animiert zur Kommunikation und unterdrückt sie.»99

Einerseits bedeutet die Doppelidentität eine enorme Steigerung des Handlungspotenzials, ${ }^{100}$ andererseits aber schränkt die Notwendigkeit der Geheimhaltung

98 Brownie/Graydon 2016, 2/69.

99 Schirrmeister 2004, 53.

ı०० Auch diese Doppelung lässt sich ebenso für das Geheimnis an sich behaupten. Simmel (1908, 272) etwa sah «durch das Geheimnis eine ungeheure Erweiterung des Lebens erreicht». Zur 
dieses manchmal empfindlich ein. Insbesondere kann sich der Protagonist auch in seiner zivilen Identität auf seine Fähigkeiten und seine Handlungskompetenz verlassen (die Superhelden verfügen ja jederzeit über ihre Kräfte; bei maskierten Helden ohne Superkräfte umfasst dies zum Beispiel die Reaktionsgeschwindigkeit und ähnliche Fähigkeiten). So kann der von Batman in den Künsten der Detektion und des Kampfes geschulte Dick Grayson alias Nightwing (Nightwing 32, I999) in der Polizeischule die Anforderungen problemlos erfüllen, muss aber aufpassen, nicht zu gut abzuschneiden, um einigermassen unauffällig zu bleiben: «I know all of this stuff. But I have to act like I don't. [...] To those guys this is the greatest challenge of their lives. To me, it's a formality.» ${ }^{\text {10I }}$ Naheliegenderweise gewinnen für den maskierten Helden die Auseinandersetzungen mit seinen Gegnern an Brisanz, wenn es nicht unbekannte Dritte, sondern seine Freunde aus Gefahr zu retten gilt, weil der persönliche Einsatz, der aber unbekannt bleiben muss, steigt. Durch den dauernden Wechsel zwischen heldischer und ziviler Identität ist der Griff zur Maske im Prinzip jedes Mal aufs Neue eine Entscheidung und damit ein bewusster Schritt, als Held in Aktion zu treten. Held zu sein, bedeutet in den hier betrachteten Werken wiederum den Zwang zum Handeln - die Doppelidentität wird besonders dann zur Herausforderung, wenn privates und öffentliches Pflichtgefühl des Protagonisten im Widerstreit stehen.

Andreas Mahler zufolge bedeutet eine Maskerade im Prinzip eine Doppelung der Identität, «der Spieler kann zugleich sich selbst und ein anderer sein», sodass sich in der Maskerade «Identität und Alterität» vereinigen. ${ }^{102}$ Die Vorspiegelung zweier Personen, wo nur eine ist, birgt so reichlich Konfliktpotenzial, denn körperlich kann der Maskenträger sich nicht verdoppeln und in seinen beiden Rollen gleichzeitig an einem Ort auftreten: Tritt der eine auf, verschwindet der andere ${ }^{103}$ Der maskierte Held entspricht damit Sandro Moraldo zufolge einem (neben dem Zwilling und dem unheimlichen Doppelgänger) dritten Typ des Doppelgängers, den ebendiese raumzeitliche Einschränkung kennzeichnet. ${ }^{104}$ Dieses Problem, die beiden Hälften nicht gleichzeitig auftreten lassen zu können, umgehen die Comiczeichnungen in ausgewählten Momenten - neben dem 〈Hemd auf -Moment - insbesondere mit zwei Strategien: Das Helden-Ich wird

Konstruktion einer «zweiten Wirklichkeit» durch die Geheimhaltung bzw. Täuschung vgl. Sievers (1974, 89) und Schirrmeister (2004, I I4), die auch die einschränkende Funktion des Geheimnisses erwähnt (ebd., 65).

Io I Double Dare (Chuck Dixon, Scott McDaniel, Karl Story et al.), in: Nightwing 32, Juni 1999.

Iо2 Mahler i995, i 8 .

I03 Vgl. für die Superhelden Harrison in Easton/Harrison 2010, 339, sowie Brownie/Graydon 20I6, 3 I.

I04 Moraldo 1996, 25-33. Moraldo bezieht sich vor allem auf literarische Klassiker wie Robert Louis Stevensons The Strange Case of Dr. Jekyll and Mr. Hyde (1886). 


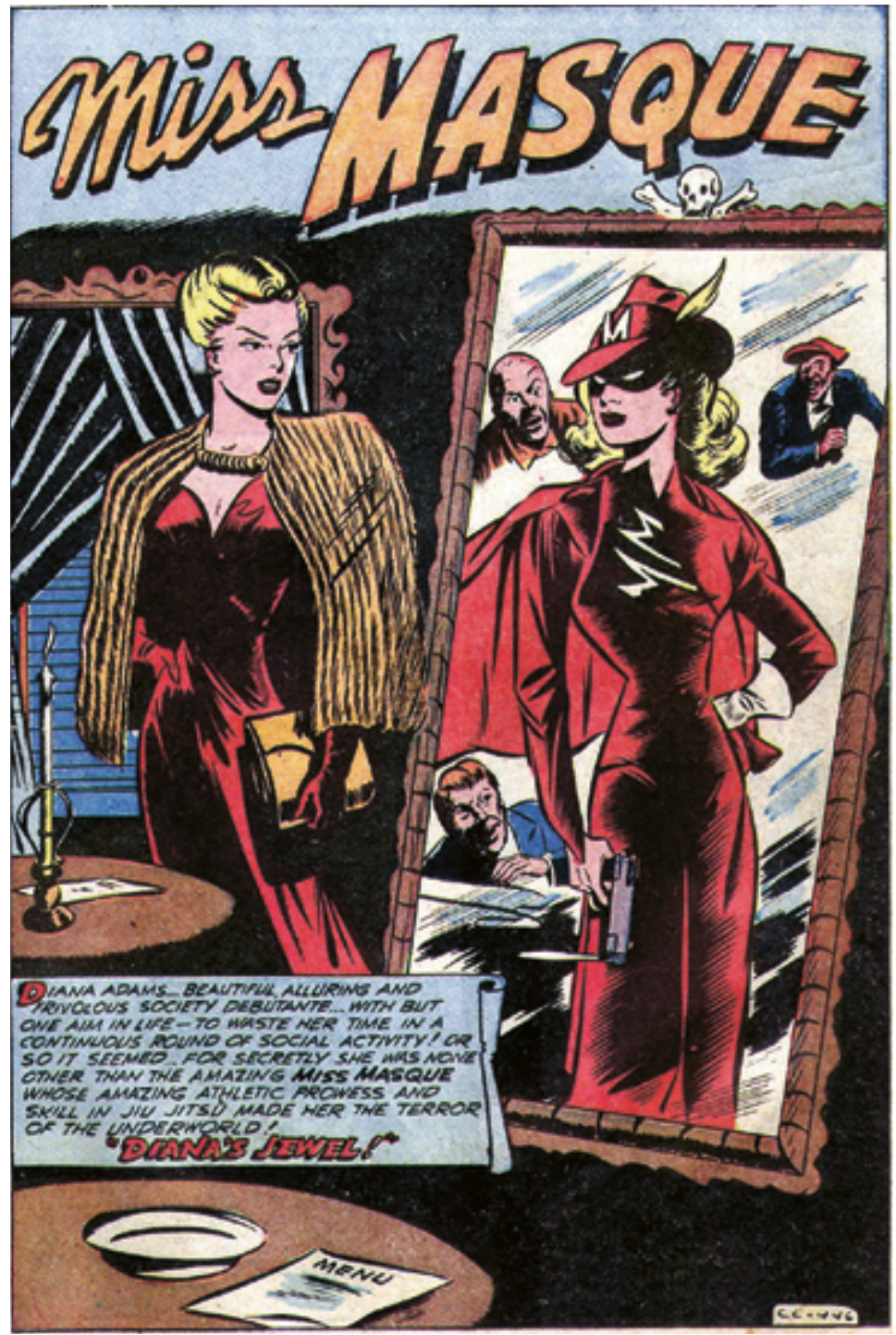

Abb. 4: Doppelidentität im Bild: Diana Adams steht im Spiegel ihrem maskierten Alter Ego Miss Masque gegenüber, wobei die Gegenüberstellung die Ähnlichkeit der beiden 〈Inkarnationen` ausstellt, die allein durch die Maske nicht erkenntlich sein soll. Miss Masque. "Diana's Jewel!» (Robert Oksner et al.), in: America's Best Comics 24, Dezember I947, Innentitelseite. 
seinem zivilen Ich als Schatten oder Spiegelbild zur Seite gestellt. Da sich das Umgekehrte nie findet, scheint das double in picture nahezulegen, dass die heldische die flüchtigere Identitätshälfte ist (Abb. 4). Aufgrund der Sequenzialität der Comics ist zudem eine Art Pseudogleichzeitigkeit möglich, wenn sich der Held so schnell umzieht, dass in einem Panel 〈beide〉 Körper zu sehen oder diese als Einheit durch den Zwischenraum zwischen zwei Panels (den sogenannten Rinnstein, englisch gutter ${ }^{\mathrm{IOS}}$ ) getrennt sind (Abb. 5). In dieser Darstellungsweise, die stärker die Dynamik der Transformation betont, kommen sich die beiden Identitätshälften visuell noch näher als bei der Schatten- oder der Spiegelvariante, die meist eher als statische Porträts erscheinen. Wenn man davon ausgehen würde, dass sich hinter den beiden äusserlich <manifesten> Identitäten eine (allenfalls 〈wahre〉) dritte befindet, so bliebe diese bei der 〈Nichtdarstellung〉 der Verwandlung im Rinnstein (oder über die Seitenumblätterung) im Unsichtbaren und somit im Ungreifbaren verhaftet - was für jegliche Bewegung gilt, die beim Comic ja im Grunde stets im Rinnstein und damit im Kopf des Lesers stattfindet, wofür Scott McCloud den Begriff closure ${ }^{106}$ geprägt hat.

Die Maske wirkt als Transformator für die <Verwandlung> des vermeintlich wenig heldenhaften Zivilisten in den kampfbereiten Helden. ${ }^{107}$ Bei den hier betrachteten maskierten Helden handelt es sich allerdings nie um tatsächliche körperliche Verwandlungen (prominente Beispiele für solche wären etwa Marvels The Hulk oder der Knabe Billy Bates, der sich in den erwachsenen Captain Marvel verwandelt, wenn er das Akrostichon «Shazam» ruft); die Maskerade des Helden bleibt streng genommen eine Verkleidung bzw. ein Kostümwechsel. Trotzdem können Kleider - ganz nach dem Diktum «Kleider machen Leute» ${ }^{108}-$ sowohl in der Eigen- wie in der Fremdwahrnehmung zweifellos eine metamorphotische Qualität haben. "All costumed heroes have a bit of the shape-shifter in them» ${ }^{109}$, bemerkt etwa Richard Harrison.

Die Verwandlungs-, das heisst die Umkleideszene gehört daher zum festen Szeneninventar des maskierten Helden. Es handelt sich dabei um einen der Momente, in welchen der Held am verwundbarsten ist, wie Brownie/Graydon dar-

ros $\mathrm{Zu}$ den spezifischen Comic-Erzähltechniken vgl. u. a. McCloud 1994, Schüwer 2002 und 2008, Dittmar 20I I, Eisner 2004 (1985), Harvey 1996, Grünewald 201 2, Meteling 2013, zu Narrationstheorie im Comic Kukkonen 2008.

I06 McCloud I994, 60-69.

107 So attestieren Brownie/Graydon (2016, 28) dem Superheldenkostüm, es transformiere den Helden ins Übermenschliche - dem widerspricht, dass der Held seine Kräfte auch ohne Maske zur Verfügung hat und auch nutzt, wenn er sicher ist, dass niemand zuschaut, oder wenn er sich in einer Notlage befindet.

ı०8 Zur Relation von Kleidung, Präsentation/Image und Identität vgl. Brownie/Graydon 2016.

I09 Harrison in Easton/Harrison 2010, I25. 

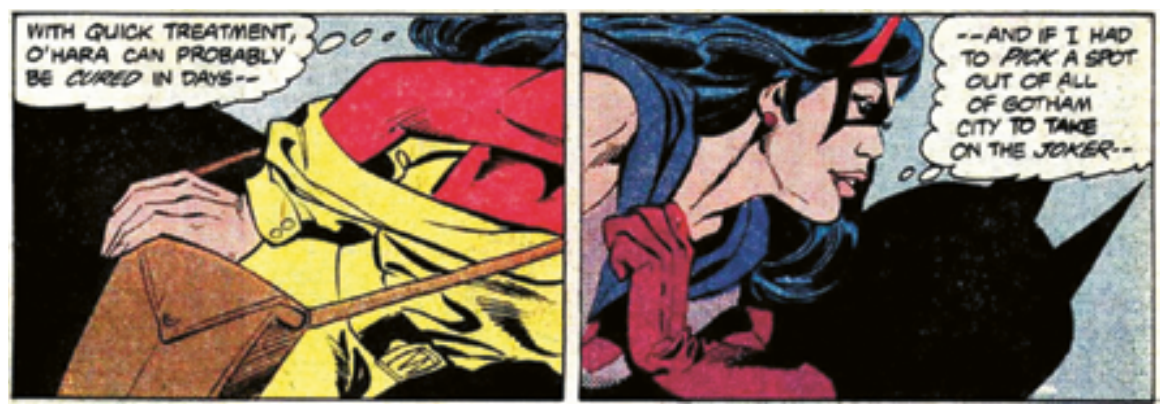

Abb. 5: Eine Umzieh- bzw. Transformationssequenz mit The Huntress/Helena Wayne, in der die «Einheit in der Zweiheit dynamisch ins Bild gesetzt ist. Während die Szene die Verwandlung auszustellen scheint, findet diese eigentlich, vor den Blicken der Leser verborgen, im Rinnstein statt. Always Leave 'Em Laughing (Paul Levitz, Joe Staton, Steve Mitchell et al.), in: Wonder Woman 28 I, Juli I98 I, 6. () DC Comics

legen, und der daher «necessarily a private act» ${ }^{10}$ ist - und bezeichnenderweise oft im Zwischenraum zwischen zwei Comicpanels stattfindet. Der maskierte Held lässt folglich nur eingeweihte Personen an seiner 〈Verwandlung> teilhaben, oftmals ist dies aber ein den Lesern vorbehaltenes Privileg. Sei es die explizite Beschreibung des heldischen Ausstaffierens in den Pulps oder in den Comics die Wechselszenen im Bild, neben den 〈If they only knew >-Momenten sind es vor allem diese Schwellenmomente, die für den Leser die Doppelung des Helden unmissverständlich sichtbar machen. «Without this insight, appreciation of the superhero's struggle with identity would not be possible, and there would be no opportunity for the dramatic irony that is staple in numerous narratives» ${ }^{111}$, betonen Brownie/Graydon.

Mit andern Worten: Mag der Held seiner Welt auch eine Zweiheit vorspiegeln, für den Leser transportieren diese Momente die maskenbedingte < Einheit in der Zweiheit und dürften nicht zuletzt über das jeweilige Aufrufen der Mitwisserschaft die Bindung an die Figur stärken. Zwar verfügen die Leser als extradiegetische Mitwisser selbstredend nicht über die Möglichkeit der Einflussnahme von

I I० Brownie/Graydon 20I6, 79; dazu auch Weltzien 2005, 233 f.

I I I Brownie/Graydon 20I6, 75; vgl. Harrison in Easton/Harrison 2010, $339 f$. 
Eingeweihten und haben auch keine Wahl, ob sie eingeweiht sind oder nicht. Doch verbindet die in ein Geheimnis Eingeweihten grundsätzlich ein starkes Band, weil es ihnen eine Ausnahmestellung gegenüber allen Nichtwissenden verleiht. ${ }^{112}$ Auch gegenüber den eingeweihten Figuren haben die Leser so die grösste Teilhabe am Doppelleben des maskierten Helden und allen damit zusammenhängenden Effekten.

I I 2 Nedelmann I995, 6; vgl. Schirrmeister 2004, 50-54, wie auch Schweizer 1992, 38, oder Smith 2009, I 26. 


\section{Masken, Rollen, Identitäten}

Do you know the big problem with a disguise, Mr. Holmes?

However hard you try, it's always a self-portrait. Irene Adler in Sherlock (SO2EOI), 2012

"You prefer to be natural?»

"Sometimes. But it is such a very difficult pose to keep up.»

Sir Robert Chiltem und Mrs. Cheveley

in Oscar Wildes An Ideal Husband, 1895

You try to be so different,

As does everybody else,

Create your own distinctions,

And flaunt them for yourself.

[...]

You think you followed your heart again,

Now it's in to be out,

Destroy the plans and just start again,

Don't pretend to not pretend at all.

The Ordinary Boys, Over the Counter Culture, 2004

Obwohl - oder gerade weil - es sich bei Identität um einen sowohl im Alltag populären als auch in mehreren wissenschaftlichen Disziplinen ${ }^{1}$ beliebten, um nicht zu sagen: inflationär² benutzten Begriff handelt, kennzeichnet ihn (in der deutschen wie der englischen Sprache) Diffusität. Welche Herausforderung der Begriff der Identität darstellt, vermag die Tatsache zu verdeutlichen, dass als wohl einfachste Definition der Identität die Antwort auf die Frage «Wer bin ich ?» gilt. ${ }^{3}$ So schlicht diese Beschreibung erscheint, die so elegant eine Definition im Grunde umgeht - ihre Komplexität offenbart sich nur schon darin, dass sie sich fast wie von selbst zu «Wer bin ich wirklich?» erweitern lässt, was bereits wieder die Möglichkeit eines 〈unwirklichen〉, ‘falschen〉 oder zumindest ‘fälsch-

I Hier ausgeblendet wird die philosophische Begrifflichkeit, vgl. dazu Henrich 1979, I 35 .

2 Keupp 1998, 239.

3 Ebd., 24I, Liebsch 2008, 76, Edgar/Sedgwick 1999, 346 (bezogen auf self). Zirfas (2010, 9) weist darüber hinaus darauf hin, dass dazu immer auch die Frage «Wer bist du?» zähle. 
lichen> Ichs erahnen lässt. Um es vorwegzunehmen: Auch in dieser Arbeit wird diese Frage nicht beantwortet werden. Umso mehr ist es nötig, wenigstens einige Punkte dazu festzuhalten.

Die staatspolitische Antwort auf diese Frage - nämlich der Name und die Daten auf der Identitätskarte - dürfte jedenfalls schnell zu kurz greifen. Doch geht Jean-Claude Kaufmann, der diese interessante Facette der Begriffsgeschichte ausgegraben hat, davon aus, dass das Wort Identität von seinem Gebrauch aus dem Kontext dieser «trivialen Verwaltungsniederungen» heraus popularisiert worden ist. ${ }^{4}$ Für eine Klärung des Begriffs hilft zudem wenig, dass er über eine ziemlich umfangreiche Verwandtschaft verfügt - und je nach Entstehungszeit eines Textes, nach Disziplin oder Geistesströmung wird ein jeweils anderes Mitglied der Verwandtschaft bevorzugt, oder die Verwandtschaftsbeziehungen werden auf je eigene Weise definiert, manchmal nur impliziert und hin und wieder sogar ignoriert.' Die begrifflich am engsten verwandte Bezeichnung ist wohl jene des Selbst, das als eigentlicher Vorgängerbegriff gesehen wird, unter dem Identitätsgesichtspunkte namentlich in der Philosophie betrachtet wurden, bevor die (Sozial-)Psychologie und die Soziologie, die sich um die Jahrhundertwende bzw. zu Beginn des 20. Jahrhunderts als wissenschaftliche Disziplinen konstituierten, Identität spätestens in den I950er-Jahren (unter anderem durch populäre soziologische Bestseller) zu einem Schlagwort machten. ${ }^{6}$

Die beiden Begriffsgeschichten weisen dabei eine bemerkenswerte Parallele auf: Eine grosse Rolle in der Popularisierung von «Identität wird Erik H. Erikson zugeschrieben, dessen Buch über den Adoleszenzprozess (Childhood and Society, 1950) zugleich die Identitätskrise in den Fokus rückte, was zum Gedanken verleitet, der Identität sei die Krise schon immer eingeschrieben. Das Selbst gilt zwar als nicht ganz so jung, seine 〈Erfindung〉 - das heisst, zu einem Thema intellektuellen Nachdenkens zu werden - wird aber doch meist (antiker und mittelalterlicher Per-

4 Kaufmann 2004, 19-26. Interessanterweise bezieht nur Kaufmann diesen Sachverhalt in seine Begriffsgeschichte ein; US-amerikanische Aufsätze dazu verbinden den Aufschwung des Wortes stärker mit Erik H. Eriksons Schriften (z. B. Gleason 1983). Tatsächlich gibt es in den USA wie in Kanada keine eigentliche Identitätskarte, wobei Kaufmanns Ausführungen für vergleichbare Papiere (Pass, Fahrausweis) durchaus Gültigkeit beanspruchen dürften. - Die Verwaltungstechnik war es laut Kaufmann auch, «die auf hinterhältige Weise die vereinfachende und substanzialistische Vorstellung von Identität fest verankerte» (ebd., 25).

5 Vgl. die Klagen zum Begriffswirrwarr um Identität z. B. von Henrich 1979, I 33, Gleason 1983 , 910, Wagner 1998, 44; Kaufmann (2004, I I, 39) spricht daher von «Zuckerwattenidentität».

6 Zur Begriffs- und Ideengeschichte von Identität und Selbst vgl. u. a. Danziger 1997, Gleason 1983, Harter 1996 und 1997, Kaufmann 2004, Baumeister 1987 und 1997, Elliott 2007, Dubiel 1976, Schrader/Schönpflug 1995, Keupp 1998, Deaux 2000, Liebsch 2008, Edgar/Sedgwick I999, Hillmann 2007, 355f., Wagner 2001, Platt 200 I. 
sönlichkeitstheorien ungeachtet ${ }^{7}$ ) erst in der beginnenden Neuzeit verortet. Die beiden frühen ¿Selbst>-Philosophen David Hume und John Locke brauchen dabei das Wort 〈Selbst〉 (self), um dessen Einheit, die 〈Selbstheit des Selbst〉, gerade anzuzweifeln. ${ }^{8}$ Man kann daher sagen, dass das Selbst, kaum dass es die Bühne der europäischen Geistesgeschichte betritt, schon gespalten ist. ${ }^{9}$

Neuere Ansätze, die Identität(en) im Zeitgeist zu verorten suchen, heben sich oft von einer als veraltet gekennzeichneten Vorstellung von Identität bzw. des Selbst ab, in welcher dieses als eine fixe Einheit empfunden wurde - woraus sich durch die Phänomene der Moderne bzw. der Postmoderne eine Art Gegenentwurf konstituierte, bei welchem die Idee einer stabilen Identität verworfen wird. Das (post-)moderne Ich zeichnet sich durch Multiplizität, Prozesshaftigkeit etc. aus, sodass Identität eigentlich nur noch im Plural existieren kann. ${ }^{10}$ Nur wird dieser Wandel bzw. dieser Bruch zu unterschiedlichen Zeitpunkten angesetzt. Roy F. Baumeister etwa geht davon aus, dass bis zum Mittelalter «notions of selfhood» viel kollektiver waren ${ }^{11}$ und sich im Laufe der gesamten Frühen Neuzeit (I 500-1 800) die Wahlmöglichkeiten vervielfachten (womit der Zwang zur Wahl stieg), die zu einer Problematisierung und Fragmentierung des Selbst (bzw. eben nicht mehr des Selbst, sondern zu diversifizierten Identitäten) führten. ${ }^{12}$ Kaufmann dagegen verortet diesen «Bruch〉 vor allem in den I960er-Jahren des 20. Jahrhunderts. ${ }^{13}$ Einen recht breit anerkannten Konsens fasst Susan Harter zusammen: «Thus, in playing out many roles as a «social chameleon», the sense of an obdurate, core self is compromised.» ${ }^{14}$

Identität und Selbst haben jedoch noch andere Begriffsverwandte: Ich, Persönlichkeit, Charakter, etwas entfernter auch Rolle's, die hier mit metaphorischer

$7 \mathrm{Zu}$ Ciceros Vorstellung einer aus vier Schichten bestehenden Persönlichkeit vgl. Weihe 2004, $330-332$.

8 Gleason I983, 91 I und 928.

9 Danziger 1997, I47: «Once the self is conceptualized as an entity that observes, evaluates, and controls itself, it is, in principle, a divided entity, unlike the soul, whose indivisibility was of essence. While the original division was between the self as observer and as observed, in the nineteenth century, with the increasing emphasis on the topic of self-control, the division between ideal self and real self assumed more prominence. From this position it was not a tremendous step to assert that there could be not just two selves in the same person, but many.»

Io Vgl. z. B. McAdams 1996; Fludernik 2007, 261.

I I Baumeister 1997, 193. Als Indizien dafür sieht er den Mangel an Autobiografien sowie an Genauigkeit in biografischen Schriften, wie etwa, dass sich Bedürfnisse nach Privatheit kaum in der Architektur spiegeln.

I 2 Baumeister 1997, I94.

I 3 Kaufmann 2004, 78. Ähnlich sieht dies Elliott (2007, I6-I9), der jedoch einen weiteren «shift in conceptions of self» in den $1980 e r-J a h r e n$ verortet.

I4 Harter $1997,87$.

is Zum Begriff der Rolle vgl. z. B. Roth 2004, 778f.: «Rolle bezeichnet ein durch Erwartungen, 
Maske gleichgesetzt wird; dazu eine Anzahl differenzierender Komposita wie 〈Ich-Identität> und attributive Adjektive wie soziale, kollektive, nationale, personale Identität. Um den unterschiedlichen Umgang mit diesen Begriffen zu illustrieren, mögen drei kurze Erwähnungen aus der Sozialpsychologie genügen: ${ }^{16}$ Richard D. Ashmore und Lee Jussim etwa setzen Identität und Selbst gleich, ${ }^{17}$ während Baumeister verkürzt gesagt Selbst als Wissensstruktur, basierend auf der Erfahrung (selbst-)reflexiven Bewusstseins, definiert und Identität als Kombination aus «being the same person» über die Zeit und «one's place in the social system, including one's roles and attachments» versteht. ${ }^{18}$ Als dritte Variante beschreibt Sheldon Stryker Identität als aus mehreren Selbsten bestehend. ${ }^{19}$

Während solche Differenzierungen für die jeweiligen Ansätze oft wohlüberlegt sind, führen sie für meine $Z$ wecke zu weit. Darum möchte ich von solchen Begriffsklaubereien absehen. ${ }^{20}$ Sofern nicht Begrifflichkeiten einer spezifischen Theorie wiederzugeben sind (was im Rest dieses Kapitels der Fall ist), werde ich die Begriffe Identität, Selbst, Ich und Rolle als 〈lose Begriffe verwenden. Selbst, Ich und Identität werde ich synonym gebrauchen, dasselbe gilt für Rolle und metaphorische Maske. Dabei möchte ich Identität mit Kay Deaux als umbrella term nutzen. ${ }^{21}$ Während man wohl zögern würde, Selbst (eher innerlich) und Rolle (eher äusserlich) gleichzusetzen, scheint Identität die Kapazität zu besitzen, diese beiden Aspekte in einem Wort zu vereinigen. Bei den maskierten Helden lässt sich durchaus argumentieren, dass die heldische und die zivile Seite eher Rollen denn Identitäten sind. Ich gebe der Bezeichnung 〈Identität> den Vorzug, da mir die heldische Seite nicht derselben Kategorie wie die verschiedenen zivilen (Teil-)Rollen des Helden - bei Peter Parker zum Beispiel Schüler/Student, Neffe, Angestellter, Actionfotograf, Freund - zuzugehören scheint und auch die

Normen, Konventionen oder Tabus geregeltes, kulturell akzeptables Verhalten von Individuen in bestimmten Positionen oder Status (wie Familie, Beruf, Gesellschaft) in bestimmten Situationen. Die Beziehungen der Rollenträger zueinander sind geregelt durch recht stabile Rollenerwartungen, die sich auf Erscheinen, Verhalten wie auch auf Eigenschaften, Wertvorstellungen etc. beziehen.» $\mathrm{Zu}$ verschiedenen Rollenbegriffen vgl. Thoits/Virshup I999, I 24 .

I6 Selbstverständlich verbergen sich hinter den unterschiedlichen Relationen oft ausgefeilte Konzepte, die hier jedoch übergangen werden müssen - es geht hier einzig darum, die unterschiedlichen Gebrauchsweisen der Begriffe zu illustrieren.

I7 Ashmore/Jussim 1997, 3. Vgl. auch deren Tabellen zu den Begrifflichkeiten in verschiedenen sozialpsychologischen Identitätstheorien (ebd., 6/9).

I 8 Baumeister 20I I, 49 .

19 Stryker 1976, 267.

20 In Anlehnung an Ralph Linton, der schon in A Study of Man 1936 den Unterschied zwischen Status und Rolle zwar formulierte, aber als rein akademischen bezeichnete (Linton 1964 (1936), II4).

2I Deaux 2000, 222. 
Superheldencomics häufiger von Identität sprechen (in den Pulps ist dagegen role oder rôle noch eher zu finden).

Während in den Analysekapiteln vor allem Identitätstheorien zur Sprache kommen werden, die sich von der Maskenmetapher gelöst haben, soll zunächst nochmals auf ebendiese Maskenmetapher bzw. das Rollenspiel eingegangen werden. Dieses Kapitel unternimmt den Versuch, aus verschiedenen Strängen ein Netz von Bezügen zwischen Maske/Rolle und Identität/Selbst - und damit zu Gesellschaft und Interaktion - zu knüpfen. Und wie ein Netz hauptsächlich aus Löchern besteht, kann dieses Kapitel keinen Anspruch auf Vollständigkeit erheben, da es in erster Linie darum geht, einen theoretischen Hintergrund zu schaffen. Dazu wird der Spur der Masken-/Rollenmetapher zuerst in traditionellen philosophischen Perspektiven gefolgt, bevor mit Erving Goffmans The Presentation of Self in Everyday Life (1959) und einigen Seitenblicken auf weitere interaktionistische Ansätze eine soziologische Sichtweise zum Zuge kommt.

\section{«Die ganze Welt ist eine Bühne» - die metaphorische Maske}

Die gegenständliche Maske soll die Identität verbergen und steht zugleich im Ruf, die 'wahre> Identität erst hervortreten zu lassen. Die metaphorische Maskerade dagegen wird eher mit der umgekehrten Relation in Verbindung gebracht: Sie verbirgt/überdeckt das «wahre> Gesicht und leistet dafür eine Anpassung. Das Spannungsfeld von Schein und Sein gilt ebenso für die metaphorische Maske. Auch diese Maske ist auf ein Publikum angewiesen; entsprechend geht es um das Individuum in einer Gesellschaft und die Wechselwirkungen dieser beiden Grössen aufeinander.

Die Vorstellung, dass die Menschen im alltäglichen sozialen Leben (und insbesondere im Dunstkreis der sogenannten besseren Gesellschaft) eine unsichtbare Maske tragen bzw. dass das Gesicht des Menschen - in der christlichen Denktradition wie erwähnt der Gegensatz der Maske - selbst zu einer Maske werden kann, führt zur Beobachtung, dass die Menschen Schauspieler sind und die Welt folglich eine Theaterbühne ist. Dieser Gedanke ist den abendländischen Denkern seit Jahrhunderten vertraut. Prominent formuliert findet er sich unter anderen bei William Shakespeare ${ }^{22}$, ebenso wie bei François de La Rochefoucauld

22 Shakespeares ebenso einschlägige wie oft zitierte Sätze lauten: «All the world's a stage, / And all the men and women are merely players. They have their exits and their entrances, / And one man in his time plays many parts» (Jacques im ca. I 599 entstandenen As You Like It, II, viii). Und Macbeth sinniert: «[...] and make our faces vizards to our hearts, / Disguising what they are» (Macbeth, III, ii, um I606). 
oder Arthur Schopenhauer. ${ }^{23}$ Die Metapher der Maske bzw. des Schauspielers, der eine Rolle spielt, erweist sich als ebenso (formal) langlebig wie (inhaltlich) flexibel. Interessant ist nämlich, mit welch verschiedenen Wertungen die Relation zwischen Person und Gesellschaft und die Funktion der Maske jeweils bedacht wird. Der Widerhall dieser Wertungen wird im Lauf dieser Arbeit immer wieder anklingen. Um dieses Spektrum zu illustrieren, möchte ich aus der Fülle der ideengeschichtlichen Stationen nur drei historische Beispiele herausgreifen: Castiglione, Rousseau und Kant.

Der italienische Diplomat und Schriftsteller Baldassarre (auch Baldesar, Baldassar o. Ä.) Castiglione entwirft in seiner I 528 publizierten Schrift Il Libro del Cortegiano ein ideales Bild des Hofmanns. Dieser muss, um seine Stellung am Hof zu erhalten bzw. diejenige eines Edelmanns würdig auszufüllen, versuchen, die Masken der andern zu erkennen bzw. zu durchschauen, zugleich aber seine eigene perfektionieren, um selbst möglichst undurchschaubar zu sein, was er sich aber nicht anmerken lassen darf. Castiglione stellt einen der eher seltenen «Denkansätze» dar, in welchen die (metaphorische) Maske nicht verwerflich geschimpft, «sondern als Lebensform verteidigt und befürwortet wird», wie Weihe betont. ${ }^{24}$ Es handelt sich um eine «zivilisierte, höfliche Maske», erklärt Weihe: «Ihr Ausdruck wird vom guten Eindruck her definiert, den sie machen soll. Die Höflichkeit wird zur Formalität, zu einer bewusst erlernten Maskerade, einer gesellschaftlich akzeptierten Form der Täuschung.»² Castigliones Verständnis der metaphorischen Maskerade ist im Hinblick auf spätere Konzeptionen in mehrfacher Hinsicht interessant, da einige seiner Grundgedanken immer wieder ein Echo finden. Castigliones Hofmann, so Weihe, «handelt immer im Hinblick auf ein virtuelles Publikum [...]. Er muss die Beobachterperspektive immer mitdenken. $»^{26}$ Für Castiglione ergibt sich im Prinzip eine klare Trennung zwi-

23 In La Rochefoucaulds Réflexions ou sentences et maximes morales (I664) lautet ein Aphorismus: «Dans toutes les professions, chacun affecte une mine et un extérieur pour paraitre ce qu'il veut qu'on le croie: ainsi on peut dire que le monde n'est composé que de mines.» Schopenhauer schreibt I 85 I in Parerga und Paralipomena kürzer: «[...] jeder trägt eine Maske und spielt eine Rolle.» Zit. n. Weihe 2004, 333/329; vgl. ebd. zu diesen beiden Autoren.

24 Weihe 2004, 77.

25 Ebd., 8 I. Montandon (201 2, 26) bemerkt, dass Castigliones «Hofmann gegen Ende der Renaissance zum Ideal des gesellschaftlichen Menschen schlechthin geworden» ist - wobei das Bild des Hofes zwischen zwei gegensätzlichen Stilisierungen oszilliert: Er kann als «Ort des moralischen Verfalls, der Ausschweifung, der Lüge und egoistischen Verhaltensweisen» oder als «Höhepunkt aller Kultur» begriffen werden. Es liegt nahe, dass die jeweilige Auffassung der metaphorischen Maske in der Bewertung des Hofes mitspielt. (Zu Machiavellis etwa gleichzeitig entworfener «Maske» des Fürsten vgl. ebenfalls Weihe 2004, 77-80.)

26 Weihe 2004, 8 r. Vgl. Castiglione o. J. ( I 528 ), i 57 f. (Buch II, Kap. XXXVI). 
schen Rolle und Person, ${ }^{27}$ wobei Weihe zufolge die <vorgespielte> Person in der Tendenz besser ist als die (vorspielende> Person, da sie Vorzüge betonen und Schwächen verbergen darf. ${ }^{28}$

Zwei wegweisende Aspekte von Castigliones Höflingsideal umschreibt Alain Montandon wie folgt:

Der Hofmann [...] setzt gleichzeitig auf Nachahmung und Einzigartigkeit. Einerseits ist der Höfling das Chamäleon schlechthin, andererseits der Pfau, der die Besonderheit des einzigartigen Individuums vertritt, das sich von allen anderen unterscheidet. Die sprezzatura, das Undefinierbare und das je ne sais quoi sind die Merkmale einer Kunst, die nach Natürlichkeit strebt, indem sie ihre Ursprünge unkenntlich macht. ${ }^{29}$

Der hier mit zwei bunten Tiermetaphern angesprochene SSpagat〉 des Individuums zwischen Individualität und Konformität wird sich als ein zentraler Punkt in vielen Identitätstheorien erweisen. Das Rollenspiel des Hofmanns ist Teil des höfischen Verhaltensideals der Galanterie ${ }^{3 \circ}$, die aber wohl nicht zufällig schon von einem gewissen Ruch der Pose umweht ist, dem zu verfallen der Hofmann aber durch die sprezzatura vermeidet. Diese Wortneuschöpfung gilt als Castigliones zentraler Begriff, und mit diesem nimmt er bezüglich der Selbstdarstellung die Beobachtungen späterer Autoren im Prinzip vorweg. Denn der noblen Gesprächsrunde im Cortegiano ist spürbare Affektiertheit ein Greuel - die Selbstdarstellung soll möglichst ungekünstelt wirken, selbst wenn sie es nicht ist. ${ }^{3}$ Es liegt auf der Hand, dass der Höfling hier durchaus Parallelen zur Figur des maskierten Helden aufweist, der in seinen beiden Rollen, der zivilen wie der heldischen, oft ebenfalls «Natürlichkeit〉 seines Verhaltens vorgeben muss, während er in einer Doppelrolle agiert. Von einer dadurch hervorgerufenen Zerrissenheit oder sogar Gebrochenheit ist in Castigliones Ideal allerdings nicht die Rede.

Metaphorisch eine Maske zu tragen, ist ebenso ein Bestandteil des Weltbilds von Jean-Jacques Rousseau. In Émile ou De l'éducation (1762) legt auch er die Erkenntnis dar: «L'homme du monde est tout entier dans son masque.» ${ }^{32} \mathrm{Im}$ Un-

27 Weihe 2004, 8I. Weihe bilanziert dazu zwar: «Jeder Anspruch auf persönliche Integrität und Innerlichkeit wird damit aufgegeben» (ebd.), aber ich möchte Castiglione, dem es vor allem um das Wie des Rollenspiels geht (es darf nicht übertrieben werden, sondern soll einem gemässigten Auftritt dienen), unterstellen, dieses als Ausdruck der Integrität seines Hofmanns zu sehen, vgl. Castiglione o. J. ( I 528 ), z. B. I $58-166$, Buch II, Kap. XXXVI-XLI.

28 Weihe $2004,83$.

29 Montandon 201 2, 27f. Sprezzatura wird gewöhnlich mit <Lässigkeit übersetzt und findet in der affettazione ihren Gegenbegriff (ebd.; auch Weihe 2004, 82).

30 Der cortegiano ist eine frühe Station in der Ideengeschichte des hônnete homme sowie der Galanterie, worauf hier aber nicht weiter eingegangen werden kann (vgl. dazu Montandon 20I2).

3 I Castiglione o. J. ( 5 28), 53 f. (Buch I, Kap. XXVI).

32 Jean-Jacques Rousseau: Emile ou De l'éducation, Paris I966 (I762), 289, zit. n. Kleine 1995, I 54. 
terschied zum cortegiano ist die metaphorische Maske bei Rousseau mitnichten Bestandteil eines Ideals. Vielmehr ist sie geradezu «Markenzeichen des modernen, korrumpierten Menschen - des ‘homme du monde»»33, wie Inge Kleine erklärt. Der homme du monde ist dabei ein Produkt der grossstädtischen Gemeinschaft, die für Rousseau eine verwerfliche Institution darstellt und so den Kontrast zum ländlichen Leben als dem erstrebenswerten Ideal liefert. Dieses wird bei Rousseau zu einem «Raum der Maskenlosigkeit und Authentizität» ${ }^{34}$. Émile als Verkörperung von Rousseaus «Naturideal ist Verstellung bzw. Maskenhaftigkeit fremd, hat er doch nichts zu verbergen. ${ }^{35}$ Wie Jörg Zirfas und Benjamin Jörissen erläutern, entwirft Rousseau ein bestimmtes Ideal von Identität, das er aber - zumindest im bomme du monde - gerade nicht erfüllt sieht:

Seit Jean Jacques Rousseau [...] gelten Identität und Authentizität als entscheidende Ziele der Erziehung: Dass das Subjekt mit sich eines und dasselbe sein will und soll, bestimmt für Rousseau nicht nur den ethischen Massstab seines Handlungs- und Bildungsprojekts, sondern bildet auch die Basis seiner Zeit- und Kulturkritik. Diese richtet sich gegen die bürgerliche Form, die es dem Individuum unmöglich macht, es selbst zu sein, da diese im Gegenteil die innere Widersprüchlichkeit des Subjekts erst konstituiert. ${ }^{36}$

Diese «innere Widersprüchlichkeit» entsteht, da die Gesellschaft dem Menschen das Aufsetzen einer unsichtbaren Maske aufzwingt, sobald er sich im öffentlichen Raum bewegt - die er jedoch in den eigenen vier Wänden wieder ablegen kann. Rousseaus Maskenphilosophie beruht also nicht nur auf Stadt-Land-Kontrast, sondern auch auf dem Gegensatz von öffentlichem und privatem Sein.

Auch bei Rousseau steht die Maske in einer paradoxen Situation. Einerseits steht sie für Korrumpierung, andererseits hat sie eine Schutzfunktion: «Der gute, nicht korrumpierte Mensch aus Rousseaus positivem Menschenbild muss eine Maske tragen, wenn er an der Gesellschaft teilhat, um das eigene, «schöne〉 Gesicht zu bewahren.»37 Die Maske ist so zwar einerseits «Mittel der Verstellung», erklärt Kleine, dient andererseits aber auch der «Wahrung der Identität» und lässt sich sogar als «Garant der Authentizität» auffassen..$^{38}$ Dennoch scheint bei Rousseau die negative Konnotation der Maske des homme du monde dominant. «Rous-

33 Kleine 1995, I 57 (Weihe 2004, 335, spricht vom «Requisit einer degenerierten Gesellschaft»); vgl. ebd. und Kleine 1995 für eine ausführlichere Beschreibung von Rousseaus Maskenkonzepten, die er in anderen Schriften ausdifferenziert hat und die für Frauen und Männer unterschiedlich ausfallen. Zum Stichwort Identität bei Rousseau vgl. Zirfas/Jörissen 2007, 76-79.

34 Kleine 1995, I 56.

35 Ebd., I55.

36 Zirfas/Jörissen 2007, 76.

37 Kleine 1995, I 57.

38 Ebd., I $57 f$. 
seaus Maskenträger trägt eine Maske, die er nicht tragen will»39, fasst Weihe das Problem zusammen. Damit klage Rousseau eigentlich ein «konformistisches Verhalten» an, wobei der «Wunsch nach gesellschaftlicher Anerkennung» letztlich zur Selbstentfremdung führt. ${ }^{\circ}$ Rousseaus Maskenträger ist «als doppelter Mensch angelegt»: Im ständigen Widerspruch zu sich selbst stehend, hin- und hergerissen zwischen der 〈Natürlichkeit〉 des Individuums und der «Unnatürlichkeit> in der Gesellschaft, ist er ein zerrissenes Wesen. ${ }^{4}$

Nicht ganz so schwarz sieht dies Immanuel Kant, der wieder eher auf Castigliones Verständnis zurückgreift, dieses jedoch um einen entscheidenden Aspekt erweitert. Unter der Überschrift Von dem erlaubten moralischen Schein führt er aus:

Die Menschen sind insgesammt, je civilisierter, desto mehr Schauspieler; sie nehmen den Schein der Zuneigung, der Achtung vor Anderen, der Sittsamkeit, der Uneigennützigkeit an, ohne irgend jemand dadurch zu betrügen, weil ein jeder Andere, dass es hiemit eben nicht herzlich gemeint sei, dabei einverständigt ist, und es ist auch sehr gut, dass es so in der Welt zugeht. Denn dadurch, dass Menschen diese Rolle spielen, werden zuletzt die Tugenden, deren Schein sie eine geraume Zeit hindurch nur gekünstelt haben, nach und nach wohl wirklich erweckt und gehen in die Gesinnung über. ${ }^{42}$

Eine Rolle zu spielen, hat für Kant nicht nur eine vorspiegelnde oder verbergende Funktion, sondern dient auch der charakterlichen Verbesserung ihres Trägers, wirkt also auf diesen zurück. Kant gesteht der Person damit Entwicklungspotenzial zu, und zwar gerade aufgrund der metaphorischen Maske (jedenfalls solange diese für <Anständigkeit> und 〈Zivilisiertheit> sorgt). Trotz dieser Positivierung des Maskengedankens vermeidet es Kant, sich Illusionen zu machen, wenn er weiter schreibt:

Alle menschliche Tugend im Verkehr ist Scheidemünze; ein Kind ist der, welcher sie für ächtes Gold nimmt. - Es ist aber doch besser, Scheidemünze, als gar kein solches Mittel im Umlauf zu haben, und endlich kann es doch, wenn gleich mit ansehnlichem Verlust, in baares Gold umgesetzt werden. [...] Selbst der Schein des Guten an Anderen muss uns werth sein: weil aus diesem Spiel mit Verstellungen, welche Achtung erwerben, ohne sie vielleicht zu verdienen, endlich wohl Ernst werden kann. ${ }^{43}$

39 Weihe $2004,336$.

$4 \circ$ Ebd., 335 .

4I Ebd., 336 (Hervorhebung im Original).

42 Kant 1798, I I I (Anthropologie in pragmatischer Hinsicht), ebf. zit. bei Wimmer/Schäfer 2000, I9. Kant spricht allerdings nicht von Maske, nur von Rolle.

43 Ebd., I $52 f$. (Scheidemünzen sind Münzen, deren nomineller Wert den Materialwert übersteigt.) Nicht so tolerant will Kant (ebd., I 53) aber der eigenen Person gegenüber sein: «Nur der Schein des Guten in uns selbst muss ohne Verschonen weggewischt $[\ldots]$ werden.» 
Für Kant stellt die Maske die «Fassade, dünne Tünche über einer immer noch unzivilisierten Natur» des Menschen dar, der erst «zum Guten erzogen werden» muss. ${ }^{44}$ Dazu soll die «Maske der Moralität [...] mit dem «Gesicht verwachsen», erklären Alfred Schäfer und Michael Wimmer: «Was anfänglich nur Maske einer tierischen Natur ist, soll selbst zur Natur des Menschen werden, die Maske mit dem Maskierten verschmelzen.»45 Die Gesellschaft fungiert so für das Individuum als «Regulativ für das eigene Agieren» ${ }^{46}$. Wie Weihe weiter ausführt: «Damit wird das Schauspielerische, die Wandlungsfähigkeit, zu einer gesellschaftlichen Kategorie, zu einer Voraussetzung für den Zivilisationsprozess aufgewertet. Schauspielen [...] erscheint als Grundvermögen des zivilisierten Menschen.»47 Das Rollenspiel bzw. die metaphorische Maske hat bei Kant einen transformierenden Charakter.

So unterschiedlich die Sichtweisen von Castiglione, Rousseau und Kant auch sind, sie haben zwei Aspekte gemeinsam. Erstens leistet das Tragen der metaphorischen Maske bei allen drei Autoren eine Anpassung an gesellschaftliche Erwartungen. Zweitens ergibt sich dadurch eine grundlegende Zweischichtigkeit des in einer Gesellschaft agierenden Menschen: der vorgespielten Rolle und der spielenden Person. Klar ist, dass diese nicht deckungsgleich sind, sodass hier wieder die Frage anklingt, ob beide Schichten zur Person gehören bzw. inwiefern die vorgespielte Rolle die 'wahre> Persönlichkeit darstellt, was zu unterschiedlichen Wertungen der Maske führt. Jedenfalls verlockt die Maskenmetapher dazu, den Menschen als geteiltes oder allenfalls gespaltenes Wesen zu sehen, wobei Kant wie gesagt die Möglichkeit einer Überwindung dieser Zweiheit in Betracht zieht. Die zwei Seiten - die zumindest implizit Dichotomien bilden können - lassen sich dabei mit verschiedenen Akzenten konturieren: Natürliches/Wahres/Authentisches und Künstliches/Verstellendes/Täuschendes, aber auch - allenfalls mit jener Wertung verbunden, aber auch losgelöst davon - als Inneres und Äusseres, Privates und Öffentliches.

Diese Zweiheit stellt naheliegenderweise eine Herausforderung für die Vorstellung einer einheitlichen, fixen Identität dar. Das Individuum erweist sich, wie Weihe treffend bemerkt, gerade als Dividuum. ${ }^{4}$ Gleichwohl lässt sich die eine

44 Wimmer/Schäfer 2000, I6.

45 Ebd., I8f. Kant sieht den Menschen auch im Spannungsfeld zwischen Vernunft und Tierhaftigkeit (ebd.). Zu Kants Begriff von Selbst und Selbstbewusstsein vgl. Schrader/Schönpflug I $995,298 \mathrm{f}$.

46 Weihe 2004, 83. Er bemerkt hierzu eine Parallele zum Schauspieler, der Erfolg hat, wenn das Publikum ihm die Rolle abkauft, und nicht, wenn er sich für gut dünkt (ebd.), ähnlich übrigens Plessner 1982 (1948), 408.

47 Weihe 2004, 84.

48 Ebd., I4, 342. 
Hälfte nicht von der anderen trennen. Weihe hat dafür ein ebenso einfaches wie anschauliches Bild gefunden: Faltet man ein Blatt Papier, so hat man zwei getrennte Seiten und zugleich bloss ein gefaltetes Blatt. ${ }^{49}$ Eine solcherart gedachte Figur bezeichnet Weihe als Homo duplex. ${ }^{50}$

Als Weiterentwicklung einiger Gedanken von Émile Durkheim ${ }^{51}$ und Helmuth Plessner ${ }^{52}$ konturiert Weihe unter dieser Bezeichnung das Bild eines Menschen, der «das Verhältnis zwischen Individuum und Gesellschaft nicht als Antagonismus versteht, sondern als Kooperation»'s3. Dazu gehört aber auch das gesellschaftliche Rollenspiel:

Der Einzelne braucht die Anderen wie der Schauspieler seine Zuschauer; die Zuschauer veranlassen den Schauspieler, möglichst viele Rollen zu spielen und so sein Ausdrucksspektrum zu erweitern. Homo duplex ist der Mensch, der sich darstellt, der Rollen spielt, der Erwartungen erfüllt oder dagegen protestiert, der wirken will, der Eindruck machen will, der akzeptiert werden will, mit möglichst vielen anderen verbunden sein will, und sei es auch nur durch das Wissen, dass seine Existenz von diesen anderen registriert worden ist. ${ }^{54}$

Diese Beschreibung könnte weitgehend auch auf den Akteur bzw. Schauspieler aus Erving Goffmans Beobachtungen übertragen werden, die im nächsten Unterkapitel im Fokus stehen. Nur fehlt dort die Betonung der Zweiheit, die aber in Bezug auf den maskierten Helden Anlass zu einem Gedankenspiel gibt: Weihe sieht seinen Homo duplex als «theoretische Personifikation einer konstitutionellen Duplizität», die «für eine Zweiheit im Persönlichen [steht], die als Einheit im Sozialen gelebt werden kann»'s. Wenn man die Zweiheit des maskierten Helden damit vergleicht - dessen beide Rollen ja getrennt sind -, so lässt sich fragen, ob es sich beim maskierten Helden nicht gerade umgekehrt verhält: Er lebt eine (freilich in hohem Masse stilisierte) Zweiheit im Sozialen, die aber im Persönlichen eine Einheit darstellt.

Wie bereits erwähnt, impliziert Zweiheit dabei stets auch Vielheit - wie es Weihe formuliert: «Die Dualität als Einheit und Vielheit zugleich: das ist eine präzise

49 Weihe 2004, I 4, I 87. Weihe erläutert zudem, dass die Figur des Homo duplex eine kirchengeschichtliche «strukturelle» Parallele im Nestorianischen Streit hat, in dem es darum ging, ob Jesus Christus als Person in oder aus zwei Naturen zu denken sei (ebd., 34, I 83f., 342).

50 Weihe 2004, I4, 340. Duplex kann sowohl «verdoppelt, zweischichtig» als auch «geteilt» meinen (ebd.).

s I Durkheim (1914, 209) sprach vom Homo duplex als sozusagen Wechselwirkung zwischen Individualität (Körper) und (sozialer) Welt.

52 Plessner 1966.

53 Weihe 2004, 353.

54 Ebd.

55 Ebd., 354. 
Umschreibung der paradoxalen Figur einer Einheit des Unterschiedenen.» ${ }^{6}$ (Um auf das Bild des gefalteten Blattes zurückzukommen, lässt sich spekulieren, ob die Weiterentwicklung vielleicht als «Origami-Ich` zu metaphorisieren wäre.) Diese Vervielfachung lässt sich wohl durchaus mit verschiedenen sozialen Rollen verbinden. Bei den maskierten Helden wird diese Vervielfachung darüber hinaus anhand der Heldenidentität plakativ deutlich, da sie sich - sobald einmal zwei Identitäten «installiert sind - weiter vervielfachen können, indem sie weitere (allerdings meist temporär) alternative Heldenidentitäten oder UndercoverPersönlichkeiten schaffen. ${ }^{57}$

\section{Interaktion und Identität, Konformität und Einzigartigkeit}

Was Kant angedacht hat - dass sich das Individuum durch das Rollenspiel entwickeln kann -, wurde zu Beginn des 20. Jahrhunderts in einer rückblickend als (symbolischer) Interaktionismus bezeichneten Strömung im Kreuzungsfeld von Psychologie und Soziologie weiterentwickelt. Ihre Vertreter gingen davon aus, dass das Selbst hauptsächlich eine soziale Konstruktion war: «[...] the personal self is crafted through the incorporation of attitudes that significant others appear to hold about one's self.» ${ }^{8}$ Diese Vorstellung muss nicht unbedingt mit dem Bild der Maske oder der Rolle verknüpft werden - nicht unerwähnt bleiben darf hier Charles Cooley, der 1902 die Metapher eines Spiegel-Selbst (looking-glass self) schuf. 59

$\mathrm{Zu}$ einem Standardkonzept in der Soziologie mauserte sich zudem die Variante von George Herbert Mead. In Mind, Self and Society ${ }^{60}$, 1934 postum erschie-

56 Ebd., 34I. So schreibt Weihe (ebd., I4f.) in Bezug auf den Homo duplex auch: «Nicht nur der Kern, auch die Hüllen gehören zur Identität einer Person.» Es gibt also nicht nur eine Hülle oder eine Schale um einen Kern, sondern die Identität kann mehrere Hüllen umfassen oder aus diesen bestehen.

57 So unterhält Bruce Wayne/Batman eine weitere Identität als in Verbrecherkreisen bekannter Matches Malone, um Informationen zu sammeln; auch Spider-Man oder Daredevil multiplizieren sich gelegentlich (worauf ich in den Kapiteln zu diesen beiden Helden näher eingehe).

58 Harter 1997, 8I.

59 Man sieht die andern wie einen Spiegel an, um ihre Meinung über einen zu erhaschen und baut diese dann in den eigenen «sense of self» (Harter I996, 4) ein. Zu Cooley vgl. etwa Scheibe 1985 , 42-45. Die Metapher des Spiegels kombinierte dann Anselm Strauss wieder mit der Maskeim fast parallel zu Goffmans Presentation of Self in Everyday Life erschienenen Mirrors and Masks (1959).

60 Der deutsche Titel des Buches lautet bezeichnenderweise Geist, Identität und Gesellschaftwobei die Übersetzung in Bezug auf den Umgang mit Meads Begrifflichkeiten des Selbst ( $\mathrm{I}$ ) und 〈Me〉) zu Recht kritisiert wird, vgl. Abels 2007, 33, sowie Jörissen 2010, 9If., I0 I. 
nen, bezeichnete er als Rollenübernahme (role-taking, auch taking the role of the other) zwei Stufen im Entwicklungsprozess des Kindes. Während play das <einfache> Rollenspiel, das 〈So-tun-als-ob〉 meint, umfasst die zweite Stufe des game das regelgebundene Spiel mit mehreren Spielern, welches strategisches Rollendenken bzw. -handeln verlangt. Erst indem sich das Kind in die verschiedenen anderen Rollen hineinversetzt, so Meads These, bildet es sein Selbst aus. Rollenübernahme ist also, so formuliert Heinz Abels in Kürze, die «Fähigkeit, von der Position des Anderen aus zu denken ${ }^{61}$. Stryker betont, dass es sich dabei um den «Prozess der Antizipation der Reaktionen der anderen, die mit einem in einer sozialen Handlung verknüpft sind», handelt. ${ }^{62}$ Das Selbst ist bei Mead so auch eine erst reflexiv herzustellende Grösse. ${ }^{63}$ Entsprechend kann das Publikum einer Vorstellung des Einzelnen auch imaginär sein oder aus ihm selbst bestehen (Stichwort Selbstgespräch). Mead führte dazu einen weiteren, inzwischen stehenden Begriff ein. Dieser Prozess der Rollenübernahme kann sich zwar auf spezifische Andere beziehen, vollzieht sich aber häufiger in Bezug auf einen generalisierten Anderen (generalized other). ${ }^{64}$ «The self for Mead is at once individuality and generality, agent and recipient, sameness and difference» ${ }^{65}$, bilanziert Anthony Elliott. Mead bezog sich in diesem Punkt freilich genau genommen nur auf die Entwicklung des Kindes.

Die wohl umfassendste Ausarbeitung der Theatermetapher für das soziale Leben hat Erving Goffman in The Presentation of Self in Everyday Life (mit dem sprechenderen deutschen Titel Wir alle spielen Theater) aus dem Jahr I959 entworfen. ${ }^{66}$ In diesem Buch geht es Goffman zwar nicht in erster Linie um die Bestimmung von Selbst oder Identität - was in seinem späteren Buch Stigma (1963) expliziter thematisiert wird -, sondern um die Mechanismen und Strategien, derer sich ein Individuum in der Begegnung mit andern bedient. ${ }^{67}$ Seine Studie beschreibt, wie sich das Individuum anderen präsentiert und mit welchen Strategien es seine Präsentation gestaltet und so den Eindruck, den es auf andere

6I Abels 2007, 22.

62 Stryker $1976,263$.

63 Jörissen 2010, 97.

64 Stryker 1976, 263.

65 Elliott 2007, 32.

66 Eine erste Version erschien in Schottland bereits 1956 (Scheibe 1985,56 ). Die folgenden Ausführungen basieren auf Goffman 1959 sowie von Engelhardt 2010, Abels 2006, 319-364, sowie 2007, I 53-198, Elliott 2007, 37-44.

67 Doch wie Deger $(2000,203)$ schreibt: «Eine soziologische Perspektive auf Identität ist fast zwingend in der Interaktion verortet.» 
macht, zu beeinflussen versucht. ${ }^{68}$ Dabei ist er sich der Grenzen der Theatermetapher von Anfang an bewusst. ${ }^{69}$

Dennoch erweist sich seine Metapher grundsätzlich als recht tragfähig (was nicht heisst, dass es keine Kritikpunkte ${ }^{70}$ gäbe). Goffman bildet eine Art Kristallisationspunkt verschiedener Denktraditionen: Einerseits greift er die althergebrachte Theatermetapher auf, entwickelt einige Ansätze der frühen Interaktionisten und der diesen vorangehenden soziologischen und sozialpsychologischen Auseinandersetzungen mit dem Selbst bzw. der Identität weiter (nach Abels führt er «Meads These von der Rollenübernahme in Richtung der kalkulierten Wirkung fort» $\left.{ }^{71}\right)$. Andererseits lassen sich viele neuere Ansätze der Identitätsdiskussion mit Goffmans Überlegungen verknüpfen. Aus diesem Grund wird nun ein Teil seiner Theorie ausführlicher dargestellt.

Wenn zwei Individuen sich begegnen, legt Goffman den Rahmen seiner Überlegungen aus, sind beide zentral an Informationsbeschaffung über den anderen interessiert, um dessen gegenwärtiges oder zukünftiges Verhalten abschätzen zu können. Es handelt sich um «a kind of information game, a potentially infinite cycle of concealment, discovery, false revelation, and rediscovery ${ }^{72}$. Zentrale Grösse ist dabei die Definition der Situation - jedes an der Interaktion beteiligte Individuum nimmt eine solche vor und entscheidet sich auf dieser Basis für eine Handlung. Diese Entscheidung kann dabei mehr oder weniger bewusst sein und ist zumindest potenziell eine strategische. In der Regel sind die Individuen ja daran interessiert, dass die Interaktion erfolgreich ist. Entsprechend werden die Situationsdefinitionen der Interaktionsteilnehmer in der Regel so vorgenommen, «dass keine offensichtlichen Widersprüche auftreten» ${ }^{73}$. Dabei betont Goffman, dass dies gerade nicht geschieht, indem alle ihre ‘wahren> Gefühle offenbaren, sondern sich einer Situationsbestimmung anpassen, die sie für die anderen Interaktionsteilnehmer zumindest temporär für akzeptabel halten.

68 Goffman 1990 (1959), xi. Deutsche Ausgabe: Goffman 2002, 3.

69 Zwei Einschränkungen stellt Goffman seinen Überlegungen voran: Erstens sei die Theatermetapher «offensichtlich inadäquat» (2002 (1959), 3), denn die Bühne präsentiere «things that are make-believe: presumably life presents things that are real and sometimes not well rehearsed» (1990, xi). Zweitens ist im Theater das Publikum die dritte (unbeteiligte) Partie, im Alltag aber fallen Publikum und Akteure zusammen bzw. der Einzelne ist zugleich beides.

70 Am meisten kritisiert wird, dass Goffmans Weltsicht eine zynische sei, voller amoralischer Manipulatoren. Dagegen argumentiert z. B. Deger (2000, 197), Goffmans Masken hätten v. a. eine Schutzfunktion. Vgl. auch Tseëlon 1992, Abels 2007, I64f., Elliott 2007, $42 \mathrm{f}$.

7I Abels 2006, 32I.

72 Goffman I990 (1959), 8f. (dt. 2002, I 2f.). Dabei bemerkt Goffman, dass man als Mensch wohl besser dafür ausgerüstet sei, die anderen zu durchschauen, als das eigene Verhalten zu manipulieren (ebd.)

73 Deger 2000, I94. 
Damit wird zwischen den verschiedenen Interagierenden ein «surface of agreement», ein Arbeitskonsens, etabliert, dem die einzelnen Darstellungen zu entsprechen suchen. ${ }^{74}$

Es ist leicht vorstellbar, dass es zu peinlichen Szenen führen kann, wenn eine Situationsdefinition fehlschlägt. Schlüsselfaktor für eine gelungene Interaktion ist die Aufrechterhaltung einer einzigen Definition einer Situation aller Teilnehmer, «this definition having to be expressed, and this expression sustained in the face of a multitude of potential disruptions» 75 . Denn eine von dieser abweichende Situationsdefinition «treibt einen äusserst störenden Keil zwischen den allgemein anerkannten Entwurf und die Realität, denn es gehört gerade zur Projektion, dass sie als die einzig mögliche akzeptiert werden kann». ${ }^{6}$ Dass eine darstellerische Stimmigkeit des Ausdrucks eine Voraussetzung dafür ist, deutet laut Goffman auf eine 〈Diskrepanz zwischen zwei Seiten hin: Als menschliches Wesen ist man grundsätzlich Stimmungsschwankungen unterworfen, denen man als Darsteller vor einem Publikum jedoch nicht nachgeben kann. ${ }^{77}$ Das Publikum der einen Darstellung ist dabei in der Regel nicht dasselbe wie in der nächsten; Goffman spricht hierbei von Segregation des Publikums (audience segregation). $7^{7}$ Für den Spezialfall des maskierten Helden lässt sich sagen, dass dies für ihn zwar gilt, wenn er etwa als Held verschiedene Statisten rettet und als Zivilperson verschiedene Freunde trifft, dass er aber zuweilen zwei verschiedene Rollen vor demselben Publikum (seinen Freunden und Bekannten) spielen muss, ohne dass jenes dies wissen darf.

$\mathrm{Da}$ Goffmans «zentrale Analyseeinheit»79 die Situation ist, befasst er sich sozusagen mit einer Mini-Einheit des alltäglichen Lebens. Unter 〈Rolle〉 darf man aber in der Regel eine mehreren Situationen übergeordnete Kategorie verstehen. Goffman selbst macht dabei einen Unterschied zwischen den Wörtern role und part oder routine (was die deutsche Übersetzung seines Textes geflissent-

74 Goffman I990 (1959), 9 (dt. 2002, I3).

75 Goffman 1990 (1959), 254 (dt. 2002, 233).

76 Goffman 2002 (1959), 49 (engl. 1990, 52).

77 Goffman 1990 (1959), 56 (dt. 2002, 52).

78 Goffman I990 (1959), 49. Wie Goffman anfügt, ist dies auch im Interesse des Publikums: Gerade in der Grossstadt wäre es doch nicht auszuhalten, wenn man von jedem Sorgen, Geheimnisse etc. mitgeteilt bekäme. Zugleich bezieht er sich hier auf einen viel zitierten Satz aus William James' Psychology von 1905: «We may practically say that he [the individual] has as many different social selves as there are distinct groups of persons about whose opinions he cares. He generally shows a different side of himself to each of these different groups» (ebd., $48 \mathrm{f}$.; dt. 2002, 46). Zu James' mehrteiligem Selbstkonzept vgl. Harter 1996, I-3, Scheibe 1985, 37-39, McAdams 1997, 55 f.

79 Deger 2000, 193. 
lich unterschlägt $\left.{ }^{80}\right)$. Routine definiert Goffman als «pre-established pattern of action which is unfolded during a performance and which may be represented or played through on other occasions $»^{{ }^{8}}$. Ergänzend dazu definiert Goffman social role als «enactment of rights and duties attached to a given status [...], will involve one or more parts [...], each of these [...] may be presented by the performer on a series of occasions to the same kinds of audiences or to an audience of the same persons ${ }^{8_{2}}$. Damit orientiert er sich an der klassischen Definition von Rolle und Status von Ralph Linton, ${ }^{8}{ }_{3}$ der Rolle als dynamischen Aspekt von Status (Position in einem gesellschaftlichen Muster) begreift, wobei jedes Individuum mehrere Rollen und Status hat und zugleich als deren Summe eine Rolle und einen Status. Insofern lassen sich Goffmans für eine sehr kleine Einheit gemachte Beobachtungen auf eine solche «Summe aller Rollen〉 eines Individuums übertragen.

Goffman differenziert folgende Elemente der Darstellung: ${ }^{84}$ Fassade (front) bezeichnet das Standardrepertoire an Ausdrucksmöglichkeiten, die das Individuum in seiner Darstellung routiniert anwendet. Die Fassade beinhaltet dabei das Bühnenbild (setting), das kurz gesagt Räumlichkeiten und Szenen umfasst. $\mathrm{Zu}$ den szenischen Komponenten zählt in erster Linie eine persönliche Fassade (personal front), die sich in Erscheinung (appearance), also äussere Merkmale wie Kleider ${ }^{85}$ oder Körperlichkeiten, und Verhalten (manner) aufteilen lässt. Im Idealfall sind diese übereinstimmend, doch kann es dabei auch zu Widersprüchlichkeiten kommen.

Dabei ist oft der Fall, dass für verschiedene Rollen die gleiche Fassade benutzt werden kann. Laut Goffman gibt es meistens bereits eine bestehende Fassade, die für eine Rolle übernommen werden kann (oder muss). Übernimmt jemand eine neue Rolle, so kann er in der Regel zwar eine Fassade wählen, muss diese aber nicht neu erschaffen. Dank diesem Umstand kann der Zuschauer seine Er-

80 In der deutschen Übersetzung (Goffman 2002) wird nicht nur role mit Rolle übersetzt, sondern auch part, routine, mithin sogar status und character - was eine gewisse Austauschbarkeit der Begriffe doch nahezulegen scheint.

8I Goffman I990 (1959), I6 (dt. 2002, I8).

82 Ebd.

83 Linton I964 (1936), I I 3 .

84 Goffman 1990 (1959), 22-25 (dt. 2002, 23-27).

85 Zum gegenseitigen Einfluss zwischen Rollen und Kleidern allgemein sowie in Bezug auf Superhelden vgl. Brownie/Graydon 2016, 34-37. Sie ziehen auch eine interessante Parallele zur Mode, die sie als Ausdruck des Bedürfnisses nach Konformität bei gleichzeitiger Individualität auffassen (ebd., 7I): «All fashion relies on negotiation between the conflicting desires for competition and conformity [...]. When we dress, we do so to conform to a social contract, while simultaneously expressing our individuality [...]. [...] this is a balancing act that must be performed with every garment or outfit.» 
wartungen stereotypisieren, denn selbst wenn jede Situation stets ein bisschen anders ist als die nächste, kann der Zuschauer diese kategorisieren. ${ }^{86}$ In der erzählten Welt des maskierten Helden macht sich der Protagonist diesen Umstand zweifellos zunutze. Ist er einmal als heldenuntauglich abgestempelt, fällt es ihm viel leichter, diese unwahre Darstellung (misrepresentation) aufrechtzuerhalten, allerdings darf er auch nicht allzu sehr davon abweichen, um dieses Bild (oder Image) nicht zu beschädigen.

Die Fassade aufrechtzuerhalten, ist dabei nicht immer einfach; die angemessene Selbstdarstellung kann auch Opfer verlangen. Insbesondere wenn jemand in seiner Darstellung bestimmten Idealen gerecht werden will - bzw. die Darstellung eine idealisierte Sicht der Situation präsentieren soll (idealisation) -, muss er Handlungen, die diesem Ideal nicht entsprechen, ganz vermeiden oder nur im Geheimen ausführen. Selbstredend wird der Darsteller Schwachpunkte möglichst verbergen und Positives in den Vordergrund rücken. Unter Umständen kann dies auch eine Täuschung bedeuten, doch da sich das Publikum dieser Möglichkeit bewusst ist, muss der Darsteller darauf achten, "was sein Tun in den Augen der anderen implizieren könnte» ${ }^{87}$. Dabei ist es nach Goffman unerheblich, ob der Darsteller aufrichtig ist oder nicht. So oder so muss er dafür sorgen, dass seine Darstellung den adäquaten Ausdruck erhält. Schliesslich kann unter Umständen bereits eine diskreditierende Handlung in einer der Rollen (routine) den gesamten Status (role) bedrohen. ${ }^{88} \mathrm{Zu}$ den Massnahmen, um die eigene Darstellung zu schützen und zu verteidigen, zählen dabei insbesondere dramaturgische Disziplin und Sorgfalt sowie Selbstbeherrschung.

Der Darsteller ist sich bewusst, dass das Publikum selbst kleine Hinweise als wichtige Momente der Vorstellung erkennt. Doch besteht hier die Gefahr von Missverständnissen, nur schon wenn zufällige oder versehentliche Gesten oder Ereignisse als zur Vorstellung gehörend aufgefasst werden. Um dies zu vermeiden, versucht der Darsteller, möglichst viele «Nebenereignisse» innerhalb der Darstellung zu kontrollieren (Ausdruckskontrolle, maintenance of expressive control) - schliesslich sollen diese möglichst keinen oder zumindest nur einen mit der allgemeinen Situationsdefinition zu vereinbarenden Eindruck machen. ${ }^{89}$ Denn für eine erfolg-

86 Der Einzelne muss dabei nicht jede Rolle spielen können (das ist lernbar), er muss nur über genügend Ausdrucksweisen verfügen, um jede Rolle (part) ausfüllen zu können (Goffman 1990 (1959), 26, dt. 2002, 27).

87 Goffman 2002 (1959), 54 (engl. 1990, 58).

88 Goffman 1990 (1959), 64 (dt. 2002, 60).

89 Als Hauptgruppen von ungewollten Gesten nennt Goffman kurz zusammengefasst solche, die Unfähigkeit, mangelhafte Manieren oder Respektlosigkeit offenbaren; solche, die den Darsteller als inadäquat an der Situation Beteiligten wirken lassen; und schliesslich mangelhafte 
reiche Darstellung muss das Publikum den Darsteller als aufrichtig (sincere) einstufen - obwohl freilich Spontaneität inszeniert werden kann..$^{\circ}$

Goffman merkt an, dass das alltägliche Verhalten in der westlichen Welt relativ stark regelgebunden ist. Der Eindruck von der Realität einer Darstellung wird daher schnell gestört und ist entsprechend empfindlich, allen Bemühungen der Darsteller zum Trotz. ${ }^{\text {I }}$ Solche Störungen aber bedrohen die vom Darsteller aufgebaute Realität, was alle Interaktionsteilnehmer verwirren kann. Nervosität etwa ist, so Goffman, in der Regel nicht Teil der Rolle, sondern des Darstellers, wodurch sich das Bild vom «Mann hinter der Maske» aufdränge..$^{2}$

Für die Frage, inwiefern der Mensch in Gesellschaft eine Rolle spielt, ist natürlich auch die Frage relevant, ob der Betreffende seine eigene Darstellung für 'wahr〉 hält, also selbst «an den Anschein der Wirklichkeit glaubt, den er bei seiner Umgebung verbreiten will»93. Goffman fasst dies mit dem Begriff der Rollendistanz. Ihm zufolge gibt es hierbei eine Skala, die von einem aufrichtigen Darsteller, der an die «real reality» seiner Darstellung glaubt, bis zum zynischen Darsteller reicht, der von der eigenen Rolle nicht im Geringsten überzeugt ist. ${ }^{94}$ Doch auch dieser, wendet Goffman ein, kann zumindest von seiner Maskerade befriedigt sein. Und die zynische Haltung kann «als Mittel zur Isolierung des inneren Selbst gegen den Kontakt mit dem Publikum»95 dienen, also eine Schutzfunktion erfüllen. Zudem handelt es sich hierbei nicht um einen dauerhaften Zustand, vielmehr kann sich ein Individuum mehrfach von einem Pol zum andern oder in verschiedenen Zwischenpositionen - die nach Goffman mit «etwas Selbsttäuschung» möglich sind bewegen. ${ }^{6}$ Wie Abels betont, bedeutet die Rollendistanz gerade nicht das Ende des Spiels, auch wenn sie für die Trennung von Individuum und Rolle sorgt, sondern steht für eine «hohe Kompetenz», mit der Rolle umzugehen, sodass es sich dabei letztlich gerade um eine Strategie der Identitätsbehauptung handelt. ${ }^{97}$

Eine Pause von der Rolle ermöglicht Goffmans Darsteller auch die Hinterbühne (back region oder back stage). Im Gegensatz zur Vorderbühne (front region), wo die Darstellung stattfindet, ist die Hinterbühne der Ort, «where the suppressed facts make an appearance [...], where the impression fostered by the

Inszenierung, wenn etwa das Bühnenbild Mängel aufweist oder weitere Figuren ihre Abgänge oder Auftritte vermasseln (Goffmann 1990 (1959), 52f., dt. 2002, 49 f.).

90 Goffman I990 (1959), 7I (dt. 2002, 66).

91 Goffman 2002 (1959), 52 (engl. 1990, 56).

92 Goffman 2002 (1959), I 92 (engl. 1990, 2 I 2 ).

93 Goffman 2002 (1959), I9 (engl. 1990, 17).

94 Goffman 2002 (1959), 20 (engl. 1990, 18).

95 Goffman 2002 (1959), 22 (engl. 1990, 20).

96 Goffman 2002 (1959), 22 (engl. I 990, 2 1, «a little self-illusion»).

97 Abels 2006, 329, und 2007, I68, ähnlich Elliott 2007, 39. 
performance is knowingly contradicted as a matter of course»98. Hier werden beispielsweise Requisiten gelagert, produziert und ausprobiert (beispielsweise Kostüme und andere Teile der persönlichen Fassade auf mögliche Makel geprüft) und Auftritte geplant. Die Hinterbühne ist auch ein Ort der Entspannung für den Darsteller, an dem er aus seiner Rolle heraustreten kann. Ein typisches Beispiel für Vorder- und Hinterbühne sind Wohn- und Schlafzimmer. Um auf die Zweiheit der Maskenhaftigkeit zurückzukommen: Hier wäre das private, wahre Selbst am ehesten sichtbar, doch vermeidet Goffman diese Anspielung auffällig. ${ }^{99}$ Für die maskierten Helden sind als Hinterbühnen in erster Linie alle jene Orte zu bezeichnen, an welchen der Identitätswechsel stattfindet, teils also flüchtige> Plätze wie dunkle Strassenwinkel, Besenkammern oder Dächerfluchten und teils sozusagen institutionalisierte Rückzugsorte wie Batmans Bathöhle oder Supermans Festung der Einsamkeit - wobei auch diese zur Vorderbühne werden, sobald sie ein Nichteingeweihter, besonders ein Gegner, betritt; dann muss auch der jeweilige Protagonist dezidiert in seiner Heldenrolle auftreten, da er seinem Gegenüber ja keine Rückschlüsse auf seine zivile Identität erlauben will. Dies gilt umgekehrt auch für die Wohnung des Protagonisten, in der sich sein ziviles Leben abspielt.

Rollenhandeln bedeutet, so Lothar Krappmann, dass das Individuum eine Situation zunächst aufgrund «symbolischer Indikatoren» definiert und dann entscheidet, welche Rolle es einnehmen und wie es diese umsetzen möchte. Komplementär zu Meads role-taking postulierte Ralph Turner diesen Vorgang als role-making. ${ }^{100}$ Die Rolle ist also nicht a priori gegeben, vielmehr liegt es am Einzelnen, die jeweilige Rolle konkret auszugestalten bzw. zu modifizieren, wobei in jeder konkreten Situation mit Unwägbarkeiten umzugehen ist, das heisst, man muss oft unklare und inkonsistente Erwartungen interpretieren.

Auch in Goffmans Modell besteht die Möglichkeit, dass ein Individuum für sich eine neue Rolle bzw. eine neue Position zu kreieren versucht. Goffman benennt dies mit role enterprise und betont, dass es sich dabei in der Regel um «a position involving duties which suitably express attributes that are congenial to him ${ }^{\text {10r }}$ handelt. Es liegt auf der Hand, dass maskierte Helden - zumindest die frühen

98 Goffman I990 (1959), I I 2 (dt. 2002, 104).

99 Wie Scheibe $(1985,57)$ bemerkt, ignoriert Goffman das «inward self» weitgehend.

I00 Krappmann I976 (I97I), 3 I sf. Hierin liegt auch einer der Hauptunterschiede des interaktionistischen Rollenverständnisses zur strukturalistischen Rollentheorie von Talcott Parsons, dessen Modell ideale, also starrere Bedingungen beschreibt (vgl. ebd. sowie Callero 2007 und Turner I 976 (1962)).

I0I Goffman I990 (1959), 248 (dt. 2002, 226). 
Versionen, die in der Regel als Erste ihrer Art in die erzählte Welt eingeführt werden - mit ihrer Heldenidentität eine solche role enterprise unternehmen.

In Goffmans Studie ist das Individuum, wie er im Schlusswort selbst reflektiert, implizit in zwei Teile geteilt, einen Darsteller (fabricator of impressions) und einen Dargestellten (character):

$[\ldots]$ the performed self was seen as some kind of image, usually creditable, which the individual on stage and in character effectively attempts to induce others to hold in regard to him. While this image is entertained concerning the individual, so that the self is imputed to him, this self does not derive from its possessor, but from the whole scene of his action, being generated by that attribute of local events which renders them interpretable by witnesses. A correctly staged and performed scene leads the audience to impute a self to a performed character, but this imputation - this self - is a product of a scene that comes off, and is not a cause of it. The self, then, as a performed character, is not an organic thing that has a specific location [...]; it is a dramatic effect arising diffusely from a scene that is presented, and the characteristic issue, the crucial concern, is whether it will be credited or discredited. ${ }^{102}$

Das Selbst sieht Goffman hier vor allem als performativen Effekt der Darstellung. In The Presentation of Self in Everyday Life sprach Goffman noch vom Selbst, in Stigma (1963) jedoch ist das Wort Selbst zugunsten von Identität verschwunden. ${ }^{103}$ Mit dem neuen Begriff präsentierte Goffman ein erweitertes Modell von Identität, das jedoch auf einer anderen Ebene zu situieren ist und diverse Identitätsaspekte (mit verschiedenen Kombinationen um identity) anspricht. ${ }^{104}$ Kurz zusammengefasst, sieht er zwei gegensätzliche Sets von Erwartungen, die das Individuum in seiner Darstellung konfrontieren: Die persönliche Identität (personal identity) setzt sich aus den sogenannten «Identitätsaufhängern` einer Person (Merkmale wie Name, Körper, die eine Identifizierung im staatlichen Sinne erlauben) sowie dem «ganze[n] Satz von Fakten», ${ }^{\text {1os }}$ die für ein Individuum jeweils zu einer einzigartigen Kombination zusammenfinden, also insbesondere den biografischen Daten und Erfahrungen, zusammen. Hier ist es gefordert, individuell und keinem andern gleich zu sein (da niemand genau dieselbe Lebensgeschichte aufweist). Die social identity vereinigt die zu einem bestimmten Zeitpunkt nebeneinander aktualisierbaren Rollen. Obwohl ihr durch die verschiedenen Zugehörigkeiten zu gesellschaftlichen Gruppen auf unterschiedlichen Stufen (etwa Geschlecht, Alter, Beruf,

I02 Goffman I990 (1959), 252f. (dt. 2002, 23I).

I03 Gleason 1983, 917; Ashmore/Jussim 1997, 9. Auf die Stigmata komme ich im Kapitel zu Daredevil zurück.

I04 Goffmann 1975 (1963), 67-80 (engl. 1963, 51-66). Die folgenden Ausführungen stützen sich zudem auf von Engelhardt 2010, Krappmann I 976 (1971), Abels 2006, 347-364.

I05 Goffman 1975 (1963), 74 (engl. 1963, 56). Vgl. von Engelhardt 2010, I 27. 
Nationalität) Pluralität inhärent ist, wird in dieser sozialen Identität Konformität und Anpassung an alle andern verlangt. ${ }^{106}$

Zwischen diesen beiden Ansprüchen ergibt sich unweigerlich eine gewisse Spannung. An diesem Punkt nun setzt Lothar Krappmann seinen eigenen Identitätsbegriff: Zwischen diesen beiden einander eigentlich ausschliessenden Ansprüchen eine balancierende Identität zu bilden, ist eine Leistung, die das Individuum immer wieder neu zu erbringen hat ${ }^{107}$ - oszillierend zwischen Individualität und Konformität, zwischen Auffälligkeit und Unauffälligkeit, zwischen Pfau und Chamäleon.

Neben die soziale und die persönliche Identität, über die «die Identifizierung des Gegenübers bzw. die Identifizierung durch die Anderen» ${ }^{108}$ erfolgt, stellt Goffman schliesslich noch (in Anlehnung an Erik Erikson) eine Ich-Identität (ego identity) - die vom Individuum subjektiv empfundene und selbstreflexive Identität. Dabei handelt es sich gewissermassen um jene Instanz, welche die angesprochene Balance dirigiert, und zwar mit einem grossen Freiraum, aber doch stets in Rückbindung an die soziale und persönliche Identität sozusagen sein Selbstbild konstruiert, sodass «[d]er Pluralität der sozialen Identität [...] eine 〈Vielzahl von Ichs` [entspricht], zwischen denen der Mensch zu wechseln hat ${ }^{\text {rog, }}$ wie Michael von Engelhardt formuliert.

Obwohl Goffman mit der Ich-Identität in Stigma anreisst, wie eine mögliche dirigierende Instanz des rollenspielenden Individuums zu erfassen wäre, lässt er diesen Punkt wie erwähnt insgesamt merkwürdig unbestimmt, sodass eine <innere Identität> oder sogar ein 〈Identitätskern ${ }^{110}$ in seinen Schriften letztlich flüchtig bleibt. Damit aber erweist sich Goffman als Vorläufer all jener Identitätsvorstellungen, die die Idee von Identität als einer festen Grösse ablehnen bzw. davon ausgehen, dass ein solcher 〈Identitätskern〉 überhaupt nicht existiert. ${ }^{1 I I}$ Was nicht existiert, kann nicht verborgen werden, und insofern erstaunt es nicht, dass jene Theorien der Metapher der Maske nicht mehr bedürfen.

I06 Goffman i 975 (1963), 77 (engl. I963, 59). Vgl. von Engelhardt 2010, г $27 f$.

I07 Krappmann I976 (1971), 316f.; vgl. Veith 2010.

I08 von Engelhardt 2010, I 28; vgl. Goffman 1975 (1963), I 32, oder ferner Krappmann (1976, 3 I6), der in dieser Ich-Identität seine balancierende Identität sieht.

I09 von Engelhardt 20I0, I28, der seinerseits Goffman (I975, 8I) zitiert; im englischen Original (Goffman I963, 63) übrigens spricht Goffman hier wieder von Selbsten: «multiplicity of selves». Vgl. auch Turner 1976 (1962), 37f.

I Io Die Vorstellung eines solchen erwähnt Goffman zwar (1963, 56), aber nur um das «Innerste [des] Seins» (Goffman I 975 (1963), 74) aus seinem Begriff der persönlichen Identität auszuschliessen. Vgl. Elliott 2007, 37: «The self consists for Goffman in an awareness of the multiplicity of roles that are performed in various situated contexts $[\ldots]$.»

I I Vgl. Elliott 2007, 44, oder etwa auch Fludernik 2007, 26I. 


\title{
Interpretationsansätze zur Doppelidentität (der Mann aus Stahl und der unscheinbare Reporter)
}

\author{
... who is in reality... \\ Diverse Superbeldencomics, $x$-fach
}

Die Doppelidentität der Superhelden ist in der Forschung bereits verschiedentlich thematisiert worden, und auf einige der bestehenden Deutungen möchte ich nun näher eingehen. Die ausgewählten Ansätze beziehen sich vor allem auf Superheldencomics. Für die maskierten Helden der Pulps liegen noch keine vergleichbaren Deutungen vor; die zahlreicheren Interpretationen einzubeziehen, die sich mit Superheldenfilmen ${ }^{\mathrm{I}}$ beschäftigen, würde dagegen den Rahmen dieser Überblicksdarstellung sprengen. Die ausgewählten Interpretationen der Doppelidentität sind aus verschiedenen Gründen interessant. Es handelt sich um Ansätze, die entweder in der Sekundärliteratur immer wieder auftauchen, scheinbar sehr naheliegend sind und/oder einen bestimmten Aspekt des Themas Identität fokussieren bzw. die Doppelidentität unter einem bestimmten Aspekt greifbar machen. Die ersten beiden Schlaglichter fallen auf zwei Erklärungsversuche für die Doppelidentität: die zivile Identität als Identifikationshilfe für den Leser und den Superhelden als Corporate Man. Mit der Frage nach der «wahren> Identität folgt dann der Übergang zu zwei Ansätzen, die sich als Deutungen der Doppelidentität bezeichnen lassen: das Männlichkeitsbild maskierter Superhelden und schliesslich Carl Gustav Jungs Konzept des Schattens. Diese Thesen sollen dabei nicht als Grundlage für meine Einzelanalysen dienen, vielmehr möchte ich sie als Ergänzung meiner Perspektive auf die Doppelidentität verstehen; weitere Ansätze werden in späteren Kapiteln zur Sprache kommen. Die hier versammelten Interpretationsansätze kennzeichnet, dass sie einen eher allgemeinen Charakter beanspruchen - was sogleich wieder einzuschränken ist, denn die meisten Betrachtungen der Doppelidentität sind klar der Figur Supermans verpflichtet. Selbst wenn er nicht explizit genannt wird, dient der Mann aus Stahl oft implizit als Folie. Aus diesem Grund steht Superman auf den folgenden Seiten ebenfalls im Zentrum.

I Zur Doppelidentität in Superheldenfilmen vgl. z. B. Sitz 2015, Friedrich/Rauscher 2007, von Holzen 20I 2a. 
Superman, der als erster <richtiger Superheld gilt, ${ }^{2}$ wirkt auch in Bezug auf die Doppelidentität zugleich als Blaupause wie als Sonderfall. Da Superman ein Ausserirdischer ist, der als Baby auf die Erde gelangte, kann man sagen, dass er im Vergleich zu den meisten anderen Superhelden <umgekehrt funktioniert: Nicht Clark Kent, sondern Superman ist die sangestammte> Identität des Helden - passenderweise fehlt dem Superman-Kostüm die Gesichtsmaske. ${ }^{3} \mathrm{Da}$ Superman sein ziviles Leben als Reporter Clark Kent meistert, kann man dem entgegenhalten, dass die Figur erzählerisch nicht anders funktioniert als die anderen maskierten Helden. Clarks Brille, hinter der er Supermans Gesichtszüge versteckt, ist dann als Minimalmaske ${ }^{4}$ aufzufassen, in welcher metaphorische und gegenständliche Maske zusammenfallen. Superman ist diesbezüglich nicht der einzige Sonderfall unter den Superhelden, trifft dies doch zum Beispiel auch auf Wonder Woman zu, die ihre Kräfte ihrer mythischen Herkunft von der Amazoneninsel Paradise Island/Themyscira verdankt, in Zivil aber als (oft bebrillte) Diana Prince auftritt.

Superman dient in der Sekundärliteratur als erste Folie für die Konventionen des Superhelden-Genres. Dazu ist eine starke Tendenz zu beobachten, den nur wenig später entstandenen Batman als sein Gegenstück von ihm abzuheben. Diese zwei Aushängeschilder des DC-Verlages werden als Pole eines Spektrums verstanden, das sie seit den Anfängen des Superheldenparadigmas im Golden Age der US-Heftcomics (I938 bis 1956/196I)'s aufspannen. Obschon diese Gegenüberstellung der beiden Figuren berechtigt ist, ${ }^{6}$ drängt sich der Verdacht auf, dass sich diese Sichtweise vor allem rückblickend etabliert und namentlich unter

2 Über die Kandidaten für diese Würde lässt sich trefflich debattieren, wofür nur auf Coogan 2006 verwiesen sei, der so lange argumentiert, bis allein Superman die Position als Gründerfigur des Genres auszufüllen vermag.

3 Dass Superman in seiner Heldenrolle keine Maske trägt, wird in neueren Versionen damit erklärt, dass sein Gesicht Vertrauen bei den Leuten schaffen soll - hier schwingt indirekt die Konnotation der Maske als wenig vertrauenswürdig und erschreckend mit. Dies ist der Fall in

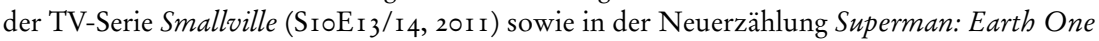
(Michael Straczynski, Shane Davis et al. 2010); vgl. dazu Brownie/Graydon 2016, r $9 f ., 38$.

4 Vgl. Weltzien 2005, 235/24I, Beritela 2007, 55.

5 Zur Einteilung der Superhelden-Comicgeschichte in verschiedene Phasen vgl. Rhoades 2008, 3-7, Easton in Easton/Harrison 2010, 55-87. Über das Golden Age und das Silver Age ist sich die Forschung mehrheitlich einig, das Silver Age beginnt meist 1956 mit der Neuauflage des Flash in DCs Showcase 4 oder 1961 mit Marvels Fantastic Four und endet mehrheitlich 1970/72 (selten 1985, Oropeza 2005a, I I), wobei teils Zwischenphasen genannt werden. Als Meilenstein gilt zudem das Jahr 1986 (oder schon 1983/84), doch sind sich die Chronisten uneins, ob daran ein Iron, Copper, Modern oder sogar Postmodern Age anschloss und wie lange dieses andauerte.

6 Vgl. McCue/Bloom I993, 22f. Sehr gut illustriert diese Tendenz die Suche nach Bezügen zur Antike: So erkennt Mackie $(2007,83)$ bei Superman und Batman eine «similar rivalry» wie 
dem Eindruck von Frank Millers The Dark Knight Returns (1986) noch verstärkt hat. In den ersten Jahrzehnten ihrer reichhaltigen Publikationsgeschichte waren die beiden bedeutendsten Helden im DC-Universum jahrzehntelang ebenbürtige Partner in der Verbrechensbekämpfung; von einer prinzipiellen Gegensätzlichkeit in ihrer Motivation und ihren Methoden, die als Achse ihrer von Spannungen durchzogenen Beziehung wirkt, ist noch wenig zu spüren. Oft erhält dieses Spektrum der beiden prägenden Figuren des DC-Verlages mit den Marvel-Helden der frühen 1960er-Jahre (mit den Fantastic Four, Spider-Man, Iron Man, Daredevil, X-Men, Hulk, Thor), die das Silver Age einläuten bzw. dessen Blütezeit prägen, eine dritte Perspektive. Das Triumvirat der am häufigsten besprochenen Doppelidentitäten komplettiert Spider-Man; in unterschiedlichem Ausmass werden andere Superhelden, etwa Iron Man, einbezogen oder eine Vielzahl von Helden erwähnt.

In ihrer äusserst umfangreichen Publikationsgeschichte haben sich die Superheldencomics immer wieder gewandelt. Unterschiedliche Bewertungen sind nicht selten darauf zurückzuführen, dass die Comics aus verschiedenen Zeiträumen stammen und jeweils zeitgenössische Verlagsstrategien, Autorvorlieben etc. spiegeln. Leider bleibt in einem nicht geringen Teil der einschlägigen Sekundärliteratur relativ vage, auf welche Zeiträume und Heftreihen die Autoren sich beziehen - nicht selten gehen die Verfasser offenbar von einer allgemeinen Vorstellung des Superhelden oder der einzelnen Figur aus, die von den Versionen aus anderen Medien (vor allem Filmen und Fernsehserien, aber auch Hörspielen, Zeitungsstrips etc.) beeinflusst ist. Verkompliziert wird diese Vielfalt noch durch zahlreiche Elseworlds- oder What if ...? ?-Erzählungen, die ausserhalb der jeweils verlagsspezifischen Continuity, die seit dem Silver Age für die fortlaufende Serialität aller Heftprodukte eines Verlagshauses (Marvel oder DC) bürgt, angesiedelt sind. Hinzu kommen sogenannte Reboots, also Neustarts von Reihen oder Figuren, und weitere narrative Strategien, die die Superheldenuniversen so faszinierend, aber uneinheitlich machen.7

$\mathrm{Da}$ es in diesem Kapitel mehr um das Schema als um dessen Variationen geht, beziehe ich mich hier ebenfalls hauptsächlich auf die Comics aus dem Goldenen sowie teilweise dem Silbernen Zeitalter, für Superman auf die ersten dreizehn

bei Achilles und Odysseus, und Morris $(2008,262)$ setzt die Helden parallel zu Platon und Aristoteles; beide Ansätze überzeugen letztlich wenig.

7 Zur Superhelden-Publikationsgeschichte und den Tücken ihrer seriellen Erzähluniversen vgl. für ergiebige Kurzüberblicke Schikowski 2014, 79-I04, Nehrlich 2013, I08-I 20, Knigge 2004, I 89-202, 260-273, 340-349; ausführlich Rhoades 2008, McCue/Bloom I993; spezifisch zur Serialität u. a. Meteling 20I3, Kelleter/Stein 20I 2, Hoppeler/Rippl 20I 2, Jenkins 2009, Wandtke 2007, Reynolds 1994, 38-49. 
Ausgaben der Action Comics (1938/1939) sowie danach auf die ersten 230 Hefte der nach dem Helden benannten Reihe Superman (1939 bis 1970). Für den gelegentlichen Blick auf Batman habe ich mich auf die ersten zwölf Batman-Ausgaben der Detective Comics (Hefte 27 bis 38, I939/1940), die ersten vier Ausgaben von Batman (1940/4I) sowie die im Band Batman in the Forties (2004) gesammelten Geschichten beschränkt, da Batman im letzten Kapitel im Zentrum stehen wird.

\section{Die zivile Identität als Identifikationshilfe für den Leser}

Superman sei, so urteilten schon Wolfgang J. Fuchs und Rainer C. Reitberger, «der ultimative Held, Inbegriff der Wunschträume seiner jugendlichen Leser» ${ }^{8}$. Gemeint ist offenkundig nicht das Gesamtpaket Clark Kent/Superman, sondern allein dessen heldische Hälfte mit dem reichhaltigen Bündel an übermenschlichen Fähigkeiten, welches Superman bis heute als einen der kräftemässig komplettesten Superhelden auszeichnet. (Dass der Held jederzeit über seine Kräfte verfügt, auch wenn er diese als Zivilperson verbirgt, bleibt dabei unbeachtet.) Sieht man in den Superkräften - die Action, Kämpfe und fantastische Herausforderungen garantieren - die Hauptattraktion für die Leserschaft, stellt sich die Frage, warum dergestalt überirdische Heldenfiguren auf eine irdisch-alltägliche Existenz nicht verzichten und sich überhaupt mit einer Doppelidentität abmühen. ${ }^{9}$

Die Frage scheint mit Blick auf das Leserbedürfnis schnell beantwortet: Die unspektakuläre Alltagsidentität diene dem Leser als Brücke für die Identifikation mit dem nahezu gottgleichen Superhelden. Hal Blythe und Charlie Sweet etwa erklären 1983 den Zweck der zivilen Identität folgendermassen: «This everyday persona makes reader identification possible, and so when Mr. Commonman is transformed into Captain Superhero the reader can follow right along. When the hero has solely a superpowered self, there can be no identification: the reader/ hero gap is too great. $\rangle^{10} \mathrm{Im}$ Kontrast zu seinem übermenschlichen Held-Sein setzen Blythe/Sweet die zivile Identität mit dem Mensch-Sein des Helden gleich in diesem sehen sie den zentralen Anknüpfungspunkt für die ebenfalls menschlichen Leser: «The superhero is human. Readers find it difficult to identify with

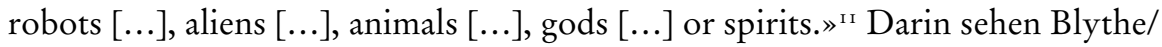

8 Fuchs/Reitberger 1973, I3 I.

9 Vgl. etwa Darowski 2009, 20-22.

I0 Blythe/Sweet I983, I84.

I I Ebd. So noch Darowski (2009, 2 I ): «Few readers could relate to the concept of bulletproof skin.» 
Sweet denn auch die Erklärung dafür, dass Superhelden ohne zivile Identität ihrer Ansicht nach - weniger erfolgreich sind als solche mit Doppelidentität. ${ }^{12}$ Die Fans der genannten Beispiele - unter anderen Aquaman, Hawkman, Submariner, Plastic Man, Martian Manhunter, Inhumans oder Captain Marvel - dürften dem vehement widersprechen. Zwar sind die genannten Figuren tatsächlich nicht die erfolgreichsten aller Superhelden, dennoch verfügen sie über eine bemerkenswerte Langlebigkeit und eine treue Leserschaft. Auch angesichts weiterer beliebter Superhelden ohne Doppelidentität, wie Marvels Fantastic Four (ab I96I), der X-Men (ab I963) oder des ausserirdischen Silver Surfers (ab I966), greift das Argument von Blythe und Sweet nicht. ${ }^{13}$ Zudem besteht wohl kein Zweifel, dass es über das Superheldengenre hinaus zahlreiche populäre nichtmenschliche Protagonisten gibt, denen es an Identifikationspotenzial keineswegs mangelt.

Diese These von der zivilen Identität als einer Art Steigbügel für die Identifikation des Lesers mit dem übermenschlichen Superhelden scheint in der Sekundärliteratur immer wieder auf. ${ }^{14}$ Meistens wird sie als auf der Hand liegend verstanden, sodass eine vertiefte Auseinandersetzung oder Hinterfragung nicht nötig scheint. Dazu hat wohl beigetragen, dass sich diese These nahtlos mit der Bewertung von Comics als eskapistischem Lesestoff verbinden lässt. So erläutert etwa Reinhard Schweizer in Weiterführung des «reader/hero gap»: «Der Akt der Verwandlung [...] steuert den Identifikationsprozess des Lesers und macht ihn und die Comicfigur gleichermassen zum Superhelden. Die Flucht aus der banalen Alltäglichkeit, die Hauptantriebsfeder zum Lesen von Abenteuerliteratur per se, wird auf der Geschichtenebene selbst vorgemacht und damit besonders wirksam.» ${ }^{\text {Is }}$ Während hier die zivile Identität als zwar effektives, aber doch blosses Mittel zum Zweck dient, den Leser die heldischen Abenteuer miterleben zu lassen, geht der ehemalige Marvel-Editor und Comic-Autor Danny Fingeroth noch einen Schritt weiter. Bei Fingeroth erhält die geheime Doppelidentität eine

I 2 Blythe/Sweet I983, I84.

I 3 Man kann durchaus argumentieren, dass Heldenfiguren immer eine Schwäche brauchen, um menschlich zu erscheinen und damit die Identifikation der Rezipienten mit dem Helden erst zu ermöglichen (so etwa Ludwig I978, 270), doch bleiben die Ausführungen von Blythe/Sweet hier, wie bei vielen ihrer Nachfolger, an der Oberfläche.

I 4 Die These findet sich bereits I 964 bei Jules Feiffer: "The truth may be that Kent existed not for the purposes of the story but for the reader» (Feiffer: The Great Comic Book Heroes, zit. n. Darowksi 2009, 2 I). Ein jüngeres Beispiel bieten etwa Duncan/Smith (2009, 228): «The dual identity is also a way for the ordinary person to identify with extraordinary characters. Perhaps one of the most alluring aspects of the Superman mythos is that Clark Kent is an average guy.» Vgl. z. B. auch Kahan/Stewart 2010, i i i, oder Andrae i980, I03.

Is Schweizer I992, 39. Die Unzulänglichkeit des Ansatzes, Superheldencomics als blosse Eskapismuslektüre zu werten (bzw. abzuwerten), legen etwa Thurtle/Mitchell (2007, 295) dar. 
zentralere Rolle, denn er sieht deren Anziehungskraft in ihrer Funktion als Ermächtigungsfantasie für die Leser:

The appeal of the secret identity is as primal as ever. Don't underestimate me. I may not be who you think I am. Or to put it another way: IF ONLY THEY (whoever your "they" may be) KNEW THE TRUTH (whatever that truth may be) ABOUT ME (whoever you believe yourself to be), THEY'D BE SORRY FOR THE WAY THEY TREAT ME. That's a powerful fantasy and a powerful human need. It's what makes people read and watch works of fiction. [...] «This may seem like my life - but it is not my life. In my true life, I fly above buildings $[\ldots]$, I defend the defenseless and I am true to my truest self.. ${ }^{16}$

So einleuchtend es scheint, die zivile Identität als «Steigbügel für den Leser hin zur eskapistischen Ermächtigungsfantasie zu verstehen, schwingen hier doch Annahmen mit, die durchaus zu hinterfragen sind. Abgesehen davon, dass in diesem Zusammenhang nie geklärt wird, was denn unter der Leseridentifikation genau zu verstehen wäre (und was auch hier den Rahmen sprengen würde), ${ }^{17}$ offenbart sich spätestens bei Fingeroth eine gewisse Vorstellung von typischen (männlichen) Superheldencomiclesern als sozialen Mauerblümchen, als zurückhaltenden und unsicheren Jugendlichen und (jungen) Erwachsenen, die im Alltag unterschätzt und zurückgesetzt werden und somit gesellschaftlich wenig erfolgreich sind. Sie werden der ebenso als Stereotyp präsentierten zivilen Identität des Helden, namentlich dem «Schwächling〉 Clark Kent, gleichgesetzt - der gerade im Golden Age als Journalist im Büroalltag Herabsetzungen durch seine Arbeitskollegen und mitunter schroffe Zurückweisungen seiner oft etwas linkischen Avancen durch Lois Lane erduldet, während er als Superman ihr fernes Liebesobjekt abgibt. Diese Parallele sah 1964 bereits Umberto Eco in seinem berühmten Superman-Aufsatz: «[...] Clark Kent personifiziert hinreichend typisch den durchschnittlichen Leser, er ist diesem ähnlich und nährt dessen geheime Hoffnung, eines Tages die Fesseln der Mittelmässigkeit [...] abstreifen zu können, von einem Biedermann zu einem Weltbeweger zu werden.» ${ }^{18}$

Im Fall von Superman erscheinen als drittes Glied dieser Gleichsetzung dessen Erfinder Jerry Siegel (1914-I996) und Joe Shuster (1914-I992). Die Eskapis-

I6 Fingeroth 2008, 60 (Hervorhebung im Original). Dies nehmen etwa Smith (2009, 26) und Costello (2009, I9) auf.

I7 Blythe und Sweet widersprechen m. E. ihrer eigenen Annahme, die Identifikation des Lesers mit dem Superhelden könne erst über den 〈Umweg〉 der zivilen Identität gelingen, wenn sie bemerken, in «popfic» sei der Protagonist im Grunde stets ein idealisiertes Selbstbild des Lesers: «Representing the optimum development of the reader's positive traits, the hero is someone with whom the reader can readily identify» (I983, I84). Am Rande sei angemerkt, dass die Leserbriefspalten vieler Superheldenhefte ausserdem die Vermutung nahelegen, dass nicht wenige Fans fast mehr Interesse an den Schurken- als an den Heldenfiguren haben.

Eco 1992 (1964), 194. Vgl. dazu Frahm 2005, 37. 
musfunktion der Figuren wird nicht nur mit dem Bedürfnis der Leser, sondern auch aus der Biografie der Superman-Schöpfer erklärt, erdachten diese ihre berühmteste Kreation doch noch im Teenageralter und scheinen einer stereotypen Vorstellung des schüchternen, gehemmten Jugendlichen überaus entsprochen zu haben. ${ }^{19}$ Joseph J. Darowski, der mehrere Erklärungen für die Doppelidentität versammelt, spricht von «an odd mix of self-flagellation and adolescent fantasyfulfillment by Superman's creators», oder noch plakativer: "Clark Kent was an exaggerated version of themselves and Superman was everything they weren't. ${ }^{20}$ Superman und mit ihm Superhelden als solche werden in dieser Perspektive im Grunde auf Kompensationsfiguren für die von ihrem Umfeld verkannten Leser reduziert. Diese Annahme ist letztlich wenig überzeugend: Einerseits will sich der Leser als Superheld fühlen, um eine gewisse Machtfantasie auszuleben, andererseits soll ihm diese Identifikation nur über den Umweg der zivilen Identität, die seiner eigenen, von Ohnmacht geprägten Lage entspricht, gelingen können. Selbst wenn man diesem Bild des typischen Comiclesers folgen möchte (und dabei leicht alle Leser und Lesesituationen über einen Leisten schlägt), besteht ein fundamentaler Unterschied darin, dass viele Protagonisten in Zivil nur vorgeben, unfähig zu sein, also sich oft mit voller Absicht als ungeschickt, schwächlich oder sogar feige präsentieren, es aber de facto nicht sind.

Im Fall von Superman bieten gerade die frühen Geschichten einige bemerkenswerte Beispiele, wie wenig sich Clark von sozialen Schmähungen beeindrucken lässt. Gehen Clark nämlich die Bürosticheleien eines Kollegen namens Curly zu weit, erteilt er diesem mit dem heimlichen Einsatz seiner Kräfte einen Denkzettel. ${ }^{21} \mathrm{Da}$ jener jedoch nicht merkt, wer hinter seinem Missgeschick steckt, sorgt Clark/Superman selbst für poetische Gerechtigkeit - was in späteren Jahren eine Figur namens Steve Lombard, ein Sportjournalist, mehrfach erfahren wird. In Action Comics 6 nutzt Lois Lane Clarks Gutmütigkeit für ihre Zwecke aus und denkt: «How easily I can twist you around my finger!» War Clark in dieser Story bisher als gutgläubiger und gutwilliger Naivling präsentiert worden, bricht dieses Bild auf, als er zur Entgegnung denkt: «How easy you are to convince that I'm putty in your hands.» $»^{22}$ Statt über Lois' Verhalten ärgerlich oder traurig zu

I9 Es ist klar, dass das nicht für alle Erfinder von Superhelden gelten kann, doch zeigt dies, wie sehr Superman als Leitbeispiel einen oft übermächtigen Schatten wirft. Zum Entstehungsprozess Supermans vgl. u. a. Knigge 2004, I89-197, Dooley 1987, Andrae 1980. Da es sich bei den beiden um Söhne jüdischer Einwanderer handelte, wird die Doppelidentität auch als Ausdruck der damaligen US-Immigrantenerfahrung gelesen (mehr dazu im Golden-Age-Kapitel).

20 Darowski 2009, 20 und 23. Diese Aussage steht auch auf den Leser bezogen etwa schon bei Reitberger/Fuchs 1973, I56.

2 I [Superman Joins the Circus] (Jerry Siegel, Joe Shuster), in: Action Comics 7, 1938, Panels roof.

22 Superman's Phony Manager (Jerry Siegel, Joe Shuster), in: Action Comics 6, I938, Panel 29. 
sein, freut er sich über seine gelungene Rollenvorstellung. Kurz darauf wird dies noch überboten: Lois gesteht Clark, dass sie nicht ihn, sondern Superman liebt. Darauf geht Clark scheinbar tief verletzt («Dazed - bewildered - crushed») in einen anderen Raum, nur um hinter verschlossener Tür laut loszulachen: «Another moment ... and I couldn't have suppressed it ... any longer!» ${ }^{23}$ Als Paradebeispiel für einen menschlichen 〈Fussabtreter〉 mangelt es Clark/Superman in diesen Situationen erstaunlich am Underdog-Gefühl (Abb. 6). Im Lauf der Jahre erweist er sich als gewiefter heimlicher Strippenzieher, der besonders Lois ebenfalls manipuliert und ihre Reaktionen auf sein Verhalten genau abzuschätzen weiss.

Die These von der zivilen Identität als «Steigbügel〉 geht damit einher, den Kontrast zwischen den beiden Seiten des Helden besonders zu betonen, wobei die Gewöhnlichkeit und damit Unterlegenheit der zivilen Identität manchmal fast schon beschworen wird. Einen gewissen Widerspruch stellen aber nur schon all jene Superhelden dar, die in Zivil dem Millionärsdasein frönen (etwa Bruce Wayne/Batman, Tony Stark/Iron Man, Oliver Queen/Green Arrow, Danny Rand/Iron Fist). Der Alltag eines «socialite» dürfte mit jenem eines Durchschnittsbürgers bzw. -lesers wenig gemein haben - so scheint ein Krösus wie Bruce Wayne doch wenig(er) geeignet, den «reader/hero gap» zu überbrücken. ${ }^{24}$ Darüber hinaus wird diese Wahrnehmung den zivilen Identitäten der Helden nicht gerecht. Die Protagonisten üben nämlich fast ausnahmslos gängige Wunschberufe Heranwachsender aus. Wohl nicht zufällig verkörpern Polizisten, Journalisten und Laborwissenschaftler ssinnreiche> Tätigkeiten, als deren Ziel der Dienst an der Gesellschaft postuliert werden kann (was man ansatzweise sogar den reichen Müssiggängern unterstellen kann, sofern ihr Einsatz für Wohltätigkeitsprojekte oder die Investition in Forschung als ihre soziale Verpflichtung, und zugleich ihr inneres Bedürfnis, präsentiert wird). ${ }^{25}$ Schweizer zufolge spiegelten die zivilen Berufe namentlich in den I960er-Jahren, also dem Beginn des Silver Age mitten im Kalten Krieg, «die damals propagierten Ziele der naturwissenschaftlich orientierten Lehrpläne, mit denen die amerikanischen Schulen den befürchteten knowledge gap zum Osten zu überbrücken versuchten» ${ }^{26}$.

23 [Wanted: Superman] (Jerry Siegel, Joe Shuster), in: Action Comics 9, I939, Panels I 8-2 I.

24 Zwar könnte man gerade im Fall von Batman einwenden, dass er eben ein Mensch ist, da er keine Superkräfte hat, doch ist Batman stets ein so überlegener Charakter, dass dieser Einwand hinfällig scheint. Ein besseres Beispiel dafür wäre Green Arrow als superkräfteloser Meisterschütze, der aber selten einbezogen wird.

25 Für die Superheldinnen sind keine so klaren Berufsfelder zu beobachten, doch sind es in der Mehrzahl auch Mädchen-Wunschberufe; im Golden Age etwa bilden die socialites-Heldinnen die grösste Gruppe.

26 Schweizer 1992, I2I. 

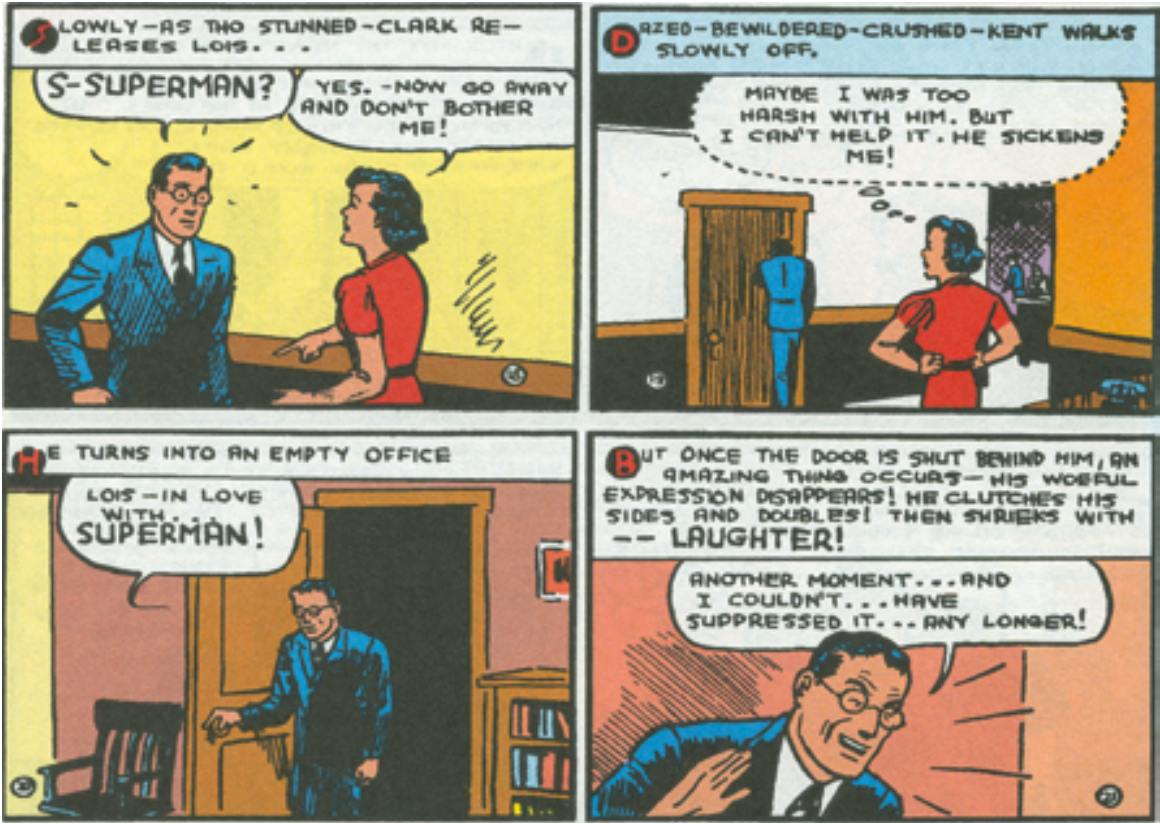

Abb. 6: Auch im vergleichsweise ungelenken Stil der frühen Superman-Comics sind die Empfindungen der Figuren klar: Clark Kent lacht sich heimlich halbtot, weil Lois in Superman verliebt ist. [Wanted: Superman] (Jerry Siegel, Joe Shuster), in: Action Comics 9, 1939, Panels I 8-2 I. (C) DC Comics

Schweizer bemerkt für die Protagonisten von Marvel, dass Captain America/ Steve Rogers im Zweiten Weltkrieg noch «einfacher Soldat» gewesen sei, während die Marvel-Epigonen des Silver Age «allesamt in materiellem Wohlstand» (entsprechend dem damals propagierten «Überlegenheitsgefühl der USA») lebten. ${ }^{27}$ Dies gilt schon für die meisten Helden des Golden Age: Wie Schweizer und Greg M. Smith ${ }^{28}$ erläutern, handelt es sich bei deren Tätigkeiten besonders

27 Ebd., I 24, vgl. Kniep 2009, I I 8. Allerdings erfährt das Ansehen eines <einfachen> Soldaten in Kriegszeiten wohl eine gewisse Steigerung. Steve Rogers befand sich in guter Gesellschaft, neben ihm und The Shield standen viele Superhelden in den Kriegsjahren im Dienst ihres Landes. Schon im Golden Age ist es schwierig, Superhelden zu finden, die in Zivil am Fliessband, als Müllmänner oder Taxifahrer etc. arbeiten. Entgegen Schweizers Aussage ist das Silver Age bekannt dafür, dass einige Superhelden, allen voran Spider-Man, auch Geldnöte haben.

28 Smith 2009, I29. 
in der Nachkriegszeit um Berufe des sozialen Aufstiegs, die in einem gewissen Rahmen Ansehen wie Wohlstand verheissen.

Hinzu kommt, dass kein Superheld in seinem Zivilberuf am falschen Ort wäre. Vielmehr ist stets klar, dass die Protagonisten von ihrem Können her zu den Besten des Faches zählen bzw. zählen könnten oder müssten. Anders als viele Comicinterpreten zu behaupten nicht müde werden, führt Clark Kent gerade nicht «das unscheinbare Leben eines einfachen Reporters» ${ }^{29}$, er ist, wie Ole Frahm festhält, «keineswegs ein durchschnittlicher Biedermann, sondern ein berühmter Reporter, der regelmässig den Aufmacher für die Titelseite der Zeitung schreibt» ${ }^{\circ}$. In Clarks Karriere gibt es durchaus Problemphasen - gelegentlich muss er um seine Stelle fürchten oder wird sogar kurzfristig gefeuert. ${ }^{31}$ Aber schon in der ersten Geschichte ist er ein Starjournalist und bleibt über die Jahre ein «ace reporter». In den I980er-Jahren wird dies sogar noch gesteigert: Da ist er Pulitzerpreisträger und nebenbei erfolgreicher Schriftsteller. Spätestens dann ist Clarks Unscheinbarkeit weniger als Unsichtbarkeit ${ }^{32}$ (der Mittelmässigkeit) auszulegen, sondern scheint eher die Strategie hiding in plain sight auszuloten. Wie Frahm bilanziert: «In der angeblichen Durchschnittlichkeit der Protagonisten kann die Identifikation ihre Ursache jedenfalls nicht haben, denn ihre Abenteuer erleben sie [Clark und Lois] als berühmte Reporter.»33 Sogar Spider-Man, Inbegriff des problembeladenen Superhelden, hat gleich zwei Wunschberufe: Er ist prädestiniert für die universitäre Wissenschaft (und wird trotz vieler heldenbedingter Stolpersteine immer wieder gefördert) und arbeitet zugleich als Action-Fotograf, was zwar in seinem Fall notorisch unterbezahlt, aber ideal mit seinen Superheldentätigkeiten verknüpfbar ist.

Statt die zivile Identität überspitzt formuliert als Gleichsetzung mit dem eigenen Elend der Gewöhnlichkeit der (jungen) Leser und damit als notwendiges Übel für die Leseridentifikation zu betrachten, bietet Smith eine alternative Lesart. Denn während der Superheld realistischerweise für immer ausser Reichweite

29 Kniep 2009, 30 (ebenso 200I, I4I), ähnlich u. a. Oropeza 2005a, 2 («meek and frail nobody»), Weltzien 2005, 232, oder als älteres Beispiel Drechsel/Funhoff/Hoffmann 1975, 97.

30 Frahm $2005,43$.

3 I Z. B. in Action Comics 5, Oktober 1938, Superman 79, November 1952, Action Comics I39, Dezember 1953 .

32 Bukatman 2003, 2 I 4 . Er verweist darauf, dass Sichtbarkeit und Sichtvermögen weiterere Aspekte des Kontrastes zwischen den Identitäten sind (ebd.): «[...] Superman is the hero without a mask, his strue face revealed to the world, at once monumental and generic. [...] But Clark is about more than assimilation and even about more than geek dreams of godhood. This Everyman in a dependable suit depends on invisibility, the anonymity permitted by a great metropolis. $\mathrm{He}$ cannot be visible, and he has a secret. And so Superman and Clark Kent subvert one another: the man who sees everything meets the man who is not seen.»

Frahm 2005, 43. 
bleibt, bieten die zivilen Berufe gerade für jugendliche Leser Berufsziele, die mit Ehrgeiz durchaus zu erreichen sind. ${ }^{34}$ «[A]s fallback fantasies go, being a metropolitan journalist is not a bad one», erklärt Smith am Beispiel Superman und führt weiter aus:

One of the beauties of the corporate secret identity is that it sneakily disguises an upscale career choice as being within the grasp of a hardworking Kansas farm boy. It seems a small step from the Smallville paper to a job on the leading newspaper in Metropolis. Young readers for whom the work sphere is a mysteriously fantastic future world can feel <realistic about their aspirations [...] while simultaneously «settling> for what is a dream job (rich industrialist, television news anchor). ${ }^{35}$

Das Bild des im Alltag zahlreiche Widrigkeiten erduldenden Protagonisten kommt indes nicht von ungefähr, denn oft kommentiert ein maskierter Superheld seine jeweilige Situation selbst mit einer gewissen Geringschätzung. Auch wenn dies zuweilen mit einem Augenzwinkern für die Leser inszeniert wird, umgibt sich der Held so mit einer Art Nimbus des Unglücklichen. In gewisser Weise maskieren so die Texte die zivilen Identitäten als ‘ganz gewöhnlich`, wenn nicht sogar als «ewige Loser, wovon freilich die Millionäre unter den Superhelden ausgenommen sind. Dabei gibt es auch für (mitunter selbsternannte) ২Problemhaufen〉 - wie Marvels Spider-Man/Peter Parker oder Nova/Rich Ryder (ab 1976) - immer wieder Lichtblicke und schrittweise Erfolge (worauf ich im Kapitel zu Spider-Man zurückzukomme). Dies gilt sowohl für die kürzeren, abgeschlossenen Geschichten des Golden Age als auch für die langfristigen Handlungsbögen der folgenden Jahrzehnte.

\section{Der Superheld als Organization Man}

Die superheldische Doppelidentität lässt sich nicht nur als Kunstgriff zur Leserbindung ${ }^{36}$ erklären, sondern auch als zeitgeschichtliche Reflexion ihrer Entstehungsjahre, als Ausdruck sozialer Befindlichkeiten verstehen. Neben der Immigrantenerfahrung, die viele Comic-Künstler des Golden Age teilten, ${ }^{37}$ ist einer der möglichen historischen Kontexte, die sich hierfür heranziehen lassen, der Arbeitsplatz. Am ausführlichsten hat dies bisher Greg M. Smith anhand des Or-

34 Schon laut Blythe/Sweet (1983, 185) sind die «[w] hite collar jobs» der Helden «to what readers aspire».

35 Smith 2009, I29.

36 Zum kommerziellen Aspekt der Doppelidentität und zur Kritik daran vgl. Drechsel/Funhoff/ Hoffmann $1975,99 f$.

37 Engle 1987, 85, Fingeroth 2007 und 2008, 53-55. Als Ausserirdischer gilt Superman als ultimativer und idealer Einwanderer (u. a. Naficy 2008, i76). 
ganization Man erörtert. Denn in ihren zivilen Identitäten sind die Superhelden, wie Smith schreibt, «professionals who fit within their corporate, institutional world $\aleph^{8}$. Smith sieht darin eine bisher vernachlässigte ${ }^{39}$ Erklärung für die Doppelidentität und betont die Bedeutung des «corporate professional» für die Superheldencomics: «[...] the portrait of the Organization Man $[\ldots]$ is consistently articulated in the superhero secret identity.»40

Damit nimmt Smith einen Gedanken auf, dem bereits Thomas Andrae nachgegangen ist. Andrae verfolgt eine der vielen Wurzeln der Superhelden und kontextualisiert Superman als Umwandlung vorangehender buchliterarischer Entwürfe von Supermenschen. In dieser Umwandlung sieht Andrae einen deutlichen Niederschlag des New Deal, Roosevelts Massnahmen zur Wirtschaftsförderung ab 1933, um die Grosse Depression zu überwinden. Andrae zufolge ersetzte der New Deal das bisherige Ideal des Erfolgs aus individueller Leistung - sprich den amerikanischen Traum von aufwärtsgerichteter Klassenmobilität - durch ein «organizational ideal», in welchem Erfolg aus Aufopferung und kollektivem Effort unter einer starken Führung resultierte..$^{4 I}$ Die Supermenschen, die während dieses «crucial institutional shift from entrepreneurial capitalism to the state regulated monopoly capitalism of the New Deal» ${ }^{42}$ die Bühne der Literatur betraten, entsprachen dem Feind der Stunde: Sie verkörperten als selbstsüchtige Machtsuchende, die soziale und moralische Verpflichtungen ablehnten, einen negativen Individualismus und waren meist tragische Gestalten. ${ }^{43}$ In Siegels und Shusters erster, unpublizierter Superman-Geschichte (1933) entsprach ihre Figur diesem Typus, doch die 1938 veröffentlichte Version hatte eine Drehung um I 80 Grad erfahren. Laut Andrae bestand die Innovation darin, dass Supermans Kräfte keine Gefahr für Freiheit und Sicherheit

38 Smith 2009, I 27.

39 Bemerkenswerterweise zieht Karrer $(1985,90)$ für die Pulps eine ähnliche Verbindung zur Arbeitswelt der Leser: In "phantastisch-verfremdeter Weise» kompensiere diese Literatur die «reale Entfremdung der Arbeitenden» und schreibe sie zugleich fest. Hierin sieht er auch einen Wandel gegenüber früheren Abenteuerhelden: «[D]er abenteuerliche Held wird zum Lohnabhängigen ohne Aufsicht», dessen Tugenden nebenbei propagiert werden, sodass «Einstellungs-, Arbeits-, Belohnungs- und Beförderungsszenen» in Genreliteratur einen markanten Aufschwung erhielten, im Krimi deutlich illustriert von Detektiv und Auftraggeber (ebd., 9r).

40 Smith 2009, I 27.

4I Andrae 1980, 95f. Vgl. auch DiPaolo 201 I, 2 If.

42 Andrae 1980, 85.

43 Mit der grossen Ausnahme von Edgar Rice Burroughs' John Carter of Mars (ab I9I 2) wurden die Supermenschen der Literatur vor oder in den I930er-Jahren in der Regel als Monster gesehen und erlitten ein tragisches Ende, so auch der Protagonist Hugo Danner in Philip Wylies Gladiator (1930), für Andrae (1980, 90-92) der unmittelbarste Prototyp des Superhelden (vgl. zu diesen Superhelden-Vorläufern auch Coogan 2006, bes. I27-I47). 
darstellen, sodass er kein Aussenseiter ist, sondern von der Gesellschaft akzeptiert und sogar verehrt wird. ${ }^{44}$ Ein Teil der Gesellschaft zu sein, gelingt ihm nur aufgrund seiner Doppelidentität. Der zivilen Identität kommt nach Andrae insofern eine zentrale Rolle zu:

$[\ldots]$ the erosion of individual autonomy under monopoly capitalism is apparent from the beginning. The introduction of an alter ego in the Superman stories shows this change. Superman differs from his predecessors in science fiction by being able to exist within society by disguising himself as the self-depressing and mild-mannered Clark Kent. It is the Kent alter ego which is supposedly a fiction, while the Superman personality is taken as real. This schizoid situation both reflects and distorts the corporate context in which the stories take place. [...] the stories expose a degenerate power structure which turns Kent into an archetypal organization man. ${ }^{45}$

Doch um dazugehören zu können, muss Clark/Superman seine Kräfte und damit sein Machtpotenzial nicht nur verschweigen, sondern auch verleugnen. Insofern spiegelt Clark/Superman eine Befindlichkeit der Zeit: «Kent's powerlessness, alienation, and inauthenticity are symptomatic of the status frustration of the new middle class of salaried employees who can neither find fulfillment and dignity in their professional life nor hope for the security and independence that once came with proprietorship.» ${ }^{46}$ Zugleich aber unterwandern die SupermanStorys laut Andrae den «corporate context», indem sie mit der Superheldenidentität sozusagen einen phantasmagorischen Befreiungsschlag aus dem Konformitätszwang bieten. ${ }^{47}$

Smith rückt dagegen die Situation am Arbeitsplatz stärker in den Fokus. ${ }^{4}$ Er lehnt den Superhelden als Arbeitskraft dabei vor allem an das Konzept des Organization Man an, das William H. Whyte in seinem gleichnamigen (und kontrovers diskutierten) Buch von I956 geprägt hat, knüpft aber zudem an The Lonely Crowd (1950) von David Riesman, Nathan Glazer und Reuel Denny an. Diese beobachteten im «social character of the American man» eine Wandlung zu einem neuen Typus, einer bürokratischen Mittelklassefigur, die sich nicht mehr von Tradition oder inneren Wertmassstäben leiten lässt, sondern sich als otherdirected-Charakter an der Resonanz ihrer Umwelt misst. Die beiden populären

44 Superman war in den ersten Geschichten noch nicht völlig der Ordnung ceinverleibt), er wurde teilweise von der Polizei verfolgt und ging recht unzimperlich vor. Doch seine Überzeugung, seine Kräfte nie aus Eigennutz einzusetzen, spiegelt laut Andrae $(1980,98)$ das New-Deal-Ideal des «collectivist ethos of the nascent welfare state».

45 Andrae 1980, 102.

46 Ebd.

47 Ebd.

48 Die folgenden Ausführungen beziehen sich auf Smith 2009. 
soziologischen Studien erschienen zwar in den I950er-Jahren, beanspruchen jedoch schon für die vorangehenden Jahrzehnte eine steigende Relevanz. Whytes Organization Man kennzeichnet, dass sein erstes Bedürfnis die Zugehörigkeit («belongingness») ist. Dafür ordnet er Autonomie und Individualität einer Organisation unter, mit welcher er sich identifiziert und die folglich Teil seiner Selbstdefinition ist: «The Organization Man does not simply work for a corporation, but he belongs to it, recognizing its superior claims on his loyalty and his conduct.»49 Dies bedeutet einen Konflikt zwischen Angepasstheit und Individualität. Den Superhelden und den Organization Man verbindet damit ein ähnliches Dilemma: Er versucht die an ihn gestellten Erwartungen zum Wohle aller in der Organisation zu erfüllen, kann aber seinen Willen nur ausführen, wenn er die Organisationsstruktur umgeht..$^{\circ}$

Auch die Arbeitsstruktur stellt eine Gemeinsamkeit zwischen fiktionaler Figur und abstrahiertem sozialem Typus dar: Der Corporate Worker, wie ihn Smith versteht, strukturiert seine Arbeit (im Unterschied zum Kleinunternehmer) nicht selbst, sondern wartet auf ein ¿Startkommando in Form eines Auftrags. Sodann versucht er die nötigen Arbeitsschritte möglichst effizient zu erledigen. Ebenso wird der Superheld bekanntlich nur aktiv, wenn seine Kräfte gebraucht werden, wobei er seine Aussergewöhnlichkeit in den Dienst des Kollektivs stellt. ${ }^{\text {sI }}$ Der Rhythmus dieser Einsätze, die ja nicht selten zu einem ungelegenen Zeitpunkt kommen (Abb. 7), entspricht der Häufigkeit der Unterbrechungen, die der Organization Man zu gewärtigen hat: «The classic superhero/secret identity pair models the handling of interruptions that is at the heart of corporate survival.»s2 Hier kommt allerdings eine weitere Superhelden-Standardkomponente zum Tragen: Zur Lösung des Problems braucht es seitens des Helden einen ExtraEffort. ${ }^{33}$ Smith erklärt dies im Zusammenhang mit dem Organization Man nicht allein aus Gründen der narrativen Spannung, sondern sieht darin ebenjene An-

49 Smith 2009, I30 (Hervorhebung im Original).

50 Vgl. dazu Meyer (20I I, I 36): «[Superman und Batman] verkörpern damit ein typisches Dilemma der modernen Angestelltenkultur - sie müssen ihr wahres Wesen [...] öffentlich geheim halten, um in einer nivellierten Massengesellschaft nicht aufzufallen [...]. Die Doppelidentität [...] ist also kein Identitätsverlust, vielmehr bestätigt sie [den Superhelden] in seiner ausserordentlichen Individualität.»

5 I Den Superhelden kennzeichnet in der Regel reaktives Handeln (Reynolds I994, 5 of.).

52 Smith 2009, I3 I. Wie Smith bemerkt, ist dies nur mit beruflichen Tätigkeiten in Einklang zu bringen, die zeitliche und örtliche Freiräume bieten. Freie Zeiteinteilung erscheint als Vorteil eines solchen professional jobs, deren Kehrseite aber die ständigen Unterbrechungen sind (wovon die Superhelden ein langes Lied singen können).

53 Den Extra-Effort hat Reynolds (1994, 4I) als Merkmal von Superheldenstorys beschrieben. Smith (2009, I32) erklärt, Superheldenstorys müssten dazu jeweils erst Momente der Machtlosigkeit schaffen, in denen er durchaus die «frustrations of corporate bureaucracy» erkennt. 


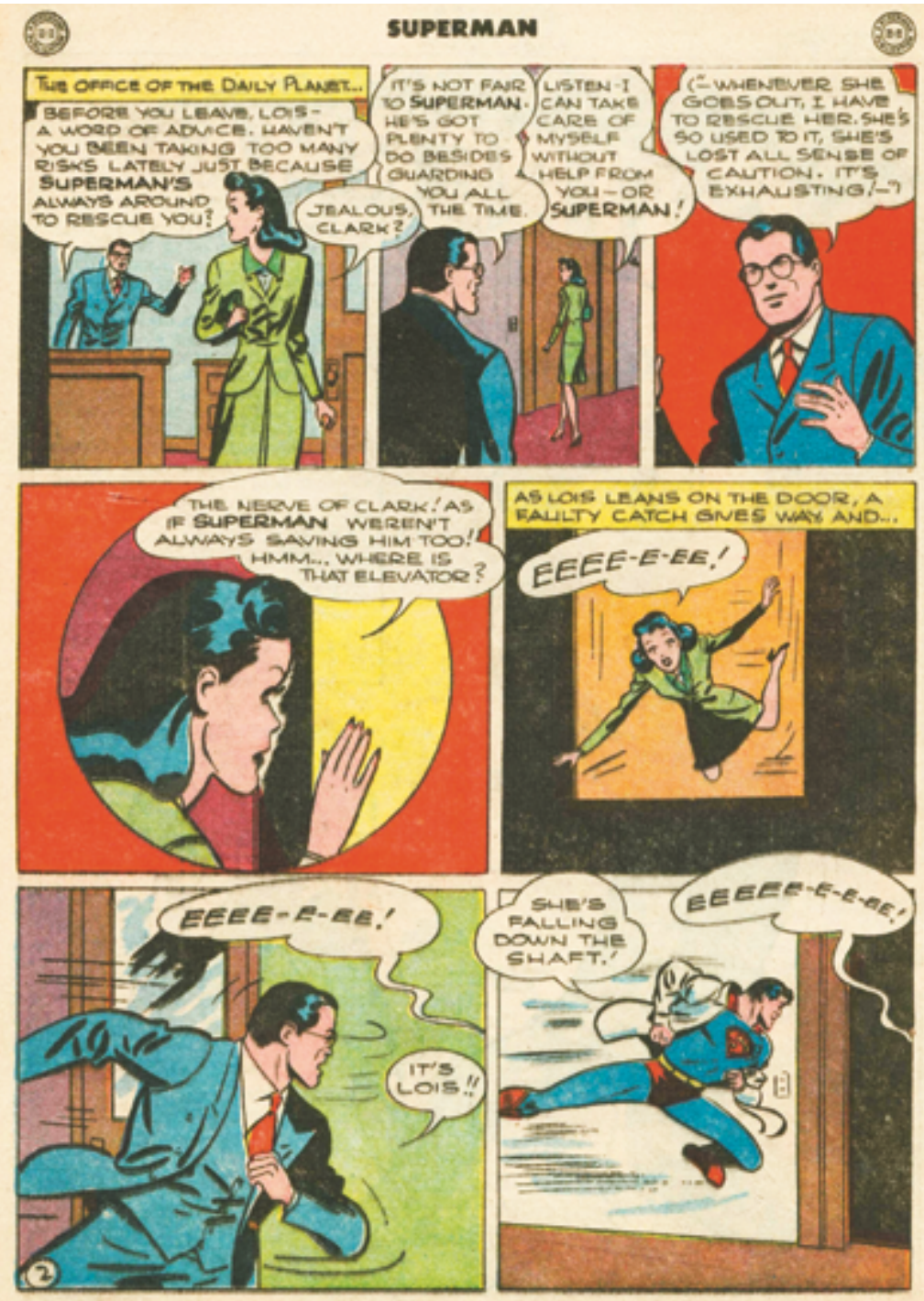

Abb. 7: Clark Kent/Superman hat für einmal Mühe mit seiner Arbeitslast womit gleichzeitig ein gängiges Element seiner Geschichten aufs Korn genommen wird -, doch wenn die Pflicht ruft, muss der Held wie ein geölter Blitz lossausen. Bezeichnenderweise fällt Lois von ihrem Panel auf den einsatzbereiten Superman herunter (statt ins Bodenlose), obwohl es sich eigentlich umgekehrt verhält und er sie von oben rettet. Clark Kent's Bodyguard (Alvin Schwartz, Pete Riss, Stan Kaye), in: Superman 4I, I946, 2. (C) DC Comics 
strengung, welche den professional von den <einfachen> Arbeitern unterscheidet. Für Smith betrifft dies aber beide Seiten des Helden: «[T] dividualist realms [are linked]. The two worlds, so seemingly different, demand similar tasks from their participiants. In many instances the lessons made salient by the superhero are exactly the same skills needed by the secret identity to survive in the corporate world.» ${ }^{4}$ Solange der Held bzw. der Organization Man in Aktion ist, um das aktuelle Problem zu bewältigen, wird die zivile Identität bzw. werden die privaten Bedürfnisse in der Regel auf Eis gelegt. «The classic corporate secret identity exposes the seemingly monstrous nature of the Organization Man's task», bilanziert Smith." Angesichts der Gefahr für den professional, seine private Identität im Dienst der Firma zu verlieren, zeigen die Comicfiguren für Smith durch die Doppelidentität, dass es eine Balance braucht.

Weder Riesman noch Whyte zogen laut Smith für ihre Akteure einen Wechsel zwischen den beiden Rollen(konzepten) in Betracht. Genau dies aber führen die maskierten Superhelden laut Smith exemplarisch vor: Die Doppelidentität ist um eine Reihe von Rollenwechseln in Raum und Zeit organisiert - für den Helden gilt es immer wieder herauszufinden, welche seiner präsentierten Identitäten besser ausgerüstet ist, um der jeweils aktuellen Krisensituation die Stirn zu bieten. In der Regel ist dies der Superheld als Individuum, der die Regeln der Gesellschaft umgeht und auf eigene Initiative aktiv wird; sporadisch kann vorkommen, dass sozusagen der «Organization Man working within the social network» das Problem aus der Welt schaffen kann. Smith sieht in der Doppelidentität den Wunschtraum gestaltet, die Effizienz zu besitzen, alle Hindernisse überwinden zu können - also immer das entsprechende Bündel an Fähigkeiten zur Lösung jedes Problems zu besitzen. ${ }^{56}$ Als Schwierigkeit nennt Smith die Umsetzung des Rollen-/Identitätswechsels, ohne erwischt zu werden, und sieht entsprechend die eigentliche «fantasy» der Doppelidentität darin, dass ein Wechsel zwischen den Rollen - inklusive der Rollenerwartungen und deren Erfüllung - möglich ist, ohne dass es zu einer vollends gespaltenen Persönlichkeit kommt. Dazu sind in der Perspektive auf den Superhelden als Corporate Man dessen beide Identitäten auch zu eng miteinander verquickt.

54 Smith 2009, I3I.

s5 Ebd. Die Doppelidentität bedeutet auch Hybridität, darum erfüllen Superhelden ein Grundkriterium für Monstrosität (ebd., I 30 ).

56 Smith sieht darin die Verbindung zweier notwendiger Modi des Heldentums (des official hero und des outlaw hero). Als «radical fantasy aspect» wertet Smith (2009, I 34f.) die Notwendigkeit des ständigen Wechsels zwischen den Rollen, was die Begrenzung ebenso wie die Notwendigkeit beider Modi verdeutliche. 
Ein weiterer Punkt ist dazu noch kurz anzuschneiden: Die gut situierte Zivilidentität mag in mancherlei Hinsicht Schwäche vorgaukeln, erweist sich aber als ökonomische Stärke, ohne die der Held mit seiner ganzen Selbstlosigkeit nicht weit käme. Diese Konvention wird indes mit Marvels Neukonfigurationen des Superheldenschemas in den i960er-Jahren aufgebrochen: Im Silver Age geht das Heldentum nicht mehr automatisch mit monetärer Versorgtheit einher - nun erst wird thematisiert, dass Superheldentum eigentlich ein schlechtes Geschäftsmodell ist. 57 Dennoch bleibt die Regel, dass die zivile Tätigkeit dem typischen maskierten Protagonisten quasi erst den Luxus ermöglicht, jenseits pekuniärer Verstrickungen als Held zu wirken.

\section{Die Frage nach der wahren Identität}

Wie jede Maskerade fordert die Doppelidentität des maskierten Helden die Frage nach seinem ‘wahren〉 Selbst, seiner ‘wahren〉 Identität heraus. Diese Frage wird in der Sekundärliteratur zu Superheldencomics keineswegs einheitlich beantwortet. Dabei bedarf es zunächst einer sprachlichen Präzisierung: Wenn im Folgenden von ‘wahrer Identität die Rede ist, ist dies die Übersetzung von zwei englischen Entsprechungen, nämlich 〈true und 〈real> (bzw. 〈in reality>). Übersetzt man beides wörtlich (〈wahr〉 und 〈real〉), erschliesst sich eine Bedeutungsnuance, die vielleicht am besten durch Hinzunahme der Antonyme sichtbar wird: Das Paar «wahr - unwahr/falsch〉 bezeichnet eine andere Ebene als <real - irreal>, neben der für beide gültigen Ebene <echt - unecht〉. Eröffnet das eine Wortpaar eine Spannung zwischen Wahrheit und Täuschung, rückt das andere jene zwischen Wirklichkeit und Unwirklichkeit oder Fantasie in den Blick, was in der oben erwähnten Interpretation der superheldischen Seite des Protagonisten als Leserfantasie eine Abbildung auf Wortebene nahelegt. Dennoch erscheinen die beiden Wörter in den meisten hier betrachteten Texten, wie im allgemeinen Sprachgebrauch, als austauschbare Synonyme und werden deshalb begrifflich nicht unterschieden.

Wie bereits erwähnt, folgen die meisten Origin-Storys der maskierten Superhelden demselben Muster: Der Protagonist wächst als «gewöhnlicher Mensch` auf und erhält durch ein besonderes Ereignis Superkräfte (oder verschafft sich diese durch technische Hilfsmittel, eine Erfindung, jahrelanges Training etc.) und zugleich

57 Smith 2009, I 37. Neben Spider-Man macht dies vor allem der schwarze Ex-Sträfling Luke Cage (ab 1972) deutlich, der zwar den Namen Power-Man erhält, sich aber eine Doppelidentität gar nicht leisten kann (und folglich keine solche aufweist), wie sein Motto «hero for hire» auf den Punkt bringt. 
oder aufgrund einer weiteren Begebenheit den Impuls, fortan als Held zu wirken. Den Sonderfall des Ausserirdischen vom Planeten Krypton umschreibt etwa Morris: "With Clark, the powers preceded the developed civilian identity. And his real identity was not that of a human at all. Uniquely, it seems, his superhero identity is his real, core identity.» ${ }^{8}$ Morris übersieht hier ähnlich gelagerte Fälle wie Wonder Woman/Diana Prince, doch macht er das erste Argument zur Beantwortung der Frage nach der ‘wahren> Identität deutlich: die Herkunft vor Erhalt der Kräfte oder eben mit den Kräften, sprich die «angestammte> Identität. Die Ansicht «Kent was not Superman's true identity as Bruce Wayne was Batman's» 99 vertrat bereits Jules Feiffer. Auch andere Autoren sind für Superman zu dieser Beurteilung gekommen; sie ist entsprechend weit verbreitet. ${ }^{60}$ Feiffer sah in der Clark-Kent-Fassade ein Spiegelbild oder sogar ein Zerrbild menschlicher Durchschnittlichkeit: «He's Superman's opinion of the rest of us, a pointed caricature of what we, the noncriminal element, were really like. ${ }^{61}$ Die Frage nach der «wahren> Identität von Superman/Clark Kent führt so zur Frage, ob Clark als reine Fassade aufzufassen ist oder trotz aller vorgetäuschen Helden-Untauglichkeit nicht doch eine authentische (Teil-)Identität des Protagonisten darstellt. ${ }^{62}$

Betrachtet man die allererste Superman-Geschichte, die mit der damals noch sehr knapp gehaltenen, nur gerade eine Seite umfassenden Origin-Story beginnt, wird zwar zuerst erzählt, wie ein Baby von Krypton in einer Rakete auf der Erde landet und von einem Passanten ins Waisenhaus gebracht wird, wo es aufwächst und übermenschliche Stärke zeigt. Dann heisst es aber explizit: «Early Clark decided he must turn his titanic strength into channels that would benefit mankind, and so was created ... SUPERMAN!» ${ }^{63}$ Wenn erst der erwachsene Clark die Entscheidung fällt, ${ }^{64}$ Superman zu kreieren, dann ist durchaus debattierbar,

58 Morris 2008, 258.

59 Jules Feiffer: The Great Comic Book Heroes, Seattle 2003 (I965), I I-I 3, zit. n. Darowski $2009,22$.

60 Jüngere Beispiele dafür sind Fingeroth 2008, 57, Meyer 201 I, I36, Darowski 2009, 22f., Morris 2008, 257, Bukatman 2003, 2 I4.

6I Jules Feiffer: The Great Comic Book Heroes, New York I965, I 8-19, zit. n. Smith 2009, I 42. Smith erwähnt dazu die Szene in Quentin Tarantinos Film Kill Bill Vol. 2 (2004), in der die Figur Bill Feiffers Aussagen wiedergibt. Auf diese Szene beziehen sich auch Bainbridge 2009, 7I, sowie diese zu Recht verwerfend Naficy 2008, I78f., und Weltzien 2005, 23 I/24I/247.

62 Vgl. Gavaler (2015, I 27), der vier mögliche Antworten auf die Frage nach Supermans Kernidentität auflistet.

63 [Superman, Champion of the Oppressed!] (Jerry Siegel, Joe Shuster), in: Action Comics I, Juni 1938, Panels I-9, meine Hervorhebung. Die Origin-Story wurde dabei schon im Zeitungsstrip (1939) erheblich und in Superman I, Juli 1939, etwas ausgebaut, doch blieb dieser Satz in diesen drei ersten Versionen fast identisch. Lesenswerte Analysen der Origin-Story bieten u. a. Reynolds 1994, I0-1 5, und Harrison in Easton/Harrison 2010, 37-54.

64 Superboy, der erstmals I945 in More Fun Comics ro I auftrat, wird hier ausgeblendet (vgl. Harrison in Easton/Harrison 2010, 43-45). 
welche 〈Hälfte〉 denn nun zuerst da war. Denn wer war Superman vor dieser Entscheidung, wenn nicht Clark Kent - der allerdings schon immer die Superman definierenden Superkräfte hatte?

Doch des Dilemmas nicht genug: Während die meisten Superhelden nahelegen, sie auf bloss zwei Identitäten bzw. Identitätshälften mit zwei Namen zu behaften, hat Superman offiziell noch einen dritten, seinen kryptonischen Taufnamen Kal-El. Dieser kam in den ersten Jahren zwar nicht vor, sondern wurde in den Comic-Heften erst 1957 (in Superman I I 3 ) etabliert. ${ }^{65}$ In den Comics erfolgt die Benennung Kal-El meist nur dann, wenn die Verbindung zu Krypton gerade eine Rolle spielt. Ob der Name bloss als Hintergrundinformation eingestreut wird oder fast eine dritte (Teil-)Identität des Protagonisten darstellt, kann je nach Umsetzung sehr unterschiedlich ausfallen. ${ }^{66} \mathrm{Ob}$ zwischen Superman und Kal-El zusätzlich zu unterscheiden wäre, lassen die Vertreter von Feiffers Ansicht indes unbeantwortet.

Dafür überträgt beispielsweise Jason Bainbridge diese Auffassung der beiden Identitäten auch auf Batman: «Even Bruce Wayne, while being a real person who becomes the Batman [...], becomes a performance [...]; the true Bruce Wayne is the brooding face beneath the cowl of the Batman.» ${ }^{67}$ Bainbridge, der dies als Charakteristikum der DC-Superhelden bezeichnet, schreibt dies sicherlich mit den Batman-Versionen ab den I980er-Jahren vor Augen - für ihn liefert aber nicht die Herkunft das Hauptargument, sondern der Performanzaspekt der zivilen «Kunstfigur» ${ }^{68}$. Nochmals etwas anders klingt diese Sichtweise bei Mathias Kniep:

Sein [des Superhelden] wahres Ich ist somit das heldische Ich, das vor dem Hintergrund wechselnder Erscheinungen die Einheit und Dauer eines geschlossenen Subjekts verbürgt. Daraus folgt, dass es nicht der Mensch ist (Clark Kent, Bruce Wayne usw.), der seine eigentliche Identität hinter der Maske eines Superhelden verbirgt, sondern umgekehrt der Held selbst, der mit Hilfe der Konstruktion einer Alltagspersona unendeckt zu bleiben hofft. ${ }^{69}$

In Knieps Worten wird eine bestimmte Identitätsvorstellung greifbar: Obwohl die Protagonisten über eine «wahre` und eine nur vorgegebene Identität verfügen, stellen sie ein «geschlossene[s] Subjekt» dar, was Kniep als kennzeichnend

65 Laut Engle $(1987,86)$ kam «Superman's real $[\ldots]$ name» zuerst 1942 in George Lowthers novelization vor.

66 Sehr weit geht etwa die TV-Serie Smallville, die Clarks Jugend thematisiert. Kal-El erscheint quasi als abgespaltene Persönlichkeit von Clark (der erst am Schluss der Serie als Superman auftritt) und weist jede Verbindung zu Clark bzw. dessen sozialem Umfeld von sich (siehe z. B. So ${ }_{4} \mathrm{E}$ I, 2005).

67 Bainbridge 2009, 7I (meine Hervorhebung); ähnlich formuliert dies Darowski 2009, 82.

68 Meyer 20II, I36.

69 Kniep 2009, 32 (identisch 2001, I 42f., meine Hervorhebung). 
für die Golden-Age-Helden beschreibt. Kniep sieht dabei die Origin-Story des Helden parallel zur Schmetterlingsmetamorphose. In seinem fremdwortmäandernden Stil führt er aus: «Das prästabilisierte Telos seiner Verwandlung ist das Heldentum, d. h., er wird, nachdem er von der Chrysalide zur Imago alle Stationen seines Entwicklungsprozesses durchlaufen hat, zu dem, was er vorher bereits gewesen ist: ein Superheld.»70 Ein einmal entpuppter Schmetterling kann jedoch nicht erneut Raupengestalt annehmen. Die «wechselnden Erscheinungen» des Protagonisten erklären sich daher laut Kniep wie folgt: «[...] der Prozess, der in der Alltagspersona den Gott präzipitiert, [ist] grundsätzlich irreversibel [...], tatsächlich aber kehrt der Held zum Schein immer wieder zu seiner alten Gestalt zurück, er wird [...] zu dem, der einen verloren gegebenen Aspekt seines Selbst repräsentiert. ( $^{11}$ Knieps Verständnis der Doppelidentität umfasst nicht nur einen Zustand, sondern auch eine zeitliche Ebene, die aber - nach einem einmal erreichten linearen Entwicklungsschritt, der ebenso als Enthüllung verstanden werden könnte - einen zyklischen Charakter aufweist.

Kniep bemerkt, in den Golden-Age-Geschichten von Batman und Superman fänden sich «zahlreiche Belege», dass die beiden «die Welt lediglich glauben machen wollen, sie wären jemand anderer» ${ }^{72}$. Dies ist zweifellos der Fall, doch ist die Sache selbst in den Comics des Golden Age nicht gänzlich eindeutig. Ein leicht greifbares Indiz dafür liefern die Erzählerkommentare bzw. Erläuterungstexte, in denen eine der beiden Identitäten mit «in reality» oder «really» verbunden wird. In den frühen Batman-Comics schwankt der Gebrauch: Man findet sowohl «Batman, in reality Bruce Wayne»73 als auch das umgedrehte «Bruce Wayne, in reality the Batman» ${ }^{74}$, was - entgegen Feiffers Auffassung - häufiger vorkommt. In Batmans Origin-Story spricht Bruce Wayne übrigens zunächst klar von einer Verkleidung, die er benötigt: «Criminals are a superstitious cowardly lot. So my disguise must be able to strike terror in their hearts.» Als die

70 Ebd.

7I Kniep 2009, I47. Dabei spricht Kniep an einer Stelle der zivilen Identität konsequenterweise die Existenz ab (ebd., 97): «Im Falle von Superman und Batman war das der Öffentlichkeit präsentierte Leben [...] reine Fassade. Es gab keinen Clark Kent in Metropolis und keinen Bruce Wayne in Gotham City. Ihre wahre Identität blieb sunter den Rosen`. Ein residuales Ich, das sich im Körper einer Alltagspersona einnistet, konnte nicht existieren, weil Superman und Batman vor und nach dem Abschluss ihrer Entwicklung bereits Superhelden waren.»

72 Ebd., 33 (identisch 200I, I43).

73 Z. B. in Detective Comics 32, Oktober 1939, oder in Batman 4, Winter 194I (beide von Bill Finger/Bob Kane), als «Batman's real identity», also Bruce Wayne, enthüllt zu werden droht (letzte Story im Heft: [Victory for the Dynamic Duo]).

74 Z. B. in Detective Comics 29, Juli 1939, ähnlich in Detective Comics 80, Oktober 1943, 2, oder Batman 4, Winter 194I (alle von Bill Finger, Bob Kane), zweite und dritte Story im Heft: Blackbeard's Crew and the Yacht Society sowie [Public Enemy No. I]. 

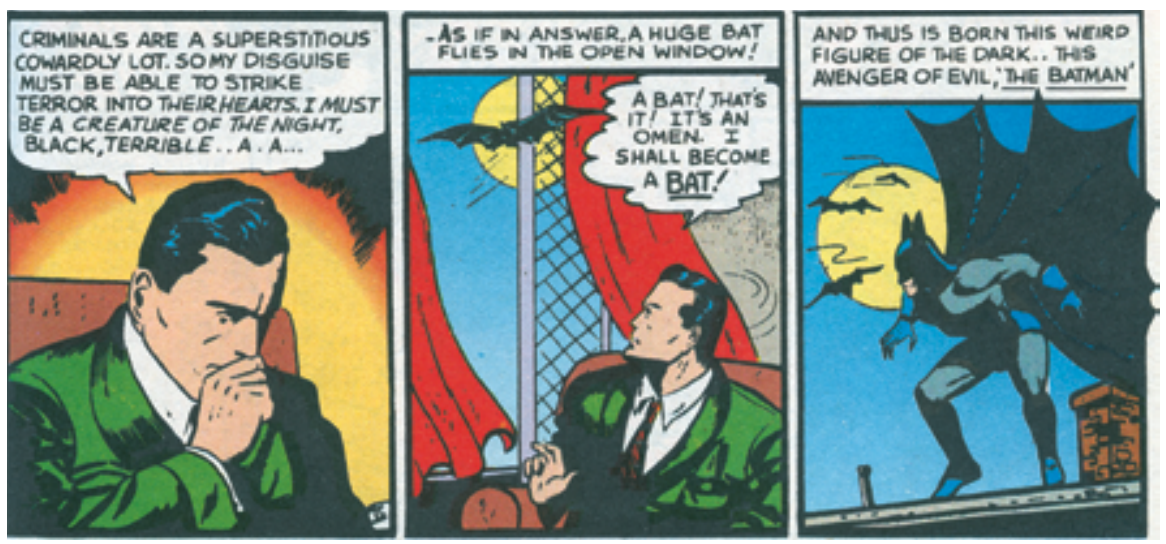

Abb. 8: In den letzten drei Panels von Batmans erster Origin Story geht es von der Idee zur Umsetzung vermeintlich ganz schnell - nämlich nur einen Bildzwischenraum lang. The Batman Wars Against the Dirigible of Doom (Bob Kane, Bill Finger/Gardner Fox et al.), in: Detective Comics 33, I939, II. (C) DC Comics

inspirierende Fledermaus ins Zimmer fliegt, ruft er aus: «I shall become a bat!»75 In diesem «become» kann man schon eine Andeutung darauf lesen, dass die Batman-Robe mehr als eine Verkleidung sein wird (Abb. 8).

Bei Superman dagegen wird im Golden Age ziemlich konsequent die heldische Seite des Protagonisten mit den Worten «real» und «reality» gekoppelt. ${ }^{6}$ Allerdings sind solche Wendungen weniger zahlreich, als man vermuten könnte. Gerade in Bezug auf den Kleiderwechsel ist häufiger von «transformation», «switch» oder «change» die Rede. Spätestens im Silver Age finden sich aber auch bei Superman gegenteilige Formulierungen. I962 etwa rechnet Superman einmal mit seinem baldigen Tod. Als Vermächtnis brennt er mit seinen Laseraugen eine Botschaft in den Mond, die er mit «Superman (Clark Kent)» unterschreibt.

75 Origin-Story in Detective Comics 33, November 1939, II, und Batman I, Frühling 1940; auch in der etwas abgeänderten Version in Batman 47, Juni/Juli I 948 - alle von Bill Finger und Bob Kane - bleiben die letzten beiden Panels nahezu unverändert. Batmans Origin-Szene wird im Batman-Kapitel noch ausführlicher diskutiert.

76 Z. B. in Superman's Phony Manager (Jerry Siegel, Joe Shuster), in: Action Comics 6, November 1938, Panel $5:$ «For in reality, Clark Kent is Superman.» 
Dabei denkt er: «[...] people will read my last message ... and learn my real identity!»77

Zwar erscheint Clark im Golden Age über weite Strecken als Hilfskonstruktion für Superman, doch gibt es schon im Golden Age immer wieder Momente, die zumindest eine «own personality» für die Clark-Hälfte andeuten. So lautet die Einleitung zu einer Geschichte von 1945:

You've seen a lot of Clark Kent's exploits as Superman - how about an eyeful of Superman's exploits as Clark Kent? What's the difference, you ask? Well, you see, when Superman unleashes his magnificent powers to vanquish crime, Clark Kent's own personality is sort of put in the shade. But in this tale, while Superman does plenty and then some, we're going to get a full measure of «Clark Kent, Star Reporter!».7

In der Geschichte wird Clark wegen einer Artikelserie von einer Verbrecherbande vermeintlich umgebracht, während einer der Kriminellen als Clark-Double dessen Platz in der Redaktion einnimmt. Clark/Superman begibt sich im Geheimen auf Recherche, sersteht in jenem Moment wieder «aufs, als der Doppelgänger Lois küssen will, und legt der Bande das Handwerk (Abb. 9). Solche Geschichten, die auf die Unteilbarkeit der beiden Seiten des Helden hindeuten, gibt es immer wieder, manchmal auch ohne Betonung, dass eine «Clark Kent»Story vorliege. Der Reporteralltag und damit der «normale〉 Clark Kent rückte noch stärker in den Vordergrund in einer Reihe von Geschichten unter dem gesonderten Label The Secret Life of Clark Kent, die zwischen 1962 und 1982 in den Superman-Heften erschien.

In Clark nur die Fassade zu sehen, legt nahe, Superman als authentische Identität aufzufassen. Auch dies lässt sich zumindest in Ansätzen hinterfragen, wenn man sein Verhältnis zu Lois festzunageln versucht. Für die Frage nach seiner ‘wahren〉 Identität nehmen die Gefühle des Protagonisten für seine Arbeitskollegin zumindest eine Indikatorfunktion ein. Lois wird zur konstantesten Bezugsperson des Helden und dient als primäre Reibefläche für seine Doppelidentität, umso mehr, da sie zeitweise fast schon toposhaft den Verdacht hegt, dass Clark und Superman derselbe sind, mit ihren Beweisversuchen aber regelmässig scheitert. Obwohl Lois Superman bereits in Action Comics 5 zum ersten Mal küsst und zwar ohne explizite bildliche Darstellung, nämlich im Rinnstein (Zwischenraum) zwischen zwei Panels, dafür mit Lois’ Worten «A Super-Kiss for a Super-Man!» 79 -, ist in den ersten zwei bis drei Jahrzehnten schwer zu sagen,

77 The Last Days of Superman, Part III: Superman's Last Day of Life (Edmond Hamilton, Curt Swan u. a.), in: Superman I 56, Oktober 1962, 4. Vgl. auch Superman 176, April 1965.

78 Clark Kent, Star Reporter! ([Bill Finger], Ira Yarbrough et al.), in: Superman 36, Sept.-Okt. 1945, I.

79 Superman and the Dam (Jerry Siegel, Joe Shuster), in: Action Comics 5, Oktober 1938, Panels $5 \mathrm{I}-53$. 
Abb. 9: Für einmal löst Clark statt Superman den Fall, wobei Clark visuell in die Zeitung eingebettet bleibt, während Superman einerseits als blosser Zuschauer/Leser erscheint, zugleich aber zusammen mit der Zeitung das Geschehen um Clark umfasst. Clark Kent, Star Reporter! ([Bill Finger], Ira Yarbrough et al.), in: Superman 36, September-Oktober I945, I. (C) DC Comics

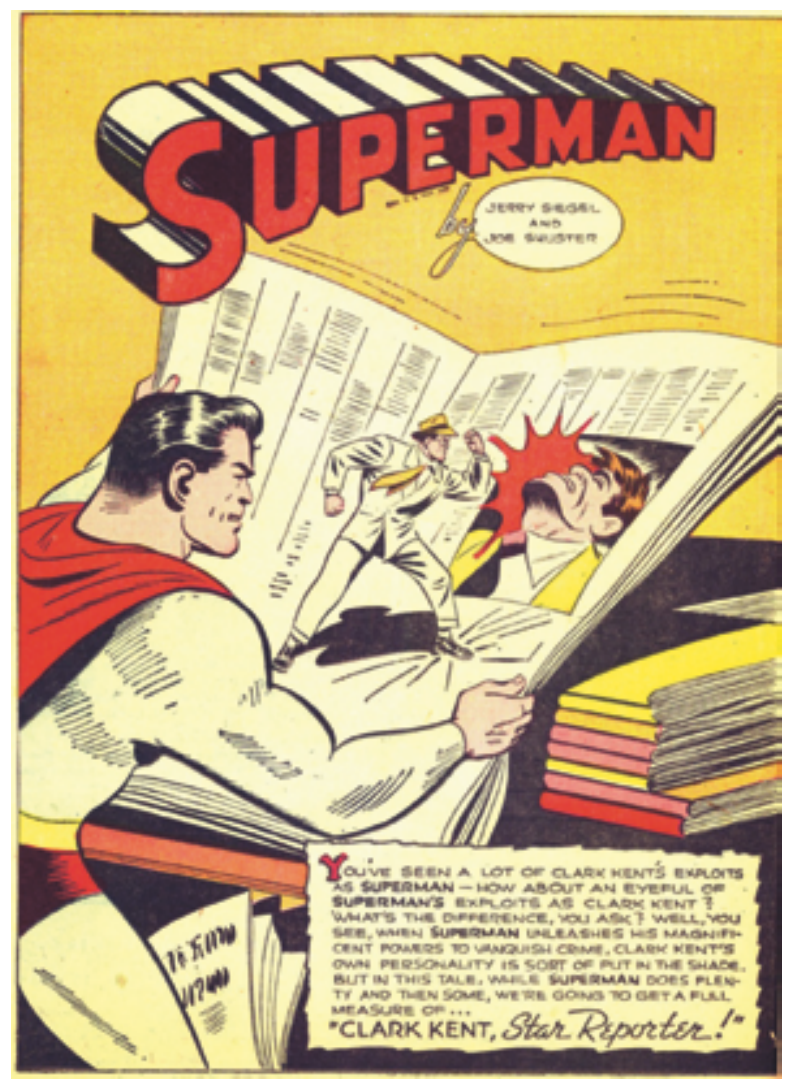

in welchem Ausmass Clark/Superman ihre Zuneigung tatsächlich erwidert. Im Golden Age untermauern zahlreiche Momente die Annahme, dass «Superman als Clark Kent> nur vorgibt, in Lois verliebt zu sein. Denn als Superman hält er sie ziemlich konsequent, zuweilen recht ruppig, auf Abstand. ${ }^{8 \circ}$ Gleichwohl ist er immer da, um sie aus Gefahr zu retten - und <er heisst in diesem Fall: als Superman bzw. in Supermans Rolle entreisst er sie einer Bedrohung, was oft nur möglich ist, weil er sie als Clark bzw. in Clarks Rolle auf den nächsten Gefahrenherd zusteuern sieht und in ihrer Nähe bleibt. Diese Konstellation ändert allmählich, wenn auch nicht kontinuierlich. Daran nicht unschuldig waren zwei-

8० Die heiratswütige Lois - oft in Konkurrenz zu Clarks Jugendfreundin Lana Lang - ist eine Art Running Gag in den I950er-Jahren. Zu Lois und Lana vgl. Beritela 2007, Schenck 2005, $4 \mathrm{I}-44$. 
fellos die Produktionsumstände, denn die wechselnden Superman-Autoren im Golden Age und auch danach liessen es immer wieder an Kontinuität mangeln. Dies zeigt sich etwa darin, inwiefern Clark sich als (adoptierter) Angehöriger der Kent-Familie versteht. Beispielsweise sagt Clark/Superman einmal, er habe keine Kent-Verwandten mehr, erhält aber ein andermal einen Besuch von seiner alten Tante Minerva (samt ihrem sprechenden Papagei), deren Anwesenheit, wie zu erwarten, eine Herausforderung für sein Identitätsgeheimnis bedeutet. ${ }^{81}$ Ähnlich verhält es sich mit der Liebe: Während gewisse Geschichten klarstellten, dass Lois - falls der Protagonist denn überhaupt einmal an einer Liebesbeziehung interessiert sein sollte - die Richtige wäre, präsentierten unter anderem Imaginary Stories ebenso andere Szenarien.

Im Lauf der Zeit, in der sich auch die typischen Erzählweisen ändern, gesteht sich Clark/Superman auch als Superman ein, dass er Lois liebt, ${ }^{82}$ und schliesslich sollten sie sogar ein Paar werden (Liebeserklärung in Superman 333, 1979), ohne dass Lois in sein Geheimnis eingeweiht ist. Dies wird oft als Verschiebung der «wahren〉 Identität von Superman zu Clark betrachtet, wobei verschiedene Wendepunkte genannt werden können. Einer davon ist der Neustart der Reihe 1986 von John Byrne. Clarks Eltern Martha und Jonathan Kent waren nun nicht mehr schon lange tot, sondern lebten noch immer im ruralen Smallville, wo Clark/ Superman aufgewachsen war, was die Clark-Seite gestärkt hat. ${ }^{83}$ Wie Darowski betont, ist es mit den Jahren zu einer Annäherung der beiden Identitäten gekommen. $^{8}{ }^{8}$

Die unterschiedlichen Antworten auf die Frage nach der wahren Identität in der Sekundärliteratur werden wie erwähnt auch als Teil des unterschiedlichen Heldenkonzeptes der beiden grossen Verlagshäuser Marvel und DC aufgefasst. Damit verbunden werden die beiden Verlage als jeweils für ein Zeitalter prä-

8 I Vgl. The Pride of the Kents, in: Superman 29, Juli-August 1944; Superman's Aunt Minerva, in: Action Comics I60, September I95 I.

82 Vgl. die Story, in der Lois beinahe Mrs. Futureman wird (The Bride of Futureman, in: Superman I 2 I, Mai 1958) oder als sie kurzfristig einen anderen heiratet und Superman als Trauzeuge nur die innerliche Klage «I'm heartbroken» bleibt (The Man Who Married Lois Lane (Robert Bernstein, Wayne Boring, Stan Kaye), in: Superman I36, April I960, 6). Erst I99I gestand Clark Lois endlich sein Geheimnis; 1996 folgte die Heirat, was selbstverständlich nur ein zeitweiliges Happy-End bedeutete - die Serialität forderte inzwischen ihre Tribute.

83 Gavaler (2015, I 27) und Rosenberg (2008, 31) sehen den Wendepunkt mit dem Neuanfang (Reboot) unter John Byrne 1986, Darowski (2009, 30) in Lois' Einweihung (199r); Andrae ( 1980, I0, f.) sah dies schon in den Jahren vor 1980 , und noch früher interpretierte dies Wiener $(1970,96)$ gerade gegenteilig, ihm zufolge ist «alles unbeholfene und ängstliche an clark kent nur gespielt [...], früher [...] liebte [er] sie [Lois] damals offenbar wirklich» [sic].

84 Darowski $(2009,32)$ bemerkt aber trotzdem: «Superman and Clark Kent seem to resist true synthesis.» 
gend gesehen: Als Epigonen des schemabildenden Goldenen Zeitalters gelten vor allem die DC-Figuren. Von ihnen werden dann die Anfang der I960er-Jahre in einem neuen Anlauf geschaffenen Marvel-Superhelden als gegensätzlicher frischer Wind abgehoben, der das Silberne Zeitalter begründet und prägt. Die Häufung von seltsamen Unfällen in den Origin-Storys der neuen Superheldenfiguren von Marvel, in denen Verseuchung zu Superkräften führt, wird etwa von Kniep und Bainbridge als bedeutsamer Unterschied erachtet. ${ }^{85}$ Da viele MarvelHelden unerwünschte Folgen davontragen und oft als Resultat schiefgelaufener moderner Wissenschaft (meist radioaktiver Strahlung) monströse Züge erhalten, sieht Bainbridge in ihnen die Kehrseite der Moderne verkörpert und befindet: «[...] the Marvel heroes are real〉 people. [...] Here then is the complete reverse of the DC hero. Peter Parker dresses up as Spider-Man; Peter Parker is not the disguise that Spider-Man wears. ${ }^{86}$ Kniep verknüpft dies stärker mit einem unterschiedlichen Identitätsverständnis. Während die Golden-Age-Epigonen noch durch «das göttliche Bei-sich-selbst- und Mit-sich-selbst-identisch-sein [sic]» geprägt gewesen seien, zeige der typische Silver-Age-Superheld eine «Dissoziation von Alltagspersona und Heldenrolle», worin Kniep die Gebrochenheit und den Hang zum Hadern, der viele Marvel-Helden charakterisiert, begründet sieht. ${ }^{87}$ Im Silver Age gehe es nicht mehr um «Auftrag und Sendung», sondern um die "Queste des neuen Helden nach seinem wahren Selbst». ${ }^{88}$

Einen Wandel im Lauf der Zeit sprechen auch Thomas Andrae und Tom Morris an - aber weniger als Kennzeichen von Heldengruppen, sondern als sozusagen biografische Entwicklung der Heldenfiguren Superman und Batman sowie (für Superman) als Ausdruck sich verändernder Genrekonventionen bzw. narrativer Ansprüche. Morris postuliert zunächst einen «biografischen` Wandel für Batman. Bruce Wayne habe als Industrialist angefangen, der nebenbei Verbrechensbekämpfung betrieb; im Lauf der Zeit sei aus ihm aber ein Verbrechensbekämpfer geworden, dessen zivile Identität nur noch ein Hilfsmittel sei. Mit andern Worten:

85 Vgl. Kniep 2009, 204, und 200I, I 52, Bainbridge 2009, 73f. Wenn man für das Golden Age nicht nur Superhelden von DC, sondern auch von anderen Verlagen betrachtet, ist der Unfall und die damit verbundene Zufälligkeit aber schwerlich «der alleinige Auslöser einer im Vergleich zu den Entstehungsmythen von Superman und Batman ganz neuartigen Genese des Helden [im Silbernen Zeitalter]», wie Kniep schreibt (2009, 204, 200I, I 52). Den Unfall als Heldenursache erleben z. B. schon Plastic Man, Human Bomb (beide ab 194I in Police Comics), Green Mask oder Hydroman (beide ab 1940) und bei DC The Flash (ab 1940) sowie Dr. Mid-Nite (ab I94I). Bainbridge 2009, 73. Vgl. für Spider-Man auch Darowski 2009, 82 (Weiteres dazu im SpiderMan-Kapitel).

87 Kniep 2009, 203 (identisch 2001, I 52).

88 Ebd. 
At the start of his dual identity, his core identity was clearly that of Bruce Wayne, and his alternate, secondary identity, taken on for a purpose, was that of Batman. But as it stands now, years down the road, it seems to me that there has been a gradual, surprising transformation such that the core identity may have become that of Batman $[\ldots]$. The image of Bruce Wayne may have become the real mask at this point. ${ }^{89}$

Für Superman entwirft Morris dagegen eine umgekehrte Geheimnisbiografie: Dieser habe seine Cover-Identität Clark ja nicht geplant, sondern sei als dieser aufgewachsen. ${ }^{\circ}$ Obwohl Superman zunächst die «true identity» gewesen sei, möchte ein grosser Teil von ihm eben doch Clark sein, da nur dieser dem Ausserirdischen eine Verbindung zu den Menschen ermöglicht. Die Clark-Identität wird so «a crucial part of a real quest to live the human adventure»91. Wenn Superman nur Clark Kent, also «mehr Mensch», sein möchte - und diese Entwicklung sieht Morris 2005 erst als potenzielle -, resultiere womöglich «not a transformation of core identity from Kryptonian to Kansan, but rather a similar blended duality enhancing what would otherwise be a singular person merely using a costume - [i. e.] of a newsman - for special purposes» ${ }^{92}$.

Andrae argumentiert hingegen mit der Erzähllogik, mit der es die Autoren im Golden Age bekanntlich nicht so genau nahmen: «The attempt to portray Kent as merely a fabrication and Superman as a real personality results in the creation of paradoxes in the narrative.»93 Selbstverständlich ist das Paradebeispiel eines solchen Paradoxes das Beziehungsdreieck Lois-Clark-Superman. Zunächst könnte man es als Verschiebung der ‘wahren Identität> zwischen den beiden Identitäten verstehen, wenn Superman/Clark Kent in einigen Geschichten wünscht, Lois möge ihn als ihn selbst, das heisst in seiner zivilen Identität, lieben. ${ }^{94}$ Andrae aber zieht mit Blick auf die Erzähllogik einen salomonischen Schluss: «Since this would mean loving a purely fake, fabricated personality it does not make sense.

89 Morris 2008, 263.

90 Ebd., 257. Die TV-Serie Smallville (200I-20I I) setzt diese Entwicklung ebenfalls biografisch um: Ist anfänglich Clark die 〈reale> Person bzw. «wahre> Identität, beschliesst dieser in der letzten Staffel bewusst, seine bisherige Identität zur Verkleidung zu machen, statt im Heldenkostüm eine Maske zu tragen (SioEr3/I4, 20II). Auch die frühere Serie Lois E Clark (I993-1997) präsentiert Clark als «eigentliches Ich〉 des Helden, dort erklärt er einmal: «Clark is who I am, Superman is what I can do» (So2E I 8, I 995).

9I Morris 2008, 26I.

92 Ebd., 264.

93 Andrae 1980, 103.

94 Ebd., I05. Andrae beobachtet denn auch eine entsprechende Entwicklung in den Jahren vor I980, als sein Text erschien: Wiederholt gebe Superman seine Heldenidentität auf, um ganz Clark Kent sein zu können, oder tausche die Rollen. (Allerdings spielt eine der Geschichten, die Andrae als Beleg nennt, jene in Action Comics 484, 1978, auf Earth-2, also in einem anderen Universum als dem der allgemeinen DC-Continuity.) 
The only logical conclusion is that Kent is not merely a put on and Superman the true identity, but that both identities are aspects of a single personality, each autonomous in its realm.»95 Andrae scheint somit einer der Ersten zu sein, die es vermeiden, einer der beiden Identitäten oder Identitätshälften das Etikett 〈wahr〉 zuzuordnen.

In diese Kerbe schlägt auch Frahm, der in Bezug auf eine Superman-Geschichte aus dem Golden Age festhält: «[...] Superman [darf] auch nicht als «wahre Identität> von Clark Kent verstanden werden, und Clark Kent nicht als «Maske> von Superman. Beide sind Masken. 〈Er〉, wer immer 〈er〉 ist, muss beides werden können, um 〈übermenschlich〉 zu handeln [...].» ${ }^{96}$ Auch für Batman und Spider-Man wird die Frage nach der ‘wahren> Identität inzwischen explizit zurückgewiesen. So erklären etwa Söll/Weltzien für Spider-Man: «Die Maske macht die Metamorphose des Helden deutlich sichtbar, wobei in der Schwebe bleibt, welche der beiden Identitäten die ‘wahre> ist.»97 Für den Dunklen Ritter formuliert Nehrlich, in Batman die ‘wahre> Identität zu sehen, sei unhaltbar, denn «Batman und Bruce Wayne sind zwei Seiten einer Identität» ${ }^{8}$. Nehrlich sieht die Ursache für die häufige Fixierung auf die 'Wahrheitsfrage in fehlenden alternativen Begrifflichkeiten für das Doppelleben der Superhelden: «Die behelfsmässige Rede von einer <dualen Identität> - aufgeteilt in Superhelden- und ziviles Ich - ist irreführend. [...] bürgerliche und superheroische Gestalt [sind] zwar unterschiedliche Rollen, sind dabei aber Elemente einer ungeteilten Identität und bilden eine Einheit.»99 Nehrlichs Kritik ist berechtigt, auch weil die Bezeichnung als duale bzw. doppelte Identität (nur) eine Zweiheit impliziert - dennoch ist dieser Begriff nur schon deshalb nicht zu umgehen, weil er in den Comics fest implementiert ist. Etwas versteckt in einer Fussnote fasst David Coughlan das Problem wohl am treffendsten zusammen:

The common temptation to assign <true> and ‘false identities, where Spider-Man, for example, is 〈really Peter Parker, obscures the fact that the link between the two identities is the true secret. The lure of assigning a <real identity is so strong that rethinking the two identities has always been a means of reinterpreting comic book characters. However, ultimately, the fluidity of these identities is more significant than any assertation that 〈Superman's the real guy, Clark's the disguise>. ${ }^{100}$

95 Andrae 1980, 104 (meine Hervorhebung).

96 Frahm 2005, 44 (Hervorhebung im Original).

97 Söll/Weltzien 2003, 307.

98 Nehrlich 201 3, I 26f. (Fussnote 57).

99 Ebd., I 27.

I00 Coughlan 2009, 250 (Fussnote 6). Die zitierte Aussage stammt von Comicautor Mark Waid (2004). Für Batman deutet Meißner (2009, 8) an, dass für die «wahre Identität die Frage wich- 
All diese Zitate deuten darauf hin, dass eine vielleicht nicht ganz so offensichtliche Erklärung für die differierenden Meinungen in der Frage nach der «wahren〉 Identität darin liegt, dass die jeweiligen Autoren unterschiedlichen Identitätsvorstellungen verpflichtet sind. Tendenziell sind es dabei neuere Ansätze, die nicht mehr von Identität als fester Einheit ausgehen, sondern stattdessen ein fluides Selbst in Betracht ziehen, was die Zuordnung von «wahr» und «vorgegeben/ unwahr> entsprechend obsolet werden lässt.

\section{Doppelidentität und Männlichkeitsbilder}

Ähnlich wie bei der Frage nach der wahren Identität gibt es auch in Bezug auf das von den Superhelden verkörperte Männlichkeitsbild verschiedene, teils kontroverse Interpretationen, wobei hier in Bezug auf die Doppelidentität nur eine kleine Auswahl angesprochen werden kann. Eine vor dem Hintergrund gängiger Vorstellungen von Männlichkeit und Weiblichkeit als Gegensatzpaar naheliegende Sichtweise ist, die superheldische Seite als die männliche von ihrem untrennbaren Gegenpart abzuheben. Die zivile Identität wird aber als Kontrastfolie verschieden konnotiert. Sie wird teilweise als die weibliche, effeminierte Seite des Helden verstanden. ${ }^{\text {10I }}$ So bemerkt etwa Coughlan, die meisten Superhelden verkörperten eine dominante Maskulinität, die als das pure Gegenteil zu Feminität definiert und konstruiert werde. Die Heldenidentität werde zur einzigen verfügbaren männlichen Identität, da alle sonstigen Männerrollen feminisiert seien. ${ }^{102}$ Bainbridge indessen sieht eine Feminisierung der Helden vor allem im Kontext von Marvels Neuausrichtung des Genres Anfang der i960er-Jahre, als die Superhelden - vor allem, aber nicht nur in ihrer zivilen Identität - von Abenteuerund Krimi-Paragonen zu Protagonisten des Melodramas werden (das laut Bainbridges Meinung traditionell weibliche Protagonistinnen favorisiert). ${ }^{103}$ Einen

tiger sein könnte als die Antwort: «Das Rätsel seiner wahren Identität - Bruce Wayne oder Batman - wird zur Gretchenfrage seines Lebens.»

IOI So etwa bei Smith (2009, I26) oder Klein (1993, 267f.): Indem sich der Protagonist in einen «real man» verwandle, negiere er seine Feminität. Klein bemerkt dazu, dass erst die mittelmässige zivile Identität der «more macho metamorphosis» als Kontrastfolie eine übermenschliche Qualität verleihe (ebd.). Vgl. Bukatman (2003, 6I), für den Superman die hypermaskuline Version von Clark Kent darstellt.

I02 Coughlan 2009, 238f. Interessanterweise bemerkt Coughlan, dass in der ersten SupermanGeschichte von 1938 nicht etwa eine Frauenfigur das Rollenmodell für die Feminisierung abgebe, sondern der wife-beater, der angesichts von Supermans Präsenz in Ohnmacht fällt.

I03 Bainbridge 2009, 70: «In making their heroes melodramatic protagonists, Marvel effectively feminized their heroes [...] by placing them in the [...] role of the good, passive victim. They disguised this feminization> by simultaneously reinforcing hegemonic masculinity through 
alternativen Kontrast in die zivile Seite des Helden setzt wiederum Coughlan: Superman stelle ein Männlichkeitsideal dar, weil er den Mann verkörpere, der jeder Junge werden könne. Die zivile, private Seite des Protagonisten steht nach Coughlan nicht nur für Freizeit von den Heldenpflichten, sondern auch für die Knabenzeit, die der Teenager hinter sich lassen muss - wobei das Ergreifen des Kostüms den Schritt in den öffentlichen Bereich, ins Arbeitsleben und die Übernahme von Verpflichtungen Erwachsener bedeutet. ${ }^{104}$ Für diese Zuschreibung (die zivile Seite als Teenager, die heldische als Erwachsener) argumentiert Coughlan hauptsächlich mit der Öffentlichkeit der Heldenrolle: «The public identity created by the costume makes a man ssuper, or really a man, because it places him within a male-centered system of public acknowledgement.» ${ }^{\text {10s }} \mathrm{Da}$ der typische Superheld in der zivilen Identität jedoch ebenfalls zur Arbeit geht sowie Lohn erhält und oft auch als öffentliche Person bezeichnet werden kann, erscheint diese Zuschreibung etwas willkürlich, denn das Verhältnis der beiden Identitäten zueinander lässt sich genau andersherum ebenfalls rechtfertigen, ja wird in den Comics sporadisch sogar explizit so formuliert. ${ }^{106}$

Wird nur die superheldische Seite des Protagonisten als maskulin konnotiert, stellt der Kleiderwechsel, vor allem das Ablegen der Maske, ${ }^{107}$ eine Bedrohung für dessen Männlichkeit dar und findet darum meist im Verborgenen statt, wie Friedrich Weltzien schreibt. ${ }^{108}$ Weltzien hält dieser Perspektive die These entgegen, dass der Kostümwechsel gerade keine Gefahr, sondern die Voraussetzung für das Männlichkeitsideal der maskierten Superhelden ist. ${ }^{109}$ Für Batman, Superman und Spider-Man erläutert Weltzien dazu erst: «[They] only become an unmistakable and singular personality when they dress up. In their costume, they do not lose or hide their identity, rather they get a manifest identity as a

bodily performances [...] and the masculine values of strength, activeness, speed, virility, stamina, and fortitude [...].»

I04 Coughlan 2009, 237.

I05 Ebd., 238. Dabei werde Kraft «in the masculine public sphere» zum «truest sign of manhood» (ebd.).

I06 Beispiele dafür finden sich etwa in The Amazing Spider-Man 275, April 1986, oder in Daredevil I 28, Dezember 1975, 2: «Face it, Mathew [sic] - you've grown up now. You've gotta leave the kid games behind. And being Daredevil was the longest kid-game you've ever played!»

I०7 Das Ablegen der Maske wird mitunter als symbolische Kastration interpretiert (Söll/Weltzien 2003, 3 I I), ebenso wie Clarks unterordnendes Verhalten - was Coughlan (2009, 239) verwirft.

I08 Weltzien 2005, 234. Die folgenden Ausführungen beziehen sich auf diesen Aufsatz, wobei einige Punkte schon bei Söll/Weltzien ${ }_{2003}$ (dort in Bezug auf Sam Raimis Film Spider-Man, 2002) formuliert sind.

I09 Weltziens Prämisse (2005, 23I) lautet, dass es in den Superheldencomics um die Konstruktion eines gewissen Rollenmodells von Männlichkeit geht, das als eine Art Pendant zum superfemininen Pin-up-Girl der 1930er-/r940er-Jahre (und parallel zur Nazi-Ideologie des Übermenschen) entstand. 
hero. The masquerade as a hiding place is signified in the non-superhero persona [...].» ${ }^{1 \circ}$ Weltzien scheint hier an das Paradox der gegenständlichen Maskerade, die in der Verkleidung das 'wahre> Ich enthüllt, anzuschliessen, doch sind für ihn beide Seiten der Doppelidentität Manifestationen der (männlichen) Identität des Superhelden: «[...] each mode of appearance, the nerd's as well as the hero's, is a staging [...] of masculinity.» ${ }^{11}$ Die Transformation vom einen zum andern erfolgt stets durch einen Kleiderwechsel, der verdeutlicht, wie unterschiedlich die beiden Identitäten des Helden sind, wobei Weltzien betont, es handle sich nur um zwei (und nicht mehr) Identitäten. Söll/Weltzien zufolge entsteht Männlichkeit hier erst durch den Umkleidevorgang: «Ohne essentielle, vorgängige, stabile Männlichkeit erzeugt sich diese in der kulturellen Praxis des Umziehens, der Loser als verkleideter Superhero, der Übermensch als maskierter Versager. Die zweifache Identität des Superhelden macht die Strategie der Erzeugung von Männlichkeit erkennbar.» ${ }^{12}$ Der «Mechanismus der Männlichkeit» basiert in dieser Perspektive auf den beiden Polen der Doppelidentität («clumsy nerd» und "exceptional hero» ${ }^{13}$ ) und auf der Fähigkeit, zwischen diesen beiden Identitäten hin- und herzuwechseln.

Männlichkeit erscheint so nicht als Zustand, sondern als dynamischer Prozess bzw. etwas, was andauernd aufs Neue erst performativ hergestellt werden muss. Entsprechend kann der Held sich nie zurücklehnen, eine Auszeit nehmen und das Familienleben geniessen. ${ }^{14} 4$ Weltzien bemüht den Begriff der Larve - der im Deutschen ja auch eine Maske bezeichnen kann - und greift ebenfalls auf eine Teenager-Analogie zurück. Wie eine gewisse Larve, die nie 〈reif〉 wird, stecke die Super-Männlichkeit in einer Entwicklungsphase fest, die unabschliessbar ist. ${ }^{\text {Is }}$ Das Problem der Männlichkeit des Superhelden sei das «invariable pubertal problem of becoming a man» ${ }^{16}$. Ähnlich wie bei Kniep ist die Metamorphose des Helden hier keine lineare Entwicklung, sondern zirkulär: «It is a steady doing

I IO Weltzien 2005, 24I.

I I I Ebd., $245 f$.

I 2 Söll/Weltzien 2003, 3 I0.

I 3 Weltzien 2005, 232.

I 4 Weltzien (ebd.) bemerkt dazu, dass sich die Super-Männlichkeit mit der oft unerfüllten Sexualität und abwesenden sozialen Kontakten durch einen Mangel (an sozialer Kompetenz) definiere. Ähnlich argumentieren Kahan/Stewart 2010, I Iо. Anzumerken ist, dass dies vor allem für die «Ursprungsversionen〉 maskierter Superhelden gilt; oft wird nur nebenbei erwähnt, dass es im Laufe der Zeit durchaus langfristige Beziehungen und tragfähige soziale Kontakte gibt, auch wenn dies von Story zu Story anders gewichtet sein kann. Vgl. zur (stets verwehrten) Häuslichkeit der Helden Coughlan 2009.

I Is Weltzien 2005, 243.

I 6 Ebd., 246. Vgl. dazu Bukatman (2003, 49), der im Superheldenkörper eine Entsprechung zu jenem des Teenagers an der Schwelle zum Erwachsenen sieht. 
and undoing of two separate identities, which restlessly constructs masculinity within the act of changing costume.» ${ }^{117}$ Wichtiger als diese Feststellung erscheint mir aber, dass es um doing gender geht, was sich als pars pro toto von Maskulinität bzw. Genderidentität als Teilaspekt von Identität auf diese übertragen lässt: Die beiden Maskeraden des Superhelden lassen sich aus diesem Blickwinkel als doing identity verstehen.

Im Fall des Superhelden scheint sich Männlichkeit als Maskerade deshalb grundsätzlich von Weiblichkeit als Maskerade zu unterscheiden, wenn man für diese der bekanntesten Theorie von Joan Riviere (Womanliness as Masquerade, I929) folgt. Bei Riviere nimmt die Maskerade eine Schutz- und Bewahrungsfunktion für den Persönlichkeitskern ein und stellt sozusagen eine Reaktion, einen Verteidigungsakt gegen äusseren Druck, dar. ${ }^{118}$ Dagegen bekräftigt Weltzien für den männlichen Superhelden: «[...] it is not possible to call either of the two personalities the real one and the other the disguised one, there is no (true identity> and its 〈alias〉. Each persona is closely dependent upon its counterpart.» ${ }^{119}$ Entsprechend stecke gar kein «substantial male subject» unter der Oberfläche: Die beiden Identitäten stellen nicht Kern und Fassade dar, sondern zwei alternative Schichten, die beide Masken sind.

Der ideale Mann wie Superman besteht aus verschiedenen «layers of identity ${ }^{120}$ und muss andauernd hin- und herwechseln, um salopp gesagt seine Z Zwiebelhaftigkeit bzw. Männlichkeit zu zeigen. Insofern ist bezeichnend, dass beim berühmt-berüchtigen 〈Hemd auf>-Enthüllungsmoment eben nicht nackte Haut und Haar zum Vorschein kommen, sondern unter der Camouflage der Gewöhnlichkeit ein zweites Kostüm steckt; ${ }^{\mathrm{I} 2 \mathrm{I}}$ der Moment wird zur «Ikone performter Maskulinität» via Umziehen, so Weltzien. ${ }^{122}$

Indem ¿Super-Männlichkeit ein stetes Überschreiten der Grenze zwischen Nerd und Held bedeutet, beweisen Superhelden, dass ein ständiger Wechsel möglich ist. Einen erfolgreichen «performer of masculinity» kennzeichnet folglich, dass er durch und über alle Transformationen die Kontrolle behält; seine Identitäts-

I 17 Weltzien 2005, 246.

I 8 Ebd. 245. Zu Riviere vgl. Benthien 2003 und Funk 1995, $22 \mathrm{f}$.

I 9 Weltzien 2005, 24I.

I 20 Ebd., 235 .

I 2 I Hier liesse sich einwenden, dass die Kostüme im Lauf der Jahre mit zunehmender zeichnerischer ২Plastizität>und dem Aufkommen der Bodybuilding-Actionhelden so eng anliegend (bzw. die Heldenkörper derart hypermuskulös) gezeichnet werden, dass die Protagonisten trotz Heldenanzug «visually naked» scheinen (Coughlan 2009, 240; vgl. Bukatman 2003, 49-73, Söll/ Weltzien 2003, 3 I I).

I 22 Weltzien 2005, 235. In diesem oft hoch stilisierten «Hemd auf $>$-Moment sieht Beritela (2007, 55) eine Parallele zum Demaskierungsakt einer Drag Queen am Ende ihrer Show. 
wechsel erfolgen weder willkürlich noch unfreiwillig. Geht diese Kontrolle verloren, bedeutet dies eine «failed masculinity» ${ }^{123}$. Dies ist der Fall bei einigen bekannten Superschurken, die über ähnlich verlaufende Origin-Storys wie die Superhelden verfügen. Aufgrund von psychischer Krankheit (Wahnsinn) oder körperlicher Entstellung ist ihnen jedoch die Wahlmöglichkeit verwehrt, da sie über keine einigermassen <intakte> zivile Identität mehr verfügen, in die sie sich zurückziehen könnten, weil sie aus der Gesellschaft verstossen sind, oder die Wahl für eine der beiden Identitäten nicht bewusst treffen können. ${ }^{124}$ Insbesondere die Galerie von Batmans grotesken Lieblingsschurken liefert hier mit dem Joker, Two-Face, Clayface oder dem Penguin eindeutige Beispiele. Nach Weltziens Theorie unterliegen sie in Bezug auf die Männlichkeit den Superhelden a priori. Denn der ideale Mann, so Weltzien, «does not need luck but changes as the situation or circumstances demand» ${ }^{125}$.

Interessanterweise kommt Coughlan zu einer ziemlich differenten Bewertung: Für ihn bedeutet der stete Rückfall in die Gewalttätigkeit als Superheld, die ein häusliches Leben verhindert - also gewissermassen auch der stete Wechsel zwischen Held und Zivilperson -, eine stete Krise der Männlichkeit (die sich allerdings stets über Krisenhaftigkeit definiert). ${ }^{26}$

Diese unterschiedlichen Lesarten der Doppelidentität als Ausdruck von Männlichkeitsbildern weisen meines Erachtens ein namhaftes Manko auf: Eine Auseinandersetzung mit den weiblichen Pendants fehlt. Wenn es bei der Doppelidentität um Männlichkeitsbilder geht, müsste es bei den Superheldinnen um Weiblichkeitsbilder gehen. Es wäre aber die Frage, inwiefern sich die Superheldinnen-Weiblichkeitsbilder generell von den Superhelden-Männlichkeitsbildern unterscheiden können (und wie sich Weiblichkeit im Akt des Umziehens anders als Männlichkeit konstruiert), wenn man davon ausgeht, dass sowohl männliche wie weibliche Figuren auf demselben Konstruktionsprinzip - des maskierten Helden bzw. der maskierten Heldin - beruhen. Insofern scheint es sich bei den hier als Männlichkeit gefassten〈Rollen〉 eher oder zumindest ebenso um einen Ausdruck der von den Superhelden/-innen transportierten (gender-unspezifischen) Identitätsvorstellungen $\mathrm{zu}$ handeln. $\mathrm{Ob}$ es sich dabei um ein Ideal oder Identitäten in der Krise handelt, sei an dieser Stelle dahingestellt.

I 23 Weltzien 2005, 242/244. Zu einem ähnlichen Schluss kommen auch Kahan/Stewart 2010, I 32. Leider gehen weder sie noch Weltzien auf Marvels Hulk ein, der seine physische und psychische Transformation meist nicht kontrollieren kann.

I 24 So auch Bukatman 2003, 2 I 4, sowie für die Marvel-Filmschurken von Holzen 20I 2a, 200.

I 25 Weltzien 2005, 244.

I26 Coughlan 2009, 249 . 


\section{G. Jungs Schatten}

Carl Gustav Jungs (1875-1961) Konzept des Schattens erfreut sich in Superhelden-Interpretationen einer gewissen Beliebtheit, weshalb die bisher dargestellten Lesarten an dieser Stelle damit ergänzt werden. Der Komplexität von Jungs Theorien und ihrer grundsätzlichen Problematik kann hier keine Rechnung getragen werden; vielmehr geht es darum, wie die jungsche Theorie auf unterschiedliche Weise als Interpretationslinse für die Doppelidentität des maskierten (Super-) Helden genutzt wird. Der Schatten bezeichnet bei Jung einen von verschiedenen Archetypen, die Inhalte des kollektiven Unbewusstsen darstellen, aber individuell verändert werden, sobald sie bewusst wahrgenommen werden. ${ }^{127}$ Neben dem (weisen) alten Mann und den jeweils gegengeschlechtlichen Gestalten Anima und Animus zählt der Schatten zu den zentralen Archetypen. «Die Figur des Schattens personifiziert alles, was das Subjekt nicht anerkennt und was sich ihm doch immer wieder - direkt oder indirekt - aufdrängt, also zum Beispiel minderwertige Charakterzüge und sonstige unvereinbare Tendenzen.» ${ }^{128}$ Mit dem Begriff der Persona, den man verkürzt als Rollenzwang umschreiben kann, ${ }^{129}$ ist dem jungschen Persönlichkeitsverständnis die Konnotation einer wahren gegenüber einer vorgegebenen Identität inhärent, umso mehr, da der Schatten als etwas Verborgenes erscheint, das erst zu enthüllen ist bzw. aktiv in die eigene Persönlichkeit integriert werden muss und das auch eine gewisse kompensatorische Funktion besitzt. In seiner frühen Schrift Über die Archetypen des kollektiven Unberoussten spricht Jung davon, dem eigenen Schatten gegenüberzutreten, sei die erste «Mutprobe» in der Herausforderung der Selbstbegegnung - nämlich statt alles Negative ausserhalb seiner selbst zu lokalisieren. Wer dazu nicht imstande sei, neige dazu, stattdessen ein Fantasiegebilde zu hegen, wie Jung sich zu bemerken nicht verkneifen kann: «Starke Naturen - oder soll man eher sagen schwache? - lieben diese Anspielung nicht, sondern ersinnen sich irgendein heroisches Jenseits von Gut und Böse [...].» ${ }^{130}$ Jung geht es in der Folge mehr um den Jenseitsaspekt, hier ist jedoch die Dichotomie von Gut und Böse interessanter. Sie trifft nämlich mit jenen Interpretationen zusammen, die in gewissen

I 27 Jung $1989 \mathrm{~b}(1935 / 54)$, i 5 .

I 28 Jung I989a (1934/50), 302.

I 29 Vgl. z. B. Jung I989c, I37: «[...] Persona, jene[s] Anpassungssystem oder jene [...] Manier, in der wir mit der Welt verkehren. [...] Die Welt erzwingt ein gewisses Benehmen, und die professionellen Leute strengen sich an, diesen Erwartungen zu entsprechen. Die Gefahr ist nur, dass man mit der Persona identisch wird [...]. Damit ist das Unglück geschehen.» Vgl. auch ebd., 30 .

I 30 Jung I989b (1935/54), 30 . 
Superschurken den Schatten des Helden verkörpert sehen - Held und Schurke erscheinen wie erwähnt oft als zwei Seiten derselben Sache. «[T] he villain embodies the dark side of the hero», hält so Fingeroth in Bezug auf Jungs Schatten für die Superheldencomics fest. ${ }^{13 \mathrm{I}}$ Als naheliegendstes konkretes Beispiel sieht etwa Robert Terrill in seiner tiefenpsychologischen Analyse von Tim Burtons Film Batman (1989) den Joker als Schatten sowohl von Batman/Bruce Wayne als auch von Gotham City. ${ }^{132}$

Batman und der Joker stellen auch für Gregory Pepetone ein Paradebeispiel für eine nahezu symbiotische Beziehung von Held und Bösewicht dar. ${ }^{133}$ Pepetone bezieht sich allerdings ausnahmsweise nicht auf Superhelden, sondern auf die Pulp-Protagonisten (die er aus ähnlichen sozial-wirtschaftlichen Umständen entstanden sieht wie die biblischen Helden ${ }^{134}$ ). Wie Pepetone ausführt, wird der Schatten bei solchen Helden der «gothic imagination» auf einen Feind projiziert, der dann gnadenlos verfolgt wird: «[...] the conscious target of such zeal is, in reality, a discarded aspect of the vigilante's own disintegrated psyche.» ${ }^{135}$ Entsprechend sind Pulp-Helden wie The Shadow, The Spider oder The Black Bat quasi ihre eigenen Gegner bzw. haben einen manifesten Schatten, der sich in ihrer zuweilen sehr brutalen Vorgehensweise äussert: «While presented as embodiments of right and righteousness [...], the pulp heroes frequently use ethically questionable means such as violence and deception to achieve virtuous ends. In some cases - the Shadow is a prime example - their commitment to fighting evil is grounded in their own prior corruption, and they mirror some of their dark qualities.» ${ }^{136}$

Mit dem Hinweis auf die Brutalität der Pulps könnte sich Pepetone klar weniger gut auf die frühen Comic-Superhelden berufen. Anzumerken ist auch, dass die meisten Pulp-Helden äusserst selten über wiederkehrende Gegner verfügten - es kommt also kaum zu «Busenfeindschaften`, wie sie sich inzwischen in den Superheldencomics entwickelt haben (und deren Betonung ebenfalls in den

I3 I Fingeroth 2008, I64.

I32 Terrill I993. Für Terrill nimmt zudem Bruce Wayne im Batman-Kostüm die Identität des Schatten-Archetyps an (ebd., 330).

I33 Pepetone 2005, 217. Als weitere Beispiele nennt er unter anderem Hamlet - Horatio und Sherlock Holmes - Professor Moriarty.

I34 Ebd., 22 I: «[...] the pulps offered America’s huddled masses a brief but affordable respite from the misery and disappointment of a society ruled by cosmopolitan «Philistines` such as Al Capone, Henry Ford, and Adolph [sic] Hitler.»

I35 Pepetone 2005, 219.

I36 Ebd., 2 17. Pepetone hat hier wohl eher den Shadow-Film von I 994 (Regie: Russell Mulcahy) und teilweise die Shadow-Hörspielreihe (1932/37-54) vor Augen, denn in der Origin-Story in den Pulp-Novels gibt es keinerlei Hinweis auf eine «prior corruption» des Charakters. 
Superheldenfilmen stärker wirkt als im Meer der Comics). Pepetone bietet gleich beide grundsätzlichen Auslegeordnungen des Schattens, zum einen den Gegner als Verkörperung der SSchattenseite des Helden, zum andern die Spaltung zwischen Bewusstsein und Schatten in einer Person.

Dieser zweiten Variante ist auch der Aufsatz von D. E. Meyer gewidmet, allerdings nicht am Beispiel des Helden, sondern für die Gestalt des Bösewichts Green Goblin in Sam Raimis Film Spider-Man von 2002, der die Sorte des wahnsinnigen Superschurken darstellt, der zwischen 〈gewöhnlichem〉 und «schurkischem> Ich pendelt, wobei ihm Spiegel und Maske zur Kommunikation zwischen den beiden Seiten dienen. Meyer schlägt dabei vor, den Schatten entgegen der Tradition nicht nur vom Helden aus zu definieren, da der Schatten so nur als generelle «Anti-Grösse» verstanden werden könne - wie es laut Meyer die Abspaltung des Schattens in eine separate Figur (sprich den Bösewicht) illustriert. ${ }^{37}$ Meyer votiert dafür, den Schatten nicht als etwas Abgetrenntes, sondern als intrinsischen Teil einer Verdoppelung (doubling) zu betrachten, bei der die Koexistenz scheinbar gegenteiliger Aspekte (Licht - Schatten oder Held Schurke) im Vordergrund stehe: «Doubling allows us to view shadows as extension rather than shadows as $\langle$ other $\rangle .{ }^{13^{8}}$ Allerdings sieht Meyer dadurch weniger eine Verschmelzung oder Koexistenz von Schatten und Persona gegeben; vielmehr könne der Schatten durch seine Präsenz die Abwesenheit des Schattenwerfers markieren. Da der maskierte Held ja immer nur in einer seiner beiden Identitäten auftreten kann, bedeutet die gerade inkorporierte die notwendige Absenz des jeweiligen Alter Egos - zugleich ist es intradiegetisch vital für den Helden, dass nichts an der einen Identität auf die andere hindeutet.

Die Psychologin Sharon Packer nutzt den jungschen Schatten in ihrer an ein breites Publikum gerichteten Auseinandersetzung mit Superhelden als eine Erläuterungshilfe für die Relevanz der superheldischen Doppelidentität. Für sie ist der Superheld «a poster child for Jungian psychology» ${ }^{139}$. Auch Packer betont, dass der Schatten bei Jung nicht nur negativ, sondern auch eine Stärke sein kann, die aber womöglich noch im Verborgenen liegt. ${ }^{I 0}$ Packer erläutert ausführlich, welches «conundrum» die Superhelden für die Frage nach Persona und Schatten darstellen, schliesslich kann man sowohl für die heldische als auch die zivile Identität Argumente finden, um sie der Persona oder aber dem Schatten zuzuweisen:

I 37 Meyer 2003, 52I.

I 38 Ebd. (Hervorhebung im Original).

I39 Packer 2010, I3 I.

I40 Vgl. Jung r989d (I954), 288. 
Which is the shadow and which ist the persona? The iconic superhero is recognizable to everyone-and so the signature costume could constitute the persona. On the other hand, the superhero is hidden inside a civilian self, or a secret identity, and so the secret identity [...] may also be called the persona. If this is the case, which is the shadow? Is the super self that is hidden inside the same as the hidden shadow? Or is the cowering Clark Kent the shadow, because he represents clear-cut insecurities that should be hidden and that could be trapped inside a superhero ${ }^{\text {I4I }}$

Packer geht zum einen ebenfalls davon aus, dass das «super self» des Helden als «true self» aufzufassen ist: «In general, we can say superheroes reverse the usual order of persona, outside, shadow, inside. They turn the shadow inside out and show us the inside first. ${ }^{142}$ Zum andern betont sie aber, dass die Zuordnung nicht der springende Punkt sei, vielmehr gehe es um das Nachdenken darüber wozu die jungschen Begriffe nützliche Konstrukte seien: «The interchangeability between shadow and persona, and secret self or super self, adds to the allure of the superhero.» Auch sie kommt letztlich zum Schluss, dass die Superhelden, die ihre Kostümwechsel stets unter Kontrolle haben, eine positive Variante darstellen: «[...] we can still show that superheroes have split selves, not just for the better or for worse, but (almost) always for the better [...].» Packer führt diesen Gedanken nicht mehr zu Jungs Konzept zurück, geht aber noch auf das Gegenbeispiel von DCs Rose/Thorn ein - einer Figur, die an der landläufig irreführenderweise als Schizophrenie bezeichneten psychischen Störung leidet (eine vergleichbare Figur bei Marvel ist Typhoid Mary, die allerdings eher als Superschurkin gilt). Die <brave> Rose entwickelt aufgrund eines Traumas eine gespaltene Persönlichkeit, kann aber nicht beeinflussen, wann ihre andere Hälfte namens Thorn sozusagen das Steuer übernimmt, und erinnert sich im Nachhinein oft nicht an Thorns Erlebnisse. Sie unterscheidet sich also grundlegend von der Doppelidentität des maskierten Helden, die auf Freiwilligkeit beruht.

Daran schliesst sich die Frage an, ob man in jenen Superschurken/-helden, die den Wechsel zwischen ihren Ichs nicht kontrollieren können, das Ausbrechen des Schattens - der sich laut Jung ja nur eine gewisse Zeit unterdrücken lässt sehen kann, während jene Helden mit ‘Wechselkontrolle〉 als Beispiele für eine gelungene Integration ihrer Schattenaspekte in die eigene Persönlichkeit gelten können. Trotz der erwähnten Versuche zur Positivierung muss das Konzept des Schattens aufgrund der von den hinzugezogenen Ansätzen referierten Definitionen nach wie vor als negativ konnotiert bezeichnet werden. Zentral erscheint dabei der starke Aspekt des im Unbewussten Verborgenen und Unterdrückten,

I4I Packer 2010, I34 (Hervorhebung im Original).

I42 Ebd., I35 (Hervorhebung im Original). 
das eine potenzielle Gefahr des (möglicherweise befreienden) 〈Umschlagens〉 beinhaltet. Für den maskierten Superhelden ist aber kennzeichnend, dass er sich seiner beiden Identitäten oder Rollen stets bewusst ist, dass er - ausser in einer temporären Krise - beide in ihrer Notwendigkeit anerkennt und beide Seiten nach denselben moralischen Maximen handeln, sodass insofern kein Konflikt zwischen den beiden Hälften besteht. Als Manifestation von dem Protagonisten selbst nicht bewussten inneren Vorstellungen erscheint weder die superheldische noch die zivile Seite adäquat erfasst. (Gerade Superman/Clark Kent gilt mit und ohne Uniform als proprer und damit oft etwas biederer Protagonist.) Dies kann gewiss für einzelne Superheldengeschichten überzeugend sein - für eine generelle Beurteilung jedoch scheint die Hypothek einer negativ konnotierten Schatten-Vorstellung zu schwerwiegend, umso mehr, da diese implizit ebenfalls eine Wahr-falsch-Dichotomie enthält. Dass Packer, obwohl sie diese Dichotomie übernimmt, letztlich das Offenhalten des «conundrums» als wichtiger erachtet, erscheint daher bezeichnend für die in den letzten Jahren veränderten und differenzierteren Wahrnehmungen der Doppelidentität.

Die Doppelidentität des maskierten Helden scheint sich dabei nicht nur für eine Interpretation im Hinblick auf eine spezifische Teilidentität des Menschen anzubieten, sondern auch auf einer allgemeinen Ebene, wie diese Arbeit deutlich machen möchte. 


\section{Die maskierten Helden in den Pulp-Novels}

Dashing about with a cutlass is quite out of fashion. Hasn't been done since the Middle Ages. Diego Vega in The Sign of Zorro (Regie:

R. Mamoulian), 1940

And fortunately the hands of George Chance were always hanging out of the sleeves of the Green Ghost.

G. T. Fleming-Roberts: The Case of the Astral Assassin, 1942

"Remember - the Bat! By that name you shall know me! [...]"

"Ob! So we've got another fancy freak in town, have we?"

"The Bat is not a crook, Sergeant. He is the

Nemesis of crime and corruption.»

"One of these here confounded amateur detectives, bub?»

Dawson Clade/The Bat stell sich telefonisch vor, in C. K. M. Scanlon (Pseud.): The Bat Strikes!, I934

Bevor der Figurentypus des maskierten Helden in den Comics mit dem Motiv fantastischer körperlicher Kräfte eine oft fast symbiotisch erscheinende Verbindung einging, ${ }^{,}$traten maskierte Helden auf unzähligen Seiten in den PulpNovels in Aktion. Einige der maskierten Pulp-Helden erlangten als eigene, stets wiedererkennbare Figuren ${ }^{2}$ grosse Bekanntheit und Popularität; ebenso gab es sehr kurzlebige Exemplare, die kaum in Erinnerung blieben. ${ }^{3}$ In den Pulps, möchte ich behaupten, wurde der maskierte Held als populärer Figu-

I Tatsächlich wird in der Sekundärliteratur zu Pulp-Novels aus rückblickender Perspektive von "pulp superheroes» (vgl. z. B. Murrays Pulp Superhero Index, 2009) und «superhero pulps» (Server I 993, 24) gesprochen, was Helden mit Doppelidentität ohne Superkräfte einschliesst. Zur seltenen Verwendung des Wortes superhero in den Pulps vgl. Coogan 2006, I89-192.

2 Dabei dürften viele Pulp-Helden als serielle Figuren nach Denson/Mayer 2012 (auf die ich im Kapitel zu Batman etwas näher eingehe) angelegt sein.

3 Für einen ausführlichen Überblick über Pulp-Figuren vgl. Sampsons Yesterday's Faces (6 Bde., 1983-1993). 
rentypus erst gefestigt. Zugleich zählen die maskierten Helden zu den prägenden Gestalten der goldenen Jahre dieser an die Massen gerichteten, vornehmlich US-amerikanischen Publikationsform. Weil die Pulps als Trivialliteratur par excellence galten, erhielten sie lange nur wenig wissenschaftliche Aufmerksamkeit, sodass zunächst einige Ausführungen zu dieser Publikationsform angebracht scheinen. ${ }^{4}$ Auch ist ein kurzer Blick auf verschiedene Vorläufer zu werfen, bevor ich auf die maskierten Helden der Pulps eingehen werde.

Die periodisch erscheinenden pulp magazines (auch pulp fiction, pulp novels oder kurz pulps) erhielten ihre Bezeichnung vom Trägermaterial - einem billigen, chemisch behandelten Papier aus Holzstoff bzw. einem Holzbrei ( $p u l p)$, das zwar relativ dick war, aber unbeschnitten verwendet wurde, charakteristisch roch und, anders als Zellstoffpapier, rasch vergilbte. Mit einem kaum dickeren, meist nach sogenannter englischer Art der Broschur leicht überstehenden Papiereinband, der entsprechend zum Verschliss neigte, wurden die Pulps klar nicht für eine lange Lebensdauer, doch für massenhafte Verbreitung produziert. Viele Jahre erhielt man im üblichen Format I 28 Seiten Lesestoff für blosse zehn Cent.

Als Geburtsstunde der Pulps gilt das Jahr i 896, als der Verleger Frank A. Munsey sein an Kinder und Jugendliche adressiertes Magazin Argosy inhaltlich neu ausrichtete: Er publizierte darin nur noch fiktionale Geschichten und zielte damit eher auf ein erwachsenes Publikum. Dies hatte eine markante Auflagensteigerung zur Folge, sodass Munsey selbst und andere Verleger diesen Erfolg mit anderen Titeln nachzuahmen versuchten, die «ein Gemisch aus Kurzgeschichten, Langgeschichten und serialisierten Romanen»' präsentierten. So lösten die Pulps mit der Zeit die dime novels ${ }^{6}$ als den preiswerten Lesestoff der USA ab. ${ }^{7}$

Dabei handelte es sich um einen sehr schnelllebigen Markt. Was sich nicht zufriedenstellend verkaufte, verschwand rasch wieder aus dem Angebot; manchmal konnte oder musste auch der Publikationsrhythmus angepasst werden. Dadurch wurden die Pulps zu einem fruchtbaren Experimentierfeld für ver-

4 Die folgenden Erläuterungen zur Entwicklung der Pulps beruhen auf Karrer 1985, De Forest 2004, Server 1993, Goulart 1988, Earle 20I 2, Nicholls I999, Murray 2009, Smith 20 2 b, Nagl 2003 sowie Blackbeard 1978.

5 Karrer 1985, 81. Auch technische Entwicklungen spielten dabei eine Rolle, z. B. wurden gewisse Drucktechniken günstiger, und auch die Distributionsmöglichkeiten waren ein wichtiger Faktor.

6 Dime novels waren zunächst frühe Taschenbücher ( $\mathrm{ab}$ I 858 ), sie enthielten eine Geschichte pro Band - die Bezeichnung, die sich vom Preis (zehn Cents) ableitete, wurde dann allgemein für günstige periodische Publikationen von fiction gebraucht, wobei Formate und Preise sehr variierten (DeForest 2004, I 5-25; Smith 20I 2b).

7 Einer der Meilensteine für diese Entwicklung war, dass Street \& Smith, in der Folge einer der wichtigsten Pulp-Verlage, I9 Is sein gesamtes Programm von dime novels auf Pulps umstellte. 
schiedenste neue Ideen. Ein Resultat davon waren nicht nur einprägsame Helden- und Schurkengestalten, ${ }^{8}$ sondern auch wegweisende Impulse für einige populäre Genres. ${ }^{9}$ Manfred Nagl beschreibt diese Rolle der Pulps wie folgt:

Die Pulp Magazines setzten - wie eine genrebezogene Illustrierte - an die Stelle des Autorenprinzips das Redaktionsprinzip. Die Pulps wurden damit zwar zu periodisch-dauerhaften, gleichzeitig aber flexiblen Plattformen für die unterschiedlichsten belletristischen Formate eines Genres, aber auch für genrerelevante Sachinformationen, für die professionelle Spezialisierung von Autoren und Illustratoren, für Verweise auf Verwandtes in anderen Medien und für den ständigen Kontakt mit den Lesern. $^{10}$

In der Literaturgeschichtsschreibung wohlbekannt ist der prägende Einfluss gewisser Pulps für die Etablierung bzw. Weiterentwicklung und auch Popularisierung neuer (Sub-)Genres. Eine zentrale Rolle wird namentlich Amazing Stories (1926-1953) für Science Fiction, The Black Mask Magazine und seinen unzimperlichen Detektivfiguren für den hard-boiled-Thriller/-Krimi und Weird Tales (1923-1954) als berühmt-berüchtigter «Brutstätte` von (oft fantastischem) Grusel und Horror zuerkannt. Damit ist freilich nur die Spitze des Eisbergs benannt, da die Pulps eine schier unerschöpfliche Fundgrube an genreorientierten Geschichten aller Art sowie seriellem Erzählen darstellen, die allerdings erst in den letzten Jahren durch neue Nachdrucke, Faksimile-Ausgaben und dem Phänomen gewidmete Internetseiten, welche immense Verzeichnisse, Zusatzinformationen sowie Einzeltexte bereitstellen, wieder einigermassen bequem und wohl erstmals systematisch greifbar geworden ist.

Der Versuchscharakter vieler Heftreihen wird bereits bei einer Übersicht über die publizierten Titel offensichtlich. Schon Munsey hatte versucht, neben Heften mit gemischtem Inhalt (All-Story) durch thematische Spezifizierung bestimmte Kundengruppen anzusprechen (The Railroad Man's Magazine, ab i906, oder Ocean, ab 1907). Den breiten Aufschwung brachten dann in den I920er-Jahren jedoch genrebezogene Titel. In den I930er-Jahren wurde diese Taktik ergänzt

$8 \mathrm{Zu}$ den namhaften fiktionalen Gestalten, die durch regelmässige Nacherzählungen besonders im Film zu Ikonen ihres Genres werden sollten, ihre ersten Auftritte aber in den Pulps hatten, zählen etwa auch Edgar Rice Burroughs Tarzan und John Carter of Mars (beide I9I 2 in Munseys The All-Story Magazine).

9 Vgl. u. a. DeForest 2004, I , 29, Server 1993, 9-1 5 .

Io Nagl 2003, 535. Die von Nagl erwähnten Leserkontakte gelten namentlich für die Genregeschichte von Science-Fiction (I926 erschien erstmals das nur Science-Fiction gewidmete Amazing Stories) als sehr wichtig. Sporadischer finden sich Leserbrief- und Herausgeberspalten aber auch in anderen Genre-Pulp-Magazinen; diese dürften neben der Informationsfunktion in einem gewissen Mass wohl als Füller fungiert haben (neben Kreuzworträtseln und «Diverses/ Kurioses zu einem Thema»-Rubriken). 
durch die weitere Spezialisierung in Subgenres; ${ }^{\text {II }}$ diese Titel waren aber tendenziell deutlich kurzlebiger. Um nur einen Bruchteil zu nennen, umfasst die Titelliste $^{\mathrm{I2}}$ von A wie Astounding Stories (1930-1960) bis Z wie Zeppelin Stories (1929) neben naheliegenden Titeln wie Detective Story Magazine (I91 5-I949), Western Story Magazine (1919-1949), Love Story Magazine (192 I-I947), Sport Story Magazine (1923-1943) oder Wings (1928-I953) eine Bandbreite eng fokussierter Titel, wobei einzelne etwas kurios anmuten mögen: Baseball Stories (1938-1954), Co-Ed Campus Comedy (1924-1925), Fire Fighters (1929), Gang World (1930-1934), Jungle Stories (1938-i954), Magic Carpet Magazine (19331934), Pirate Stories (1934-1935), Planet Stories (1939-1955), Ranch Romances (1924-1971), Saucy Movie Tales (1935-1938), Sky Fighters (1932-1948), Speakeasy Stories (193 I), Submarine Stories (1929-1930) etc.

Trotz dieses reichen Angebots ist festzuhalten, dass die meisten Geschichten den dynamischen Handlungsstrukturen von Abenteuer, Action und Rätsel verpflichtet sind. Karrer zitiert hierzu Frank Blackwell, einen Verleger von Street \& Smith, der schon 1920 schrieb, dass es im Grunde nur zwei Plots gäbe, "pursuit and capture» und «delayed revelation», wobei Letzteres schon eine Variante von Ersterem sei. Karrer selbst kommt immerhin auf vier Grundvarianten: Neben den drei grundlegenden Plots «Helden verfolgen Menschen, suchen Schätze oder klären Geheimnisse auf» erkennt er als Variante von Typ drei oder eben vierten Typ noch Wissenschaftler und ihre Entdeckungen. ${ }^{13}$

Der Variantenreichtum der Pulp-Geschichten, für welche die Autoren pro Wort bezahlt wurden, wird denn auch auf anderer Ebene sichtbar, wie dies etwa Henry Steeger, Gründer und Präsident von Popular Publications und damit Verleger von insgesamt über 300 Pulp-Titeln, beschreibt: «They traveled a golden rail from very bad to very excellent and they appealed to all strata and all vintages of people.» ${ }^{14}$

I I Dies ist ein massgebender Aspekt in Karrers Einteilung der Pulp-Entwicklung in fünf Phasen: I 896-I 906 Gründerphase (Munsey, Argosy); I 906-I9 Is Adressierung bestimmter Kundensegmente (Munsey); I9 I 5-1930 Differenzierung in Genres, 1930-1942 weitere Ausdifferenzierung in Subgenres und «eigentliches «Golden Age»» und schliesslich 1942-1954 Niedergang (Karrer I 98 5, 8 2f.). Die letzten beiden Phasen fasst Murray (2009) als «Heroic Era», als Zeit der «Pulp Superheroes» (193I-I953), zusammen.

I 2 Umfassende Auflistungen der Titel und ihres Publikationsrhythmus bieten gedruckt Ellis/ Locke/Gunnison 2000 sowie online die Seite Galactic Central (mit Titelblättern) - eine unschätzbare Hilfe.

I3 Karrer I985, 84 f.

I4 Steeger fügt pointierend hinzu, dass Harry S. Truman und Al Capone zeitgleich auf der Abonnentenliste seines Verlags standen (Henry Steeger, in: Goodstone 1970, v). 
Rückblickend erscheinen die I930er-Jahre als das Goldene Zeitalter der pulp magazines. Murray bemerkt allerdings, dass die Pulps ihren eigentlichen Höhepunkt bezüglich Auflagenhöhe und literarischer Anerkennung bereits in den I $920 e r-J a h r e n$ fanden, die I930er-Jahre bei Fans und Sammlern jedoch besser im Gedächtnis geblieben seien ${ }^{15}$ - dafür dürften nicht zuletzt die heute als einschlägig geltenden Helden-Pulps verantwortlich sein, wobei The Shadow (ab I93 I) und Doc Savage (ab 1933) die Begründer der single-character magazines (auch hero pulps, mystery man pulps) darstellen. ${ }^{16}$ Ein wesentlicher Faktor ist zudem in den Titelbildern zu sehen, die ab den I $9300 r-J a h r e n$ durch immer grellere Farben und Sujets mit Sensationscharakter die Aufmerksamkeit der potenziellen Käufer $\mathrm{zu}$ erheischen suchten. ${ }^{17}$ Karrer sieht für diese Phase eine «Rückkehr zur Heldenserie der dime novels» sowie eine "zunehmende Brutalisierung und Sexualisierung von Titelblättern und Inhalten» als kennzeichnend..$^{18}$

Trotz spektakulärer Covers erlosch die Ära der Pulps ab Ende der 1940er-Jahre sukzessive. ${ }^{19}$ Anfang der 1950er-Jahre waren die Hefte grossenteils vom Markt verschwunden. Der Verlag Street \& Smith hatte bereits 1949 sein gesamtes PulpSortiment eingestellt, und bis 1953/54 folgten die meisten weiteren Epigonen des Formats. Nur einzelne Titel erschienen noch bis in die 1970er-Jahre. Neben der Unbill der Kriegsjahre trugen wirtschaftliche Probleme, namentlich steigende Versandspesen, ebenso dazu bei wie die zunehmende Konkurrenz von Comics (die allerdings in den 1950er-Jahren ebenfalls in eine Krise gerieten), Radio, Fernsehen und vor allem den handlicheren Taschenbüchern, die den Pulps den Rang abliefen.

$\mathrm{Zu}$ betonen ist auch, dass viele Pulps in ein Mediengeflecht eingebunden waren: ${ }^{20}$ Die erfolgreicheren Heldengestalten wurden nicht nur in einem Medium verbreitet, sondern traten, weiter der Serialität verbunden, möglichst sowohl in gedruckter Form - in Pulps, in Buchausgaben (Pulps-Sammelbänden), in ComicHeften und Zeitungsstrips - als auch in Radiohörspielen oder sogar Filmreihen auf. Teilweise gab es zudem von den Verlagen organisierte Fanclubs (die etwa

Is Murray 2009.

i6 Vgl. u. a. DeForest 2004, 92, Sampson 1989, 5, Murray 2009.

I7 Für Erwachsenenliteratur waren die Pulps auch im Inneren reich bebildert - lange novels (wie etwa Shadow-Storys) hatten in der Regel fünf grössere Illustrationen, dazu kamen kleinere Vignetten von Gegenständen (Pistolen etc.) oder Figurenporträts, die teilweise immer wieder (Teammitglieder) und in verschiedenen Reihen abgedruckt wurden.

I 8 Karrer i985, 82.

I9 Vgl. Server 1993, I03: "The heyday of the hero pulps ended as the r940s began. Many titles were canceled, while others such as The Shadow and Doc Savage were toned down, losing much of the ripe melodrama and outrageousness that had distinguished them.»

20 Vgl. u. a. DeForest 2004. 
Fanabzeichen oder Ringe mit Helden-Emblemen erhielten) und diverse Merchandising-Artikel. Wenn beispielsweise The Lone Ranger in den Pulps mit acht Heften (1937) nicht besonders erfolgreich war, erwies sich die Figur in Hörspielen und Comic-Strips sowie später in Comic-Heften und einer TV-Serie als Dauerbrenner.

Bevor nun aber auf die maskierten unter den Heldenfiguren in den Pulps eingegangen wird, ist festzuhalten, dass der maskierte Held der Pulps freilich nicht aus dem Nichts kommt, sondern wohl als Resultat bzw. Fortschreibung verschiedener Stränge von Motivtraditionen zu betrachten ist. ${ }^{21}$ Sieht man ihn etwa als Weiterentwicklung von Verkleidungsmotiven und -topoi, könnte man seine Geschichte bis in die Antike zurückverfolgen. ${ }^{22}$ Für die Neuzeit sind unter anderem zahlreiche literarische Maskenbälle, die namentlich im I 8. Jahrhundert in England beliebte Sujets waren, zu erwähnen. Trotz grundsätzlich differierendem Kontext sind auch dort Mechanismen zu beobachten, die sich bei den maskierten Helden wiederfinden: "To get to the masquerade in the first place, one must journey out of ordinary existence, away from the patterns of everyday life, into a world of strangeness, transformation, and mystery. In eighteenth-century fiction the masquerade is literally a topos, or place, somewhere out there, waiting to be discovered.» ${ }^{23}$ - Daneben sei auf eher isolierte Werke wie beispielsweise Johann Heinrich Daniel Zschokkes Abällino der grosse Bandit (1793/94) verwiesen, wo sich ein junger Adliger zwei maskierte Identitäten schafft, um dem Verbrechen in Venedig den Garaus zu machen. ${ }^{24}$

2I Zahlreiche mögliche Superhelden-Vorläufer sind das Thema etwa von Coogan 2006 sowie Gavaler 2015. Gavaler (2015, I78-180, I I 8) will in den Aktivitäten des Ku-Klux-Klans und besonders dem Roman The Clansman: An Historical Romance of the Ku Klux Klan von Thomas F. Dixon aus dem Jahr 1905, in dem Ku-Klux-Klan-Mitglieder als Helden präsentiert werden (und der I9Is als The Birth of a Nation, Regie: D. W. Griffith, verfilmt wurde), den bedenklichen ‘wahren> Vorläufer der superheldischen Doppelidentität identifiziert haben (die KKK-These erwähnt auch Günthart 20I3, 429). M. E. besteht ein bedeutender Unterschied zu den hier betrachteten Figuren darin, dass es sich beim KKK um eine Organisation mit mehreren Mitgliedern, die alle die gleiche Verhüllung tragen, handelt; es fehlt die im Heldenkostüm zur Schau gestellte Individualität.

22 Vgl. von Matt 2006, 46: «Die Verkleidung, die optisch frappante Situation einer andern sozialen Rolle und damit einer andern Identität, durchzieht die Weltliteratur als ein ununterbrochenes Spektakelgeschehen, vom trivialsten Poltertext bis zum vergeistigten Spiel.»

23 Vgl. dazu Castle 1986, hier i 16.

24 Der junge, hübsche Graf Obizzo aus Florenz schwingt sich als Abällino, fast grotesk hässlich verkleidet, zum Hauptmann einer venezianischen Banditenbande auf und tritt zudem in der Deckidentität eines Edelmanns namens Flodoardo auf, um der Bande und ihren adligen Auftraggebern das Handwerk zu legen. Dabei stellt die Einheit seiner Identitäten die finale Überraschung der Geschichte dar (Zschokke i 994). 
Spätestens im I9. Jahrhundert scheinen sich die Stränge zu verdichten bzw. die bekannten Beispiele beginnen sich zu vermehren. So bemerkt etwa Robert Sampson, dass es bereits in den dime novels und story papers in der zweiten Hälfte des I9. Jahrhunderts von verkleideten Heldenfiguren gewimmelt habe: «[...] cowboys, detectives, and general avengers - who donned costumes to champion the right» ${ }^{25}$. Er fügt aber sogleich an, dass Kostüme vor allem extravaganten Kriminellen vorbehalten waren. Dabei scheint es sich jedoch in den seltensten Fällen um ‘feste〉 Maskeraden gehandelt zu haben; Sampson nennt etwa Teufels-, Piraten- oder Geisterkostüme. ${ }^{26}$ Als Verkleideter hat der maskierte Held zweifellos Einflüsse von Figuren auf beiden Seiten des Gesetzes erhalten: Der dime novelDetektiv Nick Carter (ab i 886) und Sherlock Holmes ( $\mathrm{ab}$ I 887) gelten ebenso als Verkleidungskünstler wie die Verbrechergenies Fantômas (ab I 9 I i in der gleichnamigen Romanreihe von Pierre Souvestre und Marcel Allain) und Dr. Mabuse (ab I9I9 in der gleichnamigen Romanreihe von Norbert Jacques), die beide als ¿Gesichterdiebe> ihr Unwesen trieben. ${ }^{27}$

Vorläufer des maskierten Helden finden sich zweifellos auch in den französischen Feuilletonromanen von Paul Féval (1816-1887), die in verschiedenen Epochen des i 8. und frühen i 9. Jahrhunderts angesiedelt sind. Févals wohl berühmtester Protagonist, der Degenfechter Henri de Lagardère aus Le Bossu, ou le Petit Parisien ${ }^{28}$ ( 1847 in Le Siècle veröffentlicht), verkleidet sich nach zwanzig Jahren im Exil als buckliger Bediensteter, um sich endlich an seinem adligen Kontrahenten Gonzague zu rächen. Dieser hatte seinerzeit aus Besitzgier den Duc de Nevers ermordet, dessen Tochter Lagardère im Exil aufgezogen hat und die am Ende ihr Erbe erhält. Während Lagardère keine gegenständliche Maske trägt, kennzeichnet eine solche Le Capitaine Fantôme im gleichnamigen Roman $^{29}$ (1 862 in Le Pays publiziert). Dahinter verbirgt sich César de Cabanil, der nach einer Familienintrige als tot gilt und sich darum im letzten Drittel der Geschichte als waghalsiger Soldat im Spanischen Unabhängigkeitskrieg einen Namen macht, bevor es zur finalen Anagnorisis kommt. Févals in diesem Zu-

25 Sampson 1987, 126. Auch Goulart (1988, I67) erklärt, dass in der US-amerikanischen wie englischen Populärliteratur im I9. Jahrhundert «masked men, bent on various sorts of revenge and retribution» häufig gewesen seien: «Phantoms on both sides of the law were frequently to be found in penny dreadfuls, nickel weeklies, and dime novels.» $\mathrm{Zu}$ dime novels siehe etwa DeForest 2004, I 5-25, oder Sheldrick Ross 20 I I.

26 Sampson 1987, i26. Aus dem Bereich der Penny Dreadfuls zu nennen wäre hier wohl auch Spring-Heeled Jack, nicht selten in einem Teufelskostüm dargestellt (Coogan 2006, I 54 f.).

27 Insbesondere zu Mabuse siehe Holzmann 200I, I94-200, und 2005, 26-28, sowie Meyer 20I I, I $4 \mathrm{I}-\mathrm{I} 48$.

28 Féval I 997.

29 Féval 2007. 
sammenhang spannendste Figur ist der Albino Jean Blanc in Le Loup blanc $3^{3}$, einem von Févals frühesten Romanen (I 843 in Le Courrier Français unter dem Pseudonym Francis Trolopp erschienen). Nach einem schicksalsträchtigen Erlebnis hat dieser seine <angestammte> Identität sozusagen suspendiert und lebt in Zivil als Kohlenbrenner Pelo Rouan, während er zugleich mit einer weissen Wolfsmaske als Anführer einer Gruppe antifranzösischer Rebellen im Wald von Rennes wirkt, die schwarze Wolfsmasken tragen und den tyrannischen bretonischen Grundherrn in die Schranken weisen wollen. Jean Blanc ist dabei nicht der eigentliche Protagonist des Romans; vielmehr geht es darum, dass der als Kind verschollene Erbe eines in tyrannische Hände gekommenen Adelstitels wieder auftaucht und zu seinem Recht kommt.

Févals Figuren schaffen sich durch ihre Maskerade ebenfalls einen Handlungsraum, der ihnen sonst verwehrt bliebe. Allerdings sind Févals Geschichten von Anfang an so konstruiert, dass die Handlung auf das Ziel ihrer Entlarvung und damit der Rückkehr zu ihrer «angestammten〉 Identität hinarbeitet. Angelpunkt von Févals Plots sind nicht die Maskeraden seiner Protagonisten, sondern die für die (populäre) Literatur des I9. Jahrhunderts typischen Familiengeheimnisse und -intrigen, die zum Ende hin stets aufgedeckt werden, sodass eine weitere Maskerade des Helden nicht mehr nötig ist. Die Maskerade bzw. die <zweite Identität bedeutet im Grunde für Févals Figuren eine von Anfang an zeitlich begrenzte Angelegenheit. Mit der Ausnahme des etwas komplizierteren Falls von Jean Blanc kommt es so auch nicht zu einem ständigen Hin und Her zwischen den Rollen, da die sangestammte> Identität so lange gänzlich von der Bildfläche verschwindet. Obschon es sich hier letztlich um graduelle Unterschiede handelt, werden Févals Figuren aus diesen Gründen hier als Vorläufer statt bereits dem Modell des maskierten Helden vollends entsprechende Figuren verstanden. So ist es möglich, den maskierten Helden als Figur des 20. Jahrhunderts zu fassen. Im Folgenden werden die verschiedenen Stationen des maskierten Helden in den Pulps anhand inhaltlich und mehr oder weniger chronologisch gruppierter Schlaglichter näher betrachtet. Am Anfang steht das Mantel-und-Degen-Genre, in welchem The Scarlet Pimpernel (1903/1905) - der zwar kein Pulp-, sondern ein britischer Romanheld ist und noch keine gegenständliche Maske trägt - die zivile Identität als Tarnung etabliert und dann Zorro (1919) als massgebendes Beispiel erscheint; ein Seitenblick wird auf dessen Imitation The Whirlwind geworfen. Die Tradition der jeweils zeitgenössisch situierten maskierten Helden eröffnet Jimmie Dale (1914), ein Gentleman-Gauner, auf dessen Spuren namentlich Johnston McCulleys maskierte Protagonisten der I920er-Jahre wandeln. 
Anschliessend liegt der Fokus auf den maskierten Verbrechensbekämpfern, die das Goldene Zeitalter der Pulps mitprägen: The Shadow sowie vier weitere seiner 〈Mitstreiter». Schliesslich folgt ein kurzes Zwischenfazit, in welchem einige übergreifende Unterschiede zwischen den Pulp-Protagonisten und den ComicSuperhelden festgehalten werden.

\section{Mit Mantel, Degen und Maske}

\section{Scarlet Pimpernel/Percy Blakeney}

The Scarlet Pimpernel wurde 1903 in London uraufgeführt und erschien 1905 als Buch; mit den Jahren verfasste die Autorin Emmuska Orczy (I 865-I947) mehrere Fortsetzungen. ${ }^{31}$ Die Handlung setzt im September 1792 ein, als - so das im Roman gezeichnete Geschichtsbild - die französischen Aristokraten unter der Schreckensherrschaft der Revolutionäre täglich reihenweise den Kopf unter die Guillotine legen mussten, was ein ebenso makabres wie beliebtes «Unterhaltungsprogramm> für die gaffende Menge der sensationslüsternen Pariser Bürger abgab. Sehr zum Ärger von Robespierre und seinen Adlaten werden jedoch immer wieder «aristos» aus dem abgeriegelten Paris ins englische Exil geschmuggelt. Bei jeder Rettungsaktion erhält einer der Revolutionsführer eine Nachricht, die mit einer kleinen roten Blume ${ }^{32}$ signiert ist - dem Zeichen des Scarlet Pimpernel, des Anführers der englischen Rettungstruppe. Dank seines kühnen und listigen Vorgehens wird dieser innert kürzester Zeit eine legendäre Figur - von den französischen Revolutionären verflucht und von den Engländern gefeiert, die rote Blümchen zur Dekormode der Saison erheben, obschon niemand weiss, wer sich hinter seinem Namen verbirgt. Der Roman singt ein unverhohlenes Loblied auf die charakterlichen Tugenden und die kulturelle Überlegenheit der Engländer (und ihrer Aristokratie) gegenüber den masslosen und aufbrausenden Franzosen.

Der Scarlet Pimpernel ist also bereits etabliert, als die Handlung einsetzt, und sein Ruf eilt ihm auch in der Erzählung voraus: Indem in der ersten Szene ein prahlerischer Wachsoldat erzählt, wie der Scarlet Pimpernel seine Kollegen

3 I In den Folgeromanen liegt der Fokus oft auf anderen Figuren, z. B. einem von Percys Gefolgsmännern (Lord Tony's Wife, I917), dazu kommen Kurzgeschichten-Bände sowie Prequels und Sequels mit Percys Vorfahren (The Laughing Cavalier, 19I4) und Nachkommen (Pimpernel and Rosemary, 1924).

32 Scarlet pimpernel (lat. anagallis arvensis) ist ein Primelgewächs mit kleinen roten, fünfblättrigen Blüten, das auf Deutsch den wohl wenig heldenwürdig klingenden Namen Acker-Gauchheil trägt. 
überlistet habe, ihn jedoch niemals austricksen werde, erfährt man zuerst durch Hörensagen von diesem Scarlet Pimpernel, bevor er selbst unerkannt auftritt und das Tor unentdeckt passiert. Als «Passierschein $>$ dient dem Scarlet Pimpernel (und seinen Schützlingen) eine stets clever gewählte, aber immer neue Verkleidung. Im Roman täuscht er die Franzosen als Hauptmann (dessen Soldaten zu rettende Adlige sind), alte Vettel (in deren Wagen sich die Familie des Marquis de Tournay versteckt) und schliesslich als (an Kleidung und Haartracht als solcher erkennbarer) Jude. Obwohl der Scarlet Pimpernel also einen spezifischen Heldennamen mit einem spezifischen Heldenzeichen besitzt, tritt er nicht als maskierte Gestalt auf - die spezifische Maske ersetzen bei ihm zahlreiche temporäre Verkleidungen. Die Rolle seines Lebens, könnte man etwas tautologisch sagen, ist dabei aber er selbst - «Sir Percy Blakeney, Baronet».

Dass Percy der Scarlet Pimpernel ist, erfahren die Leser explizit allerdings erst nach gut der Hälfte des Romans, als seine Frau hinter das Geheimnis ihres Gatten kommt (zuvor wird dies allenfalls durch gewisse Erzählweisen angedeutet ${ }^{33}$ ). Bemerkenswerterweise folgt die Erzählstimme nämlich nicht der Heldengestalt, sondern Marguerite Blakeney - die weibliche Partnerin des geheimnisvollen maskierten Helden als Protagonistin ist dabei bis heute ungewöhnlich, sind doch die meisten Genres mit maskierten Helden dezidiert männerdominiert. Indem erzählt wird, wie Marguerite zwischen Schuld, Angst, Hoffnung und Liebe schwankt, ist The Scarlet Pimpernel mehr noch als eine Abenteuereine Liebesgeschichte.

Wie Percy anfänglich zu seiner Heldenrolle gekommen ist, erfährt man nicht. Als Englishman bedarf er anscheinend keines konkreten Anlasses, Sportsgeist und Abenteuerlust sind Motivation genug. Dies formuliert jedenfalls sein Gefolgsmann Lord Tony, wenn er erklärt, warum er zur Liga des Scarlet Pimpernel gehört: «[...] as for me, I vow, I love the game, for this is the finest sport I have yet encountered. - Hair-breath escapes ... the devil's own risks! - Tally ho! - and away we go!»34 Ausser den neunzehn Liga-Mitgliedern (von denen einige wie

33 Namentlich ist hier und da vom Scarlet Pimpernel die Rede, bevor jeweils Percy Blakeney auftritt, so bei Percys erstem Auftritt im Wirtshaus in Dover, wo zuvor die geretteten de Tournays mit zweien seiner Gefolgsleute angekommen sind, sowie deutlicher auf dem Ball, als Chauvelin aus seiner Fantasie, wie der Scarlet Pimpernel unter der Guillotine den Kopf verlieren wird, gerissen wird, als der Haushofmeister Percy ankündigt (Orczy 2007, 107, Kap. XI) - was freilich keine zwingenden Hinweise sind.

34 Orczy 2007, 36, Kap. IV. Ganz so todesmutig, wie man hier denken könnte, sind die Unternehmungen Percy Blakeneys bzw. des Scarlet Pimpernels indes nicht, diese beruhen nämlich stets auf kalkuliertem Risiko. In der Fortsetzung I Will Repay (1906) gibt es eine Szene, in der Percy mehrfach attestiert wird, dass seine Taten der reine Wahn sind, es wird aber deutlich, dass er das Risiko eines Plans sehr genau abschätzt und bewusst eingeht (Orczy 1924, 74-79, 
Tony als solche bekannt sind) würde allerdings niemand Percy Blakeney einen solchen Wagemut zutrauen - zu gelungen ist die Selbstdarstellung, mit der er allen Sand in die Augen streut. Dabei wäre seine zivile Identität geradezu augenfällig: Gross, blond und blauäugig, hätte er die besten Voraussetzungen, um einen idealen Helden abzugeben. Doch mit Äusserlichkeiten ist es eben nicht getan:

Physically, Sir Percy Blakeney was undeniably handsome - always excepting the lazy, bored look which was habitual to him. He was always irreproachably dressed [...] with the perfect good taste innate in an English gentleman. [...] his coat [...] set off his massive figure to perfection, and in repose one might have admired so fine a specimen of English manhood, until the foppish ways, the affected movements, the perpetual inane laugh, brought one's admiration of Sir Percy Blakeney to an abrupt close. ${ }^{35}$

Bei Percy kommt es dabei zu einer in gewisser Weise paradoxen Situation: Eine zivile Rolle verlangt üblicherweise, ein möglichst natürliches Verhalten vorzugeben. Percys Rollenverhalten hingegen ist durch Gekünsteltheit geprägt, wobei es in seinem spezifischen, adligen und vermögenden Umfeld gerade diese Gekünsteltheit ist, die seiner Täuschung - nämlich durch und durch heldenuntauglich zu sein - in den Augen aller anderen Authentizität verleiht. Percy gibt sich als Gecken und gutmütigen Phlegmatiker aus. Entgegen jeder traditionellen Heldenetikette seines Genres hält er es beispielsweise rundweg für sinnlos, sich wegen einer Beleidigung zu duellieren, als ihm der gerettete Vicomte de Tournay ein Duell anbietet, nur weil dessen Mutter Marguerite beleidigt hat:

Once more Blakeney turned, and from his high altitude looked down on the choleric little man before him; but not even for a second did he lose his own imperturbable good-humour. He laughed his own pleasant and inane laugh, and [...] said leisurely «A duel? La! Is that what he meant? Odd's fish! you are a bloodthirsty young ruffian. Do you want to make a hole in a law-abiding man? ... As for me, sir, I never fight duels,» he added [...]. «Demmed uncomfortable things, ain't they, Tony?»36

Tatsächlich ist Percy eine grosse Ausnahme unter maskierten Helden, da es im gesamten Roman zu keiner kämpferischen Auseinandersetzung mit einem Kontrahenten kommt. Percy verkauft seine Haltung zu Duellen hier als Teil seiner Trägheit, die aber im Grunde als Besonnenheit betrachtet werden kann, mit welcher der Brauch des Duells aufgrund geringer Ehrverletzungen ad absurdum ge-

Kap. VI). Die Szene qualifiziert ihn, nebenbei bemerkt, klar als sogenannten Merchant Adventurer, der seine Taten zwischen Wahnsinn und Genialität im Bewusstsein um sein Können plant und Risiko (wie auch merkantilen Nutzen) wohl abzuwägen weiss. 
führt wird (wie angemerkt wird, sollen Duelle in England zu jener Zeit bereits verboten, in Frankreich jedoch noch gang und gäbe gewesen sein). ${ }^{37}$

So viel Subversivität wird ihm indes nicht zugetraut, denn: «Everyone knew that he was helplessly stupid, but then that was scarcely to be wondered at, seeing that all the Blakeneys for generations had been notoriously dull, and that his mother had died an imbecile. ${ }^{3}{ }^{8}$ Diese Randinformation deutet an, dass Percys Rollengestaltung auch deshalb so gut funktioniert, weil sie von einer gewissen Tradition zehrt, die er allerdings überbietet. ${ }^{39}$

Percys Glamourfaktor wird noch gesteigert durch seine Gattin. ${ }^{\circ}$ Zusammen sind sie innert weniger Monate «the acknowledged leaders of fashion and style. Sir Percy's coats were the talk of the town, his inanities were quoted, his foolish laugh copied by the gilded youth at Almack's or the Mall.»4 Percys Charakterisierung bzw. seine Selbstinszenierung ist hier ansatzweise widersprüchlich: Als gefeierter 〈Stilmacher〉 der Schönen und Reichen (und überdies persönlicher Freund des Kronprinzen) müsste ihm doch durchaus ein gewisses Charisma zugestanden werden. Zudem illustriert der Vierzeiler ${ }^{42}$ über sein heldisches Alter Ego, am Ball das bon mot des Abends, dass Percy, ungeachtet der Doppelidentitätskomik, nicht ganz ohne Geist oder Witz sein kann. Doch scheint sein exaltiertes Äusseres seine Kategorisierung so zu dominieren, dass für Zwischentöne kein Platz bleibt. So ist der Romangesellschaft schleierhaft, wie er - «the sleepiest, dullest, most British Britisher that had ever set a pretty woman yawning»43 - Marguerite für sich gewin-

37 Noch deutlicher macht er die Lächerlichkeit von Duellen, als ihn Marguerite wegen seiner vermeintlichen Trägheit aufzieht, worauf er erklärt: «Odd's life, m’dear! Be reasonable! Do you think I am going to allow my body to be made a pincushion of, by every little frog-eater who don't like the shape of your nose?» (ebd., 57, Kap. VI).

38 Ebd., 5 I, Kap. VI.

39 Zudem wird impliziert, dass ein weiterer Faktor für Percys erfolgreiche Darstellung seiner selbst ist, dass er «abroad» aufgewachsen ist, sodass ihn in London niemand von klein auf kennt (ebd.).

40 Gavaler (2015, I48) interpretiert diese Verbindung kreativerweise vor einem eugenischen Hintergrund, mit dem Scarlet Pimpernel als deren 〈perfektem» «figurative offshoot».

4I Orczy 2007, 5 I, Kap. VI. Man möchte Orczy hier auch einen ironischen Blick auf die englische Oberschicht im Roman unterstellen, aber diese gesellschaftliche Funktion Percys dient wohl eher einer Überhöhung, ohne die auch seine zivile Identität nicht auskommt.

42 Der Vierzeiler lautet (ebd., I I 4, Kap. XII): «We seek him here, we seek him there, / Those Frenchies seek him everywhere. / Is he in heaven? - Is he in hell? / That demmed, elusive Pimpernel?»

43 Ebd., 48, Kap. VI. Anders als bei Zorro (der im nächsten Unterkapitel besprochen wird) geht es hier allerdings nur marginal um den Widerstreit verschiedener Männlichkeitsideale, obschon dies etwa in den Verfilmungen von 1934 (Regie: Harold Young) und 1982 (Regie: Clive Donner, TV-Produktion) implizit ein Thema ist. Im Roman scheint Percys «Lahmheit in erster Linie mit einer gewissen Britishness verknüpft. Expliziter erfolgt m. E. in der Beschreibung von Marguerites Gefühlswelt ein Diskurs um (ideale) Weiblichkeit. 
nen konnte. Der feinen Gesellschaft ist von vornherein klar, dass es sich bei dieser Ehe um eine überstürzte mésalliance handeln muss: $\mathrm{Zu}$ gross scheint der Unterschied zwischen der schönen, geistreichen französischen Schauspielerin Marguerite St. Just, die von ihrem Freundeskreis als «the cleverest woman in Europe» gelobhudelt wird, und dem zwar vermögenden, aber intellektuell unterbelichtet geltenden Percy Blakeney.

Tatsächlich hat sich das junge Ehepaar aufgrund eines Zerwürfnisses entzweit, an dessen Ausmass Percys heimliches Heldentum, von dem Marguerite nichts ahnt, nicht unbeteiligt ist. Denn er glaubt, sie habe die Hinrichtung des Marquis de St. Cyr und dessen Familie verschuldet, was er einen Tag nach der Hochzeit erfahren hat. Marguerites Schuld beruht aber nicht auf einer willentlichen Tat, sondern Unbedachtheit, was wiederum Percy nicht weiss. ${ }^{44}$ Deshalb behandelt er sie zwar dienstfertig, aber mit emotionaler Kühle. Ihre spitzen Bemerkungen auf seine Kosten lässt er mit gutmütiger Miene über sich ergehen, was Marguerite umso mehr trifft, da sie ursprünglich von der Intensität seiner Liebe zu ihr beeindruckt war. Der Fall aus den vorehelichen romantischen Höhen scheint tief.

So ist es kein Wunder, dass Marguerite für den kühnen Helden ins Schwärmen gerät und ohne ihr Wissen ihren eigenen Ehemann anhimmelt. Angelegt ist hier bereits das bei späteren maskierten Helden immer wieder aufgegriffene Motiv, dass der love interest des Helden oder der Heldin nur Augen für die eine Hälfte der Doppelidentität hat: «[...] the mysterious hero! Ah! there was a man she might have loved had he come her way: everything in him appealed to her romantic imagination; his personality, his strength, his bravery, the loyalty of those who served under him in the same noble cause, and, above all, that anonymity which crowned him, as if with a halo of romantic glory.» ${ }^{45}$ In einem Aspekt steht Marguerite hier aber im Gegensatz zu zahlreichen späteren Heldenfreundinnen, die oft sehnsüchtig wissen möchten, wer der Held in Zivil ist (man denke nur

44 Der Liebeskonflikt beruht genau genommen auf beiderseitiger Kommunikationsverweigerung aus Stolz: Marguerite weigerte sich, ihm zu dieser Anschuldigung eine Erklärung abzugeben, weil sie entrüstet war, dass er so etwas von ihr überhaupt glauben konnte, und als Liebesbeweis erwartete, dass er ihr ohne Erklärung glaubte, worauf er zu stolz war, um nachzuhaken, und lieber den Distanzierten gab. Überdies war St. Cyr ein österreichischer Spion und tyrannischer Aristokrat, der Marguerites Bruder Armand schwer verprügeln liess, weil dieser sich in St. Cyrs Tochter verliebt hatte - gleichwohl hatte Marguerite, als moralische Heldin, alles in ihrer Macht Stehende versucht, um diesen zu retten.

45 Orczy 2007, 77, Kap. VIII. Als Marguerite zu Beginn des Balles Chauvelin neckisch erklärt, dass alle Frauen in London den Scarlet Pimpernel als «hero of old» anbeten würden, lockert Percy die Spannung, indem er erklärt: «And we poor husbands [...] have to stand by ... while they worship a demmed shadow» (ebd., I I 2, Kap. XI). 
an Lois Lane). In Marguerites Augen liegt der romantische Reiz gerade in der Anonymität und der Flüchtigkeit der mysteriösen Heldenfigur, die im Kontrast zu ihrem verkorksten Eheleben eher eine anhaltende romantische Illusion zu ermöglichen scheinen.

Erst recht in Seelennöte bringt sie dann der französische Agent Chauvelin, der zur Ergreifung des Pimpernels nach England gesandt wurde. Um die gebürtige Französin als Spionin zu rekrutieren, schreckt er nicht vor Erpressung zurück: Entweder sie liefert ihm den Scarlet Pimpernel aus oder ihr Bruder Armand stirbt auf der Guillotine - denn Chauvelin ist im Besitz eines Briefes, der Armand als Ligamitglied identifiziert. Auf einem Ball gelingt es Marguerite, eine Information zu erhalten, dass der Gesuchte um ein Uhr im Speisezimmer sein werde. Dort findet Chauvelin nur den schlafenden Percy vor - dennoch schöpft er Verdacht und plant, den Pimpernel auf französischem Boden zu fassen. Marguerite verliert derweil fast die Hoffnung, denn dass ihr eigener Gatte, den sie nur zu gern belächelt, der irrlichternde Held ist, würde ihr im Traum nicht einfallen. Wie pikant die Situation tatsächlich ist, in die sie mit Chauvelins Intrige zur Entlarvung des Scarlet Pimpernel geraten ist, wird ihr erst klar, nachdem sie dessen Geheimnis entdeckt hat. Das erneute Zusammenfinden des Ehepaars, die Liebeshandlung, ist also eng mit der heldischen Doppelidentität verknüpft.

Nach dem Ball trifft Marguerite im Garten auf Percy und versucht, sich ihm anzuvertrauen. Dazu erklärt sie ihm endlich ihre unglückliche Verstrickung in St. Cyrs Schicksal. Gegenüber der aufgewühlten Marguerite gelingt es Percy zwar, seine distanzierte Fassade beizubehalten, diese erhält jedoch Risse. Denn obschon er geradezu heldisch versucht, die dramaturgische Disziplin aufrechtzuerhalten, kann auch er den Tumult in seinem Inneren nicht ganz verbergen: «She need not complain now that he was cold and impassive; his very voice shook with an intensity of passion, which he was making superhuman efforts to keep in check.» ${ }^{46}$ Interessanterweise wird das Wort mask im ganzen Roman für metaphorische Masken gebraucht (es gibt freilich keine gegenständlichen). So wirft ihm Marguerite in dieser Szene vor, eine «mask of somnolent indifference» $\mathrm{zu}$ tragen, worauf er nicht zuletzt aus Stolz die Rollenhaftigkeit seines Verhaltens bestreitet, indem er eisig erklärt: «[...] it is no mask.»47

Als Marguerite gesteht, in welcher Gefahr ihr Bruder schwebt (ohne allerdings ihren Verrat des Scarlet Pimpernels zu erwähnen), zeigt sich auch Percys anderes Gesicht: «[...] Sir Percy's face had become a shade more pale; and the look of determination and obstinacy appeared more marked than ever between his 
eyes.» ${ }^{4}$ Dies ist ein 〈klassischer Moment des maskierten Helden, wenn er in der zivilen Identität eine für sein heldisches Tun wichtige Information erhält. Percy verspricht ihr Armands Wohlergehen und reist unverzüglich ab, angeblich um seinen Einfluss in London geltend zu machen - in Wahrheit begibt er sich nach Frankreich.

Obwohl Percy nur wenige Momente seiner Darstellung verpatzt hat, hat sich Marguerites Bild von ihm komplett verändert, da sie nun sicher ist, ihre Sorge um Armand in den richtigen Händen zu wissen. Zudem erkennt sie, dass sie Percy noch liebt, und fragt sich, wie sie seine Performance je für etwas anderes als eine Maske halten konnte. «She marvelled at herself for having ever looked upon him as an inane fool; of course, that was a mask worn to hide the bitter wound she had dealt to his faith and to his love.»49 Noch sieht sie den Grund für sein Rollenspiel nur in der Beziehung zu ihr; sie durchschaut also erst die metaphorische Maske, die er über seine Gefühle für sie gelegt hat, bevor sie dahinterkommt, dass er der Scarlet Pimpernel ist.

Allein zurückgeblieben, schaut sie sich erstmals in seinem Arbeitszimmer um, dessen schlichte Gestaltung den Verdacht nährt, dass noch mehr hinter seiner Performance steckt. Mit Goffman gesprochen, verschafft sich Marguerite hier Einblick in die Hinterbühne, jenen privaten Raum («Sir Percy’s sanctum»), in dem er sein Maskenspiel nicht aufrechterhält. Dieser passt mit der von ihm inszenierten Fassade nicht recht zusammen, ${ }^{\circ}$ eher damit, dass er sein riesiges Erbvermögen geschickt zu verwalten vermag, wie Marguerite nun erstmals auffällt. Sie kommt zur Gewissheit: «[...] with his wordly inanities, his foppish ways, and foolish talk, he was not only wearing a mask, but was playing a deliberate and studied part. Marguerite wondered again. Why should he take all the trouble?» ${ }^{\text {I }}$ Als sie das Zimmer schon verlassen will, stösst sie auf einen heruntergefallenen Siegelring mit der fünfblättrigen Blume.

Damit fällt der Groschen, obwohl Marguerite die Schlussfolgerung zuerst zu entkräften versucht, wobei sie auf das <alte> Percy-Bild zurückgreift:

Bah! It was ridiculous! she was dreaming! her nerves were overwrought, and she saw signs and mysteries in the most trivial coincidences. Had not everybody about town recently made a point of affecting the device of that mysterious and heroic Scarlet Pimpernel? [...] What was there strange in the fact that Sir Percy

48 Ebd., I55, Kap. XVI.

49 Ebd., I66, Kap. XVII (Hervorhebung im Original).

so Ebd., I 70, Kap. XVIII: «[It] in no way recalled to her mind the lazy man about town, the lover of race-courses, the dandified leader of fashion [...].»

s I Ebd., I72, Kap. XVIII. Marguerite unterscheidet dabei offenbar zwei Stufen metaphorischen Maskentragens, Maske (mask) und Rolle (part). 
should have chosen to use [it] as a seal-ring? He might easily have done that ... yes ... quite easily ... and ... besides ... what connection could there be between her exquisite dandy of a husband, [...] and the daring plotter who rescued French victims beneath the very eyes of the leaders of a bloodthirsty Revolution? Her thoughts were in a whirl - her mind a blank ... ${ }^{2}$

Nur selten wird der Erkenntnisprozess über die Doppelidentität derart ausführlich geschildert. Durch Marguerites Gedankengänge wird der Kontrast zwischen den beiden Identitätshälften in der mehrmaligen Wiederholung betont. Hier ist leicht vorstellbar, dass Percy, wenn er auf seinem Geheimnis bestehen sollte, es genau so <wegerklären> könnte, wie es Marguerite in ihrem Kopf tut. Zwei weitere Informationen lassen jedoch keine Zweifel übrig, und Marguerite kann sich nur über sich selbst wundern:

She ought to have known! she ought to have known! How could she imagine that a man who could love with so much intensity as Percy Blakeney had loved her from the first? - how could such a man be the brainless idiot he chose to appear? She, at least, ought to have known that he was wearing a mask, and [...] she should have torn it from his face, whenever they were alone together. Her love for him had been paltry and weak, easily crushed by her own pride; and she, too, had worn a mask in assuming a contempt for him, whilst, as a matter of fact, she completely misunderstood him.s3

Implizit offenbart die Stelle, wie <durchsichtig> die ganze heldische Maskerade (typischerweise) wäre, wie stark aber umgekehrt soziale Zuschreibungen den Blick auf den Charakter des Gegenübers verstellen können (wobei dem implizit die Vorstellung eines Charakters als konstanter Grösse zugrunde liegt). Indem Marguerite hier reflektiert, dass sie selbst ebenso wie ihr Gatte eine metaphorische Maske getragen hat, deutet sie an, dass alle eine Maske tragen, und erkennt, dass sie sich davon nicht hätte irreführen lassen und diese Masken zumindest im Privatleben nicht hätte dulden sollen. Implizit erscheint der Scarlet Pimpernel so als die <wahre> Identität von Percy Blakeney. Allerdings bleibt der Scarlet Pimpernel - im Vergleich zu anderen maskierten Helden - flüchtig, da eben verschiedene Verkleidungen Percy als Scarlet Pimpernel ausmachen und er bis auf den Schluss nie als 〈Percy-ausser-Rolle〉 auftritt. ${ }^{54}$

52 Ebd., I74f., Kap. XIX.

53 Ebd., I 82, Kap. XIX. Es scheint eine gewisse Ironie darin zu liegen, dass Marguerite, die selbst Schauspielerin ist, sich von den Masken hat täuschen lassen. Darauf wird im Roman jedoch nie angespielt.

54 Da aus Marguerites Sicht erzählt wird, erhält man keinen Einblick in Percys Innenleben, was seine Identitäten betrifft. Es ist zu vermuten, dass er höchstens noch in den Besprechungen mit 
Mit der Erkenntnis realisiert Marguerite die potenziell monströsen Folgen ihrer Kollaboration mit Chauvelin und die Gefahr für ihren Liebsten. Mit dem Liga-Mitglied Andrew Ffoulkes reist sie Percy über den Kanal nach, um ihn vor Chauvelin zu warnen. Als sie in einem Wirtshaus in Calais auf Percy wartet, trifft Chauvelin zuerst ein - Marguerite kann nur aus einem Versteck heraus beobachten, wie die beiden Kontrahenten einander gegenseitig Arglosigkeit vorspielen. Da Chauvelin für die Festnahme auf Verstärkung wartet, gleitet ihm Percy mit einen Trick dennoch durch die Finger. Schliesslich heuert Chauvelin einen Juden an, der ihn und seine Männer zu jener einsamen Hütte führen soll, in welcher Armand und die flüchtigen Aristokraten auf ihren Retter warten. Marguerite folgt ihnen heimlich, wird aber von Chauvelin aufgegriffen und kann so nichts ausrichten. Nach einer Nacht des Wartens vor der umzingelten Hütte ist diese leer; in der Dunkelheit ist der Scarlet Pimpernel Chauvelin erneut durch die Lappen gegangen. Chauvelin lässt Marguerite und den aus Missgunst verprügelten Juden in der einsamen Landschaft zurück. Der Jude entpuppt sich nun als Percy, den Ffoulkes noch in Calais warnen konnte. Das Paar ist versöhnt, und die Flüchtlinge erreichen mit Percys Schiff, der Day Dream, das sichere England.

Obwohl Marguerite bereits um die Doppelidentität weiss, kommt es so dennoch zu einer finalen Anagnorisis-Szene. Erst jetzt tritt Percy sozusagen als 〈er selbst> auf: Er rekapituliert, wie er bereits einen Plan hatte, nach Ffoulkes' Warnung aber auch improvisierte. Insbesondere hat er Chauvelins Handlungsweise akkurat eingeschätzt. Allerdings legt er die typischen Percy-Verhaltensweisen nicht völlig ab: Er benutzt dieselben Ausdrücke («Odd’s life»), scherzt mit Ffoulkes über den Zustand seiner Kleidung, und es wird erwähnt, dass er auf dem Schiff einen grossen Vorrat jener luxuriösen Kleider hat, die er so liebt. Damit wird zumindest angedeutet, dass nicht alles an der Percy-Identität gespielt ist. Mindestens vor Marguerite muss er nun aber nichts mehr verbergen. Erzählt wird so nicht von einer etwaigen Heldwerdung des Protagonisten, sondern wie die Geheimidentität des Helden einmal entdeckt wird (von Marguerite) und wie einmal der Plan (von Chauvelin), ihn zu entlarven und zu fassen, fehlschlägt..s

Obwohl der Scarlet Pimpernel keine gegenständliche Maske trägt, bietet der Roman bereits grundlegende Elemente, die in der Geschichte der maskierten

seinen Mitstreitern, wie etwa in den Folgebänden, sein ‘wahres) Selbst zeigt, Besprechungsszenen werden aber in The Scarlet Pimpernel nicht erzählt.

5s Chauvelin hegt zwar die richtige Vermutung, kann diese aber nicht beweisen bzw. scheitert an seiner eigenen «Blindheit`, da er den als Juden verkleideten Percy direkt unter seiner Nase nicht erkennt, der freilich mit den französischen Überlegenheitsgefühlen gegenüber Juden gerechnet hatte (Orczy 2007, 299f., Kap. XXXI). 
Helden zu Konventionen werden sollten. Insbesondere finden sich deutliche Gemeinsamkeiten zwischen Percy und Don Diego, dem das nächste Kapitel gewidmet ist.

\section{Zorro/Diego Vega}

The Curse of Capistrano von Johnston McCulley (I883-1958) erschien als fünfteilige Fortsetzungsgeschichte im amerikanischen Magazin All Story Weekly vom 9. August bis am 6. September 1919, die Buchausgabe wurde i919 unter demselben und 1924 unter dem Titel The Mark of Zorro ${ }^{6}{ }^{6}$ herausgegeben. Bereits I920 verfilmte Douglas Fairbanks die Geschichte und löste deren nachhaltige Popularität aus, ${ }^{57}$ sodass McCulley im Lauf seines Lebens insgesamt noch über 60 Fortsetzungen, darunter mehrere Prequels, verfasste.

Das Geschehen ist in der ersten Hälfte des I9. Jahrhunderts im spanischen Kalifornien angesiedelt. ${ }^{58}$ Unter der Herrschaft eines despotischen Gouverneurs nimmt Beamten- und Soldatenwillkür überhand. Die alteingesessenen Adelsfamilien haben diesen Missständen wenig entgegenzusetzen, da sie selber Repressalien fürchten müssen. Abhilfe zu schaffen, wagt nur einer: Zorro, der Fuchs. Er besitzt die Kühnheit und keine Skrupel, die korrupten Staatsangestellten auszurauben und ihr Vermögen an Bedürftige umzuverteilen. Auch ungerechtfertigte Gewalt gegen Schwächere bestraft er mit Degen oder Peitsche. Zugleich wandelt der stets schläfrige, Überanstrengung fürchtende und höchst unromantische Adelsspross Diego Vega auf Freiersfüssen. Lolita Pulido, die erkorene Braut, schenkt ihr Herz jedoch lieber dem agilen Zorro. ${ }^{59}$ Dass Zorros Maske keinen anderen als Diego verbirgt, wird erst als finale Pointe enthüllt. Auch hier wird also nicht erzählt, wie der Protagonist seine Doppelidentität erfindet, sondern

56 Die folgenden Ausführungen beziehen sich auf die Buchausgabe von 1924 (McCulley 1998). Dieser Titel entsprach dem der Verfilmung von 1920 (mit Douglas Fairbanks, Regie: Fred Niblo). Laut Curtis (1998b, ix) wählte Fairbanks den Titel nach einer Stelle im Roman (als Zorro seinen Gegner Ramón mit einem Z «verziert)); nach Seesslen (I 996, I46) war das geritzte Z als Signatur Fairbanks' Erfindung, die McCulley so gefallen haben soll, dass er dieses Element in die Buchausgabe eingefügt habe.

57 Zorro war nicht von Anfang an ganz in elegantes Schwarz gekleidet, das seine Gestalt durch Fairbanks' und zahlreiche andere Filme unverkennbar gemacht hat, sondern trug einen Sombrero, eine schwarze, das ganze Gesicht bedeckende Stoffmaske und einen roten Umhang (McCulley 1998, I4f., 247, Kap. 3, 36). Zu Zorro als globalem «Trade Image» vgl. Lie 200 , zu den Filmen Curtis 1998a, Dusi 2007, Seesslen 1996, I45-149.

$58 \mathrm{Zu}$ der historischen Situierung (und künstlerischen Freiheiten) vgl. Curtis 1998b, ferner Gerigk 2007, 202.

59 Die Geschichte wurde auf dem Titelblatt des Heftes vom 9. August I919 denn auch mit den Worten «When Romance and Rapiers Ruled Old California» angepriesen. 
wie es kommt, dass er sein Rollenspiel aufgeben kann. ${ }^{60}$ Seine Demaskierung in aller Öffentlichkeit setzt den Schlusspunkt unter das über den gesamten Text sorgfältig arrangierte Wechselspiel zwischen diesen beiden Identitäten. ${ }^{61}$

Das Muster dieses Wechselspiels ist bereits in der (fünf Kapitel umfassenden) Wirtshausepisode am Anfang konsequent ausgestaltet: Im Gespräch der Gäste wird Zorro als mysteriöse Figur eingeführt, die gerade den Übernamen «The Curse of Capistrano» erhalten hat. Es wird von seinen Taten erzählt, und Sergeant Gonzales macht seinem Ärger Luft, dass dieser Zorro nie am selben Ort wie er ist, sonst hätte er die auf Zorro ausgesetzte Belohnung längst in der Tasche. Gerade, als er nochmals lauthals wünscht, Zorro möge an Ort und Stelle erscheinen, geht mit dem letzten Satz des Kapitels die Tür auf - wo man Zorro erwartet, steht jedoch Don Diego, der Gonzales regelmässig den Wein spendiert. Angesichts von Gonzales' Prahlereien bittet er ihn, ihm doch erst von seinem Erfolg über Zorro zu erzählen, wenn dieser Tatsache sei (dann aber ausführlich); ausserdem hegt er Sympathien für den Räuber, wie er doch einwenden muss: "The fellow, no doubt, is sincere in his purpose. He has robbed none except officials who have stolen from the missions and the poor, and punished none except brutes who mistreat natives. [...] Let him have his little day in the public eye, my sergeant. ${ }^{62}$ Diego verteidigt hier seine Motive für seine Handlungen als Zorro, versucht aber mit dem letzten Satz auch, der Aufbauschung seiner ZorroAuftritte etwas entgegenzuwirken. Kaum ist Diego gegangen, prahlt Gonzales weiter - bis Zorro hereintritt. Er will Gonzales eine Lektion erteilen, weil dieser kürzlich grundlos einen native verprügelt hat. Zorro erweist sich als überlegener Fechter, und trotz der Soldaten unter den Gästen kann er in der Dunkelheit entschwinden. Kurz darauf erscheint Diego erneut und streut - scheinbar ganz arglos - zumindest metaphorisch kräftig Salz in Gonzales Wunden; mit Fragen nach dem Muster «Hat nicht ...?» zählt er die ganzen in der Begegnung gescheiterten Pläne von Gonzales auf, bis dieser unwillig zugeben muss, dass er Zorro nichts anhaben konnte.

60 Dass sein Held demaskiert und dessen Identität bekannt war, hat McCulley in seinen vielen späteren Zorro-Storys häufiger ignoriert, sie bilden insgesamt ein uneinheitliches Werk (Curtis I 998a, I4-20).

6I Es ist etwas schade, dass man als heutige Leserin, die a priori von der Doppelidentität weiss, sowohl bei Zorro wie beim Scarlet Pimpernel nicht mehr einschätzen kann, ob dies bei Ersterscheinung tatsächlich eine Überraschung war oder ob der Textaufbau auch dem unwissenden Leser einen Verdacht aufgedrängt hätte - was etwa D’Ammassa (2009, I40) bejaht -, zumal viele Stellen ihren Reiz oder ihre Komik nur im Wissen um die Doppelidentität voll entfalten. McCulley 1998, I0, Kap. 2. 
Hier wie auch an späteren Stellen ${ }^{63}$ übernimmt Diego sozusagen die Vor- und Nachbereitung seiner Auftritte als Zorro. Diese Taktik dient zum einen der Informationsbeschaffung (etwa wo sich die Soldaten aufhalten werden). Zum andern scheint darin eine Art heimlicher Triumph zu liegen, denn meistens erzählen seine Gegner eine ganz andere, aufgeblasene Version von ihrer Begegnung mit Zorro. Für allfällige Dritte (Wirtshausgäste, Lolita und ihre Familie) und die Leser führt der Held so seine Gegner (bzw. Opfer) insgeheim nochmals vor, indem ihre Charakterschwächen offensichtlich werden ${ }^{64}$ - nachdem er sie bereits als Zorro fast spielerisch, mit der abenteurertypischen Überlegenheit, bestraft hat.

Diese Handlungskonstruktion betont, dass sich die beiden Identitäten wechselseitig ergänzen. Wo Diego nicht weiterkommt, hilft Zorro (bei der Werbung um Lolita); wo es für Zorro brenzlig wird, bedeutet Diego den Ausweg (wenn die Soldaten Zorro fangen wollen, er aber als Diego erscheint, können sie freilich lange suchen). ${ }^{65}$ Obwohl die Einheit von Diego und Zorro an zahlreichen Stellen im Text klar impliziert wird, äussert in der erzählten Welt nie jemand einen solchen Verdacht; die Gefahr der Entdeckung wird daher nie konkret - abgesehen vom Schluss, als Zorro umzingelt wird.

Der Kontrast zwischen den beiden Identitäten ist ähnlich wie beim Scarlet Pimpernel angelegt, wobei Diego nicht als fashion icon gilt oder sonstwie zur Nachahmung einladen würde. Schon zu Beginn wird klargemacht, inwiefern sich Diego bedauerlicherweise von andern jungen Männern seines Standes abhebt: «It appeared that he disliked action. He seldom wore his blade, except as a matter of style and apparel. He was damnably polite to all women and paid court to none. He sat in the sun and listened to the wild tales of other men - and now and then he smiled. He was the opposite of Pedro Gonzales in all things [...].» ${ }^{66}$ Gonzales ist jedoch nur eine der Kontrastfiguren für Diego (neben Ramón); zentraler ist,

63 Auch seinen Vater Alejandro und die Pulidos besucht er erst als Diego, dann als Zorro und gleich darauf nochmals als Diego, und als später die Soldaten Zorro suchen, treffen sie in Fray Felipes Hütte Diego an, der schwört, keinen Zorro gesehen zu haben - wie er am Schluss erklärt, war das nicht gelogen, da der Fray keinen Spiegel besitze, in dem er sich selbst hätte sehen können.

64 Dies tut er etwa auch, als Ramón Ausflüchte macht, warum er Zorro noch nicht gefasst habe. Diego bemerkt, es sei doch «a most remarkable thing [...], that none of you soldiers can meet this Curse of Capistrano when you can be on equal terms. Always he descends upon you when you are helpless, or threatens you with a pistol while he fights you with a blade, or has his score of men about him» (McCulley 1998, I3 If., Kap. I9).

65 Sein Erfolg gründet übrigens auch auf seinem speziell dressierten Pferd, das beispielsweise alleine davongaloppieren und Zorros Verfolger so auf eine falsche Spur locken kann, derweil Diego auftaucht.

66 McCulley I998, 9, Kap. 2 (meine Hervorhebung). 
dass Diego als das pure Gegenteil von Zorro erscheint, besteht Letzterer doch nur in Aktion. Diese Kontrastierung wird über die gesamte Handlung durchgespielt: Lolita und ihre Eltern, Diegos Vater, Gonzales, Fray Felipe sowie das gesamte gesellschaftliche Umfeld thematisieren Diegos vermeintliche Unzulänglichkeiten immer wieder, während sie Zorro als positiven Gegenentwurf zu ihm postulieren. Die Zorro-Geschichte durchzieht damit eine Diskussion um ein bestimmtes Männlichkeitsideal, das auf dem Stereotyp der «feurigen〉 Spanier/Kalifornier beruht, nach welchem diese etwa äusserst aufbrausend reagieren, wenn sie sich in ihrem Stolz oder ihrer Ehre verletzt fühlen. Diego verkörpert bzw. inszeniert sich in seiner zivilen Identität als einen alternativen Entwurf von Männlichkeit, der jedoch in seinem Umfeld als nicht erstrebenswert angesehen wird - jedenfalls nicht für einen Mann seines adeligen Standes. Es ist zu betonen, dass dieses Männlichkeitsideal kein allgemeingültiges ist, sondern dezidiert mit dem Stand des Edelmanns, des caballeros (wörtlich: Ritter), verknüpft wird. ${ }^{67}$

Dies wird besonders im Kontrast zu Captain Ramón deutlich, der auf der Jagd nach Zorro in das Haus der Pulidos kommt und ebenfalls um Lolita wirbt. Ramón hält sich selbst für einen hervorragenden Heiratskandidaten für Lolita. Diego gegenüber bezeichnet er sich als caballero, worauf jener aber naserümpfend bemerkt, dass dies bei einem Soldaten selten sei. Tatsächlich beweist Ramón etwas später, dass ihm der Respekt vor Frauen und dem Adel fehlt, als er Lolita in Diegos Haus, wo sie mit ihren Eltern zu Besuch ist, aufsucht. Er bedrängt sie so lange, bis er eine Ohrfeige erhält; doch statt die Absage hinzunehmen, will er einen Kuss erzwingen, was der plötzliche Auftritt Zorros verhindert, der ihn verjagt und den Kuss geschenkt bekommt. ${ }^{68}$

Zur Adelspflicht gehört, dass Diego auf väterlichen Befehl heiraten muss, weil er bald 25 Jahre alt wird; Lolita ist nicht etwa aufgrund bestehender Gefühle die Auserwählte, sondern weil sie nach den Vegas die beste Herkunft, «the best blood» ${ }^{69}$, aufweist (was offenbar wichtiger ist als der momentane sozi-

67 Es geht bei Zorro m. E. weniger um ein Männlichkeitsideal, dessen Gegensatz Weiblichkeit (oder sogar <das Weibische)) darstellt - obschon etwa der Film von I940 (The Mark of Zorro, Regie: Rouben Mamoulian) klar damit spielt, dass Diego etwa von glänzenden Stoffen schwärmt und so auf verbreitete Homosexuellen-Stereotype anspielt -, sondern um den Gegensatz des wahren caballeros zu allen andern.

68 Indem Ramón als negatives Beispiel vorgeführt wird, wird das Ideal des caballero in Bezug auf den Umgang mit Frauen ausbalanciert: Zwar soll der Mann als stürmischer Liebhaber die Frau erobern (bzw. sich als solcher inszenieren, denn die Werbetaktiken sind wie das Gitarrenständchen geradezu ritualisiert) - doch ist es ihr Vorrecht, sich zu zieren (McCulley I998, I44, Kap. 2I); er hat sie und ein allfälliges Nein zu respektieren.

69 Zur historischen Grundlage dieses Bildes vgl. Curtis I 998b, xiv: «A distinct aristocracy existed in Spanish California, where social class was based on rank, bloodlines and parentage.» 
ale Status, da die Pulidos politisch in Ungnade gefallen und verarmt sind). Es wäre allerdings Diegos Aufgabe, diese Vernunftsbeziehung durch stürmische Werbung zu einer Liebesbeziehung zu machen. Nur scheint Diego das partout nicht einsehen zu wollen/können. So erklärt er ihren Eltern, als er um die Werbungserlaubnis bittet:

«It will be rather a bore, I expect. Love and marriage, and all that sort of thing, is rather a necessary nuisance in its way. The idea of a man of sense running about a woman, playing a guitar for her, making up to her like a loon when everyone knows his intention! And then the ceremony! Being a man of wealth and station, I suppose the wedding must be an elaborate one, and the natives will have to be feasted, and all that, simply because a man is taking a bride to be mistress of his household.»

«Most young men,» Don Carlos observed, «delight to win a woman and are proud if they have a great and fashionable wedding.»

«No doubt. But it is an awful nuisance. However, I will go through with it, señor. It is my father's wish, you see. [...]»

[...] Doña Catalina said[:] «I hope that you may win her heart, señor.»

"As to that,» said Don Diego, «I trust there will be no undue nonsense. Either the lady wants me and will have me, or she will not. Will I change her mind if I play a guitar beneath her window, or hold her hand when I may, or put my hand over my heart and sigh? I want her for wife, else I would not have ridden here to ask her father for her.» ${ }^{\circ}$

Diego geht, so macht er alle glauben, der Sinn für Romantik gänzlich ab. Die Krönung seiner <rationalen> Werbungstaktik ist das Ansinnen, Lolita für ein Ständchen unter dem Fenster seinen Diener zu schicken, da dieser besser singen könne als er; die gesellschaftlichen Bräuche wären somit pro forma erfüllt. Da Lolita davon wenig angetan ist, sucht er sie zur Siesta im Garten nochmals auf - aber nun als Zorro, der anscheinend augenblicklich in Liebe für sie entbrennt. Lolita ist geschmeichelt, auch wenn sie andeutet, dass sie bereits einen Bewerber hat, «[b]ut he does not seem to put much life into his wooing». Dieses Verhalten seines vermeintlichen Konkurrenten Diego kann Zorro ganz und gar nicht nachvollziehen: "What ails the man? Is he ill? [...] What an imbecile! 'Tis the wooing that gives the spice to romance.» ${ }^{71}$ Als Zorro sabotiert er sein eigenes Liebeswerben, dessen Rituale er in seiner Rolle als Diego gänzlich zu verweigern scheint. ${ }^{72}$ Als «man of

70 McCulley 1998, 35-37, Kap. 6. Diegos herzlose> Werbung heisst aber nicht, dass er seine Frau nicht lieben würde, wie er später erklärt (ebd., I 29, Kap. I9): «But certainly I shall love and cherish her. Does not a man promise that in the ceremony? Would a Vega break his word [...]?» Aber die Brautwerbungsanleitungen der Pulidos und sogar von Fray Felipe (ebd., I44, Kap. 2 I) machen Diego fassungslos: «What a perfectly silly idea!»

7I McCulley 1998, 46, Kap. 7.

72 Illustriert wird dies etwa durch den unterschiedlichen Umgang mit der Geste des Handkusses. Während Zorro sich diesen einfach erlaubt, bittet Diego linkisch um Erlaubnis: «I suppose I should - er - kiss your hand?» Darauf kann Lolita verzichten: «You need not take the trouble 
sense» ${ }^{73}$ scheint dies für Diego ein sinnentleertes, ja lächerliches Erfüllen von Rollenerwartungen, ist doch die Verbindung aufgrund der Familienzugehörigkeit der beiden Partner nahezu vorbestimmt. Mehrfach wiederholt er sein Unverständnis für das Absolvieren des konventionalisierten, ja fast zu einem Ritual erstarrten Werbungsverhaltens, das freilich als Regungen von Spontaneität und Leidenschaft auszuführen bzw. darzustellen wäre. Zorro und Diego haben daher unterschiedliche Prämissen: In der Zorro-Identität ist, im Gegensatz zur Diego-Identität, der Ausgang des Werbungsspiels noch offen und dieses daher berechtigt. ${ }^{74}$

Anders als spätere maskierte Helden hat Diego Vega kein Problem damit, dass seine Liebste ihn in seiner Heldenidentität liebt und in seiner zivilen Identität zurückweist. Er sieht darin die Bestätigung, dass sie <ihn selbst>, sogar als vermeintlichen "outcast and outlaw»,75 und nicht sein Vermögen liebt. Allerdings treibt er das Spiel am Schluss doch sehr weit: Als Zorro von Gegnern umzingelt und mit Lolita den Tod erwartend, schlägt er ihr vor, sie könne immer noch zurück und Diego heiraten, was sie selbstverständlich ablehnt, womit sie sich in seinen Augen auch auf der persönlichen, nicht nur der sozialen Ebene als seiner würdige Ehefrau erweist. ${ }^{76}$

Als Diego verkörpert der Protagonist dabei eine andere Werte bevorzugende Männlichkeitsvorstellung: nämlich den Gescheiten, Vernünftigen, der rational denkt und nicht heissblütig durch die Gegend stürmt und sich zur Begleichung von Ehrenhändeln auf Duelle einlässt. Als Lolita sich doch sorgt, dass Diego auf dem Heimritt von Zorro überfallen werden könnte, begründet er mit einer unerwarteten Überlegung, warum er nichts zu fürchten hat:

«But, if this highwayman should stop you?»

«I need not fear, señorita. Have I not wealth? Could I not purchase my release?»

«You would pay ransom rather than fight him, señor?»

«I have lots of money, but only one life, señorita. Would I be a wise man to risk having my blood let out?»

«It would be the manly part, would it not?» she asked.

[...]. It might fatigue you.» Worauf Diego nur meint: «Ah - thank you. You are thoughtful, I see. I am fortunate if I get me a thoughtful wife» (ebd., 76, Kap. I I).

73 Freilich ist «sense» kein absoluter Wert - Lolita sieht das nämlich anders: «Why did he [Diego] not exhibit a certain measure of common sense? Why did he not show that he was a young man bursting with health, instead of acting like an aged don with one foot in the grave?» (ebd., I74, Kap. 26).

74 Allerdings kritisiert Diego nur die Form (die gesellschaftlichen Rituale), nicht den Inhalt (die zugrunde liegenden Werte), schliesslich wirbt er in beiden Rollen um dieselbe Braut.

75 Ebd., 265 , Kap. 39.

76 Ebd., 253, Kap. 37. 
«Any male can be manly at times, but it takes a clever man to be sagacious,» he said. Don Diego laughed lightly, as if it cost him an effort, and bent forward to speak in lower tones. ${ }^{77}$

Während Lolita hier erneut die Erwartungen an einen Mann seines Standes ausdrückt, formuliert Diego - zumindest für die Leser des 20./2 I. Jahrhunderts durchaus weitere Kritik an der in hohem Masse stilisierten Gesellschaft, in der er lebt und deren Männlichkeitsideal Klugheit und Besonnenheit eben nicht umfasst, ${ }^{78}$ dafür einen letztlich fragwürdigen Umgang mit dem Konzept der Ehre.

Lolita erkennt zwar an, dass Diego eine sehr gute Partie wäre - das Problem ist nicht, dass er kein Potenzial hätte, sondern dieses nicht ausschöpft: «That is what angers me! What a lover the man could be, if he would! [...] Why does he let himself be made the laughingstock of the country? He is handsome and rich and talented. He has health, and could lead all the other young men. Yet he has scarcely enough energy to dress himself, I doubt not.»79 Der perfekte Mann für sie wäre eine Mischung aus beiden: «If Don Diego Vega were only more like the highwayman! If some man appeared who combined Vega's wealth with the rogue's spirit and dash and courage!» ${ }^{80}$

Aufgrund seiner Herkunft wäre er sogar zum Anführer prädestiniert, und Lolitas Wunsch hegt auch Diegos Vater Alejandro, der dieselbe Erwartung, Diego möge einem caballero entsprechen, an ihn heranträgt:

«[...] I would rather have you, my son, in his [Zorro's] place, running the risk of death or imprisonment, than to have you a lifeless dreamer of dreams that amount to naught!»

«My father! I have been a dutiful son.»

«I would you had been a little wild-it would have been more natural,» Don Alejandro sighed. «I could overlook a few escapades more easily than I can lifelessness. Arouse yourself, young sir! Remember that you are a Vega. When I was your age, I was not a laughingstock. I was ready to fight at a wink, to make love to every pair of flashing eyes, to stand up to any caballero in sports rough or refined. Ha!» [...] «You must be more of a man.»

77 Ebd., 70, Kap. Iо.

78 Wie Gonzales' Frage zusammenfasst, mit der er Diego animieren will: «Why not cease thought and take to action? What a man you would make, caballero [...]. What you need is a few bitter enemies.» Diego gibt zu, dass er fast überzeugt ist, aber: «I never could endure the exertion» (ebd., I 20, Kap. 17).

79 Ebd., 43 f., Kap. 7.

80 Ebd., 73, Kap. I I. Im Lauf der Handlung kommt es schon auch zu einer Annäherung zwischen Lolita und Diego, insbesondere gewinnt er in ihren Augen, als er ihr von Zorro erzählt und ihr - als «true caballero» - nicht übel nimmt, dass sie ihn nicht heiraten kann (weil sie heimlich einen andern liebt), und trotzdem bereit ist, noch etwas länger den Werber zu spielen. Dies bedeutet für ihn die Bestätigung ihrer Liebe zu Zorro, als Diego sieht er den Vorteil, dass er nun matt sein darf, weil er dies mit Liebeskummer entschuldigen kann (ebd., I77, Kap. 26). 
«I shall attempt it immediately,» Don Diego said, straightening himself somewhat in his chair. "I had hoped to avoid it, but it appears that I cannot. I shall woo the Señorita Lolita as other men woo maidens. You meant what you said about your fortune? ${ }^{8 \mathrm{I}}$

Als Diego weigert sich der Held, den an ihn gestellten Rollenerwartungen zu entsprechen, da er Hitzköpfigkeit und Kampfgewalt als wenig erstrebenswert postuliert, sondern auch Denker und Schöngeist sein möchte. Erst als sein Vater droht, ihn zu enterben, scheint er sich ändern zu wollen. Sein «I shall attempt it immediately» ist dabei doppeldeutig, denn kurz darauf tritt er als Zorro auf der hacienda seines Vaters auf, als der er den Wunsch des Vaters ja längst erfüllt hat. Vor seinen hier versammelten peers gelingt es ihm, diese zum Widerstand aufzurufen und zu seinen Gefolgsleuten zu machen.

Indem Diego zum highwayman und schliesslich zum Anführer seiner Standeskollegen wird, erfüllt er die soziale Verpflichtung des Adels, dem Machtmissbrauch der korrupten Amtsträger Einhalt zu gebieten. Als Zorro kann er die Initiative ergreifen, die ihm sein sozialer Stand eigentlich nahelegt und doch zugleich verwehrt, da es nicht ratsam ist, sich zu exponieren, wie das Beispiel der Pulidos zeigt. Die Maskerade wird so eine List, das gesellschaftliche Korsett sowohl in der Politik ${ }^{82}$ wie in der Liebe zu umgehen und so die gestörte Ordnung wiederherzustellen. Die caballeros sind sich dabei der Missstände wohl bewusst und billigen Zorros Vorgehen - nachdem er ihnen versichert hat, dass auch er ein caballero ist, ist klar, dass sie ihn unterstützen werden. Die erste Unternehmung ist die gewaltsame Befreiung der Pulidos aus dem Kerker, die aufgrund einer Denunziation von Ramón allesamt als Beihelfer Zorros und damit Verräter in den Kerker geworfen wurden.

Indem Diego den antriebslosen Schöngeist mimt, kann er Gefahren von sich und seiner Familie abwenden. Als er so Ramón wegen dessen verwerflichen Verhaltens gegenüber Lolita zur Rede stellt (und nicht, wie sie erwartet, zum Duell fordert), überdenkt dieser seinen Plan, neben den Pulidos die Vegas als Helfer Zorros anzuschwärzen, da Diego einfach einen zu unwahrscheinlichen Kandidaten dafür abgibt («The man has not enough spirit to be a traitor! ${ }^{8_{3}}$ ).

Da die Doppelidentität erst am Schluss enthüllt wird, erhalten die Leser keinen Einblick in Diegos/Zorros Innenwelt. Identitätsunsicherheiten scheint Diego/

8I Ebd., I62, Kap. 24.

82 Gerigk (2007, 20I) sieht Diego dabei als Gegenentwurf von Stevensons Jekyll und Hyde (I 886) und erklärt: «Die Maske des Zorro eröffnet einen Raum körperlicher Gewalt, einen Raum für Selbstjustiz [...]: im Namen der Gerechtigkeit. Das Motiv des Doppelgängers erhält somit eine Variante, die eine politische Grundlage hat.»

83 McCulley i998, I33, Kap. I9. 
Zorro deswegen - wie Percy Blakeney - nicht zu kennen. Es wird entsprechend nie erzählt, dass er etwa mit der jeweiligen Rolle im Widerspruch stehende Gefühle hätte. Souverän jongliert Diego seine gegensätzlichen Rollen. Nur an wenigen Stellen wird angedeutet, dass Diego nicht ganz so phlegmatisch ist, wie er tut. Seine Fassade bröckelt am deutlichsten, als er die Auspeitschung des zu Unrecht verurteilten Fray Felipe ansehen muss. Er will schon eingreifen, als ihn ein Kollege davon abhält - und so verhindert, dass er sich rollenbezogen eine Blösse gibt. Nur schon damit hat er die Aufmerksamkeit auf sich gezogen, aber auf entsprechende Fragen eines Beobachters, ob von Diego etwa Gefahr ausgehe, beruhigt der Wirt, der sei «as dangerous as a lizard basking in the sun» ${ }^{84}$. Hier kommt Diego - wie Percy - die von Goffman benannte Kategorisierung, die die Zuschauer einer Darstellung stets vornehmen, zugute: Indem er als harmloser Schöngeist abgestempelt ist, werden die Patzer in seiner Rollendarstellung der bestehenden Vorstellung von ihm untergeordnet. Ein weiteres Element, das nicht zu dieser Kategorisierung passt, findet Lolita in seiner Bibliothek: Sie wundert sich, dass er mehrheitlich Bücher über Reiten, Fechten und Kriegshandwerk sowie mit Poesie zu Liebe, Romantik und Leidenschaft besitzt. ${ }^{85}$ Ähnlich wie in Percy Blakeneys Arbeitszimmer schimmert hier durch, dass er nicht auf das stereotype Bild, das er präsentiert, zu reduzieren ist.

Diego wie auch Percy machen ihre <angestammte> Identität zu einer genau kalkulierten Rolle. In rollentheoretischen Begriffen übernehmen sie dabei zwar eine Rolle aus dem bereitstehenden Rolleninventar der Gesellschaft, was eine Anpassung an die Gesellschaft bedeutet (role-taking). Indem sie sie aber auf ihre eigene Weise ausgestalten und modifizieren (role-making), betonen sie ihre Individualität. Bei Zorro wie auch dem Scarlet Pimpernel gilt das für beide dargestellten Identitäten: Mit ihrer Heldenidentität kreieren die beiden Protagonisten eine von der Gesellschaft nicht a priori zur Verfügung gestellte Rolle (abgesehen davon, dass wohl jeder Gesellschaftsentwurf Heldenrollen beinhaltet). In ihrer zivilen Identität sind sie aufgrund ihrer sozialen Position in den Augen ihrer Gesellschaft dazu prädestiniert, deren herausragendste Repräsentanten abzugeben bzw. als Musterbeispiele zu dienen, was sie in ihrer Heldenrolle auch - im Geheimen und in gewissem Sinne im Übermass, da sie die Heldenrolle sowohl der ihnen zugedachten Rolle wie auch den meisten restlichen Rollen des Rolleninventars 〈enthebt - erfüllen. Doch verfolgen sie mit ihrem speziellen role-making in der zivilen Rolle gerade das Ziel, diese Erwartung zu verneinen und so jeden 
Verdacht zu zerstreuen, dass sie die Helden sein könnten. Zur Aufrechterhaltung ihres spezifischen Rollenideals, das dem allgemeinen Heldenideal widerspricht, nehmen sie um der guten Sache willen als persönliche Nachteile etwa in Kauf, dass sie ihr Licht unter den Scheffel stellen müssen und über sie gespottet wird. Damit sind sie freilich auf andere Art herausragend> bzw. nonkonform. Sie manipulieren bewusst und geplant den Eindruck, den sie auf andere machen, und steuern so, in welche Kategorien und Stereotypen ihre Darstellung in den Augen ihres Umfelds bzw. der Öffentlichkeit eingeteilt wird. Dies funktioniert in beiden Fällen weitgehend bestens, wobei das Gerede und die öffentliche Meinung über den Protagonisten - in dessen beiden Identitäten - auffällig oft referiert werden, sodass man auch die öffentliche Wahrnehmung als ein wesentliches Thema in den beiden Romanen bezeichnen kann.

Nach der Befreiung der Pulidos zwingt Zorro Ramón, dem Gouverneur zu gestehen, dass er die Pulidos fälschlicherweise angeschwärzt hat. Es kommt zum Duell, in dem Zorro Ramón tötet, danach aber fliehen muss. Auf der Flucht holt ihn Lolita ein, und zusammen retten sie sich in eine leere Gaststube, während sie von den Soldaten umzingelt werden, die schon versuchen, die Tür einzubrechen (Abb. Io). Lolita will bis zum Schluss an seiner Seite bleiben, auch wenn sie seinen Namen und sein Gesicht immer noch nicht kennt. Nun aber treffen Zorros Gefolgsleute, die caballeros, ein und verlangen seine Begnadigung. Der politischgesellschaftliche Konflikt wird somit letztlich durch politischen Druck gelöst. ${ }^{86}$ Dies ist aber nur möglich, weil Zorro zum einen «nicht viel> verbrochen hat (er hat nur diejenigen ausgeraubt, die vorher geraubt hatten, hat ein paar Leute ausgepeitscht und «[h]e resented insults as any man has the right to do! ${ }^{87}$ ) und zum andern durch seine Standesprivilegien, die ihm die Fürsprache seiner Kollegen sichern. Denn der ausmanövrierte Gouverneur kann ihn selbst für Ramóns Tod nicht belangen, da er als caballero das Recht hatte, diesen im Duell zu töten. Erst jetzt wird aber die Demaskierung des Helden verlangt. Als Diego vor ihnen steht, den alle mit Fieber («Feiglingsfieber», wie alle denken) im Bett wähnen, zeigt die Reaktion die Sympathien, die er als Zorro erworben hat:

He chuckled, glanced down at the Señorita Lolita, and then put up a hand and tore off his mask.

86 Genau besehen ist die Notwendigkeit der ganzen Zorro-Aktion ziemlich fragwürdig, heisst es doch einmal, dass ein Wort der Vegas ebenso bedeutsam wie das Gesetz sei und sie über entsprechenden Einfluss verfügen (ebd., 3 I, Kap. 5). Doch insofern Zorro Gewalt der Diplomatie vorzieht, entspricht er freilich dem behaupteten Ideal des jungen, hitzköpfigen Adeligen.

87 Ebd., 260, Kap. 38. 
A chorus of gasps answered the motion, an explosive oath or two from the soldiers, cries of delight from the caballeros, and a screech of mingled pride and joy from one old hidalgo.

«Don Diego, my son - my son!»

And the man before them seemed to droop suddenly in the shoulders, and sighed, and spoke in a languid voice. "These be turbulent times! Can a man never meditate on music and the poets?» And Don Diego Vega, the Curse of Capistrano, was clasped for a moment in his father's arms. ${ }^{88}$

Dies ist in der Geschichte der maskierten Helden einer der seltenen Fälle, in welchen der in der Figur stets angelegte Fluchtpunkt der Auflösung des Geheimnisses und der Anagnorisis tatsächlich - und zwar als totaler, öffentlicher Triumph - erreicht wird.

Erst jetzt erfährt man in Diegos kurzer Nacherzählung, von wie langer Hand er seine Doppelidentität geplant hat:

«It began ten years ago, when I was but a lad of fifteen,» he said. «I heard tales of persecution. I saw my friends, the frailes, annoyed and robbed. I saw soldiers beat an old native who was my friend. And then I determined to play this game. It would be a difficult game to play, I knew. So I pretended to have small interest in life, so that men never would connect my name with that of the highwayman I expected to become. In secret, I practiced horsemanship and learned how to handle a blade $\rightarrow$ [...] "One half of me was the languid Don Diego you all knew, and the other half was the Curse of Capistrano I hoped one day to be. And then the time came, and my work began.» $[\ldots]$

«It was difficult to fool you all, but it has been done,» Don Diego continued. «Only years of practice allowed me to accomplish it. And now Señor Zorro shall ride no more, for there will be no need, and moreover a married man should take some care of his life.» ${ }^{89}$

Notabene bezeichnet er sein Doppelidentitätsvorhaben als ein Spiel. Um dieses erfolgreich zu gestalten, brauchte er freilich nicht nur Disziplin, um sich athletisches und kämpferisches Können anzueignen, sondern ebenso eiserne Rollendisziplin, auch wenn diese nicht immer einfach einzuhalten war. Interessanterweise wird ihm die Täuschung mit keinem Wort zum Vorwurf gemacht - anders als späteren maskierten Helden.

In der Schlussszene versucht Diego auch zu erklären, was bei einem seiner Rollenwechsel vor sich ging. Maske und Umhang dienten ihm dabei als Transformatoren, der Kleider- bzw. Kostümwechsel bedeutete für ihn auch eine Identitätsverwandlung:

88 Ebd., 262, Kap. 38.

89 Ebd., 263-265, Kap. 39. 


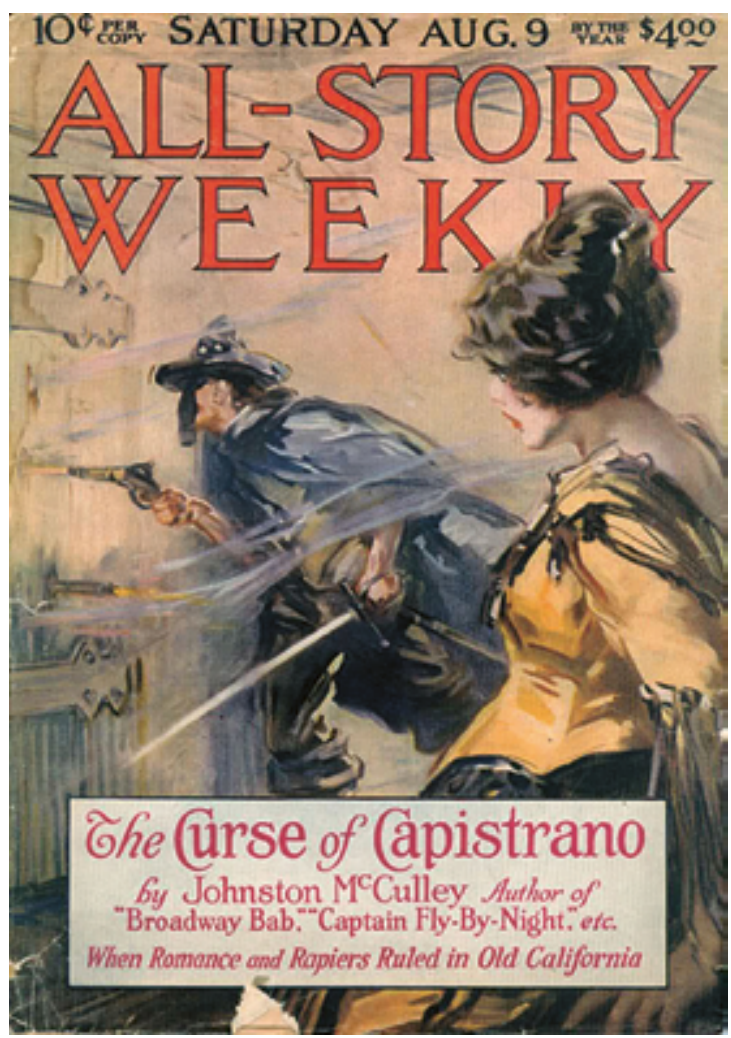

Abb. Io: Der letzte Teil der Fortsetzungsgeschichte erhielt eine Cover-Illustration, die den Spannungshöhepunkt zeigt, als Zorro und Lolita sich verbarrikadiert haben. Gut zu erkennen ist die noch fformlose Maske, obwohl Mantel und Hut bereits - entgegen der Beschreibung im Text - schwarz gehalten sind. All-Story Weekly, 9. August 1919, Titelbild, Künstler unbekannt.

«It is a peculiar thing to explain, señores. The moment I donned cloak and mask, the Don Diego part of me fell away. My body straightened, new blood seemed to course through my veins, my voice grew strong and firm, fire came to me! And the moment I removed cloak and mask I was the languid Don Diego again. Is it not a peculiar thing?»90

90 Ebd., 264, Kap. 39. Eine freudianisch inspirierte Interpretation von Diegos Demaskierung bietet Gavaler 20I 5, 21 2-2 I 5 . 
In der zweifachen Bezeichnung als «a peculiar thing» impliziert Diego, dass der Vorgang, den das Aufsetzen bzw. Abnehmen der Maske in ihrem Träger auslöst - die 〈Innenwirkung> der Maskerade -, nicht restlos erklärbar ist. In Diegos Beschreibung seiner zwei Hälften liegt der Akzent der Doppelidentität auf der Getrenntheit der beiden Ichs des Protagonisten. Schliesslich fragt Lolita, welchen Mann sie denn nun heiraten werde, und er fragt zurück, welchen sie denn liebe, worauf sie erklärt: «I had fancied that I loved Señor Zorro, but it comes to me now that I love the both of them [...]. But I would rather have you Señor Zorro than the old Don Diego I knew.» Daraufhin verspricht er die harmonische Verbindung seiner beiden Hälften: «We shall endeavour to establish a golden mean, he replied, laughing again. ¿I shall drop the old languid ways and change gradually into the man you would have me. People will say that marriage made a man of me. ${ }^{91}{ }^{\mathrm{I}}$ Indem Diego nicht etwa seine matte Hälfte, die eine nur vorgeschützte war, mit Zorro ersetzt, deutet er an, dass die Zorro-Identität nicht mit seinem <wahren> Ich gleichzusetzen ist, sondern ein solches (wenn es denn existiert) eher irgendwo in der Mitte liegt; auf einige Züge der Diego-Rolle scheint er trotz allem nicht verzichten zu wollen. Die Aufgabe der gegenständlichen Maske bedeutet entsprechend auch das Ende seiner metaphorischen Diego-Maske; angedeutet wird so die Integration der äusserlich getrennten Hälften in ein Ganzes, das schliesslich mit den Anforderungen der Gesellschaft bzw. deren Männlichkeitsideal («made a man of me») konform geht.

\section{The Whirlwind/Pedro Garza}

Johnston McCulley beschränkte sich nicht auf das Mantel-und-Degen-Genre, sondern erfand über die Jahre eine kleine Schar «moderner> maskierter Helden (zu diesen später mehr). Einmal allerdings griff er noch auf das alte Kalifornien zurück: Gut ein Jahrzehnt nach Zorro (und eine Weltwirtschaftskrise später) imitierte er offensichtlich seine erfolgreichste Schöpfung. The Whirlwind, oft auch spanisch El Torbellino genannt, war indes deutlich weniger Erfolg beschieden. Er brachte es von 1933 bis 1935 auf sieben Geschichten in Thrilling Adventure. ${ }^{92}$ Dennoch ist interessant, wie McCulley sein ¿Zorro-Schema abgewandelt hat.

Insbesondere ist der Kontrast zwischen den beiden Identitäten des Protagonisten anders gelagert. Die heldischen Identitäten von The Whirlwind und Zorro

9I McCulley 1998, 265, Kap. 39.

92 Warum McCulley eine Neuversion seiner berühmtesten Figur erfand, scheint nicht bekannt. Eine naheliegende Vermutung ist, dass von Zorros Erfolg auch bei einem anderen Verlag profitieren werden sollte, da El Torbellino in einem Pulp-Heft der Verlagsgruppe Standard und nicht einem Munsey-Heft erschien. Abgesehen von The Whirlwind hat McCulley noch diverse andere Romane über Old California verfasst (Curtis 1998a, I4). 
sind weitgehend austauschbar - The Whirlwind gibt entlang von El Camino Real den schwarzen Reiter (schwarzer Umhang, schwarze Kapuzenmaske, schwarzes Pferd), bricht gegenüber Gegnern und Gefahren in spöttisches Lachen aus und spendet zwar nicht alles, aber neun Zehntel der Beute seiner Raubzüge über den kirchlichen Opferstock den Armen; selbstverständlich raubt er nur andere Banditen aus, wenn auch im Gegensatz zu Zorro keine 〈Staatsbanditen〉. Stärker modifiziert hat McCulley dagegen die zivile Identität seiner neuen Figur, was den Whirlwind-Geschichten einen eigenen Reiz verleiht. Pedro Garza ist nämlich nicht Teil der besseren Gesellschaft, sondern arbeitet als Handlanger in einem Wirtshaus. Doch ist die Identitätsfrage beim Whirlwind etwas verwickelter, denn ganz auf adliges Blut wollte McCulley offenbar auch bei dieser Figur nicht verzichten: Pedro Garza ist in Wahrheit ein spanischer Adelsspross, ${ }^{93}$ der sich nach einem Streit mit seinem Vater nach Kalifornien abgesetzt hat und jetzt in dieser Deckidentität lebt. Seine Motive dafür sind unklar, doch führt er so in der zivilen Identität ein relativ <einfaches> Leben. Er gehört zur Minderheit maskierter Pulp-Helden, die kein Vermögen verfügbar haben. Das Wirtshaus - schon bei Zorro und dem Scarlet Pimpernel ein zentraler Handlungsort (vor allem für Exposition und Höhepunkt oder Finale) - wird so zum Angelpunkt der Geschichte, da es eine wahre Informationsdrehscheibe darstellt: Nicht nur wird es von Soldaten frequentiert, sondern meist kehren auch die Opfer des Whirlwinds (vor oder nach seinem Überfall) dort ein, wodurch Pedro das Wissen erlangt, wann und wo seine Whirlwind-Auftritte nötig sind. ${ }^{94}$

$\mathrm{Da}$ er als Arbeitnehmer nicht frei über seine Zeit verfügen kann, führt er ein Handlungselement ein, welches von späteren maskierten Helden wohlbekannt ist: das Jonglieren mit Ausreden, um die eigene Abwesenheit während der Aktivität als Held zu erklären (was Diego und die meisten anderen Pulp-Helden so nicht nötig hatten). Pedros Standardentschuldigung lautet, dass er dem unzähmbaren schwarzen Pferd des Wirts Salz auf die Weide bringen muss, auf dem er, wie zu erwarten, die Ausflüge als El Torbellino unternimmt.95 Aber wie Diego steht er als Pedro Garza im Wirtshaus, während Hauptmann Juan Cassara und seine Soldaten die Gegend nach ihm absuchen; dabei gilt Pedro ebenfalls als nicht

93 Allerdings nimmt der Whirlwind im Gegensatz zu Zorro einmal explizit davon Abstand, er sei ein caballero: «I am an honest thief, señor Sergeant. I do not pretend to be a caballero.» (McCulley 20I Ia, 97, The Whirlwind's Rage, Kap. IV).

94 Auffällig ist übrigens, dass es vielen Gegnern des Whirlwinds zunächst gelingt, ihn zu überlisten (indem sie nur klirrendes Zeug im Geldbeutel haben oder ihn anlügen), was er im Lauf der Geschichte dann korrigiert.

95 Mit diesem Pferd verfügt auch Pedro über ein Fortbewegungsmittel, das ihm allein zur Verfügung steht. 
zum Helden geboren. ${ }^{6}$ Cassara will den Whirlwind zwar dingfest machen, wird aber bei gewissen Gelegenheiten zu dessen zeitweiligem Verbündeten, wenn es etwa darum geht, einen anderen Banditen zu überführen - Gonzales dagegen liefert Zorro in dessen Identität als Diego solche Informationen unwissentlich. Dadurch pendelt der Whirlwind zwischen Gesetzeshelfer und Gesetzlosem.

Wohl auch, weil es sich bei den einzelnen Whirlwind-Storys um abgeschlossene Episoden handelt, sind die Leser fast von Anfang in die Doppelidentität des Protagonisten eingeweiht. So werden die Wechsel von einer Identität in die andere oft kurz erwähnt, manchmal aber ausführlicher beschrieben. Im folgenden Beispiel wird aus The Whirlwind wieder Pedro:

Smiling, The Whirlwind went to the rear of the building, stopped an instant outside the kitchen door. Animation fled his face. The man seemed to change into a lifeless, ambitionless clod. Now he was but Pedro Garzo, a stranger who had wandered into the town and had been given work by Carlos Lazaga, the landlord. It was a hard role for him to portray. Only by playing The Whirlwind at times could he bring adventure into his life. And this double life called for great care. None here to come to his aid if he were captured. The disguise, the wild rides, the clashes with travelers on the road - these things kept his real spirit alive and offset the menial labor he performed. ${ }^{77}$

Die Stelle illustriert, wie der Protagonist in seine undankbare Rolle als Pedro Garza schlüpft (bzw. mit der Änderung seiner Körperhaltung die metaphorische Maske überzieht) und wie diese Handlanger-Rolle für ihn, der ja eigentlich so anders und nicht für die Ausführung von «menial tasks» geschaffen wäre, eine Herausforderung bedeutet. The Whirlwind stellt dagegen sozusagen eine actionreiche Erholungspause dar. Die Maske des Handlangers erhält dabei zuweilen Risse, wenn Pedro sich etwa passiv-aggressiv weigert, für einen schurkischen Gast eine Dienstleistung zu erbringen..$^{8}$ Tatsächlich verrät er sich (als Pedro wie als Whirlwind) in Bezug auf seine Herkunft und seine Doppelidentität gegenüber diversen Kontrahenten, die dies indes nicht immer bemerken oder aus sonstigen Gründen schweigen. 99

96 McCulley 20I ra, I9, Alias The Whirlwind, Kap. IV: «I did not engage to fight outlaws», erklärt Pedro dem Wirt Lazaga, worauf dieser erwidert: «Ha! [...] You are not the sort to fight anybody, señor.»

97 Ebd., 4I, The Whirlwind's Revenge, Kap. III.

98 In The Whirlwind's Revenge etwa will ein Spanier im Rahmen einer Familienfehde den Whirlwind anheuern, um aus einem jungen, erst kürzlich nach Kalifornien migrierten spanischen Adligen einen Narren und Feigling zu machen - dabei handelt es sich «natürlich um den Whirlwind selbst. Als Pedro Garza weigert er sich mit einem einzigen Blick, dem herrischen Spanier, der überdies Teeschmuggel betreibt, die Stiefel zu putzen, selbst wenn ihn dieser erkennt, da er seinem Vater gleicht (ebd., 4 If., Kap. III).

Um bei the Whirlwind's Revenge zu bleiben: Der Spanier erkennt in Pedro nicht nur den 
Als letzter Punkt dieses kurzen Vergleichs sei noch die Frauenfigur angesprochen, die in Bezug auf die heldische Doppelidentität eine andere Rolle einnimmt als Lolita, deren Unwissenheit über die Einheit von Diego und Zorro den Kontrast und die Trennung zwischen diesen beiden Rollen stark akzentuiert. ${ }^{100}$ Die Wirtstochter Juanita ist hier gewiefter, denn sie durchschaut seine Täuschung, was doch eine veränderte Beziehungskonstitution ergibt. Allerdings konfrontiert sie ihn nie direkt mit ihrem Wissen, sondern macht in jeder Geschichte Andeutungen, dass sie um sein Geheimnis weiss und dieses wahren wird. Weil Pedro dieses Spiel fortführt und ihre Vermutungen nie explizit bestätigt, ihr gegenüber aber trotzdem doppeldeutige Kommentare macht, reden die beiden bezüglich Geheimidentität - und damit ihren romantischen Gefühlen füreinander - stets um den heissen Brei herum. ${ }^{\text {Ior }}$

Anders als Diego/Zorro ist Pedro/The Whirlwind kein absoluter Einzelkämpfer mehr, sondern hat ansatzweise ein Team: Juanita hat in ihm gegenüber den Schurken unter den Gästen, die nicht selten aufdringlich werden, einen heimlichen Beschützer, da er diese als The Whirlwind in die Schranken weist. Umgekehrt ist sie seine heimliche Helferin, die ihm gezielt Informationen liefert ${ }^{102}$ oder ihm durch die Blume mitteilt, dass es jetzt Zeit wäre, in Aktion zu treten. Statt der stürmischen Romanze zwischen Lolita und Zorro drängt sich bei Pedro Garza/ The Whirlwind und Juanita eher der Eindruck einer «stillen> Liebe auf, die keiner grossen Gesten oder Worte bedarf, was einen Gegenentwurf zum stark konventionalisierten Werberitual bei Zorro darstellt. Andererseits passt dies, auch als Teil der insgesamt statischen Verhältnisse der Figuren bei The Whirlwind, vielleicht besser zur Form der Geschichten als austauschbare Episoden - es gibt (und braucht) keine Liebeswerbung, die die Handlung auf ein Ziel zutreiben würde, wie es im Fortsetzungsroman um Zorro der Fall war. ${ }^{103}$

gesuchten Adelsspross, sondern später im Whirlwind auch Pedro. Mit einer Drohung kann El Torbellino ihn aber vom Ausplaudern abhalten: «Do not speak what is in your mind, else this pistol shall speak also [...]» (ebd., 54, Kap. 4).

ı०० Auf die Spitze getrieben wird dies übrigens, als Lolita Zorro verspricht, ihn ohne Maske jederzeit zu erkennen, egal, wie er darunter aussehe - womit sie sich ja völlig falsch einschätzt (McCulley i 998, 96, Kap. I3).

Iо I So entspinnt sich zum Beispiel in The Whirlwind's Ready Blade (McCulley 20 I Ia, I Iof., Kap. II) folgender Dialog zwischen den beiden: [Juanita:] «But looks are often deceiving [...]. You, for instance, appear to be a servant!» - «And am I not?» - «A very good one - which does not prevent your being other things also.»

I02 So weist sie Pedro einmal darauf hin, dass der Whirlwind einen Schnitt auf seinem Lederstiefel hatte, der ihn identifizierbar macht - tatsächlich hatte er vergessen, die Stiefel zu wechseln (ebd., 22; Alias The Whirlwind, Kap. IV).

I03 Die statischen Verhältnisse gelten jedenfalls für die erschienenen sieben Geschichten, ob es in weiteren Entwicklungen gegeben hätte, muss dahingestellt bleiben. 


\section{Gentleman-Gauner in Grau, Rot und Violett}

\section{Jimmie Dale/The Gray Seal}

Noch bevor McCulley Zorro zum ersten Mal seinen Degen ziehen liess, hatte mit Jimmie Dale ein maskierter Held Bekanntheit gewonnen, dessen Abenteuer in der damaligen Gegenwart und in der Grossstadt New York spielen. Diese Verlagerung des Aktionsfeldes war insofern wegweisend, als die meisten maskierten Pulp- und Superhelden seither diesen Schauplatz und die jeweilige Gegenwart durchstreifen.

The Adventures of Jimmie Dale von Frank Packard (1877-1942) wurden erstmals im People's Magazine I9I4 als Fortsetzungsgeschichte publiziert; I917 folgten die Buchausgabe und eine Verfilmung (Jimmie Dale, Alias the Grey Seal, Regie: Harry McRae Webster); bis 1935 schrieb Packard noch drei jeweils unmittelbar anschliessende Fortsetzungen. ${ }^{104}$

Jimmie Dale ist ein gut situierter Harvard-Absolvent, der die ererbte Safe-Fabrik verkauft hat und nun das Leben in der besseren Gesellschaft geniesst - er kommt also wie Percy Blakeney und Diego Vega aus wohlhabendem Haus. Insbesondere ist er Mitglied im höchst exklusiven St. James Club, der nur über jeden Zweifel erhabene Gentlemen aufnimmt. "Could there be any doubt that Jimmie Dale was innately a gentleman?» ${ }^{\text {Ios }}$, fragt die Erzählstimme zu Beginn des Textes gleich zweimal, was den Verdacht der Leser weckt, bevor sie eingeweiht werden, dass Jimmie Dale eine abenteuerliche Zweitidentität hat. Er ist nämlich der Meister-Safeknacker ${ }^{106}$ The Gray Seal, der alle seine Tatorte mit rautenförmigen grauen Klebesiegeln markiert, sonst aber für die Polizei der grosse Unbekannte ist. The Gray Seal trägt dabei kein besonderes Kostüm, seine Standardausrüstung umfasst nur eine schwarze Seiden-Dominomaske, einen utility belt mit Einbruchswerkzeug, die Klebesiegel und einen automatischen Revolver.

Auch The Gray Seal ist zu Beginn der Geschichte bereits eine berühmtberüchtigte Person der öffentlichen, also der Zeitungsberichterstattung. Allerdings war er bei Einsetzen der Handlung ein Jahr lang inaktiv. Dies bietet Jimmie Dales altem Schulfreund Herman Carruthers, inzwischen Journalist

I04 Zu Jimmie Dale vgl. v. a. Sampson I983, I32-162, auch Goulart 1988, I68. Anders als bei Zorro merkt man diesem Text durch die zahlreichen Rekapitulationen, die freilich zur charakteristischen Atemlosigkeit der Erzählung beitragen, an, dass er zuerst als Fortsetzungsroman publiziert wurde.

Ios Packard 2005, 4, Kap. I.

Io6 Zwei Jimmie Dale vergleichbare Meistereinbrecher waren The Lone Wolf von Louis Joseph Vance (mehrere Bände, I9I4-1947) sowie die britische Romanreihe um Blackshirt von Bruce Graeme (d. i. Graham Montague Jeffries) ab I923; vgl. dazu ebf. v. a. Sampson I983, I 20-I 29, bzw. 1987, I88-192. 
bei den Morning News-Argus, Gelegenheit, das spurlose Verschwinden dieses kühnen Meisterdiebs zu beklagen (und so den Lesern die Figur ausführlich schmackhaft zu machen):

«He was the most puzzling, bewildering, delightful crook in the annals of crime,» said Carruthers reminiscently, after a moment's silence. «Jimmie, he was the king-pin of them all. Clever isn't the word for him, or dare-devil isn't either. I used to think sometimes his motive was more than half for the pure deviltry of it, to laugh at the police and pull the noses of the rest of us that were after him. [...]» [...]

"You don't get it at all, Jimmie,» he said earnestly. «The Gray Seal wasn't an ordinary crook - he was a classic. He was an artist, and the art of the thing was in his blood. A man like that could no more stop than he could stop breathing - and live. He's dead; there's nothing to it but that [...]. I'd bet a year's salary on it.. ${ }^{107}$

Jimmie Dale lässt sich selbstredend nicht im Geringsten etwas anmerken, dass er selbst das Objekt von Carruthers Ruhmrede ist und quicklebendig neben ihm steht. Was Carruthers am meisten fasziniert, ist, dass The Gray Seal seine Taten eben nicht aus gemeiner Geldgier, sondern als l'art pour l'art, zur Demonstration seiner - wenn auch kriminellen - Kunstfertigkeit und (wie Percy und Diego) aus purer Abenteuerlust begeht. «It is not thieving, not really. It is, actually, a representation of high personal skill» ${ }^{\text {108 }}$, wie Robert Sampson leicht ironisch beschreibt.

Mit seiner zumindest vordergründig kriminellen Passion steht Jimmie Dale laut Sampson in der Tradition der von ihm sogenannten bent beroes. In der von Sampson über seine Bücher verstreut angedachten kleinen Typologie der PulpProtagonisten ist der bent hero «a more socially acceptable form of the criminal hero» ${ }^{109}$. Charakteristisch für den bent hero ist, dass er sich aus Liebe zu einer Frau einer moralischen Rehabilitation unterzieht und seine besondere Kunstfertigkeit in den sozialen Dienst stellt. Sampson sieht in solcherart geläuterten Figuren einen gewaltigen Vorteil gegenüber einem rogue, einem zwar charismatischen, aber eigennützigen Kriminellen: «At once, the bent hero became a popular favorite. In his adventures could be found all the excitement of the criminal hero with all the greed left out. Suddenly you could crack safes, swindle, lie, and tie people up, and still remain among the blessed.» ${ }^{10}$

I07 Packard 2005, 5f., Kap. I (meine Hervorhebungen).

I08 Sampson I983, I 19. Zu Jimmie Dale (und Richard Wentworth/Spider) als Künstler ebd., I 47.

I09 Ebd., I I I. Vgl. zu den typischen Figuren auch Gavaler 2015, I 45 f.

I I० Sampson 1983, I I. Exemplarisch verkörpert wird der bent hero etwa auch von Maurice Leblancs Gentleman-Gauner Arsène Lupin (ab 1905) und dem geläuterten Safeknacker Jimmy Valentine aus Paul Armstrongs Broadway-Stück Alias Jimmy Valentine von r910 (ebd.). An 
Jimmie Dale hat dabei in Tat und Wahrheit wenig wieder einzurenken: Wie mehrfach betont wird, hat er kaum je ein ‘wirkliches> Verbrechen begangen selbst wenn er so hat aussehen lassen. ${ }^{\text {II }}$ In der ersten kriminellen Aktion, die The Gray Seal nach seinem 〈Sabbatjahr〉 begeht, bricht er in einen Secondhandshop ein, ohne jedoch etwas mitgehen lassen zu können, da der Safe schon leer ist. Indem er den Tatort trotzdem mit einem seiner Klebesiegel markiert, deckt er einen armen Angestellten des Shops, der das Geld aus Verzweiflung gestohlen hat, um seiner kranken Frau Medikamente kaufen zu können. ${ }^{\text {I2 }}$

Ein einziges, schicksalhaftes Mal hat Jimmie Dale/The Gray Seal bei einem Einbruch etwas mitgehen lassen: Er wurde überrascht und hat aus Versehen eine Perlenkette nicht zurückgelegt. Dies ist der Moment, da eine geheimnisvolle Frau in sein Leben tritt: Sie hat ihn beobachtet, sein Geheimnis erraten und erpresst ihn nun, ihre Anweisungen auszuführen. Mittels Briefen erteilt sie ihm jeweils innert kürzester Zeit zu erledigende Aufträge, die immer ein schlimmeres Verbrechen vereiteln oder die Opfer eines Verbrechens entschädigen. In ihrer Anrede - «My Dear Philanthrophic Crook» - bringt sie Figuren wie Jimmie auf den Punkt: Jimmie Dale wird zum Auftragsdieb für gute Zwecke. Wie The Scarlet Pimpernel und The Mark of Zorro ist auch The Adventures of Jimmie Dale nicht nur eine Abenteuer-, sondern auch eine Liebesgeschichte. Während er als The Gray Seal in die Bredouille kommt, versucht Jimmie fieberhaft, die Identität der mysteriösen Frau zu entschleiern, was ihm trotz einiger Indizien - die ihn etwa dazu führen, sie in Gedanken als The Tocsin zu bezeichnen - nicht gelingt. Schliesslich stellt sie sich ihm zunächst in einer Verkleidung als alte Frau vor und verrät ihm dann ihre Identität. Interessanterweise kommt The Tocsin einer maskierten Heldin relativ nahe: Wie dem Scarlet Pimpernel fehlt ihr zwar die gegenständliche Maske, doch verfügt sie über eine Origin-Story und wird in Verkleidung zur Verbrechensbekämpferin. ${ }^{\text {I3 } 3}$ Durch ihr gut vernetztes Undercover-Leben in

anderer Stelle bezeichnet Sampson (ebd., I53) allerdings Jimmie Dale als «first full-length presentation of the bent hero».

I I J Jimmies Taten werden etwa wie folgt beschrieben (Packard 2005, I9, Kap. 2): «Affairs that had mystified and driven the police distracted with impotence there had been, many of them; and on the face of them - crimes. But no act ever committed had been in reality a crime - none without the highest of motives, the righting of some outrageous wrong, the protection of some poor stumbling fellow human.»

I 2 Als Jimmie bzw. The Gray Seal den Angestellten anschliessend konfrontiert, will dieser bereitwillig ins Gefängnis. Jimmie beruhigt ihn aber: Wenn er schweige, werde nie jemand erfahren, wer der tatsächliche Dieb war; und der Angestellte verspricht hoch und heilig, den gestohlenen Betrag nach und nach heimlich wieder in die Kasse seines Arbeitgebers zu stecken (Packard 2005, I3-I 5, Kap. I).

I 3 Marie LaSalle ist die vermögende Nichte eines Mannes, der heimlich ermordet wurde, dessen Platz jedoch der Mörder übernommen hat. Dessen nicht genug, ist der Onkelmörder Chef eines 
der Unterwelt erfährt sie von zahlreichen kriminellen Plänen und setzt Jimmie als Gegenmittel ein - sie plant, er führt aus. ${ }^{114}$ Es sind ihre Verstrickungen, die den zielführenden Handlungsstrang ausmachen, während Jimmies Gray-SealEskapaden klar episodisch angelegt sind. ${ }^{115}$

In der erwähnten Episode mit dem Secondhandshop folgt auf das erhebende Gefühl des guten Samariters jedoch ein Schock. Denn einen Tag später wird The Gray Seal in den Zeitungen als Mörder eines Polizeispitzels angeprangert. Dies wühlt Jimmie entsprechend auf, fühlt er sich doch in seinem Berufsethos empfindlich verletzt:

Murder! At times it had occurred to him that there was a possibility that some crook of the underworld would attempt to cover his tracks and take refuge from pursuit by foisting himself on the authorities as the Gray Seal. That was a possibility, a risk always to be run. But that MURDER should be laid to the Gray Seal's door! Anger, merciless and unrestrained, surged over Jimmie Dale. There was peril here, live and imminent. Suppose that some day he should be caught in some little affair, recognised and identified as the Gray Seal, there would be the charge of murder hanging over him - and the electric chair to face! But the peril was not the only thing. Even worse to Jimmie Dale's artistic and sensitive temperament was the vilification, the holding up to loathing, contumely, and abhorrence of the name, the stainless name, of the Gray Seal. It WAS stainless! He had guarded it jealously - as a man guards the woman's name he loves. ${ }^{116}$

Jimmie Dale sieht sich hier dem Problem der Unidentifizierbarkeit des Maskenträgers gegenüber - wenn niemand weiss, wer unter der Maske steckt, kann jeder andere behaupten, er sei es, und Imitatoren haben ein leichtes Spiel. Dabei scheint Jimmie der Ruf seiner Helden-Identität - von der einzig er und The Tocsin wissen - fast wichtiger zu sein als sein eigener; dass ihn die Rufschädigung fast mehr trifft als die reale Gefahr, die daraus erwächst, deutet auf seinen nicht geringen Künstler- bzw. Berufsstolz. Das Vorgehen des Imitators bildet dabei

Crime Clubs und will auch Marie beseitigen. Diesem Komplott durch Zufall auf die Schliche gekommen, kann sie aus dem Haus fliehen und etabliert sich unter dem Namen Silver Madge in Verbrecher- und Halbweltkreisen, um mit diesem Netzwerk das Haus ihres falschen Onkels unter Beobachtung halten zu können.

I 4 Vgl. Sampson 1983, I 5 8f. In der Tat war er nur deshalb ein Jahr lang nicht als Gray Seal aktiv, weil sie ihm in einem Brief nahegelegt hatte, dies zu tun, da der Boden langsam zu heiss werde (Packard 2005, I0, Kap. I).

I I Sampson (1983, I 56) beschreibt ihre zentrale Position im Plot wie folgt: «Marie La Salle is the heart and blood in the story of the Gray Seal. The series rests on the bedrock of her personal problems. Her mind manipulates the Gray Seal's activity. Her efforts transform the Seal into a hero of significance and purpose.»

I 6 Packard 2005, i 8f., Kap. II (Hervorhebungen im Original). 
den Gegensatz zu Jimmies Tun, markiert dieser seine Tatorte doch darum mit Klebesiegeln, damit niemand Unbeteiligtes für seine Taten belangt wird.

Dessen nicht genug: Carruthers und andere Zeitungen schreiben auch noch ein Kopfgeld von insgesamt 85000 Dollar aus, und Jimmie Dale wird seine ungemütliche Lage bewusst, denn: «[...] the five million men, women, and children of New York were automatically metamorphosed into embryonic sleuths.» ${ }^{17}$ Hier kommt die Situierung in der modernen Grossstadt zum Tragen. Etwas plakativ ausgedrückt, konnten Zorro und der Scarlet Pimpernel (in Bezug auf seine englische Heimat) letztlich auf die Billigung ihrer Taten nicht nur durch ihre eigene gehobene soziale Schicht, sondern durch das 〈Volk〉 zählen; mit den überwiegend klaren gesellschaftlichen 〈Einheiten〉 wirkt das Mantel-und-Degen-Setting im Vergleich zur Grossstadt geradezu familiär. Denn bei Jimmie Dale wird die im Grunde dichotomische Welt des maskierten Helden von Ordnungshütern und Ordnungsstörern um einen dritten Faktor erweitert. Anders als der Scarlet Pimpernel oder Zorro, die im Grunde nur eine Partei als Gegner haben (die pervertierte französische bzw. die korrumpierte eigene Staatsgewalt), steht Jimmie Dale zwischen nicht nur zwei, sondern drei Feuern, wie es in der folgenden Szene mit fast schon ausufernder Dramatik beschrieben wird:

«DEATH TO THE GRAY SEAL!» - through the underworld, in dens and dives that sheltered from the law the vultures that preyed upon society, prompted by self-fear [...], the whispered sentence grew daily more venomous, more insistent. «THE GRAY SEAL, DEAD OR ALIVE - BUT THE GRAY SEAL!» It was the «standing orders» of the police. Railed at by a populace who angrily demanded at its hands this criminal of criminals, mocked at and threatened by a virulent press, stung to madness by the knowledge of its own impotence, flaunted impudently to its face by this mysterious Gray Seal to whose door the law laid a hundred crimes, for whom the bars of a death cell in Sing Sing was the certain goal could he but be caught, the police, to a man, was like an uncaged beast that, flicked to the raw by some unseen assailant and murderous in its fury, was crouched to strike. Grim paradox - a common bond that linked the hands of the law with those that outraged it! ${ }^{118}$

Nachdem bekannt geworden ist, dass The Gray Seal die Verhaftung einiger Krimineller verursacht hat, hat es die Unterwelt auf diese anonyme Gestalt abgesehen, die zugleich nach wie vor selbst als Verbrecher gilt und entsprechend von der Polizei gejagt wird. Hinzu tritt eine gesichtslose Masse von Millionen von Stadtbewohnern (auf den Aspekt der Grossstadt komme ich im Shadow-Kapitel zurück), die letztlich unberechenbar bleibt, angeführt von den Zeitungen, die zugleich als Stimme der Öffentlichkeit und Manipulatoren der Meinungsbil-

I 7 Ebd., i6, Kap. II.

I 8 Ebd., I42, Kap. X (Hervorhebungen im Original). 
dung agieren. Dabei handelt es sich gewissermassen um eine entkörperlichte und damit auch entpersönlichte, anonymisierte Form der Verfolgung - im Gegensatz etwa zu den Soldaten, die Zorro leibhaftig nachreiten.

Die Zeitungen haben jedoch eine doppelte Funktion inne. Während sie zur Jagd auf The Gray Seal blasen, nutzt Jimmie Dale im Gegenzug seine persönliche Verbindung zu einer Zeitung, um selbst den wahren Mörder zu finden. ${ }^{19}$ Jimmie Dale tritt hier - komplementär zu seinen illegalen Aktivitäten - auch als erfolgreicher Detektiv in Erscheinung. Ebenso weiss er als Gray Seal die Medien zu nutzen, wenn er etwa Carruthers anruft, um ihm einen scoop zu melden, und dabei Indizien nennt, die für den Tathergang bedeutsam sind, damit diese von den Beteiligten nicht vertuscht werden können.

$\mathrm{Da}$ die Leser bei Jimmie Dale fast von Anfang an in seine Geheimnisse eingeweiht sind, wird auch erzählt, wie sich der Wechsel zwischen den Identitäten vollzieht. Dabei wird betont, wie The Gray Seal gewissermassen das Steuer von Jimmie Dale übernimmt: «[...] Jimmie Dale's debonair nonchalance dropped from him as a mask instantly - and it was another Jimmie Dale - the professional Jimmie Dale. Quick now in every action, [...].» ${ }^{120}$ Sobald er die Rolle als The Gray Seal einnimmt, der ja stets eine klare Aufgabe zu erledigen hat, besteht er sozusagen nur noch in deren Ausübung. Die Gefühle und Unsicherheiten werden beiseitegeschoben, so heisst es beispielsweise: «There were no tremours of the muscles now. It was Jimmie Dale, the Gray Seal, every faculty alert, tense, keyed up to its highest efficiency; the brain cool, keen, and active - fighting for his life. ${ }^{121}$ Die Maskerade ist nicht nur eine äusserliche Verhüllung, sondern bedeutet zudem innerlich einen mentalen Wandel.

Anders ist es, wenn Jimmie Dale in seinem ‘Territorium>, etwa dem St. James Club, unerwartet mit etwas konfrontiert wird, was seiner Grey-Seal-Identität zugehörig ist. Als er im Club einmal einen Brief seiner Auftraggeberin erhält, darf er sich trotz des inneren Tumults, den dieser Brief auslöst, nichts anmerken lassen:

One glance was enough - it was HERS, that letter. The Tocsin again! His brain seemed suddenly to be afire, and he could feel his pulse quicken, the blood begin to pound in fierce throbs at his heart. Life and death lay in that white, innocent-looking, unaddressed envelope, danger, peril - it was always life and death, for those were the stakes for which the Tocsin played. But, master of many things, Jimmie Dale was most of all master of himself. Not a muscle of his face moved. He reached nonchalantly for the letter.» ${ }^{122}$

I 9 Als Carruthers' Begleiter erhält er Zutritt zum Tatort und findet dort das ihn entlastende und den Mörder überführende Indiz, den Fingerabdruck auf dem gefälschten Klebesiegel (ebd., 20-23, Kap. II).

I 20 Ebd., 39, Kap. III.

I 2 I Ebd., 250 , Kap. XV.

I 22 Ebd., I33, Kap. VIII. 
Hier wird deutlich, dass eine Voraussetzung für ein erfolgreiches geheimes Doppelleben die absolute Selbstbeherrschung («master of himself») ist bzw. die Fähigkeit, die Darstellung der Rolle auch bei Störfaktoren souverän zu kontrollieren.

Was die Erzählweise wohl am auffälligsten von anderen Pulp-Geschichten unterscheidet, ist die ausführliche Beschreibung von Jimmie Dales inneren Konflikten und den in ihm lodernden Angstgefühlen, wenn sein Geheimnis in Gefahr scheint. ${ }^{\mathrm{I} 2}$ Oft wird geradezu fiebrig geschildert, wie ihn die Nervosität ergreift, etwa nachdem ihm The Wowzer, der geschickteste Taschendieb der Stadt, an einem Konzert sein Notizbuch mit einem Brief, der Jimmie als Gray Seal entlarvt, geklaut hat, wie der folgende Auszug aus Jimmies anschliessendem «Gedankenkarussell> illustriert:

It was - the END! An hour, two hours, and New York would be metamorphosed into a seething caldron of humanity bubbling with the news. It seemed that he could hear the screams of the newsboys now shouting their extras; it seemed that he could see the people, roused to frenzy, swarming in excited crowds, snatching at the papers; he seemed to hear the mob's shouts swell, in exultation - it seemed as though all around him had gone mad. The mystery of the Gray Seal was solved! It was Jimmie Dale, Jimmie Dale, Jimmie, [sic] Dale, the millionaire, the lion of society - and there was ignominy for an honoured name, and shame and disaster and convict stripes and sullen penitentiary walls - or death! A felon's death - the chair!» ${ }^{124}$

Die Introspektion zeigt, dass Jimmie nicht der stets auf alle Eventualitäten vorbereitete kühle Planer ist - im Gegensatz zu einigen späteren maskierten Helden (zum Beispiel The Shadow). Zum Glück hat Jimmie Dale ein Ass im Ärmel: Bei Bedarf hat er eine dritte Identität vorrätig, was ihm hier ermöglicht, den belastenden Brief zurückzuholen. Mittels Schminke verwandelt er sich in die drogensüchtige Nachtgestalt Larry the Bat, die in einem schlecht reputierten Stadtteil eine Wohnung mit drei Ausgängen, das sogenannte Sanctuary, und beste Unterweltkontakte besitzt. Larry the Bat ist dabei für Jimmies Doppelleben eigentlich bedeutender und kontrastiert den Harvard-Absolventen Jimmie Dale noch stärker als The Gray Seal, da er als die noch unwahrscheinlichere alternative Rolle Jimmie Dales gesehen wird. ${ }^{125}$

I23 Vgl. Sampson 1983, I46f.

I24 Packard 2005, 82, Kap. IV.

I $25 \mathrm{Um}$ zu betonen, wie <unglaublich diese Identitätsdreiheit ist, ruft Jimmie innerlich etwa aus: «Larry the Bat! The Gray Seal! Jimmie Dale the millionaire! What if it were ever known that that strange three were one! What if - Jimmie Dale smiled whimsically» (ebd., 80, Kap VI). 
Besonders anhand von Larry the Bat werden die Möglichkeiten der MehrfachIdentität explizit thematisiert. Beispielsweise entwirft Jimmie ein ausführliches imaginäres Szenario, in welch verworrene Situation er geraten könnte:

[...] his mind for the moment electing to face the situation in a humour as whimsical as his smile. Supposing that, as Larry the Bat, he were caught and arrested during the next hour, in Jimmie Dale's residence on Riverside Drive! With his arrest as Larry the Bat, Jimmie's [sic] Dale would automatically disappear. Would follow then the suspicion that Jimmie Dale, the millionaire, had met with foul play, and as time went on, and Jimmie Dale, being then in prison as Larry the Bat, did not reappear, the assurance of it; then the certainty that suspicion would focus on Larry the Bat as being connected with the millionaire's death [...] - and he would be accused of his own murder! It was quite humourous, of course, quite grotesquely bizarre - but it was equally an exceedingly grim possibility! There were drawbacks to a dual personality! «In a word,» confided Jimmie Dale softly to himself, and a serious light crept into the dark, steady eyes, «I'm in a bit of a nasty mess! ${ }^{126}$

Die Erkenntnis, dass es «drawbacks to a dual personality» gibt, denen potenziell Komik wie Tragik gleichermassen innewohnen, können Jimmie Dale (der hier übrigens das typische Lächeln des Abenteuers zeigt) zahlreiche spätere maskierte Helden nachseufzen.

Die Alternatividentität als Larry the Bat ist viel stärker ausgestaltet als The Grey Seal: Letzterer erscheint mehr als stets nur kurzfristige <Arbeitsidentität>, während Larry the Bat eine viel zeitintensivere Undercover-Rolle darstellt. Denn als einzelgängerischer Meisterdieb in der Ausführung einer Tat hat The Gray Seal ja keine sozialen Kontakte, während Larry the Bat regelmässig in der Unterwelt verkehren muss. Dennoch ist auffällig, dass Larry the Bat deutlich häufiger als role bezeichnet wird, während The Gray Seal öfter mit identity verbunden wird. Diese Rolle aufrechtzuerhalten, erfordert einiges, ist die Mühe aber wert: «[...] the role, too, that often enough had been a bulwark of safety to him when hard pressed by the police; the role out of which he had so carefully, so painstakingly created a now recognised and well-known character of the underworld - the role of Larry the Bat.» ${ }^{127}$

Als The Gray Seal allerdings von allen Seiten gejagt wird, wird dieser «bulwark of safety» zum Rollenzwang. So reflektiert Jimmie, wie sein Spielraum aufgrund der erzwungenen Beschränkung auf eine seiner Rollen eingeengt wird: ${ }^{128}$

I 26 Ebd., 69, Kap. V.

I 27 Ebd., i I4f., Kap. VIII.

I 28 Es wird dabei nicht erklärt, warum er als Larry nicht einfach abwesend und als Jimmie Dale weitab von der Gefahr sein kann. Anders als Larry hat er als Jimmie nämlich zwei ihm näher stehende Personen, den greisen Butler Jason und den Chauffeur Benson, denen er seine Ab- 
Was it indeed the beginning of the end? Some day, he had told himself often enough, the end must come. Was it coming now, surely, with a sort of grim implacability when it was too late to escape! Slowly, but inexorably, even his personal freedom of action was narrowing, being limited, and, ironically enough, through the very conditions he had himself created as an avenue of escape.

[...] In the old days, the role of Larry the Bat had been assumed at intervals, at his own discretion, when, in a corner, he had no other way of escape; now it was forced upon him almost daily. The character of Larry the Bat could no longer be discarded at will. [...] Almost daily now he must show himself as Larry the Bat in some gathering of the underworld - a prolonged absence from his haunts was not merely to invite certain suspicion, where all were suspicious of each other, it was to invite certain disaster. He had now either to carry the role like a little old man of the sea upon his back, or renounce it forever. And the latter course he dared not even consider - [...], and the role of Larry the Bat was still a refuge, the trump card in the lone hand he played. ${ }^{129}$

Auch Jimmie beurteilt sein Pendeln zwischen Identitäten letztlich als ein (manchmal verzweifeltes) Spiel. Hier wird freilich ein stilisiertes Bild der New Yorker Unterwelt gezeichnet, ${ }^{13}{ }^{\circ}$ indem alle, die sich darin bewegen, durch die <Affäre Gray Seal> von Misstrauen ergriffen sind, sodass die Erwartungshaltung an Larry the Bat intensiver wird, worauf sich Jimmie Dale mit seiner Darstellung einstellen und anpassen muss.

Dass Jimmie Dales Geheimnis auffliegen könnte, ist die ganze Handlung hindurch (mit der ominösen Phrase «the end») konstant eine Bedrohung - manchmal im Vordergrund, manchmal mehr im Hintergrund. Am Schluss, als The Gray Seal und Marie LaSalle endlich den Anführer des Crime Clubs unschädlich machen können (er wird verwundet und nimmt Gift, um der Verhaftung $\mathrm{zu}$ entgehen), passiert es aber: Der Kriminelle Magpie findet heraus, dass Larry the Bat The Gray Seal ist, sodass die Erzählung zumindest teilweise am narrativen Fluchtpunkt eines maskierten Helden, der Entdeckung, ankommt. Um The Gray Seal zu töten, will eine Gangstertruppe das Sanctuary stürmen, welches durch den Schusswechsel in Brand gerät. Jimmie und Marie können sich zwar gerade noch über die Dächer in Sicherheit bringen, aber das Sanctuary und

wesenheit ebenfalls erklären müsste, da sie nicht eingeweiht sind, die aber dennoch auch die seltsamste Anweisung fraglos ausführen.

I 29 Packard 2005, I42, Kap. X.

I30 Sampson (1983, I39-145) weist darauf hin, dass Packards Bild der Unterwelt New Yorks der Zeit etwas hinterherhinkte und eher aus den Umständen der Jahrhundertwende schöpfte: «His [Packard's] backdrops were immigrant-jammed slums, drinking dens, fetid alleys, the Old Bowery, the lower East Side, Chinatown. [...] This is the world of [Charles Dickens'] Fagin, updated to I9I4.» Um I910 war die Polizei neu organisiert worden und griff härter durch, worauf sich die grossen Gangs in kleinere Gruppierungen zersplitterten; die Prohibition (1919-1933) führte darauf wieder zu formellen Organisationen (ebd.). 
scheinbar Larry the Bat als dessen Bewohner sind ein Raub der Flammen, und dies bedeutet auch: «The Gray Seal was dead!» ${ }^{131}$, wie der letzte Satz lautet. Dies gilt freilich nur bis zur Fortsetzung. Denn obwohl Larry the Bat wie erwähnt die stärker ausgestaltete Rolle war, ist es The Gray Seal, dessen Einsatz erneut nötig wird. Statt als Larry tritt Jimmie in einer neuen Identität als «junkie artist» Smarlinghue auf (bevor dann auch Larry reaktiviert wird). ${ }^{132}$ Obschon Jimmie Dale einer der ganz seltenen maskierten Helden ist, deren Geschichten nach ihrer zivilen und nicht der heldischen Identität benannt sind, erweist sich The Gray Seal, in der sich des Safeknackers besondere Kunstfertigkeit ausdrückt, so dennoch als die konstantere, die unverzichtbarere Alternatividentität.

\section{The Man in Purple/Richard Staegal und The Crimson Clown/Delton Prouse}

Unter den zahlreichen "criminal heroes», die die Pulps der I920er-Jahre bevölkerten, ${ }^{\mathrm{r} 3}$ fallen als maskierte Helden zwei weitere Schöpfungen Johnston McCulleys auf: der Man in Purple und der Crimson Clown, die sehr ähnlich angelegt sind und klar Jimmie Dales Setting verpflichtet sind. Vom Man in Purple ${ }^{134}$ erschienen I92 I nur gerade drei Geschichten in Detective Story Magazine. Im selben Magazin trat der Crimson Clown zwischen 1926 und I93 I 16-mal auf; eine letzte Story erschien 1944 in Popular Detective. Je vier Storys waren schon $1927^{135}$ und 1928 gesammelt als Buch publiziert worden.

Wie es ab den I 920er-Jahren in Pulps üblicher ist, stellen die Abenteuer des Man in Purple und des Crimson Clown jeweils einzelne Episoden dar. In jeder geht es um einen «Fall〉, in welchem der Protagonist allen ein Schnippchen schlägt und mit der Beute entkommt. Die Geschichten um diese beiden Gentleman-Gauner steuern somit nicht von Beginn an auf ein narratives Ziel zu. Vielmehr sind sie

I3 I Packard 2005, 258, Kap. XVI.

I 32 In den Fortsetzungen sieht sich auch Marie gezwungen, eine neue Tarnidentität namens Mother Margot, «ancient push-cart hag», anzunehmen (Sampson I983, I $34 \mathrm{f}$.).

I33 Vgl. zu diesen v. a. Sampson I987, I23-175. - McCulley hatte vor Zorro bereits zwei andere maskierte Figuren erschaffen, The Black Star (ab I9I6) und The Spider (1918/1919), die in verschiedenen Kurzgeschichten auftreten (zu diesen ebd., 38-52). Diese sind aber klar Verbrecherhirne, mit denen jeweils ein junger männlicher Protagonist, Roger Verbeck bzw. John Warwick, in Kontakt kommt (McCulley 20 r ib, 2007). Roger Verbeck macht es sich zur Aufgabe, The Black Star, Kopf eines auf Anonymität beruhenden Verbrechernetzes, zu schnappen. John Warwick dagegen wird «a criminal of a sort, a clever member of the band controlled and commanded by the Spider, a supercriminal [...]». Die Taten der Spider-Bande aber «had not been so very nefarious (...). [They] committed thefts, but generally on the side of right» (ebd., Kap. I). Zu McCulleys maskierten Helden vgl. auch Goulart 1988, I69-17I.

I 34 Zum Man in Purple vgl. Sampson 1987, I95-199.

I35 Meine Ausführungen beziehen sich auf diese Buchausgabe (McCulley 1929, 2. Auflage). Zum Crimson Clown vgl. Sampson 1987, 199-208. 
grundsätzlich so angelegt, dass Setting und Figurenkonstellation, einmal etabliert, in Variationen immer wieder durchgespielt werden können. ${ }^{136}$

Auch der Man in Purple und der Crimson Clown haben sich zu Beginn ihrer jeweiligen Geschichte ihren Ruf bereits erarbeitet. Der Man in Purple ist erst seit einem Monat aktiv und war bei den Zeitungen und der Polizei eine «instant sensation», nicht zuletzt, weil der Maskierte zu Spekulationen über seine Person einlädt. ${ }^{137}$ Die erste Story beginnt damit, wie der Schmalspurganove Broph vom Man in Purple als Gehilfe rekrutiert und in dessen Doppelidentität eingeweiht wird. Die «purple coveralls, purple gloves, a purple mask, and a soft hat drawn down on his forehead ${ }^{13^{8}}$ trägt Richard Staegal, ein vermögender junger Mann der Stadtprominenz, von dem man solche Eskapaden niemals erwarten würde, umso mehr, da er verlobt ist. Allerdings ist seine Verlobte Betty Hayler seine Komplizin, und zusammen wollen sie vor der Hochzeit noch etwas erleben, wie Richard Broph Motivation und Zielsetzung des Unterfangens erklärt:

«[...] we are going to have a little excitement. [...] We both want thrills. So we decided to turn crooks for a certain length of time. But we are good crooks, Broph. [...] We steal only from men who have stolen themselves. We rob swindling financiers, profiteering merchants, and folks like that. We steal from the rich and give to the poor [...]. We are not in the game for the profit. [...] We give the proceeds to charity.»139

Broph komplettiert dieses Team nur zu gern und ist in der Folge als Chauffeur für Richard Staegal und als Hilfsganove für den Man in Purple tätig, was auch für ihn zu einer Art Doppelleben führt, was er ausdrücklich begrüsst. ${ }^{10}{ }^{\circ}$ Mit dem Motto «rob the robbers» verstehen sich die Protagonisten als Nachfolger Robin

I36 Der Man in Purple weist dabei einzigartigerweise zu Beginn als eine Art Vorbemerkung eine Realitätsfiktion auf, wenn die Erzählstimme erläutert, dass die Geschehnisse nun erzählt werden können, weil sie schon lange vorbei und der Man in Purple ein respektabler Mann geworden sei - darum könne die Geschichte nur mit geänderten Namen erzählt werden (McCulley 20 г, I, The Man in Purple, Kap. I). Dies wird allerdings nicht mehr aufgenommen.

I37 Vgl. ebd., I 2, Kap. 2: «Nobody seemed to have an idea as to his identity. Some said that he was a famous European crook, others a man out for private revenge, who had the ability to get it.» Letztere Spekulation ist für andere McCulley-Figuren (Mme Madcap, The Thunderbolt, The Avenging Twins, The Mongoose) durchaus zutreffend.

I38 Ebd.

I39 Ebd., I7, Kap. 2 (meine Hervorhebung). Erstaunlicherweise war das Ganze sogar Bettys Idee (ebd., 99, The Man in Purple Meets a Man in Blue, Kap. V), die ihn einmal sogar im passenden Kostüm (quasi als Woman in Purple, obwohl sie nie so genannt wird) begleitet (ebd., 54-65, The Man in Purple, Kap. VII-IX).

I40 Auch Broph kommt sozusagen zu einer Doppelidentität, wenn auch ohne Maske: «Broph, wo had tried on his own to be a crook and hat not succeeded, found himself in a real Eden. Here he was right-hand man to The Man in Purple one moment, and the chauffeur of the well-known and popular Richard Staegal the next. The situation to Broph was amusing, entertaining, adventurous, and exciting. He loved it.» (Ebd., 90, The Man in Purple Meets a Man in Blue, 
Hoods. ${ }^{141}$ Sampson zufolge schimmert durch diese «laudable guidelines» die Reflexion des Zeitgeistes: «Behind the words you detect the public outcry at those profiteers who made, it was thundered from the newspapers, vast fortunes during the First World War.» ${ }^{142}$

Der Crimson Clown alias Delton Prouse hat ähnliche Grundsätze. So hat er sich bereits unter Kriminellen einen speziellen Ruf erworben, wie Yogi Ra, der Bösewicht der ersten Story, Delton Prouse erklärt, den er für einen unbescholtenen Bürger hält. Zuerst versichert Yogi Ra aber, dass der Crimson Clown mehr als ein Gerücht sei:

«The Crimson Clown exists, Mr. Prouse, as many can assure you. He is a man of flesh and blood. What his real name is, nobody seems to know. His identity is a mystery. You have heard of master-criminals, no doubt? The Crimson Clown, Mr. Prouse, is the supreme master-criminal, as far as I know. [...] When I call him [that], do not gather the idea that he is leader of a band of men and women, as so many so-called master-criminals are supposed to be. I mean that he is master of the criminals. No doubt he engages in enterprises of his own. But his principal activities are robbing other criminals.»

«That's something fresh,» Prouse commented.

«He has become a terror to criminals. They fear him more than they do the police. [...] He seems to know everything. [...] $\gg^{143}$

Yogi Ra empört sich über die Masche des Crimson Clown, von der gemachten Beute - in seinem Fall ungeschliffene Diamanten - die Hälfte zu verlangen, nur um wiederum die Hälfte davon wohltätigen $\mathrm{Zwecken}$ zu spenden. ${ }^{144} \mathrm{Zu}$ Yogi Ras Ärger ist dabei nicht bekannt, woher der Crimson Clown stets weiss, wer gerade ein Ding gedreht hat. ${ }^{145}$ Diese Seite des Crimson Clown wird aber

Kap. IV). Es lässt sich spekulieren, dass Brophs Wertung seiner Situation der intendierten Wertung der Geschichte durch die Leser entspricht.

I4 I Ebd., 33, The Man in Purple, Kap. IV: «The main thing, as I see it, is to continue to be merry while we rob the robbers! We don't want any troubles or sorrows!»

I42 Sampson 1987, I96 (in Bezug auf den Man in Purple).

I 43 McCulley 1929, 2 I, The Crimson Clown (Introduces Himself), Kap. III.

I 44 Der Aufbau von Yogi Ras Intrige verdient Erwähnung: Um den Crimson Clown zu täuschen, von dem er eine Vorwarnung/Drohung erhalten hat, lockt er (durch einen von seiner Nichte in einer Menschenmenge gezielt fallen gelassenen Brief mit einem gefälschten Hilferuf) einen vermeintlich unbeteiligten Passanten in sein Haus, den er dem Crimson Clown als 〈Yogi Ra〉 verkaufen will. Nur ist der Passant Delton Prouse, sodass Yogi Ras Plan von Anfang an gescheitert ist, was er jedoch erst viel später merken wird. Denn selbstverständlich entschwindet das «Opfer Delton Prouse am Ende mit den Diamanten.

I45 Wie aus einer späteren Story zu erfahren ist, hat Delton Prouse ähnlich wie Jimmie Dale noch eine zweite ‘zivile〉 Rolle namens «Slick Sambell», der im Kriminellenviertel wohlbekannt ist, auch wenn niemand weiss, in welchem Zweig der Verbrechensbranche er genau arbeitet, wo er wohnt oder wo er steckt, wenn er wieder mal tagelang verschwunden ist (McCulley i 929, i6 I, The Crimson Clown Pursues Himself, Kap. I). 
kaum gezeigt. In den erzählten Geschichten sind auch bei ihm die meisten Opfer heimliche Kriminelle. ${ }^{146}$ So kommt es stellenweise $\mathrm{zu}$ einer scheinbar <verkehrten Welt>, wenn die beiden Gentleman-Gauner, die ihre Opfer gerade mit einer Pistole bedrohen, diese als Diebe und Räuber bezeichnen, was die Ehrbarkeit der zahlreichen betrügerischen Geschäftsleute in den Geschichten als Maskerade entlarvt. ${ }^{\text {I }} 7$

Richard Staegal spekuliert dabei als Erster bewusst auf den Ruf seines maskierten Alter Egos in der Öffentlichkeit und sieht, im Gegensatz zu Jimmie Dale, in sensationalistischer Berichterstattung einen Nutzen. Wie er Betty erklärt: «But taking chances and doing fool stunts is a part of our game [...]. Let the public fear The Man in Purple, and his work will be twice as easy.» ${ }^{148}$

Im Gegensatz zum Man in Purple hat der Crimson Clown eine Vorgeschichte, die allerdings erst in der vierten Story nachgeliefert wird. Nach einem nicht näher benannten «Fehler» verbrachte er fünf Jahre im Gefängnis. Wie er seinem ehemaligen Kumpel, dem Juwelendieb Geranium George, erklärt, prägte ihn die Strafe, doch befolgt er dennoch eigene Regeln: "That term stamped me. It made me a real crook. I'll always be a crook, but I'm different. [...] I only steal from those who can afford to lose. I never resort to violence. Between tricks, I live like a gentleman.» ${ }^{149}$ Anders als der typische bent bero haben der Crimson Clown und erst recht der Man in Purple keine Läuterungabsichten.

Was diese beiden Protagonisten der i 920er-Jahre sowohl von den Mantel-undDegen-Exemplaren als auch späteren ikonischen Beispielen maskierter Helden unterscheidet, ist, dass ihre zivile Identität keinen performativen Akt bedeutet, der vor allem das Ziel hat, dass die Protagonisten als heldenuntauglich - respektive bei den beiden Gentleman-Gaunern wäre es dann 〈gauneruntauglich〉 - abgestempelt werden. Weil ihre soziale Position eine Berufung als crook grundsätzlich auszuschliessen scheint, müssen sie keinen möglichst grossen Kontrast zwischen zivilem Ich und maskierter Identität inszenieren; entsprechend gibt es auch kaum Reibeflächen zwischen den beiden Identitäten. Es scheint, als hätte sich das Motiv der Doppelidentität hier bereits so etabliert, dass es als bekannt

I46 Zu den Opfern des Crimson Clown zählen in den ersten vier Storys neben dem falschen Yogi ein Geschäftsmann, der ungerechtfertigt die Lebensmittelpreise erhöht hat, der Boss eines Diesbesrings, der bei einem Einbruch unnötigerweise eine Frau geschlagen hat, und eine gut situierte Dame, die auf ihrer Gartenparty als Gag einen Crimson-Clown-Imitator auftreten lässt, sodass sich der echte Crimson Clown herausgefordert fühlt.

I47 Etwa in The Man in Purple Meets a Man in Blue: «The great Hannibal Carle!> The Man in Purple said sarcastically. $<$ The big thief. The man who has made a fortune robbing widows and orphans and swindling youngsters just starting out in business!» (McCulley 2010, 78, Kap. II).

I48 Ebd., I64, Breath of Disaster, Kap. IV.

I49 McCulley I929, 265f., The Crimson Clown's Competitors, Kap. VI. 
vorausgesetzt werden konnte. Wichtig ist vor allem, dass die Einheit der beiden Identitäten nicht entdeckt wird. So kommt es nur in einer Szene der Gefahr ausnahmsweise zu einer Vermischung der beiden Identitäten, als sich der Protagonist in der Bredouille wähnt: «The Man in Purple [...] prepared to make a fight of it. [...] now that he was cornered he scarcely knew what to do. For an instant, he was Richard Staegal instead of the Man in Purple, and he realized what capture and arrest would mean.» ${ }^{150}$ Es kennzeichnet den souveränen maskierten Pulp-Helden, dass diese Unsicherheit nicht länger als einen Moment anhält.

Der Wechsel von der zivilen Identität in sein kostümiertes Alter Ego hat dabei für den Crimson Clown denselben Effekt wie für Diego Vega und Jimmie Dale:

This was the time of peril. To be caught while in that costume would mean disaster arrest and incarceration, trial, a term in prison. But the knowledge of danger only served to make the Crimson Clown more alert and cautious. And, through some peculiar psychology, Delton Prouse passed from existence for the time being, and the Crimson Clown took his place. He seemed to grow in stature. The voice that the Crimson Clown used was not the voice of Delton Prouse. And his manner of speech was different, also, for the Crimson Clown was inclined to be sarcastic, cynical, and often dealt out biting satire. ${ }^{\mathrm{ISI}}$

Das heldische Ich ist auch hier klar eines der Konzentration auf eine Aufgabe bzw. der Professionalität während hektischer Umstände und Momenten der Gefahr. Die Maske verleiht nicht zuletzt mehr Selbstvertrauen und Selbstbewusstsein; sie transformiert den Protagonisten in eine Phase, während der das normale zivile Ich sozusagen verschwindet.

Sowohl dem Man in Purple als auch dem Crimson Clown mangelt es nicht an Selbstsicherheit. Inbesondere deklarieren sie ihre Überlegenheit, indem sie ihre Opfer und die Polizei vorwarnen, wo sie als Nächstes zuschlagen werden (Abb. I I). Eine solche Vorankündigung - jeweils in den Farben des Kostüms gehalten - kann allerdings auch taktische Ziele erfüllen. Als Richard Staegal auf einem Maskenball etwa Jasper Carlen trifft, erzählt ihm dieser brühwarm, dass er eine Vorankündigung des Man in Purple erhalten habe und wie er diesen ins Leere laufen zu lassen gedenke. In der zweiten Story dann treibt Richard Staegal das Spiel eine Stufe weiter. Er kündigt seinem Opfer, dem Financier Hannibal Carle, drei Besuche vom Man in Purple an. Den zweiten Besuch macht er allerdings als Richard Staegal. Die Zählung ist also nur mit dem Wissen über die Doppelidentität korrekt, wobei sich Richard Staegal mit Broph diebisch darüber freut. ${ }^{152}$

I 50 McCulley 2010, i80, Breath of Disaster, Kap. VII.

I I I McCulley I929, 286, The Crimson Clown's Competitors, Kap. IX.

I 52 Doch als Carle dies einwendet, weil er denkt, er werde schon beim zweiten Besuch beraubt, wischt Staegal dies beiseite: «Well, I am not in the mood for explaining just now» (McCulley 
Wie damit bereits deutlich geworden ist, wird in den Geschichten um die beiden bunten Gentleman-Gauner der spielerische Charakter der Maskerade zuweilen fast schon überbordend zelebriert. Im Lauf der einzelnen Episoden, die oft zu einem grossen Teil an einem Abend in einem Haus spielen, wechseln die Protagonisten mehrfach zwischen ihren Identitäten hin und her. Das Absurditätspotenzial der verhüllten, vertauschten und vorgetäuschten Identitäten loten sie in einem Katz-und-Maus-Spiel mit ihren Gegnern (der Polizei, ihren Opfern oder seltener Konkurrenten) aus.

In der ersten Geschichte des Man in Purple etwa tritt Richard Staegal auf einem Maskenball zuerst in einem blauen Dominokostüm auf. In Absprache mit dem anwesenden Detective Troman, der den Man in Purple fassen soll, zieht er dieses aus: Darunter kommt der Man in Purple zum Vorschein (hinter der Maske steckt eine weitere Maske). Er tanzt mit der Gastgeberin, raubt ihre Perlenkette - «Just a little joke [...]. Just a little thrill for the crowd»-, rennt damit die Treppe hoch und tut dann so, als ob ihn im Obergeschoss der «wahre> Man in Purple überfallen hätte: «Confound it, he handled me!»153 Dabei hat ihn Betty gefesselt, damit er sein eigenes Opfer spielen kann. Auch Delton Prouse nutzt diese Taktik, sich als Opfer seines Alter Egos auszugeben, mehrfach und betäubt sich dazu sogar selbst. Delton Prouse bringt es darüber hinaus fertig, in seinem Club zu prahlen, dass der Crimson Clown doch zu schnappen sei, schliesslich sei dieser «no superman» (was niemand besser weiss als er). Dies wird noch überboten, als ihn Detective Donler in Reaktion darauf um seine Hilfe bittet, den Crimson Clown dingfest zu machen. Donler schätzt dazu Prouses Charakter ein, ohne zu ahnen, wie richtig er liegt - Prouse sei doch ein Mann für Aufregung und Abenteuer. ${ }^{154}$ Mit seiner Bitte rennt er bei Prouse, so scheint es Donler, offene Türen ein. Als Crimson Clown nämlich hat er sich (Prouse) schon einen Brief geschickt mit der Aufforderung, genau dies doch zu versuchen. ${ }^{\text {ss }}$ Delton Prouse reflektiert die Situation mit Wohlgefallen:

So he was to go in quest of the Crimson Clown and at his side would be the police officer in charge of the case. That would be very nice indeed! He would know every move that the police were making [...]. Delton Prouse chuckled as he thought of it. He had anticipated that Sam Rassan, bent on revenge for Slick Sambell's coup,

2010, I 6, The Man in Purple Meets a Man in Blue, Kap. VII) - er könnte es ja auch nicht erklären, ohne seine Doppelidentität zu enthüllen.

I 53 Ebd., 42-49, The Man in Purple, Kap. VI.

I 54 McCulley 1929, I83f., The Crimson Clown Pursues Himself, Kap. III.

I 55 Der Brief lautet: «Mr. Delton Prouse, - The other evening at your club, you made the remark that the Crimson Clown was no wonder, but merely lucky in keeping out of the clutches of the police. You said that you could catch him yourself if you applied yourself to the task. Why not try it, Mr. Prouse? The Crimson Clown.» (Ebd., I 85 , Kap. III.) 
Abb. i i: Der Crimson Clown mit einem seiner herausfordernden Briefe an Inspector Donler («Dear Detective Donler! I have returned and am about to resume work»). Auffällig sind in dieser realistischen Malweise die Augen des Helden, die durch die Maske schauen; die Darstellung der Augen als weisse Schlitze in der Maske wurde erst in den Comics üblich. Detective Story Magazine, I 8. Oktober I930, Titelbild, wohl von John A. Coughlin.

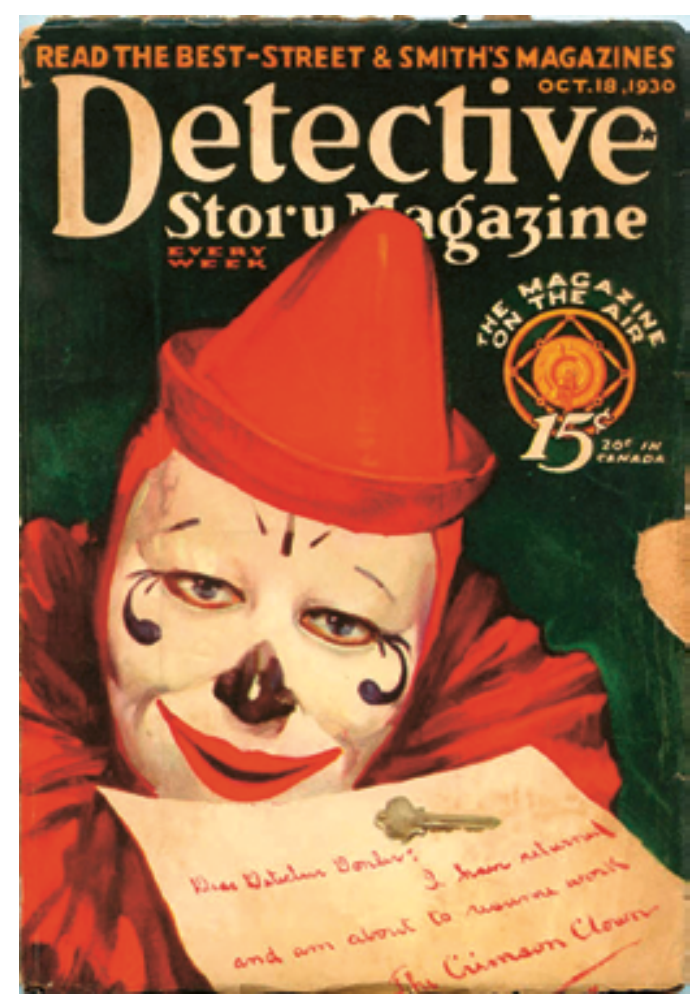

would reveal to the police that the Crimson Clown intended to rob Jaggren. Sam Rassan would guess that the Clown would make an effort to get that pearl necklace. For that was the real quest of the Crimson Clown. ${ }^{156}$

Wie diese Stelle aufzeigt, werden der Crimson Clown und der Man in Purple nicht nur als Männer der Aktion, sondern auch als gewiefte Planer präsentiert. ${ }^{57}$ In der jeweiligen battle of wits mit dem auf sie angesetzten Polizisten behalten die beiden Gauner in der Regel die Überhand auch dank ihrer Ausrüstung. Beide werden ihr Kostüm in prekären Situationen los, indem sie eine Chemikalie darauf träufeln, worauf es spurlos verpufft. Zum Arsenal des Crimson Clown

I 56 Ebd., i 87, Kap. III.

I 57 So wird der Man in Purple einmal wie folgt gelobt: «He never made a move without knowing where the move was going to carry him.» (McCulley 2010, 89, The Man in Purple Meets a Man in Blue, Kap. IV.) 
(der gegenüber dem Man in Purple aufgerüstet hat) gehören zudem ein Stockdegen und eine Betäubungsspritze - einmal verwendet er sogar ein K.-o.-Toffee, hin und wieder auch eine Gaspistole. Selbst als Donler Prouse verdächtigt, der Crimson Clown zu sein, kann er diesen Verdacht abwenden, da er als Crimson Clown falsche Fingerabdrücke (aus Kunststoff zum Überziehen) hat. Doch obwohl die beiden Protagonisten Meister darin sind, das Verhalten ihrer Gegner zu antizipieren, laufen ihre Aktionen selten wie geplant, sodass sie während ihrer Coups früher oder später improvisieren müssen, was freilich das Erkennen von Handlungsmöglichkeiten beinhaltet. So deklariert der Crimson Clown gegenüber dem gründlich ausgetricksten Yogi $\mathrm{Ra}$ (der empört ausruft: «You are the Fiend himself!») seine diesbezügliche Professionalität: «Only a clown! [...] And a clown, you know, is always playing tricks. They are his stock-in-trade. So, naturally, he is always looking for them, everywhere, always anticipating them.» ${ }^{158}$ Der Crimson Clown stellt, in den Worten Sampsons, «the final major costumed character» ${ }^{159}$ der 1920er-Jahre dar - in den 1930er-Jahren sollten die maskierten Pulp-Helden einem anderen Kaliber entsprechen. Doch diese Eigenschaft, das Handeln der anderen stets voraus- und sie durchschauend zu antizipieren, ist auch für ihre Nachfolger eine unabdingbare Grundlage für ihre Aktionen - die insbesondere The Shadow zur Meisterschaft bringt.

\section{Maskierte Verbrechensbekämpfer in der Metropole}

\section{The Shadow und die Schatten der modernen Grossstadt}

Im April 193 I erfolgte mit der ersten Ausgabe von The Shadow - A Detective Magazine die Initialzündung für die sogenannten single-character pulps oder auch hero pulps. The Shadow war zweifellos eine der erfolgreichsten Pulp-Publikationen überhaupt. ${ }^{160}$ Aufgrund der grossen Nachfrage wurden die Hefte viele Jahre sogar vierzehntäglich gedruckt. So erschienen unter dem Pseudonym Maxwell Grant 325 Shadow-Geschichten, davon 282 von Hauptautor Walter B. Gibson (I 895-1985), ${ }^{161}$ bevor Street \& Smith 1949 ihr gesamtes Pulp-Programm

I 8 McCulley 1929, 47, The Crimson Clown(Introduces Himself), Kap. VI.

I59 Sampson 1987, 208.

I60 Zum Shadow vgl. DeForest 2004, 92-96, Goulart 1972, 43-54, Sampson I989, I08-I I4, Server I993, 9I-95, Eisgruber 2007, Lai 2007 sowie die zahlreichen Erläuterungen von Will Murray und anderen in den (hier benutzten) Shadow-Neuausgaben von Sanctum Productions/Nostalgia Ventures.

I6I Die restlichen Storys waren von Theodore Tinsley (in der Regel vier Geschichten pro Jahr, 1936-I943); von 1946-1948 war Bruce Elliott Autor. 
einstellten. Die Figur hatte dabei ihre Anfänge als Erzähler einer Radiosendung und sollte von 1937 bis 1954 eine eigene Hörspielreihe erhalten; ferner gab es nicht nur Comic-Hefte, sondern auch einige, zwar nur lose auf der Figur basierende Shadow-Filme. ${ }^{162}$ Abgerundet wurde das Angebot durch zahlreiche Merchandising-Artikel. ${ }^{63}$

The Shadow lehrt die Verbrecherwelt mit der Mystifikation seiner Gestalt, mit vorausschauender Cleverness sowie brachialer Waffengewalt das Fürchten. Seine Operationsbasis ist New York, wenn er auch zuweilen Ausflüge zum Beispiel nach Miami unternimmt. Ein umfangreiches Netz von eigenen Agenten steht ihm dazu auf Abruf zur Verfügung. Er ist ein Verkleidungskünstler und besitzt mehrere Alter Egos. Als Shadow trägt er einen schwarzen Hut und einen schwarzen Mantel, die sein Gesicht, bis auf die Augen und eine Hakennase, verbergen. The Shadow trägt keine (sichtbare) Maske, stellt aber dennoch für den Typus des maskierten Helden eine Kristallisationfigur dar, in der verschiedene Fäden von Vorläufern zusammenlaufen und die zahlreiche Konkurrenz- und Nachfolgerfiguren inspiriert und stark beeinflusst hat. ${ }^{164}$

Mit dem Shadow wird das Repertoire des maskierten Helden als Retter-RächerSafeknacker durch den Detektiv erweitert, der sich in seinem Kampf gegen die Kriminalität allerdings bewusst nicht auf legale Mittel beschränkt. Im Unterschied zu den Gentleman-Gaunern der I920er-Jahre, deren Aktionen nur auf die Finanzwerte ihrer Gegner zielten, scheuen die maskierten Verbrechensbekämpfer der I930er-Jahre nicht davor zurück, mit harten Bandagen und tödlichen Schusswaffen den nicht minder gewalttätigen Kriminellen den Meister zu zeigen. ${ }^{165}$ Obwohl

I62 Zu den Shadow-Hörspielen vgl. Treat/Grano/Croghan 2009, zu den Filmen Backer 20ı。, 86-96.

I63 Sampson (1989, I09) erwähnt als Shadow-Merchandise-Artikel «wrist watches, coloring books, disguise and finger-print kits, sheet music, Better Little Books, comic books, and a succession of nearly worthless moving pictures».

I64 Insbesondere Partners of Peril (1936) von Theodore Tinsley stand dem allerersten BatmanComic Pate (Murray 2007; Tollin 2007a). Die beiden Geschichten haben denselben Plot, und auch aus der Beschreibung des Shadow springt einem Batman sozusagen in die Augen: So stürzt sich der Shadow, nach einem Kampf mit einem maskierten Kriminellen, ebenso kalkuliert wie todesmutig von einem Dach ins Leere, schleicht in einem alten Kirchturm unter Fledermäusen herum und wird selbst mehrfach mit einer Fledermaus verglichen. Dazu kommt die Kombination seiner von Dunkelheit verhüllten Gestalt und sein geradezu gleissender Blick («burning eyes»). Zudem finden sich Phrasen wie «a super being who lived like a wraith in the darkness of the night, without identity or name» oder «But whoever he is, I say he's the cleverest and most daring detective in America» (Tinsley 2007, I3 I, Kap. XXII).

I65 So spielt sich etwa ein Schusswechsel in The Masked Lady (1939) ab: «With two guns spread in [...] V formation, The Shadow stopped them [the crooks] short. Thugs were rolling from their cars, hauling out submachine guns [...]. [...] [The Shadow] was thinning out the mob, but they had reserves coming up and The Shadow could hear the raucous voice of the thuggish leader: 
die einzelnen novels jeweils mit «From The Shadow's Private Annals As Told to Maxwell Grant» überschrieben sind, folgt die Erzählperspektive dabei abwechselnd dem Shadow, dessen Agenten, den Kriminellen oder weiteren Figuren.

Zentrales Element der Shadow-Geschichten ist die Mystifizierung seiner Gestalt. Zum einen sind es sein durchdringender Blick und seine Stimme - die er wie eine Klaviatur beherrscht und die bei seinem jeweiligen Gegenüber in der Regel genau jene Reaktion verursacht, die er hervorrufen will -, die ihm einen starken Hauch Übermenschlichkeit verleihen. Zum andern sind es die ihm eigenen Möglichkeiten der Bewegung durch die metropolitanen Räume, die seine Gestalt spezifisch kennzeichnen, und zwar, indem sie ihn einer Festschreibung letztlich stets entziehen. ${ }^{166}$ Für diese Mystifizierung bedient sich die Erzählweise oft geradezu filmischer Techniken, wenn beispielsweise beschrieben wird, wie er sich als ein Schatten zwischen Schatten bewegt - zwischen entkörperlichter Form und körperhafter Fläche schwankend. Das Spiel mit Licht und Schatten ist dabei ständiges Leitmotiv (Abb. I 2) ${ }^{167}$ Eine typische Beschreibung liest sich wie folgt:

It was exactly ten o'clock when The Shadow departed from his sanctum. A half hour later, a strange phenomenon occurred at the intersection of two obscure streets on the lower East Side. A moving patch of blackness passed along the sidewalk beneath the glare of a street lamp. It was one of the many shadows that had crossed that spot during the evening. But in one respect, this moving splotch differed from all others. There was no sign of the person who cast it. A long streak of darkness, which terminated in a perfect silhouette. This was the only mark that betrayed the presence of The Shadow. Somewhere in the darkness of the brick wall beside the sidewalk, the being whom the underworld so greatly feared, had passed unseen. ${ }^{168}$

The Shadow beherrscht es wie kein Zweiter, sich unter bestimmten Raumvoraussetzungen nahezu unsichtbar zu machen, indem er sich dem Raum total anpasst - er ist also ein äusserst raumbezogener Protagonist. In den radio shows wurden daraus die explizit fantastischen Fähigkeiten Hypnose und Unsichtbarkeit, in den Pulps dagegen verharrt die Gestalt stets an der Grenze zum Fantas-

‘Make him use his slugs! When he's out of them, go in after him. Give him the typewriters when you get there! > The Shadow answered that shout with a challenging laugh, a strident mockery that crooks didn't like» (Gibson 2008a, 75, Kap. IV).

I66 Laut Sampson ist die schwarz gekleidete, schattengleich durch die Gegend gleitende «mystery figure $[\ldots]$ a convention of visual menace established firmly in the gothic novels and later exploited by fifty years of dime novels and story papers» (Sampson I987, 29, vgl. auch I 26).

I67 Hier dürfte auch der Schwarzweissfilm, namentlich der kurz zuvor entstandene Gangsterfilm, Einfluss gehabt haben; diesen weisen deutlich die Innenillustrationen auf. Zur Bedeutung von Beleuchtung, Licht und Schatten im Krimi dieser Zeit vgl. Holzmann 200 I, bes. I93-2 I 2. I68 Gibson 2006, 7, The Red Blot (1933), Kap. II. 


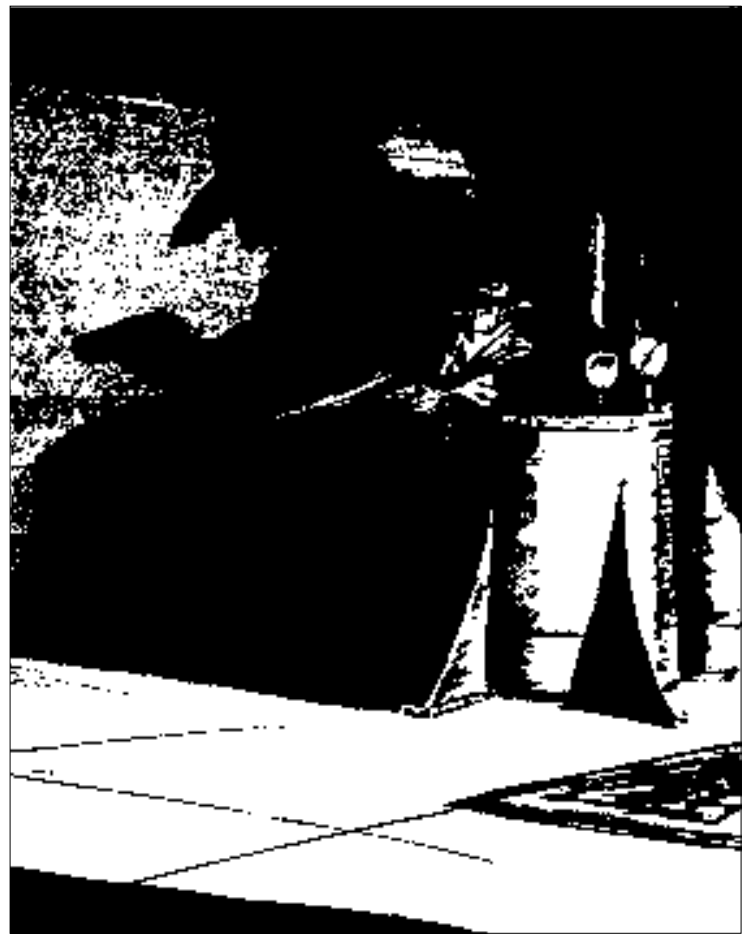

Abb. I 2: The Shadow's shadow: Das Spiel mit Licht und Schatten prägt auch die Illustrationen zu den ShadowGeschichten. The Shadow. Partners of Peril, I. November 1936, rechte Seite einer doppelseitigen Illustration von Tom Lovell. (C) Sanctum Productions.

tischen. ${ }^{169}$ Die Konzeption des Shadow beruht stark darauf, dass er auf verschiedenen Ebenen ungreifbar ist. ${ }^{170}$

I69 Dies wird zeitweise sogar im Intro festgehalten: «The Shadow» uses his hypnotic power to cloud men's minds so that they cannot see him» (Slon 2008, I 16, The Laughing Corpse, I940, Radio-Script). Dagegen als Beispiel eine kurze Beschreibung aus The Grove of Doom (1933): «Donning these clothes, Cranston took on a strange, sinister appearance. His figure no longer possessed a human bearing. It was a form that might well have been conjured from another world» (Gibson 2008a, I9, Kap. V, meine Hervorhebung). Vgl. dazu Murray 2006.

I70 In der allerersten Story, The Living Shadow von I93 I (Grant I976), waren die Auftritte des Shadow sogar sehr sparsam dotiert. Er zeigt sich insgesamt nur gerade zwölfmal, Protagonist der Geschichte ist dagegen der junge Harry Vincent, der als neu rekrutierter Shadow-Agent einen neuen Lebensinhalt findet. 
Die Bewegungskunst des Shadow umfasst, dass er ganz eigene Wege und Fortbewegungsarten durch die unübersichtliche Wolkenkratzermetropole (und ihre Unterwelten) findet, sodass er Zugänge und Räume erschliesst und nutzen kann, die anderen verwehrt bleiben (Abb. I3). ${ }^{171}$ Dieses Element, das auf irgendeine Weise alle maskierten Helden für sich in Anspruch nehmen können, werden die Superhelden dann definitiv ins Fantastische steigern.

Seine Beweglichkeit spielt The Shadow nicht nur in geografischen und räumlichen Gegebenheiten aus, sondern genauso in sozialen Räumen. Dazu bedient er sich verschiedenster Rollen bzw. Alternatividentitäten und Verkleidungen. So kann er als Bettler vor dem Tabakladen oder Blinder an der Ecke posieren oder sich über eine längere Zeit als Mitwirkender in einem Geschehen etablieren, bevor er an sein Ziel kommt. Zum Beispiel lässt er sich als Gangster «Lingo Queed» zum Anführer einer neuen «crime dynasty» wählen, um dann im finalen Tusch den ganzen Zirkel zu zerschlagen. ${ }^{172}$ Regelmässig tritt er in wiederkehrenden Tarnidentitäten auf, die von «Fritz the janitor», der das Spionieren im Polizeihauptquartier erlaubt, bis zum reichen Müssiggänger Lamont Cranston reichen.

Der Wechsel von seiner gerade vorgegebenen in seine Shadow-Identität wird dabei oft über die Augen illustriert, wenn er sich etwa als Lamont Cranston an einem Tatort befindet, es in der Beschreibung aber die aus Lamonts Gesicht blickenden Augen des Shadow sind, die ein wichtiges Indiz nicht übersehen:

Back in the office, the tall form of Lamont Cranston stood above the body of Professor Lessep. There was no smile upon the firm, straight lips. Keen eyes stared - the eyes of The Shadow. [...] The Shadow looked upward. Turning, he moved quickly to the desk in the other corner. The lamp was illuminated there, [...]. Rapidly, the Shadow opened a drawer. He saw the box of lightbulbs; [...]. One appeared to be burnt out. The Shadow removed it and closed the drawer. Resuming the slow motion of Lamont Cranston, he strolled into the laboratory to join the commissioner and the others. ${ }^{173}$

Oft wird in solchen Szenen durch die Zerstückelung des Körpers in der Schilderung eine innere Spaltung impliziert, die hier eine Interpretation von Lamont als Rolle und dem Shadow als «wahrer Identität erlaubt. Diese erscheint aber nicht als absolut, sondern beinhaltet eine Gleichzeitigkeit der beiden Rollen, deren Zusammenspiel unumgänglich ist.

I7I Die Shadow-novels bieten eine Vielzahl an Geheimgängen und dergleichen sowie an halsbrecherischen, kreativen Fortbewegungsarten. Zu den Räumen und der Raumbeherrschung des Shadow vgl. von Holzen 20 2 b.

I72 Gibson 2007, Lingo (1935).

173 Gibson 2008c, 25 , The Unseen Killer (1934), Kap. VII. 
Abb. I 3: The Shadow schwingt sich durch eine moderne Grossstadt bzw. über deren normale Verkehrswege hinaus, wobei es sich hier um Chicago statt $\mathrm{New}$ York handelt. The Shadow Magazine, I. Oktober 1936, Titelbild von George Rozen.

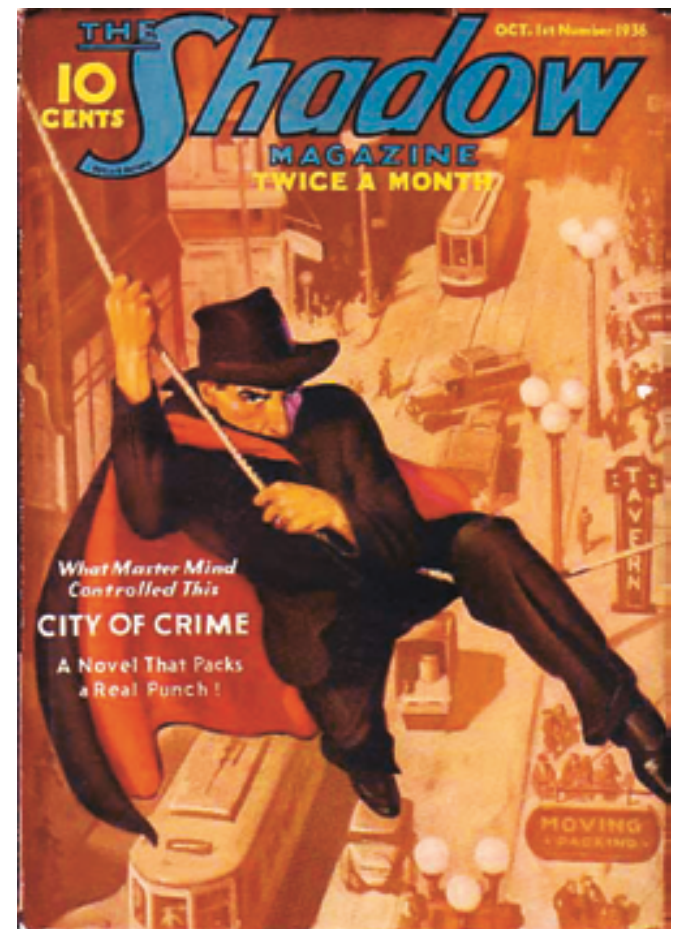

Lamont Cranston ist dabei jene Rolle, die einer zivilen Identität am nächsten kommt und den typischen zivilen Gentleman-Ichs der früheren Pulp-Helden (Percy Blakeney, Diego Vega, Jimmie Dale, Richard Staegal, Delton Prouse) entspricht (Abb. I4). Als Lamont Cranston ist er nämlich mit dem Polizeichef (Commissioner Ralph Weston, alternativ Wainwright Barth) befreundet, den er regelmässig im exklusiven Cobalt Club trifft. Auch in seiner bevorzugten zivilen Rolle etabliert sich The Shadow so als eine Stütze der Polizei. Denn als Lamont Cranston bespricht er mit ihnen und vor allem Inspector Joe Cardona ihre aktuellen Fälle - sie ahnen nicht, dass sie ihre Informationen direkt dem Shadow liefern. ${ }^{174}$ Die Polizisten halten The Shadow zuerst für ein blosses Gerücht, mit den Jahren verlassen sie sich jedoch auf seine Hilfe.

I74 Vgl. z. B. Tinsley 2007, 75, Partners of Peril (1936), Kap. I: «Both [Weston and Cardona] were good friends of this tall clubman [Cranston] who took a sort of amateur interest in police affairs and had occasionally helped Weston with a suggestion or two in past cases into which, seemingly, he had been accidentally drawn. That this affable gentleman with the keen eyes 
Gerade in seinen zahlreichen Verkleidungen benötigt der Shadow gegenüber seinen Agenten Erkennungszeichen. Zum einen trägt er dazu einen Ring mit einem blau-rot irisierenden Feueropal, einem sogenannten girasol («Lone emblem of The Shadow, that stone was a mark of identity» $\left.{ }^{175}\right)$. Zum andern ist es vor allem sein zugleich unverwechselbares wie zahlreiche Schattierungen aufweisendes Lachen ${ }^{176}$, das durch Adjektive wie eerie, mirthful, mocking, sinister, strange, weird, chilling ebenfalls einen mystifizierenden Beiklang erhält. Es dient als Identitätsmarker, mit dem er seine Präsenz anderen Figuren kundtut - oder aber nur den Lesern diese Präsenz bestätigt. Ein Beispiel aus The Unseen Killer (1934): «Cranston [...] laughed softly through immobile lips. A strange whisper, that repressed mirth! Yet it told a story of its own. It revealed the true identity of this personnage who wore the masklike countenance of Lamont Cranston; it marked a secret purpose - a design of The Shadow.» ${ }^{177}$

Obwohl hier als «true identity» bezeichnet, ist davon auszugehen, dass der heldische Verbrechensbekämpfer in seiner fiktionalen Biografie nicht schon als Shadow auf die Welt kam. Die radio shows machten daher der Einfachkeit halber Lamont Cranston zur <angestammten> Identität des Shadow; wie jeweils bereits das Intro verkündete: «The Shadow [...] is, in reality, Lamont Cranston, wealthy young man about town. $»^{178}$ Auch in den Pulps musste The Shadow daher noch eine ‘wahre`, eine ‘Herkunftsidentität> erhalten. ${ }^{179}$ Der Sensationscharakter dieser Enthüllung wird im Lead der Story The Shadow Unmasks (1937) deutlich: «For the first time [...] The Shadow thrusts aside his veil of mystery! Not under one of his many aliases but in his true identity, The Shadow reveals himself! ${ }^{180}$

could be The Shadow would have seemed utterly ridiculous to the two men with whom now he was idly conversing.»

I75 Gibson 2008c, I20, The Golden Masks (1936), Kap. XX.

I76 Abgesehen vom selbstbestätigenden Lachen in seinem Sanctum, hat das Lachen des Shadow vor allem zwei Formen: Es ist zum einen das Lachen als Ausdruck von Wagemut und Tollkühnheit angesichts von Gefahr (das u. a. die Gegner verunsichern soll), zum andern ein «stilles〉, 'wissendes> Lachen, wenn andere Figuren nicht merken, dass sie es mit dem Shadow zu tun haben. In beiden Formen ist es ein Lachen der Überlegenheit.

I77 Gibson 2008b, Io, Kap. II.

I78 Slon 2008, I 16, The Laughing Corpse, 1940, Radio-Script. Dies und die Figur der Margot Lane übernahm der Film von 1994 (The Shadow, Regie: Russell Mulcahy), die einzige HollywoodAdaption eines Pulp-Helden in den letzten Jahrzehnten.

I79 Nach Murray (2008b, 62) war es Gibsons Intention gewesen, die ‘wahre> Identität des Shadow wie sein Gesicht (über das mehrfach spekuliert wird) noch länger im Dunkeln zu lassen, doch musste er sich einer herausgeberischen Entscheidung beugen, da die radio show Lamont Cranston als feste zivile Identität setzte. Auch Margot Lane, am Radio Lamonts Verlobte und Mitstreiterin (vgl. z. B. Bierstadt 2008, Danger in the Dark, 1937, Radio-Script), erhielt in den Pulps nie eine gewichtige Rolle, sondern blieb als Shadow-Agentin unter «ferner liefen».

I80 Gibson 2008b, 4 . 
Abb. I4: Lamont Cranstons Schatten entlarvt, dass dies The Shadow in seiner LieblingsZivilidentität ist, jener eines vermögenden Müssiggängers und clubmans mit sehr guten Kontakten zur Polizei. The Shadow, I. Januar 1939, Titelbild von George Rozen.

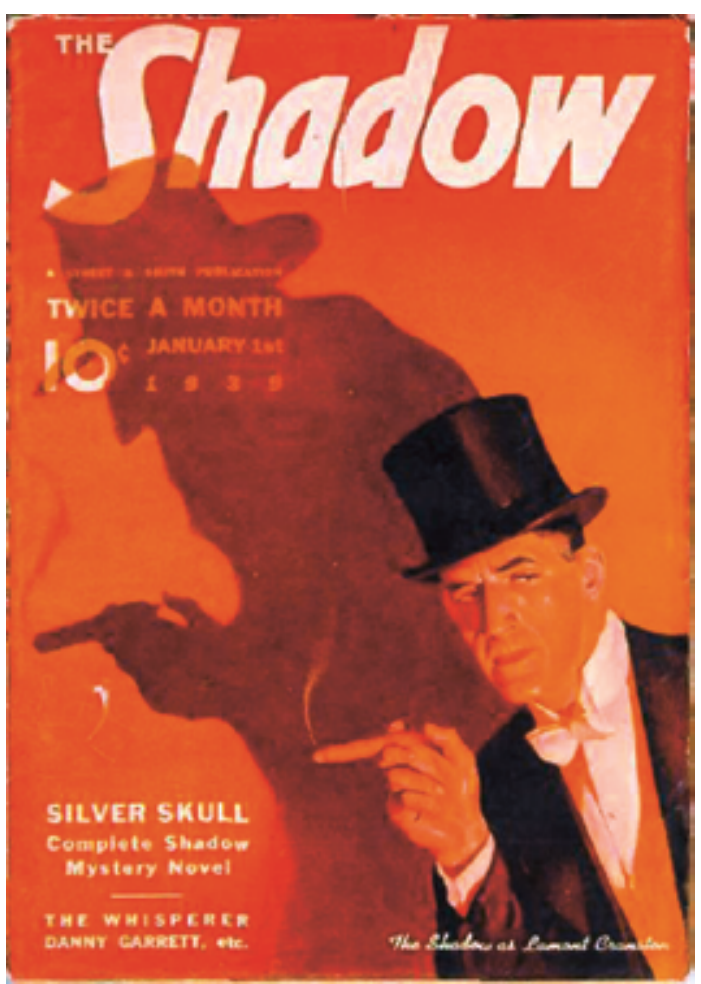

$\mathrm{Zu}$ Beginn der Story wird es dabei für den Shadow brenzlig, droht er doch als Double von Lamont Cranston aufzufliegen - ausgerechnet gegenüber Commissioner Weston. Denn als Weston vor dem Cobalt Club eine Zeitung kauft, sind beide von der Schlagzeile überrascht, dass der bekannte Weltenbummler Lamont Cranston auf einer Auslandsreise verletzt wurde und länger im Krankenhaus liegen wird. Die Meldung kann nicht den «Lamont» betreffen, der gesund und munter neben Weston steht. (Sie bezieht sich auf den echten Cranston, der absichtlich oft im Ausland weilt, damit seine Identität und seine Kontakte vom Shadow genutzt werden können.) Mit Goffman handelt es sich hier um ein Paradebeispiel für eine Bühnenpanne, die Schlagzeile konnte der Shadow in seiner Bühnenpräsentation nicht kontrollieren. ${ }^{81}$ Bis sich Weston gefasst hat, hat sich

I8I Goffman 2002 (I959), 50. 
The Shadow jedoch längst aus dem Staub gemacht, um schnell alles zu organisieren, damit er die Szene leicht 〈hinwegerklären> kann. ${ }^{182}$

Weil Lamont nun eine Zeit lang ausfällt, muss eine neue Identität her, die aber dasselbe leistet wie die Lamont-Identität: «That was the matter of a new identity to replace his impersonation of Lamont Cranston. The Shadow needed a guise that would serve him through the future; one which no one, even in wildest fancy, would ever link with The Shadow. ${ }^{{ }^{83}}$ Die Wahrung des Geheimnisses scheint hierbei ein zentrales Kriterium für die Wahl einer neuen Deckidentität. $\mathrm{Da}$ The Shadow stets auf alle Eventualitäten vorbereitet ist, kann er eine solche Identität tatsächlich aus dem Hut zaubern. In der typischen Shadow-Erzählweise erfahren die Leser dabei über den Journalisten Clyde Burke (als ShadowAgent ein häufig auftretender Charakter), dass der seit zwölf Jahren im mittelamerikanischen Urwald verschollene Entdecker Kent Allard wieder aufgetaucht ist; New York heisst den Heimgekehrten mit einer feierlichen Parade willkommen. Erst nach der Parade wird offenbar, dass Allard niemand anders ist als die neue Rolle des Shadow. Doch ist diese einzigartig, ist es doch seine eigene, angestammte> Identität: «At last, The Shadow had decided to arrive as himself. The Shadow would be unmasked at last. $\gg^{184}$

Dies erweist sich aber als irreführendes Versprechen, denn Allard wird keineswegs als Shadow identifiziert. Nur zugunsten der Leser - losgelöst vom eigentlichen Plot der Story - besucht The Shadow seinen wohl besten Freund unter seinen Agenten, den Kriminologen Slade Farrow, und erzählt diesem seine Biografie: Kent Allard war im Ersten Weltkrieg ein Pilot mit Übernamen Dark Eagle, der hinter den feindlichen Linien spionierte. Nach dem Krieg fand er im Kampf gegen die Kriminalität seine Berufung. ${ }^{185}$ Tatsächlich lebte er, solange er als verschollen galt, nur eine Weile im Dschungel von Guatemala bei den Xincas, $\mathrm{zu}$ denen er auch hin und wieder zurückkehrte, die meiste Zeit widmete er jedoch seinen Aktivitäten als Shadow. Dass er die Kent-Allard-Identität nicht frü-

I 82 Trotz einer von Weston anberaumten Untersuchung gelingt es The Shadow durch gekaufte Zeugenaussagen und falsche Belege, Weston zu überzeugen, dass es sich beim «Lamont» vor dem Club um dessen (inexistenten) Neffen gehandelt habe, was eine eher lahme Erklärung darstellt (Gibson 2008b, 7-9/2 I-23, Kap. II/VII.)

I 83 Ebd., 2 I, Kap. VI.

184 Ebd.

I 85 Ebd., 36f., Kap. XIII. The Shadow entpuppt sich dabei ähnlich wie The Phantom Detective (der im nächsten Unterkapitel besprochen wird) als eine Art Kriegsgeschädigter: «[...] aviation offered part of the life I needed; but it provided neither the action of battle, nor the keen work of the secret agent. I rejected the idea of becoming a soldier of fortune. I considered warfare an uncivilized institution [...].» Der Kampf gegen die Kriminalität bedeutet aber den nötigen Krieg (ebd.). 
her ‘zurückgeholt` hat, erklärt er explizit damit, diese bewusst in der Hinterhand behalten zu haben, falls die Lamont-Rolle einmal kompromittiert würde. Die Allard-Rolle gerät so nicht in Gefahr, als «wirklich wahre> Identität des Helden zu gelten, da sie klar als Lamont-Ersatzidentität gehandhabt wird (auch wenn in der folgenden Geschichte ${ }^{186}$ sowohl Allard wie auch Cranston auftreten, wobei Cranston zum Zug kommt, sobald die Polizei von Miami gegen Allard einen Mordverdacht hegt).

Obwohl Kent Allard also die «angestammte Identität des Shadow sein soll, wird diese vom Shadow nur als ein weiteres Werkzeug gesehen. The Shadow nutzt seine Identitäten bzw. sozialen Rollen als eine Art Arsenal, wobei je nach Bedarf ein bestimmtes Instrument - eine bestimmte Identität oder eine Verkleidung daraus zum Einsatz kommt. Er praktiziert so ein aktives und bewusstes Be- und Ausnutzen von sozialen Rollen, deren jeweiligen Freiheiten und an sie gestellten Erwartungshaltungen. Dies resümiert die Erzählstimme wie folgt: «The Shadow had needed another role; so he had become himself. $\gg^{187}$

Wie aus der Episode mit Kent Allard mehr als deutlich wird, ist The Shadow ebenfalls ein Planungsgenie. ${ }^{188}$ Sein Erfolg beruht dabei wesentlich auf seinem Informationsvorsprung, den er aus seinem eigenen Informationsnetzwerk (und seinen weiteren Wissenbeständen, darunter Menschenkenntnis und Rategeschick) bezieht. The Shadow sammelt dabei nicht nur Informationen, er verheimlicht auch welche oder manipuliert ihren Fluss. Insbesondere neigt er dazu, die Polizisten zu bevormunden, indem er falsche Spuren legt und ihnen Indizien vorenthält, weil sie diese sowieso falsch interpretieren würden. (Und ähnlich wie Sherlock Holmes hat The Shadow in Joe Cardona einen Lieblingspolizisten.) Die gesammelten Informationen seiner Agenten fliessen über den «contact man» Burbank, der bei Bedarf Tag und Nacht als Telefonzentrale des Agentennetzes waltet (bzw. schaltet), beim Shadow zusammen, der über diesen Weg ebenfalls Anweisungen erteilt. Seine sozial sehr breit gestreuten Agenten verhelfen ihm zu

I 86 Gibson 2008b, The Yellow Band (1937).

I 87 Gibson 2008b, 37, The Shadow Unmasks (1937), Kap. XIII.

I 88 Der Text spielt dabei gern mit ominösen Vorausdeutungen und spiegelt so gegenüber den Lesern den Informationsvorsprung des The Shadow, der indes nicht alles kontrollieren kann, wie etwa eine Stelle aus The Voodoo Master (1936) illustriert: «Luck alone could balk The Shadow. Chance was the one element that he could not counteract. Oddly, fate was tricking him tonight. While the autogiro sped shoreward, minor events were happening over which The Shadow had no present control. [...] The Shadow's trail to Doctor Mocquino would be a quicker one than The Shadow had originally planned. But because of haste that would soon prove necessary, the trail would become incomplete. Danger, struggles, blind search - all would be involved before The Shadow would gain his final goal. Doctor Rodil Mocquino, the Voodoo Master, was destined to become a foe of formidable proportions. One who would fight The Shadow to the finish» (Gibson 2006, 8 5, Kap. VI). 
einem erweiterten Beobachtungs- und Bewegungsradius, und auch sie arbeiten nicht selten undercover - dies ist etwa die dauernde Aufgabe der beiden Agenten Hawkeye und Cliff Marsland, die sich als Kriminelle ausgeben. Das Netzwerk des Shadow präsentiert sich als unsichtbare Struktur, die die Grossstadt durchzieht. Sie ist insofern Installationen wie Stromleitungen, Wasserkanälen oder UBahn-Tunneln vergleichbar, die dem (oberflächlichen) Blick - zumal gegenüber den spektakulären City-Hochbauten - verborgen bleiben und die Grossstadt Nichtkundigen als undurchsichtiges Labyrinth erscheinen lassen. ${ }^{189}$

Die gesamte Konzeption der Shadow-Gestalt ist, wie erwähnt, auf eine Millionenmetropole als Tummelfeld zugeschnitten, die insbesondere seine virtuose Handhabung verschiedener Rollen/Identitäten erst ermöglicht. Obwohl in mancher Hinsicht klar aus dem Zeitgeist der Depression gespiesen, erscheint The Shadow darüber hinaus als idealtypische Verkörperung eines stilisierten Grossstadtbildes im Allgemeinen und im Besonderen von New York, das oft als prototypische westliche Metropole des 20. Jahrhunderts gilt.

Grossstädten wird allgemein ein bedeutender Einfluss auf das gesellschaftliche Zusammenleben und damit auf die Identität der Einzelnen zuerkannt; dies gilt auch für die historische Entwicklung des Identitätsgefühls. Im Zuge von Modernisierung und Industrialisierung kam es ab dem i 8. Jahrhundert zunehmend zu Verstädterung und Urbanisierung, wie etwa Antje Dallmann festhält. ${ }^{19 \circ}$ Gemessen an ihrem Gegenpol, den traditionell organisierten ländlichen (bzw. dörflichen) Gemeinschaften, verfügten Grossstädte stets über «Attraktivität und Attraktion», so Dallmann, boten sie doch «bessere ökonomische Bedingungen [...] [und] günstigere Voraussetzungen für Freiheit und Selbstverwirklichung nicht zuletzt durch bessere Bildungsmöglichkeiten und die Auflösung überkommener Normen und Rollenzwänge» ${ }^{191}$.

Das moderne grossstädtische Leben schien eine neue Lebenserfahrung zu bieten. Diese wurde jedoch nicht nur als verheissungsvoll, sondern auch als zutiefst problembehaftet wahrgenommen, was Dallmann wie folgt zusammenfasst:

Neben unzureichenden materiellen Bedingungen wurde auch die Form des menschlichen Zusammenlebens in Städten zunehmend als problematisch empfunden. Millionenstarke Stadtbevölkerungen [...] mussten sich mit einer Form der menschlichen

I 89 Vgl. zu diesem Stadttopos Gunning 1997, $38 \mathrm{f}$.

I90 Dallmann 2009, I 8. Laut Dallmann wurde mit dem Beginn des 20. Jahrhunderts «die Schwelle von der agrarischen zur industriellen und so im engeren Sinne modernen Gesellschaft» überschritten (ebd.). Auch laut Baumeister (1987, 170) brachte der Wandel zum industriellen, grossstädtischen Leben eine veränderte Ökonomie und damit eine veränderte Identität mit sich: «Self-sufficiency was obsolete, and economic depressions [der I 890er- und I930er-Jahre] threatened personal survival.» (Damals fehlte eine umfassende staatliche Wohlfahrt.)

I9I Dallmann 2009, i 8. 
Interaktion arrangieren, die sich grundsätzlich von der im ländlichen Raum unterschied. Vereinsamung, Anonymisierung, die Beschleunigung des Lebens sind Phänomene, die bis heute die Grossstadterfahrung - in der Tendenz negativ - charakterisieren. ${ }^{192}$

Räumliche Nähe zwischen Einzelnen bedeutet in der Grossstadt nicht auch soziale und gesellschaftliche Nähe. ${ }^{193}$ Das grosse Schlagwort der negativen Konnotationen der Grossstadt lautet bekanntlich Anonymität innerhalb der Masse. ${ }^{194}$ Für die Stellung des Individuums in der Gesellschaft besteht zwischen modernem grossstädtischem und (stets implizit althergebrachtem) ländlichem Leben ein fundamentaler Unterschied: In der Grossstadt löst sich die in ländlichen Gemeinschaften bestehende «konstante Identifizierbarkeit» ${ }^{195}$ auf. Anders als in einem Dorf, wo alle alle (inklusive deren Verwandtschaft) kennen, bedeutet die Urbanisierung eine Trennung von sozialer und persönlicher Identität, wie Gertrud Nunner-Winkler formuliert. Die soziale Identität des Gegenübers lässt sich nur mehr vage vermuten, derweil man die persönliche Identität gar nicht kennt. ${ }^{196}$ Nunner-Winkler beschreibt die Folgen dieses Umstands wie folgt: «Social differentiation and cultural pluralization produce consistency problems: individuals increasingly partake in several subsystems or subcultures, each operating according to their own code or claiming specific value commitments. Thus, in different contexts, they find themselves exposed to specific role expectations which quite often make conflicting demands. ${ }^{\gg 97}$ Die hier angesprochene Teilhabe an verschiedenen (Sub-)Gesellschaften, die unter Umständen als Zerstückelung des

192 Ebd. Dallmann bemerkt dazu, dass dieser Zeitpunkt je nach Stadt variiert, beispielsweise vollzogen sich diese "Transformationsprozesse» in London und Paris früher als in Berlin und New York, die diese erst gegen Ende des i9. Jahrhunderts durchmachten (ebd.).

193 Wie Dallmann $(2009,26)$ betont, war Georg Simmel einer der Ersten, die die Stadt nicht mehr nur negativ sahen, sondern unter anderem als «einen Ort der Akzeptanz auch des Fremden» werten, da die grossstädtische Gesellschaft von «der räumlichen Nähe zwischen Fremden charakterisiert» ist.

I94 Als willkürliches Beispiel zum Thema der grossstädtischen Anonymität in der ‘hohen> Literatur sei auf die Ausführungen von Ferry (2002) zur Poesie des frühen 20. Jahrhunderts verwiesen. Ferry verfolgt die Worthistorie von «anonym> und zeigt, dass sich in den I920er-Jahren die Anonymität als Konzept etablierte und nicht mehr nur als fehlende Verfasserangabe, sondern als ein allgemeines Phänomen moderner Befindlichkeit, als zeitgenössisches Lebensgefühl von «city living», erfasst wurde, demzufolge Individualität in der Massengesellschaft untergeht (ebd., 200-202).

I95 Nunner-Winkler 2015 (200I), I I 247.

I96 Ebd.

I97 Ebd. Die soziale Identität bezeichnet kurz gesagt die Kategorienzugehörigkeit, die personale das spezifische Individuum. 
sozialen Lebens gesehen werden kann, kann zu Anonymität und Entfremdung, den wohl prominentesten Topoi der Grossstadtliteratur, führen. ${ }^{198}$

Obwohl die Figuren in der actionkonzentrierten Pulp-Welt kaum Zerrissenheitsgefühle zu bewältigen haben, wird das Gefühl von Entfremdung und Verlorenheit in der Stadt zuweilen angedeutet. Beispielsweise will Harry Vincent vor dem allerersten Auftritt des Shadow von einer Brücke springen, weil er, der auf dem Land aufgewachsen ist, in der Stadt nur Misserfolge hatte. Aber es finden sich auch kleinere Szenen, die die negativen Konnotationen der Grossstadt evozieren, zum Beispiel wenn Clyde Burke im folgenden Zitat dringend etwas Shadow-Action ersehnt: «As he [Clyde] strolled up Broadway, he tossed the newspaper into a rubbish receiver and looked about him glumly. Throngs of meaningless people - lights that showed dully against the brilliance of day - teeming, useless traffic. Such were Clyde's impressions as he viewed the heart of the metropolis. ${ }^{199}$

Distanz zwischen einem Individuum und dem nächsten und die Reduzierung des Individiuums in der Wahrnehmung der anderen auf eine (nämlich die in der jeweiligen Interaktion gerade dominante) Rolle, kann aber auch wünschenswert sein. So bemerkt etwa Goffman im Zusammenhang mit der audience segregation: «Urban life would become unbearably stick for some if every contact between two individuals entailed a sharing of personal trials, worries, and secrets.» ${ }^{200} \mathrm{An}$ onymität innerhalb der Masse erscheint je nach Perspektive als Vorteil oder als Last. Die Stadt erweist sich jedenfalls als gutes Pflaster, um Geheimnisse, wie die Doppelidentität eines ist, zu hegen. ${ }^{201}$

Doch als die fiktionalen Selbstjustizler und (hard-boiled-)Privatdetektive die Goldene Ära der Pulps lostraten, befand sich New York noch mitten in den Jahren der Depression, als sich die negativen Konnotationen der Grossstadt insbesondere im «Schmelztiegel〉 New York noch zu verdichten und zu bestätigen schienen. ${ }^{202}$

I98 So ist es vielleicht kein Zufall, dass in der allerersten Shadow-Geschichte der soeben vom Shadow als Agent angeheuerte Harry Vincent einen unbekannten Mann durch die Stadt New York verfolgen muss und der Crimson Clown bei seinem ersten Auftritt ebenfalls einer rätselhaften jungen Frau in London hinterhergeht, erinnern diese Szenen doch an Edgar Allan Poes Kurzgeschichte The Man in the Crowd (I 840), die als eine der «klassischen> Beschreibungen der Anonymität in den modernen Grossstädten und deren Faszination gilt (vgl. Gunning 1 997, 25) - doch anders als bei Poe werden die Geheimnisse der Verfolgten aufgedeckt.

199 Gibson 2007, 46, Lingo (1935), Kap. XVI.

200 Goffman 1990 (1959), 49.

20 I Dies beschreibt Bukatman (2013, 2I 2) anschaulich: «The city is a haven for imposters: by the early nineteenth century physical mobility had made a mockery of social standing. [...] The city attracted them all: false noblemen, deceptive charity workers, strange and disguised visitors from other planets [Superman].»

202 Baumeister $(1987,170$ ) weist allerdings darauf hin, dass in der shohen> Literatur der USA schon 
Die Metropole, die schon seit Ende des 19. Jahrhunderts das Publikationszentrum und den «kulturellen Motor» der USA darstellte, erlebte in den I920er-Jahren trotz (und wegen) der Prohibition (1919-1933) einen Boom. ${ }^{203}$ Das Zentrum des Finanzbooms bildete die Wall Street, welche indes immer unpersönlicher wurde, so Shaun O'Connell - 1929 war der Fall dafür umso tiefer. ${ }^{204}$ In New York verkörperten das Gefühl der «human helplessness», das die Depressionsjahre prägte, unter anderem die zahllosen Obdach- und Arbeitslosen, die sich höchstens mit Gelegenheitsjobs durchschlagen konnten, aber auch die leeren, ominösen Wolkenkratzer $^{205}$, an denen das wirtschaftliche Versagen klar sichtbar war. Die hochfahrenden> Projekte wurden nicht mehr als Feier des Fortschritts gesehen, sondern schienen - mit vielen leer stehenden Büroräumlichkeiten - in einem ironischen Kontrast zum Elend auf der Strasse zu stehen.

Ein dunkles Kapitel der Depressionsjahre stellt dabei auch eine jahrelang anhaltende Welle von massiven Gewaltverbrechen mehr oder weniger organisierter Kleinbanden oder grösser strukturierten Verbrechergemeinschaften dar. Sampson weist darauf hin, dass die Shadow-Storys ein eher nostalgisches Verbrecherbild präsentieren: «Gibson's version of the underworld was, in fact, based on the New York street gangs of 1900 , rather than the more sophisticated, Mafia-based organization that rose during the $19205 . »^{206}$ Dies stimmt wohl, was den Aufbau der Unterwelt mit den zahlreichen Mobs angeht. Indessen ging die erste Hälfte

in den I920er-Jahren Entfremdung, Machtlosigkeit, Leere und Frustration zentrale Themen waren. Laut Baumeister äusserte sich hierin das Zeitgefühl: Die Menschen fühlten sich unentrinnbar im Griff sozialer Zwänge und Kräfte, die dem Individuum gegenüber gleichgültig schienen.

203 Die Vorstellung der Stadt erstreckte sich auch dann zwischen zwei Polen: der Verkörperung von Idealismus und dem Sumpf aus Korruption und organisiertem Verbrechen, woraus die Stadt einen Nimbus zog, der Gefahr und Abenteuer verhiess (O'Connell I995, I 22f.). Diese zwei Topoi prägen freilich die Wahrnehmung der Grossstadt schon seit der Antike, bereits das alte Rom galt den einen als Hochburg der Zivilisation und den andern als verachtenswerter Sündenpfuhl.

204 Gerade als Sitz der Wall Street erschien New York auch während der Depression als die symbolische Stadt der USA, wie O’Connell (ebd., 207) erklärt. Im Gegenzug war dann die New Yorker World Fair, die Weltausstellung 1939/40, deren Motto «Building the World of Tomorrow» lautete, Ausdruck eines Gefühls der Genesung und der Zukunftshoffnung (ebd.).

205 Einige der ikonografischen Gebäude New Yorks wurden Anfang der 1930er-Jahre gerade erst fertiggestellt (u. a. Chrysler Building 1930, Empire State Building 193 I, Rockefeller Center 1932); vgl. ebd. und zur Repräsentation von New Yorks Architektur in den Künsten Lindner 2015 , bes. I I -24 .

206 Sampson 1989, I I r. Server $(1993,94)$ sieht das Setting des Shadow allerdings noch in einem anderen Licht: «The setting [...], although ostensibly contemporary, had little in common with the mean streets realism of pulp crime fiction of that time [gemeint sind wohl die 〈klassischen> hard-boiled-Figuren wie Dashiell Hammetts Continental Op und Sam Spade]. Filtered through Walter Gibson's theatrical imagination, The Shadow existed somewhere near the foggy gaslit 
der I930er-Jahre, als die Depression wie auch die Prohibition noch andauerten, als «Enemy of the State»-Jahre in die Verbrechensgeschichte ein, in denen überdurchschnittlich viele Gewaltverbrecher ihren berüchtigten Ruf erwarben und Shootouts zwischen Polizei und Gangstern erschreckend häufig Schlagzeilen lieferten. Dies schildert rückblickend auch Shadow-Autor Walter Gibson:

When The Shadow stories began in I93 I, mob crimes were rampant. New Number One Enemies were popping up as fast as the newly activated FBI could shoot them down. Prosperity was giving way to the Depression and the New Deal was still unknown. So it was only logical that The Shadow should be doing his part to bring order out of chaos. By 1936 Recovery was under way, but the gradual collapse of the League of Nations and impending European war clouds marked an era of international intrigues that fitted with the schemes of master villains. By 194I World War II was a grim reality. ${ }^{207}$

The Shadow und seine beiden Kaliber-45-Handfeuerwaffen scheinen dabei der Realität doch weniger fern, als einem lieb sein kann. Wie Goulart ausführt, waren es gerade die Depressionsjahre, die den Detective Pulps endgültig den Aufschwung brachten - laut ihm wurden zwischen 1929 und I94 I (dem Kriegseintritt der USA) über I60 neue Detektiv-Titel eingeführt, von I930 bis I935 zählte Goulart 85 neue Titel an «mystery and crime pulps». ${ }^{208}$ Gary Hoppenstand vertritt die Auffassung, dass die «Gewaltorgien» der pulp vigilante beroes nach $193 \mathrm{I}$ in den «mean streets of Depression America» insofern den Zeitgeist bzw. die Wünsche der Leserschaft abbilden, als sie eine einfache Lösung für komplexe Probleme bieten. ${ }^{209}$

Obwohl es in manchen Geschichten einen Mafia- oder Gangsterboss unschädlich zu machen gilt (etwa Rook Hollister in Lingo), entpuppen sich häufiger (scheinbar) wohlsituierte und angesehene, aber überaus gierige Geschäftsleute

world of Sherlock Holmes and Count Dracula.» Allerdings hat Gibson selbst Dracula als eine Inspiration für seinen Protagonisten genannt (Murray 2006).

207 Gibson 1979, ix-x. Ähnlich beschreibt dies auch Goulart I 988, 5 I.

208 Goulart I988, 5 I. Dazu gehören freilich auch die Privatdetektive der hard-boiled school. Schon in den späten I $920 e r-J a h r e n$ aber hatte die Prohibition die Darstellung von Kriminellen als «acceptable dramatic characters» ermöglicht, woran auch der ebenfalls entstehende Gangsterfilm grossen Anteil hatte (ebd., I9). Vgl. dazu auch Darowski 2009, 5of., ferner Pepetone 2005. In den Ruf einer Gangsterstadt kam vor allem Chicago.

209 Die Depression sei damals nicht als soziales, sondern persönliches Problem und nicht durch ein fallierendes System, sondern individuelles Versagen verursacht verstanden worden. Entsprechend habe man sich dem traditionellen puritanischen Arbeitsethos zugewandt, so Hoppenstand (1983), was sich in den Pulp-Formeln spiegle: Für die Kontrahenten tödliche Selbstjustiz ersetzt dort die unfähige Staatsgewalt. Allerdings irrt Hoppenstand, wenn er meint, die meisten Pulp-Schurken gehörten den untersten sozialen Stufen an. Dies gilt zwar für die Mobs oder Fremdenstereotypen (Asiaten), deren Bosse sind aber häufig gut situierte Geschäftsleute. 
als die grossen Fieslinge, sofern es sich nicht sowieso um «master villains» ${ }^{210}$ handelt, die quasi beides mit Machthunger und Shadow-Beseitigungsgelüsten verbinden. Häufig wird erst auf den letzten Seiten enthüllt, wer als geheimer Drahtzieher hinter allem steckt (was The Shadow in der Regel spätestens in der Mitte der Story herausgefunden hatte und was die Leser mit etwas Erfahrung durchaus erraten können $\left.{ }^{211}\right)$. Zwar sind die «mob henchmen» meist von Anfang an bekannt, doch sind diese in der Regel nicht mehr als Mittelsmänner. Genau besehen ist die Welt des Shadow also nicht so <einfach ' gestrickt, wie es seine Waffengewalt gegen Kriminelle nahelegen mag. Die Geschichten um The Shadow lassen sich vielmehr als ein dauerndes, zusätzlich durch die Erzählweise betontes Spiel mit Identitätsverschleierungen und -enthüllungen bezeichnen, sowohl auf Seiten des Helden wie auf Seiten der grossen Bösewichte. Die Metropole erscheint als Nährboden multipler Identitätskonstruktionen, die sich jedoch hinter einer Fassade als Vexierspiegel zwischen Sein und Schein präsentieren. ${ }^{22}$

Von allen (hier besprochenen) Pulp-Figuren erscheint The Shadow am konsequentesten als eine Ansammlung von Rollen, in der eine ‘wahres, eine 〈Kern>-Identität nicht greifbar bleibt. Selbst wenn man eine solche zweifellos in der Verkörperung von «The Shadow» sehen kann, bleibt dieser 〈Kern〉 seines Wesens letztlich geheimnisvoll. Die räumliche Abbildung dazu liefert das Sanctum des Shadow: Dieses ist nur durch ein Telefonkabel mit der Telefonzentrale ${ }^{213}$ von Agent Burbank verbunden, doch stellt der inmitten der pulsierenden Stadt völlig abgeschnittene, bis auf eine einsame Lampe stets völlig verdunkelte und schalldichte Raum als Denkraum und Kommandozentrale den 〈Kern〉 der Shadow-Operationen dar. Doch selbst in diesem völlig privaten Raum bleibt The Shadow auch für die Leser stets The Shadow, wie sein jeweiliges Lachen dort deklariert - so entsteht Goularts Eindruck: «The Shadow never appears before the reader undisguised.» $»^{214}$

2 I0 Gibson 1979, ix.

2 I I Wie Sampson (1989, I I I) schreibt: «His agile mind was always four chapter ahead of everyone else.»

2 I 2 Vgl. Bukatman (2003, 2 I If.), der dieses Thema (für Superhelden) im Rückgriff auf Simmel ebenfalls streift: «Superheroes are all about multiple identities and so embody the slippery sense of self that living in the city either imposes or permits. [...] The city was a place of aspiration and anonymity, a site of failure and rebirth. [...] In the city, [...] the crowd becomes you, and you wend your way through the crowd. [...] superheroes play a continuous game of deception and duplicity that could only be played in the city. Admittedly, none of these characters approach the ambiguity of The Shadow [...].»

2 I 3 Tatsächlich verfügen gerade diese beiden Orte, als Schaltstellen die einzigen örtlich fixierten Elemente im Shadow-Agentennetz, über keine sichtbaren Verbindungen bzw. Nachbarschaften $\mathrm{zu}$ andern Räumen.

2I4 Goulart 1972, 45, und 1988, I75. 
Gewisse Probleme umgeht The Shadow durch seine «Nichtexistenz in Zivil〉 (die regelmässigen Verpflichtungen eines «gewöhnlichen` Soziallebens existieren für ihn nicht), vor allem aber verweigert er durch seine Beweglichkeit bzw. Identitätsflexibilität die Konformität, obwohl er diese in seinen vielen Rollen durchaus vorspiegelt und zu nutzen weiss. The Shadow zeigt keine Spur von Ohnmachtsgefühlen gegenüber einem überwältigenden Stadtgefüge. Indem er nicht nur sämtliche Geheimgänge der Stadt, sondern auch ihr Sozialsystem unterwandert, gelingt es ihm stets aufs Neue, die Herausforderungen der Grossstadt und ihrer Schattenseiten zu überwinden.

Als wandelndes Identitätsrätsel ist The Shadow unter Pulp-Gestalten einzigartig, doch aufgrund seines Erfolgs wurden rasch vergleichbare fiktionale Welten mit ähnlich gelagerten - vielleicht aber schon «klassischer» maskierten - Protagonisten geschaffen, die nun in den Mittelpunkt rücken.

\section{The Phantom Detective/Richard Curtis Van Loan, The Spider/Richard Wentworth, The Black Bat/Tony Quinn und The Green Ghost/George Chance}

In den Pulps der 1930er-Jahre traten maskierte Helden erstmals gehäuft auf, wobei unter dem Sammelbegriff Verbrechensbekämpfer die Grenzen zwischen maskierten und maskenlosen Protagonisten nicht scharf zu ziehen sind. Beispielsweise benutzt The Whisperer - tagsüber New Yorks jüngster Polizeidirektor «Wildcat» Gordon - keine eigentliche Maske, während der Spion Red Finger, der zur Tarnung eine kleine Buchhandlung führt, für seine Aktionen eine graue Maske (und Handschuhe mit einem roten Zeigefinger) anzieht. ${ }^{215}$

Neben jenen Figuren, die sich die Verbrechensbekämpfung im Allgemeinen auf die Fahne geschrieben hatten, gab es eine kleinere Gruppe, die ihre Aktivitäten spezifischer fokussierte: die Rächer. In ihren Geschichten ist meist ein Konsortium für den Ruin, seltener den Tod eines Familienangehörigen verantwortlich, wofür die Protagonisten zielbewusst Vergeltung suchen, womit die Rachemotivik aus Dumas' Le Comte de Monte-Cristo und Févals Le Bossu aufgegriffen wird. ${ }^{216}$ Wie die Gentleman-Gauner neigen sie dazu, ihre Opfer jeweils vorzuwarnen; dies gehört etwa zum modus operandi von The Mongoose alias Sidney Carleigh, der zusammen mit seiner Schwester Eleanor seinen Vater rächt, der als unschuldig Verurteilter im Gefängnis gestorben ist (Abb. I 5$){ }^{217} \mathrm{Oft}$ ist dabei in der erzählten Welt

2 I $5 \mathrm{Zu}$ den 49 Whisperer-Storys (1936-1939) in The Shadow vgl. v. a. Sampson I989, 38-52; Goulart 1972, 56. Die I 2 Red-Finger-Storys (Zagat 2010) erschienen 1934-1938 in Operator 5.

216 Es fällt auf, dass es sich meist um relativ unpersönliche «Racheverhältnisse> handelt. Selten erfolgt die Rache für ein vom Helden selbst erlittenes Unrecht - wie es im Comte de MonteCristo der Fall war -, sondern für einen Verwandten, meist Vater oder Onkel.

217 McCulley 1932. Von The Mongoose gab es 9 Geschichten in Detective Fiction Weekly (1932/33). 


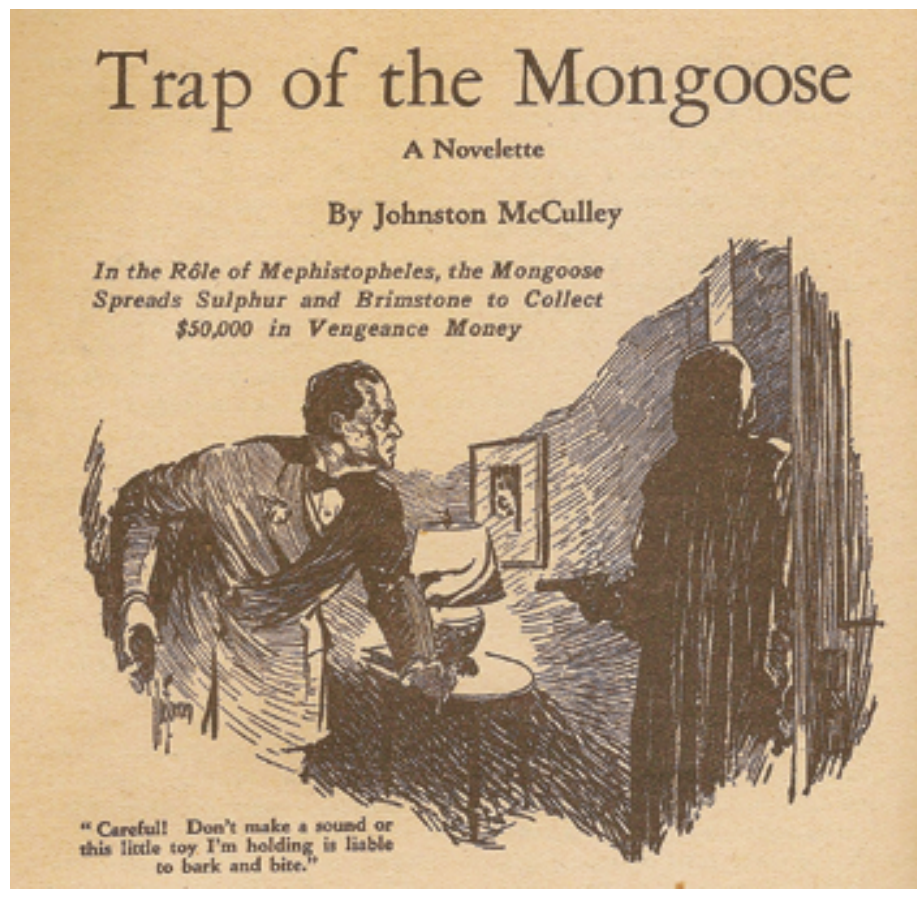

Abb. is: Wie das eher simple Kuttenkostüm von The Mongoose zeigt, legten die frühen maskierten Helden noch wenig Wert auf ein Kostüm, das visuell auf ihren Namen Bezug nimmt, sondern beschränkten sich meist auf eine Domino- oder eine solche Kapuzenmaske. Bezeichnenderweise nimmt der maskierte Rächer auf diesem Bild, wenn man es ohne Kontextwissen betrachtet, eine <Verbrecherhaltung> ein. Detective Fiction Weekly, 27. Mai I933, Innenillustration, Künstler unbekannt.

recht naheliegend, wer die rächende Kraft sein muss, doch ziehen meist weder die Polizei noch die designierten Opfer den richtigen Schluss. Da sich diese Strafaktio-

Johnston McCulleys Portfolio maskierter Helden wäre wohl nicht komplett gewesen, wenn er nicht ebenfalls solche Rächerfiguren erfunden hätte. Nebst dem Thunderbolt in den Pulps (1920/2I) ist seine einzige maskierte Heldin erwähnenswert: The Masked Woman erschien am 2. Januar I92 I in der Washington Post. Dennoch hat die Geschichte einen männlichen Protagonisten, den etwas schrulligen Anthropologen James Xenophon Salwick. Er wird zufällig zum Gehilfen von Mme Madcap, die aber nie in Zivil auftritt und ihre Identität erst am Schluss enthüllt: Mit der Hilfe ihrer Zwillingsschwester Dorcas hat sich Doris «Madcap» Darcan als Kriminelle inszeniert, um einem angesehenen Herrn eine Falschaussage zu vergelten, die für ihren Vater böse Folgen hatte (McCulley 2006). 
nen gegen konkrete Racheopfer wenden, ist die Anzahl der Abenteuer im Prinzip von Anfang an begrenzt, bis die Rache komplett ist. ${ }^{218}$

Auch hier sind die Übergänge fliessend: Nicht selten weiten Protagonisten die Vergeltung für (am eigenen Leib) erlittenes Unrecht zu einer Bekämpfung krimineller Machenschaften im Allgemeinen aus. Dies ist etwa der Fall bei The Green Ghost alias Danny Blaney (von Johnston McCulley) und The Bat alias Dawson Clade - der eine verliert wegen eines ihm angehängten Verbrechens seine Polizeiuniform, der andere landet deswegen auf dem elektrischen Stuhl und wird zu Beginn seiner Geschichte in hochdramatischen Szenen in letzter Minute davor bewahrt ${ }^{219}$ - oder The Crimson Mask alias Robert «Doc» Clarke, der nach dem gewaltsamen Tod seines Vaters beschliesst, nicht nur Drogist zu werden, sondern (mit Billigung des Polizeichefs) auch eine Karriere als privater Verbrechensbekämpfer zu verfolgen.

Einzelne maskierte Verbrechensbekämpfer finden sich zudem in variierten Situierungen. So kreuzte Arch Whitehouse in seinen The Griffon-Kurzgeschichten den maskierten Helden mit dem Piloten. Denn das Aktionsfeld von Ballistikexperte Kerry Keen, der als The Griffon eine rote Maske unter seiner Fliegerbrille trägt, ist der Himmel über New York, wo er mit seinem Kumpel Barney und einem genialen Kampfflugzeug Saboteuren und anderen Verbrechern keine Chance lässt und einen der skrupellosesten maskierten Helden überhaupt abgibt. ${ }^{220}$

Vielleicht nicht zufällig ist es die wohl einzige maskierte Heldin der I 930er-Jahre, die man als Gentlewoman-Gaunerin bezeichnen könnte: Ellen Patrick wird nach dem Verlust ihres Vaters als Domino Lady zur Juwelendiebin, die zwar manchmal auch um soziale Gerechtigkeit bemüht ist, aber weniger als Verbrechensbekämpferin im engeren Sinn zu sehen ist. ${ }^{221}$

2 8 Das hält die Pulp-Autoren indes nicht davon ab, einen beendeten Storyzyklus wiederzubeleben: In D. L. Champions Alias Mr. Death (1932 in Thrilling Detective) begeht der Protagonist Jimmy am Schluss der letzten Story anscheinend Suizid, um seinerseits für seine Rachemorde zu sühnen, 1939 gab es dann aber zwei Fortsetzungen von G. F. Eliot (Champion/Eliot/Ward 2009).

219 Von The Bat gab es leider nur vier Storys in Popular Detective, 1934/35. Von einem anonymen Autor unter dem Hauspseudonym C. K. M. Scanlon publiziert, wurden sie zwar Johnston McCulley zugeschrieben, doch bleibt dies letztlich spekulativ. Obwohl Dawson Clade als tot gilt, kommt immer wieder vor, dass er seine Identität dennoch sorgfältig schützen muss. In The Bat Strikes! findet sich die Vorlage für jene Szene in Batmans Origin-Story, als die Fledermaus ins Zimmer fliegt (vgl. das Batman-Kapitel). Auch Clade benutzt übrigens schon ein schönes Bat-Arsenal, z. B. «hypodermic needles», Bat-Stempel, Bat-Lichtprojektionen etc. (McCulley 2009).

220 Die Griffon-Storys erschienen ab 1935 in Flying Aces (Whitehouse 2010).

22 I Von dieser «adventuress» (Anderson 2005, 46, Emeralds Aboard, Kap. I) gab es 1936 nur gerade 6 Storys in Saucy Romantic Adventures (wovon nur fünf Hefte erschienen) und Mystery Adventure Magazine. 
Der Inhalt der Geschichten war selbstverständlich gewissen Strömungen unterworfen. Namentlich waren es im Zweiten Weltkrieg (vor allem nach dem Kriegseintritt der USA Ende I94I) nicht mehr hauptsächlich racketeers oder master villains, sondern Saboteure und Spione fremder Mächte, die es in allen möglichen Formen (und Farben) zu bekämpfen galt. Nach dem Krieg dagegen glitten die Geschichten oft in ruhigere Fahrwasser; so waren öfter lang vergangene Verbrechen aufzuklären. ${ }^{222}$

Nach diesem kleinen Rundblick wird der Fokus in diesem Kapitel auf vier Beispiele ${ }^{223}$ gelegt, deren Publikationsdaten wie folgt lauten: The Phantom Detective und The Spider kamen klar als Nachahmungs- und Konkurrenzprodukte von The Shadow auf den Markt. Trotzdem verfügten sie über genügend eigenes Profil, um ebenfalls jahrelang erfolgreich zu sein. The Phantom Detective ist dabei der langlebigste Pulp-Titelheld überhaupt. Seine Publikationsgeschichte erstreckt sich über volle zwanzig Jahre, von Februar 1933 bis 1953 erschienen I70 Geschichten von verschiedenen Autoren unter den Pseudonymen G. Wayman Jones und Robert Wallace. ${ }^{22}$ The Spider, dessen Geschichten im Ruf besonders drastischer Gewalttätigkeit stehen, schwang sich von 1933 bis I 943 I I 8-mal in den Kampf gegen allerlei grausame Bösewichte. Nach den ersten beiden Storys von R. T. M. Scott ${ }^{225}$ wurde als Verfasser «Grant Stockbridge» angegeben, wobei die meisten Geschichten aus der Schreibmaschine von Norvell Page (1904/06I 96I) stammten. ${ }^{26}$ Als letzter «grosser> Held nach der Façon des Shadow gilt The Black Bat, Titelheld von Black Book Detective (Magazine), der 1939 fast zeitgleich mit den Batman-Comics das Licht der Welt erblickte. ${ }^{27}$ Doch während

222 Vgl. Johnson 2010. Sogar Bühnenzauberer George Chance trägt im Krieg sein Scherflein bei: Ohne dass der Krieg in der Handlung thematisiert würde, wird nebenbei erwähnt, dass er zwar nichts gegen Spieler habe, aber «he could not endure the thought of the men of America's army losing to gambling crooks» und deshalb Soldaten deren Tricks aufzeige (Fleming-Roberts $20 \mathrm{I}$ I, 83, The Case of the Bachelor's Bones (1943), Kap. I).

223 Überblicke über die Protagonisten der Single-Character Pulps bieten u. a. Goulart 1972 und I988, Server 1993 sowie bes. Sampson 1989, und zwar zum Phantom Detective 7-19, zum Spider 66-75, zum Green Ghost 52-66; zum Phantom Detective vgl. bes. auch die Beiträge im Phantom Detective Companion (Johnson et al. 2009); zu The Black Bat vgl. Johnson 2010.

224 The Phantom Detective kam recht spät (1946-1949) auch zu Comic-Ehren in Thrilling Comics 53-62/65-70 sowie America's Best Comics 26, teilweise abgedruckt in Johnson et al. 2009, digital lückenlos zu finden.

225 Es ist unsicher, ob dieser Name für Reginald Thomas Maitland oder dessen Sohn Scott stand.

$226 \mathrm{Zu}$ The Spider gab es auch zwei sog. movie serials, 1938 The Spider's Web (Regie: James W. Horne, Ray Taylor) und 194I The Spider Returns (Regie: James W. Horne).

227 Unter diesem Titel war das Heft schon seit 1933 erschienen, fokussierte jedoch erst mit Black Bat auf einen Protagonisten. Dabei wäre es fast zum Rechtsstreit mit DC wegen Batman gekommen (Murray 2007, 70). So erschien eine relativ kurzlebige Comic-Reihe unter geändertem Namen - The Mask - in Exciting Comics I-20 (1940-42). - The Black Bat alias Tony Quinn ist 
Batman seither nie out of publication war, bedeutete das Ende der Pulps auch das Ende von The Black Bat. ${ }^{228}$ Nachdem die Publikationsabstände immer grösser geworden waren, erschien die letzte von 63 Bat-Stories I953. Bat-Hauptautor war Norman A. Daniels (1905-1995), veröffentlicht wurden die Geschichten unter dem Pseudonym G. Wayman Jones. The Green Ghost schliesslich vertritt die oft kurzlebigeren Helden, die in den I940er-Jahren an die Erfolge ihrer Vorbilder anzuknüpfen versuchten. Vom Green Ghost gab es von I 940 bis 1943 zunächst sieben Single-Character-Hefte, ${ }^{229}$ danach trat er noch in sechs deutlich kürzeren Storys in Thrilling Mystery auf, alle verfasst von G. T. Fleming-Roberts (eigtl. George Thomas Roberts, i910-1968).

Allen diesen Verbrechensbekämpfern gemeinsam ist eine Aversion gegen «red tape», die Schlupflöcher bietende Bürokratie, die die effiziente Arbeit der Polizei wie der Justiz verhindert, was sie mit ihren Aktionen wettzumachen versuchen. Stets wird betont, dass (nur) ihre Vorgehensweise mit ungewöhnlichen - und das heisst illegalen - Mitteln ermöglicht, die Gesetzesbuchstaben zu umgehen und so den Geist der Gerechtigkeit umzusetzen bzw. im Kampf gegen die Kriminalität zu verteidigen, wie es etwa für Black Bat in Anspruch genommen wird: «The cold eyes that gleamed through the slits in the mask made Warner chill. Yet he knew those eyes were those of an honest man, of an individual who fought on the side of the law. Without the law's red tape, possibly, and without much mercy for desperadoes who shot and killed their way to riches. ${ }^{23} 3^{\circ}$ Entsprechend sieht Sampson in seiner kleinen Pulp-Helden-Typologie diese Figuren als eine Variante des bent hero, als sogenannte justice figures, die er wie folgt definiert: «A justice figure has voluntarily stepped outside the law to correct injustices that the law and its representatives are unable to deal with it. Seeking neither personal

nicht zu verwechseln mit mindestens zwei ähnlich bzw. gleich benannten Pulp-Protagonisten, dem bereits erwähnten The Bat alias Dawson Clade (1934/35) und The Black Bat, einem maskenlosen Detektiv (sechs Ausgaben The Black Bat Detective Mysteries, 1933/34, von Will F. Jenkins unter Murray Leinster). Zudem gab es offenbar noch einen Black Bat in Flying Aces: The Blue Ghost Patrol (Oktober 1932, von Lester Dent).

228 Dies gilt jedenfalls für die folgenden Jahrzehnte, denn nach der Jahrtausendwende belebte der Dynamite-Verlag in seinen Comics diverse einschlägige Pulp-Helden in eigenständigen Interpretationen neu, darunter The Shadow, The Spider und The Black Bat (sowie u. a. die ehemaligen Radio-Stars The Green Hornet und The Lone Ranger).

229 Die ersten drei Ausgaben erschienen unter The Ghost Super-Detective, das vierte Heft hiess The Ghost Detective, die letzten drei The Green Ghost Detective. The Green Ghost alias George Chance ist nicht zu verwechseln mit dem gleichnamigen Helden von Johnston McCulley (alias Danny Blaney, 1934/35). Zum Green Ghost gab es ferner eine Comicreihe The Ghost in Thrilling Comics 4-52 (1940-1946), die ausser der Hauptfigur jedoch nichts mit den PulpStorys zu tun hatte (kurioserweise besass dieser George Chance in Tibet erworbene okkulte Kräfte und ging vor allem auf Zeitreisen).

230 Daniels 2010, 258, Murder Calls the Black Bat (1939), Kap. XXI. 
gain nor revolution, he is an agent of stabiliy, a freelance law enforcement agent $[\ldots] » .{ }^{231}$ Dabei übernahmen alle Ausprägungen dieser Spielart der r93oer- und I940er-Jahre, so Sampson, «the cracksman's skill» eines Jimmie Dale. ${ }^{232}$

Den einzelnen Protagonisten werden dabei von der Polizei verschiedene Haltungen entgegengebracht. The Phantom Detective gehört zu den Helden, die das uneingeschränkte Vertrauen der Polizei geniessen; er ist sozusagen ein <externer Superpolizist>. So wird er etwa per Kurzwellenradio gebeten, an einen Tatort zu kommen, später gibt es sogar ein Phantom Light (ein rotes Licht auf dem Clarion Building) - vergleichbar mit dem späteren Batman-Leuchtsignal. Der Phantom Badge, gewissermassen eine Identitätskarte in Form einer Maske aus Platin, sichert ihm die volle Unterstützung sämtlicher Polizisten, selbst wenn sie ihn noch nie gesehen haben. Auch der Green Ghost agiert mit der Billigung und auf Bitten des örtlichen Polizeichefs. Dagegen sind The Spider und The Black Bat von der Polizei als Verbrecher gesucht und müssen die Verhaftung fürchten, obwohl die Polizei ihre Aktionen insgeheim begrüsst und in der Regel dennoch kooperiert: «My duty», sagt Commissioner Warner zu Tony Quinn alias The Black Bat, «is to put him behind bars. But my heart tells me to shake his hand.»233

Üblicherweise führen die Pulps maskierte Helden als in der erzählten Welt bereits bekannte Grössen ein und beginnen nicht mit der Heldwerdung des Protagonisten (eine Ausnahme ist The Black Bat von 1939). Dennoch erhalten die maskierten Helden der i93oer-Jahre in der Regel eine Hintergrundgeschichte, die erklärt, was den Protagonisten dazu bewogen hat, das Verbrechen als maskierter Held zu bekämpfen, wie er zu seinen Mitstreitern gekommen ist und was diese auszeichnet. Meistens nämlich agiert der maskierte Pulp-Held der I930erund I940er-Jahre in einem kleinen Team von Eingeweihten. Die Origin-Story wird in der Regel als nacherzählte Information relativ früh in die jeweilige Geschichte eingeschaltet. So wird den Lesern anhand der Hauptfiguren als narrative Koordinaten im Prinzip stets zuerst erklärt, welchem Muster die Geschichte folgt. Wie bereits erwähnt, liegt der Fokus des Erzählens in den Pulps nicht auf der Entwicklung der Charaktere (obschon es solche - mitunter aus publizistischen Gründen - durchaus geben kann), vielmehr resultiert der narrative Reiz aus der erneuten, variierten Erfüllung des Schemas.

Interessanterweise muss die Idee, maskiert den Kampf gegen die Kriminalität anzutreten, nicht unbedingt vom Protagonisten selbst stammen. Bei Richard Curtis Van Loan (kurz «Van») war es nämlich sein bester Freund, der

23 I Sampson 1983, I 1 0 . Sporadisch nennt er die justice figures auch avenging heroes (ebd., I 20).

232 Ebd., I 20.

233 Daniels 2010, 168, Murder Calls the Black Bat (1939), Kap. VI. 
Zeitungsverleger Frank Havens, der ihm dieses Wirkungsfeld nahelegte. Vans Entscheidung, zum Phantom Detective zu werden, basiert letztlich auf einem vom Zeitgeschehen verursachten Bruch in seiner Biografie. Zwar früh verwaist, aber wohlbehütet und mit reichem Erbe gross geworden, zieht Van als Pilot in den Ersten Weltkrieg. Im Kontrast zu seinem bisher völlig sorglosen Leben wirken die Kriegsgräuel auf ihn umso mehr wie ein äusserst krasser Kulturschock, der ihn erkennen lässt, wie bedeutungslos sein vorheriger Lebensstil war. Nach Kriegsende gelingt Van die Rückkehr ins friedliche zivile Leben nicht besonders gut - aus heutigem Blickwinkel lässt sich seine Phantom-Tätigkeit als eine Art Therapieversuch eines Kriegstraumas betrachten, wie die folgende Beschreibung aus Diamonds of Death (1934) nahelegt:

It was then that he realized for the first time the utter futility of his own life. He had come from the world of illusion to the grim realities of the most terrible war that man had ever waged. [...] He knew he could never return to the juvenile pleasures which had concerned him before [...]. Van Loan returned home - [...] to a lie far more empty than ever it had been before. After a time, when he thought his nerves must crack under the enforced prosaic life of peacetime, Havens had suggested a course to him, which had metamorphosed his whole life. As a journalistic stunt to aid the circulation of his paper, Havens had suggested that Van essay to solve a murder mystery [...]. ${ }^{234}$

Für Havens stand hinter seinem Vorschlag (in dieser Version) ein eigener Nutzen in Form von Schlagzeilen, doch ist die Presse bzw. die öffentliche Meinung in den Phantom-Storys eher selten ein Thema. Obschon hier erklärt wird, dass Vans ganzes Leben durch das Phantom-Sein verändert wurde, lässt sich vor dem Kriegshintergrund behaupten, dass er gewissermassen den Kriegszustand in seinem Leben verlängert, indem er die Gegner auf dem Schlachtfeld durch die Kriminellen an der «home front» ersetzt (Abb. I6). Van springt entsprechend sofort auf den Vorschlag an; diesen umzusetzen, bedeutet jedoch auch ein grosses vorbereitendes Engagement. Stets wird darum betont, dass Van sich in intensivem Lernen alle möglichen Kenntnisse und Fähigkeiten angeeignet hat, die die Verbrechensbekämpfung erfordert: «And as the underworld could testify in fluent profanity, thus far he had brilliantly succeeded.»235

Auch beim Green Ghost liefert nicht der Held selbst, sondern der Polizeikommandant Edward Standish die Idee, die besonderen Fähigkeiten von George

234 Wallace 2008, 20f., Kap. III. Dass er im Krieg ein Actionbedürfnis erworben hat, wird noch deutlicher schon in der ersten Story, Emperor of Death (1933), formuliert: «On the flaming Eastern front he had learned to grapple with death daily. Furthermore, he had learned to like it. Peace-time adjustment was hard-impossible. That was the reason he had so eagerly jumped at his best friend's suggestion to combat crime in the rôle of the Phantom» (Jones 2008, I3, Kap. II).

235 Jones 2007, The Yellow Murders (1933), Kap. XX, 23. 

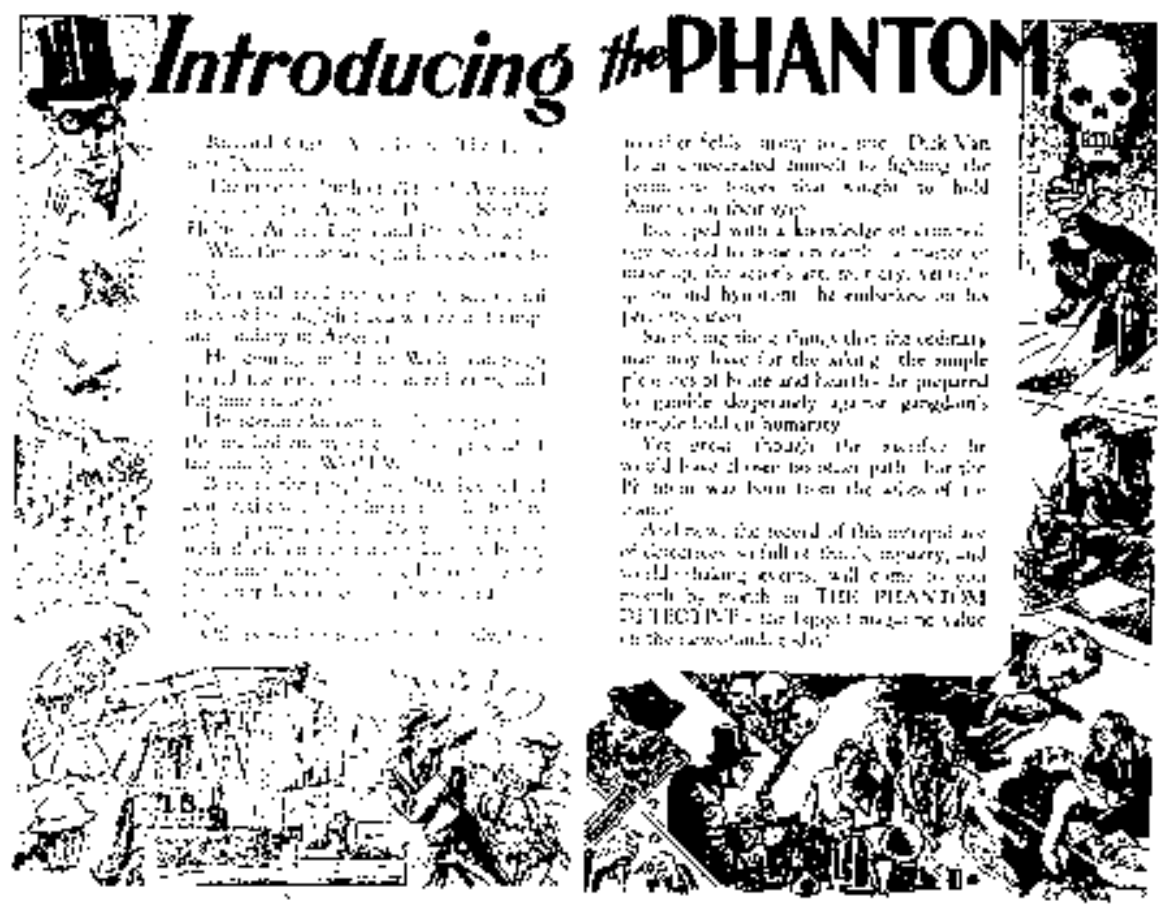

Abb. I6: Im ersten The Phantom Detective-Heft umrahmt dieser Bildrahmen einen Einleitungstext zum Protagonisten. Indem rechts die Kriegsschrecken und links die Verbrecherwelt inszeniert werden, werden diese auch bildlich in Analogie gesetzt. The Phantom Detective, Februar 1933, Innenillustration, Künstler unbekannt.

Chance - seines Zeichens so kometenhaft zu Ruhm gelangtem Bühnenzauberer, dass er bereits eine Magierschule gründen und sich zur Ruhe setzen konnte - für gute Zwecke einzusetzen. Ihre Zusammenarbeit zeitigt schliesslich das Konzept des Green Ghost, wobei es sich um einen längeren Prozess handelte: «In the days and weeks that followed I found one concept more and more dominating my thoughts - Magic and Crime Detection, how to merge the two and make them one. And so, not all at once, but gradually, slowly - but surely, the idea of the Ghost took form.» ${ }^{236}$ (Die ersten Green-Ghost-Geschichten sind in Ich-Per-

236 Chance 2003, 4, The Ghost Strikes Back (1940), Kap. I. Als Inspiration für die Kombination von Detektiv und Zauberer dürfte Harry Houdini, der mehrfach Tricks von Spiritisten entlarvte, naheliegend sein; enge Beziehungen zum Zauberkünstlerzirkel unterhielt aber besonders Shadow-Autor Walter B. Gibson (vgl. Sampson 1989, 54; Tollin 2007b). Im Gegensatz dazu nutzte Douglas Fairbanks Zaubertricks als einen Marker für Diegos vermeintliche Oberflächlichkeit in The Mark of Zorro (1920; was der gleichnamige Film von 1940 beibehielt). Anzumerken ist, 
spektive geschrieben, was äusserst unüblich ist und erst Jahrzehnte später in den Comics Schule machen sollte.)

Beim Green Ghost fällt auf, wie jeweils seine verschiedenen Spezialfähigkeiten aufgezählt werden, die ihn für seine Heldenrolle zu prädestinieren scheinen. Die Grundlagen, nämlich Schminktechnik, Bauchreden, Zaubertricks und Messerwerfen (er zieht Wurfmesser einer Pistole vor, da er kein guter Schütze ist), hat er im Zirkus gelernt, die Detektion hat ihm Standish beigebracht. The Green Ghost verknüpft so die Talente, die er bereits gepflegt hat, mit einem neuen Fachgebiet, in dem er diese gewinnbringend anwenden kann.

Für Richard Wentworth dagegen ist es ein ganz bestimmtes Ereignis, das ihn veranlasst, seine Karriere als The Spider zu beginnen. Diese Origin-Story ist bemerkenswerterweise nicht Bestandteil der ersten Spider-Story, sondern wird nur in «The Web», einer Rubrik am Ende des Heftes, wiedergegeben. ${ }^{237}$ Angesichts eines Unrechts nämlich (einer seiner Lehrer wird fälschlich des Mordes beschuldigt), entscheidet er sich - der Konsequenzen voll bewusst - für ein Dasein als Spider; er wird zum strafenden Mörder des wahren Täters. Dieser Moment stellt eine unumkehrbare Initiation dar: «Gone from that moment on was the Richard Wentworth of classroom and football field. Gone were the dreams and plans he'd made for the future ... And in their place stood the SPIDER, a legendary figure of justice swift and terrible ... A bodiless, unseen scourge [...]. A flaming sword of righteousness [...].» ${ }^{23}{ }^{8}$ Dabei wird Wert auf die Feststellung gelegt, dass Richard davor «quite like the average run of normal human beings» gewesen sei - ungeachtet der Tatsache, dass er ein talentierter Quarterback und aus äusserst vermögendem Haus war. Auch hier greift die textliche Maskierung des sozial bevorteilten Protagonisten als Durchschnittstyp. Doch trügt eben der Schein, denn statt mit seiner Jugendliebe Nita van Sloan ein luxuriöses Leben zu führen, ist seinem Charakter in Wahrheit ein ganz anderes Schicksal angemessen:

But such a fate - such a life - was not in the cards for Richard Wentworth. For within him there burned such fire of zealous righteousness and fierce resentment against wrong as to make impossible those daily compromises with right and wrong which are so necessary a part of modern-day living. He was born a crusader in the truest sense of that glorious word; and a crusader in fact he very shortly became. ${ }^{239}$

dass der Bühnenzauberer oft einige Eigenschaften mit dem Gauner teilt, was wiederum zeigt, wie unscharf die Konturen bei Figuren aus diesen Bereichen sein können.

237 Viele Pulps enthalten wie erwähnt solche Infoseiten über ihre Protagonisten und die Teammitglieder - diese lesen sich oft so, als hätten die Herausgeber den Konzeptentwurf der Figur abgedruckt.

238 The Web, in: Scott 2006 (The Spider. Master of Men!, I933), I 27 (Hervorhebung im Original).

239 Ebd. 
Die Stelle bietet eine der wenigen expliziten Bezugnahmen auf die «Kompromisse» des modernen Lebens, für die ein Held schlicht nicht geschaffen ist, der hier durch die Kreuzritter-Metapher als klar anachronistische Figur entworfen wird. Nichtsdestotrotz ist sein Kampf äusserst zeitgemäss, wie interessanterweise etwa in einer weiteren Rubrik, einer Art Editorial unter dem Titel The Home Frontier in Slaves of the Laughing Death (1940), propagiert wird. Darin wird zunächst festgehalten, dass Pioniere und Abenteurer grosse Ähnlichkeiten miteinander haben und The Spider beides ist. Der Text führt aus: «Every big city is honeycombed with the secret byways of the underworld, every metropolis offers untold opportunities - not only for adventuring, but for pioneering - in crime fighting. ${ }^{24} 4^{\circ}$ Das Betätigungsfeld des <modernen> Helden, die Grossstadt, wird so als Äquivalent der traditionellen exotischen Abenteuerwelten postuliert (Abb. 17). Dies belegen die Protagonisten in jedem Heft durch ihre Erlebnisse und Taten, wobei eben nur die Grossstadt dem mehr oder weniger organisierten Verbrechen einen idealen Nährboden bietet - beispielsweise nur schon durch die grosse Anzahl von Juwelengeschäften und Bankfilialen, die häufig eine ganze Reihe von Kriminaltaten erdulden müssen - und so auch genügend ¿Zielobjekte` für die heldischen Aktivitäten bereitstellt.

Die ausufernde Kriminalität in der Grossstadt stellt denn auch den Grundstein für die ausführliche Origin-Story dar, mit der die Erzählungen um The Black Bat ihren Anfang nehmen. ${ }^{241}$ Da Tony Quinn einen Unfall erleidet und danach ansatzweise ins Fantastische gesteigerte Fähigkeiten bekommt, entspricht diese der typischsten Origin-Variante der Superhelden-Comics - bevor diese in den Comics Wurzeln schlug. ${ }^{242}$ Interessanterweise beginnt bei The Black Bat die Rekrutierung seines Teams schon vor dem schicksalhaften Ereignis. Mitten in der Nacht weckt der Einbrecher Norton «Silk» Kirby sein Opfer, den Staatsanwalt

240 The Home Frontier, in: Stockbridge 2005, 4. Im selben Atemzug wird ausserdem erklärt, warum fiktionale Helden besser sind als reale: «There is more glamour in fiction», weil man das langweilige «ground work» weglassen und gleich zu den «high spots of actual crime adventure» kommen kann: «That is why we find our most adventurous crimefighting pioneers in fiction.» Und klar erscheint The Spider als die Nummer eins dieser Zunft.

24I Wie erwähnt gab es in den früher I930er-Jahren maskierte Rächer, deren Erzählung mit einer Origin-Story begann (u. a. Alias Mr. Death), jene hatten aber noch keine fantastischen Kräfte.

242 Alle einschlägigen Comic-Helden, die vor The Black Bat erstmals erschienen sind, begannen zu dem Zeitpunkt nicht mit einer (Unfall-)Origin-Story. Dies sind namentlich The Clock und (in Zeitungsstrips) The Phantom ab I936, 1938 Superman und der (maskenlose) Zauberer John Zatara in Action Comics I, The Arrow (1938-42 in Funny Pages, Centaur Publications) und The Crimson Avenger (Debüt in Detective Comics 20, Oktober 1938). Ausser Supermans Ausserirdischen-Origin-Story zeigte nur Will Eisners Wonder Man im gleichnamigen Heft (Mai 1939) halbwegs, wie er zu seinen Kräften kam (man sieht, wie er von einem Mann mit Turban einen seine Kräfte symbolisierenden Ring erhält). 


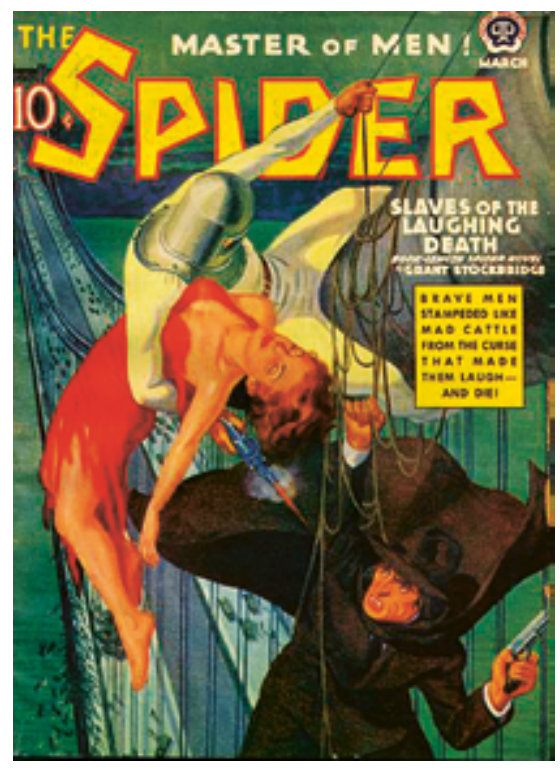

Abb. I7: Dieses typische Spider-Cover mit einer leicht bekleideten Frau in Gefahr weist durch die Brücke im Hintergrund auf die Grossstadt als Abenteuerfeld hin. Dargestellt ist eine Szene, in welcher The Spider an seinem Seidennetz - ähnlich dem späteren Superhelden Spider-Man - eine Brücke entlangschwingt, um Nita zu retten, bevor der Schurke Munro sie in den Abgrund werfen kann. In Umkehrung des üblichen Gut-Böse-Schemas ist die schwarz gewandete Gestalt der Held, während der Schurke an einen Ritter in weisser Rüstung erinnert.

Slaves of the Laughing Death, März 1940, Titelbild von Rafael de Soto.

Tony Quinn, weil unabhängig von ihm auch noch ein Mörder in dessen Haus eingestiegen ist. Von Silk gewarnt, entgeht Tony diesem Mordanschlag, worauf er den ehemaligen con man Silk als Diener einstellt. Doch in der Gerichtsverhandlung am nächsten Tag trifft ihn das Unglück in Form von Säure, mit der ein Handlanger des angeklagten Grosskriminellen Snate die Beweise vernichten will, mitten ins Gesicht. Er überlebt zwar, ist aber unheilbar blind und zieht sich völlig zurück, bis ihm eine geheimnisvolle junge Frau Heilung verspricht, wenn er sich von einem unbekannten Augenarzt in Illinois operieren lasse. Nach einer Hornhauttransplantation verbringt Tony Monate im Dunkeln und bereitet sich mit Silks Hilfe darauf vor, als Erstes dem inzwischen noch mächtiger gewordenen Snate das Handwerk zu legen und dann andere Kriminelle heimzusuchen, wobei bald ebenjene junge Frau, Carol Baldwin, und als Mann fürs Gröbere Jack «Butch» O'Leary zum Team stossen.

Schon während seiner Zeit als Blinder verfeinern sich seine Sinne immens, inklusive einer Art Radarsystem für die räumliche Wahrnehmung. ${ }^{243}$ Dank einer

243 So erklärt Tony: «[...] how strange my sense of touch has become. [...] already I can distinguish things by merely passing my hands over them. [...] Objects I cannot see tend to warn me in some way. I know they are in front of me and I can avoid them» (Jones 2006, I4, Brand of the Black Bat (1939), Kap. III). Später wird dies als Radar - «the blind man's body was almost 
experimentellen Vergrösserung ${ }^{244}$ seiner Linsen in der Operation besitzt er überdies einen übermenschlichen Sehsinn: Selbst bei absoluter Dunkelheit sieht er fast ebenso gut wie bei Tageslicht. Weil die Säure üble Narben hinterlassen hat, braucht er eine Maske; auf die Fledermaus als Namenspatin für seine «nocturnal identity ${ }^{245}$ kommt er, weil Fledermäuse (wie man damals dachte) so blind sind wie er. ${ }^{246}$ Laut Sampson werden die Hinweise auf Fledermäuse bzw. den Fledermausumhang ab I 944 ganz fallen gelassen. Dies mag für die Texte gelten, wo nur noch von schwarzer Kleidung und schwarzer Ganzmaske die Rede ist, nicht aber für die Bebilderung, denn in den Innenillustrationen ist der Fledermausflügelumhang mindestens bis 1949 (vermutlich I952) dargestellt (Abb. I 8). ${ }^{247}$ Schon in der zweiten Geschichte aber hatte Tony Quinn sein Maskenrepertoire erweitert: Da man mit Fledermausumhang und -maske besonders tagsüber schlechterdings immens auffällt, bedient er sich einer narbenbedeckenden Schminke, um auch im Tageslicht unkenntlich und damit beweglich zu sein. The Spider dagegen verfügt über zwei Varianten seiner Heldenmaske(n): Er trägt manchmal nur eine schwarze Dominomaske (insbesondere auf fast allen Titelbildern ${ }^{24}$, Abb. 19), wohl öfter aber schützt eine vampirisch anmutende Fratzenmaske, die ihn ebenso als The Spider kennzeichnet, seine zivile Identität.

In den Pulps verfügen die meisten einschlägigen Protagonisten über verschiedene Abstufungen der Heldenmaske, deren gegenständliche Vollform durch Schminktechniken ergänzt sein oder sogar ersetzt werden kann. Hierbei fällt auf, dass die maskierten Pulp-Protagonisten nebst ihrer «angestammten zivilen

like a radar instrument» (Jones 2010, I3, The Murder Prophet (1947), Kap. IV) - bezeichnet, erstaunlicherweise allerdings ohne einen direkten Bezug zu Fledermäusen herzustellen.

244 Schon in der dritten Story wird dies nicht mehr durch ärztliches Können, sondern als 〈Wunder〉 der Natur («some strange freak of Nature») erklärt und als Kompensation für die erlittene Blindheit gewertet (Daniels 2010, 300, The Black Bat Strikes Again (1939), Kap. 5).

245 Ebd., 283, Kap. II.

246 Tatsächlich sollte der Protagonist offenbar zuerst The Tiger heissen (aufgrund seiner Narben), doch dann befand offenbar der head editor Leo Margulies, eine dunkle Figur passe besser zum bestehenden Magazintitel Black Book Detective (Johnson 2010, I). Als ebenfalls der Dunkelheit verpflichtete Fledermausfigur echote er sowohl The Shadow als auch The Bat/Dawson Clade, von dem er unter anderem die Bat-Kleber und die Wechselbeziehung als Gejagter und Verbündeter der Polizei übernahm.

247 Auf den Titelblättern ist das Bat-Cape letztmals 1947 klar ersichtlich, diese zeigen jedoch oft, vor allem in den späteren Jahren, nur seinen vermummten Kopf im Hintergrund einer Gefahrenszene - ein Gestaltungsprinzip, das sehr oft auch die Cover des Phantom Detective und des Green Ghost prägt.

248 Tatsächlich trägt er auf fast allen Titelbildern eine schwarze Dominomaske, nur von März bis September 1940 wurde er nach einem Leserbrief, der ebendies kritisierte (in: Slaves of the Laughing Death, 1940, Stockbridge 2005, 95; Rubrik The Web), «in full war paint» - mit einer Art Vampirfratze - dargestellt (Abb. 17). 


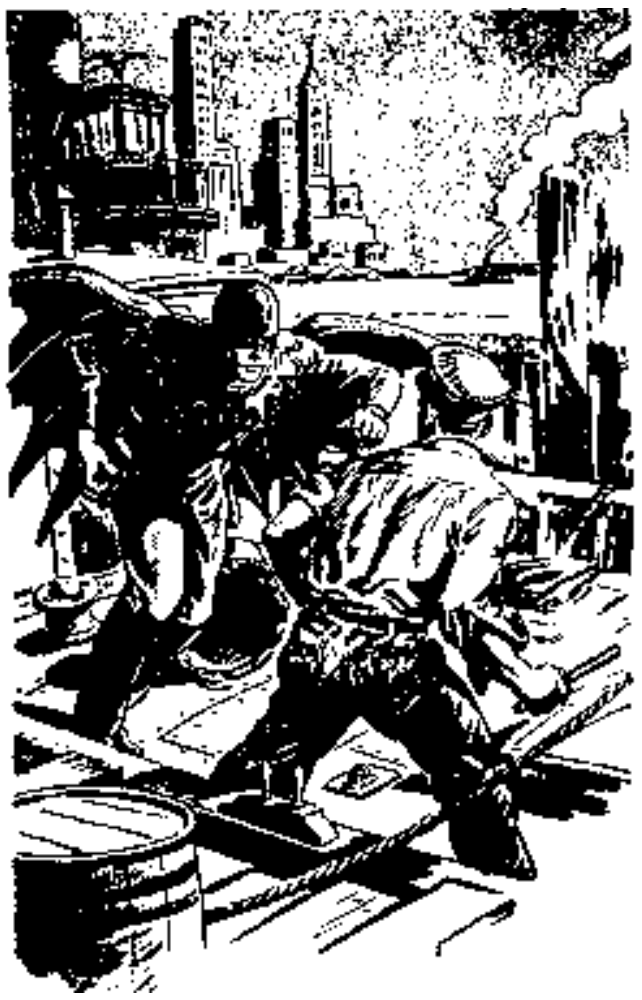

Abb. I 8: Vor dem statischen Hintergrund der Grossstadtarchitektur bringt der wehende Fledermausumhang von The Black Bat Bewegung in die Hafenszenerie. The Black Bat and the Red Menace, in: Black Book Detective, Mai I94 I, Innenillustration, Künstler unbekannt. (CAdventure House

und der Helden-Identität meistens noch diverse weitere Verkleidungen unterhalten («His present rôle was that of $\left.[\ldots] »^{249}\right)$, von denen wie beim Shadow einige mehrfach und andere einmalig gebraucht werden, da sie alle die Utensilien eines Maskenbildners virtuos einzusetzen wissen. ${ }^{250}$ Beides kombiniert der Green Ghost, dessen Maskerade zweistufig konzipiert ist: Zunächst schminkt er sich als möglichst unscheinbarer Zeitgenosse, in Ghost-Action geht dies eine Stufe weiter, zum einen durch das totale Beherrschen der Gesichtsmuskulatur, zum andern durch einen Trick: Auf Knopfdruck beleuchtet seine Krawattennadel sein Gesicht grün, sodass er eben wie ein grünlicher Geisterschädel erscheint. Diese Technik wird im Text explizit gelobt: «His make-up was simplicity in itself - and yet how tricky! As he had frequently remarked to Standish, the Green

249 Fleming-Roberts 201 I, 24, The Case of the Murderous Mermaid (1942), Kap. VII.

250 Teilweise dient die Maskenbildnerkunst der Überhöhung des Helden, beispielsweise bei The Crimson Mask (Johnson 2008), aber auch beim Phantom Detective. So erklärt Havens einmal, als Van sich für einen Einsatz schminkt: «Every time I see you make such a change, I don't believe you're quite human, Dick» (Wallace 2004, 4I, The Grim Shadow of Hate (194I), Kap. X). 
Abb. I9: Auf diesem Cover ist es nicht die Form der Maske, die Richard Wentworth als Spider (mit Dominomaske) kennzeichnet, sondern das Netz im Hintergrund. Zwar ist das heldische Ich als Schattengestalt flüchtiger, doch übersteigt es die zivile Erscheinung an Grösse und wirkt mit den sichtbaren Gesichtszügen und den feuernden Pistolen fast dreidimensional. The Spider and the Scarlet Surgeon, August I94I, Titelbild von Rafael de Soto.

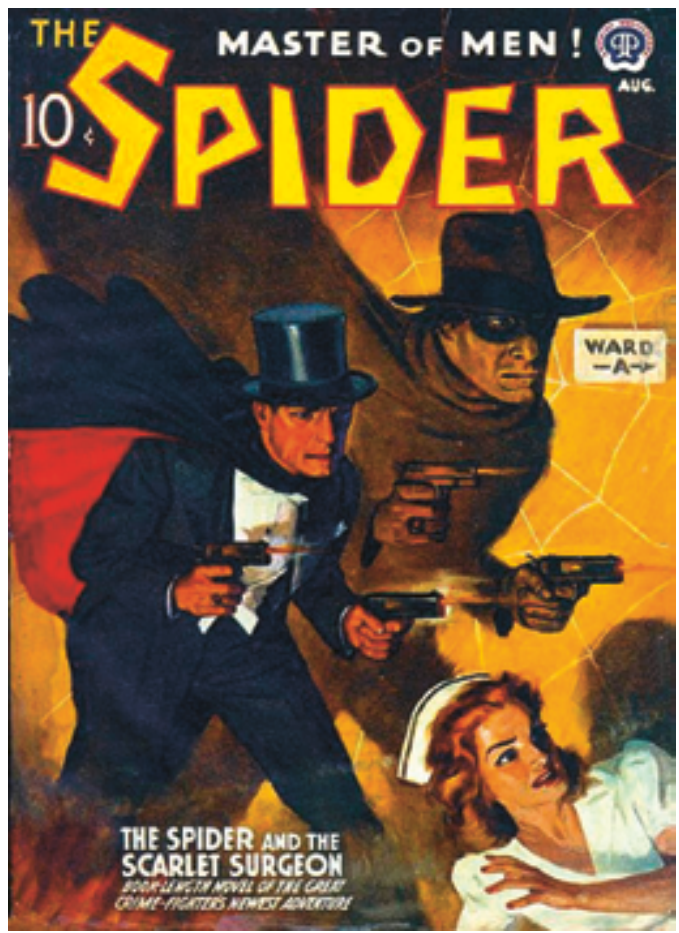

Ghost was two-faced. He could be rather an obscure person, with nothing but night club pallor to distinguish him, or he could instantly change into the laughing death's head which had brought terror to the underworld.» ${ }^{251}$ Diese distinkte Green-Ghost-Maske ist klar darauf angelegt, eine Schreckwirkung zu entfalten. ${ }^{252}$ Wie diese Stelle impliziert, kennzeichnet auch den Ghost ein besonderes Lachen (einmal beschrieben als «the gruesome chuckle that identified the

25 I Fleming-Roberts 20I I, 45, The Case of the Astral Assassin, Kap. II. Falls er keine Zeit für die Grundierung hat, besitzt er für den schnellen Wechsel auch eine Ghost-Gummimaske (ebd., 38, The Case of the Murderous Mermaid (1942), Kap. XI).

252 Dies funktioniert, wie die folgende Stelle belegt: «The effect on the three men who blocked my entrance was evident at once. The gun in the masked man's hand wavered a little. The two toughs bunched close together. Those of the criminal element in New York who have never had direct contact with the Ghost nevertheless know of his existence, have heard descriptions of him. These three knew they were having contact with him now, and were speechless.» (Chance 2003, 29, The Ghost Strikes Back (1940), Kap. XIV). 
Ghost»253). Die anderen Helden lassen dabei eher angesichts unmittelbarer Todesgefahr regelmässig ihr Lachen erschallen.

Dafür, dass die Maske das heldenbestimmende, identifikatorische Requisit darstellt, findet ein relativ flexibler Umgang damit statt, dies gilt zuweilen auch auf der narrativen Ebene. Obwohl etwa die «dual identity» ${ }^{254}$ von Van/Phan(tom) stets behauptet wird, scheint es oft fast Zufall, wie bedeutsam diese in einer Story tatsächlich ist. In der frühen Geschichte The Yellow Murders (1933) beispielsweise wird zwar sein gesamter Charakter inklusive Herkunft und Doppelidentität erklärt, er hat gegenüber anderen Figuren jedoch keinen einzigen Auftritt als Richard Curtis Van Loan. ${ }^{25 s}$

Beim Phantom Detective rücken im Lauf der Zeit Verkleidungen bzw. Schminkmasken in den Vordergrund, während die kennzeichnende schlichte Dominomaske immer seltener zum Einsatz kommt. ${ }^{256}$ Dabei erhält die schwarzseidene Maske bei der ersten Erwähnung noch vollstes Vertrauen, die Identität ihres Trägers zuverlässig zu verhüllen. Sobald er die Maske trägt - «Now satisfied that he was beyond recognition»257 -, kann er loslegen. Doch nur schon im Laufe dieser ersten Story droht ihm dreimal die Entlarvung. ${ }^{258}$ Tatsächlich wird der stets nicht nur als Meisterdetektiv, sondern auch als Verkleidungsmeister präsentierte Phantom Detective erstaunlich oft erkannt oder plaudert selbst sein Geheimnis aus.

Dennoch behält die Geheimhaltung der Doppelidentität, die auch immer wieder explizit als oberste Priorität genannt wird, ihre Wichtigkeit. Erkannt zu werden, ist das Damoklesschwert, welches stets über allen Protagonisten schwebt. So ist vielleicht nicht verwunderlich, dass der Phantom Detective in seiner ersten Ge-

253 Fleming-Roberts 20I I, i 17, The Case of the Broken Broom (1943), Kap. IV.

254 Wallace 2004, 19, Grim Shadow of Hate (194I), Kap. III.

255 Jones 2007. Anzufügen ist, dass The Phantom Detective, obwohl der langlebigste, als jener maskierte Pulp-Held mit den heterogensten Geschichten gilt, da die Autorschaft vergleichsweise häufig wechselte. Darin mag ein Grund dafür liegen, dass die vom Text behauptete Genialität des Detektivs und das während der Handlung gezeigte Ausmass von Klugheit beim Lösen der Fälle auseinanderklaffen. Sampson ( 1989 , I I) erklärt schonungslos: «He investigates by coincidence and escapes by accident.» Server (1993, 95) stösst ins selbe Horn: Phantom-Geschichten «tended to be bloody nonsense».

256 In einer Verkleidung ohne Maske gibt The Phantom allerdings seine Identitätsmarkierung ab, entsprechend braucht er ein Erkennungszeichen, damit seine Helfer Muriel Havens und die später dazukommenden Reporter Chip Dorlan und Steve Huston (die ebenfalls nicht wissen, dass Dick Van Loan und der Phantom Detective dieselbe Person sind) ihn in jeder Verkleidung als Phantom erkennen.

257 Jones 2005, 9, The Emperor of Death (1933), Kap. I.

258 Und zwar droht ihm zweimal das Entreissen der Maske, das dritte Mal aber kann er gerade noch verhindern, dass der als Phantom-Kontaktmann bekannte Frank Havens ihn unter Hypnose an den Oberbösewicht verrät. 
schichte den emotionalsten Moment in der ganzen Story erlebt, als er die unmittelbare Demaskierung befürchten muss: «The hand plucked at the black silk. For the first time in his life Van knew the full meaning of utter and black despair. His heart turned to lead, and his stomach was suddenly empty. This, then, was the end. The Phantom had lost.» ${ }^{259}$ Notabene fürchtet er hier nicht direkt um sein Leben, sondern «nur die Entlarvung. Selbstverständlich wird er gleich darauf gerettet, mit entsprechendem Effekt: «An ecstatic joy surged up in the Phantom's breast. ${ }^{260}$ Später trifft er dann Vorsichtsmassnahmen und schminkt sich unter der Maske ein anderes Aussehen (diesen Trick nutzen andere Protagonisten später ebenfalls).

Die gewaltsame Demaskierung ist die eine Form dieser Gefahr, die Entlarvung durch Zufall oder das Aufspüren des Geheimnisses durch Detektion die andere. Als bester Schutz für das Identitätsgeheimnis erscheint so auch in den Pulps ein starker Kontrast zwischen den beiden Identitäten. Allerdings erweist sich dieser bei genauem Hinsehen manchmal als mehr herbeigeschrieben als in der Handlung umgesetzt. So fällt auf, dass Van zwar gern als «idle playboy» benannt, doch nur selten als solcher gezeigt wird. Da Muriel Havens die einzige ständige Figur darstellt, die Van/Phantom in seinen beiden Identitäten kennt, ohne aber eingeweiht zu sein, wird die Kontrastierung vor allem in der Interaktion mit ihr aufgebaut bzw. inszeniert: «Little did she realize as she sat there in the security of her own home talking to the most eligible bachelor in the city, that only a short while ago, he had been engaged fighting for his life in a section of the city that she could not have known existed.» ${ }^{261}$ Der Kontrast ergibt sich hier weniger daraus, dass die zivile Identität als völlig heldenuntauglich erschiene - implizit ist wie bei Percy Blakeney und Diego Vega klar, dass der Protagonist die Voraussetzungen für Heldentaten grundsätzlich hätte, diese aber nicht zu nutzen weiss und insofern heldenuntauglich ist -, vielmehr sind es zwei unterschiedliche Lebensstile, die als inkompatibel wahrgenommen werden (obwohl jener des Helden wohl nur auf der Basis des unbeschäftigten Millionärs umzusetzen ist).

Bei The Spider wird der Kontrast auf dieser Ebene sogar noch deutlicher inszeniert. Beispielsweise gibt es am Schluss der ersten Spider-Story eine Szene häuslichen Idylls, in welcher Richard Wentworth angesichts eines glücklich vereinten jungen Paares Klavier spielt: «It was such a moment as this which gave to Wentworth that peculiar satisfaction which rivaled the thrill he experienced

259 Jones 2005, 100, The Emperor of Death (1933), Kap. XIX.

260 Ebd.

26I Ebd., 45, Kap. VIII. 
in moments of violent combat and great danger. There were two opposing sides to his character and probably neither side could exist without the other.» ${ }^{262}$ «Richard Wentworth» stellt hier die harmonisch-häusliche, «The Spider» die actiongeladene Seite des Protagonisten dar. Implizit ist hierin bereits ein oft als grundsätzlich empfundener Konflikt angelegt, da diese beiden Seiten als unvereinbare Gegensätze angelegt sind (in dem Sinne, dass sie allenfalls nacheinander, jedoch niemals miteinander ausgelebt werden können oder sich zeitweilig quasi gegenseitig ausschalten ${ }^{263}$ ). Dass The Spider und Richard Wentworth dieselbe Person sind, ist dabei in der erzählten Welt relativ offensichtlich, da Richard ebenfalls als privater Ermittler tätig ist und vorzugsweise in Fällen mitmischt, in die auch The Spider eingreift ${ }^{264}$ - was ihm (kaum erstaunlich) ständige Verdächtigungen einbringt.

Bei Tony Quinn sorgt die als noch bestehend vorgegaukelte Behinderung für jenen Kontrast zwischen seinen beiden Identitäten, der deren Einheit a priori als unwahrscheinlich bzw. unmöglich erscheinen lassen soll. Die 〈Verwandlung〉, wenn er seine Blindenrolle abstreift, wird gern als deutliche Veränderung beschrieben: «Just as soon as it was dark enough to venture out, Tony Quinn's personality slipped from him. Gone were the stark, staring eyes of a blind man. His resigned, almost morose look vanished. As the Black Bat he became alive and alert. His nerves were tingling, his eyes shining brilliantly.» ${ }^{265}$ Impliziert wird hier wiederum, dass das 'wahre Leben(sgefühl) nur im Abenteuer und in der Gefahr bestehen kann, also mit der Heldenidentität gekoppelt ist. Doch gerade das Doppelidentitätsgeheimnis bringt diese Momente der Gefahr ja auch stets in jenen Teil des Lebens, den der Protagonist in Zivil bestreitet.

Mit Verweis auf seine (vorgetäuschte) Behinderung kann Tony darauf beharren, dass er unmöglich The Black Bat sein kann. Denn genau das vermuten - trotz aller Unmöglichkeit - Polizeichef Warner als auch dessen Mann für alle Fälle,

262 Scott 2006, 88, Master of Men! The Spider Strikes (1933), Kap. I 8.

263 Dies deutet Richard Wentworth jedenfalls an, wenn er Nita, die ihn darauf hinweist, dass er von The Spider wie einer anderen Person spreche, lachend erklärt: «Someone else! Child, sometimes when I get behind that mask and go out with a gun in my pocket, I feel that no such person as Richard Wentworth ever lived» (Stockbridge 2004, I 3, Wings of the Black Death (1933), Kap. 4).

264 Ein weiteres Beispiel für einen Helden, der aufgrund mangelnden Kontrasts zwischen ziviler und heldischer Identität unter Dauerverdacht steht, ist der als Verbrecher gesuchte Griffon/ Kerry Keen.

265 Daniels 2010, 353, The Black Bat Strikes Again (1939), Kap. XIV. Bei Tony Quinn schwingt zudem oft der Beschreibungstopos vom Gegensatz zwischen äusserem Anschein und innerer Tatsache mit: «[...] Tony Quinn's utterly blank eyes stared into space unwinkingly. Behind them a shrewd, smoothly functioning brain went over the case» (Jones 2003, 33, The Black Bat and the Red Menace (194I), Kap. IX). 
Detective McGrath. Ähnlich wie beim Spider ist ein fester Bestandteil der BatGeschichten, dass Tony Quinn unterstellt wird, er sei The Black Bat. Polizeichef Warner fährt hierbei einen Kurs der «plausible deniability» - immer wieder gibt er zu, dass Tony als Blinder nicht der Held sein kann, aber da er dies dennoch vermutet und sogar wünscht, sucht er ihn immer wieder in der Hoffnung auf, eine bestimmte Information gelange so zu The Black Bat:

«If only you were the Black Bat! I need help - desperately. [...] If I've ever hoped before, I hope now that the Black Bat can hear me.» Tony Quinn's face didn't move a muscle. «You know, Commissioner,» he said quietly, «that a bat has abnormally large ears. He might hear around corners.» Warner [...] put a friendly hand on Quinn's shoulder. «I also know that bats are - blind. If you think of any way to help, just call on me, Tony. I-» $\aleph^{266}$

Dagegen legt McGrath mehr Spürsinn an den Tag und will dies regelmässig beweisen. Er beobachtet Tony Quinn stets mit Sperberaugen und hofft auf einen verräterischen Patzer in dessen Darstellung. ${ }^{267}$ Tony aber beherrscht seine vorgetäuschte Rolle zu gut, da seine Blindheit eben eine Zeit lang keine Vortäuschung war. Immer wieder kommt es so zu dramatischen Versuchen McGraths, Tony aufs Glatteis zu führen und zu überlisten:

Quinn stared straight into the fireplace with his blank eyes. «Silk was fortunate. I was too. I couldn't have defended myself, not being able to see.» Quinn's apparently sightless eyes watched the big officer. McGrath was getting set to pull a fast one. Quinn could sense it and he steeled himself. [...] McGrath [...] suddenly flipped the flaming cigarette straight at Quinn's nose. It missed Quinn's face by a fraction of an inch and landed in the fireplace. But Tony Quinn never moved a muscle. His staring blank eyes never flickered. And that had taken tremendous will power. McGrath sighed deeply and relaxed. No man, possessed of his sight, could have avoided jerking his head back, or at least blinking as the cigarette came flying toward him. ${ }^{268}$

Die Szene inszeniert The Bat hier nicht als Helden der Tat, sondern der absoluten Mimikbeherrschung, der totalen Eindrucks-/Darstellungskontrolle, die hier auch den Sieg des Willens ${ }^{269}$ über den Impuls beinhaltet (Abb. 20). Oft dient es als amü-

266 Daniels 2010, 335, The Black Bat Strikes Again (1939), Kap. X (Hervorhebung im Original).

267 Typisch sind dazu solche Situationen: «[McGrath] watched Tony Quinn going through the door, guided by Silk. McGrath was hoping that either one would make some mistake, some false move that would give them away. But Quinn knew his act too perfectly (Jones 1947, I7, The Murder Prophet, Kap. IV).

268 Daniels 2010, I 52f., Murder Calls the Black Bat (1939), Kap. IV. Einen ähnlichen Trick mit einem Zündholz versuchte schon ein Verbrecher in der ersten Story (Jones 2006, 32, Brand of the Black Bat (1939), Kap. VII).

269 Die Willenskraft des Helden als oft eigentlicher Erfolgsfaktor ist dabei vor allem bei The Spider immer wieder explizit ein Thema, wie schon Sampson $(1989,78)$ ausführte. The Spider lehnt 
sante Schlussnote, wenn McGrath wieder einmal einsehen muss, dass er sich vergebens bemüht hat. Dass dies klappt, ist regelmässig auch das Verdienst von Tonys Team, ohne das die Aufrechterhaltung der beiden Rollen sicher sehr viel schwieriger wäre. So beklebt Tonys Gehilfe Butch die Frontscheibe von McGraths Auto, während dieser im Haus mit Tony Quinn spricht, mit Bat-Aufklebern und lacht sich hinter der Hecke ins Fäustchen, als McGrath die «Bescherung〉 sieht, oder als McGrath auf einer weiteren augenärztlichen Untersuchung beharrt, kann Carol Baldwin den Patienten Tony ungesehen mit einem echten Blinden austauschen. ${ }^{270}$ Tony und seinem Team gelingt es stets nur zeitweilig, McGraths Verdacht zu zerstreuen. Spätestens mit dem nächsten Fall ist McGrath wieder skeptisch, und seine Beschuldigungen und Entlarvungsintrigen können von vorne beginnen.

Tony ist dabei äusserst vorsichtig, er spielt den Blinden sogar bei sich zuhause (ausser in von aussen nicht einsehbaren Räumen wie dem geheimen Labor/ Team-Treffpunkt im Keller). Tony muss zwar immer mitdenken, dass McGrath ihn im Visier hat - er ist einer der wenigen maskierten Helden, der die Voraussicht besitzt, auf einem Schiff (also klar begrenztem Raum mit einer festen Anzahl Personen darauf) nicht in seinem Black-Bat-Kostüm in Erscheinung zu treten, wenn er als Tony Quinn Passagier ist -, zugleich aber findet er durchaus gute Seiten an diesem Katz-und-Maus-Spiel: «Despite the bulldog tenacity he [McGrath] used in trying to connect Tony Quinn with the Black Bat, Quinn liked him for it. McGrath lent a certain spice of excitement to life.» ${ }^{271}$

Obwohl McGrath stets betont, dass er The Black Bat verhaften müsste, wenn er ihn denn in die Finger bekäme, kommt es schon bald zu einer Zweckallianz. Wenn McGrath nämlich tatsächlich einmal einen einigermassen stichhaltigen Beweis hätte, ist er The Black Bat aus irgendeinem Grund gerade so dankbar (nach Auflösung eines Falles oder wenn dieser ihm gerade das Leben gerettet hat), dass er auf seine Chance verzichtet. Wenn er etwa die potenziell belastende Bat-Handschriftenprobe ${ }^{272}$ in Tonys Beisein vernichtet, hält Tony stets die Täuschung aufrecht, dass er nicht ganz begreift, was sich gerade abgespielt hat. Schliesslich ist es McGrath eigentlich ebenfalls lieber so, wenn seine diesbezügliche Unsicherheit das Fortdauern der Bat-Aktivitäten bedeutet: «Captain

sich dabei auch an The Shadow an: «[The Spider's] will blazed at them from his eyes - the will of the Spider, who was justly called Master of Men!» (Stockbridge 2005, 2 I, Slaves of the Laughing Death (1940), Kap. 3, Hervorhebung im Original).

270 Jones 2003, 40-43, The Black Bat and the Red Menace (194I), Kap. X-XI.

27I Daniels 2010, 352, The Black Bat Strikes Again (1939), Kap. XIII. Vgl. auch Jones 1947, I 5 , The Murder Prophet, Kap. IV.

272 Daniels 2010, 402, The Black Bat Strikes Again (1939), Kap. XXI. 
Abb. 20: Tony Quinns Darstellung als Blinder ist selbst angesichts des «Flammentests〉 dank seiner absoluten Selbstkontrolle makellos. Auch hier «schwebt > sein heldisches und maskiertes Alter Ego im Hintergrund - im Gegensatz zu Tony mit sehenden Augen. Black Book Detective, Oktober I947, Titelbild von Rudolph Belarski.

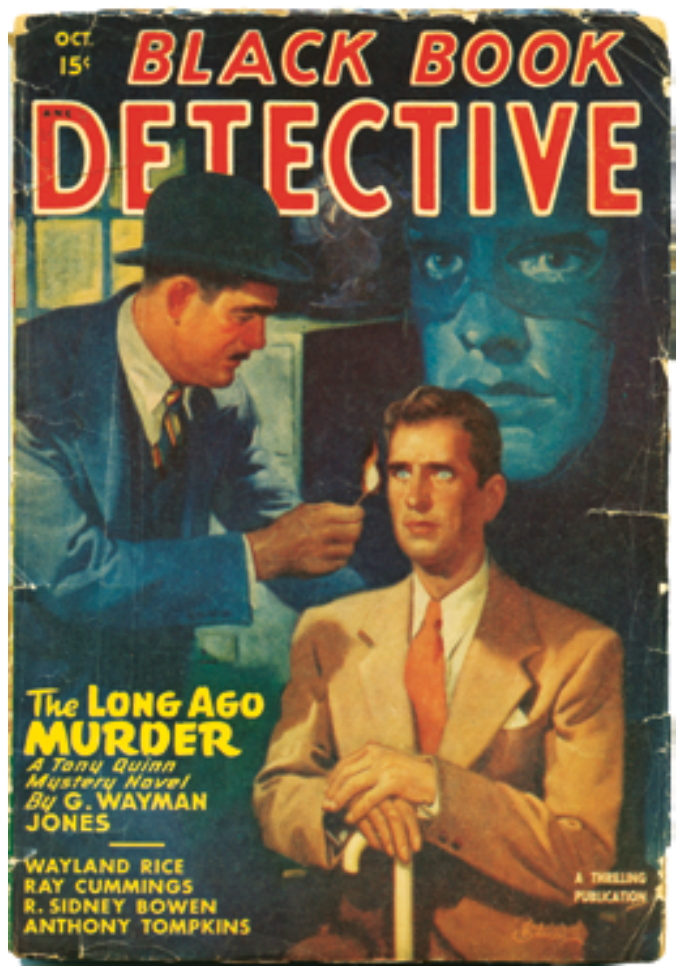

McGrath was not sure anymore. Then he chuckled. That was really the way he wanted it.» ${ }^{273}$

Tony Quinn vollzieht dabei eine durchaus plausible Entwicklung. Am Anfang schiebt er stets seine Behinderung vor, indem er betont, dass er nun zu nichts mehr nütze sei, er könne der Polizei bei ihren Fällen nicht helfen. Er reduziert sich auf seine Behinderung, die ihm die Teilhabe am sozialen Leben weitgehend verwehre, was die anderen Figuren indes keineswegs einsehen: "You're blind but that hasn't affected that keen legal mind of yours», erklärt etwa ein früherer Klient von ihm, der seine Hilfe sucht. ${ }^{274}$ Im Lauf der Zeit eröffnet er jedoch wieder eine Anwaltskanzlei und wird schliesslich erneut Staatsanwalt für besondere Aufgaben. Interessant ist die Begründung für diese <Rückkehr ins Leben`: Er geht wieder arbeiten, weil ihm sonst zwischen den einzelnen 
Fällen zu langweilig ist, was auch für das Erhalten oder Einholen von Informationen Vorteile bringt. ${ }^{275}$ Bei Tony Quinn kommt es so zu einer Umkehrung des üblichen «Held aus Langeweile-Topos. Und während er in den frühen Geschichten zuweilen noch mangelndes Interesse am Weltenlauf als Folge der Behinderung vorschützte, wird Blindheit nun sozusagen zu seinem alleinigen Alibi.

Bei Richard Wentworth kommt wie erwähnt ebenfalls regelmässig vor, dass ihn jemand als Spider identifizieren will ${ }^{276}$ - insbesondere sein bester Freund, der "Commissioner of Police» Stanley Kirkpatrick, der ein erbitterter Feind von The Spider ist, selbst wenn er ihn heimlich bewundert. Besonders schwierig wird es für The Spider und The Black Bat jeweils, wenn ihnen etwas zur Last gelegt wird, was sie nicht getan haben. Dies kann leicht geschehen, da sie wie Zorro und Jimmie Dale ein bestimmtes Zeichen - Aufkleber in Form einer roten Spinne bzw. einer schwarzen Fledermaus - benutzen, um ihre Opfer zu markieren bzw. ihre Taten zu signieren. Von weniger skrupellosen Gestalten lassen sich solche Zeichen oder sogar das Kostüm des Helden leicht fälschen. So muss sich die Mehrheit der Pulp-Helden früher oder später mit untergeschobenen Verbrechen oder Doppelgängern mit unlauteren Absichten herumschlagen. Polizeichef Stanley und Richard Wentworth strapazieren ihre Freundschaft regelmässig, weil Stanley Wentworth aufgrund gefälschter Indizien für The Spider und eines Verbrechens schuldig hält (das jedoch der jeweilige Schurke begangen hat) und weil Wentworth durch seine Aktionen und Forderungen diesen Verdacht oft noch bekräftigt, bevor er ihn wieder zerstreut.

The Green Ghost hat keinen solchen Polizisten im Figureninventar. Er spraktiziert seine Doppelidentität in einer einzigartigen Konstruktion. In der zweiten Geschichte soll George Chance am Anfang einen falschen Zauberer entlarven, doch bevor er dies tun kann, stirbt das menschliche Versuchskaninchen auf der Bühne. George wird des Mordes bezichtigt. Verhaftet zu werden, ist freilich äusserst ungünstig, wenn man eigentlich einen Mörder suchen sollte, wie George den Lesern erläutert:

275 Jones 2007 I 2, The Blackout Murders (1942), Kap. II.

276 In Slaves of the Laughing Death (1940) etwa besuchen Richard Wentworth drei Grosswildjäger, die einmal in der Stadt jagen wollen - und zwar The Spider. Zugleich stürzt ein sterbender Mann in Wentworths Arbeitszimmer und bittet ihn mit dem letzten Atemzug um Hilfe, weil er ja The Spider sei. Selbstverständlich kann sich Wentworth auch hier herausreden - diese Spekulation sei er schon gewohnt, sie sei dennoch falsch -, und am Ende lassen die Jäger The Spider gehen, weil er den eigentlichen Schurken der Story, «Munro, The Faceless One», für den Moment unschädlich gemacht hat. Munro übrigens kennt das Geheimnis des Protagonisten, dies ist aber für die Handlung kaum relevant (Stockbridge 2005). 
The Ghost had made all of New York's underworld his happy haunting ground. And if it takes a crook to catch a crook, why not a Ghost to catch a spook crook. But there was a joker in the deck [...]. Here's the joker: If George Chance and the Ghost were the same person and the half of the dual identity named George Chance got pinched for the murder of Palmer how in the devil was the Ghost to solve the crime and bring the real criminal to book? 277

Nur gut, dass George Chance/The Green Ghost allzeit bereit ist. Als die Polizei ihn zur Verhaftung abholt, nimmt sie nicht etwa den «wahren> George Chance mit, sondern bringt Glenn Saunders ins Gefängnis. Denn dieser verkörpert buchstäblich die wohl ausgeklügeltste Strategie, damit niemand auf die Idee kommen soll, dass George Chance und The Ghost ein und derselbe sind. Durch Zufall war George auf einen Mann gestossen, der ihm ausserordentlich glich und mit wenigen kosmetischen Operationen sein Ebenbild wurde ${ }^{278}$ und zudem seine Stimme perfekt imitieren kann. ${ }^{279}$ Wenn er also als Ghost unterwegs ist, übernimmt dieser die 〈Rolle` von George Chance. Die folgende Stelle erläutert die Vorteile dieses Arrangements ausführlich:

Whenever Chance decided to adopt the identity of the Green Ghost in order to hunt down some murderer, Glenn Saunders was always at hand to step into Chance's shoes. In such manner the identity of the Green Ghost and George Chance could always be kept separate, even though Detective Green Ghost frequently employed magic to snare his murderers. So many enemies had the Green Ghost made in the underworld that had he not always been able to protect the secret of his dual identity through the use of Saunders as double, his life would not have been worth a plugged nickle. ${ }^{280}$

Als Gegenleistung weiht George Chance Glenn Saunders in die Zauberkunst ein. The Ghost ist damit die Ausnahme von der Regel: Er kann durch diesen Trick an zwei Orten gleichzeitig sein. Durch diese Variante geht allerdings manchmal etwas dramatisches Potenzial verloren. Doch sobald diese Möglichkeit fehlt, erhält das Doppelleben einen grimmigeren Anstrich. So denkt George, als er sein Haus verlässt, nachdem Glenn an seiner statt verhaftet wurde: «Leaving there [the home of George Chance] was like divorcing myself from my own identity. I was

277 Chance 2003, I I, The Ghost Strikes Back (1940), Kap. IV.

278 Konsequenterweise gibt es in den Green-Ghost-Storys für alle Figuren des Teams immer wieder abgedruckte Charaktervignetten, auch für Glenn Saunders, nicht aber für George Chance, dessen Porträt ihn nur als Ghost zeigt.

279 Und zwar so perfekt, dass George jeweils ein seltsames Gefühl überkommt, wenn er Glenn hört: «Hearing it unexpectedly like that always gives me the uncomfortable feeling that I have somehow escaped from my body» (ebd., is, Kap. VII).

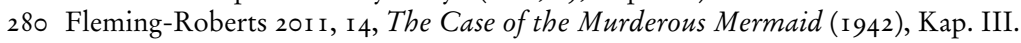


the Ghost in grim earnest this time and would be compelled to live the life of the Ghost until the real murderer [...] was brought to justice.» ${ }^{28}$ Gewiss wird in den Ghost-Geschichten das Potenzial dieser Konstellation ausgeschöpft: So ist Glenn auch einmal nicht $\mathrm{da},{ }^{282}$ wenn George ihn brauchen könnte, und wird bei anderer Gelegenheit als Green Ghost identifiziert (was allerdings unlogisch ist, da Glenn niemals in George Chances Heldenrolle auftritt, sondern stets nur dessen zivile Identität ausfüllt).

Der Green Ghost bedarf eines gegebenen Alibis durch sein Double, weil seine Helden- und seine zivile Identität durch dieselben Fähigkeiten, die Zaubertricks, für Aufsehen sorgen, weil also zwischen seinen Identitäten kaum ein Kontrast besteht (umgekehrt betrachtet, macht die Verwendung eines Doubles einen solchen Kontrast nicht mehr unbedingt nötig). Entsprechend aber bedeutet es für die Narration keinen nennenswerten Unterschied, ob die Story wie in den frühen Geschichten in der ersten oder wie später in der dritten Person Singular erzählt wird. The Green Ghost hat dabei ein originelles Vokabular für seine Identitätswechsel: Er spricht von «ghosting out» oder «turning on» bzw. «turning off the Ghost», wenn er in seine grün-gruslige Rolle und zurück wechselt. Insofern ist bei ihm implizit klar, dass George Change seine ‘wahre> Identität ist und der Green Ghost eine Erweiterung derselben («ghosting» wird einmal bezeichnet als "when (he) deserted his real identity» ${ }^{283}$ ).

Wie erwähnt handelt es sich bei den Pulp-Protagonisten der I93oer-Jahre nicht mehr um Einzelkämpfer, wie es etwa Zorro war. Vielmehr sind sie alle getragen von einem kleineren oder grösseren Team von Eingeweihten. Dieses umfasst mindestens einen Vertrauten - bei The Phantom Detective etwa nur Havens als alten Freund -, der oft zugleich als Diener und Mitstreiter amtet (Silk bei The Black Bat und Ram Singh, der indische Diener von The Spider). Gewisse Teams erhalten darüber hinaus Unterstützung von einem wohlwollenden Polizeichef (einer Art Passivmitglied) und/oder einem Mann für gröbere Aufgaben, wobei etwa The Black Bat seine beiden männlichen Kumpel fast häufiger aus den brutalen Händen der Verbrecher befreien muss als seine Freundin Carol. Mit sechs Personen das umfangreichste Team unterhält The Green Ghost. ${ }^{28}$ Indem die

28I Chance 2003, I9, The Ghost Strikes Back (1940), VIII.

282 So gerät der Ghost ohne Glenn schon mal in die Bredouille, wenn er in Handschellen im Polizeiauto sitzt, das George Chance zur Konsultation abholen will: «Had all this not been downright dangerous to the future safety of Mr. Chance, the Ghost might have got quite a kick out of the situation» (Fleming-Roberts 20I I, I r6, The Case of the Broken Broom (1943), Kap. IV).

283 Fleming-Roberts 201 I, 3 I, The Case of the Murderous Mermaid (1942), Kap. IX.

284 Es umfasst seine Verlobte Merry White, sein Double Glenn Saunders, seine zwei Freunde Tiny Tim Terry (einen zigarrenrauchenden Kleinwüchsigen) und den etwas zwielichtigen Joe Harper, dazu den Polizeidirektor und einen Gerichtsmediziner. 


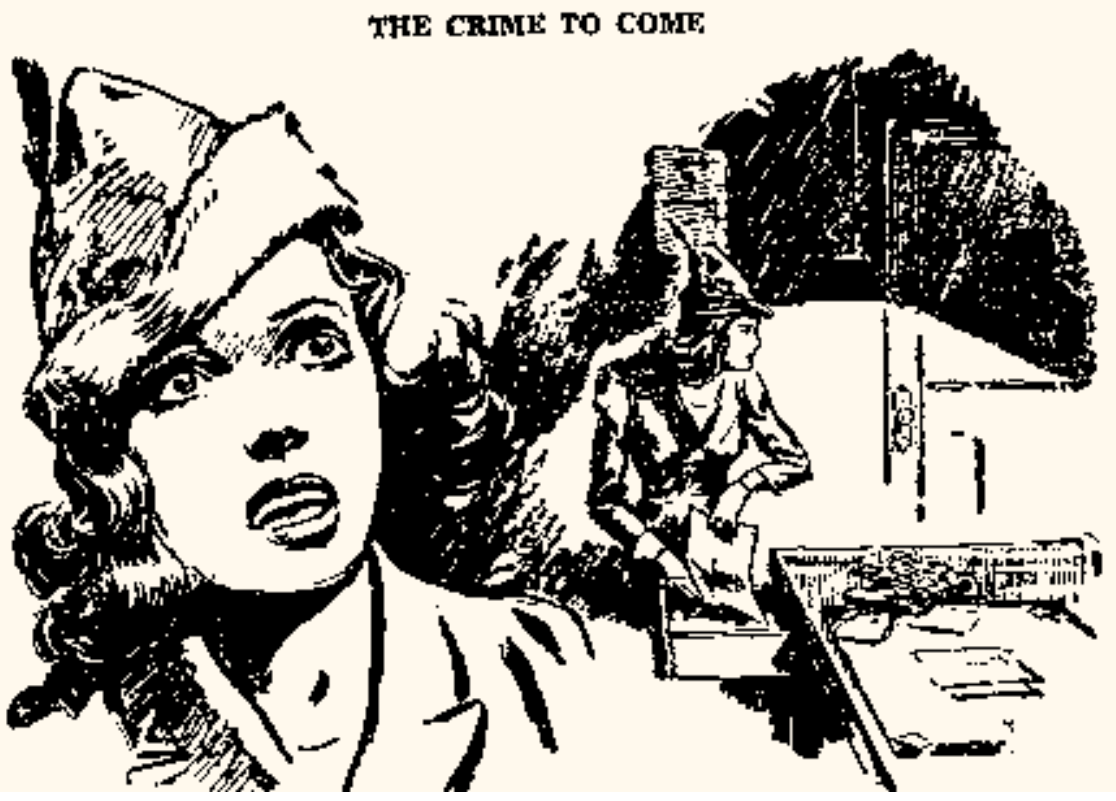

Abb. 2 I: Die Charaktervignette für Tony Quinns Freundin Carol Baldwin zeigt die beiden Seiten der Frauenrolle: mit dem Gesichtsausdruck die emotionale Seite, im Hintergrund aber auch ihre aktive Rolle bei Ermittlungen. The Crime to Come, in: Black Book Detective, Februar 1947, 33, Innenillustration, Künstler unbekannt.

maskierten Helden als Teamleader ihren Helfern jeweils Ermittlungsaufgaben zuteilen, demonstrieren sie ebenfalls Planungsfähigkeiten.

Meistens gehört eine Frauenfigur, die grosse Liebe des Protagonisten, zum Team der Eingeweihten - ausser beim Phantom Detective, wo Muriel Havens vor allem am Anfang nur wenige Auftritte hat und oft auf die Funktion der damsel in distress reduziert wird, bevor sie sich dem Phantom als Helferin aufdrängt. ${ }^{285}$ Die eingeweihten Frauen, vor allem Nita van Sloan, müssen zwar ebenfalls oft als $<$ Rettungsobjekte herhalten, doch sind Nita, besonders Carol Baldwin und teilweise George Chances Verlobte Merry White oft massgeblich an den Ermittlungen beteiligt; sie sind somit wichtige Stützen des Protagonisten, die seine Helden-Unternehmung mit vollem Einsatz mittragen (Abb. 2I). Durch ihre Teams verfügen die Protago-

285 Zwei weitere Beispiele für eingeweihte Frauenfiguren sind die patente Sandra Gray, die Bob Clarke alias The Crimson Mask liebt (Johnson 2008), und Gloria, die Sekretärin und Freundin von Perry Morgan alias Red Mask, aus der gleichnamigen, sehr kurzlebigen Reihe von I94I (Richards 2005). 
nisten stets über soziale Kontakte zu Menschen, die ihr volles Vertrauen geniessen und auf deren Unterstützung sie in jeder Situation zählen können; oft scheint das soziale Umfeld ausserhalb des Teams kaum noch Bedeutung zu haben (es sei denn als Zuträger von neuen Fällen). Angesichts dieses Umstands ist es nicht verwunderlich, dass die Pulp-Helden Identitätskrisen und Selbstzweifel nicht kennen ausser vielleicht in einer Beziehung.

Denn was zumindest in den frühen Phantom-Romanen stark betont wird, ist das Opfer, das der Protagonist für seine Karriere bringt. Um sein Heldentum erfüllen zu können, zahlt er nämlich - aus seiner Sicht - den hohen Preis, der Liebe zu entsagen, wie detailliert schon in der ersten Geschichte geschildert wird:

Yet, despite the fact that he had risen to the top of his chosen profession, he was not altogether happy. In order to pursue the hazardous career of the Phantom, [...] he was compelled to forego the things which any normal man may have for the asking. Love, romance, children, a home - these things were not for Richard Van Loan. These tranquil joys were not for a man who faced death daily, who gambled with his life with criminals every moment. No, all life is a compromise and [his] compromises $[\ldots]$ were no small things. [...] Muriel [...] possessed all the charms and virtues that he would have asked in his wife. But he realized he could never realize that dream. For the Phantom was born on the ashes of romance. ${ }^{286}$

Hier ist der maskierte Held nicht mehr nur der abenteuerlustige Draufgänger, sondern bekommt eine Kehrseite des Verlusts und der Einsamkeit. Gewiss findet dadurch zugleich eine gewisse Überhöhung des Helden statt - weil er der häuslichen Idylle entsagt und ein Leben führt, das auch auf diese Weise eine gewisse Exklusivität aufweist. Obwohl Van einerseits bedauert, dass er Muriel nicht heiraten kann, ändert dies nichts an seiner Entschlossenheit, als Phantom zu wirken. (Kurz vor Schluss der Reihe, in The Silent Killer von I952, findet Muriel Vans Geheimnis schliesslich heraus, und zwar auf unerwartet unspektakuläre Weise: Dass Van und The Phantom Detective ein und derselbe sein müssen, hat sie erkannt, weil sie beide genau gleich liebe. ${ }^{287}$ )

Auch bei Richard Wentworth und Tony Quinn wird zuweilen darauf verwiesen, dass sie ihre Freundinnen gerne heiraten würden, dies aber aufgrund ihres Status als «Verbrecher〉 nicht möglich ist. Bei Richard Wentworth und Nita van Sloan steht dabei eigentlich fest, dass die Heirat geplant ist, sobald er seinen Spider-Mantel an den Nagel hängen würde. Hingegen wird es bei Tony Quinn und Carol Baldwin so dargestellt, dass dies schlicht der Wermutstropfen ist, den sie

286 Jones 2005, I4, Emperor of Death (1933), Kap. II (meine Hervorhebung). Ganz ähnlich wiederholt wird dies etwa in Jones 2008, 23, The Yellow Murders (1933), Kap. IV.

287 Zit. n. Sampson 1989, I2, und Johnson et al. 2009, i 5 f. 
zur Erfüllung ihrer selbst gewählten Aufgabe in Kauf nehmen, weil beiden klar ist, dass sie als Unverheiratete mehr erreichen können. ${ }^{288}$ Für den Green Ghost hingegen ist das kein Thema, was auch daran liegen mag, dass seine Fälle weniger Thriller mit rauchenden Schusswaffen darstellen, sondern mehr den klassischen Whodunnit-Rätseln verpflichtet sind. An der Liebe der Paare besteht so in den Pulps mehrheitlich kein Zweifel, und der Protagonist steht in seiner zivilen Identität in der Regel auch nicht in einem Konkurrenzverhältnis zu seinem heldischen Alter Ego, wie es in den Golden-Age-Comics häufiger der Fall sein wird. ${ }^{289}$

\section{Maskierte Pulp-Helden und Comic-Superhelden (Zwischenfazit)}

Um die Ausführungen zu den maskierten Pulp-Helden abzuschliessen, sollen noch einzelne Aspekte angesprochen werden, die sie von den Superhelden zumindest in der Tendenz unterscheiden. Verglichen mit den Superheldencomics bieten die Pulps dabei eine grössere Bandbreite an Genresituierungen, in welchen die maskierten Helden auftreten. Der Scarlet Pimpernel und vor allem Zorro als maskierte Epigonen des Mantel-und-Degen-Genres erhielten nie ein nennenswertes Pendant in den Golden-Age-Comics, ebenso sind maskierte Gentlemen-Gauner, wie sie in den Pulps der i920er-Jahre auftraten, kaum zu finden. ${ }^{290}$ Die Comics bedeuten für den maskierten Helden so in gewisser Weise eine Genre-Verengung nach dem Vorbild der Verbrechensbekämpfer der I930erJahre-Pulps, die je nachdem eher (Rätsel-)Krimi- oder Thrilleraspekte betonen bzw. den Protagonisten mehr als Detektiv oder mehr als Retter und Rächer auftreten lassen.

Die Pulp-Protagonisten werden in den Geschichten üblicherweise als bereits bekannte Heldenfiguren eingeführt. Zwar werden die Umstände, warum der Pro-

288 Vgl. Jones I 947, 2 I, The Murder Prophet, Kap. VI: «They made no secret of the fact that they were in love, but neither talked much about marriage. The Black Bat's game was too dangerous to consider it, and besides, both realized that they could do more in fighting crime if they went their separate ways than if they undertook marriage, with its obligations.»

289 Bezeichnenderweise findet sich ein solches Konkurrenzverhältnis in den Pulps bei The Black Hood alias Kip Burland, denn dieser debütierte in den Comics und erwies sich dort zumindest im Golden Age als langlebiger (vgl. Kap. 6). In den Pulps erschienen 194I/42 nur gerade drei Black-Hood-Storys (Fleming-Roberts 2008).

290 Da die ersten maskierten Pulp-Helden (Zorro, Jimmie Dale, Man in Purple, Crimson Clown) nicht auf der Seite des Gesetzes stehen, schwingt in ihnen freilich auch etwas vom edlen Räuber oder vom Meisterdieb mit, wenn es mehr um die Eleganz und die Überlegenheit als um die Beute geht und die Motivation eine Mischung aus Abenteuerlust, Stolz auf das eigene Können und teilweise Vergeltungswünschen umfasst. 
tagonist zur Maske gegriffen hat, meistens früh in jeder einzelnen Story nachgeschoben, doch steht die Origin-Story nur im Ausnahmefall am Beginn der Erzählung. Dass dies später anders wurde, dürfte damit zusammenhängen, dass bei Superhelden eher das Bedürfnis besteht, die fantastischen Kräfte des Protagonisten zu erklären. Hingegen werden die Fähigkeiten der Pulp-Helden zwar zweifellos überhöht dargestellt, sind aber in der Regel nicht oder nur ansatzweise fantastisch $\mathrm{zu}$ nennen. ${ }^{291}$

Anders als bei Helden mit Superkräften, welche salopp gesagt vom Himmel fallen, wird bei maskierten Protagonisten ohne solche Kräfte (in Pulps wie Comics) in der Regel der immense Arbeitseinsatz betont, den sie geleistet haben, um ihre hervorragenden Kenntnisse und Fähigkeiten in allen Bereichen, die der Verbrechensbekämpfung zuträglich sein könnten, zu erwerben. Für Helden mit und ohne Superkräfte zählt dazu zur Aufrechterhaltung einer Doppelidentität insbesondere auch Rollendisziplin, wie für die Pulps Diego Vega/Zorro oder Tony Quinn/The Black Bat besonders betonen. Zugleich bedeutet die Heldenaktivität für die maskierten Helden, ihre vorhandenen Fähigkeiten zum Nutzen der Gesellschaft am gewinnbringendsten (ihrer Meinung nach eben als Verbrechensbekämpfer) einzusetzen, seien dies nun der kriegserprobte 〈Actiondrang〉 des Shadow und des Phantom Detective, die Zirkus- und Zauberkünste des Green Ghost oder eben die diversen Superkräfte.

Eine Fähigkeit, die bei Pulp-Helden ausgeprägter erscheint, ist die Verwendung unterschiedlicher 〈Make-up-Identitäten〉 in Ergänzung zur zivilen Alltags- und der durch eine Maske explizit gezeigten Heldenrolle. Dass Superhelden seltener als Meister der Schminkkunst inszeniert werden und so stärker auf nur zwei Identitätshälften 〈beschränkt〉 werden, dürfte mit den medialen Bedingungen, also dem Golden-Age-Zeichenstil der Comics, zu erklären sein: Während in den romanlangen Pulps zum einen detaillierte Beschreibungen von Schminktechniken und Maskenbildnerrequisiten einfliessen können, wäre in einem kurzen Comic ein Protagonist, der über mehrere Panels vor dem Spiegel sitzt, wohl wenig spannend, während im Gegenzug der 〈Hemd auf>-Moment visuell ungleich einprägsamer und dynamischer daherkommt. Ein Äquivalent dazu ist in den Pulps so gut wie nie zu finden. Zum andern ist das bunte Kostüm des Helden stets auf den ersten Blick sicht- und erkennbar; dagegen wäre es wohl

29I Gewiss auch den damaligen Genrekonventionen von Thriller und Krimi verpflichtet, spielen die Pulp-Geschichten indes gerne mit vermeintlich fantastischen Elementen, die dann aber als wenn auch clever gemachte, so doch restlos rational erklärbare Phänomene enthüllt werden (die Faszination mit möglicherweise fantastischen Vorgängen belegen nur schon die Titel der Green-Ghost-Storys, aber auch Erfindungen wie die vermeintliche Unsichtbarkeitsmaschine in der Shadow-Geschichte The Unseen Killer, 1934). 
schwieriger, dem Protagonisten in verschiedenen zivilen Verkleidungen zu folgen, in denen man ihn ja gerade nicht erkennen soll (jedenfalls in dem zwar <realistischen', aber dennoch relativ schematischen Zeichnungsstil des Golden Age). Ohne Superkräfte scheint das Heldentum der Figuren zwar keineswegs allein, aber doch stärker auf ihren eigenen Entschluss zurückzuführen zu sein und weniger auf ein schicksalhaftes Ereignis, womit die Bedeutung der Vorsehung, die traditionellerweise das Heldenleben bestimmt, etwas geschmälert wird; sie ist zumindest nicht so offensichtlich. Damit lässt sich behaupten, dass die PulpProtagonisten stärker dem Typus des Abenteurers zuzuordnen wären als einem ‘klassischen〉, schicksalsunterworfenen Heldenideal (sofern man diese Konzepte unterscheidet, die stets eine grosse Schnittmenge aufweisen). ${ }^{292}$ Zwei weitere Eigenschaften, die bei den maskierten Pulp-Gestalten stärker zur Geltung kommen, lassen sich hier heranziehen. Im speziellen Lachen der Pulp-Protagonisten - das die jeweilige Figur nicht nur charakterisiert, sondern geradezu als deren Identitätsmarkierung dient - erklingt das Lachen des Abenteurers, welches dessen Wagemut im Angesicht der Gefahr, mitunter einen gewissen Zynismus, und zugleich seine Überlegenheit ausdrückt. ${ }^{23}$ Dazu werden die Pulp-Protagonisten stärker als Planer wahrnehmbar, die Risiken, Chancen und Wahrscheinlichkeiten zu kalkulieren suchen (worauf sie insbesondere auf den neuzeitlichen Abenteurer, den sogenannten Merchant Adventurer, ${ }^{294}$ verweisen). Freilich haben auch einzelne Superhelden für ihre stets überlegene Planung und Voraussicht Ruhm erlangt - namentlich Batman, doch ist Superman ebenso ein Meister der Gegenintrige, wenn ihn Lois Lane oder jemand anders zu entlarven versucht. Doch neigen die vierfarbigen Comic-Helden in der Regel deutlich stärker dazu, sich planlos in die 〈Action〉 zu stürzen oder diese (in späteren Jahrzehnten) ‘herauszufordern, indem sie durch die Stadt patrouillieren, worauf die Pulp-Figuren verzichten.

Obschon die Pulp-Helden keine Superkräfte haben, die ihre Handlungsreichweite vergrössern (etwa Superspeed), verfügen sie über eine Entsprechung in Form eines exklusiven Transportmittels - von Percy Blakeneys Schiff Day

292 Zur Relation von Abenteurer und Held vgl. von Holzen 2007, dort auch ausführliche Literaturhinweise. Damit sei nicht behauptet, die Superhelden entsprächen im Gegensatz zu den Pulp-Protagonisten dem Helden als Typus; m. E. weisen beide Figurengruppen Merkmale des Abenteurers (namentlich als Selbstjustizler das Befolgen eigener Regeln) auf, dennoch scheinen mir die beiden Begriffe nützlich, um diese Tendenzen festzumachen.

293 Interessanterweise nutzt Percy Blakeney/Scarlet Pimpernel für sein Rollenspiel als adeliges Phlegma das Lachen als Werkzeug; sein kalkuliertes «inane little laugh» soll seine Heldenuntauglichkeit betonen. Scheinbar verkehrt er so in gewisser Weise das Lachen des Abenteurers, dennoch passt es, wenn man seine Percy-Rolle als Teil seiner Kühnheit betrachtet.

294 Hügel 2003, 92. 
Dream über Zorros namenloses Pferd bis hin zu den zahlreichen Helden-Helfern bzw. -Dienern, die ihre Arbeitgeber jederzeit durch die Grossstadt chauffieren. In Bezug auf Gestaltung des sozialen Umfelds, in welchem sich der Held bewegt, fällt auf, dass die Pulp-Helden der 1930er-Jahre öfter ein Team von eingeweihten Helfern haben und insbesondere die Herzensdame des Protagonisten das Unternehmen mitträgt. Dies bedeutet weniger Kontraste bzw. Reibungsflächen und Konfliktpotenzial zwischen den beiden Identitätshälften. Im Gegenzug kann dies stete Verdächtigungen in Bezug auf die Doppelidentität hervorrufen, besonders wenn der maskierte Held in den Augen der Polizei als Verbrecher gilt und sich mit seinem «Lieblingspolizisten> ein stetes Katz-und-Maus-Spiel um das Wissen über seine Doppelidentität liefert, das so stets in der Schwebe gehalten wird.

Zuweilen werden die Superhelden-Comics als Nachfolger (und Verdränger) der Pulps genannt. Dies ist nicht unberechtigt, doch ist dabei nicht zu vergessen, dass Pulps (mit den letzten Heften von The Phantom Detective und The Black Bat bis 1953) und die Superhelden-Comics (mit Superman ab 1938) über ein Jahrzehnt nebeneinander existierten und sich auch gegenseitig beeinflussten (wie auch Radiohörspiele, Filme, Zeitungsstrips etc.). Ende der I940er-, Anfang der I950er-Jahre gerieten schliesslich beide Medien in die Krise, von der sich jedoch nur die Comics, sozusagen durch eine Rundumerneuerung, die dann das Silver Age einläutete, zu erholen vermochten. Doch bevor die Comics des Silver Age in den Blick rücken, ist das nächste Kapitel dem Goldenen Zeitalter der Superhelden-Comics gewidmet. 


\title{
Die maskierten Superhelden im Golden Age der Comic-Hefte
}

\author{
Criminals, beware! The Black Hood- \\ is everywhere! \\ Einfübrungsslogan der The-Black-Hood- \\ Radiobörspiele, \\ Mutual Broadcasting System, I943-I944 \\ "Hello, Doiby! Say ... what are you reading?» \\ "I'm reading one of dem comic magazines about a \\ guy named Colosso who flies tru' de air and chases \\ crooks!» \\ "Fairy Tales! Fly thru' the air-people don't do \\ that in real life!" \\ "I guess yer right ... Hey! What about de Green \\ Lantern? Now how are you gonna figure him \\ out?" \\ Alan Scott/Green Lantern und Doiby Dickles \\ in All-American Comics 32, November I94I
}

Das Goldene Zeitalter der Superheldencomics ist untrennbar mit einem neuen Medienformat verbunden - dem Comic-Heft. Vor allem in Form von Zeitungsstrips waren Comics schon seit wenigen Jahrzehnten bekannt, als Anfang der I93oer-Jahre in den USA die ersten Comic-Hefte produziert wurden. Diese sogenannten Funnies $^{1}$ druckten zunächst gesammelte Zeitungsstrips nach, bevor sie ebenso mit neuem Material gefüllt wurden, wobei relativ rasch auch das Krimigenre bedient wurde. Als erster maskierter Held im Comic-Heft gilt George E. Brenners Detektiv The Clock, der bereits 1936 in Funny Picture Stories I seinen ersten Auftritt hatte. In diesem noch relativ kleinen Markt forderte dann, wie bereits erwähnt, der überragende Erfolg von Superman (erster Auftritt in Action Comics I, Juni 1938) besonders ab I 940 zahlreiche Nachahmer heraus, was die Anzahl der Comic-Titel markant steigerte. Rückblickend drängt sich der Eindruck auf, dass die durch-

I Als erstes eigentliches Comic-Heft (der USA) identifiziert Rhoades $(2008$, 10) Funnies on Parade aus dem Jahr I933, verlegt von Max «Charlie» Gaines. Laut Wright (200I, 3) und Knigge (2004, I 85 ) hatte der Dell-Verlag aber bereits 1929 einen ersten Versuch mit Heften (The Funnies) gestartet, allerdings noch im Tabloidformat - davon gab es 36 Ausgaben. Die Comic-Hefte wurden dabei anfänglich als Werbegeschenke konzipiert. 
gängig im Vierfarbendruck ${ }^{2}$ hergestellten Comic-Hefte und die Superhelden mit ihren farbenfrohen Kostümen und fantastischen Bewegungen, für deren maximale Wirkung sie auf Visualität angewiesen scheinen, wie füreinander geschaffen waren - jedenfalls erwiesen sich Comic-Hefte und Superhelden als zündende Kombination. ${ }^{3}$

Die Superheldencomics des Golden Age von 1938 bis 1956 sind dabei, wenngleich manchmal zu ungleichen Teilen, immer beides: ein künstlerisches Werk und ein Produkt für die Unterhaltungsindustrie, das sich finanziell auf einem Markt behaupten musste. Mit einer bemerkenswerten Zahl von initiativen Verlegern bzw. kleinen Druckereien, die oft unter mehreren Namen firmierten, formierte sich - ähnlich wie bei den Pulps - eine eher unübersichtliche und dynamische Verlagslandschaft. Nicht wenige Verleger beauftragten kleine Zeichnungsstudios, comic shops genannt, das Druckgut herzustellen. Die Comics wurden meist arbeitsteilig und (in übertragener Bedeutung) wie am Fliessband hergestellt. In diesem «work for hire»-System ${ }^{4}$ lagen die Rechte für die Figuren allein bei den Verlagen - ein Missstand, der noch Jahrzehnte andauern sollte. Während einige Künstler ihre Werke signierten, verzichteten andere ganz darauf oder nutzten ein Pseudonym - vielleicht umso mehr, da Comic-Hefte nicht besonders angesehen und die Arbeit dafür nicht gut bezahlt war (im Gegensatz zu den Zeitungsstrips). S Obwohl auch die Comicbranche von Inkonsistenz und Schnelllebigkeit gekennzeichnet war, konnten sich vergleichsweise konstante Publikationen, Protagonisten (sowohl auf Seiten der fiktionalen Helden wie der sie erfindenden Künstler) und Institutionen etablieren.

Während die Pulps, wie übrigens die Zeitungsstrips, sich eher an Erwachsene richteten, suchten die bunten Comics im handlichen Format ein kindliches und jugendliches Publikum. ${ }^{6}$ Dies bedeutete entsprechende Anpassungen der inhalt-

2 Die ganz frühen Comic-Hefte (vor 1938) waren noch nicht durchgehend farbig gedruckt, sondern wiesen einen gewissen Anteil an Schwarzweissseiten auf.

3 Harvey 1996, 35 . Überblicke zur Epoche bieten u. a. Wasielewski 2009, Knigge 2004, I 89-2 9 , Rhoades 2008, 2 I-68, Sieck I999, I I-45, Schikowski 20I4, 79-86, Harvey I996, I6-49, Kniep 200I, I38-I I I, und 2009, 23-187.

4 Wright 200I, 7, 22.

5 Wright (ebd., 27) erwähnt etwa einen Artikel von Sterling North, der bereits am 8. Mai 1940 in der Chicago Daily News erschien und die Comic-Hefte als «national disgrace» oder «poisonous mushroom growth» verunglimpfte. Zu den Produktionsbedingungen vgl. ebd., auch Rhoades 2008, 2 I-26, Harvey 1996, I6-28.

6 Dazu finden sich teils widersprüchliche Aussagen (vgl. McCue/Bloom I993, 90, Interview mit Tom DeFalco). So sollen Comic-Hefte zum Beispiel unter den US-Soldaten grossen Anklang gefunden haben, laut Knigge $(2004,202)$ sollen sie ein Viertel der an die Front geschickten Druckerzeugnisse gestellt haben. Knigge erwähnt fürs Golden Age weitere Leserzahlen (allerdings ohne deren Quelle zu nennen): Demnach sollen 1942 in den USA 95\% aller 8- bis I I-Jährigen Comics gelesen haben, bei den I 2 - bis I7-Jährigen $84 \%$ und bei den I 8 - bis 35 -Jährigen immerhin noch $35 \%$. Auf dem Höhepunkt der Superhelden-Explosion〉 1942 produzierten 42 Verlage insgesamt 
lichen Konventionen: So ging es in den Superheldencomics deutlich weniger blutig zu und her als in den Pulps.7 (Die Einführung von Superkräften unterstützte dies, schliesslich machen diese den Gebrauch von Schusswaffen durch den Helden weitgehend überflüssig.) Ebenfalls für eine junge Leserschaft gedacht war die Einführung eines kindlich-jugendlichen Partners für den Protagonisten, des sogenannten Sidekicks, der in die Doppelidentität des Helden eingeweiht war, diesen (oft im Partnerlook) begleitete und teilweise dieselben Superkräfte besass.

Üblicherweise erstreckte sich eine Comicgeschichte über nur gerade fünf bis zwölf Seiten. Gegenüber Pulp-Romanen und späteren Comic-Heften waren die Geschichten also deutlich kürzer. Gewisse Titel wie Police Comics fokussierten stark auf maskierte Helden, Agenten, Detektive und andere Abenteurerfiguren, in anderen kam es zu wilderen Mischungen. Üblich waren zudem ein- bis zweiseitige schriftliche Kurzgeschichten, ebensolange Comics mit lustigen Figuren (à la «Burp the Twerp» und ähnlich schmeichelhaft benannten Geschöpfen), dazu Füllmaterial wie «True Facts» oder Rätselrubriken. Mehrere Helden teilten sich ein Heft (ausser in einem einzelnen Helden gewidmeten Magazinen). ${ }^{8}$ Pro Heft und Held wurde in der Regel ein abgeschlossenes Abenteuer präsentiert, wobei es durchaus Handlungsbögen gab, die sich über mehrere Hefte hinzogen und mitunter Cliffhanger nutzten. ${ }^{9}$ Im Vergleich zu heutigen Superheldencomics, wie man sie seit dem Silbernen Zeitalter kennt, wirken die alten Storys oft geradezu hastig erzählt. ${ }^{10}$

Wie bei den Pulps strebte man bei den frühen Comic-Helden nach der Teilhabe an Medienverbünden; auch dafür war Superman das Paradebeispiel. ${ }^{\text {II }}$ Ein um-

rund 3 Millionen Hefte, bevor es mit dem Markt recht rapide bergab ging. Ein interessantes Indiz sind die Fotos von Kindern (selten Erwachsenen), die im Rahmen einer Leserbriefseite einen Preis bekamen - in Top Notch Comics (u. a. Hefte 30-45, November 1942-Mai 1944) waren teils mehr als die Hälfte Mädchen.

7 Dies belegt etwa der bekannte «Batman mit Waffe`-Vorfall (Näheres dazu im Batman-Kapitel).

8 Auch einem bestimmten Protagonisten gewidmete Heftreihen enthielten oft noch Storys mit anderen Charakteren. Beispielsweise versammelten Captain America Comics pro Heft drei bis fünf Storys mit dem Titelhelden sowie eine über einen Superhelden namens Hurricane und ein Abenteuer von Tuk, Caveboy.

9 Die ganz frühen Hefte (vor 1938) allerdings erschienen eher als Sammelsurium von Fortsetzungsgeschichten. Gewisse Hefte präsentierten nur gerade zwei Seiten einer fortlaufenden Story. Solche Mini-Folgen gab es etwa von Dr. Mystic, the Occult Detective, einem früheren Charakter der Superman-Erfinder Jerry Siegel und Joe Shuster (etwa in Comics Magazine I, 1936, übrigens schwarz-weiss), oder von The Clock (z. B. in Funny Pages 6-10, November I936-Juni 1937), wobei Clock-Geschichten mit mehr Seiten gleichzeitig in Funny Picture Stories (ab November 1936) erschienen.

Io Aufgrund des beschränkten Platzes und der Produktionsbedingungen gab es regelmässig inkonsistente Geschichten (was heute als Element besonders künstlerischen Erzählens gilt und bewusst eingesetzt wird, wird den Golden-Age-Comics manchmal gern als Pfusch ausgelegt).

I I Für Superman wurde laut Knigge (2004, I9I) bereits 1940 eine eigene Firma zur Lizenzvergabe 
fassendes multimediales Palmarès lag für die meisten Comic-Superhelden indes ausser Reichweite - es ist bereits als ein gewisses Erfolgszeugnis zu werten, wenn sich ein Golden-Age-Held über mehrere Jahre in einem Heft halten konnte oder sogar eine eigene Heftreihe bekam. Immerhin erlebte der eine oder andere Superheld eine Reihe von Abenteuern auch in Radiohörspielen, Zeitungsstrips oder eben Pulp-Novels.

Im Sog von Superman erfuhren Superhelden ab 1940 vor dem Hintergrund des Zweiten Weltkriegs und dem sich abzeichnenden Kriegseintritt der USA wie erwähnt anzahlmässig einen rasanten Aufschwung; von 1938 bis 194I sollen nicht weniger als 700 Hefttitel publiziert worden sein. ${ }^{12}$ Bereits I940/I94I waren die 〈Meilensteine> der Superheldenkonvention ausgeformt: ${ }^{13}$ Die Tradition der Sidekicks wurde mit Batmans Robin/Dick Grayson begründet. The Shield/Joe Higgins und Captain America/Steve Rogers etablierten mit ihren Kostümen das Patriotenmotto. Als erster nur über eine ganz bestimmte Superkraft verfügender Held gilt The Flash/Jay Garrick, Superheldinnen ${ }^{14}$ ergänzten die Palette, und mit The Red Tornado/Ma Hunkel und vor allem Plastic Man/Eel O’Brien lassen sich bereits die ersten Parodien nennen. Mit der Justice Society of America bildete DC mit seinen einzelnen Protagonisten das erste Superheldenteam.

Der Krieg hatte dabei grossen Einfluss auf die Inhalte, ${ }^{15}$ da sich viele ComicHefte an der Propaganda beteiligten. ${ }^{16}$ Berühmt ist das erste Titelbild von Captain America Comics (194I), auf welchem «Cap» Adolf Hitler höchstper-

für Spielzeug und Merchandise gegründet. Zu Superman in verschiedenen Medien vgl. etwa Knigge 2004, I 92-194, sowie v. a. Meier 2015, dessen Ausführungen hier nicht weiter berücksichtigt werden konnten.

I 2 Knigge, 2004, $20 \mathrm{I}$.

I3 Coogan 2006, 200.

I4 Als erste Superheldin wird oft Wonder Woman/Diana (Prince) genannt (so noch von Nehrlich 2013, I09), die wohl als einzige weibliche Heldin bezüglich Popularität und Langlebigkeit wenigstens einigermassen mit Superman und Batman mithalten kann. Doch offenbart ein Blick in Don Marksteins Toonopedia oder in Knigge (2004, 195), dass es mindestens eine Handvoll früherer Superheldinnen gab (bzw. je nach Definition gut ein Dutzend). Erste maskierte Comic-Heldin dürfte übrigens die superkräftelose Polizistin Peggy Allen alias The Woman in Red sein, die im März I 940 in Thrilling Comics debütierte und in diesem Heft bis I945 Fälle löste. Ihre Doppelidentität ist allerdings narrativ kaum von Bedeutung.

Is Beispielsweise wurden in Exciting Comics 194I bzw. 1942 die beiden nichtfantastischen maskierten Helden The Sphinx/Ellsworth Forrester (Heft 2-I4) und The Mask/Tony Colby (Heft I-20, die eigenständige Comic-Version des Black Bat aus den Pulps) durch zwei Superhelden in klar patriotisch inspirierten Kostümen ersetzt, The Liberator (Heft I 5-35) und The American Eagle (Heft 22-47). Ersterer wurde schon vor Kriegsende 1944, eventuell aufgrund von Papierknappheit, gestrichen, Letzterer 1946 durch eine nicht kriegsbezogene Reihe ersetzt (entweder durch Miss Masque, die aber wohl eher Kara the Jungle Princess ablöste, oder den an die Archie-Comics erinnernden Teenager Roger Dodger).

I6 Zur Kriegspropaganda in Superheldenheften vgl. Murray 2000. Je nach Verlag gab es Unter- 
sönlich ins Gesicht boxt. ${ }^{17}$ Diverse patriotisch kostümierte Figuren wurden eingeführt, und bereits bestehende Protagonisten setzten ihre besonderen Fähigkeiten nun in Kriegsscharmützeln gegen feindliche Truppen ein, wobei die Feindbilder repräsentierenden Figuren (den Grundsätzen der Propaganda gemäss) despektierlich dargestellt wurden. ${ }^{18}$ Vor allem wurden die Superhelden aktiv gegen Spione, Verräter, Verschwörer und Saboteure - die Zahl all dieser Kollaborateure im Landesinnern erscheint im Spiegel der Comics als nahezu unermesslich.

Nach dem Krieg gingen die Umsätze stark zurück. Die Superheldenmode war passé, viele Protagonisten verschwanden schon bis Ende der I940er-Jahre aus den Verlagsprogrammen. Stattdessen erhielten Slapstick-, Western-, romantische sowie Gangster- und Horrorcomics Zulauf; zum Beispiel füllte sich Police Comics, das jahrelang vor allem Super- und maskierte Helden umfasste, mit True Crime Stories. Doch im allgemeinen Verfolgungsklima des McCarthyismus kam die ganze Comic-Heft-Branche in Verruf und als Folge in die Krise. Namentlich der Psychologe Fredric Wertham (I895-I98 I) führte ein Kesseltreiben gegen Comic-Hefte an. Nachdem seine (aus heutiger Sicht haarsträubenden) Ideen von der Verwerflichkeit der Comics bzw. ihrer Schädlichkeit für die Jugend bereits durch verschiedene populäre Medien verbreitet worden waren, gipfelte dies 1954 in der Publikation seines Buches Seduction of the Innocent. Zwar wurde ihm schon früh widersprochen, die Kritik an diesem Machwerk verhallte aber ungehört. Um in dieser Situation einer staatlichen Zensur zuvorzukommen, führten die Comicverleger im selben Jahr mit dem sogenannten Comics Code eine Selbstzensur ein - geprüfte Hefte erhielten das Siegel Approved by the Comics Code Authority aufgedruckt. Der Kodex verbot mitunter Flüche, Slang, Gewalt, Nacktheit, Figuren wie Werwölfe und Vampire und untersagte etwa auch, Scheidung als etwas Positives oder Lustiges darzustellen. Ebenfalls war nicht erlaubt, Polizei und Beamte der Lächerlichkeit preiszugeben. Offiziell war der Code zwar freiwillig, doch da sich die Distributionsfirmen weigerten, Comics ohne das Siegel zu vertreiben, hätte der Nichtbeitritt wohl den finan-

schiede: Während DC das Kriegsthema eher vermied, sstürzte〉 sich Timely (später Marvel) darauf (Schweizer 1992, 42).

17 Die Szene spielte sich dann allerdings erst in Captain America 2 (I94I) ab, wobei Hitler und Göring die Prügel nicht von Captain America, sondern von Bucky, dessen Sidekick, einstecken mussten. Zu Captain America vgl. u. a. Dittmer 2007 und 2009, Kniep 2009, I I I-I 35.

I8 Murray 2000. Vgl. u. a. Knigge 2004, I98-203. Nicht nur in Geschichten, sondern auch mit Textzeilen unter den Comics riefen die Hefte etwa zum Kauf von Kriegsanleihen und zum sparsamen Umgang mit Papier und Gummi auf oder verbreiteten das Luftwaffenmotto «Keep 'em flying». 
ziellen Ruin bedeutet. ${ }^{19}$ Allgemein gilt die Einführung des Codes als Verursacher eines beträchtlichen wirtschaftlichen Schadens für die US-Comicbranche und eine jahrzehntelange, massive künstlerische Einschränkung, bevor er nach mehreren Revisionen bzw. Lockerungen in der Bedeutungslosigkeit verschwand (und erst 20I I ganz aufgehoben wurde).

Die Superheldencomics waren von diesen Entwicklungen ebenfalls betroffen. Ohne Publikationspause überlebten das Golden Age nur gerade Superman, Batman, Wonder Woman, Green Arrow und Plastic Man - Letzterer wurde 1956 eingestellt, was als ein Markstein für das Ende des Golden Age gilt. ${ }^{20}$ Unter dem Regime des Codes bemühte man sich, politische Inhalte abzuschwächen; bei Superman und Batman rückten Familienbande, inklusive einer Schar von Haustieren, in den Vordergrund. Trotzdem ist wohl davon auszugehen, dass die Superheldencomics nach dem Neustart im Silver Age Ende der 1950er- bzw. Anfang der I960er-Jahre auch deshalb den gesamten US-Comicmarkt auf Jahrzehnte hinaus beherrschen konnten, weil sie relativ problemlos mit dem Code in Einklang zu bringen waren; möglicherweise profitierten also die Superhelden in gewisser Weise auch vom Code.

In diesem Kapitel werden die Erzählkonventionen der Doppelidentität im Goldenen Zeitalter näher betrachtet, wobei auch hier aus der grossen Zahl möglicher Beispiele nur eine Auswahl besprochen werden kann. Da die Hefte von kleineren Verlagen als National/DC und Timely/Marvel inzwischen durch Onlinesammlungen und Nachdrucke wieder zugänglich sind, diese aber bisher kaum wissenschaftliches Interesse geweckt haben, möchte in den folgenden Erläuterungen drei heute eher unbekannte Charaktere aus drei verschiedenen Verlagshäusern in den Blickpunkt nehmen: The Black Hood/Kip Burland (MLJ Magazines, heute Archie Comics), The Owl/Nick Terry (Dell Comics) sowie The Black Terror/Bob Benton (Verlagsgruppe Better/Nedor/Standard/Pines), wobei ich gelegentlich auf zusätzliche Beispiele verweisen werde. Im Anschluss folgen Überlegungen zu einigen bekannten Deutungen der Entstehungsgeschichte der Superhelden.

I9 Interessanterweise gab es einen äusserst namhaften Verlag, der dem Code nie beitrat und dies umgehen konnte: Der Disney-Konzern vertrat den Standpunkt, dass die Kinderfreundlichkeit seiner Comics über jeden Zweifel erhaben war. Zu Wertham und dem Comics Code vgl. v. a. Nyberg 1998, auch Rhoades 2008, 58-69.

20 Kniep 2009, i86. Den nahtlosen Sprung ins Silver Age schafften auch die Blackhawk-Comics um eine Militärpilotentruppe (ebd.), die damals noch keine Superhelden waren und die DC I956 nach Qualitys Ende übernahm. 


\section{Die Verweigerung der Identitätskrise: The Owl/Nick Terry, The Black Hood/Kip Burland und The Black Terror/Bob Benton}

Seit dem Golden Age werden maskierte Helden wie erwähnt gern mit Superhelden gleichgesetzt, durch welche der Figurentypus definitiv Aufnahme ins Repertoire des Fantastischen fand. Die Verbindung vom maskierten Helden zum Superhelden ist seither so eng, dass gängige Definitionen von Letzterem so formuliert sind, dass sie auch maskierte Helden ohne eigentliche Superkräfte umfassen können. ${ }^{21}$ Fantastische und nichtfantastische Protagonisten lassen sich im Golden Age nicht klar trennen: Einerseits bekämpfen Helden mit fantastischen Fähigkeiten oft 〈gewöhnliche〉 Kriminelle, andererseits überwinden kräftelose Helden regelmässig Superschurken, übernatürliche Monster aller Art oder erleben Reisen in fantastische Gefilde. Zudem kann sich der Kräftestatus eines Protagonisten ändern, sodass die nichtfantastischen maskierten Helden zumindest latent fantastisch erscheinen. ${ }^{22}$ Dennoch gibt es in den Golden-Age-Comics noch eine Anzahl maskierter Helden ohne Superkräfte, deren Welten auf fantastische Elemente verzichten (zwei Beispiele dafür sind The Jester/Chuck Lane, der von 194I bis 1948 in Smash Comics 23-85 erschien, und The Manhunter/ Dan Richards, der von 1942 bis 1950 in Police Comics 8-10 I auftrat ${ }^{23}$ ). Dies legt den Schluss nahe, dass es für die Doppelidentität des Helden im Grunde keinen Unterschied macht, ob er nun Superkräfte hat oder nicht; allenfalls haben diese eine Erweiterung seines Aktionsradius zur Folge, obschon die meisten Helden sich auf New York oder eine namenlose Grossstadt ${ }^{24}$ fokussieren, sofern sie nicht im Krieg allerlei Schlachtfelder rund um den Globus beehren.

Von allen Anpassungen, die der maskierte Held durch den Medienwechsel erfährt, ist wohl am bedeutsamsten, dass seine Gestalt nun unwiderruflich von Visualität geprägt ist. Eine zentrale Funktion kommt hierbei zweifellos der Farbe zu, die nicht mehr nur auf Titelblätter beschränkt war. Einhergehend mit den

2 I Vgl. etwa den Kriterienkatalog von Ditschke/Anhut 2009, I 34-I 40; zur Definition des Superhelden insbesondere auch Coogan 2006, 30-60, sowie Reynolds I994, 7-17.

22 So erhielt etwa The Green Mask/Michael Shelby in seiner Origin-Story durch eine Vita-RayMaschine fantastische Kräfte, die er danach selten einsetzte. Umgekehrt verfügte The Blue Beetle/Dan Garrett anfänglich wie Batman nur über Training, Mitte der 1940er-Jahre jedoch auch über Superstärke und Supersprungkraft (beide ab 1939 in Mystery Man Comics sowie eigenen Titeln; zum Blue Beetle vgl. Irving 2007).

23 Zwar sind beides sogenannte Backpages-Helden, doch ist The Manhunter nach Plastic Man immerhin der zweitlanglebigste Protagonist in Police Comics.

24 Zwei der wenigen Beispiele für Nicht-New-Yorker sind The Human Bomb/Roy Lincoln (in Police Comics I-58, August I94 I-August 1946), der in Washington lebt, oder der aus Miami stammende The Firebrand/Rod Reilly (in Police Comics I-I3, August I94 I-November 1942). 
Superkräften etablierte sich der Ganzkörperanzug als heldisches Kleidungsstück im Vierfarbendruck, ${ }^{25}$ wogegen die Pulp-Helden ihre Maske und ihren (wenn auch vielleicht markant geschnittenen) Umhang tendenziell eher zu üblicher ziviler Kleidung getragen hatten. In einer durchgehend bunten Welt dient ein feststehendes buntes Kostüm nicht zuletzt der raschen Identifizierbarkeit des Protagonisten auf jedem Bild für die Leserschaft. In der zeichnerischen Umsetzung der Maske fällt zudem auf, dass bei einigen (lange nicht allen) Superhelden die Augen nur noch durch zwei weisse Aussparungen dargestellt werden - die Augenlöcher der Maske ersetzen die Augen ihres Trägers (diese Darstellungsweise scheint manchmal vom Zeichner, manchmal von der Figur abzuhängen). ${ }^{26}$ Einerseits vielleicht praktischen Gründen (weniger Arbeit beim Zeichnen) geschuldet, ${ }^{27}$ handelt es sich dabei andererseits um ein markantes visuelles (Identifikations-)Zeichen. Dieses könnte man zunächst wohl mit einer gewissen Unheimlichkeit - dem heldischen mystery-Effekt à la Shadow - konnotiert verstehen. In Verbindung mit McClouds Überlegungen zu Sinn und Wirkung von Abstraktion als Verfremdung in der zeichnerischen Darstellung lässt sich diese Darstellungsweise jedoch in einem weiteren Rahmen interpretieren: Nach McCloud bietet eine «cartoonistische» (das heisst gegenüber einer fotorealistischen durch Abstraktion reduzierte) Darstellung die Möglichkeit, auf spezifische Details zu fokussieren: ${ }^{28}$ Durch die Vereinfachung bzw. Abstraktion mit den weissen Augenlöchern fällt der Blick bei den Superhelden entsprechend nicht auf das Gesicht, sondern die Maske, was klar den Wiedererkennungswert steigert (womit eine Figur bekanntlich auch leichter zu vermarkten ist). McCloud sieht in «cartoonistischen» Stilelementen gerade bei Gesichtern das Potenzial einer Verallgemeinerung, die einen stärkeren Grad von Identifikation der Leser mit dem Protagonisten erlaubt. ${ }^{29}$ Allenfalls liesse sich damit - ergänzend zu vielen

25 Die Materialität des jeweiligen Kostüms muss dabei spekulativ bleiben. Bei gewissen Helden wie dem Blue Beetle handelt es sich genau genommen um ein Ganzkörper-Kettenhemd, was in der zeichnerischen Umsetzung jedoch oft nicht oder nur für Eingeweihte zu erkennen war. Es ist wohl davon auszugehen, dass die Kostüme naheliegenderweise vor allem von Zirkuskostümen waghalsiger Akrobaten inspiriert waren (Fossati I993).

26 Als wohl zu den frühesten Comicbeispielen gehörend lassen sich hier neben dem Zeitungscomicstrip-Helden The Phantom (ab I936) DCs beide Schöpfungen von 1939 nennen, The Crimson Avenger und Batman.

27 Ein Indiz für diese Spekulation liefern m. E. Beispiele, in welchen die Augen des Helden nicht gezeichnet werden, wenn man ihn eher von ferne sieht, in Nahaufnahmen jedoch sehr wohl, wie es etwa beim Green Arrow (zumindest in den hier konsultierten Heften) der Fall ist.

28 McCloud I994, 30.

29 Ebd., 36: «Thus, when you look at a photo or realistic drawing of a face - you see it as the face of another. But when you enter the world of the cartoon - you see yourself. [...] The cartoon is a vacuum into which our identity and awareness are pulled ...» (Hervorhebungen im Original). 
anderen Gründen, darunter auch die wirtschaftlichen Zusammenhänge - erklären, warum die maskierten Helden als Comic-Superhelden zumindest in der westlichen Welt populärkulturelle ‘Ikonen` wurden, während die Pulp-Helden als Phänomen doch auf die USA beschränkt blieben.

Dennoch übernehmen die Comic-Hefte die in den Pulps etablierten Erzählmuster; sowohl auf der narrativen Ebene wie in der bildlichen Umsetzung weisen besonders die frühen Comics noch deutlich den Pulps verpflichtete Elemente auf. So hat The Clock, der zunächst nur als maskierter Detektiv auftritt, der als Verbrecher gilt, neben anderen Ähnlichkeiten mit Jimmie Dale eine vergleichbare 〈Ermittlungsidentität` wie dieser. ${ }^{30}$ Später wird dann ein ziviles Ich namens Brian O'Brien, "wealthy young sportsman» ${ }^{31}$, eingeführt, wobei das weitere Figureninventar mehrfach ändert. Klare Pulp-Einflüsse finden sich manchmal sogar in Details, zum Beispiel unterhält Green Lantern/Alan Scott einen Archivraum, sein Sanctum, das jenem des Shadow in der zeichnerischen Umsetzung alle Ehre macht. ${ }^{32}$

Von den drei im Fokus stehenden Gestalten klar am deutlichsten in der Tradition der Pulp-Verbrechensbekämpfer steht The Owl/Nick Terry, dessen eher ungewöhnliche publizistische Heimat die Crackajack Funnies waren, bevor er seine Heldentaten in Popular Comics verrichtete. ${ }^{33}$ Sein Einsatzgebiet ist in erster Linie die nächtliche Metropole (Abb. 22), deren Gefahren besonders in den ersten Folgen beschworen werden. «[...] The Owl is really Nick Terry [...] who, at the stroke of midnight, dons the robes of the mighty Owl and swoops out over the darkened city to stalk and pounce upon cringing denizens of the met-

McCloud basiert seine Ausführungen übrigens ebenfalls auf einer Auffassung des Gesichts als Maske (ebd., 34).

30 Ähnlich wie Jimmie Dales «Larry the Bat» wird eine der Identitäten von The Clock beschrieben: «A lone figure heads toward gangland - Snowy Winters, a familiar small-time dip - a drug addict - accepted by the underworld as harmless - and known only to himself as - The Clock $\rightarrow$ (Murder by Proxy (George E. Brenner), in: Detective Picture Stories 5, April 1937, Textpanel zwischen Panels 5 und 6).

3 I The Clock Strikes (George E. Brenner), in: Crack Comics I, Mai I940, I.

32 Green Lantern - The Adventure of the Underfed Orphans (Bill Finger, Mart Nodell), in: AllAmerican Comics 31, Oktober 194I, 2. Die frühen Green-Lantern-Storys setzen dabei u. a. mit dem bunten Kostüm (rot-grün-violett) stark auf die Visualität des Mediums, erzählerisch gibt es zugleich Elemente, die noch den Pulps verpflichtet sind, etwa wenn Green Lantern zuweilen mit einer Schminkmaske ermittelt (ebd.) oder über seiner Heldenmaske eine GesichtsGummimaske trägt (All-American Comics 32, November 194I, I7).

33 Es erschienen 33 Owl-Geschichten in Crackajack Funnies 25-43 (Juli 1940-Januar 1942) und Popular Comics 72-85 (Februar 1942-März 1943), zuweilen enthält das Titelpanel einen Copyright-Vermerk «R. S. Callendar». The Owl erscheint dabei eher als Fremdkörper im auf Lustiges fokussierten Verlagsprogramm. Ferner ist er nicht zu verwechseln mit der gleichnamigen Figur, die in Funny Pages 34 (I94I) einen offenbar einmaligen Auftritt hatte. 
ropolitan underworld!!»34, lautet etwa ein Einführungskästchen, das den Lesern die Figur kurz vorstellt. Als kräfteloser Protagonist führt The Owl noch die Tendenz fort, bereits zu Beginn etabliert zu sein - wie er zu seinem Eulenumhang mit den phosphoreszierenden Augen gekommen ist, erfährt man nie. ${ }^{35}$ Von Pulp-Protagonisten wie The Spider und The Black Bat übernahm er ebenfalls die Mode, seine Opfer mit einem Eulenkleber zu markieren ${ }^{36}$ und der Polizei gelegentlich freche Briefe zu schreiben - allerdings nach gelöstem Fall und nicht, um ein Verbrechen anzukündigen, wie es etwa der Crimson Clown noch getan hatte. Dabei wird The Owl von der Polizei gesucht, die ihn als Kriminellen sieht, obschon er es ist, der regelmässig die Verbrecher dingfest macht. In Zivil ist Nick Terry abwechslungsweise - hier zeigt sich die Inkonsistenz der Golden-AgeComics - Privatdetektiv oder Sonderermittler der Polizei. In beiden Positionen ist er privat äusserst vermögend; neben einem luxuriösen Penthouse mit separatem Lift und Privathangar besitzt er ähnlich wie Batman mottogerecht gestaltete Hilfsmittel wie das pittoreske Owl-Flugzeug oder das Owl-Boot. ${ }^{37}$ Neben den üblichen Gaunern, Gangstern, Saboteuren und Mördern sind einzelne seiner Gegner als Superschurken zu sehen, die allerdings nie explizit fantastische Elemente aufweisen. ${ }^{38}$

Mit einem der bemerkenswertesten frühen Superschurken sticht dagegen die Origin-Story von The Black Hood, einem Helden ohne Superkräfte, hervor (weswegen diese nun etwas detaillierter wiedergegeben wird). The Black Hood trat zuerst in Top Notch (Laugh) Comics sowie eine Zeit lang zugleich in Jack-

34 The Owl (Frank Thomas [et al.?]), in: Crackajack Funnies 32, Februar 1941, 59. Auch Phrasen wie «criminal denizens» erinnern doch stark an typische Pulp-Formulierungen, namentlich aus den Shadow-Storys oder den Jimmie-Dale-Romanen.

35 In der allerersten Geschichte (Crackajack Funnies 25) trug The Owl dabei noch nicht sein typisches Outfit, seine Maske war eher wie ein elaboriertes Papiertütengesicht gestaltet (möglicherweise wechselte der Zeichner).

36 Die Kennzeichnung der Opfer findet sich zu Beginn noch bei einigen weiteren Helden, etwa dem Black Terror (Kleber in der spezifischen Form seiner Maske) und Green Lantern (dessen Opfer vom Abdruck seines Rings gekennzeichnet sind), verschwindet dann aber relativ rasch aus den Comics.

37 Den Hangar mitten in der Stadt zu haben, bedeutet für die Geheimhaltung der Heimstation des Helden doch eine besondere Herausforderung. Als er einmal von offiziellen Kräften verfolgt wird, schreckt The Owl daher nicht davor zurück, die gesamte Stadt inklusive Times Square mit schwarzem Rauch einzunebeln und damit ein ziemliches Verkehrschaos auszulösen, damit das Owlplane ungesehen in sein Versteck zurückgelangen kann (The Owl (Frank Thomas [et al.?]), in: Crackajack Funnies 34, April I94 I, 7-8).

38 Dies gilt vor allem für den Pantherman, Chef eines Verbrecherrings inklusive Höhlensystem, und The Spectre, Leiter einer Saboteurorganisation, die in jeweils drei Geschichten umfassenden Fortsetzungsstorys auftraten (in Crackajack Funnies 7-9, Februar-März 194I, sowie Crackajack Funnies I I-I3, Mai-Juli I94I). 

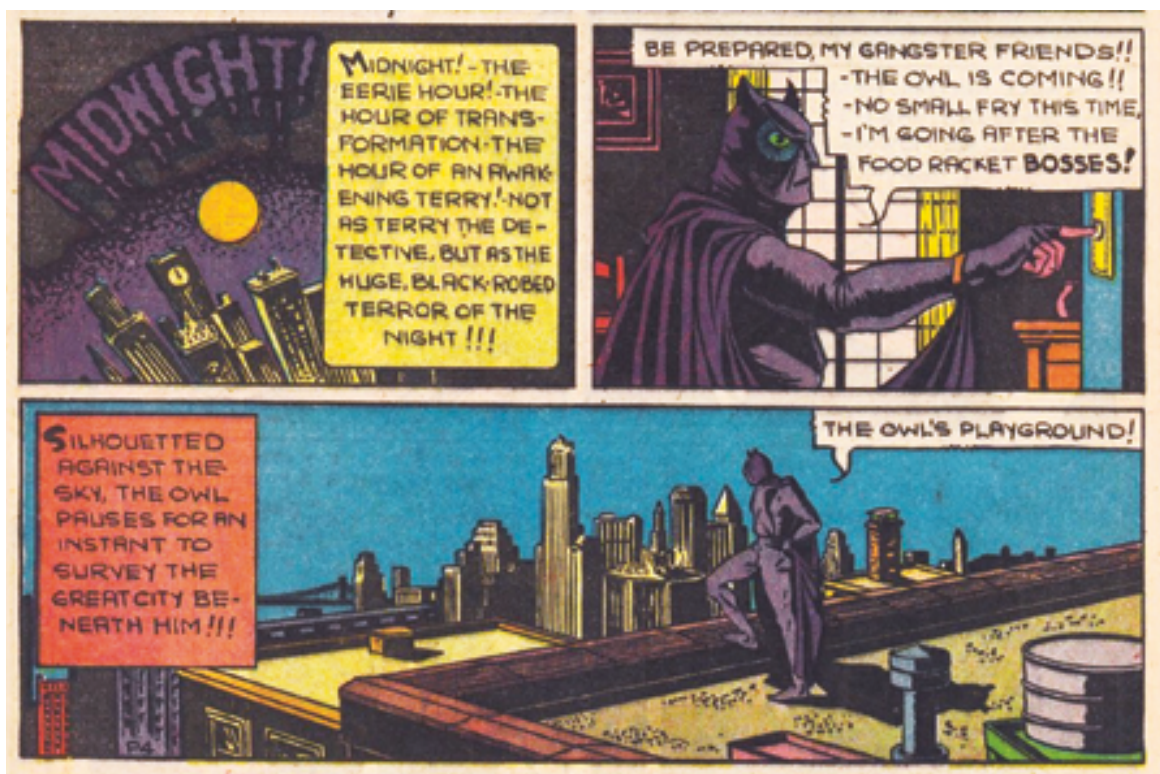

Abb. 22: Die nächtliche Metropole ist «The Owl's playground!» - seine Vogelperspektive verweist darauf, dass er - wie sein namengebendes Tier - die Übersicht über sein Tummelfeld hat. The Owl (Frank Thomas), in: Crackajack Funnies 26, August 1940, 4/52.

pot Comics auf, bevor er 1943 ein eigenes Heft erhielt. ${ }^{39}$ In Top Notch Comics 9 (Oktober 1940) überrascht der junge Musterpolizist Kip Burland den Skull (dessen Schädel von grüner Farbe ist) bei einem Einbruch, worauf dieser ihn niederschlägt und ihm das Verbrechen anhängt. Um seine Unschuld zu beweisen, sucht und findet der auf Kaution freigelassene Kip den Skull - mit noch schlimmeren Folgen: Von acht Kugeln durchsiebt, wird Kip in einer einsamen Gegend aus

39 Black-Hood-Storys erschienen in Top Notch Comics bzw. Top Notch Laugh Comics 9-45 (Oktober 1940 bis April 1944), ergänzt durch Auftritte in Jackpot Comics I-9 (Frühling I94 I-Frühling 1943). Wohl im Hinblick auf die Radiohörspiele, die im Juli 1943 starteten (und mit rund I 20 Folgen bis im Januar 1944 liefen), erhielt er eine eigene Heftreihe, Black Hood Comics 9-19 (Winter 1943/44-Sommer 1946). Die Reihe begann mit Nummer 9, weil sie The Hangman fortsetzte (The Hangman trat neben anderen Protagonisten noch einige Hefte lang in den hinteren Seiten auf) und wurde mit Nummer 20 zu Laugh Comics - mit dem Jugendlichen Archie als Titelheld. Die Jackpot-Geschichten sind mehr abenteuer- denn krimilastig (so tritt der Polizist McGinty kaum auf); jene in The Black Hood sind meist kleine Krimis, in denen der Held Detektivarbeit leistet und die mit einer «klassischen〉 Auflösungsszene enden können. Zu Black Hood vgl. Murray 2008, 217-228. 
dem Auto geworfen. Zum Glück findet ihn ein Einsiedler, der ihn gesund pflegt und selbst noch eine Rechnung mit dem Bösewicht offen hat. Da er inzwischen zu alt sei, um sich selbst nochmals mit dem Skull anzulegen, lehrt er Kip in monatelangem Training alles Nötige, damit dieser ein hervorragender Verbrechensbekämpfer wird (Abb. 23a und 23b). Batmans Argumentation fürs Maskentragen echoend, deklariert «The Hermit schliesslich: «With the name and costume of the Black Hood, you are now a man of mystery ... and that you must remain, for only mystery can strike terror into the hearts of criminals.»40 $«$ Mystery» ${ }^{4}$ hilft dabei offenbar sowohl gegen «gewöhnliche> Verbrecher als auch gegen übernatürlich begabte Kriminelle, beschränkt sich das Fantastische in den BlackHood-Storys doch auf die Seite der zahlreichen Finsterlinge.

Damit beginnt der Origin-Story zweiter Teil, die Jagd auf den Skull. Dieser kündigt weitere Untaten für Barbara Suttons Debütball an: Er werde den betuchten Gästen den Schmuck stehlen, doch wer schreie, sterbe. Als vermeintlicher maskierter Gast schleicht sich Black Hood in den Maskenball ein. Dort gelingt es ihm, nicht nur die hübsche Barbara zu bezirzen, sondern mithilfe von Partyfotos auch den Skull zu entlarven, der sich perfiderweise als Barbaras Mutter verkleidet hatte. Zwar verhaftet die Polizei den Bösewicht, doch ist dieser schon zu Beginn der nächsten Story erneut flüchtig - worauf sich die Auseinandersetzung mit dem Skull noch fast ein Jahr hinzieht. Erst in Top-Notch Comics i9 (September 194I) kommt es zum finalen Showdown, wobei der Skull schliesslich auf dem elektrischen Stuhl exekutiert wird, ${ }^{42}$ nachdem er seine Untaten gestanden hat, sodass Kip rehabilitiert ist. So kann der finale Erzählerkommentar auf das im Golden Age oft zitierte Credo «Crime doesn't pay» anspielen: «The wheels of justice grind slow but sure. The ironic tableau of the world's greatest force for

40 The Black Hood (Cliff Campbell [Pseud.], Al Camy [d. i. Al Camaratta]), in: Top Notch Comics 9, Oktober 1940. Hinter Cliff Campbell verbirgt sich laut Murray (2008a, 2 I 8) Abner Sundell oder aber Harry Shorten.

4I Seine Kostümwahl scheint dabei farblich gewöhnungsbedürftig, gegenüber seinen «schattig〉 gekleideten Kollegen kombiniert The Black Hood schwarze Accessoires mit Knallgelb. In der Beschreibung des Pulp-Autors schimmert dies deutlich durch: «[...] a weird figure in yellow tights, night-black shorts and hooded mask, his cape whipping out from his broad shoulders. $\mathrm{He}$ might have been mistaken for a man from Mars or a devil out of Hell, yet beneath the grotesque garb beat a heart that was warm and human» (Fleming-Roberts 2006, I3, The Whispering Eye, 1942, Kap II). Das schwarze Cape, das das Gelb in den Pulps zu verbergen mag, fehlt in den Comics.

42 Interessanterweise schreckte der Comic vor dieser Darstellung nicht zurück (man sieht den Skull frontal, wie er den Stromstoss erhält). Obwohl der Skull auf den beiden folgenden Heften noch auf dem Titelblatt prangte, blieb er tot (zumindest in den Comics, in den Pulps hatte er kurz darauf sozusagen eine Art Comeback). Zwar kehrte der Skull in Jackpot 6 (Sommer 1942) und Top Notch Comics 30 und 3 I (November/Dezember 1942) zurück, dabei handelte es sich aber um dessen rachedurstigen Sohn (zum Skull vgl. Murray 2008a, 2 18). 

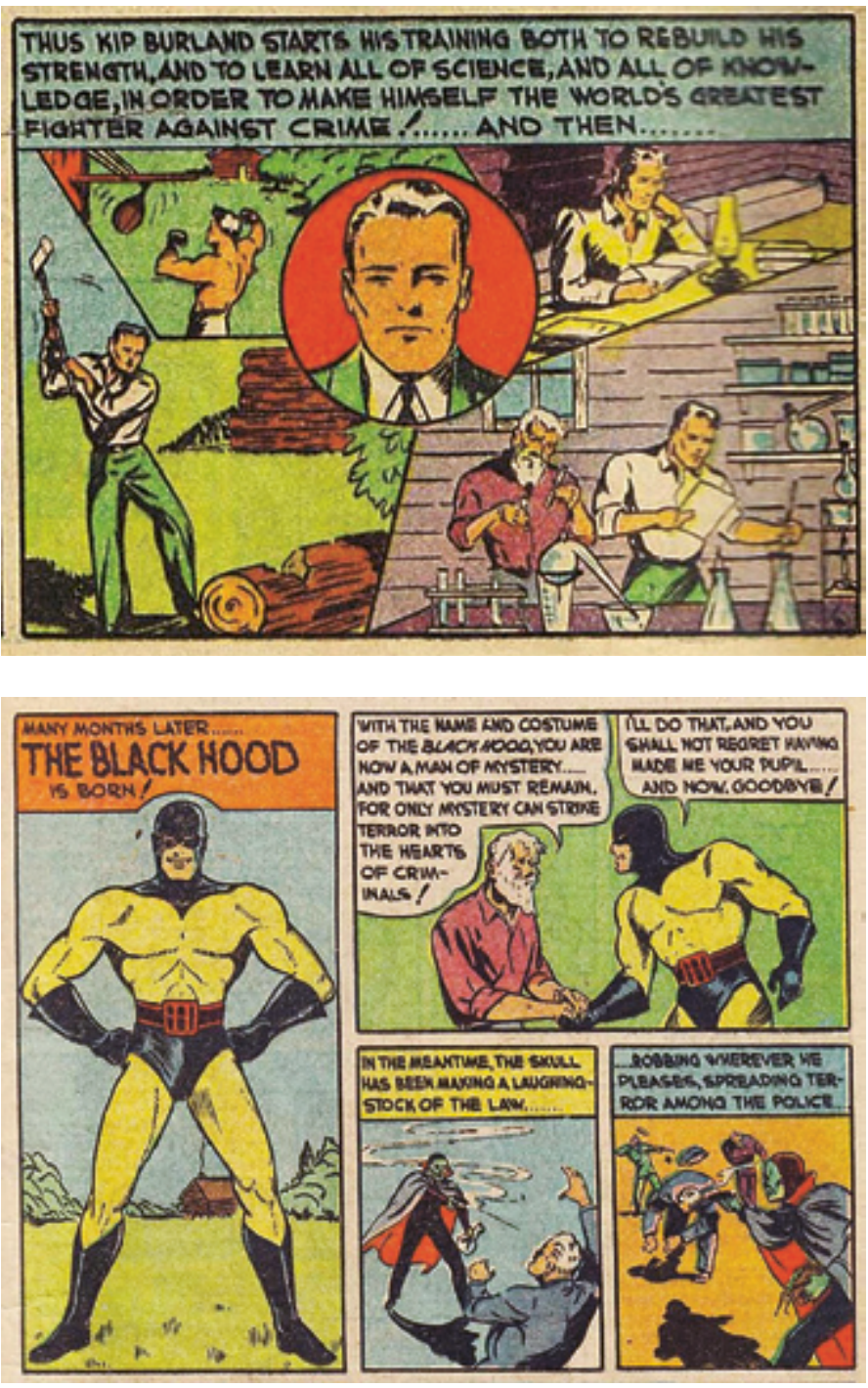

Abb. 23a und 23b: Kip Burlands monatelanges körperliches und geistiges Training wird hier gerafft in einem Panel erzählt. Zuoberst auf der nächsten Seite steht er dann bereit für seine selbst gewählte Heldenaufgabe - mit dem Skull wartet denn auch bereits ein unermüdlicher Superschurke. The Black Hood (Cliff Campbell [Pseud.], Al Camy [d. i. Al Camaratta]), in: Top Notch Comics 9, Oktober I940, 6-7. 
law and order being himself wanted by the law is no more. But fate, that master jester, has yet another quirk in store for the dark knight of justice. And the Black Hood, despite his new found liberty, meets his severest task - as The Mist steps into the scene in next month's ... Top Notch Comics.»43

Wie hier angekündigt, bedeutet die juristische Rehabilitation des Protagonisten mitnichten, dass dieser seinen amtlich nicht sanktionierten Heldenmantel an den Nagel hängen würde. Während Kip selbst nach seiner Rehabilitation jahrelang anscheinend nur als Privatmann existierte, arbeitete er offenbar mit dem Start der Radioserie ${ }^{44}$ I 943 auch in den Comics wieder als Polizist.

The Black Terror dient hier als Beleg für die Tendenz, dass eine Origin-Story den Erhalt von Superkräften erklärt. Dies geschieht zwar oft in einer Extremsituation, doch im Golden Age kann dies auch eine fast schon simple Angelegenheit sein: Der Apotheker4s Bob Benton schnuppert in Exciting Comics 9 (Mai I94I) nur gerade an einer von ihm selbst entwickelten Äthermischung - und schon besitzt er übermenschliche Stärke. Damit wurde er zum langjährigen Titelhelden von Exciting Comics (9-69, Mai I94 I-September I949), ${ }^{46}$ erhielt einen Stammplatz in America's Best Comics I-3 I (Februar I942-Juli I949) und glänzte in 27 Ausgaben seines eigenen Titels (The Black Terror, I942/43-Juni I949). Bobs Superkräfte sind das Resultat eines zwar durch Zufall geglückten, in seiner Wirkung jedoch geplanten und erhofften Experiments. Bob, der in der Story von diversen Figuren als «suzy», «softy» oder «weak-kneed pill-mixer» gescholten wird, erklärt den Zweck seiner Experimente: «It's the kind of thing a chap like me would fool around with. All my life folks have been picking on me, and I've dreamed about something which could help me build my strength.»47 Mit der richtigen Hilfe gelingt das gleich im nächsten Anlauf, ${ }^{48}$ und nachdem sein Si-

43 The Black Hood [Harry Shorten, Al Camy], in: Top-Notch Comics I9, September I94 I, I 4. (Allerdings war The Mist im nächsten Heft nicht zu sehen, dieser war vielmehr bereits in Heft I 6 eingeführt worden, kehrte aber in Jackpot Comics 3, Sommer I94 I, zurück.)

44 Auf dem Titelblatt des ersten Heftes schwört Black Hood, das Verbrechen zu bekämpfen, und derselbe Eid stand jeweils am Beginn der Radiohörspiele (bzw. zumindest der ersten und soweit bekannt offenbar einzigen erhaltenen Folge, The Emerald Ring von 1943).

45 Diesen Beruf teilt Bob Benton übrigens mit einem Pulp-Helden, The Crimson Mask/Bob «Doc» Clarke, der ab August I94I in Thrilling Stories auftrat.

46 Ausnahmen waren Heft 22 (American Eagle) und 53 (Miss Masque), ab Heft 56 (Juli I947) posierten andere Figuren auf dem Cover (v. a. Judy of the Jungle); der Hinweis «Featuring The Black Terror, Nemesis of Crime» zierte die Ausgaben aber noch bis Heft 66 (März 1948), dem viertletzten erschienenen Heft.

47 The Black Terror [Richard Hughes, David Gabrielsen], in: Exciting Comics 9, Mai I94I.

48 Eigentlich findet er seine Wunderformel nur, weil ihm Tim das falsche Fläschchen reicht, nämlich rote Ameisensäure, sodass er implizit Ameisenstärke erhält (ohne dass dies je explizit formuliert würde) - dies ist wohl kein Zufall, sind die Ameisen doch auch das erste Beispiel der «scientific explanation», die Supermans Kräfte in Action Comics I (Juni 1938) erklärt. 
dekick Tim Roland im Kostümverleih zwei passende Reststücke ergattert und sich anschliessend selbst zu einer Riechprobe der Äthermischung verholfen hat, können die «Terror Twins» loslegen. Denn dass der sanftmütige, bebrillte Bob wenngleich nicht die Kraft, so doch den Mut eines Helden hat, hat er bereits zuvor bewiesen: Als die Rohlinge, die von ihm Schutzgeld erpressen, Tim vor seinem Laden grob behandeln, eilt er diesem beherzt zu Hilfe. Obwohl er selbst zu Boden gestossen wird, gewinnt er in Tim einen Bewunderer und, nachdem er ihn als Helfer für seinen Laden und seine Versuche eingestellt hat, einen mutigen Sidekick. ${ }^{49}$

Ähnlich wie sein offensichtliches Vorbild Superman kämpfte The Black Terror trotz Superkräften vor allem am Anfang gegen sprofane> Verbrecher - atypischerweise geht es oft um Ungerechtigkeiten, von welchen Bob Benton selbst betroffen ist. So löst The Black Terror in der ersten Story Bobs Problem mit Schutzgelderpressung, in den folgenden geht es unter anderem um korrupte Beamte, Baulandspekulation und Baupfusch (die Kriminellen sabotieren in diesen Anfangsgeschichten in der Regel den angestrebten wirtschaftlichen Aufschwung der Stadt, die in Infrastrukturen wie U-Bahn, Flughafen, Dammerneuerung etc. investieren will). Allmählich wurde das Spektrum breiter, es galt auch die Folgen bösartiger Erfindungen und unlauterer Aktivitäten gegnerischer Kriegsparteien im In- und Ausland, ja sogar auf fernen Planeten abzuwehren.

Was er mit seinen Kräften anfangen will, ist Bob Benton dabei von Anfang an sonnenklar: «I'll do something I have always daydreamed about - use my strength to fight crime and evil! But none will know that poor Bob Benton's no longer a weakling!» ${ }^{\circ}$ Im selben Atemzug mit der Entscheidung zum Held-Sein erklärt er also sein Inkognito zum Imperativ. Die Notwendigkeit des Geheimnisses wird im Golden Age zwar immer wieder bestätigt, allerdings stets ohne dieses tatsächlich zu begründen; wenn überhaupt, fallen schwammige Hinweise. Eine fast schon ausführliche Erklärung findet sich einmal bei The Owl, als er einen Vorschlag, sich zu offenbaren, weil es doch eine sensationelle Story wäre, kategorisch ablehnt: «Nope! Can't be done! To be effective, the Owl must remain incognito to both the police and the underworld.» ${ }^{\text {I }}$ Eine etwaige Schutzfunktion (dass eine bekannte Doppelidentität eine Gefahr für den Helden wie sein Umfeld bedeuten würde ${ }^{52}$ ) schwingt hier allenfalls implizit mit, wird aber

49 Als Tim Bob danken will, wehrt er ab: «What for? I couldn't even defend myself!» Doch Tim weiss es besser: «That's why it took real nerve to step in! I wish I was like that [...]!» (The Black Terror [Richard Hughes, David Gabrielsen], in: Exciting Comics 9, Mai 194I.)

so Ebd.

s I The Owl (Frank Thomas [et al.?]), in: Crackajack Funnies 34, April I94 I, I.

52 Interessanterweise wird dieses Problem in den Black-Hood-Pulps - im Gegensatz zu den Co- 
vom Aspekt der Effizienz überdeckt und auch sonst nie erwähnt - ebenso wenig wie die Angst, ein Superheld könnte als Versuchskaninchen eingesperrt und missbraucht werden. ${ }^{53}$

Einen ziemlich guten Grund für eine Geheimidentität hat als eine gewisse Ausnahme Black Hood, solange er als Kip Burland wegen Diebstahl und «jumping bail» gesucht wird. Doch obwohl die Black-Hood-Autoren sich besonders in der frühen Phase merklich bemüht haben, die Geschichte sorgfältig zu erzählen, bleibt gerade dieser Punkt in den Details vage und sogar widersprüchlich; so heisst es zunächst, dass Kip jeweils unter einem anderen Namen in die Stadt zurückkehre, dann stellt er sich aber allen Figuren als Kip vor und wird auch nie anders benannt. ${ }^{54}$ Einerseits lassen es die Golden-Age-Helden so beim lückenlosen Erfüllen der an ihre Identitäten gerichteten Rollenerwartungen - Grundstein jeder erfolgreichen Doppelidentität - manchmal geradezu fahrlässig an Sorgfalt mangeln. Andererseits werden immer wieder Situationen inszeniert, in welchen sich die Protagonisten sehr bemühen, ihr Image (bzw. ihre Kategorisierung durch andere), alles andere als «Heldenmaterial zu sein, nicht zu unterminieren, sodass sie die an sie gerichteten Rollenerwartungen zuweilen schon fast übererfüllen. Die Doppelidentität erscheint als gegebener Bestandteil der Heldenexistenz, sodass die Notwendigkeit zur Aufrechterhaltung des erwartbaren Verhaltens vor allem in der zivilen, aber auch in der heldischen Identität zu einer Art absolutem Wert wird, der nicht zu hinterfragen ist.

In konkreten Situationen kann es sich beim playing along in der zivilen Identität um eine Ermittlungstaktik gegenüber Kriminellen handeln, um als vermeintlich Wehrloser Informationen zu erhalten («Better let this bird think I'm an easy mark»`s). Im Allgemeinen aber bedeutet dies in der Golden-Age-Welt vor allem,

mics - explizit angesprochen, wobei der Held als Gejagter zwischen zwei Lagern positioniert wird: «Once the secret of his dual identity became known, he knew that he faced either death from the hands of criminals or prison from the hands of police.» (Fleming-Roberts 2006, I 3 , The Whispering Eye (1942), Kap II.)

53 Für die problematischen Aspekte eines aus Experimenten hervorgegangenen Helden besteht im Golden Age kein Bewusstsein. So injiziert eine staatliche Institution Steve Rogers bewusst ein 〈Superserum», und obwohl das Serum gleich darauf zerstört und dessen Erfinder, Prof. Reinstein, ermordet wird, kann Captain America danach sein Doppelleben führen, ohne je wieder von staatlicher Forschungslust behelligt zu werden. Ein Misstrauen gegenüber Staatsinteressen, später ein wichtiges Thema in Captain-America-Comics, war im Golden Age offenbar nicht opportun. Zum Beispiel ist auch beim Black Terror die Zusammenarbeit zwischen maskiertem Helden und Kriegsgenerälen vorbehaltlos möglich.

54 Tatsächlich war Kip immer noch von der Polizei gesucht, die ihn die ganze Zeit vor der Nase hatte, doch war sein Steckbrief, wie sich kurz vor seiner Rehabilitation herausstellt, bei McGinty und dessen Kollegen schlicht vergessen gegangen (The Black Hood [Harry Shorten, Al Camy], in: Top Notch Comics I 8, August 194I, 4).

55 The Black Terror [Richard Hughes, David Gabrielsen], in: Exciting Comics Io, Juni I94I. 
gegenüber Ungerechtigkeiten zu schweigen und von Handgreiflichkeiten abzusehen, was ein weiteres Black-Terror-Beispiel illustriert: Als Rodney Clark, Jeans Arbeitskollege, Bob wieder einmal beleidigt, ohne dass dieser sich wehrt, fragt Tim danach: «Gee, Bob! Couldn't you have socked him - just once?» Doch Bob bleibt standhaft: «And reveal my power? Not a chance!» ${ }^{6}$ Es scheint, als würde hier ein jugendlicher Hang zu Gewalt mit erwachsener Besonnenheit gekontert - was Bob indes nicht daran hindert, kurz darauf sein Black-TerrorKostüm auszuführen, um Rodney eine Lektion zu erteilen (aus der hier zufällig aber nichts wird). Bob verteilt als Black Terror mehrfach persönliche Denkzettel (Rodney erhält so in der ersten Geschichte ein blaues Auge), wiewohl die Empfänger sich ja nicht erklären können, warum es der maskierte Held auf sie abgesehen hat. Dass dies kaum die feine Heldenart ist, wird dabei nicht problematisiert; deutlich verkörpert die heldische Hälfte des Protagonisten hier eine Ermächtigungsfantasie, bei der die zivile Hälfte dank der Maske keine Konsequenzen zu befürchten hat.

Entworfen wird hier das Bild, dass die zivile Identität eine totale Rollenanpassung beinhaltet, während der Griff zum Heldenmantel den Ausbruch daraus bedeutet. Explizit formuliert wird dies einmal, als Bob nicht anders kann, als seine Freundin Jean Starr 〈selbst> vor einem heranbrausenden Polizeiauto zu retten, und dies so kommentiert: «Here's where I step out of character!» (Abb. 24). Entsprechend verblüfft reagiert Jean: «I can't understand it - you were actually beroic!»\$7 Interessanterweise reklamiert Bob in seiner Antwort darauf eine gewisse Rollenflexibilität: «Huh! Think the Black Terror has a monopoly on saving you?» Freilich ist er es, der dieses «Monopol〉 sonst stets seiner kostümierten Identität zuweist, was zu einer nur implizit zu beobachtenden Spannung führt: Einerseits soll Jean von Bobs Heldentum nichts ahnen, zugleich wünscht er sich als Bob ihre Anerkennung. Im Verhältnis zu seiner heldischen Identität situiert Bob - wie die andern Golden-Age-Helden - sein ziviles Ich inkongruent: Je nach Situation äussert er sich als Rivale um Liebesgunst (der sich seiner Chancenlosigkeit bewusst ist) oder als Bewunderer des Helden.

Während der Held mit seinen Superkräften als Steigerungsform körperlicher Performanz - stärker, schneller, dehnbarer etc. - die Grenzen des gegebenen menschlichen Leistungsvermögens sprengt, ist es die Maskierung, die soziale Grenzen hinfällig werden lässt. In dieser Hinsicht ist das gegenüber den Pulps erweiterte Feld der zivilen Berufe der maskierten Helden aufschlussreich: Insgesamt handelt es sich bezeichnenderweise um Berufsfelder, die es erlauben, sich

56 The Black Terror (Elmer Wexler et al.), in: Exciting Comics I I, Juli I94I.

57 The Black Terror (Richard Hughes, David Gabrielsen), in: Exciting Comics I s, Dezember I94I. 
in allen sozialen Schichten zu bewegen. So kann der Protagonist auch in Zivil in verschiedenen Milieus ermitteln, womit der Vorwurf der Hochstapelei vermieden wird, den man maskierten Helden (damals) wohl hätte machen können (wenn etwa ein Fabrikarbeiter in der gehobenen Gesellschaft hätte agieren müssen). Denn wie bereits Goffman festhält, ist Hochstapelei nach unten für gewöhnlich durchaus salonfähig. ${ }^{8}$

Wie in den Pulps ist in den Comics die beliebteste zivile Tätigkeit das Millionärsdasein (welchem ja schon Zorro und der Scarlet Pimpernel als historische Äquivalente frönten). Während Gentleman-Gauner in den Comics kaum auf die Bildfläche treten, ${ }^{59}$ werden die Polizisten, die in zwei verschiedenen Uniformen auf Verbrecherjagd gehen, zahlreicher. ${ }^{60}$ Eine wegweisende Ergänzung stellen die (Natur-) Wissenschaftler wie Bob Benton dar, denen ihr Beruf bzw. dessen Risiken, etwa beim Hantieren mit Chemikalien, sozusagen eine Prädisposition für Superkräfte verleiht. ${ }^{6 \mathrm{r}}$ Schliesslich sind erst die gezeichneten Helden journalistisch tätig, wobei dies trotz der offensichtlichen Vorteile einer Redaktion als Arbeitsort relativ selten der Fall ist. ${ }^{62}$ Es lässt sich spekulieren, dass man hier eine Variation zum Vorbild Clark Kent schaffen wollte, um eine zu grosse Ähnlichkeit zu vermeiden.

Dies gilt allerdings nicht für die Freundinnen der Helden, denn für diese stellt der Journalismus - wohl nach Lois Lanes Beispiel - den Standardberuf dar, sofern sich ihre Tätigkeiten nicht ebenfalls im gesellschaftlichen Zirkel (als socialite) erschöpfen. Als Journalistinnen tragen die Frauenfiguren den männlichen Protagonisten immer wieder Fälle zu oder geraten auf Storyjagd in Gefahr und ‘provozieren> so ebenfalls Heldeneinsätze. ${ }^{63}$ Paradebeispiele dafür sind Nick Terrys

58 Goffman 1996 (1959), 60 (engl. 2002, 56).

59 Es lässt sich spekulieren, dass man diese für junge Leser weniger geeignet hielt und dass angesichts des bevorstehenden Krieges kriminelle Helden unpassend schienen (so wurde auch The Clock von der Polizei als Helfer anerkannt). Ein Sonderfall ist Plastic Man (ab I94I in Police Comics), der vor seinem kräftespendenden Unfall ein «richtiger> Gangster war. Seine zivile Identität wird jedoch nach den ersten sieben Geschichten sang- und klanglos gestrichen. Zu Plastic Man im Golden Age vgl. Kniep 2009, I 36-1 82.

60 Beispiele dafür sind The Blue Beetle/Dan Garrett, The Woman in Red/Peggy Allen, The Jester/ Chuck Dixon oder The Manhunter/Dan Richards, zeitweise auch The Black Hood und The Owl.

6I Damit lassen sich diese Figuren wohl auch als ins Positive gewendete Gegenentwürfe zum Protagonisten in R. L. Stevensons Novelle The Strange Case of Dr. Jekyll and Mr. Hyde ( 1886 ) sehen. Als weiterer Vorteil für die Narration können ihre Erfindungen, vom Typhus-Heilmittel über den Softdrink bis zum neusten Sprenggas, als Anlass für ein neues Abenteuer dienen, wenn Gangster oder Spione davon profitieren wollen.

62 Zwei weitere Beispiele für Medienschaffende sind Radioingenieur/-sprecher Alan Scott/Green Lantern und Reporter «Happy» Terrill/The Ray (in Smash Comics I 4-40, ab I940).

63 Bemerkenswerterweise gibt es dazu ein «umgekehrtes〉 Paar: Socialite Diana Adams alias Miss Masque (u. a. in Exciting Comics 51-54, I946/1947, und America's Best Comics 23-3 I, 1947-1949) hat einen Freund namens Russ, der Journalist ist (und nur in einem Teil der Ge- 

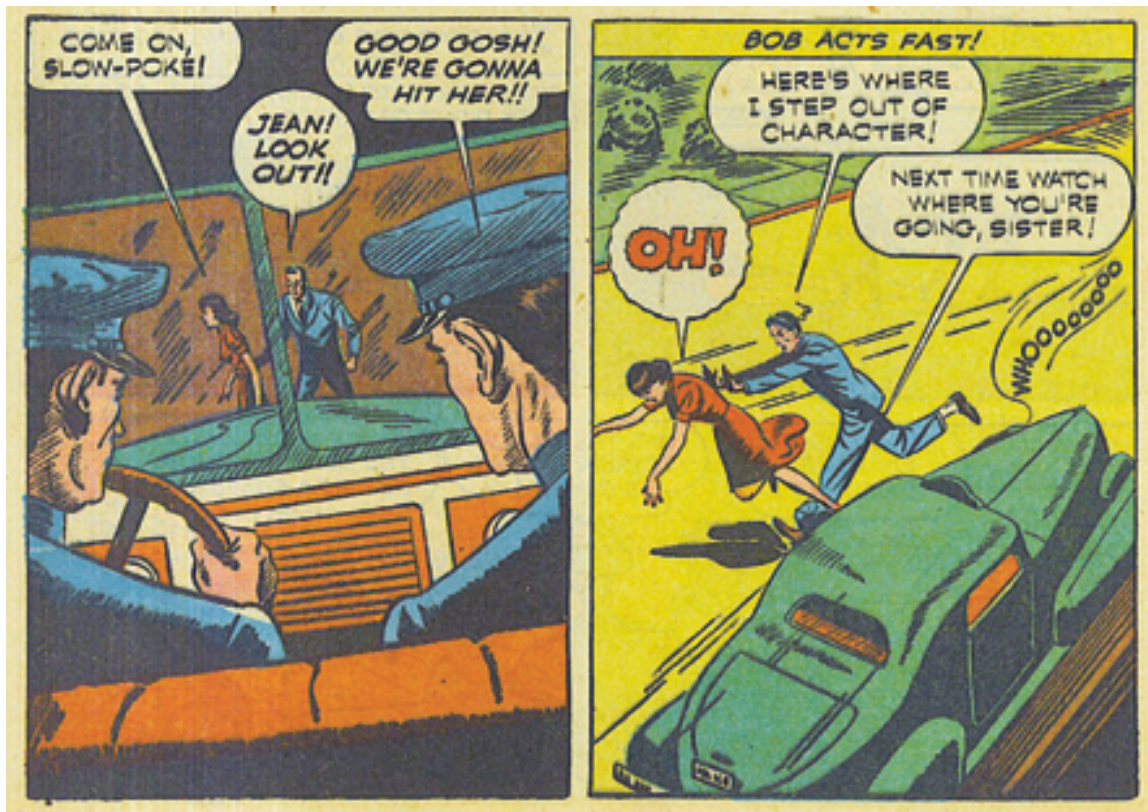

Abb. 24: Nur wenn es gar nicht anders geht, im Angesicht unmittelbarer Gefahr, bricht Bob Benton in Begleitung Jeans seine Rollendisziplin und stürzt sich in Zivil in die <Action>. The Black Terror (Richard Hughes, David Gabrielsen), in: Exciting Comics is, Dezember I94I.

Verlobte Belle Wayne und Barbara Sutton, die sich als Fotojournalistin anstellen lässt, um möglichst oft The Black Hood zu treffen. ${ }^{64}$ Auch Jean Starr, die Frau in Bob Bentons Leben, hat als Assistentin des Bürgermeisters eine vergleichbare Funktion. Der zivile Beruf des Protagonisten und die journalistische Spürnase (bzw. die Neugier) seiner Freundin sind freilich nicht die grössten Wasserträger auf die Mühle des handlungsauslösenden Moments, sondern der Zufall: Meist rutschen die Protagonisten in ein Abenteuer - freilich niemals unwillig, sondern stets voller Tatendrang. Insbesondere Bob Bentons Laden erweist sich als wahrer Anziehungspunkt für Verbrecher und Verzweifelte aller Art.

Die Golden-Age-Heldencomics haben üblicherweise - wohl nicht zuletzt aufgrund der Kürze der Geschichten - ein recht schmales Inventar fester Figuren.

schichten auftritt), doch trägt ihr dieser kaum Fälle zu, vielmehr stösst sie selbst durch Zufall, meist im privaten Umfeld, auf diese.

64 The Black Hood (Al Camy et al.), in: Top Notch Comics I I, Januar I94 I, 5. 
Die Varianten sind hier ein love interest und ein Sidekick oder als dessen Alternative ein Polizistenpartner. ${ }^{65}$ Der Protagonist hat über sein Ein- oder ZweiPersonen-Kernteam hinaus kaum soziale Bindungen, es sei denn, es ergäbe sich gerade ein narrativer Bedarf dafür (etwa bei einer Story um ein Klassentreffen); entsprechend verschwindet Black Hoods Mentor The Hermit nach dem Tod des Skulls, als er seine Funktion erfüllt hat, spurlos aus der Geschichte. Zuweilen gibt es noch einen Rivalen um die Gunst der weiblichen Figur, der jedoch oft vergleichsweise rasch wieder aus der Erzählung verschwindet - dies gilt für Rodney Clark bei The Black Terror und Joe Strong bei The Black Hood, der vor allem komischen Zwecken diente.

Als uneingeweihter Gegenpart des Helden tritt entweder die Frauenfigur oder der Partner bei der Polizei auf, der nichts lieber will, als den Helden einzufangen, obwohl er diesem jeweils die Lösung des Falls verdankt. In solchen Konstellationen stellen «If they only knew>-Momente regelmässig den Schlussgag dar - teilweise sogar ohne dass die Doppelidentität in der Story erwähnt worden wäre. Offenbar setzte man voraus, dass diese Verhältnisse den Lesern schon so bekannt waren, dass dies möglich war. Sidekick, Polizist und Herzdame stehen dabei in verschiedener Weise in Relation zur Doppelidentität des Helden.

Die Sidekicks ersetzen in gewisser Weise die fremdländischen Diener der gut betuchten Pulp-Protagonisten. ${ }^{66}$ Der Inbegriff eines Sidekicks ist von Batmans Robin geprägt. ${ }^{67}$ Als Robin hat Bruce Waynes Mündel Dick Grayson eine eigene Heldenidentität, die ebenso gehütet wird wie Batmans eigene. Bei den meisten anderen jugendlichen Sidekicks hingegen wird mit dem Identitätsgeheimnis geradezu lasch umgegangen. Obwohl der heldische Übername der Sidekicks oft eine Art Diminutiv ist, der sie als kleinformatigere Doppelgänger der erwachsenen Helden ausweist - zum Beispiel Tim Roland als The Little Terror ${ }^{68}$-, erhält ihre Doppelidentität kaum narrative Aufmerksamkeit; die typischen Doppelidentitätsmomente bleiben auf die Erwachsenen konzentriert. ${ }^{69}$ Vielmehr wer-

65 Sidekick und Polizist schliessen sich gegenseitig aus, denn im «Polizistensetting〉 ist der Protagonist meist selbst der Anfänger, was einen (jugendlichen) Sidekick überflüssig macht.

66 In Einzelfällen treten solche noch als Randfiguren auf, so atmet Nick Terry/The Owl mit seinem chinesischen Diener Soto (der ihn allerdings nicht ins Abenteuer begleitet) auch hier den Geist der Pulps.

$67 \mathrm{Zu}$ Robin und der Sidekick-Funktion vgl. u. a. Kniep 2009, 46-57, Easton in Easton/Harrison 2010, 19I-208.

68 Zwei weitere Beispiele dafür sind Eaglet und Pinky, die Sidekicks von The American Eagle (ab I942) bzw. Mr. Scarlet (ab I940/I942) sowie Kitten, Mädchen-Sidekick von Cat-Man (ab I940). Ein Beispiel ohne Diminutiv ist Green Masks Sidekick Domino (in Mystery Men Comics und The Green Mask, ab i939).

69 Zum Beispiel kommt fast nie vor, dass ein gefangener Sidekick demaskiert wird und so auf die Identität des erwachsenen Helden geschlossen werden könnte oder dass er erpresst würde, um 
den sie selbst dann, wenn sie maskiert sind, überwiegend beim Vornamen gerufen (Captain Americas Bucky hat trotz Maske nicht einmal einen eigenen Heldennamen). Dies bedeutet freilich in Bezug auf die Wahrung des Identitätsgeheimnisses eine weitere Strapaze für die willing suspension of disbelief..$^{\circ}$ Dies gilt auch für die alternative Sidekick-Variante eines älteren, in der Regel etwas schrulligen Heldenbegleiters - wie den schmerbäuchigen Taxifahrer Doiby Dickles bei Green Lantern oder Woozy Winks bei Plastic Man. In dieser Variante trägt der Sidekick allerdings nie eine Maske und hat entsprechend keine Doppelidentität, sondern ist klar auf die Funktion des comic relief ausgerichtet.

$\mathrm{Ob}$ jung oder alt, Sidekicks verkörpern eine kindliche/jugendliche Begeisterung für alles, was den Zustand der Langeweile unterbricht. Oft lechzen die Sidekicks noch mehr als der Held nach Action oder freuen sich über die Aussicht auf eine herzhafte Schlägerei. Es versteht sich von selbst, dass sie Anweisungen des Helden, zuhause zu bleiben, grundsätzlich missachten und ihm hinterherzotteln, um ja keine Aufregung zu verpassen. Dabei erweisen sie sich oft als Rettungsanker und erhalten so narrativ durchaus eine wichtige Funktion. Dank einem verlässlichen Sidekick ist es möglich, dass der Held trotz aller Superkräfte selbst in Gefahr geraten kann bzw. muss, was der (oft kritisierten) potenziellen Übermacht eines Superhelden (der noch nicht auf Superschurken als Gegner angewiesen ist) entgegenwirkt (Abb. 25). $7^{1}$

Die Polizistenpartner dagegen sind offensichtlich vor allem als komische Charaktere angelegt. Während die «Lieblingspolizisten` der Helden in den Pulps (wie McGrath bei The Black Bat) durchaus ernstzunehmende Figuren sind, deren Bemühungen, den Helden zu entlarven, auch für Spannung sorgen, kommt es in den Comics zu einer Stereotypisierung des oft etwas tölpelhaften, aber grossspurigen Kameraden, der keine Ahnung hat, dass seine maskierte Nemesis Tag für Tag mit ihm arbeitet. Diese Polizistenfiguren lassen sich als Aktualisierung bzw. Modifizierung von Zorros Soldatenkontakt Gonzales verstehen. Eines der frühesten Comic-Beispiele dafür waren Dan Garrett alias The Blue Beetle und sein Partner, der altgediente Polizist Mike Mannigan. Dieses Muster übernahm dann auch Black

diese preiszugeben - die Sidekicks sind als kindliche/jugendliche Helden so über jeden Zweifel erhaben, dass dies schlicht tabu scheint.

70 Duncan/Smith $(2009,228)$ sprechen darüber hinaus sogar von der «rather illogical tradition of adult superheroes taking on teenage sidekicks» innerhalb der Geschichten, was extradiegetisch jedoch als «powerful wish fulfillment for young readers» gedient habe.

7I Beispielsweise wäre die Karriere des Black Terror schon in der ersten Story (Exciting Comics 9, Mai I94I) vorbei, wenn der Little Terror den an Gleise gefesselten Helden nicht befreien würde, und nicht weniger als dreimal (Exciting Comics IO, 2 I, 23, Juni I94 I, August/Dezember 1942) ertränke der grosse Terror mit einem Gewicht an den Füssen, wenn nicht jeweils in letzter Minute der kleine Terror angeschwommen käme. 

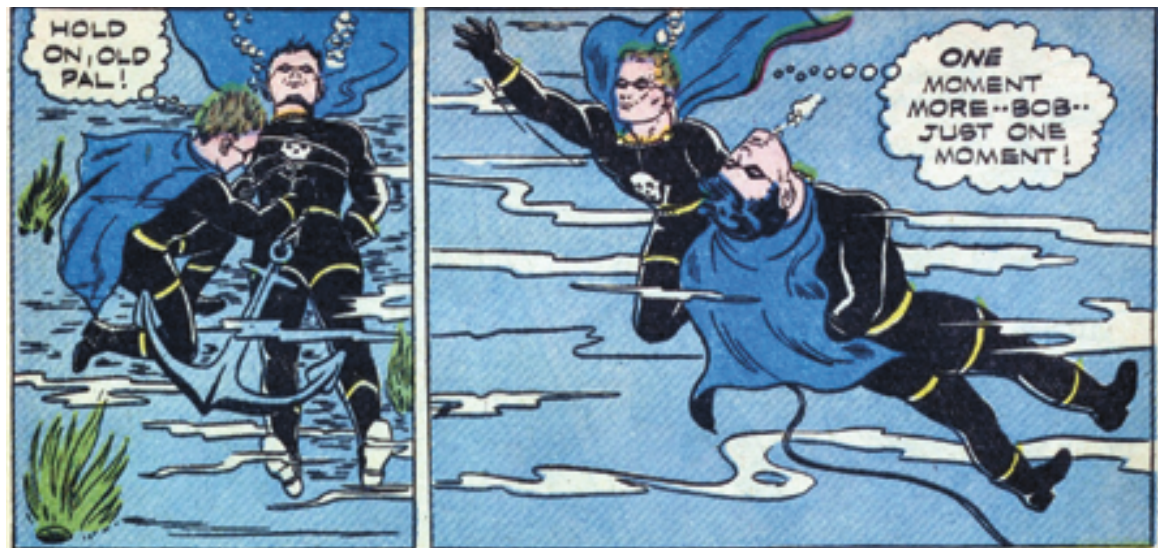

Abb. 25: Während Bob Benton fraglos der Protagonist ist und dem Jungen Tim Roland nur die Rolle des enthusiastischen Sidekicks bleibt, erweist sich The Little Terror nicht selten als eine Art <Lebensversicherung> für sein erwachsenes Pendant - der trotz aller Superkraft keineswegs unbesiegbar ist. The Black Terror (Richard Hughes [?] et al.), in: Exciting Comics 21, August I942.

Hood mit Sergeant McGinty - die Namen verraten, dass dieses Stereotyp offenbar mit irisch-schottischen Wurzeln verbunden wurde. In dieser Konstellation ist der Protagonist in der Regel der jüngste Polizist im Dienst - wenn er als ‘Anfänger> seine altgedienten Kollegen übertrumpft, stellt das deren Unfähigkeit bzw. Lächerlichkeit erst recht aus (und diese zürnen dem Helden meist auch mehr aus Eitelkeit, als weil er das Gesetz in die eigenen Hände nimmt).

Die Polizisten unter den maskierten Helden, ob Anfänger oder Spezialdetektiv wie The Owl, sabotieren durch ihre Kostümaktionen den eigenen beruflichen Erfolg, auch wenn ihnen die Genugtuung des heimlichen Helden bleibt. Wenn der Protagonist in diesem Polizeisetting sein Alter Ego dingfest machen soll, zeigt sich ein ins Absurde neigender spielerischer Charakter der Doppelidentität. In diesem Katzund-Maus-Spiel wirkt der Protagonist als Doppelagent - sozusagen als Maus, die sich als Katze ausgibt, und zugleich als Katze, die sich als Maus ausgibt. Es liegt auf der Hand, dass dieses Setting eine gute Basis für «If they only knew`-Momente bildet..$^{2} \mathrm{Zu}$ den plakativsten zählen gewiss jene Szenen, in welchen der Protagonist verdächtigt wird, der Held zu sein, und der Polizistenpartner diese Idee als gegen-

72 Bei The Jester etwa, in dessen traditionellem Narrenkostüm der «police rookie» Chuck Lane steckt, bildet diese Version des If he only knew`-Moments meist den Aufhänger der Story, besonders ausgeprägt ist hier das stereotype Ende, dass Detective Mulligan (der etwas später ebenfalls McGinty heisst), seinen jungen Partner rügt, weil ihm der Jester in der Verbrecherjagd 

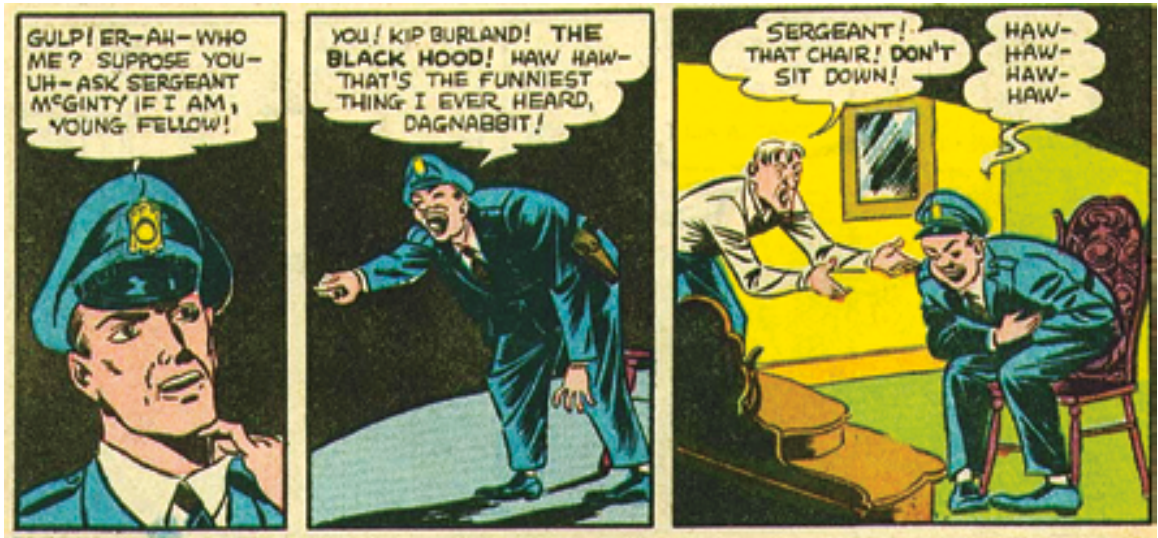

Abb. 26: McGinty hält sich wörtlich den Bauch vor Lachen über die Vorstellung, sein junger Partner Kip Burland könnte The Black Hood sein - wenn er nur wüsste, dass die Vermutung ins Schwarze trifft ... The Black Hood. The Case of the Magic Sword (Al Fagaly et al.), in: Black Hood Comics I3, Winter i944-1945, 5 .

standslos von sich weist. So krümmt sich McGinty einmal vor Lachen (Abb. 26): "You! Kip Burland! The Black Hood! Haw Haw - that's the funniest thing I ever heard, daggnabbit!»73 Weiter gehören dazu zweideutige Aussagen des Helden selbst, wenn etwa McGinty arglos anregt: «Kip! Why dont you go after the Hood? It'll mean a promotion if ye catch him!», und Kip den Lesern zuzwinkert: «Well, I don't now about catching him, Sarge! But I promise I'll follow him wherever he goes!»74 In solchen Momenten teilen Protagonist und Leser als Eingeweihte den Scherz, der dem Polizistenpartner entgeht.

Die von Zorro etablierte Konkurrenz mit dem eigenen Alter Ego, die in den Pulps kaum zu finden war, wird in vielen Comics zumindest über eine gewisse

erneut zuvorgekommen ist - er, Mulligan/McGinty, diesen aber beim nächsten Mal garantiert fassen werde.

73 The Black Hood. The Case of the Magic Sword (Al Fagaly et al.), in: Black Hood Comics I 3 , Winter 1944, 5. (In der Geschichte wird Kip als grösster lebender Held offenbart, da er das Schwert Excalibur aus einem Stein ziehen kann.)

74 The Black Hood [3. Geschichte im Heft] (Clem Weisberger et al.), in: The Black Hood I4, Frühling 1945, 9 (meine Hervorhebung). Die <If they only knew -Momente werden manchmal auch durch den Kommentar einer eingeweihten Figur hervorgehoben, wenn etwa Nick Terrys Verlobte Belle mehrfach erklärt, dass der Polizeichef explodieren würde, wenn er wüsste, wer unter dem Owl-Kostüm steckt (z. B. in The Owl (Frank Thomas), in: Popular Comics 75, Mai 1942, oder Crackajack Funnies 38 und 39, August/September 194I). 
Zeitspanne zu einem festen Bestandteil der Figurenkonstellation. Im Polizistensetting stehen die beiden Identitäten des Protagonisten in einem beruflichen Konkurrenzverhältnis - prägender, da nicht auf dieses Setting beschränkt, ist aber die Liebeskonkurrenz, in die sich der Protagonist mit seiner Doppelidentität typischerweise begibt.

Besonders unermüdlich vergleicht Jean Starr Bob Bentons Unzulänglichkeiten mit der Vollkommenheit des Black Terror. Bei diesem Helden ergibt sich so die Situation, dass seine Doppelidentität eigentlich nur in Hinblick auf die Frauenfigur ausgerichtet ist - wenn Jean nicht zugegen ist, schlägt Bob wenn nötig ebenso in Zivil zu (meistens geht es um Prügeleien). Die ersten Terror-Geschichten etablieren im Schlussmoment mit auffallender Konstanz die Grundkonstellation (Abb. 27): Jean vergleicht Bob mit dem Terror, wobei der eine makel-, der andere traumhaft erscheint, was Bob eher amüsiert, während zugleich die Geheimhaltung zementiert wird. So meint Jean am Schluss der zweiten Story: «He’s the sort of man I've dreamed about! Oh, Bob ... if you were only like him!» Darüber lacht Bob nur: «Me? Not a chance!» Kaum ist Jean ausser Sicht, bemerkt Tim: «Someday that dame's gonna get a real surprise!»75 und formuliert damit explizit, was wohl auch die Leser denken sollen. ${ }^{76}$

Doch so eng das ausgesteckte Feld ist, erlaubt es doch eine gewisse Variation. Zum einen fällt Jeans Urteil nicht immer gleich aus. Während sie Bob (zuweilen zusammen mit Tim) in der Regel für seine fehlende Abenteuerlust und seinen Mangel an Rückgrat bzw. Schlagkraft gegenüber Gaunern tadelt, kann es wie erwähnt vorkommen, dass er sich als Bob Benton auf eine Schlägerei einlässt, die mit seiner Niederlage endet - worauf sie meint, dass er das doch bleiben lassen solle, schliesslich sei er nicht der Black Terror. ${ }^{77}$ Zum andern nimmt Bob solche Herabwürdigungen nicht immer gleich auf: Mal scheint er verletzt oder verärgert, mal widerspricht er, am häufigsten aber lacht er darüber. In innere Konflikte scheint er darob jedoch nicht zu geraten. Ein bemerkenswer-

75 The Black Terror [Richard Hughes, David Gabrielsen], in: Exciting Comics ro, Juni I94I.

76 Dieses Schema wird sogar beibehalten, als The Black Terror in den Krieg zieht und rund um den Globus gegnerische Pläne durchkreuzt (nicht ohne zwischendrin nach wie vor im eigenen Land nach dem Rechten zu sehen). Obwohl es nun auch Storys ohne Jean und (seltener) ohne Bob gibt, finden sich immer wieder Wege, damit Jean und Bob oder zumindest The Black Terror am selben Einsatzort auftauchen.

77 Der Dialog deutet an, wie Bob sich gegenüber Jean einerseits von seinem Helden-Alter-Ego distanziert, diesem aber klar auch eine Vorbildfunktion attestiert: [Jean:] «You were foolhardy to resist, Bob!» - [Bob:] «Gosh! You don't ask The Black Terror to pull his punches!» [Jean:] «Maybe not - but you're not in his shoes yet, are you!» [Bob:] «Guess you're right, Jean! I'll let him do the fighting!» (The Black Terror ([Richard Hughes,] David Gabrielsen), in: Exciting Comics 20, Juli 1942). Vgl. auch Exciting Comics 21, August 1942. 
Abb. 27: In Bezug auf die Doppelidentität liest sich die letzte Seite der allerersten Black-Terror-Story wie eine komprimierte Version der Golden-Age-Comics. The Black Terror (Richard Hughes, David Gabrielsen), in: Exciting Comics 9, Mai
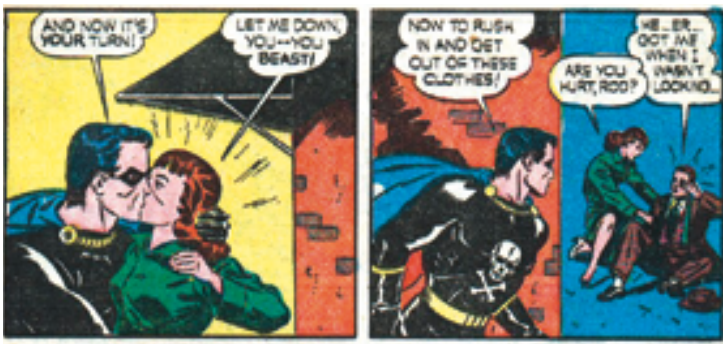
I94I.
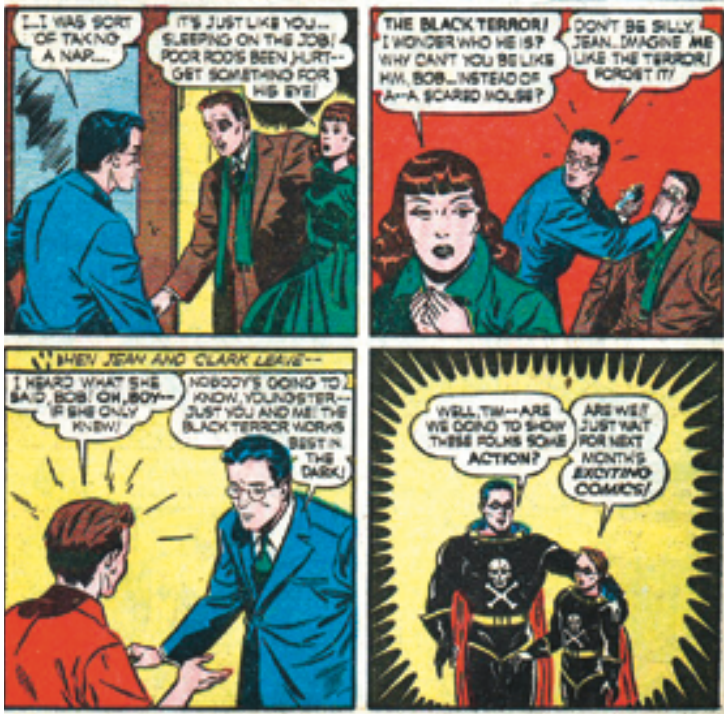

tes Beispiel dafür ist ein Schlusspanel, das im Rahmen der Kriegspropaganda steht: «Bob, have you read about the -», schwärmt Jean, worauf er sie unterbricht: «Black Terror! He's wonderful ... But I'm the guy who can sell you war bonds!» $7^{8}$ Dies wird immer wieder aufgenommen - noch in Exciting Comics 48 ruft Jean aus: «Bob Benton! You couldn't fight your way out of a soap bubble», worauf Bob in Diego Vegas Spuren kontert: «But be reasonable, Jean. They've got guns!»79 Indem Bob ihren Anspruch als absurd entlarvt, weist er implizit zugleich darauf hin, wie aussergewöhnlich der Mut bzw. die Aktionen des Black Terror sind, womit sein Kommentar letztlich der Überhöhung seines heldischen Alter Ego dient. 
Wie schon bei Zorro fällt hier eine gewisse Affinität des Themas zur idealen Männlichkeit auf. Explizit formuliert Jean Starr dies etwa in Exciting Comics 38 : "You'll never be a real man, Bob Benton! I'm ashamed for you!» ${ }^{\circ}$ Ähnlich ergeht es Kip Burland, der in Zivil ebenso einen Schwächling gibt, sodass Barbara ihn mehrmals einen Feigling nennt. Als er einmal fragt, was er denn getan habe, erklärt sie: «It's what you don't do that bothers me, Kip! You're too timid, weak! You'll never amount to anything! ${ }^{8 \mathrm{I}}$ Die Szene entlarvt, dass es eben auch darum geht, «etwas zu sein», was - wie schon bei Zorro - offenbar mit einem recht einseitigen Männerideal korreliert. Ein 〈richtiger> Mann muss sich offenbar wehren können, was körperliche Gewalt beinhaltet. Freilich pochen die Frauenfiguren nicht darauf, weil sie einen Beschützer bräuchten - obwohl der Held sie regelmässig retten muss, können sich die intelligenten und aktiven Frauen grundsätzlich gut selbst verteidigen. ${ }^{82}$

Trotz ihrer Schwärmerei für den Helden scheint die jeweilige Frauenfigur auch in dessen zivilem Ich ein latentes Potenzial zu vermuten, da sie ihn mit ihrer Nörgelei implizit oder explizit anzustacheln versucht, mehr Selbstbewusstsein zu zeigen und für seine Interessen einzustehen (was er freilich ohne ihr Wissen ja bereits tut). Da Jeans Kritik ein stereotypes Element wird, wirkt sie mit der Zeit eher als Neckerei, die einfach zum Abschluss eines Falles gehört. ${ }^{83}$ Aussagen wie «If only the Black Terror was here» fungieren dabei auch als Wink mit

80 Ähnlich schon in Exciting Comics 21, August 1942, und später in Exciting Comics 52, November 1946. In der oben zitierten Szene ist es Tims Kommentar, der Jeans Ansprüche als zu hoch entlarvt: «Aw, let her go, Bob! She thinks everybody can be a Black Terror!» (The Black Terror [Patricia Highsmith et al.], in: Exciting Comics 38, April i945.)

8I Interessanterweise kann Kip hier gleich kontern, ist er doch gerade zu Immobilienbesitz in Form einer Geisterstadt gekommen, die Babs und ihre beiden Verehrer in der Folge auf der Suche nach einer Story besuchen (The Black Hood (Harry Shorten, Al Camy), in: Top Notch Comics I5, Mai 194I, 2).

82 Im Gegensatz zu Lois Lane, die durchaus persiflierende Züge trug - während Clark Kent ein ace reporter war, musste sie sob stories schreiben und um hochrangige assignments kämpfen (z. B. Action Comics I und 5, Mai/Oktober 1938) - wird der Heldenfreundin in den hier betrachteten Beispielen ohne Weiteres Kompetenz in ihrem Beruf und Handlungsmacht zuerkannt (so ist denn auch Belle Wayne ein ace reporter).

83 In gewisser Weise scheint es gar kein so unangemessener Lohn für den Helden, von seiner Angebeteten ungerechtfertigte Kritik einstecken zu müssen, da die sIf they only knew>-Momente auf ihre Kosten gehen. Dass dies wohl mit der Zeit schal wirkte, dürfte erklären, warum Jean Starr, die niemals Verdacht schöpfte, gegen Ende des Golden Age (wohl auch wegen eines neuen Künstlerteams) spurlos verschwand; sie wurde am Ende der Black-Terror-Laufzeit noch durch einen uneingeweihten, greisenhaften Ladenmitarbeiter namens Jed Serviss ersetzt. Sie wird auch in der Black-Terror-Aktualisierung im Rahmen der Project Superpowers-Storyline (2009-20I I) des Dynamite-Verlags nicht erwähnt. 


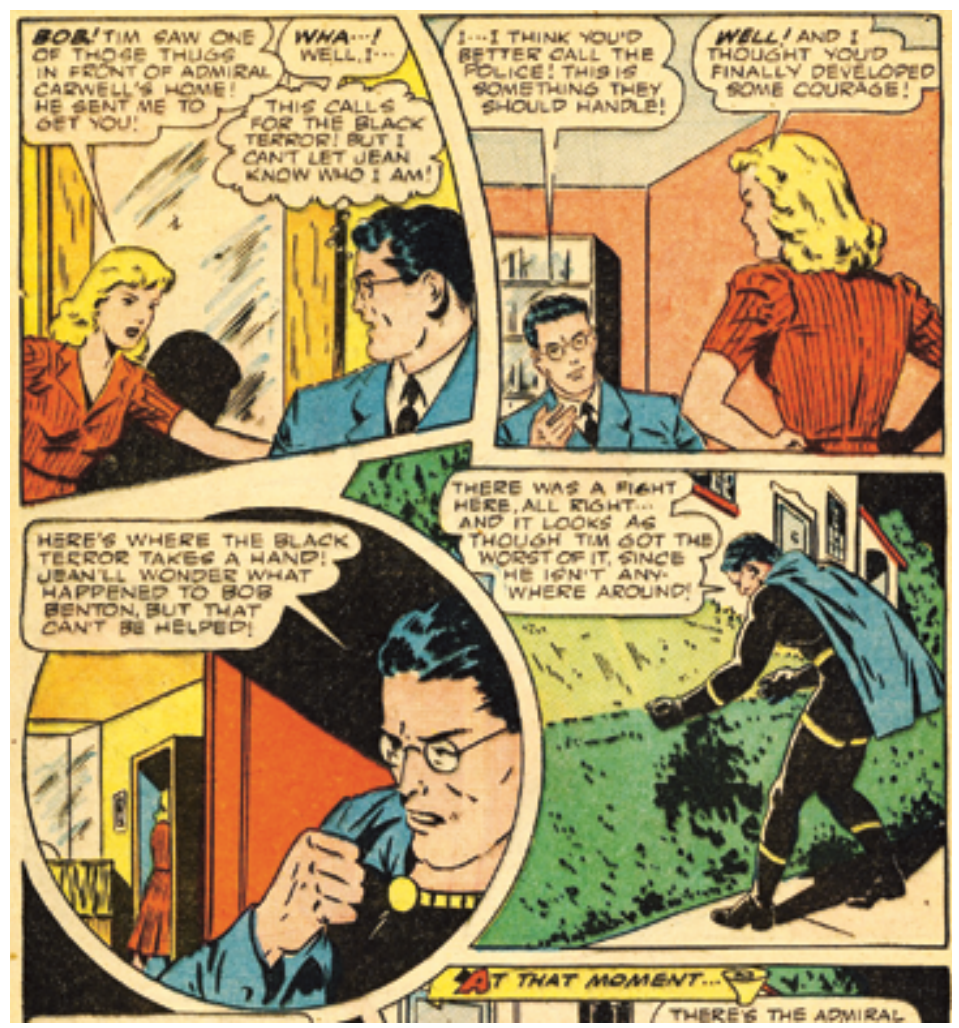

Abb. 28: Um sein Geheimnis zu bewahren und dennoch als Black Terror nach dem Rechten zu sehen, nimmt Bob Benton bewusst Jeans Missgunst in Kauf; sie zu täuschen, erscheint als unterhinterfragbare Notwendigkeit. The Black Terror ([unbekannte Künstler]), in: The Black Terror 9, Februar 1945 (dritte Story im Heft).

dem Zaunpfahl, dass es nun Zeit für das Eingreifen des Helden wäre (wenn auch die Frauenfigur nicht eingeweiht ist, so verstehen doch die Leser den Hinweis). ${ }^{{ }_{4}}$ Dass der Held trotz der Spannung zwischen den an ihn gestellten Ansprüchen und seiner selbst gewählten Rolle der Untauglichkeit (in der etwas Bescheidenheit mitschwingen mag) keine innere Krise bekommt, illustrieren besonders die Verlobungsszenarien, die dies auf die Spitze treiben und darum hier nicht fehlen

84 Z. B. The Black Terror (Richard Hughes, David Gabrielsen), in: Exciting Comics I4, November I94I. 
dürfen. Nachdem Barbara Sutton nach The Black Hood auch Kip Burland kennengelernt hat, gestattet sie Letzterem, sich wieder mit ihr zu treffen, schränkt jedoch ein, sie sei so gut wie verlobt - mit The Black Hood. Darauf erklärt Kip dem Leser: «So she's practically engaged to the Black Hood - I'll just see if I can't make her prefer Kip Burland [...] - it should be fun, being my own rival!»8s Hier wird deutlich, dass in der Reaktion der Protagonisten auf inkongruente Erwartungen der Humor und ein Sinn für die Absurdität der Situation dominierten. Innere Konflikte, die man in solchen Situationen erwarten könnte, werden erstaunlich konsequent umgangen - falls solche aufscheinen, werden sie umgehend abgewendet. Während die Doppelidentität für einige spätere Superhelden eine mehr oder weniger dauerhafte Identitätskrise bedeutet, sind Golden-AgeHelden solche Regungen fern. Da ihr Innenleben selten thematisiert wird, bleiben Selbstkonflikte meist unausgeleuchtet. Innere Zwiste ebenso wie etwaige Zweifel an der eigenen Heldenrolle sind schlicht kein Thema.

Eine temporäre Niedergeschlagenheit ist das Höchste, was im Golden Age an Heldenkrisen zu finden ist. Geradezu als Ausnahme hat The Human Bomb/Roy Lincoln einmal eine kleine Krise, deren Umsetzung bemerkenswert ist: Nach der Rettung einer jungen Dame klagt diese ihrem Vater, dass zum Schluss auch noch dieses «Monster», The Human Bomb, hereingestürmt sei, was der Betroffene hört. Zuhause hängt er sein Kostüm in den Schrank und erklärt seinem Sidekick Hustace Throckmorton: «[...] I'm only miserable. Other crime-fighters are glamourous - The Spirit, Blackhawk, even Plastic Man, but I - I wear that rig - and people call me a monster!» ${ }^{86}$ Als Throckmorton sein Mitgefühl ausdrückt, meint er lakonisch: «Sorry to pop off, Hustace! Just leave me alone!» (Abb. 29a und 29b) Das tut dieser prompt und macht sich auf die Suche, wie er seinem Freund helfen könnte, worauf die Geschichte wieder eine komische Wendung nimmt. ${ }^{87}$ Nach bestandenem Abenteuer endet die Story damit, dass Throckmorton erkennt: «[...] you weren't monster enough!», und Roy frohlockt: «Well, it was

85 The Black Hood (Cliff Campbel [sic., Pseud.], Al Camy), in: Top Notch Comics ıo, Dezember I940, I4 (meine Hervorhebung). Wonder Woman/Diana Prince trifft am Schluss einer ihrer ersten Geschichten fast wörtlich dieselbe Erkenntnis (Wonder Woman [Comes to America] (Charles Moulton [d. i. William Moulton Marston], Harry G. Peter), in: Sensation Comics I, Januar 1942, I 3), und eine vergleichbare Szene gibt es auch zwischen The Human Bomb/Roy Lincoln und seiner Freundin Jean (Human Bomb (Paul Carrol [d. i. Paul Gustavson]), in: Police Comics 6, Januar 1942, 64).

86 The Human Bomb (Paul Gustavson), in: Police Comics 35, Oktober 1944. Die anderen erwähnten Helden sind weitere Protagonisten aus Police Comics.

87 Throckmorton findet eine Wissenschaftlerin, die einen Roboter konstruieren will, der genauso aussieht wie The Human Bomb in seinem Schutzanzug, weil sie <richtige> Männer satt hat. Sie hält The Human Bomb für ihren lebendig gewordenen Roboter und ist überglücklich - bis sie erfährt, dass unter dem Anzug ein echter Mann steckt und ihn ins Pfefferland wünscht. 

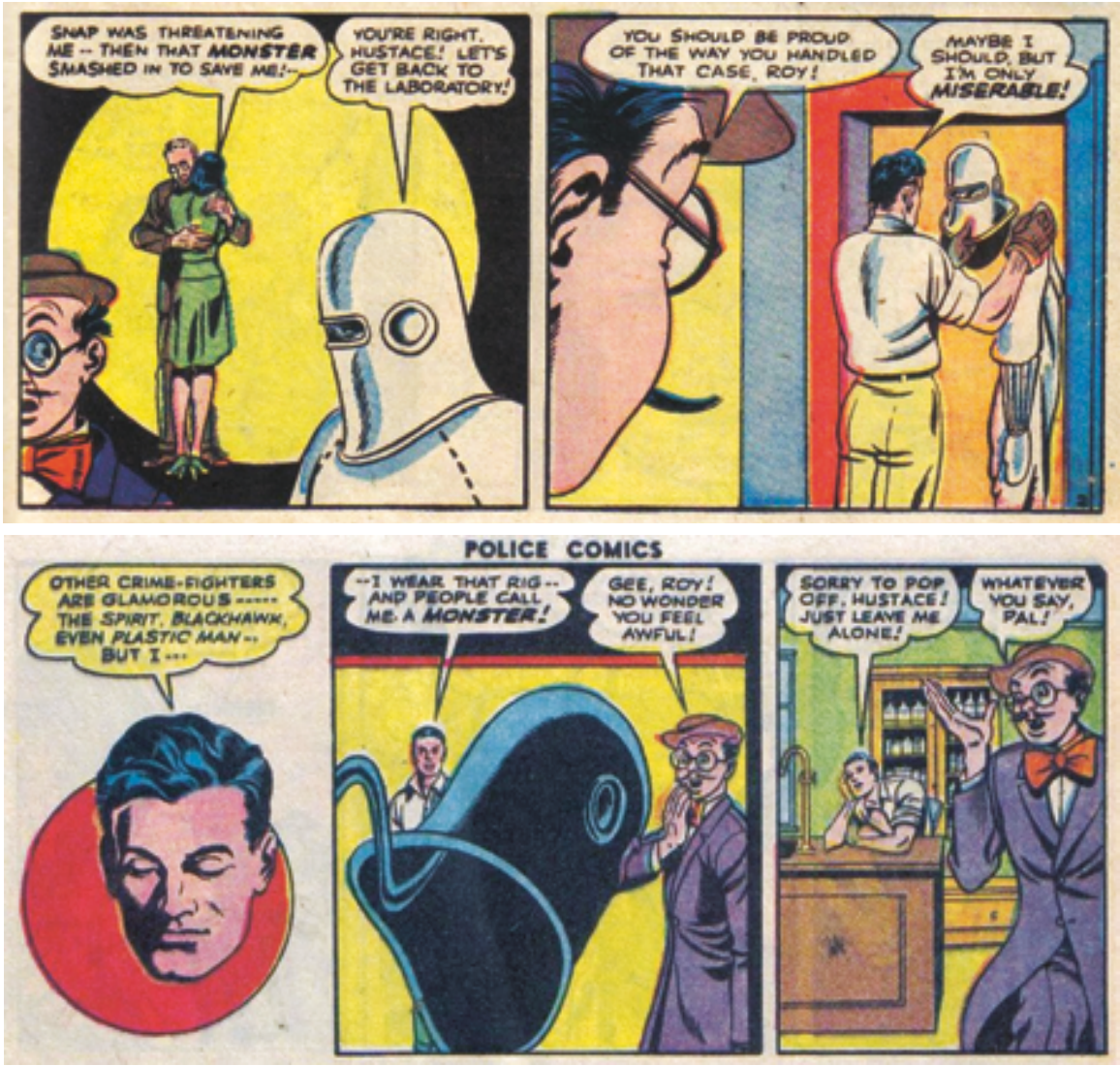

Abb. 29a und 29b: Die seltene Golden-Age-Version einer Heldenkrise: The Human Bomb ist sein Heldentum für eine halbe Story leid - dabei scheint auch sein Helm den Kopf hängen zu lassen. The Human Bomb (Paul Gustavson), in: Police Comics 35, Oktober $1944,2 / 3$.

fun, Hustace! And I'm over my blue mood! ${ }^{88}$ Das der Monsterfrage innewohnende Konfliktpotenzial wird nur gerade angetönt (dass The Human Bomb als Monster gesehen wird, ist zudem eine einmalige Angelegenheit).

Anders als bei den Pulp-Verbrecherjägern ist im Comic-Golden-Age so gut wie nie die Rede von einem ¿Opfer in Form eines Verzichts auf eheliche Bindung (bzw. dass der Held seiner Angebeteten seine Liebe nicht gestehen darf, weil 
seine Lebensart für eine Ehefrau nicht zumutbar wäre). Entsprechend kann der Held auch kein Bedauern darüber äussern. ${ }^{89}$ Dies lässt sich wohl nicht zuletzt damit begründen, dass es sich um stark formalisierte Geschichten handelt, ${ }^{90}$ die sich aufgrund des beschränkten Platzes auf eine möglichst actionreiche Handlung konzentrieren müssen - «[...] character development was the last thing to happen during the Golden Age», schreibt etwa Jerry Bails..$^{91}$ Identitätskrisen dienen erzählerisch aber vor allem der Entwicklung der Persönlichkeit einer Figur (auch wenn diese allenfalls dieselbe Entwicklung mehrfach durchlaufen muss). In diesem Zusammenhang fällt auch die Rolle der medialen Berichterstattung auf. Diese wird eher selten zum Thema, selbst wenn der Journalistin für die Narration eine zentrale Funktion zukommt. Vielmehr werden Zeitungen, oft eher am Rande, als Medien positiver Berichterstattung über die Heldentaten gezeigt $^{92}$ - damit scheiden sie als Quelle von heldischen Selbstzweifeln aus. Eine negative Berichterstattung über den Helden kommt höchstens in Plots vor, in welchen dieser ungerechtfertigt eines Verbrechens beschuldigt wird, das bis zum Ende der Story aufgeklärt ist. ${ }^{93}$ Es lässt sich spekulieren, dass es angesichts der Zeitumstände, in welchen die Medien in den USA nicht nur für Information sorgten, sondern wie die Comic-Hefte die Propaganda mittrugen, wohl kaum opportun gewesen wäre, die Medien als Anführer von Hetzkampagnen (und damit kritisch) darzustellen. ${ }^{94}$

89 In einem seltenen Moment erklärt Roy Lincoln auf Hustace' Frage, ob er jemals an Liebe denke: «Often, Hustace, but my double duties as chemical inventor and the Human Bomb keep me to busy for much romance!» (The Human Bomb [Paul Gustavson], in: Police Comics 29, April 1944).

90 Wie etwa Wright $(2001,22)$ festhält: «[...] comic books became highly formulaic.»

9I Bails 2002, 7. Damit sei nicht gesagt, dass es im Golden Age keinerlei Charakterentwicklungen gegeben hätte; in vielen Comicreihen sind zumindest in den frühen Storys durchaus Ansätze für eine gewisse Figurenentwicklung - etwa in Sachen Liebesbeziehung - angelegt, auch wenn diese dann nicht ausgeführt wird, da nicht zuletzt die Kriegsthemen das Augenmerk von persönlichen Beziehungen der Figuren wegdrängten.

92 Das bemerkenswerteste Beispiel dafür dürfte jene Black-Hood-Geschichte sein, in der sich Barbara über McGintys üble Nachrede über Black Hood so ärgert, dass sie - gegen Kips Einwand, er wolle keine Aufmerksamkeit - eine Fotoreportage («pictorial saga») über ihn druckt. Die beiden Zeitungsseiten bilden dann zwei Comic-Seiten und stellen ein «Best of» der bisherigen Black-Hood-Storys dar (The Black Hood (Harry Shorten, Al Camy), in: Top-Notch Comics 24, Februar 1942, 4-5).

93 Ein Beispiel dafür bietet The Black Terror (Elmer Wexler et al.), in: Exciting Comics I I, Juli I94I.

94 Es lässt sich spekulieren, dass man es damals wohl ebenso wenig für passend hielt, in an Kinder gerichteten Geschichten Protagonisten zu erschaffen, deren Motivation in einer Art Kriegstrauma liegen - während in den Pulps ein solches etwa für den Shadow und den Phantom Detective in Anspruch genommen wurde. 
Die 〈Krisenlosigkeit〉 der Golden-Age-Gestalten ermöglicht zwei Interpretationen: Zum einen gibt es keine (Identitäts-)Krisen, zum andern gibt es zwar Spannungen, die der Held aber aushält, ohne dies als Krise zu erkennen und folglich zu benennen (Jammern ist für Golden-Age-Helden ein Fremdwort). Zumindest bedarf ihre Identität keiner so aufwendigen Identitätsarbeit, wie sie spätere maskierte Superhelden immer wieder aufs Neue leisten müssen.

So entsteht der Eindruck, dass zumindest für die Golden-Age-Helden die Doppelidentität weniger als eine Spaltung oder Doppelung zu sehen ist, sondern aus Sicht der Helden als eine - wenn auch aus verschiedenen Teilen bestehende Rolle bzw. eine Identität. Explizit wird dies freilich nie formuliert; allenfalls als impliziter Hinweis verstehen lässt sich eine Aussage wie jene von Miss Masque/ Diana Adams, wenn sie überlegt: «I adopted this role because I was fed up with nothing but a round of social activity! But since I solved some cases I've become a dreaded symbol to the Underworld.»95 Nachdem die Identitätserweiterung einmal stattgefunden hat, ist sie nicht mehr umkehrbar. Die Doppelidentität erscheint damit als ein dem maskierten Helden ebenso beschiedenes wie von ihm selbst gewähltes Schicksal, das eben die Aufrechterhaltung zweier äusserlich scheinbar getrennter Identitäten beinhaltet.

Die Golden-Age-Comic-Helden zeichnen aufgrund ihrer Krisenlosigkeit ein eigenes Bild des maskierten Helden. Obwohl sie zwei verschiedene Identitäten unterhalten, zerbrechen sie nie an dieser Doppelbelastung; weder zweifeln sie an ihrem heldischen Vermögen noch an den Umständen. Kniep drückt dies so aus: «Dem typischen Comic-Helden des Goldenen Zeitalters eignet eine göttliche Perseität. Obwohl er ein Doppelleben führt, ist er zu jedem Zeitpunkt ganz er selbst [...]».96 Freilich kann man dies als Oberflächlichkeit und «pure[n] Eskapismus»97 werten, möglicherweise stellte aber gerade dies in den spezifischen Umständen der Kriegsjahre die Innovation und die Anziehungskraft des maskierten Helden dar, der sich in Bezug auf seine Doppelidentität stets als souverän erweist - selbst wenn sein Geheimnis aufgedeckt wird.

Tatsächlich kommt es auch im Golden Age öfter zur Demaskierung, als man aufgrund der vielbesagten Stereotypie der Geschichten vermuten könnte, wobei Verdächtigungen insgesamt selten vorkommen..$^{8}$ Kommt es zu einer Demaskie-

95 Miss Masque - «Diana’s Jewel!» [Robert Oksner et al.], in: America's Best Comics 24, Dezember I 947, 7.

96 Kniep 200I, I42, bzw. 2009, 32.

97 Schikowski 20I4, 8I.

98 Es wird noch nicht einmal besonders brenzlig, wenn McGinty The Black Hood wieder einmal temporär einsperrt, da dieser stets entkommen kann oder freigelassen wird, bevor er seine Maske ausziehen müsste (z. B. in Top-Notch Comics I 3 und 24, März I94 I bzw. Februar 1942). 
rung, wird diese oft geradezu unspektakulär inszeniert. Zu erwarten ist dies gewiss am ehesten, wenn ein Sidekick das Geheimnis entdeckt, falls er nicht wie Tim Roland von Anfang an eingeweiht ist: So läuft Bucky gerade dann in Steve Rogers Militärzelt, als dieser zwar sein Kostüm trägt, aber keine Maske, worauf er von diesem sogleich als Helfer rekrutiert wird. ${ }^{99}$

Eine grössere Gefahr bedeutet eine Demaskierung jedoch, wenn sie durch einen Gegner erfolgt - würde man denken. Im Golden Age wird auch dieses Problem meist gelöst, bevor es überhaupt ein Problem ist, wie etwa zwei Demaskierungsszenen von The Black Terror zeigen: Einmal wird er von einem Gangster k. o. geschlagen, worauf dieser - der Bob als den Drogisten erkennt - das Black-Terror-Kostüm anzieht, darin aber von seinen Kumpanen erschossen und als Toter demaskiert wird. Derweil erwacht Bob und geht gelassen nach Hause, um sein Ersatzkostüm zu holen, bevor er die Verbrecher dingfest macht. ${ }^{100}$ In den Kriegsjahren passiert dem Black Terror mehr oder weniger dasselbe Missgeschick mit Nazis. Seine Demaskierung wird erneut nur ansatzweise als Gefahr inszeniert: Als er in Latzhosen wieder zu sich kommt, beschmiert er sein Gesicht nur deshalb mit Schmierfett, damit ihn Jean nicht erkennt (Abb. 30). Erst nachdem er die Nazis so in Zivil überwältigen konnte, deswegen aber selber von der Polizei abgeführt wird, fällt ihm ein: «Holy smoke! I just happened to think - I can't explain or I'll betray the identity of the Black Terror!» ${ }^{101}$ Zum Glück agiert Tim, der ihn im Gegensatz zu Jean erkennt, als Retter in der Not und holt ihn aus dem Gefängnis. Auch die drohende Entlarvung vor der Öffentlichkeit ist in solchen Situationen jeweils kein Thema. Als der Sohn des Skull (im selben gruseligen Aufzug wie sein Vater) sich an Black Hood rächen will, kommt heraus, dass er die zivile Identität des Helden kennt. Obwohl er aus diesem Grund Barbara entführt, scheint eine öffentliche Demaskierung keine existente Möglichkeit. ${ }^{102}$ Trotz der potenziellen Gefahren, die eine Entlarvung bedeuten würde,

99 Auch Steve Rogers Reaktion zeigt, wie das geteilte Geheimnis als Grundlage für eine Partnerschaft dient: «You little rascal! I ought to tan your hide! I guess you got me dead to rights - I am Captain America! From now on we both must share this secret together ... that means you're my partner, Bucky!» (Case No. I: Meet Captain America (Joe Simon, Jack Kirby) in: Captain America Comics I, März I94I, 8.)

100 The Black Terror (Richard Hughes, David Gabrielsen), in: Exciting Comics I 2, August 1941.

Iо I The Black Terror [unbekannte Künstler], in: Exciting Comics 32, April 1944.

I02 Oder es kommt einfach nicht mehr dazu, weil dieser Skull innert zwei Heften besiegt ist. Skull junior, ganz Superschurke, ertrinkt dabei im Meer - zurück bleibt nur sein Cape, dank dem sich Black Hood retten kann (The Black Hood (Sam Cooper et al.), in: Top Notch Laugh Comics 3 I, Dezember 1942, I0). 


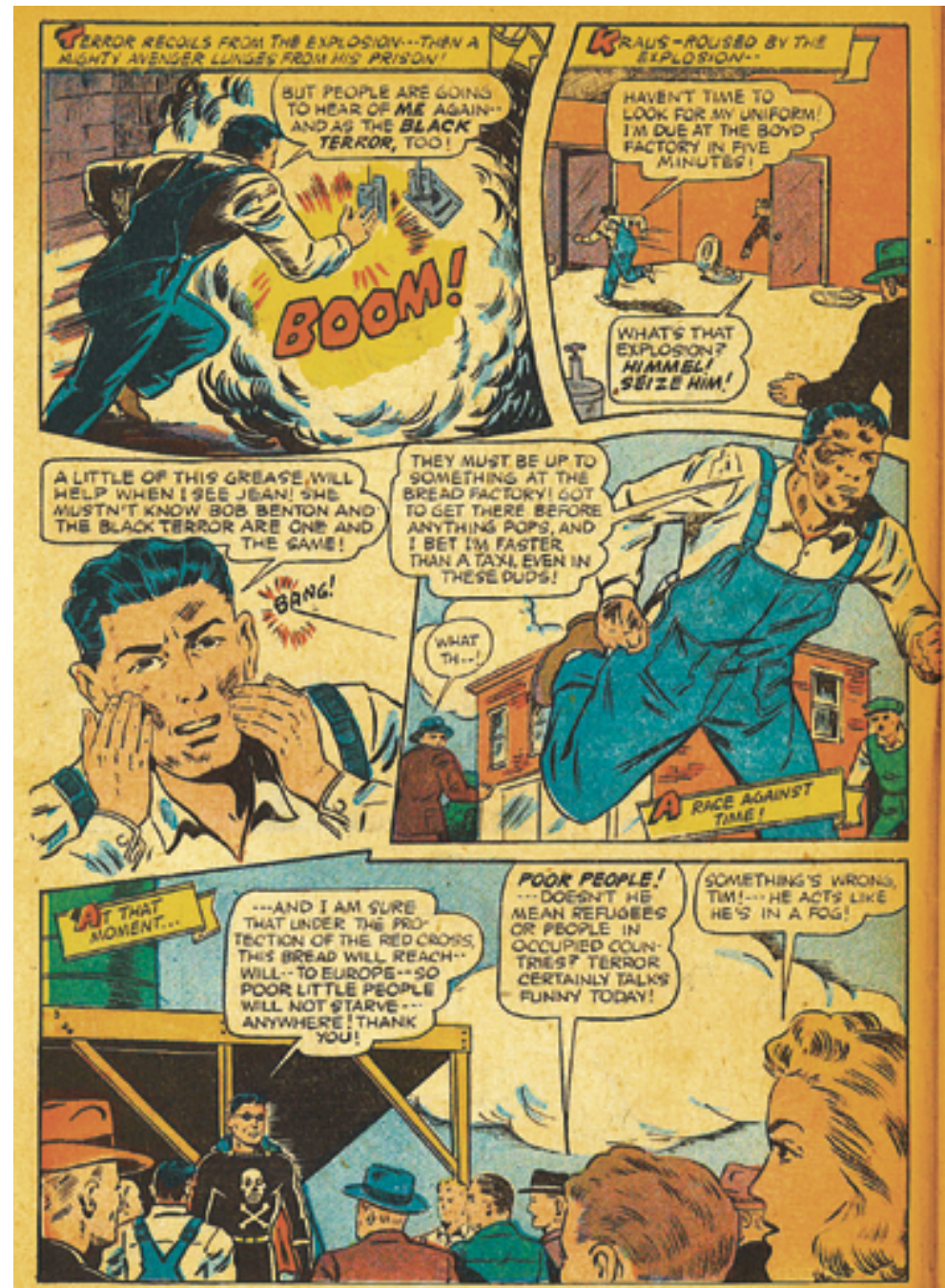

Savo your fats, waste paper and old rubber for the war effort!

Abb. 30: Zur Not muss Bon Benton auf seine Black-Terror-Maske verzichten und sein Gesicht mit Schmierfett unkenntlich machen. Derweil hält ein krimineller Doppelgänger an seiner Stelle bei einer Propagandaveranstaltung in einer Brotfabrik eine Rede, um für Kriegsspenden zu werben, soll dabei aber unauffällig die Brotlieferungen für Europa vergiften. The Black Terror [unbekannte Künstler], in: Exciting Comics 32, April I 944. 
hat keine dieser Situationen für den Helden ein temporäres Problem, geschweige denn eine innere Krise zur Folge. ${ }^{103}$

Etwas mehr Spannung liegt in der Demaskierung gegenüber der Frauenfigur, der jeweils Vorausdeutungen vorangestellt werden. Belle Wayne äussert ihren Verdacht schon in der dritten Owl-Story und lässt sich (anders als etwa eine Lois Lane) von Terrys Täuschungsmanövern nicht hinters Licht führen, selbst wenn ihr ein Beweis (noch) fehlt. Auch Barbara schöpft Verdacht, als Kip Burland sich wieder einmal fadenscheinig verabschiedet, und fragt Joe Strong: «It's suspicious, Joe! Do you think that ...», worauf Joe in Lachen ausbricht: «He's the Black Hood? That goof? Haw, haw! Don't make me laugh!» ${ }^{104}$

Sowohl Belle Wayne als auch Barbara Sutton stossen so nicht per Zufall auf das Geheimnis, sondern durchschauen die Maskerade ab einem gewissen Punkt. Nach dem Tod des Skull schwärmt Barbara mitten in der Handlung wieder einmal so von Black Hood, dass Kip sich verletzt zeigt. Barbara gibt zu, dass sie sich viel aus Black Hood macht, was sie gleich beweisen will, worauf sie Kip küsst. Während der ziemlich verdattert dasteht, erklärt sie: "You needn't pretend any more, Mr. Kip Burland! I've known you were The Black Hood for a long time. But I ... I just had to come out with it now to ... er ... let ... you know how I felt.» Im nächsten Panel fährt sie nonchalant fort: «Toodle-oo, Mr. Burland! ... Never trust a woman!», und geht davon (Abb. 3 I). ${ }^{\text {ros }}$ Damit ist das Thema erledigt, Barbara wird zu seiner eingeweihten Mitstreiterin. (Dennoch bedeutet dies nicht das <erzählerische Aus für die Doppelidentität, denn erst ab diesem Zeitpunkt wird McGinty regelmässig frequentiert.)

Fast so glimpflich kommt Nick Terry davon, als Belle ihn in seiner Wohnung im Eulenkostüm überrascht. ${ }^{106}$ Zwar versucht er noch, die Entdeckung als vermeintli-

I03 Von Gaunern demaskiert und vom Sidekick erkannt zu werden, schafft The Green Lantern/ Alan Scott übrigens in einem Heft: Nachdem die Ganoven dem bewusstlosen Helden die Maske abgenommen haben, überlegen sie nicht, ob sie dieses Wissen allenfalls nutzen könnten, stattdessen stellen sie nur fest, dass sie ihn nicht kennen. Auch Alan selbst merkt daraufhin nicht, dass er keine Maske trägt. Auf diese Weise erfährt Doiby Dickles, der in der anschliessenden Schlägerei auf ihn trifft, wer der Maskenträger ist. Alan nimmt dies bemerkenswert gelassen auf («I knew»), bittet aber um Aufrechterhaltung des Geheimnisses, wobei Doiby dies fast schon pikiert anerkennt: «What do you think I am? A tattletale?» (Green Lantern (Bill Finger, Mart Nodell), in: All-American Comics 35, Februar 1942, I3.)

I04 The Black Hood (Harry Shorten, Al Camy [d. i. Al Camaratta]), in: Top Notch Comics I6, Juni I 94 I, 3 .

ios The Black Hood ([Harry Shorten,] Al Camy), in: Top Notch Comics 20, Oktober 194I, 22. Tatsächlich ist das letzte Panel dieser Szene horizontal halbiert, in der unteren Hälfte wird die Krimihandlung vorangetrieben.

I06 Und zwar vermerkt ein Erzählerkommentar noch, dass Belle wie die Polizei Terry zwar des Owl-Seins verdächtigen - «but proof has been impossible to obtain!» Gleich im nächsten Panel ertappt ihn Belle (The Owl (Frank Thomas) in: Crackajack Funnies 28, Oktober 1940, 52). 


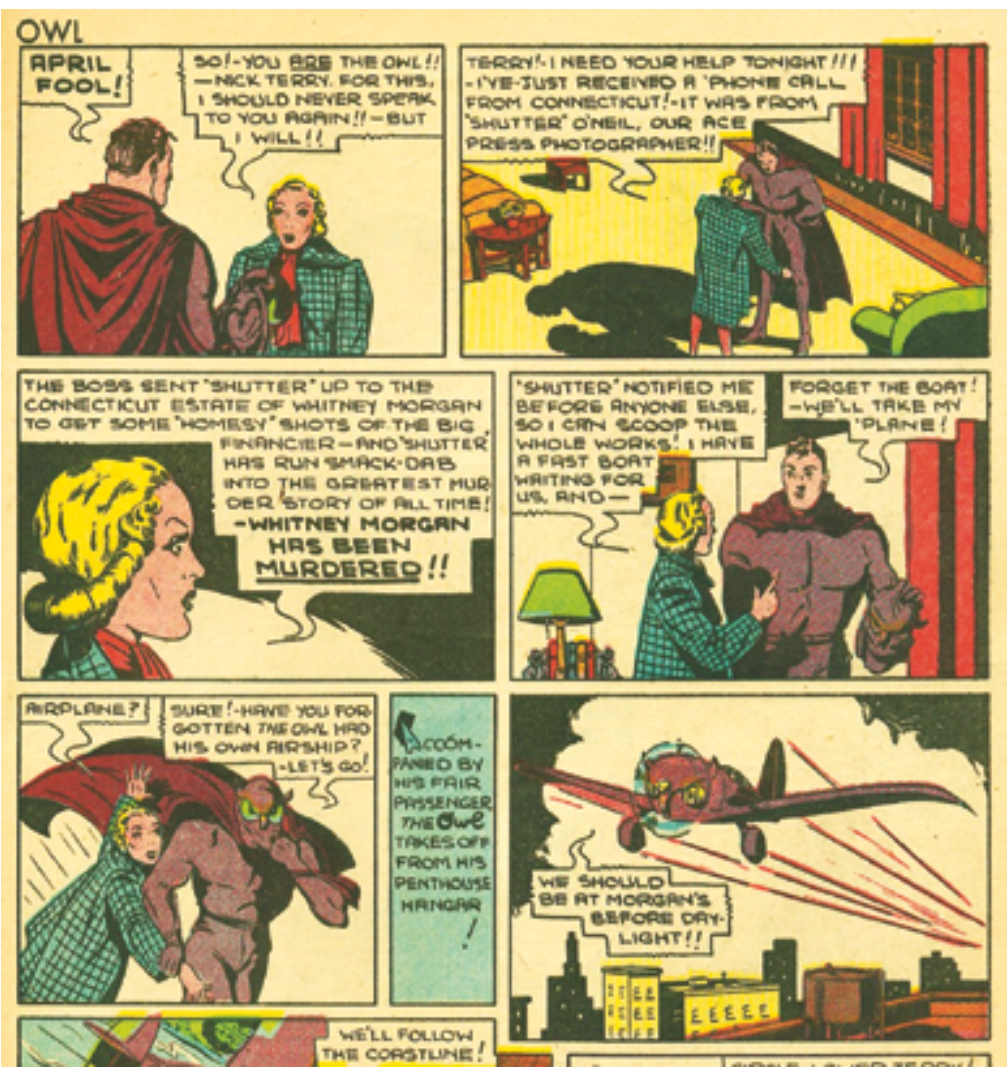

Abb. 3r: Als Belle Wayne ihren Verlobten Nick Terry als The Owl ertappt, wird eine drohende Beziehungskrise durch die Notwendigkeit eines sofortigen Heldeneinsatzes vermieden - mit der Owl-Ausstattung (wie dem pittoresken Owlplane) kann Terry sogar besser helfen als von Belle erwartet. The Owl (Frank Thomas), in: Crackajack Funnies 28 (Oktober 1940), 53.

che darzustellen («April fool!»), aber Belle sieht klar und deutet zumindest an, dass sein Verhalten nicht die feine Art gegenüber einer Verlobten ist: «So! - You are The Owl!! - Nick Terry, for this, I should never speak to you again!! - But I will!!» ${ }^{107}$ Sie braucht nämlich sofort seine Hilfe bei einem Fall. Der angedeutete Konflikt wird damit auch hier im Keim erstickt, weil die Action ruft (Abb. 3I). Ein paar Hefte

I07 The Owl (Frank Thomas), in: Crackajack Funnies 28, Oktober 1940, 53. Nick Terry ist denn auch einer der wenigen Helden, der zuvor anerkannt hat, dass es nicht recht ist, seine Verlobte direkt anzulügen und hinters Licht zu führen (Crackajack Funnies 27, September 1940, 2). 
später (in Crackajack Funnies 32, Februar I94I) ernennt sich Belle zum 〈Owlgirl〉 (wobei sie nie so genannt wird, die Erzählstimme bezeichnet sie aber als «Assistant Crusader Against Crime» $\left.{ }^{108}\right)$. The Owl zählt damit zu jenen maskierten Helden, deren Freundin auch die Rolle des Sidekicks innehat. Während Nicks Doppelidentität auch in der Folge immer wieder Anlass für lustige Szenen mit der Polizei ist, wird Belles Doppelidentität nie zum Thema, das heisst, die typischen narrativen Versatzstücke der Doppelidentität bleiben bei ihr aus. Beide Beispiele mit eingeweihten Freundinnen zeigen, dass die Frauen vorher vor allem deshalb nicht eingeweiht sein durften, damit eine feste Figur mit der Doppelidentität bespielt werden konnte - eine Funktion, die nachher in beiden Fällen verstärkt ein Polizist übernimmt. Beide Beziehungen geraten (etwa aufgrund der Lüge) nicht im Mindesten in eine Krisenphase, vielmehr schadet es beiden Helden überhaupt nicht, in ihrer Herzdame nicht nur eine Vertraute, sondern auch eine Mitstreiterin zu gewinnen. Das letzte Black Hood-Heft fragt auf der Titelseite in dicken Lettern: «Is The Black Hood Exposed?» Erfahrene Leser, die die Antwort problemlos zu kennen meinen, erwartet hier eine Überraschung, denn Black Hoods Geschichte erreicht tatsächlich den narrativen Fluchtpunkt des Identitätsgeheimnisses: The Black Hood muss seine zivile Identität offenbaren. Zu Beginn der Story erhält McGinty erneut den Auftrag, The Black Hood zu fassen - aber er weiss, dass er sich nur vergeblich bemühen kann. Kip überlegt, seinen besten Freund McGinty endlich einzuweihen, doch Barbara rät davon ab. Zufällig sieht Kip, wie McGinty entführt wird, und verfolgt die Entführer. In deren Versteck trifft er auf einen Schurken namens Needlenoodle («Kip Burland! Needlenoodle! Wow! Talk about characters!», wie die Erzählstimme kommentiert), der grosse Pläne hat, aber vorsorglich Black Hood ausschalten will. Tatsächlich hat er Kip bewusst dorthin gelockt - in all den Golden-Age-Jahren ist Needlenoodle der einzige Gegner, der zu der naheliegenden Erpressung schreitet: Entweder Kip outet sich als Black Hood, oder McGinty stirbt. Kip ist sich des Dilemmas wie dessen Lösung sofort bewusst: "What a spot! Needlenoodle means business! Once the Black Hood's exposed, he's through! And yet I can't let him kill Mac! I can't!»'09 Er wirft seine zivilen Kleider von sich, doch Needlenoodles Triumph währt genau eine Seitenumblätterung, bevor Black Hood ihn angreift.

Zwar entkommt der Schurke, doch Kip/Black Hood beschliesst trotzdem, sich nun von McGinty fangen zu lassen - was nach einer Slapstickeinlage auf der

I08 Crackajack Funnies 33, März I94 I, I. Auch hier ergibt sich also kein Konflikt, weil Nick Terry/ The Owl nach dem ersten Erstaunen Belle ohne Weiteres als seine Abenteuerpartnerin akzeptiert (dennoch wird sie sporadisch lächerlich gemacht, wenn sie auf eigene Faust ermitteln will).

I09 The Black Hood versus Needlenoodle (Irv Novick et al.), in: Black Hood Comics 19, Sommer I 946,7 . 
Abb. 32: Das Ende einer Karriere als maskierter Held: Kip Burland demaskiert sich vor McGinty und dem Polizeichef - und verwandelt sich im Lauf dieser Seite vom kostümierten Helden zum pfeifenrauchenden Detektiv. The Black Hood versus Needlenoodle (Irv Novick et al.), in: Black Hood Comics i 9, Sommer I946, I 4 .

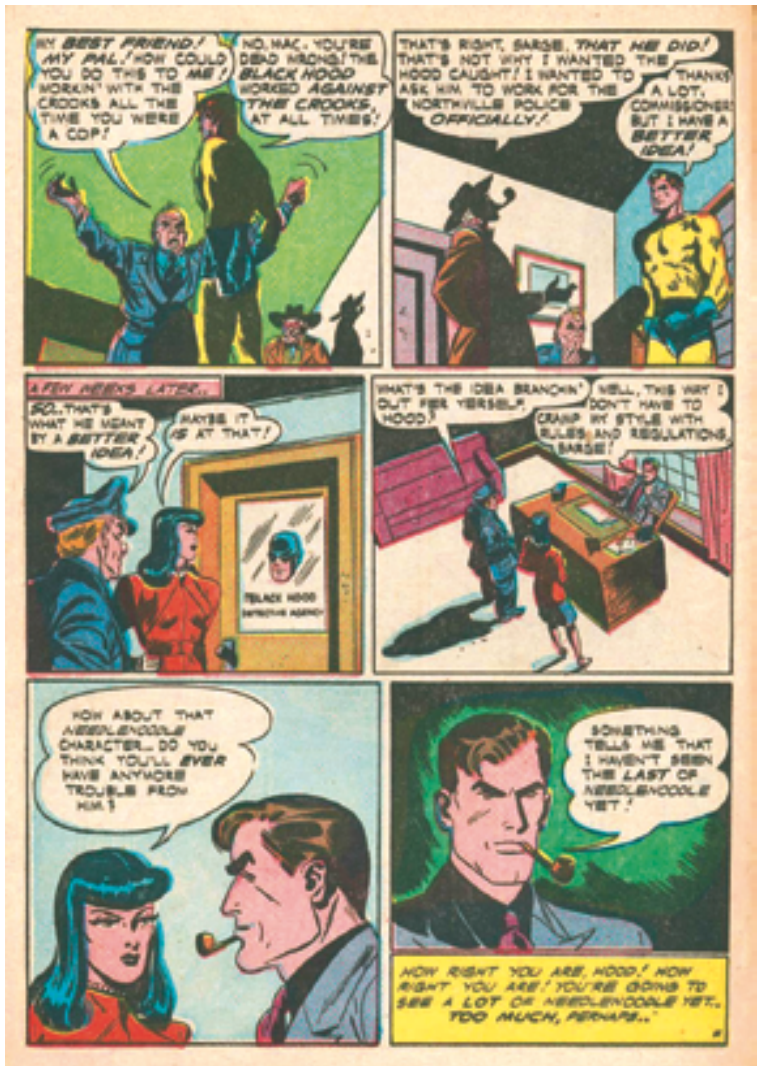

Wache gerade gelingt, als der Polizeikommandant hereintritt. Black Hood demaskiert sich und die beiden Polizisten staunen: «Well, I'll be! Kip Burland!» McGintys Reaktion kritisiert prompt nicht etwa die Geheimhaltung: «My best friend! My pal! How could you do this to me! Workin' with the crooks all the time you were a cop! ${ }^{\text {I10 }}$ Doch Kip erklärt, dass er immer gegen die Schurken gearbeitet hätte. Und der Kommandant stimmt ein - aus diesem Grund wollte er Black Hood auch finden, nämlich um ihn zu fragen, ob er offiziell für die Polizei arbeiten wolle. Kip/Black Hood hat aber eine bessere Idee (Abb. 32). Er wird Privatdetektiv, denn: «Well, this way I don't have to cramp my style 
with rules and regulations, Sarge!» ${ }^{\text {II }}$ Genau diesen Grund haben insbesondere die Pulp-Helden immer wieder genannt. Obwohl die Demaskierung von Black Hood nicht ganz so triumphal endet wie bei Zorro/Diego Vega, löst sich auch hier alles in Wohlgefallen auf - dass The Black Hood für seine unorthodoxen Methoden ausserhalb der Polizei etwa bestraft werden müsste, ist kein Thema. ${ }^{12}$ Dass The Black Hood am Ende seiner Laufzeit seine Maske aufgibt, erscheint als konsequentes Ende - obwohl seine Figur bereits gut ein Jahr nach Kriegsende aufgegeben wurde, nahm er so in gewisser Weise das narrative Ende des Genres vorweg.

Denn gegen Ende ihrer Golden-Age-Laufzeit ist bei allen betrachteten Golden-Age-Protagonisten eine Tendenz zu beobachten, dass die Doppelidentität immer mehr in den Hintergrund rückt, und zwar, indem die Protagonisten ihr Kostüm weniger häufig tragen - oft ermitteln sie in Zivil und erscheinen nur noch gerade für den Verfolgungshöhepunkt im Kostüm. Teilweise entfielen die stark mit der Doppelidentität verknüpften Figuren schon vorher ganz oder traten nur noch sporadisch auf, was der Doppelidentität die Daseinsberechtigung entzog. Offenbar musste das Genre erst fast ganz zum Erliegen kommen, bevor eine Weiterentwicklung möglich war ${ }^{\mathrm{I}_{3}}$ - womit das Silberne Zeitalter beginnen würde.

\section{Marginal Men? Das geteilte Selbst, der Zeitgeist und die Superhelden}

Die Frage, warum die (maskierten) Superhelden gerade in den USA vor dem Zweiten Weltkrieg entstanden sind und durchschlagenden Erfolg hatten, lädt zu vielfältigen Spekulationen ein. In einigen Versuchen, dies als Ausdruck des damaligen Zeitgeists ${ }^{114}$ zu erklären, spielen spezifische 〈Identitätsbefindlichkeiten〉,

I I I Ebd.

I 2 Selbstverständlich wird Needlenoodle in der zweiten Geschichte im Heft noch dingfest gemacht. Barbara stellt sich selbst als Sekretärin der Detektei Black Hood ein. Als Privatdetektiv hatte Black Hood (der maskierte Kopf wird zu seinem Logo, und seltsamerweise wird er nun, da er in Zivil unterwegs ist, nicht mehr Kip Burland genannt) noch zwei letzte Auftritte in Pep Comics 59 und 60 (Dezember 1946/März 1947). (MLJ war einer der ersten Verlage, die ihre Superhelden nach dem Krieg ausmusterten, bei MLJ zählten dazu etwa The Shield und The Wizard.)

I 3 Dass zwei das Golden Age mitprägende Figurentypen, der Sidekick und der Polizistenpartner, in den Neuschöpfungen des Silver Age nicht mehr frequentiert wurden, hatte - neben vielen anderen Gründen - auch eine einfache Ursache: Mit Robin als Leitbeispiel wurde den Sidekicks der Ruch der homosexuellen Pose unterstellt - im damaligen Zeitgeist einer Gründe, Comics als jugendgefährdend zu ächten. Ebenfalls verbot es der Comics Code, Gesetzeshüter als lachhafte Figuren darzustellen.

I 4 Die 〈Herleitung〉 von Superman aus antiken Mythen und Ähnlichem kritisiert etwa auch 
die der damaligen US-Bevölkerung oder einem Teil davon zugeschrieben werden, eine wichtige Rolle, weshalb diese nun etwas näher beleuchtet werden.

Im Pulp-Kapitel wurde bereits darauf hingewiesen, dass die Helden-Pulps in ihrer Ausgestaltung - etwa dem Verständnis der Grossstadt als Hort des Verbrechens und brachialer Gewalt - eindeutig ein Kind der Grossen Depression sind. Es ist klar, dass die Golden-Age-Comics auf den Pulps aufbauen, dass die Figur des maskierten Helden aber durch das veränderte Zielpublikum und den Medienwechsel bezeichnende Änderungen erfahren hat, wobei die nun anzusprechenden Ansätze die maskierten Pulp-Helden nicht berücksichtigen.

Dennoch sieht Darowski die Superhelden vor demselben historischen Hintergrund, der auch die Pulps geprägt hat. ${ }^{15}$ Für ihn lässt sich die Doppelidentität der Superhelden als relativ direkter Reflex auf die damaligen wirtschaftlichen Gegebenheiten erklären: Unter dem verheerenden Einfluss der Depression sei die Bevölkerung der USA in ihrem Selbstgefühl ebenso gespalten gewesen wie die beiden Identitäten von Superman/Clark Kent. Die harten I930er-Jahre hätten die Identität vieler Amerikaner verändert, "who went from at worst a sustainable income and at best upward mobility to unemployment» ${ }^{116}$. Amerika, der Hafen für Arme, erschien nun selbst als Armenhaus - dass die Leute diesem Umsturz ohnmächtig gegenüberstanden, erschütterte das Vertrauen in die eigene Wirtschaftskraft, besonders der "working-class males», so Darowski. ${ }^{117}$ In dieser entmutigenden Situation erhielt der New Deal von Präsident Roosevelt (1933) das Versprechen der Regierung, die Bevölkerung zu schützen und die Probleme zu lindern - sozusagen die Rolle als heldische Seite der Nation zugewiesen. ${ }^{\mathrm{I} 8}$ In dieser Deutung verkörpert der Mann aus Stahl also beide Seiten des gebeutelten, aber mit dem New Deal entschlossen auftretenden Landes. Nicht ganz ins Bild

Andrae $(1980,86)$ als «fundamental error», vielmehr sei das Konzept eines mit Superkräften ausgestatteten, aber menschlichen Helden «an amazingly modern and uniquely American phenomenon», das er allerdings in dem von ihm herausgearbeiteten Kontext begründet sieht, nämlich als «a product of the science fiction literature of the turn of the century».

I Is Darowski 2009, 24.

I 6 Ebd.

I 7 Ebd., 25. Wie auch Wright (200I, I0) erklärt, erschien die Distanz zwischen dem amerikanischen Traum und der Realität während der Depression als besonders klaffend. Die alten Helden des 19. Jahrhunderts vom Schlage eines self-made man aus der Feder von Horatio Alger (I 832-I 899) waren überholt; die USA des 20. Jahrhunderts verlangten, so Wright, nach einem «superhero who could resolve the tensions of individuals in an increasingly urban, consumer-driven, and anonymous mass society» (ebd.)

I 8 Darowski 2009, 25. Zum New Deal vgl. auch Andrae 1980, 95f. Dessen «new ethic» habe explizit das Ende des Individualismus des I9. Jahrhunderts verkündet und stattdessen soziale Sicherheit, staatliche Regulation und kollektive Aktion als Grundlage von wirtschaftlichem Erfolg betont, was einen Ausbau der staatlichen Eingriffe in alle Bereiche des Lebens und wachsende Bürokratie mit sich gebracht habe. 
passt dabei, dass keiner der Golden-Age-Helden in seiner zivilen Identität, die für die verarmten Angehörigen der Arbeiterschicht und Mittelklasse stehen soll, am sprichwörtlichen Hungertuch nagt, eher im Gegenteil, wie oben dargelegt wurde.

Tatsächlich aber kämpft Superman gerade in seinen ersten Abenteuern nicht etwa gegen fantastische Gegner, sondern in erster Linie gegen soziale Probleme wie Korruption, Baupfusch und mangelnde Sicherheitsbestimmungen (etwa bei Minenarbeiten oder beim Autofahren). Wie Bradford W. Wright betont, erscheint vor allem der ganz frühe Superman als «a sort of progressive ssuperreformer»» ${ }^{19}$. Auffällig sind solche Thematiken (neben dem oben erwähnten Black Terror) ebenfalls bei The Green Lantern/Alan Scott. ${ }^{20}$ Die New-DealWerte $^{\text {I2I }}$ verbanden sich dann nahtlos mit dem während des Krieges gehegten Patriotismus.

Dazu ist erwähnenswert, dass die Weltausstellung von I939 und I 940 - sozusagen als endgültige Abkehr von der Depressionsstimmung - die gleichsam Stein gewordene Hoffnung auf eine visionäre Zukunft zum Ausdruck bringen sollte und New York als Zentrum der Welt propagierte (was noch verstärkt wurde, als die Stadt New York 1946 zum Hauptquartier der Uno erkoren wurde). ${ }^{\text {I22 }}$ Auch hier war es Superman, der bewusst mit der World Fair verbunden wurde, lautete deren Motto doch «Building the World of Tomorrow» - nicht zufällig also trägt der Mann aus Stahl mitunter den Ehrennamen «The Man of Tomorrow». ${ }^{123}$

Viel mehr Aufmerksamkeit als Darowskis Erklärungsversuch hat jedoch eine andere These erhalten. Den Grundstein für diese inzwischen weitverbreitete Interpretation $^{124}$ zur Wiege der Superhelden legte Gary Engle in einem Essay, in welchem er Superman mit seiner ausserirdischen Herkunft als ultimativen

I 9 Wright 200I, I 2.

I 20 Vgl. dazu ebd., 22-27, oder Coogan 2006, 201.

I I DiPaolo (20I I, 2I) fasst zusammen, die ersten Comic-Superhelden hätten sehr spezifisch amerikanische Werte vertreten, nämlich «New Deal-era progressive political sympathies and the working-class values of the urban Jewish immigrant».

I 22 O’Connell I 995, 207. Ein heute fast vergessener maskierter Held machte die Weltausstellung übrigens gleich zum Bestandteil seines Heldennamens: The Fantom of the Fair (geschaffen von Paul Gustavson und erstmals veröffentlicht in Amazing Mystery Funnies 7 (vol. 2), 194 I, von Centaur Publishing).

I23 Diese Verbindung betont auch Wasielewski (2009, 66-68): «The Golden Age's entanglement with industrial modernity is also evident in DC's campaign to embed their superheroes within the New York’s World Fair.» DC produzierte zwei Comic-Hefte speziell für die Ausstellung und veranstaltete einen «Superman Day» (ebd.).

I 24 Unter anderem gab es eine auf die jüdischen Comic-Künstler des Golden Age fokussierte Ausstellung in mehreren Museen wie dem Jewish Museum New York (2006) oder dem Jüdischen Museum Berlin (2010). Eine ausführliche Auseinandersetzung mit dieser These (und ihrer Popularisierung) bietet Lund 2016. 
Einwanderer lesbar macht: «Clark [...] is the epitome of visible invisibility [...]. In a phrase, he is the consummate figure of total cultural assimilation, and significantly, he is not real.» ${ }^{125}$ Für Engle sind Supermans Kräfte «the comic book equivalents of ethnic characteristics, and they protect and preserve the vitality of the foster community in which he lives in the same way immigrant ethnicity has sustained American culture [...]» ${ }^{126}$. Diese These, dass die (neuartige) Kombination von Doppelidentität und Superkräften einen Ausdruck der damaligen US-Immigrantenerfahrung darstellt, wird durch die Tatsache bekräftigt, dass es sich bei auffällig vielen der meist noch sehr jungen ${ }^{127}$ Autoren und Zeichner des sich formierenden neuen Mediums um Söhne oder Enkel von Einwanderern aus ganz Europa, besonders von aus Osteuropa eingewanderten Juden, handelte.

Fingeroth, der Engles These aufgegriffen und anhand weiterer bekannter Superhelden ausgebaut und zugleich in gewisser Weise verengt ${ }^{128}$ hat, führt aus, dass es vor dem Hintergrund der europäischen Judenverfolgung und des dräuenden Weltkriegs letztlich kein Zufall gewesen sei, dass insbesondere jüdische Künstler das aufstrebende Genre dominierten: «The creation of a legion of special beings, self-appointed to protect the weak, $[\ldots]$ at a time when fascism was dominating the European continent from which the creators of the heroes hailed, seems like a task that Jews were uniquely positioned to take on. One might say they were cornered into it.» ${ }^{129}$

Nicht nur die inhaltliche Dimension spielt dabei eine Rolle, vielmehr waren laut Fingeroth die wirtschaftlichen Möglichkeiten für Immigranten während bzw. unmittelbar nach der Depression eher karg, doch hatte sich in New York - der Einwandererstadt schlechthin - eine «second-class» publishing industry» ${ }^{130}$ etabliert, die jenen Talenten ein Auskommen bot, denen ihre Herkunft den Einstieg in andere Berufszweige verwehrte oder doch schwermachte. Für diese Einwanderergeneration übernahmen die USA gewissermassen eine Doppelrolle, wie Fingeroth schreibt:

I25 Engle 1987, 85.

I 26 Ebd., 8I.

I 27 Unter den einschlägigen Superheldenzeichnern und -textern finden sich nur wenige vor I9 I0 Geborene, die Grosszahl dürfte im Alter von Anfang bis Mitte zwanzig in die Branche gekommen sein.

I 28 Wie Lund (2016, 22-25) darlegt, dürfte für diese Verengung und deren Verbreitung Michael Chabons Roman The Amazing Adventures of Kavalier E Clay (2000) um zwei fiktionale jüdische Golden-Age-Comic-Autoren eine zentrale Rolle gespielt haben.

I 29 Fingeroth 2007, 17.

I 30 Ebd., 24. 
As immigrants with a history of persecution, Jews came to America with their heads down but their eyes open. [...], Jews were faced with unprecedented freedom and opportunity. [...] [but] the barriers that were still in place in the first half of the 20 th century relegated Jews to trades and fields that had a taint of shabbiness or «second classness» to them [...] [including] the garment industry and the entertainment field..$^{13 \mathrm{I}}$

Die Gleichzeitigkeit von Freiheit und Einschränkung lässt sich in der superheldischen Doppelidentität zweifellos ohne Mühe wiedererkennen. Engle sah eine weitere Analogie zwischen Supermans Doppelidentität und den Herausforderungen für Immigranten, sich zwischen ‘zwei Welten〉 zu verorten. Ein Faktor, der dabei im Assimilationsprozess eine Rolle spielt, sind Generationenkonflikte zwischen der ersten und der zweiten oder dritten Einwanderergeneration. Wie Engle weiter erklärt, entwickelten die US-Immigranten, insbesondere osteuropäische Juden, die nach 1880 in die USA kamen und in den industriell und merkantil geprägten Zentren des Landes siedelten, alternativ zum Western eine eigene literarische Tradition. ${ }^{\mathrm{I} 2}$ In dieser bedeutete das Festhalten an der «Old World Identity» Isolation in Ghettos, die Konfrontation mit einer voreingenommenen Mainstreamkultur, einen «zweitklassigen» Sozialstatus und Verarmung. Dagegen verhiess die totale Absorption dieses Mainstreams die Möglichkeit zu wirtschaftlichem Erfolg, allerdings um den Preis des Verlusts kultureller Traditionen, die «a foundation for psychological well-being» darstellten. ${ }^{\mathrm{I} 33}$

Interessanterweise korreliert diese Beschreibung der 〈Einwanderermentalität〉 stark mit dem «divided self» des marginal man des Soziologen Robert Ezra Park (1 864-I 944). Dieses Persönlichkeitskonzept situierte Park vor dem Hintergrund seiner Theorie des kulturellen Konflikts sowie des alltäglichen Rollenspiels dieser Rahmen für das Konzept des marginal man soll als kleiner Schlenker kurz skizziert werden. Park hatte schon in den I920er- und I930er-Jahren einige Sätze formuliert, die oft als Vorläufer für die goffmansche Theatermetapher zitiert werden, nicht zuletzt von Goffman selbst. In Bebind Our Masks (1926) hielt Park seine These des allgemeinen Rollenspielens in der Welt wie folgt fest:

It is probably no mere historical accident that the word person, in its first meaning, is mask. It is rather a recognition of the fact that everyone is always and everywhere, more or less consciously, playing a rôle. We are parents and children, masters and servants, teachers and students, clients and professional men, Gentiles and Jews. It is in these rôles that we know each other; it is in these rôles that we know ourselves. ${ }^{134}$

I3 I Ebd., 27.

I32 Engle 1987, 83.

I 33 Ebd. Das Aufgeben der Vergangenheit sei dabei, so Engle, ein besonders schwerer Verlust für Juden, weil in ihrer Kultur der Geschichte eine fundamentale Rolle zukomme.

I 34 Park I950 (1926), 249, auch zitiert bei Goffman 2002 (1959), I9. (In diesem Aufsatz ging es 
Wie hier bereits anklingt, ist dies nicht nur für die soziale Interaktion, sondern auch für die Vorstellung des Selbst bedeutsam, da sich dieses nach Park als «Rollenbündel» ${ }^{135}$ auffassen lässt. Wenn Selbstdarstellung in der sozialen Umgebung eine metaphorische Maskerade bedeutet, wird das Gesicht zur deckenden Form: «Our very faces are living masks, which reflect, to be sure, the changing emotions of our inner lives, but tend more and more to conform the type we are seeking to impersonate.» ${ }^{136}$ Park sah die Notwendigkeit für diese Schauspielerei nur schon darin, dass nicht jedes Individuum in seine gewählte Rolle passt. ${ }^{137}$ Die gesellschaftlich zugedachte Rolle auszufüllen, bedeutet bei Park für das Individuum gleichsam das Unterdrücken «natürlicher Verhaltensweisen, was unweigerlich in einen inneren Konflikt mündet - in diesem Punkt erinnern Parks Überlegungen an Rousseaus Verständnis des gesellschaftlichen Maskenträgers (und ebenso an Theorien Sigmund Freuds).

Obschon das Verhalten in Gesellschaft stets eine gewisse Künstlichkeit beinhaltet, trägt Parks Vorstellung der Maske nicht nur jene Konnotation. Vielmehr wird bei ihm deutlich, wie die Wertungen der Maske im Lauf der Zeit schwanken. Da er von der Entwicklungsfähigkeit des Menschen ausgeht, wirkt auch für ihn das Rollenverhalten auf das Individuum zurück: «In a sense, and in so far as this mask represents the conception we have formed of ourselves - the role we are striving to live up to - this mask is our truer self, the self we would like to be. In the end, our conception of our role becomes second nature and an integral part of our personality. We come into this world as individuals, achieve character, and become persons. $»^{13^{8}}$ Parks Perspektive auf das «wahre> Ich bietet eine interessante Nuance: Dieses ist nicht das hinter der Maske verborgene oder durch ihre Hilfe entfesselte Ich, sondern ein ‘Wunsch-Selbst〉. Mit dem «self we would like to be» deutet diese Stelle eine konzeptuelle Verbindung zur späteren Theo-

Park allerdings in erster Linie um die Beschreibung der Herausforderungen bei Kontakten von einander fremden Kulturen.)

I35 Kim 1999, I33.

I 36 Park I950 (1926), 249. Park dachte dabei allerdings wohl vor allem auch an eine gewisse Stereotypie, der das Individuum anheimfällt (249f.): «Not only every race, but every nationality, has its characteristic ‘face), its conventional mask.» - Es lässt sich erahnen, dass Parks Schriften aus heutiger Sicht klar problematische Stellen aufweisen; darum seien seine Konzepte hier explizit als historische verstanden.

I 37 Robert Ezra Park: Human Nature and Collective Behaviour, 1926, in: On Social Control and Collective Behaviour, Chicago 1967, 190, zit. n. Kim 1999, I 34 .

I 38 Park I950 (1926), 250. Dabei ist das Individuum, wenn es auf die Welt kommt, für Park (I950 (1930), 358f.) noch nicht menschlich («the individual ist not born human»), vielmehr ist der Charakter eines Individuums als dessen persönliche Erfolgsleistung zu sehen, und zwar als Resultat der Suche nach seinem in einer Gesellschaft einzunehmenden Platz und der zu spielenden Rolle. 
rie der possible selves an, die im Thunderbolts-Kapitel angesprochen wird. Park betont mehrmals, dass es Teil der «art of life» ${ }^{139}$ sei, die angemessene Haltung in allen Gegebenheiten aufrechtzuerhalten. Als Folge davon verinnerlicht das Individuum die gesellschaftlichen Konventionen. ${ }^{40}$

Ganz ausgeliefert ist das Individuum den zu spielenden Rollen allerdings nicht: «He [the individual] can, when he chooses, make his manners a cloak and his face a mask, behind which he is able to preserve a certain amount of inner freedom while mingling freely with other persons.» ${ }^{14 I}$ Das Individuum kann sich so von der Welt zurückziehen und verfügt über eine Strategie, nicht nur soziale Distanz zu wahren, sondern auch die Unabhängigkeit seiner Gedanken aufrechtzuerhalten. ${ }^{\mathrm{I}^{2}}$ Damit spricht Park bereits an, was Goffman später (differenzierter) als Rollendistanz respektive als Hinterbühne beschreiben sollte.

In Human Migration and the Marginal Man (1928) betont Park als Ausgangspunkt die zentrale Rolle von Migrationsbewegungen in der Geschichte, genauer der Entwicklung von Nationalitäten wie auch dem Fortschritt. Migration ist für Park die Ursache für einen veränderten «type of personality» ${ }^{143}$. Park sieht dabei im Kulturkontakt stets auch einen Kulturkonflikt; seiner Ansicht nach geschieht Migration entweder durch Invasion oder, in jüngeren Zeiten, «peaceful penetration» ${ }^{144}$. Der marginal man kann so überall entstehen, "where, out of the conflict of races and cultures, new societies, new peoples and cultures are coming into existence» ${ }^{\mathrm{I} 45}$ - dennoch sieht Park diesen als "peculiarly characteristic of the modern world» ${ }^{146}$. Den marginal man definiert er als «cultural hybrid», sprich «the individual who finds himself on the margins of two cultures and not fully or permanently accomodated to either». ${ }^{47}$ Denn der Zusammenbruch einer traditionellen Strukturen verpflichteten Gesellschaft bietet dem Individuum die Chance der Emanzipation von verkrusteten Strukturen, den Zwängen der Tradition, sodass es frei werde für neue Abenteuer. ${ }^{148}$ Ein solches emanzipiertes Indi-

I39 Park i950 (1930), 36r.

I40 Ebd. Park (I950 (I926), 25 If.) geht davon aus, dass sich solche Konventionen aber ändern können, da die Welt stetigem Wandel unterliegt und der jeweilige Zeitgeist für ein Individuum ebenfalls eine Grundlage für die Selbstkonzeption darstellen kann.

I4I Park 1950 (1930), 36r.

I42 Aus diesem Grund brauche auch jeder ein Zuhause bzw. einen Ort, an welchem er möglichst sich selbst sein könne - auch hierin kann man schon Goffmans Hinterbühne entdecken.

I43 Park I950 (1928), 350. Zum marginal man vgl. u. a. Goldberg 201 2, Marotta 2006, Kim I999, I 25 -I 39 .

I44 Park 1950 (1928), 349.

I45 Park 1950 (1937), 375.

I46 Ebd., 373.

I 47 Park 1950 (1930), 370.

I48 Park I950 (1928), 350f. Er geht sogar so weit, darin mehr als nur Emanzipationsaspekte zu 
viduum werde unweigerlich zu einem Kosmopoliten, «[h]e learns to look upon the world in which he was born and bred with something of the detachment of a stranger ${ }^{149}$. Der marginal man ist dabei «nicht nur eine Folge der Zivilisation, sondern auch ein Agent in der Entwicklung der Zivilisation», wie Kim schreibt. ${ }^{150}$

Als typischen marginal man nennt Park zunächst «a mixed blood» ${ }^{15}$, letztlich aber können zwei beliebige gegensätzliche Kulturen die Grundlage für die Entwicklung dieses Persönlichkeitstypus bedeuten - Park erwähnt mitunter Protestanten und Katholiken oder Juden und Nichtjuden. ${ }^{\text {s2 }}$ Dabei ist «der Jude» für Park die deutlichste und historische Form des marginal man (der entsprechend mit Simmels Konzept des Fremden nah verwandt ist), der in und zwischen zwei distinkten Kulturen lebt, «never quite willing to break [...] with his past and his traditions, and not quite accepted, because of racial prejudice, in the new society $[\ldots] \gg^{153}$.

Diese Dichotomie zweier Kulturen beinhaltet zwei Ebenen: einerseits eine soziale, andererseits eine persönliche, wie Chad Alan Goldberg zusammenfasst: «On the one hand, he was a product of the cultural conflicts brought about by conquest, invasion, and migration. [...] On the other hand, the marginal man was himself a microcosm of cultural conflict [...].» ${ }^{\mathrm{I} 4}$ So meint Park einmal, dass Autobiografien jüdischer Einwanderer im Grunde alle dieselbe Geschichte erzählten, «the story of the marginal man»; darin sei der Konflikt der Kulturen, wie er sich im Geiste des migrierten Individuums abspiele, nichts anderes als der Konflikt des "divided self», des alten und des neuen Selbst. ${ }^{\text {Iss }}$ Gewissermassen wird der marginal man zum melting pot, in welchem die kulturellen Prozesse der Assimilation ablaufen. ${ }^{156}$ Dies birgt in Parks Sichtweise zwar andauernde innere

sehen: «[...] certain changes take place $[\ldots]$ in the character of the individuals themselves. They become, in the process, not merely emancipated, but enlightened.»

I49 Park 1950 (1928), 350.

I 50 Kim I999, I 38. Für Park ist Zivilisation gleichbedeutend mit kultureller Hybridisation (Marotta 2006, 42 I). Dabei setzt Park als Gegenbild zur modernen Zivilisation ein unklar umrissenes Leben in «traditionellen> Formen, teilweise verweist er sogar auf Stammesleben des «primitive man» (Park 1950 (1928), 352).

is I Park 1950 (1928), 356 und ebd. (1930), 370.

I 2 Park 1950 (1930), 370.

I 53 Park 1950 (1928), 354. Dieser ist denn auch das Urbild des Kosmopoliten: «The emancipated Jew was, and is, historically and typically the marginal man, the first cosmopolite and citizen of the world» (ebd.).

I 54 Goldberg 2012.

I 55 Park 1950 (1928), 355.

I 56 Park i950 (1930), 370. 
Konflikte und damit eine erhöhte Gefahr für "psychological anxieties», doch betont er, dass darin auch ein besonderes Potenzial für Kreativität liege. ${ }^{157}$

Weiter setzte Park den marginal man dabei in den Kontext der städtischen industriellen Gesellschaft. In der Grossstadt als Schmelztiegel von heterogenen Gruppen sah Park dessen eigentlichen Lebensraum. Aufgrund der weit fortgeschrittenen Aufteilung bzw. Spezialisierung der Arbeit ermöglicht und verlangt das Grossstadtleben, dass der Einzelne seine Talente und sein Engagement auf jene Tätigkeit fokussiert, «he is best fitted to perform» ${ }^{158}$. Park sieht die Qualitäten des Marginal Man explizit im intellektuellen Bereich; dieser erhalte unweigerlich eine schärfere Intelligenz und eine unvoreingenommenere, rationalere Perspektive. ${ }^{159}$

Ein so klar im Kontext von Migration und Multikulturalität situiertes Konzept mit Superhelden in Verbindung zu bringen, kann in mehrfacher Hinsicht inadäquat sein; ${ }^{160}$ und dennoch ist es ein interessanter Gedanke. Gegenüber den nach Park idealtypischen Formen des marginal man - des Juden oder aber einer Person von «mixed blood» - sind die Comic-Superhelden jener Zeit, im Einklang mit den damaligen populärkulturellen Konventionen, alles andere als ethnisch divers, sondern - Maske hin oder her - so gut wie ausschliesslich Weisse; auch ist die Religionszugehörigkeit kein Thema. ${ }^{161}$ Während der Schauplatz der Metropole zweifellos das ideale Pflaster für einen maskierten (Super-)Helden darstellt, um durch seine herausragenden Fähigkeiten in einzigartiger Weise seine selbst gewählte Aufgabe zu erfüllen, liegt die Betonung dabei jedoch klar auf körperlicher Agilität, wenngleich Eigenschaften wie

I 57 Marotta 2006, 423. Vgl. Goldberg 2012 sowie Kim 1999, I35.

I 8 Park 1950 (1928), 353. Vgl. Kim 1999, I 37. Einen grossen Vorteil bot die Grossstadt damit, «dass jeder Mensch irgendwo unter den reichhaltigen Manifestationen des Stadtlebens die Art von Umgebung findet, in der er seine Gefühle leicht freilassen kann, und in der seine Natur die Stimulierungen erhält, die seine angeborenen Veranlagungen zu vollem und freiem Ausdruck bringen» (ebd.).

I 59 Park i950 (1937), $375 \mathrm{f}$.

I60 Vgl. dazu Marotta 2008, 296f., der die Verallgemeinerung bzw. das ‘Verwässern` von Konzepten der Hybridität (vor allem aus der postkolonialen Theorie) kritisiert.

I6I Zumindest ansatzweise etwas mehr Diversität findet sich im Westerngenre, wo es einzelne indianische Helden (wohl auch beeinflusst vom edlen Wilden) gab und gewisse Helden wie The Lone Ranger mit Tonto oder The Masked Rider mit Blue Hawk einen indianischen Begleiter hatten, der zwar stereotyp, aber doch klar positiv dargestellt war (desgleichen beim Green Hornet und seinem philippinischen Diener Kato). Als zwei frühe nichtweisse, freilich kaum bekannte Comic-Superhelden lassen sich The Bronze Terror, ein Apache, und Nelvana of the Northern Lights, eine kanadische Heldin, die von einem Inuitgott abstammte, nennen (beide ab I94I, Markstein 20I I). - Den ersten schwarzen Superhelden führte erst I 966 Marvel ein, The Black Panther/T'Challa, der aus Afrika stammte. Mit Luke Cage/Power Man liess Marvel I 972 dann den ersten afroamerikanischen Superhelden folgen. 
Klugheit oder Gewitztheit gerade maskierten Helden ohne Superkräfte durchaus zugeschrieben werden und diese auch zum «Gesamtpaket` gewisser Superhelden gehören. ${ }^{162}$

In einem zentralen Punkt aber lässt sich der Marginal Man etwa in Fingeroths Auffassung wiedererkennen: Die Protagonisten des Golden Age böten für die damalige US-Leserschaft eine symbolische Parallele ihres eigenen Lebensgefühls zwischen kulturellen Wurzeln und Anpassung an die amerikanische Gesellschaft: «Dual identity superheroes would enable these readers to inhabit both sides of their dilemma.» ${ }^{163}$ Die zivile Identität des Helden steht dabei für die Anpassung an die amerikanische Gesellschaft, die heldische Seite für die eskapistische Version der «wahren> Identität. ${ }^{164}$ Hier stellt sich die Frage, ob die umgekehrte Gleichsetzung nicht ebenso plausibel wäre - wohl je nach Lebensgefühl der jeweiligen Individuen scheinen doch beide Varianten möglich. Zusätzlich stellt es für die Prämissen dieser Interpretation einen nicht unerheblichen Unterschied dar, ob der Betroffene aus seiner Doppelidentität ein Geheimnis macht oder nicht.

Fingeroths These scheint zwar bestechend (obwohl seine Interpretationen für einige der von ihm betrachteten Helden die Grenze zur Spekulation überschreiten), insbesondere ihre Pauschalisierung - Superheldencomics als <eindeutig> jüdische Erfindung oder Ausdruck «der jüdischen Kultur zu verstehen - wird aber auch (meines Erachtens zu Recht) kritisiert. ${ }^{65}$ Ausser in den Grundplots diverser Origin-Storys (Helden mit ausserirdischer, mythologischer oder fernöstlichmagischer Herkunft) und der Doppelidentität als Konzept finden sich nämlich kaum Stellen, in welchen sich der Superheld als Einwanderer konkret fassen liesse; diese Interpretation beruht in erster Linie auf allgemeinen zeitgenössischen Umständen sowie den Biografien der Künstler bzw. ihrer Religionszugehörigkeit. Betrachtet man die Golden-Age-Superhelden aus der Perspektive des maskierten Helden, ist anzumerken, dass die meisten Pulp-Autoren, die ja den maskierten Helden als Figurentypus etablierten, aus einem angloamerikanischen

I62 Dies trifft v. a. auf die Wissenschaftler zu, doch heisst es etwa bei Captain America explizit, das ihm gespritzte Wunderserum lasse nicht nur seine Muskeln, sondern auch seinen Intelligenz «to an amazing degree» wachsen (Case No. I: Meet Captain America (Joe Simon, Jack Kirby), in: Captain America Comics I, März I94 I, 5).

163 Fingeroth 2008, 55 .

I64 Die heldische Seite ist dabei nicht nur positiv: «But the regular guy» is the sham persona because the power underneath is just too dangerous for people to be allowed to observe it any time they desire» (ebd., 53 f.).

I65 Die bisher wohl ausführlichste, fundierteste, aber auch konsequenteste Kritik formuliert Lund 20I6, für ihn erscheint nicht zuletzt der Wunsch als Vater des Gedankens bzw. der These. 
Umfeld stammten. ${ }^{166}$ Damit ist freilich nicht in Abrede gestellt, dass der maskierte (Super-)Held gerade bei jungen jüdischen Künstlern auf Resonanz stiess und im von ihnen (und anderen Künstlern unterschiedlicher Herkunft) getragenen neuen Medium auf fruchtbaren Boden fiel. Wie Engle skizziert, stehen die jüdischen Künstler sozusagen als verdichtetes Beispiel für viele Gruppen im Einwanderungsland USA schlechthin.

Die diesbezügliche Anziehungskraft Supermans illustriert Engle mit der individuellen Mobilität, die zu den festen Bestandteilen des amerikanischen Traums gehört, sei sie sozial oder geografisch. «Displacement» stehe dabei am Beginn einer jeden amerikanischen Einwanderungsgeschichte und ist somit einerseits als unangenehme Erfahrung konnotiert, andererseits mit Hoffnung. Für einen Helden wie Superman aber ist laut Engle ein solches «displacement» unmöglich (bzw. er hebt dies durch seine Supermobilität auf). Hierin erkennt Engle denn auch einen tieferen Sinn von Superman: «His sense of self is not dispersed by his life's migration but rather enhanced by all the universe that he is able to occupy.» ${ }^{167}$ Engle fragt rhetorisch, wie dies keinen Erfolg hätte haben können: «What American, whether an immigrant in spirit or in fact, could resist the appeal of one with such an ironclad immunity to the anxiety of dislocation?» ${ }^{168}$ Darin liegt nach Engle ein Schlüssel zu Supermans Erfolg: «Even in the comics, [...] intimately connected with immigrant culture, there simply was no image that presented a blending of identities in the assimilation process in a way that stressed pride, self-confidence, integrity and psychological well-being.» ${ }^{169}$ Erst Superman/Clark Kent habe also ein positives Doppelrollenmodell geboten ${ }^{170}$ - und dies lässt sich wohl analog auch für die anderen Golden-Age-Protagonisten in Anspruch nehmen.

Freilich lässt sich argumentieren, dass diese Rolle so positiv nicht ist (bzw. nur aus der Warte des Schmelztiegels). Dies legt zumindest eine vergleichbare Deutung für die vom Psychologen William Moulton Marston ersonnene Wonder Woman nahe: Wie Matthew J. Smith plausibel darlegt, stellt die Ama-

I66 Interessanterweise aber war die Erfahrung von Migration schon für Emmuska Orczy, die <erste> Autorin des maskierten Helden, prägend: Noch als Teenager wanderte sie um I 880 aus Ungarn in Grossbritannien ein, was den Lobgesang auf ihre neue Heimat in den Pimpernel-Romanen erklären mag.

I67 Engle 1987, 8r. Vgl. dazu in Bezug auf die frühen Soziologen wie Park Goldberg 20 I 2.

i68 Engle 1987, 8I (meine Hervorhebung).

169 Ebd., 85 .

I70 So schlüssig diese These scheint, ist doch anzumerken, dass sie in einem gewissen Widerspruch zu der im Kapitel zu den bestehenden Interpretationsansätzen erwähnten Auffassung von Clark Kent als ‘Underdog〉 steht, die in Engles (und Fingeroths) Ausführungen aber durchaus mitschwingt. 
zone von der mythischen Paradise Island die bereits vor ihrer Ankunft völlig an die US-Kultur assimilierte und daher in gewisser Hinsicht 〈perfekte> Einwanderin in den melting pot dar ${ }^{171}-$ Ähnliches kann man Superman durchaus unterstellen. ${ }^{172}$

Nicht zuletzt im Hinblick auf die Rezeptionsseite ist ausserdem davon auszugehen, dass die Comic-Helden für ihren wirtschaftlichen Erfolg, der sich vor allem nach der Depression einstellte, ein breiteres Publikum ansprechen mussten, als die hier genannten Ansätze nahelegen. So lässt sich argumentieren, dass bereits Park für seinen marginal man einen weiter gefassten Geltungsbereich im Blick hatte: «There are no doubt periods of transitions and crisis in the lives of most of us that are comparable with those which the immigrant experiences when he leaves home to seek his fortunes in a strange country.»173 Wie schon Park verweist denn auch Fingeroth darauf, dass die mit der Immigrationserfahrung verbundenen Gefühle wohl durchaus bei jedem Menschen Parallelen finden:

In many ways, don't we all feel like strangers in a strange land when we first venture outside our homes to school or to work? [...] Again would we not all like to integrate all the sides of our personalities to, as the psychologists would put it, become one «fully realized» person? Ironically, Superman becomes integrated by splitting himself. That can be a comforting thought: our dilemma is its own solution! Unity equals duality! $!^{174}$

Damit deutet Fingeroth zumindest an, dass die Faszination der Doppelidentität vor allem darin liegt, dass sie als Ausdruck vieler verschiedener Identitätsaspekte gedeutet werden kann, die durch eine Zweiteilung (oder, davon ausgehend, Vielheit) im Sozialen gekennzeichnet scheinen - seien dies nun die oft dichotomischen Verhältnisse zwischen beispielsweise Stadt und Land, Gelehrsamkeit und Sportlichkeit, Schüchternheit und Selbstbewusstsein, Angestelltenkultur und Selbstständigkeit (einige Ansätze dazu wurden bereits im Kapitel zu den bestehenden Interpretationen erläutert). Immer wieder drängt sich dabei eine Spannung zwischen Konformität und Individualität auf - und diese gegensätzlichen

I7 I Smith 20I r. Tatsächlich würde es wohl schwierig, Wonder Woman (und weiteren einschlägigen Gestalten) einen inneren Konflikt zwischen kulturellen Identitäten nachzuweisen. Zu Wonder Woman u. a. auch DiPaolo 2007.

I72 Während in den letzten Jahrzehnten Krypton eine grosse Rolle spielt, war dies im Golden Age nicht so, es wurde meist nur am Rande als Supermans Herkunftsplanet erwähnt.

I73 Park I950 (1928), 355 f. Freilich ist «the period of crisis» für den marginal man im Gegensatz zu diesen allgemeinen Erfahrungen «relatively permanent» (ebd., 356). Doch entsprechend wurde das Konzept des marginal man fleissig in anderen Kontexten untersucht und in verschiedene Richtungen weiterentwickelt, beispielsweise für bestimmte Berufe, als allgemeines Problem von Rollenkonflikten oder auch als marginal woman (Goldberg 20I 2).

I74 Fingeroth 2008, 55f. (Hervorhebung im Original). 
Bestrebungen kennzeichnen (wie im Kapitel zu Masken, Rollen, Identitäten dargelegt) auch den goffmanschen Schauspieler bzw. den Menschen in sozialer Interaktion im Allgemeinen. ${ }^{175}$

I75 So schreibt Abels (2007, I92) in Bezug auf Goffmans Figuren: «Weil sie das Risiko scheuen, dass jemand so aufmerksam wird, dass er ihnen zu nahe tritt, vermeiden sie Aufmerksamkeit, weil sie aber auch nicht in der Masse untergehen wollen, müssen sie etwas unternehmen, was Distanz Auffälligkeit - schafft», und spricht weiter von der «Strategie, eine [...] Spannung zwischen Normalität und Einzigartigkeit aufrechtzuerhalten» (ebd.). Kürzer formuliert dies Fingeroth $(2007,53)$ für seine Fokusgruppe: «The immigrant wants to excel but stay anonymous.» 


\title{
Spider-Man/Peter Parker und das proteische Selbst
}

\author{
"How do you cope with your double-life?" \\ "Now, I'm nothing special, everyone has a \\ dayjob.» \\ "Come on, you spend half your time as a regular \\ person ..." \\ "I spend all my time that way." \\ Journalistin Lucy Fletcher und The Ghost in \\ Doctor Who - The Return of Dr. Mysterio \\ (Christmas Special), 2016
}

Nachdem der DC-Verlag Ende der 1950er-Jahre mit neuen Versionen von The Flash (1956), The Green Lantern (1959) und der Justice League (1960) nach den Krisenjahren einen Superhelden-Neuanfang gewagt hatte, war es zu Beginn der I960er-Jahre der Marvel-Verlag, dessen Neuschöpfungen dem Silver Age erst recht neuen Schub verliehen. ${ }^{\mathrm{T}}$ Marvel verkündete dabei unbescheiden gleich selbst das «Marvel Age of Comics», und die gern kolportierte Entstehungsgeschichte von Spider-Man steht ebenfalls im Geiste dieser Aufbruchstimmung: Nur weil die Heftreihe Amazing Fantasy 1962 mit Nummer Is eingestellt werden sollte, erhielt Autor Stan Lee (1922-20 18), der zum Abschied einen Comic ganz nach seinem Geschmack schaffen wollte, die Narrenfreiheit, dort eine Geschichte wie The Amazing Spider-Man unterzubringen. Von Steve Ditko (1927-2018) gezeichnet, ${ }^{2}$ verbuchte die Geschichte einen solchen Erfolg, dass dem Helden ab 1963 eine eigene Heftreihe, The Amazing Spider-Man, gewidmet wurde. So wurde SpiderMan - neben den Fantastic Four (ab I96r), The Hulk (1962) und den X-Men (ab 1963) - zu einer, wenn nicht der Galionsfigur des Marvel-Verlags.

Spider-Man gilt als erster Superheld, der als Jugendlicher zum alleinigen Protagonisten einer Reihe bzw. auch erzählerisch zu einem allein operierenden Helden wird, ${ }^{3}$ und war so erfolgreich, dass relativ bald zahlreiche parallele Netzschwin-

I Zur Genregeschichte vgl. u. a. Rhoades 2008, Sieck 1999, Ditschke/Anhut 2009, Coogan 2006, Schikowksi 2014, 79-I04; Knigge 2004, Kawa 2009, zum Silver Age u. a. Casey 2009, Easton/ Harrison 20I0, 89-I I I; weitere Hinweise im Kapitel über die bestehenden Interpretationsansätze zur Doppelidentität.

2 Zur ineinandergreifenden Arbeitsweise von Autoren und Zeichnern bei Marvel vgl. Kelleter/ Stein 201 2, für Spider-Man DiPaolo 201 I, I03-I I 2.

3 Im Golden Age waren Jugendliche auf die Rolle des Sidekicks beschränkt geblieben (obwohl 
ger-Heftreihen erhältlich waren: Neben The Amazing Spider-Man sind hier The Spectacular Spider-Man ( 1968/ab I976; mit mehrjährigen Unterbrüchen), Web of Spider-Man (1985-1995, 2009/2010), Sensational Spider-Man (1996-1998), Peter Parker-Spider-Man (1990-2003) oder die Spidey Super Stories, die von 1974 bis 1982 an ein kindliches Publikum gerichtet waren, $\mathrm{zu}$ nennen - womit die Liste keineswegs vollständig ist.

Im Lauf der Zeit haben sich die Superheldengeschichten mal sprunghaft, mal kontinuierlich weiterentwickelt. Wie erwähnt herrscht jedoch über die weitere Einteilung in Zeitalter (Ages) Uneinigkeit. Einerseits fordert die schiere Fülle an Material Kategorisierungen und Epochenbildungen geradezu heraus, wobei die Aufmerksamkeit, wie Stephan Ditschke und Anjin Anhut erläutern, jeweils auf «neue Positionen» fällt. Andererseits ist jedoch festzuhalten,

[...] dass die einer Entwicklungsstufe vorangegangenen Formen der Realisierung des Genres nicht verschwinden, sondern höchstens an Relevanz für das jeweilige Feld verlieren; wahrgenommen werden zwar v. a. Traditionsbrüche, trotzdem werden Erzählformen der verschiedenen Comic-Book-Zeitalter weiterhin von Comic-Produzenten angewandt oder bleiben als (bewusste oder unbewusste) Bezugspunkte der Produktion und Rezeption präsent. ${ }^{4}$

Zeitweise waren die Publikationen innerhalb eines Verlages auch sehr heterogen. Für die hier behandelte Fragestellung ist es daher nicht nötig, die Entwicklungen der Comic-Erzählweisen detailliert wiederzugeben; einige grundlegende Aspekte des Wandels über die Jahrzehnte seien dennoch festgehalten.

DC und Marvel etablierten sich mit dem Silver Age als die beiden grossen, rivalisierenden Superhelden-Verlagshäuser, deren Comics sich gegenseitig beeinflussen.' Als ein grosser Unterschied zu DC postuliert(e) Marvel, dass sich die Abenteuer seiner Helden - zumindest im Haupterzählstrang - in der <realen> Welt der Leser abspielen, was mit der viel zitierten Marvel-Spezialität, Helden mit Charak-

gewisse Sidekicks oder Sidekick-Teams eigene Geschichten erhielten); Johnny Storm/The Human Torch von den Fantastic Four, zu Beginn der Reihe ebenfalls ein Teenager, war/ist zwar kein Sidekick, aber Mitglied eines Teams.

4 Ditschke/Anhut 2009, I63. Sie sehen hierzu seit Ende der I990er-Jahre die 〈Ära der Epochen〉 als vorbei; ab diesem Zeitpunkt «liegt vor den Rezipienten [...] ein pluralistisches Zeitalter. In diesem gibt es zwar Moden und Trends, diese wechseln sich jedoch erstens schneller ab als die vorangegangenen Ages, zweitens existieren häufig mehrere Trends nebeneinander und drittens bleiben die zuvor entwickelten narrativen Muster weiterhin präsent» (ebd., I65).

5 Neben Marvel und DC konnten sich nur wenige Nischenanbieter im Superheldenmarkt behaupten; beispielsweise Charlton Comics, dessen Figuren schliesslich 1985 von DC übernommen wurden. Der 1969 gegründete Verlag AC Comics (heutiger Name) griff unter anderem Golden-Age-Figuren auf, die gemeinfrei geworden waren; seit 1985 auch in der Femforce, dem ersten reinen Frauenteam in den Superheldencomics. 
terschwächen zu zeichnen, korreliert. ${ }^{6}$ Dagegen werden «gewöhnliche〉 Kriminelle selten; Standardgegner sind nun Superschurken oder andere fantastische Wesen. Nicht selten kämpfen Helden aufgrund von Missverständnissen gegeneinander. Damit verwischt sich die klare Trennung zwischen Gut und Böse, ein temporärer Seitenwechsel wird Bestandteil fast jeder Heldenkarriere. Es kommt zu expliziten Problematisierungen von Heldentum wie der Doppelidentität, wofür Spider-Man ein hervorragendes Beispiel ist. 7 Die Doppelidentität sorgt weiterhin für komische Momente, doch werden deren tragische Dimensionen ebenso thematisiert und gerade im Silver Age teilweise geradezu ausgekostet.

Über das Silver Age hinaus waren es nicht zuletzt Änderungen in den Distributionsstrukturen und die Partizipation der Leser bzw. die Etablierung einer Fankultur, die Veränderungen ermöglichten oder vorantrieben. Dies gilt insbesondere für die serielle Struktur: Im Golden Age handelte es sich wie erwähnt grösstenteils um abgeschlossene Episoden, deren Reihenfolge weitgehend austauschbar war; ab dem Silver Age kam es zunehmend zu fortlaufenden Erzählungen, die sogar Teil der das gesamte jeweilige Verlagsuniversum umfassenden Erzählgebilde werden konnten. Die Continuity - das (kanonische) Seriengedächtnis, das die Geschehnisse aller Heftreihen eines Verlags umfasst - ist nur möglich, wenn alte Hefte greifbar bleiben und man ein gewisses Serienwissen bei den Lesern als vorhanden voraussetzen kann. ${ }^{8}$ Als Kompromiss zwischen episodischen Handlungen und potenziell unendlicher Handlung etablierten sich mit der Zeit die sogenannten Story-Arcs - Handlungsbögen, die zwar Teil fortlaufender Geschehnisse bleiben, aber über eine beschränkte Anzahl Hefte (einer oder mehrerer Reihen) präsentiert werden und einen gewissen (temporären) Erzählabschluss erreichen. ${ }^{9}$ Obwohl die Superhelden nicht eigentlich altern, gibt es doch Entwicklungen, die dem Lauf der Zeit Rechnung tragen: So gibt es Superhelden, die Familien gründen (Heirat, Kinder, wobei auch dies wieder geändert werden kann) oder in einer Ausbildung voranschreiten (wie Peter Parker), was umgekehrt aber wieder Strategien zur Ver-

6 Zur «profound crisis of identity» der Marvel-Comics der I 960er-Jahre in Verbindung zum «liberal consensus» vgl. Costello 2009, 90-93, zu Marvels Weltsicht bzw. Ideologie vgl. Schweizer I 992 sowie Sieck 1999.

7 Demgegenüber unterbleibt etwa bei DCs Green Arrow/Oliver Queen bis Ende der 1960erJahre eine Problematisierung der Doppelidentität fast vollständig.

8 Meteling 2013, 98: «[...] continuity [ist] das Erzählen in einem Kanon und damit das Wissen darum, welche Superheldengeschichten offiziell anerkannt und damit 〈real > und 〈gültig〉 sind und welche nicht (mehr). Continuity meint die dauerhafte Konsistenz und Kohärenz der erzählten Ereignisse [...].» Vgl. auch Hoppeler/Rippl 2012.

9 Die Story-Arcs werden ab Ende der I970er-/Anfang der I980er-Jahre vermehrt eingesetzt. Vgl. zum Story-Arc als «middle ground» des seriellen Superheldenerzählens Harrison in Easton/Harrison 20I0, 26, sowie Meteling 2013, der auch die weiteren Strategien wie One-Shot, Crossover etc. erläutert. 
jüngung der Heldengarde nach sich zieht (wenn zum Beispiel einzelne Masken an jüngere Nachfolger übergehen).

Zunehmende inhaltliche Komplexität und steigender künstlerischer Anspruch, die sich in immer elaborierteren Erzählweisen äusserten, ${ }^{10}$ gingen damit einher, dass das Zielpublikum erwachsener wurde. Superheldencomics richten sich im Allgemeinen nicht mehr an Kinder, sondern an männliche Jugendliche bzw. junge Männer. ${ }^{I I}$ Paradebeispiel für die 〈Abwendung〉 von einer Leserschaft im Kindesalter ist die Entwicklung, die als grim and gritty bekannt geworden ist und in einer «massiven Zunahme expliziter und sexualisierter Gewaltdarstellungen $»^{12}$ gipfelte, wofür auch neue Heldentypen stehen; früh pointiert dies etwa der Vietnamveteran Frank Castle/The Punisher (ab I974), der das ungeschriebene Superheldencredo, niemals jemanden zu töten, über den Haufen warf und seine Gegner mehr oder weniger einfach niedermähte. Den Höhepunkt dieser Entwicklung dürften die Helden des 1992 (von mit Marvel zerstrittenen Künstlern) gegründeten Verlags Image darstellen (zum Beispiel Spawn). Wie erwähnt wurde der Comics Code im Lauf der Jahre mehrmals überarbeitet, bis er schliesslich in der Bedeutungslosigkeit verschwand. ${ }^{13}$ Allerdings ist Spider-Man jener Marvel-Held, der bewusst stets auch jüngeren und kindlichen Lesern zugänglich bleiben sollte und insbesondere die genannte Verdüsterung und Brutalisierung in weniger prägendem Ausmass mitmachte. Zudem wurde seine Doppelidentität sehr lange beibehalten (erst im Rahmen des Events Civil War, 2006-2007, demaskierte er sich öffentlich, was allerdings mit erzählerischer Brachialgewalt rückgängig gemacht wurde). ${ }^{14}$

Auch in der visuellen Darstellung der Helden sind im Lauf der Jahrzehnte viele Entwicklungen zu beobachten - bis hin zu teilweise geradezu hyperbolisch zu nennenden Körperdarstellungen (die wohl von der Bodybuilding-Bewegung und dem Actionkino der 1980er- und I990er-Jahre mitbeeinflusst waren), in

Io So ist der allwissende Erzähler heute fast ganz verschwunden, vielmehr führen die gedanklichen Stimmen der Figuren durch das Geschehen; auch Geschichten ohne Worte sind möglich. Die Selbstreflexivität wird unter anderem von einem Charakter wie Marvels Deadpool (ab I99I) verkörpert, der die «vierte Wand durchbricht, also sich bewusst ist, dass er eine Comicfigur ist.

I I Vgl. die allerdings unterschiedlichen Altersangaben der intendierten Leserschaft in den Interviews mit Redaktoren von Marvel und DC in McCue/Bloom I993, 89f., ro If., i 8.

I2 Ditschke/Anhut 2009, I69.

I3 Zur Geschichte des Codes vgl. Nyberg 1998. Die Absurdität des Codes illustriert dabei die berühmte Episode der Amazing Spider-Man-Hefte 96-99 (1971): Auf Bitte des US-Gesundheitsamtes hatte Stan Lee eine Geschichte geschrieben, die vor Drogen warnen sollte (mit Peters Freund Harry Osborn als Drogensüchtigem). Doch wurde das CCA-Gütesiegel verweigert, sodass Marvel erstmals Hefte ohne dieses druckte.

I4 Zu Spider-Man vgl. u. a. Fingeroth 2008, bes. 73-77, I39-I 54, DiPaolo 201 I, 92-I I 4, die Beiträge in Peaslee/Weiner 201 2, Kniep 2009, $205-232$ (enthält Kniep 200I, I 55-1 59), Darowski 2009, 69-90, Oropeza 2005b, Seidl 2005. 
Abb. 33: Spider-Mans Maske verdeckt seine Mimik nicht, sondern verstärkt diese fast in cartoonistischer Weise. Humbugged! (David Michelinie, Todd McFarlane et al.), in: The Amazing Spider-Man 306, Oktober I988, 2. () Marvel Comics

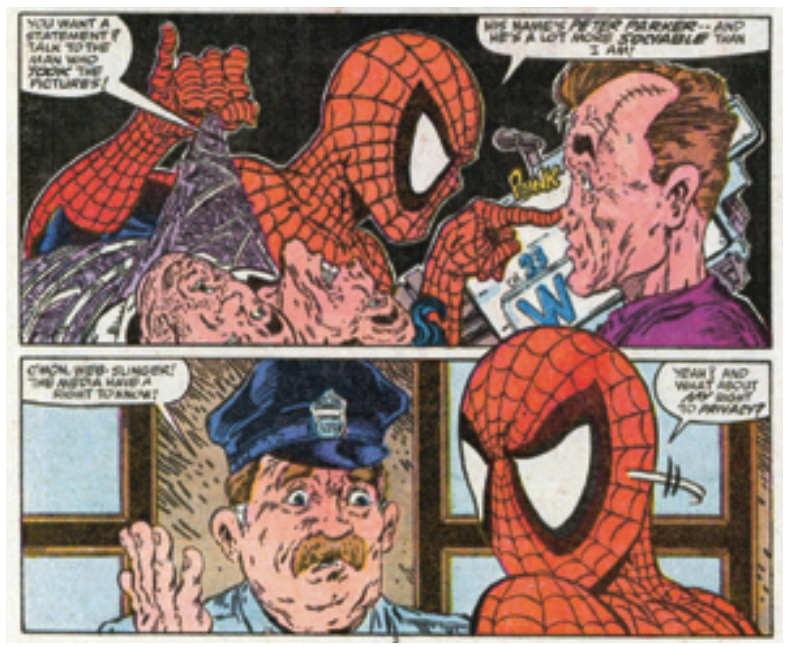

denen die eng anliegenden Kostüme jeden - in der Realität anatomisch nicht vorfindbaren - heldischen Muskel hervorzuheben scheinen. Analog dazu wird im Lauf der Jahrzehnte die Materialität der Heldenkostüme immer detaillierter thematisiert. ${ }^{15}$ Dabei wäre üblicherweise davon auszugehen, dass eine Maske (die nicht selten auch ein Helm ist oder Helmeigenschaften aufweisen muss) ein eher starres Gebilde ist, das die Mimik verunmöglicht und das Gesicht auf genau einen Ausdruck (und damit die Person auf genau eine Eigenschaft) festlegt. Die Comic-Künstler haben diesbezüglich schon seit dem Golden Age eine gewisse künstlerische Freiheit walten lassen, um diesen Eindruck zu unterwandern. ${ }^{16}$ Spätestens mit dem Silver Age aber wurde das Innenleben der Helden, und damit ihre Emotionen, zu einem wichtigen Teil der Narration. Entsprechend wurden die Masken zunehmend beweglicher, um mindestens einen Teil der heldischen Mimik durchscheinen zu lassen bzw. nach aussen transportieren zu können (Abb. 33) - obwohl die Masken, seien es Voll- oder Halbmasken, nach wie vor die Identität des Helden verdecken sollten.

Is Zur Materialität der Superheldenkostüme im Spannungsfeld zwischen «realism» und «reality» vgl. Brownie/Graydon 2016, 4I-49.

I6 Ein berühmtes Beispiel dafür ist Will Eisners The Spirit (ab I940), dessen Maske stets wie eine zweite Haut auf dem Gesicht ihres Trägers sass. Aber auch Batmans Kopfmaske hatte seit Anfang der I940er-Jahre bewegliche Augenbrauen. Während dies im Golden Age erst ansatzweise geschieht und oft vor allem im Rahmen der Bilddynamik zu stehen scheint, erhält die Maske ab dem Silver Age eine viel grössere Ausdruckskraft, so vermag Iron Mans metallener Helm seine Mund- und Augenschlitze entsprechend den Gefühlen seines Trägers umzuformen. Heute passt sich so gut wie jede Heldenmaske besonders den Stirnrunzeln ihres Trägers an. 
Peter Parker/Spider-Man, den die Konstruktion seiner Doppelidentität regelmässig in ein Dilemma treibt, lässt sich als eine Verkörperung von Robert Jay Liftons Konzept des protean self interpretieren, wie im Folgenden dargelegt wird. Die Erläuterungen dieses Kapitels stützen sich nebst Amazing Fantasy is (1962) auf The Amazing Spider-Man I-44 I (1962-1998, im Folgenden mit ASM abgekürzt), ${ }^{17}$ wobei für gewisse Storylines einzelne Hefte aus weiteren SpiderMan-Reihen beigezogen wurden.

\section{Das proteische Selbst}

Das Konzept des protean self hat der US-amerikanische Psychiater Robert Jay Lifton in seinem gleichnamigen Buch 1993 ausführlich dargestellt; wie er jedoch gleich am Anfang festhält, reichen seine Überlegungen dazu bis in die I960erJahre zurück - womit eine bemerkenswerte zeitliche Nähe zu der Entstehung von Spider-Man und dem Beginn des Superhelden-Silver-Age zu konstatieren ist. Wie der Untertitel Human Resilience in an Age of Fragmentation bereits deutlich macht, ist das protean self ausdrücklich in bestimmten zeitgeschichtlichen Rahmenbedingungen zu verorten. Diese beschreibt Lifton als insbesondere von Rastlosigkeit und ständigem Wechsel geprägt. ${ }^{18}$ Auch Lifton hebt sein Konzept von einer in früheren Zeiten verhafteten Identitätsvorstellung ab, die eine stabile und einheitliche Identität in einer traditionellen Kultur - das heisst einem sozialgesellschaftlichen System mit relativ starren Strukturen, in welchen das Individuum in Rolle, Status, Beruf und Ort fest verwurzelt war - vorsieht. ${ }^{19}$ Lifton sieht Proteismus so hauptsächlich als ein Phänomen des 20. und 2 I. Jahrhunderts (was zeitlich mit dem maskierten Helden als populärer Figur einhergeht); nun erst «does the pattern of psychological multiplicity and change take hold in everyone». ${ }^{\circ}$ Zentrale Einflüsse für die Entwicklung des protean self erblickt Lifton in drei historischen Prozessen, deren Spuren sich bis in die Renaissance zurückverfolgen lassen, die aber im 20. Jahrhundert mehr Gewicht erhalten und sich beschleunigen. Dies sind die oft geltend gemachten allgemeinen rapiden Umwäl-

I7 Der Schnitt wird bei Heft 44I gemacht, da im folgenden Heft (Januar 1999) die Nummerierung (nach einem Story-Arc namens The Final Chapter) erstmals neu gestartet wurde, obschon die Handlung mehr oder weniger nahtlos weiterlief. Die Nummerierung wurde dann im Hinblick auf die bevorstehende Jubiläumsausgabe des 500 . Heftes doppelt geführt und die neue mit der Jubiläumsnummer wieder fallen gelassen; diese Zählung hatte Bestand bis Heft 700 (Dezember 20I 2), seither gab es temporäre Neubenennungen und mehrere Relaunches.

I8 Lifton I993, I.

19 Ebd., 4; I 4 . Diese Auffassung teilt etwa Kaufmann 2004.

20 Lifton $1993, \mathrm{I} 6$. 
zungen, die zur Entwurzelung der Individuen führen, sowie die massenmediale Revolution und das Bewusstsein, dass der Menschheit das Aussterben droht. ${ }^{21}$ Was den ersten Punkt der Entwurzelung betrifft, so bringt historischer Wandel immer den Verlust oder Zusammenbruch von sozialen und institutionellen Strukturen, doch ist dies laut Lifton gravierender, wenn sich die Umstände rasch ändern. Lifton spricht diesbezüglich von «psycho-historical dislocation»; Migration und (Massen-)Urbanisierung (und umgekehrt die Flucht vor Letzterer) sind diesbezüglich von Bedeutung. ${ }^{22}$ Durch die dauernde Berieselung mit Informationen durch die Massenmedien sieht auch Lifton das Potenzial für Übersättigung und Reizüberflutung: «While [the late-2oth-century] self invokes defenses of withdrawal and numbing, it remains continuously bombarded by ideas and images and is in some measure recast by them, made more fluid in response to the surrounding fluidity.» ${ }^{23}$ Durch die Massenmedien werden schliesslich Auslöschungsszenarien (namentlich die atomare Bedrohung) bildkräftig verbreitet, wobei laut Lifton das Ich unter solchen Bedingungen den eigenen Untergang und die eigene Erneuerung mit jenem der Welt gleichsetzt. ${ }^{24}$ Obwohl Lifton davon ausgeht, dass etwas Vergleichbares wie das protean self in jeder Epoche rapiden historischen Wandels auftreten kann, ${ }^{25}$ argumentiert er, dass es für die Situation des 20. Jahrhunderts keine Präzedenzen gebe, da diese drei Phänomene interagieren ${ }^{26}$ und untrennbar mit der modernen und postmodernen Zeit mit ihrem technologischen Fortschritt verbunden sind.

Diese Entwicklungen haben freilich Folgen für das alltägliche Leben der Menschen und ihre Identität. Liftons Beobachtung und Überzeugung lautet, dass sich aus diesen Umständen ein protean self entwickelt, das nicht nur als Identi-

2 I Ebd., 3.

22 Peltz 2008, 725 . Entsprechend sieht Lifton $(1993,32)$ in den von der Grenzverschiebung gegen Westen sowie der Immigration geprägten USA die proteische Nation schlechthin, da ihrem (Selbst-)Image Fluss und Bewegung eingeschrieben seien.

23 Ebd., 2 I. Auch Elliott (2007, 3 und 5) zufolge führt die Explosion der globalen Kommunikation und das «speeding-up» of the world» zu einem Wandel in der Natur des Selbst (wobei er auch einen Zusammenhang mit der Konsumkultur sieht, in der sich das Selbst in einem komplexen Netz verortet - hier liesse sich eine Brücke zur Fankultur schlagen); nur schon die Auswahl, welche News man bewusst konsumiere, beeinflusse die Selbstpräsentation.

24 Lifton $1993,22$.

25 Als Beispiele nennt Lifton (ebd., I5) die japanische Meiji-Restauration sowie Renaissance und Aufklärung. Tatsächlich scheint aus europäischer Perspektive die krisengeplagte Frühe Neuzeit, die von Kriegen, Seuchen, Weltuntergangsstimmung und ersten sensationalistischen Druckerzeugnissen geprägt war, eine mindestens ebenso gute Kandidatin für eine Zeit, in der sich ein protean self entwickeln kann.

26 Lifton (ebd., 24) bemerkt dazu: «[T] he mass media revolution can further our sense of dislocation, which can make us more vulnerable to the imagery of extinction, its impact in turn accentuated by media saturation.» 
tätsvorstellung zu verstehen ist, sondern vielmehr einen «modus vivendi for our time $\gg^{27}$ darstellt:

This mode of being differs radically from that of the past, and enables us to engage in continuous exploration and personal experiment. [...] The protean self emerges from confusion, from the widespread feeling that we are losing our psychological moorings. We feel ourselves buffeted about by unmanageable historical forces and social uncertainties. [...] We change ideas and partners frequently, and do the same with jobs and places of residence. Enduring moral convictions, clear principles of actions and behavior: we believe these must exist, but where? Whether dealing with world problems or child rearing, our behavior tends to be ad hoc, more or less decided upon as we go along. [...] our world and our lives seem inconstant and utterly unpredictable. We readily come to view ourselves as unsteady, neurotic, or worse. ${ }^{28}$

Die Schnelllebigkeit und die Fragmentierung des sozialen Lebens stellen das Selbst vor Herausforderungen. Liftons protean self nun zeichnet sich dadurch aus, dass es diese durchaus zu meistern vermag, denn: «[...] the self turns out to be surprisingly resilient. It makes use of bits and pieces here and there and somehow keeps going. What may seem to be mere tactical flexibility, or just bungling along, turns out to be much more than that. We find ourselves evolving a self of many possibilities [...].»29

Lifton unterscheidet zudem drei Formen (manifestations) des protean self: Eine sequenzielle Variante, «a changing series of involvements with people, ideas, activities», womit bereits angedeutet ist, dass dieses in jeder sozialen Umgebung und gesellschaftlichen Position denkbar und zu finden ist (soziale Variante). Ausserdem erkennt er einen «simultanen» Proteismus (dritte Variante) «in the multiplicity of varied, even antithetical images and ideas held at one time by the self $[\ldots] \gg .^{30}$ Allerdings baut das proteische Selbst oft auf schmerzlichen Erfahrungen auf und muss sich mit Gefühlen der Vater- und Heimatlosigkeit auseinandersetzen..$^{3 \mathrm{I}}$ Es verfügt kurz gesagt über eine Survivor-Mentalität. Gekennzeichnet wird das proteische Selbst auch von einer «absence of sit between the way the world presents itself and the way one actually feels about it» $3^{2}$. Als Ausdruck und Reaktion

27 Peltz 2008, 725 (Hervorhebung im Original), ähnlich Lifton I993, 3. In der politischen Dimension seines Konzepts orientiert Lifton Fundamentalismus als Gegenpol zu Proteismus. Zwar bemerkt er, dass es sich dabei nicht um eine absolute Positionierung handle, da auch Menschen in einem «fundamentalistischen» Rahmen eine Form von Proteismus aufweisen können; doch repräsentieren diese zwei Strömungen für ihn eine «basic historical dynamic» (Lifton I 993, I I; vgl. dazu die Kritik von Arnett Jensen 1995).

28 Lifton I993, I.

29 Ebd.

30 Ebd., 8.

3 I Ebd., 74.

32 Ebd., 5 f. 
darauf zeigen proteisch veranlagte Individuuen oft eine starke Tendenz zu Spott und Selbstironie. Die Entwurzelung als Grundgefühl des Proteismus bringt zwar die Gefahr von Selbstfragmentierung mit sich, kann laut Lifton aber auch Impulse für eine Erneuerung bzw. die Suche nach neuen Zugehörigkeiten veranlassen. ${ }^{33}$ Wie Lifton selbst erläutert, teilt sein Konzept vieles, was unter der Bezeichnung «postmodern» versammelt ist: «contingency, multiplicity, and polyvocality» of postmodernism in the arts and with its 〈playful, self-ironizing> patterns» ${ }^{34}$. Lifton distanziert sich jedoch davon, Multiplizität und Fluidität mit dem Verschwinden des Selbst gleichzusetzen oder den verschiedenen Elementen eine gewisse Kohärenz abzusprechen. Im Unterschied zu anderen postmodernen Konzeptionen besteht Lifton bei aller Vielseitigkeit und Wandlungsfähigkeit (mitunter sogar Wandlungsfreude) der proteischen Identität auf einer gewissen Beständigkeit: «Though variation is the essence of the protean self, that self has certainly relatively consistent features.»35

Das proteische Selbst beinhaltet entsprechend auch die Suche nach Authentizität und Bedeutung. (Die Frage nach der Authentizität des protean self ist für Lifton indes kein Thema; es gibt allenfalls eine Priorisierung, nicht aber eine Wahr-falschWertung von Identitätsaspekten.) Denn es will sich stets auch andere Möglichkeiten offenhalten: «The protean self seeks to be both fluid and grounded, however tenuous that combination.» ${ }^{36}$ Proteismus ist, so Lifton, daher eine kontinuierliche Anstrengung, die allerdings nicht auf ein konkretes Ziel hinarbeiten kann. Die Identitätsarbeit besteht dabei aus einer Art «Mixertätigkeit: «Central to its function is a capacity for bringing together disparate and seemingly incompatible elements of identity and involvement in what I call <odd combinations', and for continuous transformations of these elements.»37 Proteismus präsentiert sich als «a balancing act between responsive shapeshifting, on the one hand, and efforts to consolidate and cohere, on the other ${ }^{3}$. Diesen Balanceakt mit all seinen Herausforderungen vermag die Figur von Peter Parker/Spider-Man durchaus zu repräsentieren. ${ }^{39}$

33 Ebd., I 5.

34 Ebd., 8. Lifton zitiert hier seinerseits Henry M. Sayre: The Object of Performance: The American Avant-Garde since 1970, Chicago 1989, xii-xiii, sowie David Harvey: The Condition of Postmodernity, Cambridge 1989, 7-8.

35 Lifton 1993, 5. Die Metapher von Proteus - dem griechischen Meeresgott, der ein Gestaltwandler war - drückt für Lifton die «free expressions of proteanism [that] depend upon the existence of relatively established corners of the self» aus (ebd.).

36 Ebd., 9 .

37 Ebd., 5 .

38 Ebd., 9 .

39 Lifton (ebd., 190) erklärt allerdings, dass Proteismus grundsätzlich gegen Gewalt eingestellt sei, dem die Superhelden ja widersprechen, bzw. für Lifton wäre Gewalt ein Indiz dafür, dass das protean self 〈schiefgegangen $>$ ist. 


\section{Peter Parker - Spider-Man: «Odd Combinations»}

Was das Wesen eines bestimmten Superhelden ausmacht, wird idealerweise bereits in der Origin-Story umrissen. Nicht anders ist dies bei Spider-Man. Im Gegensatz zu anderen Superhelden, bei welchen der Erhalt fantastischer Kräfte unverzüglich die Heldentätigkeit auslöst (und die Kostümergreifung der letzte Schritt dazu ist), ${ }^{\circ}$ zieht sich Spideys Entstehungsgeschichte nach dem Spinnenbiss über mehrere Stationen hin.. ${ }^{41}$ Als Peter nämlich bemerkt, dass er plötzlich die proportionalen Kräfte einer Spinne besitzt, ist Heldentum nicht sein erster Gedanke: «I-I've got to have time to think! I've got to

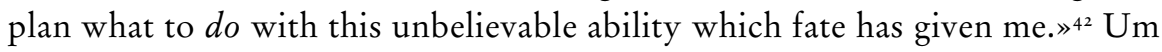
seine Kräfte zu testen, steigt er mit der Aussicht auf hundert Dollar Gewinn in den Boxring, wobei er aus Angst vor einer Blamage sein Gesicht maskiert. Nach seinem Sieg erhält er ein Angebot von einem TV-Produzenten. Erst jetzt designt er flugs Kostüm, erfindet Netzflüssigkeit und Webshooter und startet eine Showkarriere. Als Waise, die bei Tante und Onkel aufwächst und von Gleichaltrigen als Bücherwurm verspottet wird, liegt ihm der Gedanke des Dienstes an der Gesellschaft noch fern. ${ }^{43}$ So lässt Peter nach einem Auftritt einen Dieb entkommen, der nur wenige Tage später seinen geliebten Onkel Ben erschiesst. Obwohl Spider-Man den Täter fasst, zeigen ihn die letzten beiden Panels der Origin-Story keineswegs als siegreichen Helden: Vielmehr fühlt sich Peter schuldig, ${ }^{44}$ und die Erzählstimme formuliert sein seither berühmtes (und später oft Ben in den Mund gelegtes) Credo: «[...] in this world, with great power there must also come - great responsibility!»45 Ausser in der Verfolgung des Diebes tritt Spider-Man in seiner ersten Geschichte also überhaupt nicht in einer Heldenrolle auf. Bereits durch diesen Anfang trägt Spider-Man/ Peter Parker deutlich Züge des protean self: «Greatly contributing to the odd combinations and transformations of the protean self are certain vicissitudes having to do with loss or absence, as well as with perceived threat. The first category includes feelings of fatherlessness, homelessness, and the absence of

40 Dies ist für einige der im Golden-Age-Kapitel erwähnten Superhelden der Fall oder etwa auch für die Golden- und Silver-Age-Versionen von The Flash (Jay Garrick und Barry Allen) und The Green Lantern (Alan Scott und Hal Jordan).

4I Spider-Man! (Stan Lee, Steve Ditko et al.), in: Amazing Fantasy i 5 , August 1962. Zu SpiderMans Origin-Story vgl. z. B. Fingeroth 2008, 73-77.

42 Spider-Man! (Stan Lee, Steve Ditko et al.), in: Amazing Fantasy is, August 1962, 4.

43 So denkt er einmal (ebd., 8): «They're the only ones who've ever been kind to me! I'll see to it that they're always happy, but the rest of the world can go hang for all I care.»

44 Eine Interpretation von Peters frühen Abenteuern als Traumabewältigung bietet Helvie 20 I 2.

45 Spider-Man! (Stan Lee, Steve Ditko et al.), in: Amazing Fantasy i 5 , August I962, I I. 
clear mentorship - feelings that can be painful but are at the same time necessary to the protean self.» ${ }^{6}$ Tatsächlich stellt Onkel Bens Tod - und nicht der Spinnenbiss - das eigentliche Schlüsselereignis für Spider-Mans Heldentum dar. Passend führt Lifton weiter aus: «These vicissitudes can lead into confusion, and certainly to restlessness and flux. Yet they also provide strong motivation, and a certain content, of the self's quest for form.»47 Dies trifft auf ein Superheldenleben mit ständigen Kostümwechseln und herausfordernden Begegnungen mit Superschurken fraglos zu.

Lifton beschreibt mehrere patterns of the survivor, auf die das protean self ebenfalls zurückgreift ${ }^{4}{ }^{8}$ und $\mathrm{zu}$ welchen Spider-Mans Geschichte Entsprechungen bietet. Nach Lifton bemühen sich survivors oft, ihrer Existenz eine Bedeutung $\mathrm{zu}$ verleihen, «a sense of inner form that can give significance to one's survivor experience and to the reminder of one's life. One may seek meaning in a mission to combat the forces that gave rise to the disaster one has survived [...].»49 $\mathrm{Im}$ Fall von Spider-Man erfüllt dies klar die typische Heldendevise: Unschuldige schützen, Verbrecher bekämpfen. Ein weiteres dieser Verhaltensmuster besteht darin, das Erlebte als Gelegenheit, etwas zu lernen, einzustufen. ${ }^{50}$ Spider-Mans Credo kann man gewiss als «Lektion fürs Leben bezeichnen, obwohl Lifton hier in erster Linie an eine «anxiety, and also experienced as a form of knowledges of death that informs a commitment to life enhancement» dachte..$^{51}$ Offensichtlich stellt die Spider-Man-Identität eine Form von «life enhancement» für Peter Parker dar.

$\mathrm{Zu}$ den survivor patterns zählt eine weitere Eigenschaft, die fest zu SpiderMan gehört. Lifton beschreibt dies als eine simple Genugtuung bzw. Freude, am Leben zu sein (im Bewusstsein, eine durch ihren Schmerz erhellende Erfahrung überstanden zu haben). ${ }^{22}$ Bei Spider-Man/Peter Parker äussert sich eine vergleichbare Emotion immer wieder in seiner Freude an der puren Bewegung, wie sie in zahlreichen Momenten, in welchen er sich durch die Stadt schwingt, inszeniert wird (Abb. 34). Um nur ein Beispiel zu nennen, frohlockt er einmal: «Ah! This is the life! Being Spider-Man may not always be a bed of roses - but as

46 Lifton 1993, 74. - Mit dem ebenfalls gewaltsamen Tod von Captain Stacy, dem Vater seiner ersten grossen Liebe Gwen, wird sich der Verlust von Mentorfiguren für Spider-Man weiter fortsetzen ( $A S M$ 90, 1970).

47 Lifton 1993, 74.

48 Ebd., 8I: «Death and renewal - the self as survivor - is, for proteanism, both metaphor and psychological principle.»

49 Ebd., 82.

50 Ebd., 8I.

5 I Ebd.

52 Ebd., 82. 
long as I can leap and swing and unwind like this - I'll always have a warm spot in my heart for that little ol' radioactive spider who put the bite on me, and gave me these crazy powers!» 3 Denn auch Spider-Man wird durch seine Fähigkeiten ein grösserer Entfaltungsraum zugänglich.

Freilich gibt es für diese Freude bei Spider-Man noch eine andere Erklärung, die ebenso zutreffend ist: Der Spass am Heldsein ist auch die ungebrochene Freude eines Teenagers am Sich-Austoben in der Bewegung und im Kampfgeplänkel, wie Fingeroth darlegt, der Spider-Mans berühmten Witz mit dem auch von zahlreichen Widrigkeiten des Lebens unverbrämbaren jugendlichen Optimismus und der Tendenz, Schwierigkeiten wegzulachen, verbindet. ${ }^{54}$

Fingeroth hält fest, dass die Entstehung von Spider-Man auch im Kontext der Jugendkultur zu sehen ist, die sich ja erst in der Nachkriegszeit entwickelte nicht zuletzt, weil Jugendliche - mit mehr Freizeit als Erwachsene, aber schon etwas Verdienst - als eine eigene Konsumentengruppe erkannt wurden.5 Dies wirft die Frage auf, ob nicht das protean self möglicherweise bemerkenswerte Parallelen zu einem möglichen adoleszenten Selbst aufweist. Lifton bezieht Teenager zwar nicht in seine Untersuchung ein, betont jedoch, dass das protean self sich dadurch auszeichne, dass es grosse Änderungen nicht auf die Jugendzeit beschränke, sondern sich auch in fortgeschrittenem Alter noch weiterentwickeln und wandeln könne. ${ }^{6}{ }^{6} \mathrm{Umso}$ mehr, da in den letzten Jahrzehnten in verschiedenen Bereichen eine Hinwendung zu Jugendlichkeit (zuweilen wohl nicht zu Unrecht als Jugendwahn gescholten) zu beobachten ist, wäre zu überlegen, inwiefern Teenager als Verkörperung einer Lebensphase, in der noch alles im Fluss scheint, als eine Art Ideal für die «neuen〉 Erwachsenen dienen. In Bezug auf Spider-Man ist allerdings anzumerken, dass er zwar zu Beginn seiner Karriere ein Teenager war, insgesamt aber länger als (junger) Erwachsener dargestellt wurde (und zwar bis zum Reboot von 2007, der ihn mit ASM 546 wieder ins Jugendalter zurückversetzte und das Bisherige ungeschehen machte).

Peter Parkers Vorliebe, die Geschehnisse mit Humor und Ironie, insbesondere auch Selbstironie, zu kommentieren, ${ }^{57}$ lässt sich jedenfalls ebenso mit dem protean self verbinden. Spider-Man gilt als einer der witzigsten Superhelden - sein loses Mundwerk begleitet nahezu jeden Kampf. Ist er aber in Zweiflerstimmung, erhält dies einen bitteren Unterton. Lifton erklärt den Sinn des protean self für

53 Caught in the Act ... (Roger Stern, John Romita, jr., Jim Mooney et al.), in: ASM 23 I, August I 982.

54 Fingeroth 2008, I 5 I.

55 Ebd., I42-145.

56 Peltz 2008, 725.

57 Vgl. Kniep 2009, 225 f., zu Spider-Mans Frotzeleien. 
Abb. 34: Spider-Mans Freude an der schwungvollen Bewegung schlägt auch mit ironischem Unterton und mitten im Kampf gegen Elektro durch - typisch ist dabei die Darstellung der Bewegung als Entsprechung zur fotografischen Mehrfachbelichtung. The Chump, The Challenge And The Champion (Tom DeFalco, Steve Skroce, Bud LaRosa et al.), in: The Amazing Spider-Man 425, August 1997, 33. (C) Marvel Comics
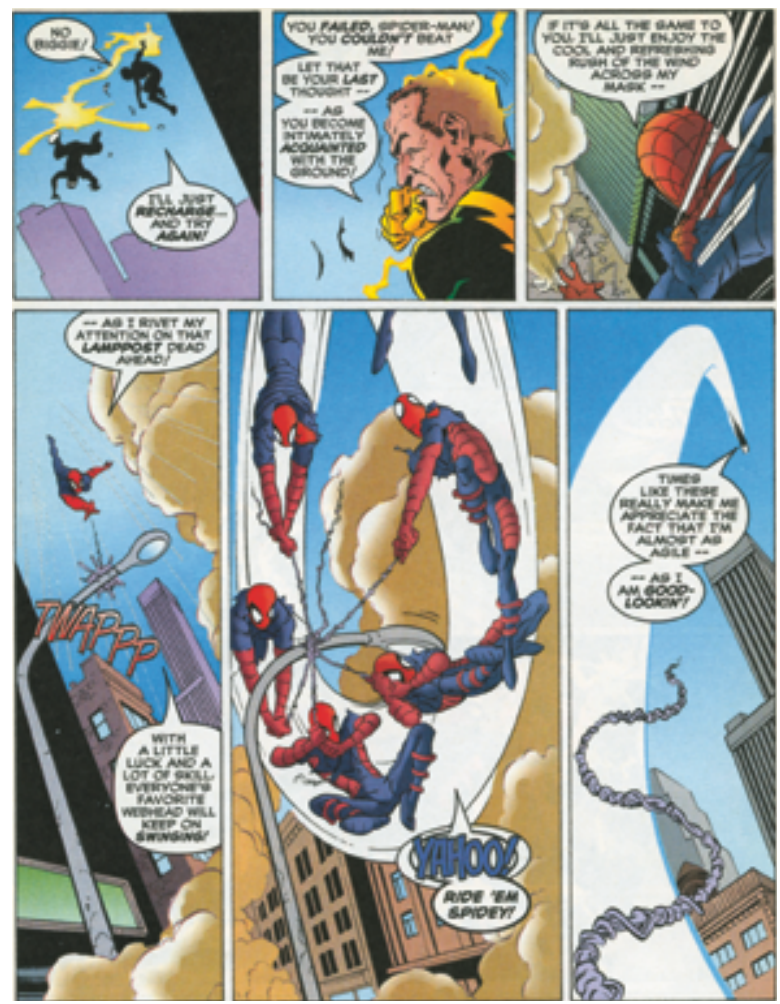

Absurditäten damit, dass die Welt als disharmonisch und das Ich und die Aussenwelt als inkongruent empfunden würden. ${ }^{8}$

Dazu hat Peter Parker denn auch nicht wenig Grund, lässt sich sein Leben doch als eine Ansammlung von "odd combinations» in Liftons Sinne verstehen. (Im Grunde lässt sich die Doppelidentität per se als Absurdität bezeichnen.) Peter Parker hat dabei ein vergleichsweise umfangreiches soziales Umfeld (bei anderen Helden beschränkt sich dieses oft auf deutlich weniger Charaktere, die regelmässig auftreten), in dem seine zivile und seine heldische Identität in den seltens-

58 Lifton I993, 94. Lifton (ebd., 98) spekuliert weiter, dass Absurdität untrennbar mit Gestaltwandel im Allgemeinen verbunden sein könnte, denn der Sinn für Absurditäten befähige das protean self, verschiedene Dinge auf einmal auszudrücken, etwa Bitterkeit und Zorn zugleich mit Zuneigung. 
ten Fällen gleich bewertet werden, 59 was die Grundlage für zahlreiche Spielereien mit der Doppelidentität und /If they only knews-Momente bildet. In der Familie, beim Arbeitgeber, in der Schule bzw. an der Universität sowie in seiner Kollegenclique ergibt sich für Peter ein klares Spannungsfeld zwischen seinen beiden Identitäten: Tante May hält diesen Spider-Man für eine fürchterliche Figur, während sie sich um das Wohlergehen ihres vermeintlich zarten Neffen sorgt, der im nämlichen Moment im Spinnenkostüm Kopf und Kragen riskiert (Abb. 35). Am anderen Ende der Skala steht Peters Schulkollege Flash Thompson, der «puny Parker», den Streber, nur zu gern piesakt, aber leidenschaftlicher Spider-Man-Fan ist. ${ }^{60}$

Zudem gerät Spider-Man in Verruf, da der Chef der Zeitung Daily Bugle, J. Jonah Jameson, diesen in seinen Editorials verunglimpft. ${ }^{11} \mathrm{Um}$ doch noch als Spider-Man etwas dazuzuverdienen, beginnt Peter, Jameson Fotos von SpiderMan in Aktion zu verkaufen. Jameson, Personifizierung medialer Sensationslust, erhält so subtil die Quittung - die gesuchte Sensation befände sich vor seiner Nase. ${ }^{62}$ Ironischerweise ist es nicht selten Jamesons Verlangen nach sensationellen Bildern, das Peter, der notorisch unter Geldnot leidet, dazu treibt, als SpiderMan auf der Suche nach Action durch New York zu schwingen. ${ }^{63}$

Der Kontrast zwischen Spider-Man und Peter Parker entfaltet sich dabei wie erwähnt in mehreren widersprüchlichen Kombinationen, die Peter Parkers/Spider-Mans Leben prägen - und das protean self charakterisieren: «The essence of the protean self lies in its odd combinations. There is a linking - often loose but functional - of identity elements and subselves not ordinarily associated with

59 Ausnahmen sind etwa der Redaktor Joe Robertson und später der Journalist Ben Urich vom Daily Bugle oder Gwens Vater Captain Stacy, die sowohl Peter als auch Spider-Man wohlwollend gegenüberstehen.

60 Zum Manövrieren in diesen unterschiedlichen sozialen Gewässern muss der Protagonist auch immer wieder Stellung zu seinem Alter ego beziehen, wobei er sich je nach Situation anders verhält: Einmal wettert er über sein jeweiliges anderes Ich, ein andermal verteidigt er dessen Handeln.

6I Eine herausragende Analyse von Jamesons widersprüchlichem Charakter in ASM I-Ioo vor dem Hintergrund der Zensur - die sich in seiner Figur als narrative Opposition für Spider-Man/ Peter Parker ausdrückt - präsentiert Drucker 20I 2, eine ausführliche Charakterbeschreibung bietet zudem Smith 20I 2a.

62 «Of course, if he knew Spider-Man was snapping all these crime photos for him, and not Peter Parker - old jolly Jonah would simply explode!», amüsiert sich der proteische Held im Geheimen (The Punisher Strikes Twice! (Gerry Conway Ross Andru et al.), in: ASM I 29, Februar 1974, 3), wobei der Witz in der Einheit der Identitäten besteht.

$63 \mathrm{Zu} \mathrm{New} \mathrm{York} \mathrm{als} \mathrm{stets} \mathrm{<unfertiger} \mathrm{und} \mathrm{damit} \mathrm{Spider-Mans/Peter} \mathrm{Parkers} \mathrm{Identitätszustände}$ spiegelnder Stadt vgl. Flanagan 20 I 2 (zu New York als Schauplatz etwa auch Bainbridge 2010 und Meißner 2009). 


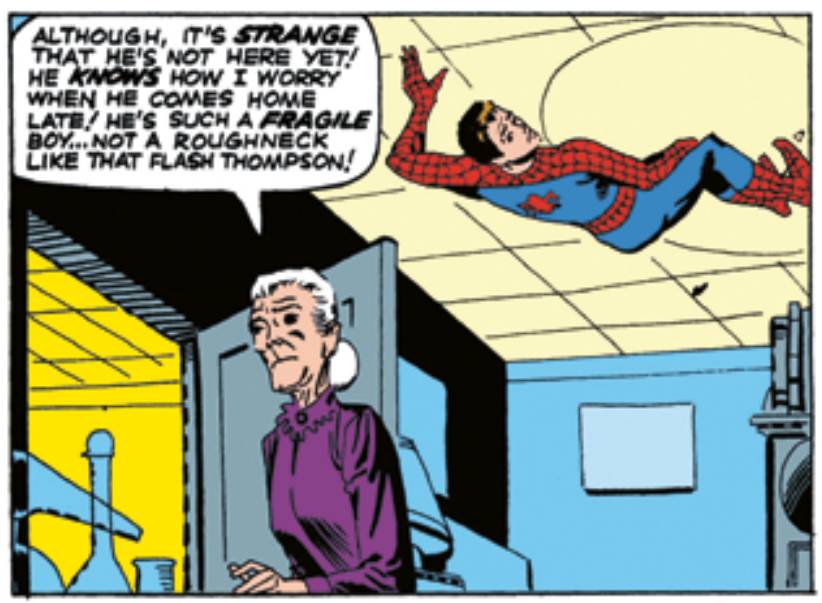

Abb. 35: Tante May sorgt sich stets um ihren vermeintlich fragilen Neffen, ohne zu ahnen, dass dieser einer der stärksten Marvel-Superhelden ist - dieses frühe Panel bringt Peters Spiel mit dem Feuer bzw. mit der Gefahr, dass seine Tante ihn erkennen könnte, visuell auf den Punkt. The Return of The Vulture (Stan Lee, Steve Ditko et al.), in: The Amazing Spider-Man 7, Dezember I963, Iо. (C) Marvel Comics

one another to the point of even seeming [...] (mutually irreconcilables.» ${ }^{64}$ Die Fähigkeit, widersprüchliche Kombinationen zu verkörpern, sieht denn auch Fingeroth als herausragendste Eigenschaft von Spider-Man: «But the thing that makes Parker so modern - and so human - is not merely the combination of emotions that spur him on, and hence his multiple motivations, but that he, despite being an iconic figure featured on pajamas [...], is like all of us, capable of encompassing contradictions. ${ }^{65}$

Peter unterliegt allerdings auch ohne seine Spider-Man-Identität konträren Wahrnehmungen: Während er in der Schule von den Gleichaltrigen als fader Streber abgestempelt wird, macht ihn gerade diese Eigenschaft für seine Tante wie seine Lehrer zu einem vorbildlichen Jugendlichen. ${ }^{66}$ Hinzu kommt, dass Bens Tod für Peter und seine betagte Tante May eine erhöhte soziale Unsicherheit bedeutet, da ein regelmässiger Verdienst fehlt. Bei Peter und May kommt es darum nach Fingeroth zu

64 Lifton $1993,50$.

65 Fingeroth 2008, 75 .

66 Obwohl er ein hervorragender Schüler ist, schafft er es dank seinen Spidey-Eskapaden immer wieder, Prüfungstermine zu verpassen, und muss so etwa seine BA-Studienzeit zweimal verlängern. 
einem Rollentausch: Da sie ständig krank ist, ist es der Jugendliche, der sich um die Erwachsene kümmern muss statt umgekehrt. ${ }^{67}$ Auch als Zeitungsfotograf erschliessen sich ihm zum Teil Handlungsräume, die ihm als Superheld oder «Peter Parker, college student» ${ }^{68}$, wie es etwa in $A S M$ I 19 (1973) heisst (als er dank der Zeitung eine Reise Richtung Norden und Hulk machen kann), nicht zugänglich wären.

Als Spider-Man aufzutreten, bedeutet für Peter die Möglichkeit, der Hackordnung in Schule und Job sowie privaten Sorgen (weil etwa May krank ist, das Geld fehlt oder er Streit mit der jeweiligen Freundin hat) zu entkommen. ${ }^{69}$ Trotzdem hat er auch als Spider-Man ein Kreuz zu tragen: eine wankelmütige und oft genug missgünstige öffentliche Meinung, als deren Sprachrohr Jameson erscheint. So wettert dieser in ASM 50 im Fernsehen:

Some misguided fools call him a super-hero! But, why does he operate outside the law? Why does he cloak his identity behind that ugly fright mask?!! Let me tell you why ... Because he's really an egomaniac ... a neurotic trouble-maker, flaunting his power before the ordinary citizens whom he despises! For all we know, he bimself provokes the criminals whom he later seems to defeat! Do we want our youngsters to make an idol of a mentally-disturbed menace??70

In seinem Gezeter spricht der cholerische Jameson einige zentrale Aspekte der Maske, wie die Schreckfunktion, an. Sein Unbehagen gründet darauf, dass die Maske Uneindeutigkeit schafft - es könnte irgendwer darunter (oder dahinter) stecken. Wer seine Identität verbirgt, so Jameson, kann nichts Gutes im Sinn haben und deshalb nur eine Bedrohung sein, ${ }^{71}$ geschweige denn die heldische Funktion eines Vorbilds für die Jugend erfüllen. Wenn er Spider-Man vorwirft, ein Egomane bzw. unheldenhaft zu sein, beruht dies auf der Annahme, dass Spider-Man, da er eine Maske trägt, etwas anderes sein muss, als was er scheint bzw. scheinen

67 Fingeroth 2008, 77. Tante May ist anfangs fast als greise gezeichnet. Obwohl sie oft krank und ängstlich ist, zeichnet sich ihre Figur durch eine bemerkenswerte Zähigkeit aus. Im Lauf der Jahre wird May sichtlich verjüngt und erhält eine etwas robustere Gesundheit, was nicht ausschliesst, dass sie mehrfach (oft durch die Aktionen von Superschurken) in Lebensgefahr gerät. Zu den Entwicklungen von Tante May über die Jahre vgl. McWilliams 20 I 2.

68 The Gentleman's Name Is Hulk! (John Romita, Gerry Conway et al.), in: ASM i i9, April I $973,9$.

69 Für Spider-Man hat die Heldenidentität oft explizit eine Eskapismusfunktion, wenn er etwa findet, dass er nach langem Lernen oder bei übermächtig scheinenden Problemen den Kopf durch Netzschwingen lüften muss - allerdings kann auch das Gegenteil eintreten, dass er froh ist, sich in seine zivile Identität zurückziehen zu können.

70 «Spider-Man No More!» (Stan Lee, Johnny [sic] Romita et al.), in: ASM 50, Juli I967, 6.

7I Bemerkenswerterweise nimmt wenig später Spider-Man selbst auf diese Konnotation Bezug, als er nach einem Kampf eine Amnesie hat und bemerkt, dass er eine Maske trägt: «Can it be that I'm some sort of scientist? But, if so ... why the mask ... why the secret identity? No! I've got to accept one fact ... I must be a criminal!» («Disaster!» (Stan Lee, John Romita et al.), in: $A S M$ 56, Januar 1968, 3). 
Abb. 36: Wenn Peter Parker in seiner zivilen Identität als Spider-Man denkt, zeigt die Spider-Man-spezifische Darstellung mittels einer halben Maske über dem Gesicht die Einheit seiner beiden Identitäten an. «Marked for Destruction by Dr. Doom!» (Stan Lee, Steve Ditko et al.), in: The Amazing Spider-Man S, Oktober 1963, 2. () Marvel Comics

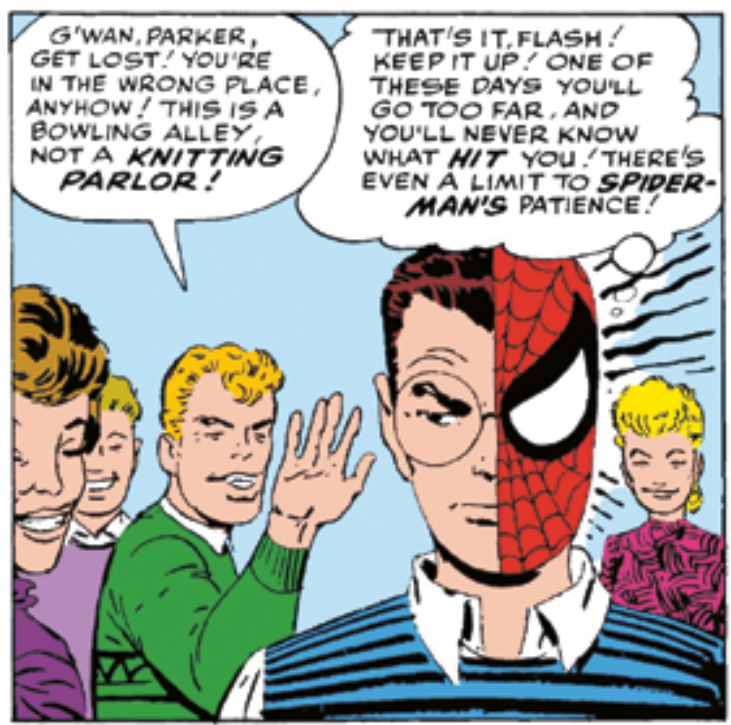

will, womit die Konnotation der Maske als Gegensatz zu Authentizität aufgerufen wird (vgl. die Ausführungen im Kapitel zu Maskerade und Geheimnis)..$^{72}$ SpiderMan gilt wie erwähnt unter den populärsten Superhelden als jener, dessen ‘wahre` Identität trotz Superkräften und Kostüm Peter Parker bleibt, bei welchem also die ¿Umkehr der Maske nicht spielt. ${ }^{73}$ Allerdings kommt Peters ziviler Identität in gewissen Aspekten nichtsdestotrotz eine Rollenhaftigkeit zu, wenn er etwa seine Kräfte nicht zeigen darf. Gerade in den frühen Jahren bedauert es Peter mehrmals, sich nicht mit Flash prügeln zu können, da der Kampf unfair wäre (Abb. 36).

Obwohl Peter mit der Doppelidentität seine Lebensbereiche als Held und Zivilperson trennen möchte - unter anderem ist ein wichtiger Grund für das Geheimnis, dass Peter denkt, seine Spider-Man-Existenz würde Tante May das Herz brechen (zum Beispiel ASM 8I, I970) -, verschränken sich diese Bereiche immer wieder miteinander. Wenn zum Beispiel May den netten Dr. Otto Octavius heiraten will, ohne zu ahnen, dass es sich dabei um den Superschurken Dr. Octo-

72 Als selten gefeierter Held, sondern meist von der Polizei gejagter und vom Daily Bugle als öffentliche Bedrohung inszenierter Maskierter übernimmt Spidey das Pulp-Setting des Helden als vermeintlichen Verbrechers (wobei dies von den Pulp-Protagonisten gewollt war).

73 Auch bei Spider-Man schwankt der Gebrauch von Formulierungen wie strues oder <real identity', diese meinen manchmal Peter Parker, manchmal Spider-Man. 
pus, kurz «Doc Ock», handelt (ASM I 30, 1974) oder wenn der entflohene Geier/ Adrian Toomes inkognito im Altersheim mit Tante May und ihren Freunden zufällig am Tisch sitzt (ASM 224, I982), macht das die Rollentrennung doch schwierig.

Diesbezüglich ist es vielleicht kein Zufall, dass es für Spider-Man eine besondere Darstellungsweise gibt, um die Gleichzeitigkeit von Held und Privatperson darzustellen. Bei den meisten anderen Helden erfüllen diese Aufgabe gängigerweise indirekte> Abbildungsweisen wie Schatten oder Spiegelbild; bei SpiderMan wird dies mit einer halben Spider-Man-Maske, die seine eine Gesichtshälfte bedeckt, visuell deutlich markiert (auch Abb. 36). Diese Darstellungsweise verdeutlicht: Die Maske zeigt das Heldentum an, macht es aber nicht aus.

Peter Parkers Leben ist dabei von Wechselfällen geprägt: Nicht nur wird May immer wieder ernsthaft krank; er wechselt auch vielfach die Wohnung (während etwa Batman maximal von Wayne Castle ins Penthouse seines Firmengebäudes und zurück zieht), lebt allein, mit einer Freundin oder in einer WG, zeitweise mausarm und zeitweise bei reichen Wohnpartnern. Ebenso ergattert er im Lauf der Zeit diverse Arbeitsstellen im Wissenschaftsbereich, die er oft allzu schnell wieder verliert oder freiwillig aufgibt; auch beim Daily Bugle wird er mehrfach gefeuert und wieder eingestellt. ${ }^{74}$ Sein Lebensstil entspricht also durchaus jenem des protean self, obwohl Peter diese Veränderungen nicht immer freiwillig erlebt. Bevor er Mary Jane Watson heiratet, hat er auch immer wieder mal eine neue Freundin. Schon vor Gwen Stacy gab es seinen Schulschwarm Liz und eine längere Beziehung mit Betty Brant, Jamesons Sekretärin (die ebenfalls beide uneingeweiht blieben); später kam es unter anderem zu einer Romanze mit der Meisterdiebin Black Cat/Felicia Hardy, die wohl als einzige seiner Freundinnen spezifisch in Spider-Man verliebt war, während sie von seiner zivilen Existenz wenig angetan war.75 Diese drei blieben wiederkehrende Charaktere, während andere nie in die Story zurückfanden. Die

$74 \mathrm{Zu}$ den sozialen Auf- und Abstiegen von Peter und Mary Jane vgl. DiPaolo 20 I r.

75 Während Peters Freundinnen sonst keine Spider-Man-Fans sind, steht Felicias Einstellung im genauen Gegensatz dazu, wie besonders deutlich wird, als sie den von einem Kampf erschöpften Spider-Man in Peters kleine Wohnung bringt und denkt: «What a dump! I still can't believe my spider really lives here in his civilian identity! Guess I just don't understand spider. Why would he ever want to be a normal person like Peter Parker, when he could be Spider-Man all the time? I love him. I do! But now that he's taken off his mask, I can hardly bear to look at him ...» («Beware the Claws of Puma!» (Tom DeFalco, Ron Frenz, Josef Rubinstein et al.), in: $A S M \quad 257$, Oktober 1984, 7). Tatsächlich verlässt sie die Wohnung, weil sie es darin nicht aushält - doch wartet vor Peters Tür nach längerer Abwesenheit schon Mary Jane, deren Geständnis, dass sie um Peters Heldenidentität weiss, nochmals verschoben wird, da der Puma angreift. Die Beziehung zu Black Cat scheint danach mehr oder weniger im Sand zu verlaufen, sie werden aber einige Zeit später gute Freunde. 
Erzählweise der Superheldencomics, bei welcher Nebenfiguren immer wieder mal eine Zeitlang aus der Narration verschwinden (sozusagen auf Eis gelegt werden), entspricht zudem in gewisser Weise der Ausschnitthaftigkeit (post-) moderner Lebensweisen.

\section{Krisen, Bestätigung, Balance}

Spider-Mans (Doppel-)Identität wird, wenig erstaunlich, gerade dann ein Thema, wenn sie in die Krise gerät. Sie kann von aussen - wenn ein Schurke das Geheimnis entdeckt oder zu entdecken droht - oder von innen - wenn der Protagonist sein Heldentum oder seine Doppelidentität aufgeben will - gefährdet sein. Nur schon aus Gründen der Serialität kommt nicht infrage, dass der Protagonist sein Heldentum aufgäbe. Dennoch kreisen gerade Spider-Mans Krisen regelmässig um diese Frage. Für die typischen Erzählachsen der Doppelidentität gibt es grob zwei Ebenen: Die eine sind kurze Gefahrenmomente und kleine lustige Szenen, wenn beispielsweise der Journalist Foswell Peter Parker in eine Gasse folgt, in der nur noch Spider-Man aufzufinden ist und dieser im Halbdunkel ein Gespräch mit seinem Alter Ego improvisieren muss, um sein Geheimnis zu wahren ( $A S M$ 46, I967), oder wenn Flash Thompson zur Erkenntnis kommt: «Parker's all right, I guess ... though he's never gonna be a Spider-Man!» ${ }^{6}$ Die andere Ebene umfasst Motive, in denen die Doppelidentität den Protagonisten in ein länger währendes Dilemma stürzt - inbesondere für Liebesbeziehungen sind geheime Doppelidentäten Herausforderungen. ${ }^{77}$ Diese führen dazu, dass Peter/Spider-Man regelmässig mit seinem Schicksal bzw. seiner auch selbst gewählten Heldenrolle hadert und seine Maske sogar mit einiger Regelmässigkeit an den Nagel hängen will. Dies wird - gerade in den Jubiläumsnummern 50 und ı०० - als prominentes Thema inszeniert («Spider-Man No More!» verkündet etwa das Titelblatt von $A S M$ 50, 1967), obschon wie gesagt a priori klar ist, dass es nie dazu kommen wird (der Reiz der Erzählung liegt dann auch darin, wie es kommt, dass der Held seine Rolle doch beibehält).

Das Erzählmuster von Spider-Mans Doppelidentität lässt sich dabei im hier betrachteten Zeitraum als ewiger Kreislauf von Krise und Bestätigung verstehen, wobei die Selbstzweifel oft über längere Zeit aufgebaut werden, bis es

76 Spidey Cops Out! (John Romita, Gerry Conway et al.), in: ASM i I 2 (1972), 22.

77 Peters Doppelidentität ist so bereits der Trennungsgrund von seiner ersten Freundin Betty Brant, obwohl sie nichts von dieser weiss - von jenem bekannten Panel illustriert (Abb. 3), in welchem ein transparent gezeichneter Spider-Man Peter und Betty auseinanderhält ( The Claws of the Cat!» (Stan Lee, Steve Ditko et al.), in: ASM 30, November 1965, 20). 
wieder zum Umschwung kommt. Wie konstant die Doppelidentität bei Spider-Man ein Thema ist, möchte ich nun mit einem auf diesen Aspekt fokussierten groben Handlungsüberblick, vor allem über die miteinander verzahnten Gwen- und Green-Goblin-Storylines, illustrieren. Anzumerken ist, dass es sich dabei um teilweise recht lange Handlungslinien handelt, während derer der Held noch zahlreiche weitere kurze und lange Abenteuer erlebt.

Zweifel an sich und der Welt begleiten Peter von Beginn weg; nicht umsonst gilt er als einer der grossen Zweifler unter den Superhelden..$^{8}$ Diese Eigenschaft teilt er mit dem protean self: «Doubt is both mother and child of proteanism and can be a valued trait.» ${ }^{79}$ Ein langer Reigen von Selbstzweifeln beginnt, als er sich bei einem Kampf den Arm bricht und sehr darauf bedacht ist, dass niemand merkt, dass Peter Parker und Spider-Man gleichzeitig den Arm in der Schlinge haben $(A S M$ 45, 1967). Es ärgert ihn, dass er wegen seiner Spidey-Tätigkeiten keine Zeit mehr für anderes hat: Er kommt nicht zum Lernen, muss Dates sausen lassen, fühlt sich schuldig, sobald May ihn etwas fragt, und muss wegen Spider-Man auf einen Job bei Norman Osborn, dem Vater seines besten Freundes Harry, verzichten. So rauft er sich einmal mehr die Haare: «hy do I do it? Why do I continue risking my life ... causing a thousand unnecessary problems ... a thousand heartaches and sleepless nights? Have I an insane lust for power ... a need to feel more important than those around me? Or is it something deeper ... more frightening? Has Spider-Man become so much a part of me that I can never lose him again? ${ }^{80}$ Hierbei handelt es sich um eine typische Peter-Parker-/Spider-ManSzene, in welcher er einerseits den Sinn seiner Heldentätigkeit anzweifelt und andererseits seine Motivation kritisch hinterfragt, wobei wie hier oft die Frage anklingt, wie ein Held zu sein hat. Zudem lässt sich hier ebenso die diffuse Angst herauslesen, dass die Maske, einmal aufgesetzt, sich nicht mehr abnehmen lässt. Doch dessen nicht genug, ein Heft später ( $A S M$ 46, 1967), als er sich eigentlich freuen könnte, dass es mit einer eigenen Wohnung respektive einer WG mit Harry geklappt hat, weicht diese Freude einem bestimmten Verdacht:

I've finally gotten what I wanted ... [...] So why this letdown feeling? Why this mood of depression that I can't seem to shake? Is it just a natural feeling of homesickness? Or, is it something deeper? On that fateful day ... when I became Spider-Man ...

78 Ditschke/Anhut 2009, I53.

79 Lifton I993, 107.

80 Während sich Spider-Man hier die Daseinsberechtigung streitig macht, sind im Bild dagegen Curt Connors alias The Lizard und dessen Familie Spider-Man für Curts Rettung dankbar und denken, dass er so stark und eigenständig sei, dass er bestimmt wunschlos glücklich sei («Spidey Smashes Out!»(Stan Lee, John Romita et al.), in: ASM 45, Februar 1967, 20). 
perhaps more than a physical change was wrought ... Perhaps, in some strange, mysterious way ... when I gained another identity ... I lost the capacity ... for happiness! $!^{81}$

Die (selbst gewählte) Heldenidentität mehr als Fluch statt Segen zu sehen und als Quelle allen persönlichen Unglücks zu verdächtigen, wäre den GoldenAge-Helden nie eingefallen. Wie hier Peter Parker, bleibt laut Lifton auch dem proteischen Selbst oft unklar, warum es welche Gefühle hegt. ${ }^{82}$ Daher bemüht es sich stetig, namentlich Emotionen wie Ängste, Ärger, Selbstverurteilungen und Verlust $\mathrm{zu}$ lokalisieren»: «But all of these emotions tend readily to emerge into amorphous forms of anxiety.» ${ }^{8_{3}}$ Die Unsicherheit im Interpretieren der eigenen Gefühle wird von Spider-Man über die Jahre immer wieder explizit reflektiert ${ }^{84}$ (wobei das Fragen nach der Identität, der eigenen Beschaffenheit und Bedeutung wohl durchaus auch damit verbunden werden könnte, dass Peter Parker in den Anfangsjahren ein Teenager ist). In seinen Überlegungen kommt er denn auch nicht immer zu den gleichen Schlüssen, wie Fingeroth festhält: «Peter has many reasons to be Spider-Man, each of which he believes to be the most important, depending on the context and on his mood.» ${ }^{85}$

In Heft 50 dann scheint die Last des heimlichen Heldentums für Peter ein nicht mehr tragbares Mass angenommen zu haben: Weil er als Spider-Man unterwegs war, war er nicht zur Stelle, als Tante May notfallmässig ins Spital musste, auch für eine Party bei Gwen Stacy hat er keine Zeit. So hat er das Gefühl, wegen seiner Spider-Man-Taten die wichtigen Momente des Lebens zu verpassen. Als schliesslich auch noch Jameson eine Anti-Spider-Man-Kampagne im Fernsehen startet (die oben bereits zitiert wurde), wirft Peter sein Kostüm entnervt in den Abfall (Abb. 37a). Anschliessend fühlt er sich wie befreit - selbst als er im Radio von einem Überfall hört, bleibt er standhaft ¿Zivilist`. Allerdings haben die Men-

8 I «The Sinister Shocker!» (Stan Lee, John Romita et al.), in: ASM 46, März I967, 20.

82 Lifton I993, 99.

83 Ebd., I०I. «Anxiety» definiert Lifton als «a sense of foreboding stemming from a threat to the vitality of the self or, more severely, from the anticipation of fragmentation of the self». (Laut Lifton ist «anxiety» dabei stets Teil anderer Gefühle wie Schuld.) Passenderweise wird die Zeit des Kalten Krieges zuweilen als «Age of Anxiety» bezeichnet, so vermerkt etwa Packer $(2010,5)$, dass in den frühen 1960er-Jahren das Medikament Librium (offenbar ein Vorläufer von Valium) zugelassen wurde, was sie im Zusammenhang mit dem Sputnik-Schock und der Angst vor nuklearer Auslöschung als «antidote for the Age of Anxiety» bezeichnet.

84 Als Beispiel eine Stelle aus ASM I 39 (Day of the Grizzly! (Gerry Conway, Ross Andru et al.), Dezember 1974, 27): «[...] I haven't had time to think - and considering the kind of thoughts I've been having lately, that's a blessing. Maybe that's the reason I became Spider-Man ... and why I've remained Spider-Man all these years. It's a way to get involved in problems that aren't my own - and it's always easier to solve a mystery - than to understand your own beart.»

85 Fingeroth 2008, 75. 
schen in seinem Leben nicht auf ihn gewartet - jetzt, wo er Zeit hätte, hat niemand Zeit für ihn. Es kommt, wie es kommen muss: Als er Hilfeschreie hört und realisiert, dass er der Einzige ist, der helfen kann, besinnt er sich auf sein Heldentum. So deklariert er zum Schluss der Story:

Now, at last ... it's all crystal clear to me once more! I can never renounce my SpiderMan identity! I can never fail to use the powers which a mysterious destiny has seen fit to give me! No matter how unbearable the burden may be ... no matter how great my personal sacrifice ... I can never permit one innocent being to come to harm ... because Spider-Man failed to act ... And I swear that I never will!

Während er dazu tendiert, in Zweifelsmomenten zwischen seiner Peter- und seiner Spidey-Hälfte zu unterscheiden, fallen diese hier im letzten «I never will» zusammen. Die Stelle bedeutet zugleich eine Bestätigung von Peters Heldentum, da er das Wohl anderer über sein eigenes stellt.

Die Dilemmata der Doppelidentität spielen eine zentrale Rolle in der Beziehung zu Gwen Stacy, die nacheinander beide stereotypen Haltungen der nicht eingeweihten Freundin, die beiden Identitätshälften fundamental verschieden zu bewerten, aufweist: Als sie nach einem Missverständnis glaubt, Peter hätte ihren Vater angegriffen, will sie ihn nie mehr sehen, hegt jedoch neue Sympathien für Spider-Man, als der sie und ihren Vater kurz darauf aus Gaunerhand errettet. Peter fasst den Kontrast zusammen: «Gorgeous Gwendolyn still thinks Peter Parker betrayed her Dad ... [...]. Life sure is funny ...! She thinks Spidey's a prince for saving her ... But I'd rather she hated the Webslinger and still had a yen for poor Petey. $\gg^{87}$ Einige Zeit später wird genau sein Wunsch erfüllt, doch wird Peters Dilemma in Bezug auf Gwen damit nur umgekehrt und nicht gelöst. Doch zunächst versöhnen sich die beiden, aber ohne dass Peter sie in sein Geheimnis einweihen würde. So kann es in ASM 87 («Unmasked At Last!», I970) zu einer «klassischen` Doppelidentitätsepisode kommen: Aufgrund einer Grippe hat Peter ein so vernebeltes Gehirn, dass er glaubt, seine Kräfte zu verlieren. Um reinen Tisch zu machen, geht er mit der Maske in der Hand zu Gwen, verkündet, dass er Spider-Man ist und lässt die Anwesenden ratlos zurück. Wenig später wird aber klar, dass bloss die Grippe seine Kräfte geschwächt hat, sodass er sein Geständnis zurücknehmen will. Dies gelingt auch, indem sein Freund Hobie Brown alias The Prowler vor Gwen als Spider-Man auftritt, für den Peter nur die Kleider aufgehoben haben soll.

Eine erste tragische Wendung nimmt Peters und Gwens Geschichte mit dem Tod von Captain Stacy während eines Kampfes zwischen Spider-Man und Doc 

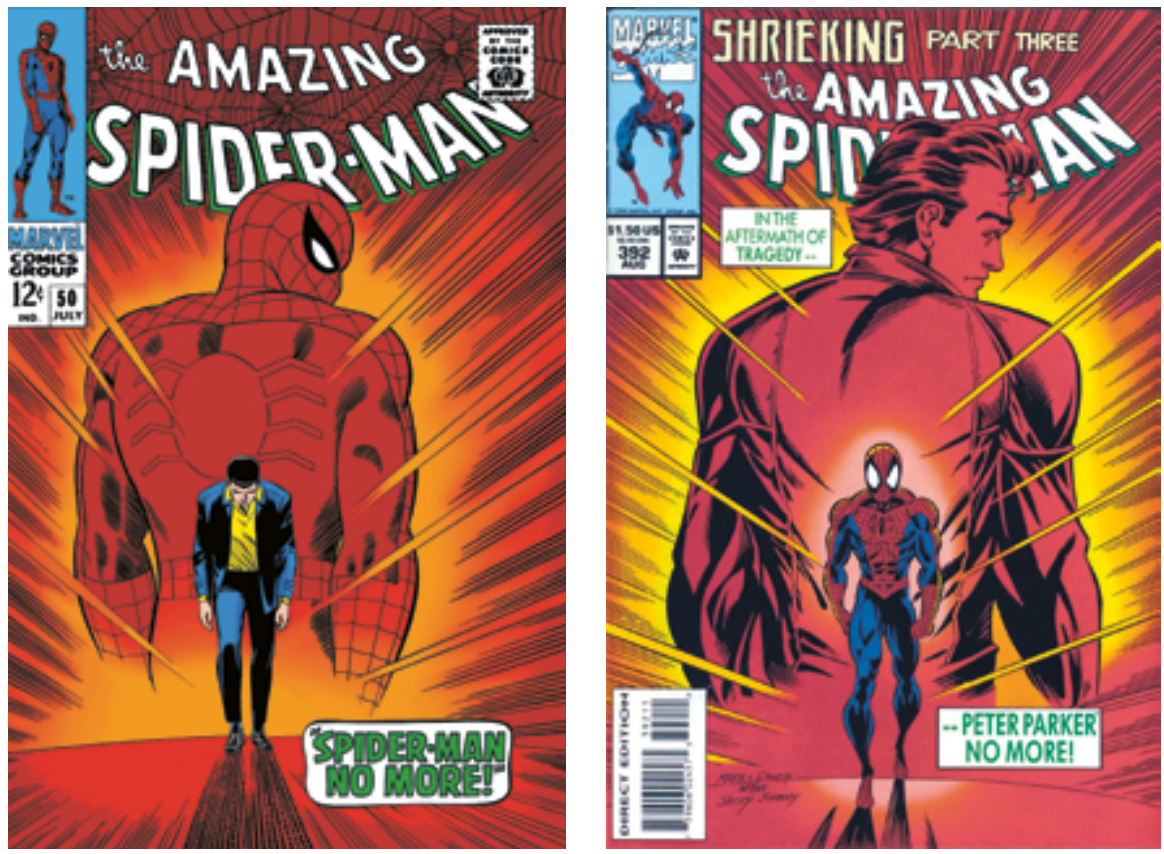

Abb. $37 \mathrm{a}$ und 37b: Spider-Mans Identitätskrise wird in The Amazing Spider-Man 50 gross auf dem Titelblatt angekündigt. Das Cover wird Jahre später in The Amazing Spider-Man 392 inhaltlich umgedreht. «Spider-Man No More!» (Stan Lee, John Romita et al.), Juli i967, und Shrieking, Part Three: The Cocoon (J. M. DeMatteis, Mark Bagley, Randy Emberlin et al.), August i994. () Marvel Comics

Ock. ${ }^{88}$ Wie zu erwarten, gibt Gwen Spider-Man die Schuld am Tod ihres Vaters und hasst ihn fortan innig. Nun kann Peter ihr sein Geheimnis erst recht nicht offenbaren, weil er fürchtet, sie sonst endgültig zu verlieren. Zur Trauer über Captain Stacys Tod kommt ein verzwickter innerer Konflikt, den er nicht lösen, sondern nur aushalten kann: «How can I ever again look at her - touch her - without being tortured by pangs of guilt? Because, deep in my heart I'll always wonder - if not for Spider-Man, wouldn't Capt. Stacy still be alive? And yet - knowing that I was Spider-Man - his dying wish was that I look after Gwen

88 Stacy rettet einen kleinen Jungen vor herunterfallenden Trümmern, wird jedoch selbst von ihnen getroffen. Spider-Man erreicht ihn gerade noch in letzter Minute, damit dieser ihm Gwens Wohlergehen ans Herz legen und nebenbei offenbaren kann, dass er die ganze Zeit wusste, wer hinter der Maske steckt ( $A S M$ 90, 1970). 
[...].» ${ }^{89}$ Angesichts solcher Probleme - ergänzt durch die schlechte Presse - ist es verständlich, wenn Peter sich erneut fragt, ob er wirklich zu den Guten gehöre, und das Gefühl hat, seine Welt zerbreche. ${ }^{\circ}$ In gewisser Weise spielen hier in Peters/Spider-Mans Leben jene drei Faktoren, die Lifton als Grundlage für die Entwicklung des protean self als eines historischen Phänomens sieht, auf einer persönlichen Ebene ebenfalls eine zentrale Rolle (Umwälzung/Mentorverlust, massenmediale Kampagne, Weltuntergangsangst). In ASM 93 (1971) kommt es schliesslich zur Trennung. Obwohl sie einander lieben, zieht Gwen nach London, da Peter sie aus Rücksicht auf sein Spider-Man-Dasein nicht ums Bleiben bitten will, was sie als mangelnde Liebe auslegt, da sie seine Gründe ja nicht kennt. Dies ist eine typische Szene für das «stille Leiden〉 des maskierten Helden, der zugunsten seiner Heldenpflicht auf sein privates Glück verzichtet, ohne dass aber irgendjemand, vor allem nicht die betroffene Person, von seinem Opfer weiss. Erneut verflucht Peter seine Heldenidentität - und dennoch ist ihm bewusst, dass er diese nicht aufgeben kann bzw. will: $\mathrm{Zu}$ sehr liebt er die Spannung und Aufregung und die Flucht vor den Alltagsproblemen, die ihm das Kostüm ermöglicht (Abb. 38).

Dass Gwen damit zeitweilig aus der Geschichte verschwindet, bedeutet für den Protagonisten mitnichten eine Verschnaufpause: Der Superschurke Green Goblin offenbart ihm, dass er sein Geheimnis kennt ( $A S M$ 96/97, 197I). Der Green Goblin ist Norman Osborn, pikanterweise der Vater von Peters bestem Freund und Mitbewohner Harry. Allerdings beruht sein Schurkentum auf Wahnsinn; im zurechnungsfähigen Zustand erinnert er sich nicht an seine Übeltaten. Auch diesmal hat Peter Parker/Spider-Man Glück, dass Osborn seine Sinne wieder zusammenbekommt, als er seinen Sohn Harry von Drogen gezeichnet auffindet. Damit ist die Gefahr der Entlarvung für den Moment gebannt - rechtzeitig für Gwens Rückkehr. In der darauffolgenden I००. Ausgabe überlegt Peter erneut, dass er Spider-Man sterben lassen müsste - doch als er aus einem Fiebertraum erwacht, stellt er mit Entsetzen fest, dass er sechs Arme hat. Ironischerweise wird er in dieser Story gerade dann zur achtbeinigen Spinne, als

89 To Smash The Spider! (Stan Lee, Gil Kane, John Romita et al.), in: ASM 91, Dezember 1970, 3. Gwen will sogar ins Wahlkampfteam eines Politikers, der mit einer Anti-Spider-Man-Kampagne Wählerstimmen gewinnen will.

90 So hadert er mit sich: «[...] have I spent a lifetime kidding myself? How do I know I'm not that bad? The whole city fears me! The law is bunting for me! And even Gwen hates me! What does it take to show me where it's at? - to show me - Spider-Man's had it? All of a sudden ... it's like my whole world is busting up all around me!» (To Smash The Spider! (Stan Lee, Gil Kane, John Romita et al.), in: $A S M$ 91, Dezember i970, i r.) 


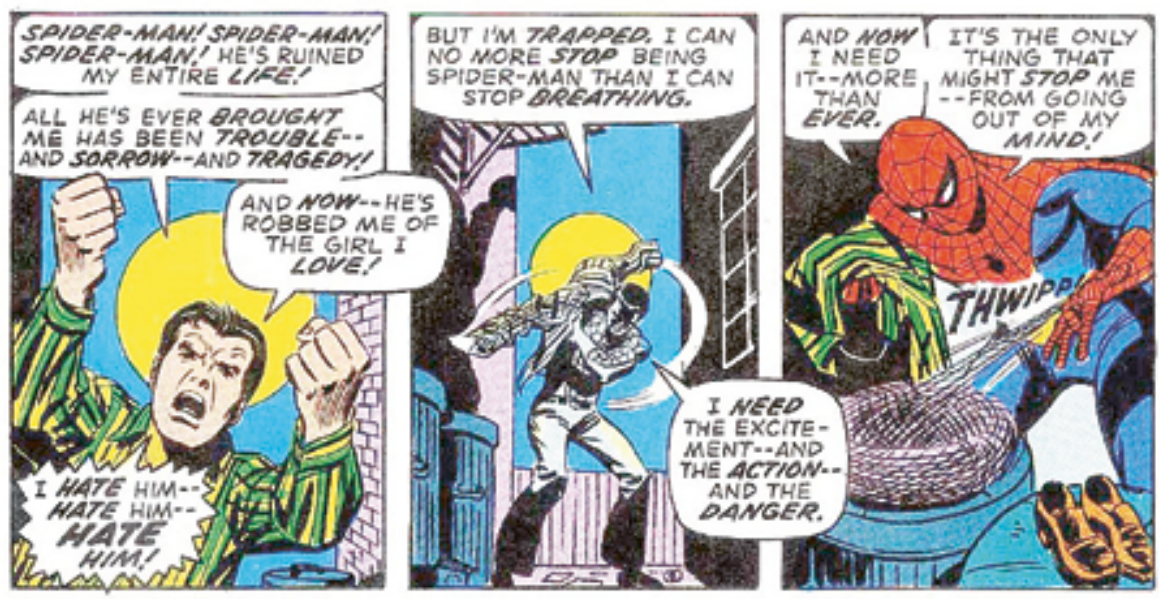

Abb. 38: Nolens volens kann Peter Parker nicht mehr auf seine heldische Identität verzichten - der Kleiderwechsel neben Mülltonnen lässt dabei einige bekannte Szenen assoziieren, in welchen Peter sein Kostüm dem Abfall übergibt, weil er sein Heldentum wieder einmal leid ist. The Lady and - the Prowler! (Stan Lee, John Romita et al.), in: The Amazing Spider-Man 93, Februar I97 I, 4. (C) Marvel Comics

er seine 〈Spinnenhälfte` aufgeben will (selbstverständlich ist dieser Zustand nur temporär).

Nach einigen weiteren Abenteuern ${ }^{91}$ kommt es 1973 in $A S M$ I 2 I zur zweiten grossen Tragödie nach Bens Tod in der Spider-Man-Story und einem der berühmtesten Spider-Man-Momente: Der Green Goblin entführt Gwen und droht Spider-Man, sie umzubringen, wenn er sich nicht selbst tötet - die Kontrahenten kämpfen, bis der Goblin die bewusstlose Gwen von der Brooklyn Bridge stösst. Spider-Man kann ihren Fall mithilfe zweier Netzstränge aufhalten. Er freut sich schon, sie gerettet zu haben, doch vergebens: Gwen ist tot. Damit wiederholt sich ein vergleichbares Szenario für Schuldgefühle wie bei Bens Ermordung. Lifton nennt als eines der survivor-Verhaltensmuster auch «death guilt», das Schuldgefühl, einerseits überlebt zu haben und andererseits vielleicht bei Ret-

9I In einer kleinen Zwischenepisode versucht der Spider-Smasher, die «true identity» von Spider-Man mit heimlich versteckten Kameras herauszufinden. Spidey kommt ihm jedoch auf die Schliche und kann ihm ein Schnippchen schlagen, indem er über seiner Maske eine Gummimaske mit Peters Gesichtzügen trägt und diese dann medienwirksam ablegt - mit diesem «Maske-über-Maske»Spiel sind auch die weiteren verbrecherischen Pläne vereitelt ( $A S M$ I05/106, 1972). 
tungs- oder Kampfaktionen nicht alles ideal oder nicht ideal genug gemacht zu haben.92 Als die Polizei eintrifft, kniet der fassungslose Spider-Man vor Gwens Leiche und erklärt: «She’s dead. And Spider-Man killed her.»93 Dass er von «Spider-Man» in der dritten Person spricht, verdeutlicht, dass hier nicht Spider-Man als Person, sondern als <Lebensweise> gemeint ist, wie er reflektiert: «Gwen: As much a victim of Spider-Man's lifestyle as Peter Parker. Didn't his spectre keep them apart -? Wasn't it Spider-Man who stood between them and happiness 'till, in the end, he stood between Gwen and life?»94 Es lässt sich sagen, dass Ben starb, weil Spider-Man nichts getan hat, während Gwen stirbt, weil Spider-Man sich zum heldischen Handeln entschlossen hat. Interessanterweise verschwendet er in dieser Situation keinen Gedanken daran, das Heldsein aufzugeben. Zunächst treibt ihn zwar Rache an, am Ende von $A S M$ I 22 (1973) aber stirbt der Goblin nicht durch Spider-Mans Hand, sondern wird von seinem eigenen Gleiter durchbohrt.

Mit dem Tod der uneingeweihten Geliebten und des wissenden Feindes sind Peter Parkers Prüfungen freilich nicht abgeschlossen. Denn nun hält Harry Spider-Man für den Mörder seines Vaters (dessen Leiche ohne das Goblin-Kostüm gefunden wurde); eine Meinung, die Peter natürlich nicht vertreten kann. Da die beiden zusammen wohnen, findet Harry nun prompt einen Beweis, dass sein bester Freund Spider-Man ist; die Beziehung der Freunde ist vergiftet. Kurzzeitig wird Harry zum (neuen) Green Goblin. Nach einem Zweikampf ohne Kostüme stehen die beiden in $A S M$ I 37 (1974) vor einigen Polizisten, und Harry sagt, dass Peter Spider-Man sei. Peter sieht schon alles verloren, doch nimmt es für ihn eine glimpfliche Wendung, denn als Harry seiner Behauptung damit Nachdruck verleihen will, dass er selbst der Green Goblin sei, glauben ihm die Polizisten nicht, da er zu jung ist, um der Goblin zu sein, der schon seit Jahren herumfliegt. Die Unidentifizierbarkeit eines maskierten Gegners erweist sich so für einmal als Vorteil für den Protagonisten.

Zwischendurch gibt es für Peter Parker an seiner Heldenrolle gar nichts zu zweifeln: In der Jubiläumsnummer 200 wird die Origin-Story wieder aufgegriffen, indem Spider-Man Bens Mörder nochmals einfangen muss. Auch hier erfolgt eine Identitätsbestätigung, wenn der Held im Epilog resümiert: «At last I realize I'm the luckiest guy in this whole, wide, wonderful world! Most people

92 Lifton 1993, 82. Das von Lifton death guilt benannte Phänomen dürfte unter der Bezeichnung survivor's guilt bzw. Überlebensschuld-Syndrom bekannter sein.

93 The Goblin's Last Stand! (Gerry Conway, Gil Kane et al.), in: ASM r 22, Juli 1973, I0. Auch visuell steht in diesem Panel erneut Spider-Man trennend zwischen Gwen und Peter (und Peters sozialem Umfeld).

94 Ebd. 
wish they could help their fellow man, but this ol' web-swinger has the power to do it!»9s Peters schwankendes Selbstwertgefühl beschreibt wiederum Fingeroth treffend: «Peter alternately - sometimes even simultaneously - feels like he's ten feet tall and two inches high. ${ }^{96}$

Peters Doppelidentität erfährt eine bedeutsame Veränderung, als Mary Jane Watson nach längerer Abwesenheit (und ausgeschlagenem Heiratsantrag) zurückkehrt und ihm eröffnet, das sie sein Geheimnis seit Jahren kennt (wie sie es herausgefunden hat, wird übrigens nicht erwähnt, $A S M$ 257-259, 1984). Nun hat Peter endlich eine Vertrauensperson und damit eine Helferin. So besteht zwar eine neue Gefahr, dass nämlich Mary Jane unter Zwang seine Identität verraten könnte, wobei sie sehr bald beweist, dass sie das nicht tut. Mit einer eingeweihten Person lässt sich jeweils ein Teil der Argumentation pro und kontra Heldsein an sie auslagern. Mary Jane wäre es zwar lieber, wenn Peter nicht Spider-Man wäre, aber sie versteht auch, was ihn antreibt. Sie nimmt denn auch keine einheitliche Position in dieser Frage ein. Dies zeigt sich etwa in ASM 275 (1986), als Peter den Heldenbettel wieder einmal hinwerfen will - unter anderem, weil der Verlobte von Tante May, Nathan Lubenski, verprügelt wurde, was er hätte verhindern können, wenn er an jenem Abend nicht von zwei anderen Schurken abgelenkt worden wäre. Dabei kommt es zu folgendem Dialog:

Mary Jane: I think you're making a big mistake!

Peter: $\quad$ You kidding?! You've always hated the idea of me being Spider-Man! Why the change of heart?

Mary Jane: I ... don't know. It's just that I don't think you're being fair ... to yourself ... or anyone else! You've done a lot of good as the web-swinger, saved a lot of lives! Surely, you can see that!

Peter: $\quad$ Nobody else cares! Why should I?

Mary Jane: Because you can make a difference! You have some pretty amazing powers, Peter. You owe it to yourself to use them! You owe it to the world to use them properly!97

Mary Jane argumentiert hier - in anderen Worten - mit Spider-Mans Credo von aus Kraft folgender Verantwortung. Selbstverständlich ist es kurz darauf unabdingbar, dass Peter erneut als Spider-Man loszieht - und vom Hobgoblin demaskiert wird, dem er allerdings die Sichtfenster des Helms mit Netz verkleben kann, bevor dieser sein Gesicht sieht. Im Anschluss ist nun Mary Jane der Ansicht, dass er sich das nicht nochmal antun solle. Doch Peter/Spider-Man kann

95 The Spider and the Burglar ... A Sequel (Marv Wolfman, Keith Pollard et al.), in: ASM 200, Januar $1980,47$.

96 Fingeroth 2008, 77.

97 "The Choice and the Challenge» (Tom DeFalco, Ron Frenz, Josef Rubinstein et al.), in: ASM 275, April 1986. 
sich seiner Pflicht doch nicht entziehen (Abb. 39): «This is personal! [...] I just know that I've got to put my own life on hold until I've beaten the Hobgoblin! [...] I just can't run away from my responsibilities. I can't change the way I am! And, for now, I've got to be Spider-Man!» ${ }^{98}$ Auch diese Priorisierung einer Identitätsseite lässt sich mit dem Proteismus verbinden: Selbstelemente und die damit zusammenhängenden Emotionen zu priorisieren, ist für Lifton ein Bestandteil der integrativen Funktion (eben das Zusammenhalten disparater Aspekte des Selbst), die das protean self auszeichnet.99

Die zentrale Fähigkeit des protean self, Widersprüche zu vereinen, ist keine absolute; die erreichte Kohärenz ist eher prekär (tenuous). ${ }^{100}$ Trotzdem (oder gerade deswegen) sucht das protean self stets ein gewisses Gleichgewicht (poise) oder eine Balance, um in der Welt zu funktionieren - das Wort poise verweist dabei sowohl auf eine innere Ausgeglichenheit als auch auf eine gedankliche Haltung. Nach Lifton zeugt diese Haltung weniger von Stabilität als solcher, sondern vielmehr von Anpassungsfähigkeit und Manövriervermögen in einer von divergenten Umständen gekennzeichneten Welt. Interessanterweise erwähnt Lifton hier auch eine «continuous improvisation in social and occupational arrangements» ${ }^{\text {Ior }}$ - ständige Improvisation ist das Fundament sowohl von Spider-Mans Wirken als auch von Peters Job als Actionfotograf. Denn es ist nicht zu vergessen: Trotz aller Momente des Haderns und Grübelns ist SpiderMan ein Actionheld, das heisst, er stürzt sich jederzeit mit vollem Einsatz, nicht selten geradezu Hals über Kopf, in die heldische Aktion. Abgesehen von seiner Liebe zu May und Mary Jane sind bezeichnenderweise jene Bereiche seines Lebens, denen Unbeständigkeit eingeschrieben ist, nämlich Spider-Man und der Job beim Daily Bugle, für ihn die beständigsten.

Bezüglich Balance interessant ist ASM 290, in dem Spider-Man zu Beginn des Heftes (nach einer neuerlichen überstandenen Krise) geradezu euphorisch ist und ihm dennoch etwas fehlt:

I'm happy, blast it! Happy! Happy! Happy! [...] I mean, after all the years of resenting my double life, of swearing to give up my costume and be plain ol' Peter ParkerI've finally accepted myself as Spider-Man! I should be content! So why do I feel like I'm being pulled in more directions than a balloon in a hurricane? I feel hollow ...

98 Unmasked! (Tom DeFalco, Ron Frenz, Brett Breeding et al.), in: ASM 276, Mai 1986. Nachdem Spider-Man den Hobgoblin besiegt hat, freut er sich schon auf seinen «Ruhestand`, doch gibt es eine unvorhergesehene Wendung: Unter der Maske steckt Flash Thompson, der nun für die Untaten des Hobgoblins angeklagt wird. Spider-Man wird also noch gebraucht, um Flashs Unschuld zu beweisen.

99 Lifton $1993,87$.

100 Ebd., 93 .

IOI Ebd. 


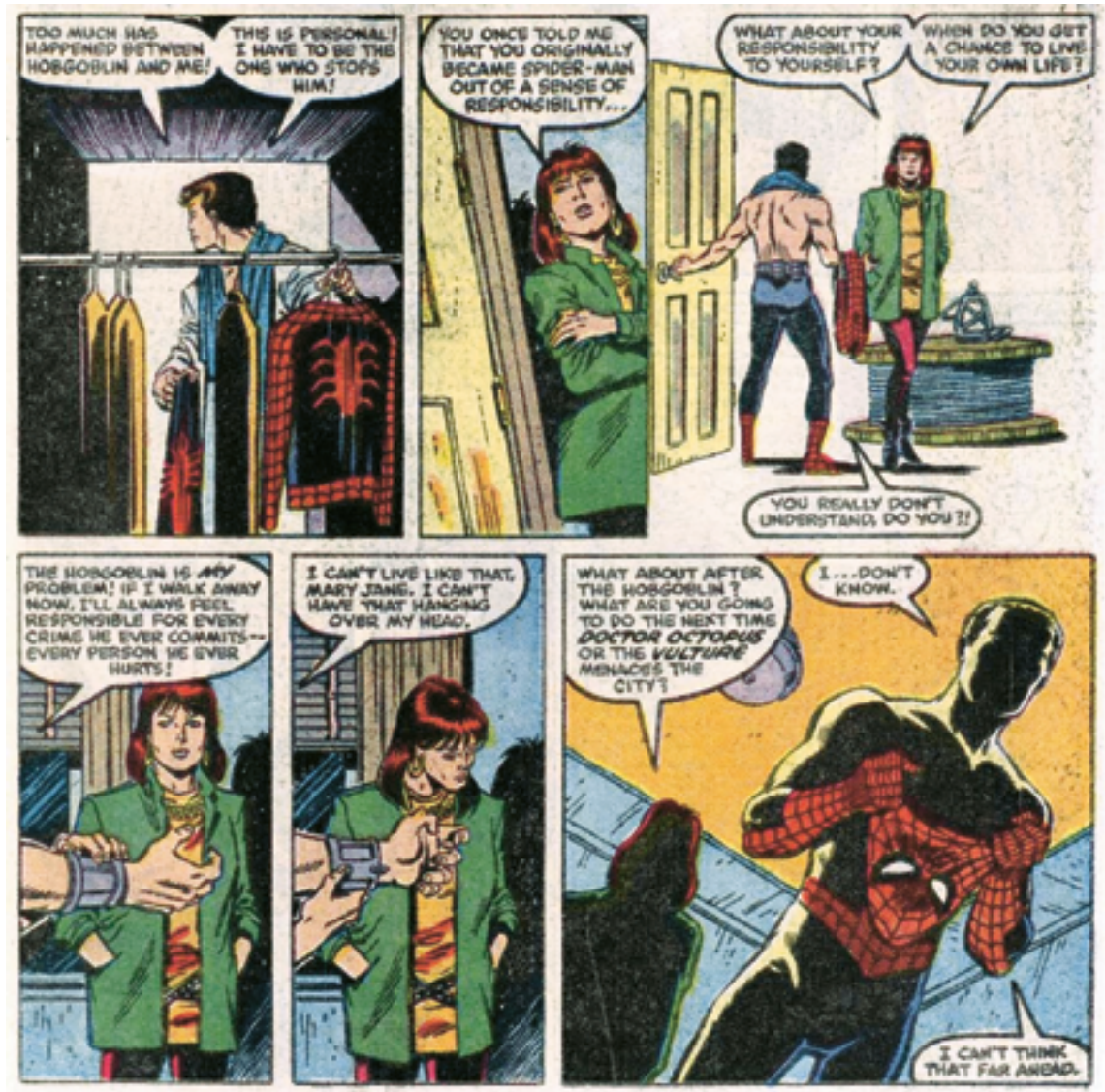

Abb. 39: Peters Pflichtgefühl, als Spider-Man weitere Verbrechen zu verhindern, erweist sich einmal mehr stärker als jede Vorsicht - entsprechend ist die Maske im letzten Panel im Licht dargestellt, während Peters Gesicht im Schatten bleibt. Unmasked! (Tom DeFalco, Ron Frenz, Brett Breeding et al.), in: The Amazing Spider-Man 276, Mai 1986. (C) Marvel Comics

incomplete... and that doesn't make sense! There's still something missing in my lifebut what? What could - uh-oh! Spider-sense tingling! [...]. ${ }^{102}$

Interessanterweise erinnert Spider-Mans Beschreibung von sich als einem dem Spiel der Winde ausgelieferten Ballon an jene postmodernen Identitätskonzepte, die Identität nur mehr als Kreuzungspunkt verschiedener Strömungen verste-

I02 The Big Question (David Michelinie, John Romita, jr., Vince Colletta et al.), in: ASM 290, Juli 1987. 
hen (und die Existenz eines Selbst bestreiten). ${ }^{103}$ Dies wird jedoch nicht weiter ausgeführt. In seinem alten Zimmer in Mays Haus dämmert Peter, dass er einen Teil seiner Identität vernachlässigt hat: «I loved science [as a boy]. Still do. But somehow I've let that part of myself slip away. I've been too busy being SpiderMan [...]. And until now - I never realized how much I've missed it.» ${ }^{104}$ Als Symbol für diese Erkenntnis ersteigert er an einer Schulhausauktion sein altes Mikroskop zurück und resümiert:

This microscope may not mean much to anyone else, but to me, it's the symbol of what I - Peter Parker - always wanted. And I think that's the key to why I've been feeling so uneasy these days! I've spent so much energy accepting the fact that I'm Spider-Man that I've actually been denying that I'm Peter Parker! And that's affected my relationships, my lifestyle, everything about me! It's time I realized that SpiderMan is only a part of what I am! It's time to put Peter Parker first, to do what's right for $m e$ ! To do things that, maybe, I should have done years ago. It's time to start my new life ....' Ios $^{\text {10 }}$

Im Prinzip argumentiert Peter hier genau gleich wie in den zahlreichen Fällen, wo er auf seine Heldenidentität verzichten wollte. Nun aber geht es nicht mehr um ein Entweder-oder, sondern um ein Gleichgewicht zwischen verschiedenen Teilen. Über die Station des Wissenschaftlers erkennt Peter, dass es um eine Balance seiner Identitäten geht - nicht nur von ziviler und heldischer, sondern von allen Seiten seiner Persönlichkeit. Um eine solche zu gewährleisten, macht er schliesslich Mary Jane einen Heiratsantrag, den sie nach einer kurzen Retardation annimmt.

Wie Lifton erläutert, sucht das proteische Selbst «mitten im ganzen Fliessen» dennoch lange, haltende Beziehungen zu anderen. ${ }^{106}$ Eine solche Beziehung findet Peter mit Mary Jane Watson, die er 1988 heiratet; trotz einiger Krisen bleibt das Paar bis zum Reboot von 2007 verliebt und zusammen. ${ }^{107}$ Indem Mary Jane das Heldentum ihres Mannes zwar nicht wirklich billigt, dieses aber (meistens) akzeptiert und ihn trotzdem liebt, lässt sich auch bei ihr ein Element des protean self wiederfinden, welches Lifton als «Leben mit Nuancen» beschreibt: «I think that people in general live with nuance; they accept some principles of their religion and reject others - they see the people they love as having flaws and yet they

I03 Elliott 2007, 8, Fludernik 2007, 260.

I04 The Big Question (David Michelinie, John Romita, jr., Vince Colletta et al.), in: ASM 290, Juli I987.

Ios Ebd.

I06 Lifton I993, I 20.

I07 Zur Beziehung von Mary Jane und Peter vgl. Weiner 2012, I66-170, sowie DiPaolo 201 I, 92-II4. 
continue loving them. So, there are nuances and contradictions that people live with, and at times I think we underestimate our capacity for them.» ${ }^{108}$ Mit der Eheschliessung sind die Doppelidentitätsprobleme für Spider-Man jedoch nicht passé. ${ }^{\circ 9}$ Tatsächlich geschieht es sogar, dass er seine zivile Identität aufgeben will - auf dem Cover der entsprechenden Story wird (in Umkehrung von ASM 50) verkündet: «Peter Parker No More!» ${ }^{110}$ (Abb. 37b). Unter anderem aus dem seelischen Gleichgewicht, weil sich seine vermeintlich zurückgekehrten Eltern als Roboter entpuppt haben, verrennt er sich in die Idee, als Peter nur Schmerz und Gefahr zu erleiden und zu verursachen und nur noch «die Maske» sein zu wollen. Auch dies geht mit einem survivor-Verhaltensmuster konform; Lifton spricht hier von "psychic numbing, or diminished capacity to feel» ${ }^{111}$. Zwar fühlt Peter hier wohl eher zu viel Verzweiflung als zu wenig, nichts zu fühlen wäre aber sein Ziel. Dies geht so weit, dass er sich sogar in einen Kokon aus Netzflüssigkeit einspinnt (ASM 392, 1994). Schliesslich aber bringt ihn die Sorge um Tante May, die erneut im Krankenhaus liegt, ‘zurück〉.

Obwohl die Doppelidentität zeitweise gegenüber längeren Plots mit Doppelgängern in Form von Robotern und Klonen - die sich mit anderen Arten von Identitätsfragen verbinden - etwas in den Hintergrund gerät, gibt es auch in den Geschichten, die hier nicht herausgegriffen wurden, zahlreiche weitere Thematisierungen der Doppelidentität. Als letztes Beispiel dafür sei der Story-Arc Identity Crisis von 1998 genannt: Hier schafft sich Spider-Man, auf den wegen einer falschen Beschuldigung gerade ein millionenschweres Kopfgeld ausgesetzt wurde, vier alternative Heldenidentitäten (in zweien davon inszeniert er sich allerdings als wenig gesetzestreuen Charakter). Auch hier steht am Schluss die Rückkehr der <richtigen〉 Heldenidentität. Obwohl insbesondere die eine Identität, «Prodigy», nicht mit Spider-Mans Ruf belastet wäre, verwirft er diese schliesslich doch, denn: «I had a lot of fun being Prodigy. [...] But the truth is, MJ, as Prodigy I'm only play-acting! [...] that's just not me! [...] none

I08 Peltz 2008, 726.

I09 Beispielsweise verliert er in $A S M 340$ (1990) durch einen DNA-Scanner seine Kräfte und will dann gleich ganz auf diese verzichten. Einige Verwicklungen später merkt er erneut, dass er doch nicht ohne diese sein kann: «I can't give up Spider-Man! The powers, the costume, even the name ... yes. But Spider-Man is more than that-he's Peter Parker, and what Peter Parker is inside! And that won't go away! Bottom line: If I don't restore my powers, sooner or later, I'll die doing what I have to do!» (War Garden! (David Michelinie, Erik Larsen, Randy Emberlin et al.), in: $A S M$ 343, Januar 1991, 8).

I Io Shrieking, Part 3: The Cocoon! (J. M. DeMatteis, Mark Bagley, Randy Emberlin et al.), in: ASM 392, August 1994.

I I I Lifton I993, 82. 
of them would really be me! Like it or not, Spider-Man is who I am! ग $^{12} \mathrm{Ob}-$ wohl hier andere Helden-Identitäten durchaus möglich scheinen, wenn es sein müsste (so behält er denn das Prodigy-Kostüm), ist Spider-Man sozusagen Peters Lieblingsidentität, zu der er zurückkehrt, sobald er keinen Grund mehr hat, nicht Spider-Man zu sein (Abb. 40). Selbst wenn Peter diese Identitätsmöglichkeiten letztlich verwirft, stehen sie dafür, dass er eine Wahl hätte. ${ }^{113}$ Es handelt sich hier um die seltene Variante, dass die Identität nicht durch Zweifel, sondern durch weitere Optionen hinterfragt wird.

Über den hier betrachteten Zeitraum gesehen, erweist sich Spider-Man also auch in Bezug auf seine Identität als ein Stehaufmännchen, wobei sich ein einmal etabliertes Credo stets erneut durchsetzt. Dies passt insofern zum protean self, als Lifton bemerkt: «So, there is a constant struggle, and the proteanism does best when it's buttressed with moral principles.» ${ }^{114}$ Und obschon sein unumstösslicher Sinn für heldische Verantwortung (bzw. die Publikationsbedingungen) Spider-Man langfristig ein Umsatteln verweigert, widerspricht dies dem protean self nicht unbedingt, ist dieses doch «a source of continuity that takes in radical discontinuity ${ }^{115}$.

I 2 Man of the People (Glenn Greenberg, Luke Ross, Al Milgrom et al.), in: The Spectacular SpiderMan/Prodigy 258, Juni 1998, 2 If. Besondere Freude hat Peter in seinen vier neuen Identitäten auch ein Moment gemacht, in dem er als Hornet dem (wiederauferstandenen) Norman Osborn, der Peter hasst und Spider-Man medial falsch beschuldigt hat, die Hand schüttelt, ohne dass dieser ahnt, wer vor ihm steht.

I 3 Dies ist regelmässig ein Thema, wenn sich Peter überlegt, ob er Spider-Man aufgeben soll, z. B. in On Wings of Death! (Stan Lee, John Romita, Sal Buscema et al.), in: ASM 94, März I97 I, 2: «Everything bad that's ever happened to me - all of my life - was because of my secret identity ... - because of - Spider-Man. But, I wasn't born with spider powers - I wasn't born wearing an icky costume ... I don't have to stay this way. Nothing's stopping me from giving it all up.»

I 4 Peltz 2008, $726 f$.

I I) Lifton 1993, 23 I. 

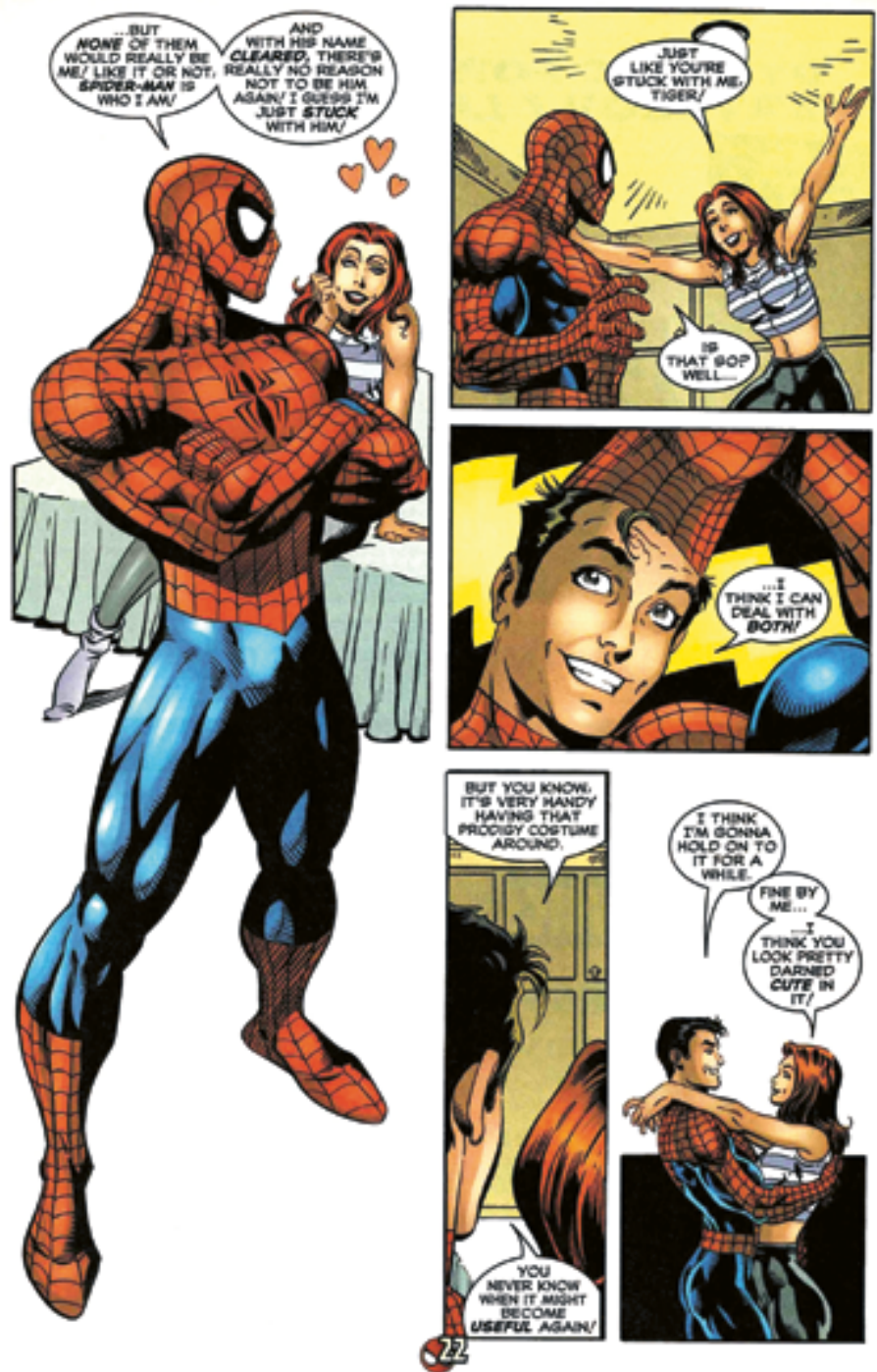

Abb. 40: Nachdem Peter Parker mit Mary Janes Unterstützung vier weitere Heldenidentitäten teilweise sehr erfolgreich ausprobiert hat, will er doch wieder Spider-Man sein und fühlt sich somit in seiner etablierten Doppelidentität bestätigt. Man of the People (Gleen Greenberg, Luke Ross, Al Milgrom et al.), in: The Spectacular SpiderMan 258, Juni I998, 22. 


\title{
Daredevil/Matt Murdock und die stigmatisierten Identitäten
}

\author{
And, after all, what is a lie? 'Tis but the truth in \\ masquerade [...]. \\ Lord George Gordon Byron, Don Juan, I 823
}

Daredevil/Matt Murdock ist vielleicht der einzige Superheld, der nicht in erster Linie für seine besonderen Fähigkeiten bekannt ist, sondern für das, was er nicht kann: Als Blindem ist ihm die Welt des Sehens verwehrt. ${ }^{.}$Sein Charakter entstand 1964 als letzter einer rasch aufeinanderfolgenden Reihe von Superhelden unter dem Motto 〈Held mit Schwäche> aus Stan Lees Feder, mit welchen Marvel zu Beginn der 1960er-Jahre das Silver Age prägte. Die Grundidee findet sich so namentlich in Iron Man/Tony Stark ( $\mathrm{ab}$ 1963 in Tales of Suspense) wieder, dessen Rüstung ihn trotz einer tödlichen Verletzung am Leben erhält, ${ }^{2}$ sowie in Marvels Version des nordischen Donnergottes Thor (ab 1962 in Journey into Mystery), dessen zivile Identität Don Blake ein lahmes Bein hatte und am Stock ging. Da es sich bei Thor nicht um eine maskierte, sondern eine körperlich verwandelte heldische Identität handelte, hatte er als Held keine Behinderung (später legte Thor die Don-Blake-Identität ganz ab). ${ }^{3}$

Matt Murdock dagegen bleibt auch in seiner heldischen Identität blind; seine Superkräfte liegen in seinen ins Übermenschliche gesteigerten restlichen Sinnen, die seine Blindheit mehr als kompensieren. So kann er andere Menschen an ihrem Herzschlag identifizieren oder an diesem hören, ob sie lügen, mit seinen sensiblen Fingerspitzen die Druckerschwärze auf Papier erfühlen, und insbesondere kann er sich mittels einer Art Radarsinn problemlos im Raum orientieren. Den Verlust seines Augenlichts wie den Erhalt seiner Superkräfte verdankt er dabei demselben Ereignis: Noch als Junge wollte er einen blinden Mann auf dem Fussgängerstreifen vor einem heranrollenden Laster retten,

I Schulte 20I2, 340 .

2 Iron Man wäre für dieses Buch gerade in den frühen Jahren ebenfalls ein hochinteressantes Beispiel gewesen, doch da sein Charakter untrennbar mit dem Thema Mensch und Maschine verknüpft ist, hätte dies zu weit geführt. Zudem gibt es zu Iron Man bereits einige lesenswerte Analysen, die auch die Doppelidentität in ihren jeweiligen Fokus einbeziehen, insbesondere Nowotny 2016, aber auch Costello 2009, Reynolds 1994, 26-29, oder Thomas 2009.

3 Zum Umgang mit Behinderung bei Thor (im Gegensatz zu Daredevil) vgl. Alaniz 2012. 
stiess dabei aber selbst mit dem Gefährt zusammen und kam mit dessen radioaktiver Ladung in Kontakt.

Mit diesen Fähigkeiten, die «The Man without Fear» mehr für ein lokales Aufgabengebiet denn für welt- oder allumspannende Heldentaten und den Kampf gegen «kleinere Superschurken qualifizieren, stand Daredevil immer etwas im Windschatten seiner innerhalb des erzählten Universums mächtigeren und extradiegetisch wirtschaftlich erfolgreicheren Marvel-Kollegen, obwohl er von Anfang an eine eigene und bis heute bestehende Heftreihe besass. ${ }^{4}$ Dass Daredevil oft eher als Held aus der zweiten Reihe gilt, impliziert auch die Tatsache, dass die kreativen Teams relativ häufig wechselten. So wurde der erste Daredevil-Zeichner und -Miterfinder Bill Everett bereits im zweiten Heft von Joe Orlando abgelöst, auf den schon in Daredevil s Wally Wood folgte. Dies macht Daredevil zu einer Heftreihe, die künstlerisch - sowohl narrativ wie visuell - vergleichsweise grossen Schwankungen unterworfen ist. So gilt die Daredevil-Reihe (1979I983) unter Autor Frank Miller (*I957) als Vorläuferin für die sogenannte grim and gritty-Phase der Superheldencomics (ab Mitte der I980er-Jahre) und war auch später zuweilen ein von Marvel für künstlerische Experimente auserkorenes Gefäss.'

Im Vergleich zu anderen Superhelden haftet Daredevils/Matt Murdocks Doppelidentität allerdings eine etwas höhere Brisanz an, da sich sein Beruf als Anwalt mit seiner (Selbst-)Berufung als Selbstjustizler offiziell nur schwer vereinen lässt - mit der Entdeckung riskiert Matt im mindesten Fall sein Anwaltspatent und damit seine berufliche Existenz. Dabei bietet eine Anwaltskanzlei auch eine gute Basis, um abseits von kämpferischen Auseinandersetzungen mit Superschurken bzw. deren zivilen Identitäten in Kontakt zu kommen - einige Superschurken lernt Matt Murdock so zunächst als Klienten kennen (wie The Owl/ Leland Owlsley und Stilt-Man/Wilbur Day), bevor er als Daredevil ihr schurkisches Alter Ego dingfest macht.

Aufgrund seiner Blindheit liegt es nahe, die Geschichte von Daredevil/Matt Murdock als passing narrative zu lesen; damit steht er jedoch exemplarisch auch für seine gesamte Zunft, postuliert doch etwa Bukatman bündig: «[The superhe-

4 Die häufigsten Titelvarianten ergänzen Daredevil zu Here Comes Daredevil oder Daredevil The Man without Fear - alle Varianten werden im Folgenden jeweils mit $D D$ abgekürzt.

5 Markante Beispiele sind etwa ein Story-Arc um Echo, eine gehörlose Superheldin/-schurkin ( $D D$ v2 5I-55, November 2003-Februar 2004), oder Wake up um ein traumatisiertes Kind, wo Daredevil nur am Schluss einen kurzen Auftritt hat ( $D D$ v2 I6-I9, Mai-August 200 I). Zu letzterer Story vgl. Krueger 2008. 
roes'] sagas are passing narratives [...].» ${ }^{6}$ Dazu gehe ich im Folgenden zuerst auf die Konzepte von Stigma, passing und closet ein.

Den Hintergrund der folgenden Analyse stellt die Daredevil-Heftreihe von 1964 bis 2015 dar, die sich in diesem Zeitraum über vier «Volumes» erstreckt; ein neues Volume - wenn die Zählung der Hefte mit Nummer I neu beginnt bedeutete jeweils einen gewissen narrativen Einschnitt, obgleich die Erzählung mehr oder weniger nahtlos weiterging.7 Erst 2015/2016 erhielt der Charakter einen Reboot, der mit der Chronologie der vorherigen Ereignisse brach. Den Fokus lege ich dabei auf die für die Doppelidentität interessantesten Abschnitte, die frühe Phase der ersten hundert Hefte (1964-1973) sowie einen kursorischen Blick auf die Geschehnisse in den Volumes 2-4 (1998-2015).

\section{Stigma - Passing - Closet}

Zeitgleich mit Marvels erster Welle von «Helden mit Schwäche〉 erschien ein weiteres Werk von Erving Goffman: Stigma (1963). Darin befasst er sich ebenfalls mit Darstellungsstrategien und Identitätstechniken, aber für den besonderen Fall von Stigmatisierungen. Das Stigma bezeichnet dabei einer Person zugeschriebene Unzulänglichkeiten, die eine diskreditierende Wirkung haben, seien dies körperliche Abweichungen, Charakterzüge oder von Goffman als phylogenetische bezeichnete Stigmata wie Rasse, Nation oder Religion. ${ }^{8}$ Das Stigma sieht Goffman dabei vor allem mit negativen Konnotationen besetzt; es zu tragen, bedeutet, «in unerwünschter Weise anders [zu sein], als wir es antizipiert hatten»?. Es handelt sich also genau genommen weniger um ein Merkmal eines Individuums, sondern es ist die «Situation des Individuums, das von vollständiger sozialer Akzeptierung ausgeschlossen ist ${ }^{10}{ }^{\circ}$, wie es Goffman bereits im ersten Satz seiner Studie umschreibt. Während ein Individuum üblicherweise von seinem Gegenüber Akzeptanz verlangen kann, kann dieser Anspruch von einem Stigma gebrochen werden, sodass sich das Gegenüber vom Stigmatisierten abwendet. Daraus ergibt sich, so Goffman weiter, eine Diskrepanz zwischen virtualer (das heisst der zugeschriebenen) und aktualer sozialer Identität. ${ }^{\text {II }}$ Ziemlich unglück-

6 Bukatman 2003, 217.

7 Die Volume-Zählung ist dabei oft eher Fansache - in den Heften selbst wird sie nicht aufgeführt; hier werden ab Volume 2 die Volume-Angaben in Kurzform, z. B. v2, ergänzt.

8 Goffman 1963, 4 (dt. 1975, I3).

9 Goffman 1975, I3 (engl. 1963, 5).

io Goffman 1975, 7 (engl. 1963, Preface (unpag.)).

I I Goffman 1963, 2 (dt. I975, I0). 
lich benennt Goffman eine durch ein Stigma geprägte Identität als beschädigt (spoiled identity), obschon er deutlich macht, dass sich dies auf die Sicht der anderen Leute bezieht: «In unserer Vorstellung wird sie so von einer ganzen und gewöhnlichen Person zu einer befleckten, beeinträchtigten herabgemindert.» ${ }^{12}$ Weil Stigmata die Aufmerksamkeit auf sich ziehen, dominieren sie oft das Bild, welches sich das Gegenüber eines betroffenen Individuums in einer Situation von diesem macht. Dies hat zur Folge, dass der Stigmatisierte nach Goffman das Gefühl gut kennt, nicht zu wissen, was die andern «wirklich〉 über ihn denken; er ist sich stets bewusst, dass er in der Welt der «Normalen» - wie Goffman jene nennt, die von den Erwartungen nicht abweichen - einen Eindruck generiert und diesen kalkulieren muss. ${ }^{13}$

Freilich sind nicht gewisse Eigenschaften oder Merkmale an sich stigmatisierend, vielmehr ist es der Kontext bzw. das gesellschaftliche Umfeld, das oft unbewusst und implizit festlegt, welche Eigenschaften Stigmacharakter erhalten und welche nicht. Potenzial zum Stigma hat so im Prinzip jedes Merkmal, das seinen Träger «von anderen in der Personenkategorie, die für ihn zur Verfügung steht, unterscheidet $»^{14}$. So kann eine herkömmlich wohl eher positiv eingeschätzte Eigenschaft in einem spezifischen Umfeld eher als Stigma gelten. Goffman erwähnt als Beispiel, dass in gewissen beruflichen Bereichen mangelnde Ausbildung totgeschwiegen wird, während es in einem andern Bereich ratsam sein kann, eine absolvierte Ausbildung (als Überqualifizierung) nicht bekannt werden zu lassen. Damit ist bereits angesprochen, dass sich gewisse Stigmata vor den Mitmenschen verbergen lassen.

Zwischen einem Stigma und den Superkräften eines maskierten Helden lässt sich damit eine Parallele ziehen. Wenn Goffman festhält: «Von der Definition her glauben wir natürlich, dass eine Person mit einem Stigma nicht ganz menschlich ist» ${ }^{15}$, so lässt sich dieses «nicht ganz menschlich» in scheinbar entgegengesetzte Richtungen deuten. Was für tatsächliche Behinderungen höchst verwerfliche Aussagen wären, lässt sich für fiktionale Superkräfte, konzeptuell argumentiert, wohl durchaus skizzieren: Fantastische Fähigkeiten lassen sich als eine Abweichung verstehen, die als über-, ausser- oder sogar unmenschlich konnotierte Attribute je nach Interpretation eher als (in Ermangelung besserer Begriffe) monströs oder als göttlich ${ }^{16}$ aufgefasst werden können. Wie schnell die Superkräfte,

I 2 Goffman 1975, iof. (engl. 1963, 3).

I3 Goffman 1963, I4, I I (dt. I975, I3, 24).

I4 Goffman 1975, I0 (engl. I963, 3).

is Goffman 1975, I3 (engl. 1963, 5).

I6 Zur antiken Herkunft des Begriffs als «körperliche[s] Zeichen göttlicher Gnade» vgl. Goffman 1975, 9 (engl. 1963, I). 
denen als körperliche Abweichung durchaus etwas Groteskes innewohnen kann, kippen können, belegen jene Superhelden, die aufgrund ihrer äusserlichen Gestalt in der erzählten Welt oft eher als Monster denn als göttlich angehauchte Athleten gewertet werden - zum Beispiel The Hulk/Bruce Banner, The Thing/ Ben Grimm, The Swamp-Thing oder der Werewolf by Night/Jack Russell.. ${ }^{17}$ In der Mehrzahl aber können Superkräfte von Heldenfiguren als eher spositive> Stigmata verstanden werden. Beispielsweise setzt Lillian S. Rosenberg Clark Kent/Superman in Bezug zu hochintelligenten Kindern, die ihr Licht ebenfalls regelmässig unter den Scheffel stellen, um nicht aufzufallen. ${ }^{8}$

So gesehen verbergen Superhelden in ihrer zivilen Identität ihre Superkräfte als (potenzielles) Stigma, zeigen dieses aber offen, wenn sie ihr Kostüm tragen (das ihren Status als einsatzbereite Helden markiert). Komplementär kommt hinzu, dass die Superhelden im Kostüm ihre zivile Identität geheim halten, sodass diese ebenfalls als eine (wenn auch sehr stark abgeschwächte) Art von Stigma gesehen werden könnte - wie im Kapitel zu Maskerade und Geheimnis erwähnt, stellt die Maske als Schutz eine der verwundbarsten Stellen des Helden aus -, was aber doch weniger greifbar scheint.

Goffman unterscheidet zwei Varianten von Stigmaträgern: Menschen mit einem offensichtlichen Stigma bezeichnet er als Diskreditierte, solche, welche ihr Stigma in Gesellschaft verbergen (können) oder deren Stigma noch nicht erkannt wurde, als Diskreditierbare. ${ }^{19}$ Für Diskreditierte besteht das Stigma-Management darin, mit der «Spannung, die während sozialer Kontakte erzeugt wird, fertig zu werden $»^{2}$. Für diskreditierbare Personen hingegen geht es darum, die Information zu steuern: «Eröffnen oder nicht eröffnen; sagen oder nicht sagen; rauslassen oder nicht rauslassen; lügen oder nicht lügen; und in jedem Fall, wem,

I7 Zur «Monstrosität namentlich von The Hulk vgl. Fingeroth 2008, I 22-I 30, sowie den Superhelden allgemein Brownie/Graydon 2016, 2, $72 \mathrm{f}$.

I 8 Rosenberg 2008, 37. Unter diesem Aspekt lässt sich ferner eine Verbindung zur Philosophie von Friedrich Nietzsche schaffen, der die Maske unter anderem in einem ähnlichen Kontext sah, wenn er etwa von der Maske der «Mediocrität» sprach, «mit der sich das geistig überlegene Individuum schützen kann, um nicht durch die Gesellschaft zum Durchschnittsmenschen zu werden» (er sah die Gefahr, dass das Rollenspiel die Subjektivität schliesslich verdrängt); wobei «tiefdenkende Menschen» sich in der Interaktion mit anderen wie Komödianten vorkämen, da sie sich, «um verstanden zu werden, immer erst eine Oberfläche anheucheln» müssten (Friedrich Nietzsche: Menschliches, Allzumenschliches I und II, in: Sämtliche Werke, Bd. 2, München I988, 627, 48 5, sowie Nachgelassene Fragmente I884-I885, in: Sämtliche Werke, Bd. I I, München I988, 543 , zit. n. Weihe 2004, 85 f.).

I9 Goffman I963, 4, 4I-43 (dt. 1975, 56f.).

20 Goffman 1975, 56 (engl. 1963, 42). 
wie, wann und wo.» ${ }^{21}$ Diskreditierbare haben also die Wahl, ob sie ihr Stigma verheimlichen, verschleiern oder eingestehen wollen. ${ }^{22}$

Für das Management «nicht offenbarter diskreditierender Informationen über sich selbst» verwendet Goffman den Begriff des passing (im Deutschen in der Regel nicht ganz adäquat als «Täuschen» wiedergegeben). ${ }^{23}$ Er spricht dabei auch von reverse passing, wenn es um die Verheimlichung von rühmlichen Fakten geht, die aber nicht sein Thema sind..$^{24}$ Das passing hat von verschiedenen Forschungsrichtungen Aufmerksamkeit erhalten, namentlich in Bezug auf Hautfarbe (racial passing), sexuelle Orientierung und Behinderung. So erklärt etwa Jan Grue: «Disability in public is, for some, a matter of trying to avoid stigma by passing as non-disabled, namely, concealing or minimising signs of problematic identity $[\ldots] . »^{25}$

Die maskierten Helden lassen sich als Diskreditierbare auffassen - ihr Geheimnis erfordert ein Informationsmanagement, damit «die jeweilige soziale Umwelt keine Kenntnis von dem Stigma» ${ }^{26}$ erhält und sie in ihrer zivilen Identität als «Normale» (Nichtstigmatisierte) wahrgenommen werden. Die Diskreditierbaren widersprechen der «für die persönliche Identität bedeutsamen [...] Norm, über sich wahrheitsgemäss Auskunft geben zu müssen» ${ }^{27}$. Wohl nicht zuletzt daraus erklärt sich, warum maskierten Helden die Selbstentlarvung so schwerfällt - wenn sie ihre Doppelidentität ihnen nahestehenden Personen enthüllen, wird ihnen nicht selten der Vorwurf der Lüge und des Vertrauensmissbrauchs gemacht, der oftmals genauso schwer oder schwerer wiegt als die verheimlichte Identität an sich. Wie Michael von Engelhardt erläutert, birgt passing die Gefahren des Entdecktwerdens und der Erpressung. ${ }^{28}$

Passing lässt sich als Darstellungsakt oder -praktik betrachten. ${ }^{29}$ Laut Kelby Harrison umfassen passing-Definitionen gewöhnlich zwei Komponenten: Zum einen wird passing meist mit Intentionalität verknüpft, zum andern ist der Er-

2 I Ebd.

22 von Engelhardt 2010, 136.

23 Goffman 1975, 57 (engl. 1963, 42). Der Begriff stammt ursprünglich aus dem Kontext des sogenannten racial passing (Alaniz 201 2, 364, Harrison 2013, 3).

24 Goffman I 963, 42. Auch hat das reverse passing («umgekehrtes Täuschen», Goffman I975, 57) als Begriff keine Schule gemacht und wird darum im Folgenden nicht verwendet.

25 Grue 2016, 961. Grue bemerkt weiter, dass die soziologische Forschung über «disability stigma» hauptsächlich der Tradition Goffmans folge, in welcher Behinderung als eine unfreiwillige soziale Devianz gesehen werde (ebd., 959).

26 von Engelhardt 2010, I36.

27 Ebd.

28 Ebd., I37.

29 Harrison 2013, 33. 
folg der Darstellung fester Bestandteil davon $3^{30}$ und bedeutet in der Regel für die Person, die sich dieser Strategie bedient, eine soziale Errungenschaft («social accomplishment»). Diese beiden Punkte betont Harrison, wenn sie passing erneut definiert - und zwar interessanterweise mit einem Fokus auf eine authentische Identität: «Passing designates a successful self-presentation in line with a socially favored identity at the expense of an <authentic $>$ one $[\ldots] . »^{3 \mathrm{I}}$ Dennoch, so Harrison weiter, sei passing - sei es bezüglich Rasse, Geschlechts oder sexueller Orientierung - eine Option für jene, die sich in einem liminalen Raum zwischen einer favorisierten und einer marginalisierten Identität befänden..$^{32}$

Da passing eine bestimmte Form der metaphorischen Maskerade ist, erstaunt es nicht, wenn Harrison ebenfalls ausführt, dieses stelle eine Herausforderung für Identitätskategorien dar. ${ }^{33}$ Passing erlaubt (mindestens) zwei mögliche Perspektiven auf Identitätsvorstellungen, wobei die eine einer «binary logic», die andere aber einer «double logic» verpflichtet sei. ${ }^{34}$ Angestiftet von einem «common sense», sei man zwar immer versucht, Identität in ein binäres Modell zu stellen (man ist entweder ein Mann oder eine Frau etc.) - darin seien am passing eine «authentische» und eben eine vorgetäuschte Identität beteiligt. ${ }^{35}$ Doch sei passing eher einer Logik des «doubling» verpflichtet (ein Mann, der als Frau «durchgeht, ist sowobl Mann als auch Frau), in der das passing als Ausdruck von (zwei) aufeinandergeschichteten und ineinandergreifenden Identitäten fassbar wird. ${ }^{6}$ Das passing echot so die Gleichzeitigkeit von Entweder-oder und Sowohl-als-auch, die auch der Maskerade im Allgemeinen eigen ist (wie ich im Kapitel zu Maskerade und Geheimnis dargelegt habe). Passing ist eng verknüpft mit dem Überschreiten von (vermeintlichen) Grenzen, seien diese kultureller, legaler oder sozialer Art. Nach Harrison funktioniert passing auf zwei Ebenen, der per-

30 Vgl. Harrison 2013, 34. Sie bemerkt dazu anschaulich, dass die erfolgreichsten passing narratives historischer Personen wohl diejenigen sind, von welchen man gar nichts weiss (ebd., 23).

3 I Ebd., I.

32 Ebd.

33 Ebd., 33: «Passing ruptures our common ordinary understanding of authenticity and natural identities.»

34 Ebd., 36.

35 Ebd., 50.

36 Ebd., 36. Sie führt weiter aus (ebd., 51): «Layers of identity are assumed under models of passing, with our ordinary logic telling us that the outer layer is performed, masqueraded or otherwise constructed for the uptake of a social gaze, while the under layer is understood as the location of truth and authenticity. It's the underlying identity that is somehow something more significant than simple social construction. It is somehow essential, inescapable, yet still capable of being hidden.» Für die Konstruktion von Identität sieht sie aber eine Synthese: Passing erkläre die Möglichkeit «for a mechanism of identity to be produced through both social construction and essentialist means, in the same individual at the same time, one wrapped around or on top of the other». 
sönlichen wie der sozialen. Oft fällt die Entscheidung zum passing im Hinblick auf den public gaze, den öffentlichen Blick, manchmal auch für das Privatleben. ${ }^{37}$ Die Situation eines Individuums, das passing betreibt, wird insbesondere im Rahmen der Queer Studies mit einer weiteren Metapher erfasst: dem closet. Dieser inzwischen wohl schon sprichwörtliche Schrank ist in den Worten von Steven Seidman, Chet Meeks und Francie Traschen «a division between a private life where homosexuality can be expressed and a public life where one passes as heterosexual» $3^{8}$. Wenn man den Begriff auf andere Stigmata als sexuelle Identität ausweitet, lässt sich der closet als eine Art übertragene Hinterbühne für das passing verstehen, um nochmals den Rückbezug zu Goffmans Theatermetapher zu machen. Zwar legt etwa Harrison Wert auf eine klare Unterscheidung von passing als Bewegungs- und closet als Raummetapher, ${ }^{39}$ doch verschwimmen diese Grenzen, wenn man diverse Weiterentwicklungen der Konzepte mitbetrachtet. $4^{\circ}$ Letztlich umschreiben beide die Wahrung eines Geheimnisses einer Person bzw. einer geheimen Identität(skomponente) - wie Siebers eingängig schreibt: «Some people have secrets, some people are secrets. ${ }^{4{ }^{4}}$ Besonders in einem Punkt ist der Unterschied zwischen den beiden Metaphern bemerkenswert: Wie erwähnt, ist dem passing der Erfolg der Darstellung eingeschrieben. Der closet dagegen ist eng mit seiner Aufhebung verbunden: dem Coming-out bzw. dem Outing - in den Begriffen des Geheimnisses der Selbst- bzw. der Fremdentlarvung (vgl. auch hier das Kapitel zu Maskerade und Geheimnis).

Der closet wird dabei als sozialer, aber auch politischer oder psychologischer Raum gesehen, der für die Person darin aber von Selbstverachtung und Unsicherheit geprägt ist. ${ }^{42}$ Der closet, der für den Kontext von sexueller Identität als Konstruktion der Binarität zwischen Hetero- und Homosexualität erscheint, markiert dabei oft gesellschaftliche Grenzen, wie Harrison erklärt: «[...] the narrative of <coming out>, as it relates to the closet, is its socially transgressive moment.»43 Seidman/Meeks/Traschen sehen im Coming-out eine «dramatic quality of privately and publicly coming to terms with a contested social

37 Ebd., 35 .

38 Seidman/Meeks/Traschen 1999, I9.

39 Harrison 2013 , I7.

$4 \circ \mathrm{Zu}$ den -vom jeweiligen theoretischen Kontext abhängenden - Nuancen zwischen den beiden Konzepten vgl. Siebers 201 I, 97-100.

4I Ebd., 98. Dazu ist erneut anzumerken, dass genau genommen aber nicht die Person bzw. eine 〈Identitätshälfte〉 das Geheimnis ist, sondern die Einheit, die Verbindung zwischen den Identitäten.

42 Harrison $2013,17$.

43 Ebd. 
identity» ${ }^{44}$. Dies führt aber zu einer Trennung zwischen jenen, die (noch) «in the closet» sind, und jenen, die sich geoutet haben. Wie Seidman/Meeks/Traschen ausführen, wird Ungeouteten (namentlich im Rahmen von Minderheitenpolitik) gern unterstellt, ein 〈falsches〉 und unglückliches Leben zu führen. ${ }^{45}$ Implizit scheint bei diesem Vorwurf an den closet wie auch beim passing als Strategie ebenfalls die Vorstellung einer authentischen, einer wahren Identität gegenüber einer vorgegebenen die Grundlage zu sein. Demgegenüber betonen Seidman/ Meeks/Traschen, dass der closet auch einen geschützten Raum bietet, um ein - in ihrem Kontext homosexuelles - Selbst zu kreieren, während zugleich das Risiko einer unintendierten «exposure» verkleinert wird. ${ }^{46}$

In Bezug auf die Superhelden ist anzufügen, dass Lee Easton, der die Superhelden im Kontext von Homosozialität und Heteronormativität verortet, das gesamte Genre (gemeint sind Superhelden mit Doppelidentitäten) als closet-Literatur sieht. Nach Easton, der in Bezug auf die eng anliegenden Heldenkostüme von einem «spandex closet» spricht, steht der closet nicht nur für «hidden secrets», sondern strukturiert ganze Wissenssysteme.47

Stigma, passing und closet sind drei Konzepte, die alle vor allem aus der Minderheitenforschung bekannt sind. Die durch sie gewonnenen Erkenntnisse können aber - zumindest partiell - für alle Identitäten Relevanz beanspruchen, wie bereits Goffman betont hat. Für ihn war Stigma-Management klar ein «Ableger» $4^{8}$ des fundamentaleren Stereotypisierens bzw. Kategorisierens in der gesellschaftlichen Interaktion (das bereits im Kapitel zu Masken, Rollen, Identitäten erläutert wurde). Am Schluss seines Buches erklärt Goffman, dass die Gegenüberstellung von Stigmatisierten und Normalen eine reine Konstruktion sei. Vielmehr gehöre das Stigma «als Abweichung von den jeweiligen sozialen Normalitätsstandards zu jedweder Identität» ${ }^{49}$, wenn auch in verschiedenen Formen und Intensitäten. Die von Goffman herausgearbeiteten Mechanismen können so für alle (personalen) Identitäten Gültigkeit beanspruchen, denn jeder macht Erfahrungen des Abweichens von sozialen Normen und Normalisierungen. ${ }^{\circ}$ Letzt-

44 Seidman/Meeks/Traschen I999, 9.

45 Ebd., I ff. Tatsächlich sucht Harrison (2013, I9) den Unterschied zwischen passing und closet auch an der «presumed psychological health of the agent» festzumachen.

$46 \mathrm{Vgl}$. Siebers 20I I, 98: "Some people hide in the closet, but others are locked in the closet.»

47 Easton in Easton/Harrison 2010, 3 I of. Vgl. zum Superhelden-closet auch Bukatman 2003, 2 I 6.

48 Goffman 1975, 68 (engl. 1963, 68).

49 von Engelhardt 2010, I 26.

50 Ebd., I 37, Goffman 1963, I38. Wie von Engelhardt festhält, stellt Stigma-Management so einen «Bestandteil des von jedem Gesellschaftsmitglied zu leistenden Identitätsmanagements» und somit ein «Grundelement sozialer Interaktion» dar (von Engelhardt 20I0, I38), einen «Prozess, der auftritt, wo immer es Identitätsnormen gibt» (Goffman 1975, 6of. (engl. 1963, I30)). 
lich sind «Normale» und «Stigmatisierte» zwei Perspektiven bzw. Rollen, «die von jedem Menschen im Wechsel eingenommen werden» ${ }^{5}$. Dagegen handelt es sich beim Protagonisten, der nun betrachtet werden soll, um einen zwar klar und dennoch besonders Stigmatisierten.

\section{Karussell der Identitäten: Daredevil und Matt (und Mike) Murdock}

Im Standardablauf einer Superhelden-Origin-Story erhält der Protagonist zuerst Superkräfte und nimmt erst anschliessend eine Doppelidentität an. Bei Daredevil hingegen lässt sich argumentieren, dass Matt Murdock schon lange vor seinem ersten Auftritt als maskierter Held in gewisser Weise ein Doppelleben führt. Da Matts alleinerziehender Vater als alternder Boxer immer schwerer ein Auskommen findet, nimmt er seinem Sohn schon früh das Versprechen ab, nur hinter seinen Schulbüchern zu sitzen und einen Prestigeberuf wie Arzt oder Anwalt zu ergreifen. Pflichtbewusst versagt sich der Junge jugendliche Raufereien und sportliche Engagements. Wie zu erwarten, verlachen ihn seine Kameraden als Memme (sissy) und nennen ihn spottend Daredevil. Ebenso verletzt wie erbost, stürzt Matt nach Hause, wo er seine Bücher durchs Zimmer wirft und sich am Boxsack abreagiert - in trotziger Sehnsucht nach Vergeltung: «Someday I'll show them! I'll make them eat those words! I'm as strong as any of them ... as rugged as any of them! And I'll prove it to them! Someday [...]!» ${ }^{\varsigma^{2}}$ Wie hier deutlich wird, fehlte es Matt Murdock nie an Selbstbewusstsein. In diesem Moment kommt ihm die Idee, dass er wenigstens für sich trainieren kann - heimlich. Für alle andern aber bleibt er ein 〈klassischer> Streber mit lauter Bestnoten. Damit ist bereits der Grundstein für seine spätere Doppelidentität gelegt. An diesem Punkt legt die Origin-Story eine Interpretation der späteren heldischen Seite als Kompensationsfantasie des gedemütigten Bücherwurms nahe. Sieht man in Matts Ruf als Streber eine Art von Stigma - welches aber auf den Kreis Gleichaltriger beschränkt bleibt und im Erwachsenenalter seine Bedeutung verliert -, kommt es bei Matt schon hier zu einer Umkehrung des üblichen Umgangs mit einem Stigma: Obwohl er sein Image als Streber mit seinen sportlichen Fähigkeiten korrigieren könnte, ${ }^{53}$ verschweigt er diese und verharrt stattdessen in einer stigmatisierten Rolle.

5I von Engelhardt 2010, I38, Goffman 1963, I38 (dt. 1975, I70).

52 The Origin of Daredevil (Stan Lee, Bill Everett et al.), in: DD I, April 1964, 6.

53 Zugrunde liegt hier offensichtlich ein stereotypes Bild (in) der Teenagerkultur, in dem Wissenschaft und Sport als implizit unvereinbare Gegensätze aufgefasst werden, wobei den Sportlichen die Beliebtheit zufällt (als «Streber» werden jene gescholten, die sich dem schulischen 
Trotz seines folgenschweren Unfalls verfolgt Matt seinen «doppelspurigen> Weg unbeirrt weiter. Er trainiert sogar noch mehr, als er sich seiner gesteigerten Sinne gewahr wird, die er explizit als Kompensation für seine Blindheit sieht ${ }^{54}-$ und ebenfalls für sich behält. Schliesslich wird kurz vor Abschluss seines Jurastudiums sein Vater erschossen (weil er sich weigerte, einen Boxkampf zu zinken). Matt und sein Zimmergenosse Franklin «Foggy» Nelson eröffnen eine Anwaltskanzlei, für die Foggy eine hübsche Sekretärin namens Karen Page einstellt, womit die drei Hauptfiguren der ersten Publikationsjahre beisammen sind. Erst in diesem Moment - bevor er mit dem Erwerbsleben anfangen müsste - erkennt Matt, dass er noch etwas zu erledigen hat und zudem seine besonderen Kräfte für etwas einsetzen sollte:

I'll never be able to concentrate on my law work until Dad's murderer is finally brought to justice! But years ago I promised Dad that Matt Murdock would use his head ... never become a fighter ... never depend on my strength ... the way Dad did! I can't break that promise I made! And yet, with my agility, my extra-sharp senses, there is so much I could do! I can't let all my powers go to waste!ss

Matt befindet sich in der Zwickmühle zwischen seinem alten Versprechen und seinem Aktivitätsverlangen und Verantwortungsgefühl. Doch verfällt er auf einen ungewöhnlichen Ausweg: «Wait! I have it! I'll see to it that Matt Murdock never does resort to force ... But somebody else will! Somebody totally different from Matt Murdock ...» Kurz darauf steht er im rasch gefertigten Kostüm parat: «There! Whenever I don this costume, I'll no longer be Matt Murdock! But I'll need a new name!» ${ }^{6}$ Mit einer fingierten Persönlichkeit glaubt er seinem Dilemma zu entgehen. Da sein neuer Name sein alter Spottname ist, enthält Matts Identitätsgeheimnis im Grunde von Anfang an eine Unvorsichtigkeit, die ihn jedoch nie einholen wird. Vielmehr wird Matts/Daredevils Mördersuche von Erfolg gekrönt, derweil Karen nach ihrem hübschen blinden Arbeitgeber schmachtet und mit Foggy über seinen Verbleib rätselt, bis Matt mit einer Ausrede wieder im Büro erscheint. So wird auch in Daredevils Origin-Story die Figurenkonstellation etabliert, die die frühen Jahre prägt.

Matt trägt dabei zwei Stigmata: Die Blindheit macht ihn zu einem Diskreditierten, während seine Supersinne (als eher positive Variante eines Stigmas) die Grundlage für seine zweite, heldische Identität darstellen, mit der er sich zu-

Wissenserwerb verschreiben und darin erfolgreicher sind als andere, der Vorwurf trifft aber selbst die ehrgeizigsten Sportler nicht). Verwandt findet sich dies ja auch in der Ausgangslage beim Teenager Peter Parker/Spider-Man.

54 The Origin of Daredevil (Stan Lee, Bill Everett et al.), in: DD I, April 1964, 10.

55 Ebd., I3f.

56 Ebd., I4. 
sätzlich zu einem Diskreditierbaren macht. In der Regel sind jene Merkmale, die (erst) in der Zuschreibung zu Stigmata werden (können), nicht selbst gewählt, was man aber zumindest für seine Heldenidentität nicht behaupten kann. Und $\mathrm{da}$ er mit seinen Supersinnen seine Behinderung mehr als kompensieren kann, bleibt auch dieses Stigma nicht völlig unumgehbar.

Einen Menschen mit einer klaren körperlichen Behinderung zu einem agilen und furchtlosen Superhelden zu machen (Daredevil bekommt bald den Ehrennamen «The Man without Fear»), verstärkt den Kontrast zwischen der zivilen und der heldischen Identität. Daredevils Taten erhalten dadurch eine eigene Sensationalität, die ihn von anderen Superhelden abhebt; in den ersten Heften wird mit verschiedenen <If they only knew〉-Kommentaren explizit auf die diesbezügliche ¿Unglaublichkeit〉 seiner Taten hingewiesen. ${ }^{57}$ Mit seinen Kräften, die ihm auch Blicke hinter die Fassaden anderer erlauben (wenn er etwa an ihrem Herzschlag hört, ob sie lügen), entspricht Matt auch dem Topos des Blinden, der mehr sieht bzw. weiss als alle andern. ${ }^{8}$ Vor allem Matts Radarsinn ist dabei «a different means of interacting with the world», der blossem optischem Sinn überlegen ist, wie José Alaniz in seinem Aufsatz über passing und disability bei Daredevil schreibt, woran die folgenden Ausführungen anknüpfen. 59

Die $D D$-Hefte zeigen dabei im Lauf der Zeit auch einen veränderten Umgang mit Matts Blindheit, das heisst deren Wertung innerhalb des Erzählten. Gerade in den ersten Heften finden sich noch Äusserungen (vor allem von Foggy und Karen), die klar mitleidige Gefühle für Matts Schicksal der Behinderung ausdrücken. ${ }^{60}$ Vor allem Karen wünscht sich, dass Matt doch sehen könnte - nicht zuletzt, damit er sie sehen und heiraten könnte. Stellenweise verhält sie sich geradezu bevormundend. Als Matt sie beispielsweise an einen Maskenball begleitet und dort der Superschurke Masked Matador eine Schlägerei startet, <verfrachtet> sie Matt kurzerhand in einen leeren Nebenraum, da ein Blinder sich ja nicht schützen könne - während sie ihre Neugier stillen will. ${ }^{61}$

57 Zum Beispiel in $D D_{2}$, Juni 1964, I5, und $D D_{3}$, August 1964, I 8.

58 Ein interessantes lebenswelt liches Beispiel zur Wirkmacht dieses Topos bespricht Siebers (20 I I, I I ff., vgl. auch i I 4-i is zu den Darstellungsmechanismen von Behinderung in Hollywoodfilmen).

59 Alaniz 201 2, 361. Eine nichtvisuelle Wahrnehmung in einem visuellen Medium darzustellen, ist eine gewisse Herausforderung für die Zeichner, die Daredevil aber eine typische Besonderheit verleihen, wobei die Darstellungsweise der Radarwahrnehmung im Lauf der Jahre immer wieder modifiziert wird.

60 So sagt Foggy einmal: «There goes one of the greatest guys in the world! It sure is a pity he's blind!» (The Unbelievable Purple Man (Stan Lee, Joe Orlando et al.), in: $D D$ 4, Oktober 1964, 22. Mitleid wird in der disability-Debatte sehr kritisch gesehen, weil es (wie hier) oft die Implikation hat (oder zulässt), das Objekt des Mitleids sei <minderwertig».

6I $D D$ 5, Dezember 1964,6 . Freilich kommt dies Matt gerade recht, kommt er so doch mühelos 
Im Lauf der ersten paar Hefte bringt Karen mehrmals die Hoffnung auf eine heilende Operation ins Spiel, wogegen sich Matt (möglichst unauffällig) mit Händen und Füssen wehrt. Für Karen ist diese Haltung völlig unverständlich, kann sie doch nicht wissen, dass er um seine Superkräfte fürchtet, wenn er wieder sehen könnte. ${ }^{62}$ Warum genau Blindheit einen Hinderungsgrund für eine Heirat darstellen soll, wird dabei nie erklärt, den Gedanken formulieren jedoch Karen sowie Matt selbst mehrmals. In DD 8 argumentiert Matt in Gedanken, dass er das Risiko einer Augenoperation nicht eingehen kann/will, wenn dies das Ende seiner Daredevil-Existenz bedeuten könnte. Für die Operation spräche aber die Chance auf Liebesglück: «But it would be the only way I could dare try to make Karen my wife. For, I could never ask her to marry a sightless man!» ${ }^{63}$ Seine Blindheit dient Matt häufig als Entschuldigung, um Karen auf Distanz zu halten, obwohl für ihn der Erhalt seiner Doppelidentität die stärkere Motivation dafür darstellt. ${ }^{64}$ Dass er Karen, die klar in ihn verliebt ist, so lange auf Abstand hält, illustriert, dass ein Stigma leicht zu einem (Liebes-)Beziehungshemmnis werden kann, bringt eine enge Beziehung doch in der Regel Vertraulichkeiten mit sich, die das Wahren eines solchen Geheimnisses kaum zulassen, wie auch Goffman bemerkt. $^{65}$

Im Lauf der Zeit verschwinden solche Thematisierungen von Matts Blindheit als Stigma, den gesellschaftlichen Wandel spiegelnd, fast ganz. So ist es kein Thema mehr, dass Matt wegen seiner Blindheit keine Beziehung oder keine Ehe eingehen könnte; mehrere seiner Geliebten, wenn auch nicht alle, sind eingeweiht. Wie Alaniz darlegt, bieten die frühen Daredevil-Jahre diesbezüglich eine eigentümliche Mischung: Einige Elemente - etwa dass Matts Blindheit seine Anwaltskarriere nicht im Geringsten beeinträchtigt - sind als progressiv zu werten, da sie «disability positive views» unterstützen. Zugleich werden diese immer wieder unterminiert, gerade wenn Matt sich als schwach und wenig wirkmächtige Person inszeniert. ${ }^{66}$ Als Daredevil widerspricht er diesem Bild dafür umso mehr. Hier lässt sich zudem eine Verbindung zum closet ziehen, sehen doch Seidman/

zu einer Gelegenheit, sich davonzuschleichen und in seiner anderen Identität die Verfolgung des Matadors aufzunehmen.

62 Tatsächlich verliert Matt in der Regel seine Superkräfte, wenn er sein Augenlicht (temporär) zurückerhält (z. B. in DD 106, Dezember 1973, 30), oder er verliert seine Kräfte, wenn ein Gegner ihn «nur> (zeitweilig) erblinden lassen will ( $D D_{30}$, Juli 1967, 20).

63 "The Stiltman cometh» (Stan Lee, Wally Wood), in: DD 8, Juni 1965, 7. Ausserdem ist Foggy ebenfalls in Karen verliebt; auch das spricht dagegen, dass Matt ihr seine Liebe offenbart.

64 So z. B. in $D D_{43}$, August 1968.

65 Goffman 1963, 99 (dt. 1975, I25).

66 Alaniz 2012, 362. Nach Alaniz steht das Genreklischee der zivilen Identität als Schwächling einer stärker ermächtigenden Darstellung von Behinderung im Wege (ebd.). 
Meeks/Traschen den closet als eine «strategy of accomodation and resistance», die Aspekte gesellschaftlicher Normen - in ihrem Fall Heterosexualität, doch könnte man stattdessen wohl ebenso die «ablist culture», von welcher Alaniz spricht, einsetzen - reproduziert und zugleich anficht. ${ }^{67}$

Sowohl in seiner Helden- wie seiner zivilen Identität bedient sich der Protagonist passing-Strategien, wobei er in diesen beiden Identitäten gegenläufige passing-Ziele verfolgt: Als Daredevil möchte er als Nichtblinder erscheinen, damit seine Gegner diese Schwäche nicht ausnutzen können. So muss er in gewissen Situationen versuchen, die wahrscheinliche Reaktion eines Sehenden überzeugend zu imitieren. Wenn ihm etwa der eifersüchtige Hawkeye einen Phosphorpfeil ins Gesicht hält (Abb. 4I), schreit Daredevil deshalb laut: "That light! Can't see!», während er denkt: «I can't see anyway, but if I don't fake being 〈blinded - my secret identity is shot! This is unreal!» ${ }^{68}$ (Damit gibt er auch gleich den Kommentar zu dieser Situation ab.) Wie hier kann diese Schwäche in der fantastischen Welt der Superhelden manchmal sogar zu einem Vorteil werden, denn die Behinderung schützt den Helden häufig vor Schurkenattacken, die auf die visuelle Wahrnehmung zielen - als Uneingeweihte rechnen seine Gegner ja nicht damit, mit einem Blinden zu kämpfen. ${ }^{69}$

Als Matt dagegen gibt er sich als Nicht-Held aus, womit das bei ihm gleichbedeutend mit der Darstellung als Blinder ist, der er verkomplizierenderweise tatsächlich ist. Genau genommen versucht Matt in Goffmans Begriffen ein cidealisiertes>, das heisst stereotypen Erwartungen entsprechendes Bild eines Blinden darzustellen, statt einen aussergewöhnlichen Blinden, der er ist. Indem er seine Schwäche übertreibt ( $\mathrm{da}$ er sie wie erwähnt problemlos kompensiert) und sich dazu zwingt, so zu tun, als ob er ein «normaler Blinder ohne Supersinne sei, übt er sich in einer Strategie, die Tobin Siebers «disability as masquerade» genannt hat. Dabei handelt es sich um eine strukturell dem passing ähnliche Strategie, die inhaltlich jedoch deren Gegenstück darstellt. Während passing darauf abzielt, als «normal durchzugehen〉, geht es hier um das bewusste <Ausstellen> einer Behinderung bzw. eines Stigmas durch dessen Übertreibung. Siebers erläutert dies wie folgt: «The masquerade represents an alternative method of managing social

67 Seidman/Meeks/Traschen I999, I0, Alaniz 201 2, 365. Unter «ablist culture» versteht Alaniz die auf «abilites» ausgerichtete Normativität, die Menschen mit Behinderungen abwertet und marginalisiert (ebd.).

68 The Mark of Hawkeye (Steve Gerber, Sam Kweskin et al.), in: DD 99, Mai 1973, I4.

69 Vgl. Alaniz 201 2, 365. Beispiele dafür bieten etwa $D D_{4}$, Oktober 1964 (Killgrave/The Purple Man kontrolliert Gedanken über seine violette Haut), $D D$ I7, April 1965 (der Masked Marauder blendet Spider-Man und Daredevil temporär und ist dann ganz erstaunt, dass Daredevil ihn dennoch angreifen kann), oder mehrfach Kämpfe gegen Mysterio, dessen Waffe Illusionen sind. 


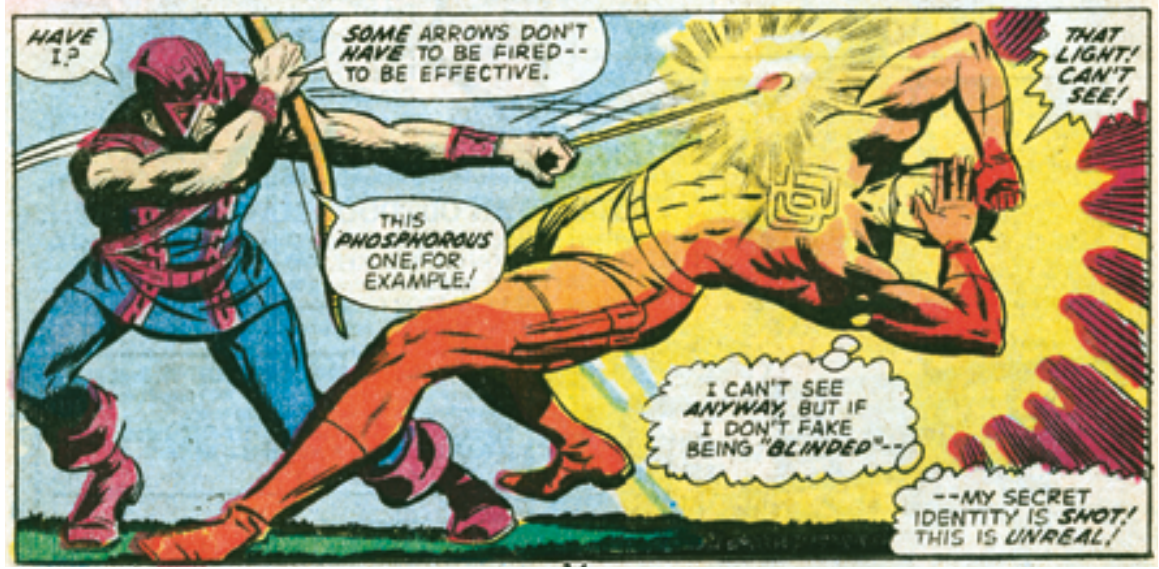

Abb. 4I: Daredevil muss angesichts von Hawkeyes Phosphorpfeil die Reaktion eines Sehenden imitieren - wie in der visuellen Umsetzung (Körperhaltung) sehr deutlich wird, bedeutet dies, grosse Überraschung, Erschrecken und eine unwillkürliche Schutzgeste (Hände vors Gesicht) vorzugeben. The Mark of Hawkeye! (Steve Gerber, Sam Kweskin et al.), in: Daredevil 99, Mai i973, I4. (C) Marvel Comics

stigma through disguise, one relying not on the imitation of a dominant social role but on the assumption of an identity marked as stigmatized, marginal, or inferior.» ${ }^{\circ 0}$

Zumindest ansatzweise hat schon Goffman diese Strategie in seine Betrachtungen einbezogen: Er sprach dabei von freiwilligen Enthüllungen oder Lapsus (slips) als allerdings flüchtigen Implikationen, die insbesondere auf eine Behinderung aufmerksam machen oder an diese erinnern können, wenn etwa eine blinde Person absichtlich ungeschickt agiert, um ihre Blindheit zu kommunizieren..$^{71}$ Demselben Zweck dienen in weniger flüchtiger Weise Stigma-Symbole (wie ge-

70 Siebers 201 I, 102. Siebers greift argumentativ auf Joan Rivieres Womanliness as a Masquerade (I 929, vgl. das Kapitel zu Männlichkeitsbildern) zurück. Für Siebers (20 I I, I I 8) betont diese Strategie nicht nur die Differenz des Stigmaträgers, sondern offenbart die gesellschaftliche Schwäche: «The masquerade counteracts passing, claiming disability rather than concealing it. Exaggerating or performing difference, when that difference is a stigma, marks one as a target, but it also exposes and resists the prejudices of society.»

7I Goffman 1963, I0I (dt. I975, I27); vgl. Siebers 201 I, 106. 
tönte Brillen bei Blinden), ${ }^{72}$ die das Stigma sozusagen «genormt» kommunizieren bzw. die Aufmerksamkeit darauf lenken.

Dies ist bei Matt Murdock/Daredevil ein wiederkehrendes Motiv. So lässt er sich beispielsweise von Foggy aus der Zeitung oder Aktenstellen vorlesen - und ist froh, als dieser gehen muss, da er mit ‘Fingerspitzenlesen〉 schneller ist: «At last! Now I won't have to pretend to be belpless anymore! I can breeze thru the rest of my work!»73 Bei einer anderen Gelegenheit verrät ihm sein Radarsinn beim Eintreten, dass Foggy gefesselt und geknebelt am Boden liegt, er tut aber so, als wisse er das nicht, sondern ruft nach ihm etc., bevor er ihn ertastet (Abb. 42): «I have to play the role of a blind man ... no matter bow much I want to go into action!»74 Indem Matt sich mehrfach bemüht, der üblichen Vorstellung eines Blinden genau zu entsprechen, wird implizit deutlich, dass Behinderung eine spezifische soziale Rolle bedeutet, wie Robert A. Scott betont: «Blindness [...] is a social role that people who have serious difficulty seeing or who cannot see at all must learn to play.»75 Laut Alaniz stellt Daredevil damit den fundamental performativen Charakter des Genres einerseits und von Behinderung andererseits aus. ${ }^{76}$

Welche Implikationen ein solches passing mit sich bringt, wird oft auch in völlig nebensächlichen Szenen offenbar, wenn etwa Karen über ein Büromöbel stolpert und Matt sie auffängt - was sie gar nicht glauben kann. Er schilt sich in Gedanken: «I was stupidly careless! When she’s so close - I forget myself! It mustn't happen again! She must never guess the truth about me!»77 Hier werden die Anforderungen offenbar, die das passing an den Stigmaträger stellt und die Goffman so beschreibt: «[...] he who passes will have to be alive to aspects of the social situation which others treat as uncalculated and unattended. What are unthinking routines for normals can become management problems for the discreditable.» ${ }^{8}$ Die perfekte Selbstkontrolle, die jeder mit einem reflexiven Geheimnis an den Tag legen muss (wie schon im Kapitel zu Maskerade und Geheimnis erläutert), entgleitet Matt hier für einen Moment, und er nimmt sich insofern zu Recht an der Nase, da Karen tatsächlich einen Moment lang auf die richtige Spur kommt: «Can it be possible that Matt really can -? Oh no! I'm acting like a child! I've got

72 Goffman 1963, 100 (dt. 1975, I 26f).

73 «And Men Shall Call Him ... Ox!» (Stan Lee, John Romita, Frankie Ray et al.), in: DD i 5 , April 1966, 5.

74 «Unmasked!» (Stan Lee, Gene Colan et al.), in: DD 29, Juni 1967, 8. Dazu auch Alaniz 201 2, 370.

75 Robert A. Scott: The Making of Blind Men, New York 1969, 3, zit. n. Siebers 201 I, 204.

76 Alaniz 201 2, 367.

77 «In Mortal Combat with ... The Sub-Mariner!» (Stan Lee, Wally Wood et al.), in: DD 7, 20.

78 Goffman 1963, 88 (dt. 1975, I I2). 


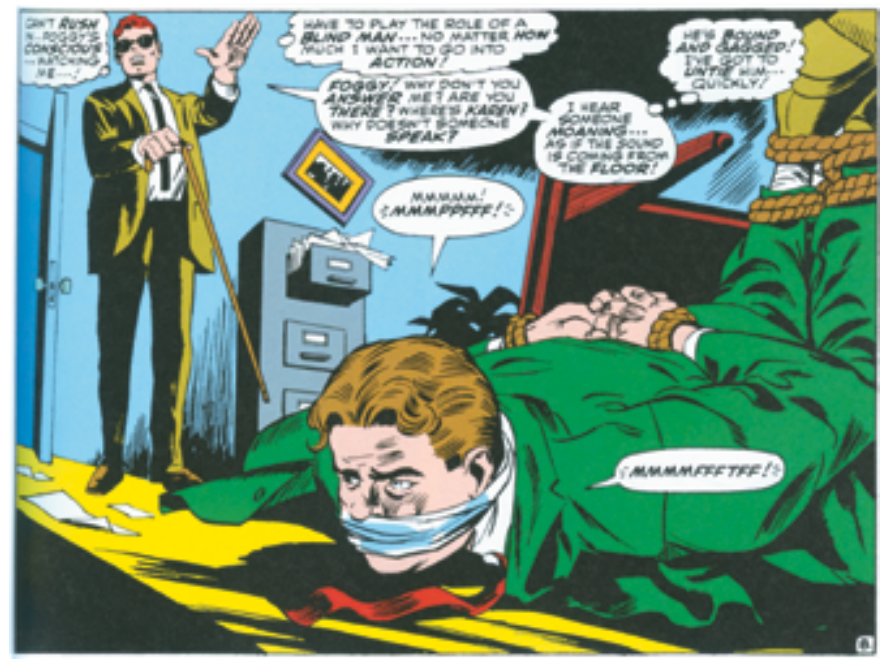

Abb. 42: Durch Brille, Blindenstock und Gestik des Tastens visuell als Blinder «markiert), spielt Matt den Unwissenden, obgleich er die Situation mit seinen Supersinnen längst erfasst hat. Dass die Denkblasen fast mehr Platz brauchen als die Sprechblasen, belegt Matts Mehrarbeit an Situationsanalyse, um sein Verhalten typisch erscheinen zu lassen. «Unmasked!» (Stan Lee, Gene Colan, J. Tartaglione et al.), in: Daredevil 29, Juni i 967, 8. () Marvel Comics

to stop this wishful thinking [...].»79 Allerdings wagt sie den Gedanken, dass hier etwas nicht stimmen könnte, nicht einmal richtig auszuformulieren (worauf ich etwas später nochmals zurückkomme).

«Disability as Masquerade» fällt teilweise mit dem covering zusammen. Dabei handelt es sich um eine bestimmte Adaptionstechnik, die Goffman ergänzend zum passing als eine verwandte Strategie des Stigma-Managements erwähnt: Covering ${ }^{80}$ meint zum einen, ein nicht vollständig verbergbares Stigma für die Wahrnehmung der Zuschauer abzuschwächen. ${ }^{81}$ Dazu gehört auch, ein Attribut als Zeichen für

79 «In Mortal Combat with ... The Sub-Mariner!» (Stan Lee, Wally Wood et al.), in: DD 7, 20.

80 Goffman I963, I02. Die deutsche Übersetzung gibt diesen Begriff mit dem kaum gebräuchlichen Wort «Kuvrieren` wieder (Goffman 1975, I28), wobei Abels $(2006,358)$ eine alternative Übertragung als «Kaschieren〉 bietet. Vgl. zum Covering Evans 2017, die als Variante auch von einem «Un/covering» spricht.

8 I Goffman 1975, I29 (engl. I963, I02f.). Goffman bemerkt dazu weiter, dass dies häufig nicht vollständig gelingt. In diesem Fall können beide Seiten so tun, als seien die <Abweichler〉 normal - es werden dann eine Scheinnormalität (phantom normalcy) sowie eine Scheinakzeptanz (phantom acceptance) praktiziert (ebd., I37, engl. 1963, I22). 
ein anderes, oft weniger deutliches als das eigentliche Stigma auszugeben oder ein Hilfsmittel als Folge einer anderen als der tatsächlichen Ursache zu erklären (beispielsweise Krücken als Folge eines Unfalls statt einer chronischen Krankheit). Genau dies aber lässt sich Matt unterstellen, wenn er seine Blindheit ‘vorschiebt), in Wahrheit aber seine heldische Identität nicht offenbaren will.

In einer Story, in der sowohl Daredevil als auch Spider-Man der Kollaboration mit Kriminellen beschuldigt werden, will Spider-Man Daredevil auf den Zahn fühlen, und sein Spinnensinn führt ihn vor das Fenster der Kanzlei Nelson \& Murdock. Im Ausschlussverfahren - Daredevil ist bestimmt keine Frau und kein Blinder - legt er sich auf Foggy als Verdächtigen fest, stürzt sich auf ihn und fordert ihn (als Cliffhanger der Story) rüde auf, zu gestehen, dass er Daredevil sei. Matt steckt in einem Dilemma, das jeder maskierte Held kennt: Er will und müsste eingreifen, wozu er aber sein Geheimnis offenbaren müsste (Abb. 43). So sieht er sich momenthaft der Möglichkeit aktiven Handelns beraubt. In diesem Dilemma ist für Matt seine Blindheit eigentlich kein Faktor, wohl aber für seine Zuschauer. Denn als er sich für sein Nichtstun entschuldigt, gehen diese davon aus, dass sich dies auf seine Blindheit bezieht. (Spider-Man zieht schliesslich unverrichteter Dinge ab.) Aufgrund der verbreiteten Annahme, Blindheit und Superheldentum schlössen einander aus, bleibt Matts Blindheit die gesamte Laufzeit der $D D$-Comics hindurch sozusagen die stärkste Verteidigung gegen den Superheldenverdacht?.

So eifersüchtig Matt sein Geheimnis hütet, so oft spielt er diesbezüglich nur zu gern mit dem Feuer - im Vertrauen auf ebendiese Annahme, dass man ihn als Blinden a priori vom Superheldenverdacht ausschliesst. Dies macht nur schon sein wichtigstes Hilfsutensil, sein Blindenstock deutlich, den er als Daredevil zur individuellen Allzweckwaffe bzw. zum Allzweckwerkzeug mit integriertem Seilzug und Wurfhaken umfunktioniert. ${ }^{82}$

Offenbar wird dies besonders durch das Motiv der «Verkleidung in der Verkleidung», das in den frühen Daredevil-Comics in mehreren Episoden auf die

82 Alaniz (201 2, $360 f$.) beobachtet dazu, dass Daredevil (paradoxerweise) in seinem Heldenkostüm jene Requisiten, die seine Blindheit anzeigen, ebenfalls offen ausstelle: Seine Maske hat keine Augenlöcher und aus seinem Blindenstock wird eben sein besonderes Utensil, um durch die Stadt zu schwingen. Allerdings scheint dies für Matt eher praktische Gründe zu haben statt ein (bewusstes) Statement zu sein: Es ist ihm stets sehr wichtig, dass niemand auf diese Verbindung kommt, und als Daredevils Werkzeug ist sein Blindenstock ja nicht mehr als solcher zu erkennen (und auch andere Helden verzichten auf Augenlöcher, etwa Spider-Man). Hinzuzufügen ist, dass damals, so Alaniz (ebd.), die sogenannten «ugly laws» in den USA noch in Kraft waren teilweise sogar bis I 974--, die zum Beispiel Blinden verboten, ihre Augen unbedeckt zu lassen. Tatsächlich sieht man Matt viele Jahre fast nie ohne eine Brille mit getönten Gläsern (er trägt diese in diversen Situationen offenbar sogar unter seiner Maske). 
Abb. 43: Die Wiederaufnahme des Cliffhangers aus DD I 6 illustriert, unter anderem mit dem 〈Heldenschatten〉, ein typisches Dilemma für jeden maskierten Helden: Er steht in Zivil vor einer Situation, die sein Eingreifen erfordert und die hier zudem seine Doppelidentität betrifft doch wie handeln, ohne sich zu entlarven? "None Are So Blind ...!» (Stan Lee, Johnny Romita, Frankie Ray et al.), in: Daredevil I7, Juni I966, I. (C) Marvel Comics

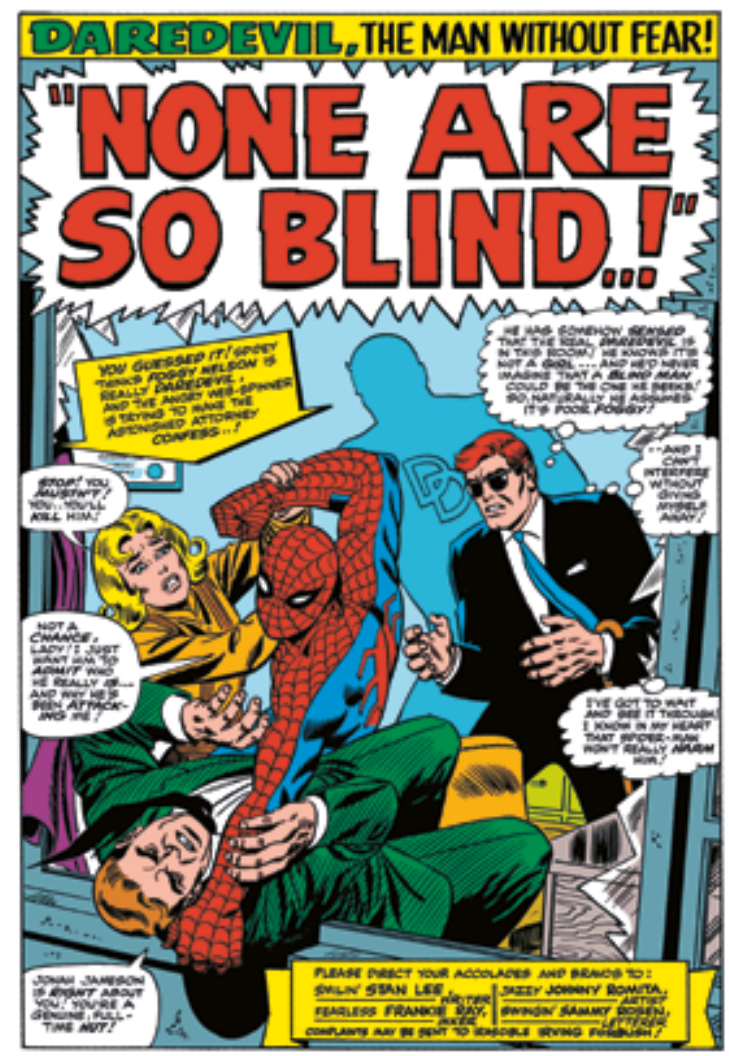

Spitze getrieben wird (und zwar deutlich stärker, als dies bei vergleichbaren Heldengestalten wie Spider-Man oder Iron Man zu beobachten ist). Wenn er es für nötig hält, schreckt Matt nicht davor zurück, so zu tun, als hätte sich der offensichtlich blinde Matt ein (nicht das) Daredevilkostüm übergezogen. Zuerst ist dies nur eine Strategie, um die Herausforderung eines Schurken zu einem Boxkampf annehmen zu können: Da Karen nicht von Matts Seite weichen will, als er im Radio diese Herausforderung bzw. Erpressung hört (der Schurke droht mit der totalen Zerstörung des Stadions), bittet er sie, ihm ein (nicht sein) Daredevil-Kostüm zu bringen, damit er zumindest Zeit herausschinden könnte, falls der <richtige> Daredevil nicht erscheinen würde. Sein Plan funktioniert denn auch, in der Menge wird er von Karen getrennt und steigt als «offizieller» Daredevil in den Ring, derweil Karen den verkleideten Matt vergeblich sucht. 
$\mathrm{Zu}$ einem späteren Zeitpunkt wendet Matt Murdock/Daredevil den Trick, den kostümierten Blinden zu spielen, in einer noch brenzligeren Situation an: In einem abgelegenen Haus wartet eine Gruppe Krimineller mit der entführten Karen, um Daredevil eine Falle zu stellen. Weil er sich dessen aber bewusst ist, wagt er eine scheinbar wahnwitzige Strategie: «There must be a dozen armed hoods waiting to drop me [...]. But I've got one slim chance [...]! They don't know who I really am ... but there's one thing they'd never believe [...] that the ol' daring dazzler could be a blind man! So it's time for me to give the greatest performance of my life ...! ! ${ }^{{ }_{3}}$ Auch diesmal geht der Plan auf: Die Gangster demaskieren den offensichtlich unsicheren Daredevil und fallen auf seine Täuschung herein. «[...] they have no idea our hero has outright revealed his deepest secret to the world [...]. But the truth is too absurd, too laughable, even when put on full display [...]», fasst es Alaniz zusammen. ${ }^{84}$ Im Rückgriff auf den closet lässt sich hier behaupten, dass ein Coming-out keines ist, wenn es niemand glaubt - wie jede Darstellung, die gelingen soll, bedarf es dazu eines Publikums, das die Darstellung als authentisch versteht (vgl. das Kapitel zu Masken, Rollen, Identitäten).

Die Maskerade des maskierten Helden steht nicht selten in der Kritik, weil sie oft schlechterdings unglaubwürdig ist. Mit den Mechanismen des passing lässt sich dies aber bis zu einem gewissen Grad erklären, sodass das Unglaubliche der Maskerade nicht mehr völlig abwegig ist. So schreibt etwa Siebers: «Passing is possible not only because people have sufficient genius to disguise their identity, but also because society has a general tendency to repress the complex embodiment of difference.» ${ }^{85}$ In den frühen $D D$-Comics ist dies gut an Karen zu beobachten: Sie befindet sich - wie oben bereits erwähnt - mehrmals auf der richtigen Fährte, unterdrückt den Gedanken, dass Matt vielleicht doch nicht blind und Daredevil ist, aber jeweils rasch wieder als gedanklichen Irrweg, da sie die Prämisse, dass ein Blinder kein Superheld sein kann, nicht zu hinterfragen wagt.

83 «Unmasked!» (Stan Lee, Gene Colan, J. Tartaglione et al.), in: DD 29, Juni 1967, I0. (Als die Gangster ihn als Matt Murdock erkennen, erklärt er, er habe schon erwartet, dass sein Trick nicht funktionieren würde, aber er habe gedacht, wenn sie zuerst auf ihn schiessen würden, hielten sie Daredevil für erledigt und würden ihn nicht mehr erwarten, wenn dann der <echtes Daredevil ankomme.)

84 Alaniz 201 2, 370. Alaniz bespricht einige weitere Episoden, in welchen Daredevil einige fast grotesk-absurde Szenarien verschachtelter Verkleidungen durchspielt, die die Prämisse der Superheldencomics, dass der Held nicht erkennbar ist, geradezu ins Extreme steigern.

85 Siebers 20II, 100. Alaniz (2012, 370, 372) führt dies noch weiter aus: «[...] the passers and their audience are collaborators in the social construction of the masquerade. The passer, and expert manipulator, plays precisely to the prejudices of the greater culture; [...] Daredevil is a superhero. Therefore, anything he does [...], is interpreted by onlookers in heroic terms.» 
Die eben erwähnte Episode mit dem Kidnapperhaus ereignet sich dabei im Rahmen der berüchtigten Storyline um Mike Murdock, die zweifellos einen frühen Höhepunkt von Daredevils/Matt Murdocks Identitätskapriolen darstellt: Mit Mike Murdock erschafft sich Matt eine dritte Identität, um sein Geheimnis zu schützen. Ironischerweise bringt die ganze Geschichte ein Brief von Spider-Man ins Rollen, in dem er Matt schreibt, er wisse, dass Matt Daredevil sei, doch sei dieses Geheimnis bei ihm sicher. Da Matt zu diesem Zeitpunkt als verschollen gilt, öffnen Foggy und Karen den Brief in der Hoffnung, darin einen Hinweis auf Matts Verbleib zu finden. Kaum von seinem Abenteuertrip im Ausland zurück, wird Matt deshalb zur Rede gestellt. Dergestalt unter Druck, improvisiert er und erklärt, er werde sie endlich einweihen: Er habe einen Zwillingsbruder namens Mike, und dieser sei Daredevil. Obwohl Foggy ihn schon seit der Schulzeit kennt (wie dieser skeptisch anmerkt), will er ihm noch nie von diesem Zwilling erzählt haben.

Die Konstruktion von Mike stellt einen zweifellos groteske Ausmasse annehmenden Fall von Sich-Hineinreiten (in-deeperism) dar, einem Phänomen, das Goffman definiert als «the pressure to elaborate a lie further and further to prevent a given disclosure» ${ }^{86}$. Um seine Lüge, er sei nicht Daredevil, bewahren zu können, wird die Täuschung immer grösser. Hier nimmt sie sogar die Gestalt einer fingierten Persönlichkeit an, denn Matt sieht nur einen Ausweg, um seine Lüge nicht gestehen zu müssen - nämlich diesen Mike zu spielen, um dessen Existenz zu beglaubigen.

Mit Mike wird die Zweiheit von ziviler und heldischer Identität zu einer Dreiheit (und damit zur Vielheit) erweitert, wenn sich diese letztlich auch als temporär erweisen wird. Wie schon in seiner Daredevil-Identität tut Matt als Mike so, als ob er sehen könnte (und beherrscht dieses passing als Sehender so gut, dass niemand je Verdacht schöpft, obwohl er stets eine auffällige Sonnenbrille trägt). Auch sonst ist Mike in vielerlei Hinsicht als Gegenpart zu Matt angelegt statt als bieder gekleideter Anwalt tritt Mike in lässiger Kleidung auf, strotzt vor Selbstbewusstsein und gibt ausserdem zumindest gegenüber Foggy und Karen $\mathrm{zu}$, dass er Daredevil ist. Laut Schulte ist Mike «to his core, a caricature of the counterculture movement ${ }^{87}$. (Karen ist denn auch im ersten Moment hin und weg von Mike, bevor sie sich wieder umbesinnt.)

Zuerst handelt es sich bei «Mike» nur um eine Verkleidung - Matt selbst macht in der ersten Umkleideszene zahlreiche Anspielungen auf Schauspielkünste. Doch

86 Goffman 1963, 83 (dt. 1975, 107). Dies entspricht in Bezug auf das Geheimnis den Stützlügen (vgl. das Kapitel zu Maskerade und Geheimnis).

87 Schulte 20I 2, 345. Schulte zeichnet diese Entwicklung im Kontext der counterculture detailliert nach. 
findet er auf Anhieb grossen Gefallen an dieser Rolle, sodass diese bald zu einer Identitätsoption für ihn wird. In einem Monolog, der als Zusammenfassung für die Leser fungiert, erklärt der Protagonist seine drei Identitäten einmal so:

I'd better change to Matt Murdock fast, and then - no! Just for kicks, I'll become Matthew's frantic, fast-talkin' twin brother! I'm beginning to enjoy the role of madcap Michael Murdock! I guess I'm really as big a ham as «he» is! Anyway, if anyone saw ol' $D D$ swingin' in thru the window, this'll help to convince 'em that the Fearless One really is brother Mike! I'm beginning to feel like a one-man repertory theatre! First, I'm conservative Matt Murdock, the blind courtroom whiz! Then, I'm also dazzlin' $D D$, the darlin' of the swashbucklin' set. And finally, to keep anyone from linking me with hornhead, I've become Mike Murdock, my own make-believe twin brother! [...] [Er zieht sich um.] Now, all I've gotta do is change my personality. ${ }^{88}$

Die Szene belegt einmal mehr das Motto «Kleider machen Leute», wenn der Protagonist nach seinem Kleiderwechsel nonchalant seine Persönlichkeit passend dazu wechseln will. Wiederum bringt Alaniz dies auf den Punkt: «Daredevil stands revealed as even more invested than the typical superhero title in the logic of passing, there is never a time, in fact, when Murdock is not passing as something or someone [...].» ${ }^{89}$ Auffallenderweise aber wird in diesem Identitätsdreiecksverhältnis entweder der Kontrast zwischen Matt und Mike (Abb. 44) oder zwischen Matt und Daredevil betont, zwischen Mike und Daredevil scheint es dagegen - ausser der äusserlichen Erscheinung - kaum eine Differenz zu geben (insofern ist Matt a priori die <bessere zivile Identität). Eine Differenz scheint allerdings auch weniger nötig zu sein, sind doch Foggy und Karen eingeweiht, dass Mike Daredevil ist.

Schon vor der Mike-Storyline gibt es Szenen, in welchen Daredevil/Matt Murdock mehrfach explizit das Gefühl ausdrückt, dass er in Wahrheit> Daredevil ist und Matt nurmehr eine gespielte Rolle - so in $D D$ I 2, als er zu spät dran ist, um ein Kreuzfahrtschiff zu erreichen:

Slow-moving Matt Murdock could never make it in time ...! But this is the sort of challenge ... that Daredevil thrives on! [...] This is what I needed! The wind in my face ... the world at my feet! Now, for the first time in days ... I feel really alive! I'm no longer acting... no longer pretending! I'm doing what I do best ... what I was meant to do!! I'm free once more ... unfettered at last! Like a bird uncaged ... Prometheus unbound! And now, it's time to really start moving!90

88 Stilt-Man Strikes Again! (Stan Lee, Gene Colan et al.), in: DD 26, März 1967, 3. Vgl. Alaniz 2012,367, und Schulte 2012, $345 \mathrm{f}$.

89 Alaniz 2012, 365.

90 «Sightless, in a Savage Land!» (Stan Lee, Jack Kirby et al.), in: DD I 2, Januar 1966, 3. 
Abb. 44: Als Mike Murdock entdeckt Matt völlig neue Seiten an sich. Aus dem 〈braven〉 Anwalt mit einem ernsten Geheimnis wird ein frecher, lebensfroher, wenn auch oberflächlicher Dandy - und Matt weiss gar nicht mehr, wer er denn nun in Wahrheit ist. " $U n$ masked!» (Stan Lee, Gene Colan, J. Tartaglione et al.), in: Daredevil 29, Juni 1967, I. (C) Marvel Comics

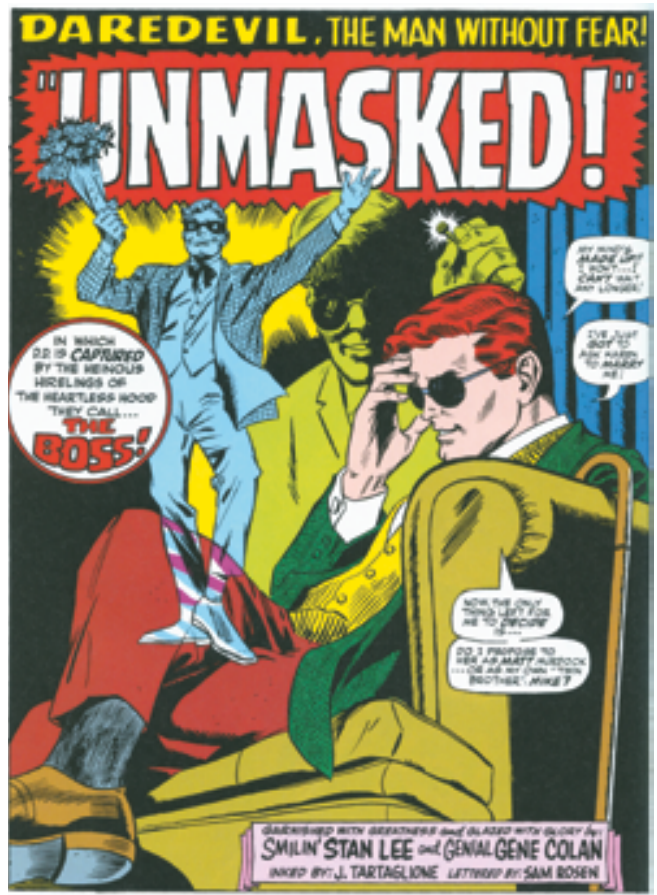

Damit scheint der Protagonist ein Paradebeispiel für die <Umkehrung der Maskerade` zu sein, dem die Maske erlaubt, sein ‘wahres Ich` zu enthüllen. Ähnlich wie bei Spider-Man sind solche Szenen auch bei Daredevil meist gekoppelt mit der schieren Freude an der eigenen, einzigartigen Bewegungsfähigkeit. $9^{\text {I }}$ Mit Mike als Drittem drängt sich die Frage nach der authentischen Identität weiter auf. Dies wird in jener absurden Szene offenbar, als der Protagonist beschliesst, Karen einen Heiratsantrag zu machen: «But I still haven't figured out ... do I propose to her as Matt Murdock or should I pop the question as Mike? If only I myself knew which one of us is the real me!! ${ }^{92}$

Ähnlich wie Spider-Man sind Daredevil Grübelei und Zweifel nicht fremd. So verweist auch Goffman darauf, dass passing oft eine innere Zerrissenheit zur

9I Eine solche Szene findet sich beispielsweise auch in "And Men Shall Call Him ... Ox!» (Stan Lee, John Romita, Frankie Ray et al.), in: $D D$ i s, April I966, if.

92 «Unmasked!» (Stan Lee, Gene Colan, J. Tartaglione et al.), in: DD 29, Juni I967, 6. 
Folge haben kann, allerdings spekuliert er auch, dass die oft beschworene Angst des passers nicht immer vorhanden sein muss. ${ }^{93}$ Entsprechend kennt Daredevil zwar auch solche Momente der Angst und des Selbstzweifels, doch fällt auf, dass er diese nicht selten resolut beiseite schiebt (oft um sich eines drängerenden, <actionlastigeren> Problems anzunehmen). So ergänzt er die eben zitierte Aussage noch mit einem Zusatz: «But, what's the difference ... as long as she says yes!!»94 Obschon also die Frage nach der <realen> Identität des Protagonisten immer wieder thematisiert wird, erscheint sie so am Ende meist unwichtig. Daredevil hat zu dieser Zeit jedenfalls noch eine starke Tendenz, seine Identitätskapriolen durchaus mit einem gewissen Sinn fürs Absurde zu betrachten, zugleich vertraut er auf seine Improvisationskünste, wie etwa eine Aussage illustriert, bevor er Mike als Wesen aus Fleisch und Blut auftreten lassen muss: «Matthew [...] - what have you gotten yourself into now? Where in the name of my little hood-horns am I gonna dig up a non-existent twin brother? Well, I'll play it by ear for a while and maybe an idea will hit me!»95

Und doch: Subtil scheint letztlich doch immer die Matt-Identität (auf der die Freundschaft zu Foggy beruht) seine identitätsbezogene Conditio sine qua non zu sein. ${ }^{96}$ Obwohl dies selten prominent inszeniert wird, lässt sich dies an gewissen Details ablesen, wenn Matt sich etwa so sehr freut, dass Karen ihn liebt ( «She loves me! Not Daredevil ... not some scarlet swashbuckler ... But me! Me!»97) oder dass er sich in reflektierenden Selbstgesprächen stets mit «Matt» anspricht. Nichtsdestotrotz aber demonstriert Mike Murdock die erstaunliche Fluidität von Matts Identität(en). Der Schlüssel dazu liegt aber wohl gerade nicht in der Trennung der verschiedenen vorgespielten Identitäten, sondern in ihrer Einheit.

93 Goffman 1963, 87 (dt. 1975, i i i).

94 Dass er Karen dabei zuerst vielleicht in sein Helden-Ich einweihen sollte, fällt ihm nicht ein; auch, wie das gehen sollte, dass er ihr als Mike auf Dauer seine Blindheit verheimlichen könnte (geschweige denn wie Mike als nichtamtliche Person heiraten könnte), übergeht der in den sprichwörtlichen rosa Wolken schwebende Held hier. Es verwundert denn auch nicht, dass er bis zum Ende des Hefts wieder überzeugt ist, dass er sie mit einem Geständnis in Gefahr bringen würde und so entsagt.

95 «Enter: The Leap-Frog!» (Stan Lee, Gene Colan, Frank Giacoia et al.), in: DD 25, 7. Die Szene bekräftigt ausserdem die 〈Umkehr der Maskerade»: «Meanwhile, I felt like I was suffocating in that business suit of mine! I'd have jumped out of my skin if I had to wait any longer to get into my working clothes! I never realized Daredevil was so much a part of me! It's like DD is my real identity - and I'm just play-acting as Matt Murdock!»

96 Freilich kommt es später dazu, dass er eine Zeitlang nur noch als Daredevil existiert (Matt gilt als tot) und sich auch nochmals eine andere Identität als Boxer (eine Hommage an seinen Vater) zulegt. In mehreren Phasen zeigen die Daredevil-Comics solche Entwicklungen des Helden, nur um schliesslich zur etablierten Doppelidentität zurückzukehren.

97 Run, Murdock, Run! (Roy Thomas, Barry Smith, George Klein et al.), in: DD 5 I, April I969, I 3. 
So betont auch Alaniz: «Daredevil and Murdock are one in ways that most other superheroes are not $[\ldots] . »^{98}$

Aus der zunächst befreienden Erfahrung der Mike-Identität wird mit der Zeit jedoch eine Last. Auch mit einer dritten Identität, lernt Matt, lassen sich Missverständnisse nicht vermeiden; auch jetzt kann er nicht erklären, wie sich etwas «wirklich〉 verhält, wenn er aufgrund fehlenden Wissens um sein Geheimnis kritisiert wird. Er konstatiert: «I'm afraid I out-smarted myself when I took on a third identity [...]! I never dreamed it would lead to such embarrassing complications! Now, my partner and best friend thinks I'm a coward - and the girl I love has lost all respect for me!»99

Aufgrund dieser Missstimmung wird er seine dritte Identität endgültig leid. $\mathrm{Zu}$ diesem Prozess lässt sich eine Passage von Siebers heranziehen: «Temporary passing is empowering, producing brief moments of freedom from the prejudice $[. .$.$] . Pretending to be able-bodied is one way of performing normalcy,$ of inserting oneself in society and escaping the alienating experience of being disabled.» ${ }^{100}$ Körperliche Unversehrtheit stellt Matt zwar auch als Daredevil dar, doch haben Superhelden a priori einen Platz ausserhalb der Gesellschaft, was die anfängliche besondere Anziehungskraft der Mike-Rolle für ihren Darsteller erklärt. Allerdings spricht Siebers gleich darauf die Kehrseite des passing an: «In the long term, however, disabled people who try to pass may feel guilty or become depressed about constructing their acceptance $[\ldots] .{ }^{101} \mathrm{Ob}-$ wohl man bei Matt Murdock/Daredevil hier nicht von einer Depression sprechen kann und auch seine Schuldgefühle nur diffus scheinen, bringt ihm die dritte Identität auf Dauer keine Vorteile mehr. So toll es sich anfühlte, einige Zeit Mike zu sein, werden die Dinge dadurch nur komplizierter: «It's easier ... just to be ... Matt Murdock!» ${ }^{102}$, erkennt er und beschliesst, Mike sterben zu lassen.

Nachdem Mike vermeintlich bei einer Explosion ums Leben gekommen ist, erhält Matt eine Gelegenheit, das Daredevil-Kostüm zu verabschieden. Doch während er sich mit dem Gedanken trägt, vereiteln die aktuellen Geschehnisse allzu

98 Alaniz 201 2, 369.

99 «Daredevil Dies First!» (Stan Lee, Gene Colan, J. Tartaglione et al.), in: DD 35, Dezember 1967, 5. Als der Trapster in die Kanzlei marschiert und sich nach dem Strafmass für Mord erkundigt, stellt sich heraus, dass er Daredevil töten will. Foggy und Karen, die immer noch Mike für Daredevil halten, wollen Matt dazu bringen, diesen zu warnen - Matt redet sich aber (etwas ungeschickt) heraus, sodass ihm die anderen Herzlosigkeit vorwerfen.

IO० Siebers 20II, II8.

IOI Ebd.

I02 «The Death of Mike Murdock!» (Stan Lee, Gene Colan, John Tartaglione et al.), in: DD 4I, Juni 1968, 20. 
langes Nachdenken (denn selbstverständlich ist der Rücktritt von der Heldenrolle für einen Serienprotagonisten in der Regel keine Option). Um Foggy und Karen erneut aus Verbrecherhand zu befreien, bleibt ihm keine Wahl, als erneut als Daredevil aufzutreten, sodass seine ursprüngliche Doppelidentität Bestand hat. ${ }^{103}$ Dabei ist ihm jedoch bewusst, dass diese auch Opfer verlangt. In diesen Anfangsjahren hegt Daredevil/Matt Murdock so noch die Vorstellung, dass er seine Angebetete nicht einweihen kann, um sie nicht in Gefahr zu bringen. Schon in $D D$ s hat er dies mit einer gewissen Bitterkeit, aber nicht weniger Entschlossenheit betont: «After all, can Daredevil offer a girl the type of life all brides dream of? No ... this must be fate's way of telling me that I'm destined to always be ... a loner! [...] Where Daredevil walks, he must walk alone! Thus do I accept my lonely fate!» ${ }^{104}$ Dieser Verzicht wird über die ersten Jahre immer wieder aufgenommen - abwechslungsweise mit seinem Wunsch, doch eine Beziehung mit Karen anzufangen und ihr seine Liebe zu gestehen. Bei diesem Aspekt könnte man vielleicht von einer weiteren Spielart eines situativen passing sprechen: In zahlreichen Szenen versuchen sowohl Matt als auch Karen, sich in einer Weise zu verhalten, dass die anderen nichts von ihrer Verliebtheit mitbekommen. Als Karen vor lauter Frustration aus unerfüllter Liebe schliesslich kündigt, geht Matt deswegen sogar so weit, dass er sie grob wegschickt, um ihr den Abschied leichter zu machen - was nur dazu führt, dass sich beide noch elender fühlen. Nach langem Hin und Her ${ }^{105}$ kommt es schliesslich dazu, dass er Karen doch noch einweiht. Nachdem er seinen (Matts) Tod inszenieren musste, um einer Erpressung des Superschurken Starr Saxon zu entgehen, demaskiert er sich (auf dem Friedhof, am Grab ihres gerade verstorbenen Vaters) und gesteht als Cliffhanger in DD 57 (1969) gleich viererlei: Er ist nicht tot, er liebt sie, er hat Superkräfte und ist Daredevil. Ausnahmsweise scheint Karens unmittelbare Reaktion, in Ohnmacht zu fallen, nicht ungerechtfertigt. Das einem passing-Geständnis innewohnende melodramatische Potenzial hat dabei schon Goffman nicht ganz in neutralem Tonfall zu beschreiben vermocht:

I03 Als Matt erklärt er die Rückkehr des vermeintlich verstorbenen Daredevil so, dass sein Bruder Mike einen Nachfolger ausgebildet habe, dessen Identität er aber nicht kenne. Wie Schulte (20 2, 345 f.) aufzeigt, vereinigt Matt nach Mikes Tod die beiden Seiten, was seine zivile Ausgestaltung angeht, indem er etwas von Mikes äusserlicher Lockerheit behält.

I04 «The Mysterious Masked Matador!» (Stan Lee, Wallace Wood et al.), in: DD 5, Dezember I964, I 2.

Ios In $D D 49$ (1969) beschliesst er, seiner Daredevil-Rolle für immer zu entsagen, weil er durch sie Karen unwiderruflich verloren glaubt. Aber als er sich ausziehen will, hat er einen mörderischen Roboter im Schrank, womit seine Rückzugspläne umgehend vereitelt sind. 
In the case of post-stigma relationships that have gone past the point where the individual should have told, he can stage a confessional scene with as much emotional fuss as the unfairness of his past silence requires, and then throw himself on the other's mercy as someone doubly exposed, [...] first in his differentness and secondly in his dishonesty and untrustworthiness. ${ }^{106}$

Nach einer Aussprache beschliessen sie, immer zusammenbleiben zu wollen doch wird die Erzählung diesbezüglich nun immer sprunghafter. ${ }^{107}$ Letztlich kann Karen sein Heldentum - in gewisser Weise sein selbst gewähltes Stigma (noch) nicht akzeptieren. Dass er dieses gegen ihren Wunsch nicht aufgeben will, führt letztlich zur Trennung. Karen beginnt eine Schauspielkarriere, und zu diesem ins Rampenlicht führenden Beruf will ein Superheld mit Doppelidentität kaum passen.

Allerdings wartet mit Black Widow/Natasha Romanova bereits die nächste Geliebte auf ihn. ${ }^{108}$ Mit ihr zieht er nach San Francisco, um dort neu anzufangen. Selbstverständlich ist es etwas auffällig, wenn ein Superheld gleichzeitig wie einer seiner bekanntermassen häufigsten Kontaktpersonen umzieht - dies bietet der Presse reichlich Material für Spekulationen. Um den medialen Verdacht zu widerlegen, greift Matt nochmals auf Mike zurück: Dieser habe seinen Nachfolger gebeten, auf seinen Zwillingsbruder Matt aufzupassen, daher habe der neue Daredevil seinen Wohnort ebenfalls verlegt. Zusätzlich aber hat er Black Panther/T'Challa, der inzwischen ein Eingeweihter ist, um einen Gastauftritt in seinem Kostüm gebeten; dieser schwingt gut sichtbar als Daredevil hinter der Pressekonferenz durchs Bild. Als Mitwisser erhält Black Panther, der ja selbst eine geheime Identität unterhält, den Status des Vertrauten. Auch hier zeigt sich ein typisches Phänomen unter Stigmaträgern: «Interessanterweise können diejenigen, die ein bestimmtes Stigma teilen, sich oft auf gegenseitige Hilfe beim Täuschen verlassen, was wieder veranschaulicht, dass diejenigen, die am bedrohlichsten sein können, oft die sind, die am meisten Hilfe leisten können.» ${ }^{109}$ Auch der Ausflug nach San Francisco wird sich als temporär erweisen - in DD Io8 (1974) zieht Matt zurück nach New York. Damit möchte ich es für Volume I bewenden lassen und dafür noch kursorisch die Geschehnisse in den Volumes ${ }_{2-4}$ in den Blick nehmen.

I06 Goffman 1963, 95 (dt. 1975, I2 I).

I07 Beispielsweise wollen sie in DD 62 (1970) zusammenziehen, nur um im nächsten Heft schon wieder (zwischenzeitlich) getrennt zu sein.

I08 Mit Natasha hat er eine Abenteuerpartnerin, doch auch dieses Paar trennt sich nach einiger Zeit. Es war das erste Superheldenpaar, das zusammenlebte, ohne verheiratet zu sein (Schulte 201 2, 355).

I09 Goffman 1975, I23 (engl. 1963, 97). 


\section{Das offene Geheimnis: «l am (not) Daredevil»}

Obwohl mit Volume 2 I998 eine neue Heftzählung begann, wurde die Geschichte inhaltlich fortgeführt. In Volume I schien die Doppelidentität des Protagonisten über teils lange Zeiträume nur noch pro forma zu bestehen. Sie spielte narrativ oft keine Rolle mehr, obwohl sie die Konnotation des Unglücksfaktors erhielt, nachdem der «Kingpin» Wilson Fisk, das Oberhaupt der kriminellen Kreise, hinter die Identität seines hartnäckigsten Gegners gekommen war. Daraufhin zerstörte Fisk Matts Leben fast völlig. Nach einer langen Krisenphase - in der er sich eine Zeit lang nochmals eine neue zivile Identität zulegte, während er Matt totsagte - konnte er sich dennoch einiges wieder aufbauen. Am Beginn der neuen Zählung stehen dabei zunächst verwickelte dramatische Ereignisse, auf deren tragischem Höhepunkt der Schurke Bullseye Karen ermordet. Am Ende dieses Handlungsstrangs ersteht die Kanzlei Nelson \& Murdock aus der Asche wieder auf, denn im Lauf der Jahre erweist sich Foggy und nicht etwa eine bestimmte Geliebte als die wichtigste Bezugsperson des Protagonisten ${ }^{10}$.

Danach folgen diverse abgeschlossene Story-Arcs, die teilweise die typischen Doppelidentitätsmotive wieder ins Zentrum des Plots rücken. Dazu zählt Parts of a Hole, in der Matt sich in die gehörlose Maya verliebt, die Daredevil für den Mörder ihres Vaters hält und als Superheldin/-schurkin Echo Rache an ihm sucht, wobei seine Demaskierung ihn schliesslich entlastet, da er schlicht zu jung ist, um das Verbrechen begangen zu haben. ${ }^{111}$

Etwas leichter wird die Erzählweise namentlich im Story-Arc Playing to the Camera, in dem es erstmals dazu kommt, dass Matt Murdock für einen Klienten Daredevil wegen Sachbeschädigung anklagen muss. Da er weiss, dass er unschuldig ist, hat er das Gefühl, seinen heimlichen Wissensvorsprung so am besten einsetzen und zudem den Fall kontrollieren zu können, der indes ziemlich ausser Kontrolle gerät. Diese Geschichte lässt sich ohne Weiteres als literarische Umsetzung einer Geheimnistheorie, wie sie zu Beginn dieses Buches präsentiert wurde, lesen, in der sich Matt Murdock auf eine glitschige Bahn der

I IO Zwar zerstreiten sich die beiden Freunde regelmässig, versöhnen sich aber ebenso oft wieder, und auch als inzwischen Eingeweihter erweist sich Foggy durch alle Höhen und Tiefen wirtschaftlichen (Miss-)Erfolgs als loyaler Vertrauter. Zum kleinen Kreis der zivilen Eingeweihten zählt (neben anderen Helden) ausser Foggy der Journalist Ben Urich, der beim Daily Bugle arbeitet und Daredevils Identität lange vermutet und dann durch seine Blindheit auch bewiesen hat (Daredevil konnte nicht sagen, was auf Fotos zu sehen ist), diese Story aber nie gedruckt hat.

I I Parts of a Hole (David Mack et al.), in: DD v2, 9-1 5, Dezember 1999-April 2001. Dieser Plot wurde übrigens in der Filmadaption Daredevil (2003, Regie: Mark Steven Johnson) auf Elektra, Matts erste grosse Liebe und Auftragskillerin einer Kampfsekte, übertragen. 
Verschleierung und Irreführung begibt, die er nur dank der Kombination der Informationsmöglichkeiten seiner beiden Identitäten meistert. Auch hier bleibt am Ende nur der 'Superheldentricks, um in zwei Personen an einem Ort zu sein: Matt Murdock befragt vor Gericht Daredevil, hinter dessen Maske jedoch Peter Parker steckt (was die Leser zwar vermuten, jedoch erst nach der Gerichtsszene bestätigt wird). ${ }^{112}$

Anschliessend erfolgte ab DD 26 (200I) ein markanter künstlerischer Wechsel, der die Tonalität der Zeichnungen wie der Narration wieder stark veränderte. Nach der vorangegangenen kurzzeitigen Aufhellung wurde Daredevils Welt in zwar nicht gerade düstere, aber doch eher Hoffnungslosigkeit denn Spass und Abenteuer evozierende Schraffuren und Schattierungen getaucht. Weniger Daredevils Heldenaktionen stehen im Zentrum, als wie sich die Figuren, ähnlich wie in einer Film-noir-Welt, durch unauflösbare Verstrickungen zu manövrieren versuchen, wobei ihnen in vielem nur das Erdulden ihres Schicksals bleibt.

In der Folge von Machtintrigen in Wilson Fisks Verbrecherorganisation stellt sich ein Mafiamitglied der Polizei. Auf dessen Hinweis hin zieht auch das FBI aufgrund von Indizien die entsprechenden Schlüsse, verhängt jedoch Geheimhaltung. Doch über einen Polizisten in Geldnot gelangt das Geheimnis zur Klatschpresse und wird so in $D D$ v2 32 (2002) zur sensationellen Schlagzeile. ${ }^{113}$ Matt sieht sich gegen seinen Willen geoutet - trotz (oder wegen) seiner zahlreichen vergangenen risikoreichen passing-Meisterstücke hätte er dies nie erwartet, wie er Foggy erklärt: «I'm an idiot, Foggy. [...] I never even imagined I would find myself in these situations. Never in a million years.» ${ }^{14}$ Dies ist insofern verständlich, da Matt/Daredevil kein Darstellungsfehler unterlaufen ist und er den 〈Verräter` gar nicht kennt. Während die Medien sein Haus belagern, berät er mit Foggy, ob er das Outing bestätigen soll oder nicht. Matt wäre im ersten Moment noch willens, reinen Tisch zu machen, doch bringt ihn Foggys Einwand, dass damit nicht nur seine berufliche Existenz, sondern die Neuverhandlung aller von ihm bearbeiteten Fälle auf dem Spiel steht, davon ab. Ab diesem Zeitpunkt aber hält Matt im restlichen Lauf des Volumes fast schon verbissen an seinem Hel-

I 2 Um seine Authentizität vor Gericht zu verifizieren, ohne sich zu demaskieren, führt Peter einige akrobatische Sprünge aus. Die Handlung erhält allerdings eine unerwartete Wendung, als ein zweiter Daredevil durchs Fenster springt, der die Schuld auf sich nimmt; dabei handelt es sich aber um eine Art deus ex machina, um einen sonst nicht in dem Fall verwickelten Schauspieler, der damit Ruhm, einen Buchdeal und eine Frau zu gewinnen sucht (Playing to the Camera (Bob Gale, Phil Winslade et al.), in: DD v2 I9-25, September-Dezember 200I).

I 3 Out. Part I (Brian Michael Bendis, Alex Maleev et al.), in: DD v2 32, Juni 2002.

I 4 Out. Part 2 (Brian Michael Bendis, Alex Maleev et al.), in: DD v2 33, Juli 2002. 
denkostüm fest, selbst wenn er sich temporär zurückhält, um nicht in flagranti erwischt zu werden.

Ein Nebenschauplatz des Skandals illustriert dabei das starke Band, das die Mitwisser eines Geheimnisses verbindet: Sowohl Peter Parker als auch der Journalist Ben Urich, die in die Doppelidentität eingeweiht sind, reagieren mit dem Versuch der Schadensbegrenzung. In dem Moment, als Daily Bugle-Chef J. Jonah Jameson Beweise für die Story finden will, beteuern sie vor der versammelten Redaktion, sie wüssten mit Sicherheit, dass Daredevil nicht Matt Murdock ist. Um den Geheimnisinhalt zu schützen, machen sie daher aus einem reflexivem ein einfaches Geheimnis (und erkennen sich erst jetzt gegenseitig als Mitwisser). ${ }^{\text {Is }}$ Dies bietet Urich und Jameson Anlass, darüber zu diskutieren, ob ein Outing, eine Fremdentlarvung, in diesem Fall in die Schlagzeilen gehört oder nicht. ${ }^{\text {I6 }}$ Urich bleibt dabei auf seinem Standpunkt, dass zwar Daredevils Taten News seien, nicht aber dessen Identität. Die Frage, warum jemand seine Identität maskiert, um als Held loszuziehen, wird in den folgenden Heften immer wieder gestellt, aber von verschiedenen Figuren anders und so nicht definitiv beantwortet. Doch allein durch das Stellen der Frage erhält das Maskentragen einen viel prekäreren Stand als zuvor, da es immer wieder gerechtfertigt werden muss.

Da der Verdacht nicht bewiesen werden kann und Matt sich weigert, diesen durch ein Coming-out zu bestätigen, ja vielmehr als Gegenangriff das Boulevardblatt auf 400 Millionen Dollar Schadenersatz verklagt, bleibt Daredevils Identität für die Öffentlichkeit in der erzählten Welt unbestätigt (Abb. 45). Dieser $<$ Schwebezustand > der Information wird untypischerweise über mehr als ein Jahrzehnt aufrechterhalten; auf einen Retcon, der die Sache ungeschehen macht, oder ein 〈definitives C Coming-out wartet man im Laufe von Volume 2 vergebens. Während alle Welt zweifelt, ob der «Man Without Fear» in Zivil nun Matt Murdock heisst oder nicht, ist für ihn die Frage danach, welche seiner Identitäten wohl die ‘wahre> sei, völlig bedeutungslos geworden (was nicht heisst, dass nicht diverse andere Identitätsaspekte thematisiert würden, die ‘wahre> Identität definiert sich nun eher über das Verständnis von Heldentum). Während er in den ersten Jahren in DD 6I noch Aussagen traf wie «Until I'm sure whether the real ‘me is Matt Murdock ... or Daredevil ... I've got to be both men!» ${ }^{\mathrm{I} 7}$, scheint es nun keine Entweder-oder-Frage mehr zu sein, vielmehr lässt sich in Volume 2 die implizite Antwort unterstellen, dass er nur beide sein kann.

I 5 Out. Part 3 (Brian Michael Bendis, Alex Maleev et al.), in: DD v2 34, August 2002.

I 6 Zur moralischen Debatte für und wider das Outing im Kontext von sexueller Identität vgl. Harrison 2013, I80.

I 7 Trapped - by The Trio of Doom! (Stan Lee, Roy Thomas et al.), in: DD 61, Februar 1970, 7. 
Abb. 45: Maskierter Held im Zwielicht: Als offenes, aber unbestätigtes Geheimnis laden Matts verschiedene, konträre Rollen die Klatschpresse zum Spekulieren ein. Doch wüsste wohl auch Matt selbst keine genaue Antwort auf die Frage, was oder wer er denn nun ist - das Aushalten von Spannungen wird sozusagen zu einer Überlebensstrategie. The Widow. Part I. (Brian Michael Bendis, Alex Maleev), in: Daredevil (Volume 2) 6I, August 2004. () Marvel Comics

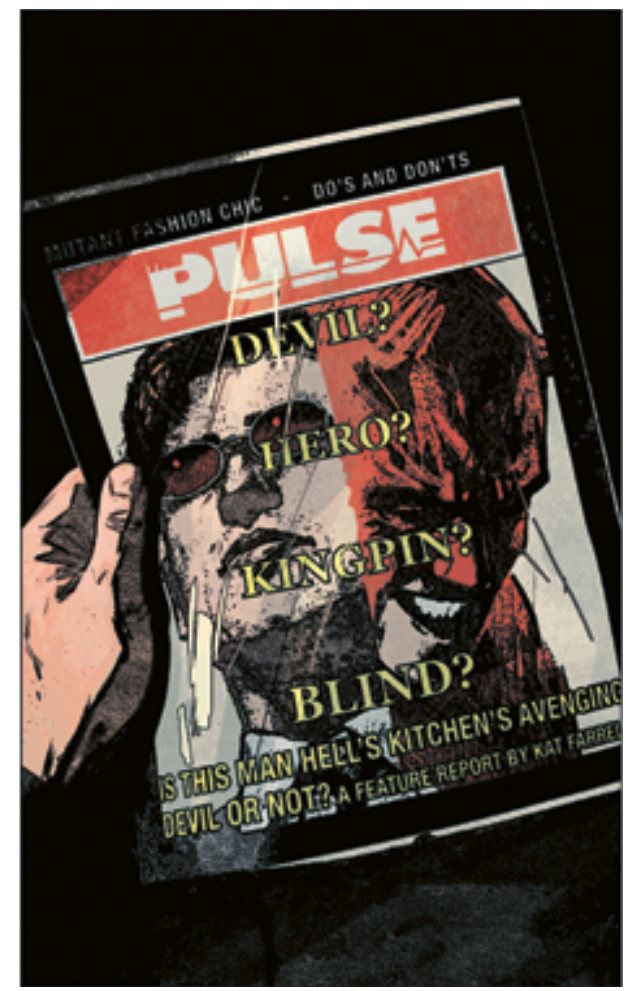

Matts Doppelidentität ist nun also ein offenes Geheimnis und entzieht sich entsprechend der Kontrolle des Geheimhaltenden. ${ }^{118}$ Mit Blick auf den closet könnte man hier vielleicht von einem open closet sprechen - die Tür steht offen, doch müsste sich erst noch bestätigen, dass die Vermutung stimmt, indem Matt diesen closet verlassen würde. Trotzdem versucht Matt, seine Täuschung aufrechtzuerhalten, und tatsächlich liefert er nie einen eindeutigen Beweis für das Gerücht. Nur gerade einmal verrät er sich, und zwar gegenüber Milla, einer Blinden, die er vor einem Verkehrsunfall gerettet hat und später heiratet, wobei auch diese Beziehung durch die Aktionen eines Superschurken getrennt wird. ${ }^{119}$

Die Situation verschärft sich noch, als Fisk und Daredevil erneut aneinandergeraten - Daredevil verprügelt Fisk auf offener, wenn auch verregneter nächtlicher

I 8 Schirrmeister 2004, 62 .

I 19 Nachdem sie mit Mr. Fears Nervengas in Kontakt gekommen ist, erleidet Milla eine dauerhafte psychische Störung und wird in eine Spezialklinik eingewiesen. 
Strasse und ernennt sich selbst zum Kingpin. Spätestens jetzt wäre davon auszugehen, dass die secret identity von Daredevil Geschichte ist. Doch im nächsten Heft erfahren die Leser nach einem narrativen Zeitsprung, dass zwar alle wissen, dass Daredevil Matt Murdock und der neue Kingpin ist, jedoch alle Zeugen schweigen und so nach wie vor nichts beweisbar ist, derweil Matt seine Klage gewonnen und die Schadensersatz-Millionen an ein Nachbarschaftsprojekt für sein Viertel Hell's Kitchen gespendet hat. ${ }^{20}$ Nach einer langen Abwärtsspirale (die später als Reaktion auf Karens traumatischen Tod psychologisiert wird) in der der Held sogar das Verständnis seiner Freunde für sein Vorgehen verliert, unter (ungerechtfertigter) Mordanklage ins Gefängnis kommt und schliesslich die Leitung der Kampf- und Killerorganisation The Hand übernimmt - sowie einer ebenfalls relativ langen Läuterungsphase ist er $\mathrm{zu}$ Beginn von Volume 3 wieder an seinem Ausgangspunkt, in der Kanzlei Nelson \& Murdock. ${ }^{\text {2 I }}$

Das offene Geheimnis wird auch nun nicht gelöst. Dennoch hat Matt grosse Schwierigkeiten, seinen Beruf auszuüben, da ein Auftreten vor Gericht fast unmöglich wird, weil die gegnerischen Anwälte nur zu gern den Fokus auf seine Person schieben; Matt und Foggy verlegen sich darum aufs Beraten von Klienten, die sich vor Gericht selbst verteidigen wollen. Schliesslich findet er in der Assistenz-Staatsanwältin Kirsten McDuffie eine neue Freundin, die von Anfang an überzeugt ist, dass er Daredevil ist. Es wird zu einem Spiel zwischen den beiden, dass sie ihn zu überführen versucht, er jedoch das Offensichtliche niemals zugibt. Auch in der Interaktion mit anderen (Neben-)Figuren muss Matt sozusagen immer wieder die offene Tür des closet in Abrede stellen. In dieser Phase zeigt sich ein Moment des closet, auf den Samuel A. Chambers aufmerksam macht: Er spricht dem Leben inner- und ausserhalb des closet ab, einen steten Zustand darzustellen, vielmehr sei auch dies ein unabschliessbarer Prozess: «One's existence in relation to the closet can never be fixed; with respect to the closet one's identity is always in a state of becoming, but never of being.» ${ }^{\text {I22 }}$ Denn man könne nie «in» oder «aus» dem closet sein - vielmehr bedeutet dies eine ständige Darstellung des Coming-outs oder des konstanten Im-Schrank-Bleibens, da ja bei jeder Interaktion die einmal gewählte Darstellung erneut aufrechtzuerhalten ist.

I 20 Interessanterweise begründet Fisk einmal, warum er selbst Matt/Daredevil nie geoutet hat: «I knew you would dodge it. I knew it. That's why I never outted [sic] you myself. I knew the threat was always stronger than the reality of it. I knew you'd spin it around somehow - deny it with sheer force of will.» (Hardcore. Part 5 (Brian Michael Bendis, Alex Maleev et al.), in: $D D$ v2 50, Oktober 2003.)

I 2 I Volume 3 umfasst 36 Hefte, September 20 I I-April 2014.

I22 Chambers $2003,38$. 
Abb. 46: «I am Dare-

devil»-indem diese drei kleinen Worte die Panelstruktur der Seite ausmachen, wird ihre inhaltliche Sprengkraft (unterstützt von der Farbgebung) offenbar, wobei die Buchstaben die Reaktionen von Matts/Daredevils Heldenfreunden auf diese Nachricht einrahmen (von links oben: Foggy im Spitalbett, Punisher, Black Widow, Fantastic Four, Captain America, Spider Woman, Iron Man, Spider-Man, Ant-Man). Stop the Presses! (Mark Waid, Chris Samnee et al.), in: Daredevil (Volume 3) 36, April 20I4. (C) Marvel Comics

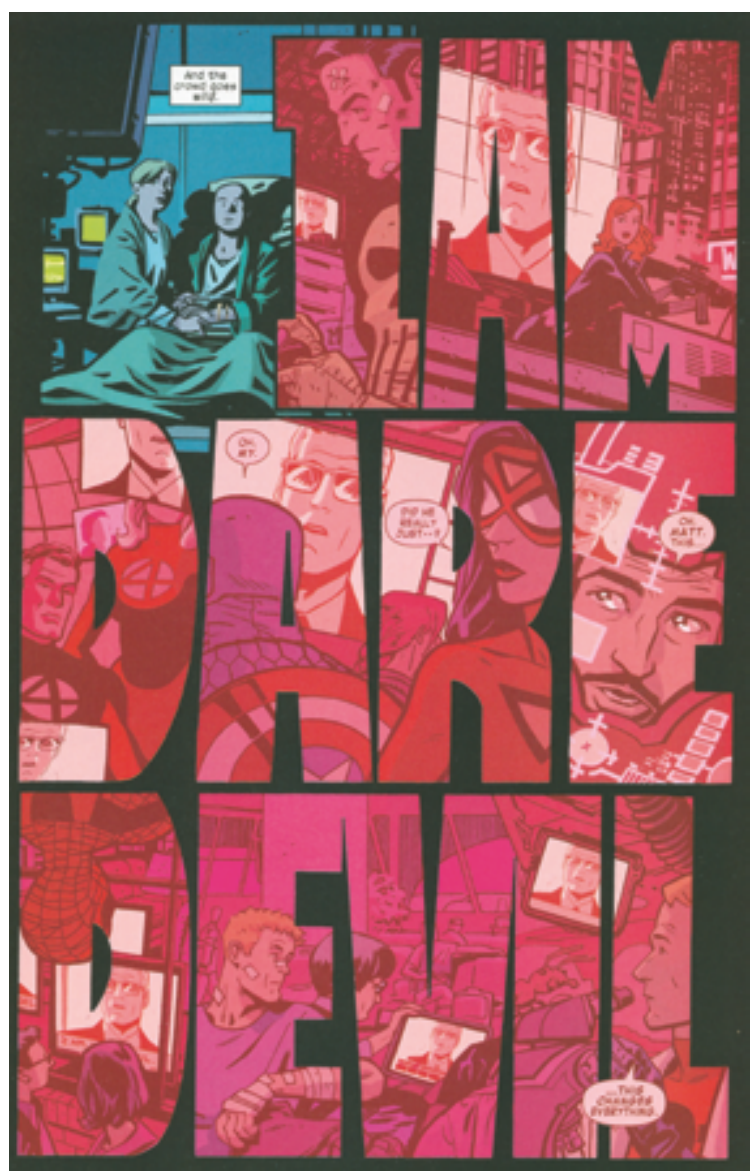

Erst im letzten Heft von Volume 3 ( $\left.D D{ }_{3} 6\right)$ sieht sich Matt gezwungen, vor Gericht unter Eid seine Doppelidentität zu gestehen und seine Superkräfte öffentlich bekannt zu geben. Obwohl er sein Coming-out aufgrund einer Erpressung vollzieht, ist es dennoch seine Entscheidung, die er nach Rücksprache mit Foggy und Kirsten getroffen hat, auch wenn es vielleicht noch andere Auswege gegeben hätte. So findet sein Geheimnis mit der lang erwarteten Anagnorisis ein Ende, womit er nach seiner langen Weigerung seine Superheldenfreunde ziemlich in Erstaunen versetzt (Abb. 46). Wie zu erwarten, verliert er sein Anwaltspatent in New York, beschliesst aber, wieder nach San Francisco zu ziehen, wo dieses noch gültig ist. In Volume 4 schliesslich muss Matt einen neuen Umgang 
mit seiner ehemals geheimen Identität finden: ${ }^{123}$ «I've got a single identity now», wie er in $D D$ v4 ${ }^{\text {I } 4}$ sagt. ${ }^{124}$ Während er sie zunächst eher nicht betonen will, tritt er schliesslich die Flucht nach vorn an: Er schliesst einen Verlagsvertrag für seine Autobiografie ab und tritt als Anwalt vor Gericht im roten Anzug mit «DD»-Gürtelschnalle auf (Abb. 47a und 47b). Zudem beschliesst er, auf seine Maske zu verzichten - obwohl ihm diese nach wie vor, wie Kirsten einwendet, eine Aura des berühmten mystery und damit eine bestimmte Präsenz verleiht -, da er der Masken müde ist und es nun um Ehrlichkeit geht bzw. darum, wer er wirklich ist. Damit legt er bezeichnenderweise nicht nur seine Daredevil-Maske, sondern auch Matts getönte Brille ab, sodass auch mit dem Ausstellen des Blindheitsstigmas Schluss ist. Zunächst hat das Coming-out auch für Daredevil/Matt Murdock gemäss dem gängigen Coming-out-Narrativ ${ }^{125}$ eine befreiende, in gewisser Weise auch neu ermächtigende Wirkung.

Und dennoch: Alte Gewohnheiten sind schwer abzulegen. Im zweitletzen Heft der Reihe droht Matt gegen einen ihm überlegenen Gegner, den asiatischen Kämpfer Ikari, alles zu verlieren. Es sieht bereits nach einer Niederlage aus, als er gleichsam seine Maske wieder aus dem Hut zaubert und danach tatsächlich das Kampfesglück wenden kann (Abb. 48). ${ }^{\mathrm{I} 6} \mathrm{Z}$ war betont Foggy als moralischer Kompass von Matt in einer langen Schlussrede, dass die Schutzfunktion des Geheimnisses - insbesondere im (überwachungstechnikreichen) 2I. Jahrhundert ein Irrglaube sei. ${ }^{127}$ Dennoch ist besagte Kampfszene (auch visuell) ein starkes Bild, das den Eindruck fördert, dass der <richtige> Daredevil eine Maske trägt, da er nur durch sie sein volles Potenzial abrufen kann. Im letzten Bild des Volumes schwingt er sich ebenfalls wieder mit Maske von einem Wolkenkratzer - ohne Geheimnis, aber in seinem gewohnten Kostüm, sodass seine etablierte Doppelidentität immer noch den Charme, aber nicht mehr die Last des Doppellebens zu verkörpern scheint.

I 23 Volume 4 zählt i 8 Hefte, Mai 2014-September 2015.

I 24 [Ohne Titel] (Mark Waid, Chris Samnee et al.), in: $D D$ v4 I4, Mai 2015.

I 5 Vgl. dazu Harrison 20I3, I9, sowie Seidman/Meeks/Traschen 1999, I 3.

I 26 Es lässt sich spekulieren, ob die Rückkehr zum alten Kostüm auch im Hinblick auf die 20I 5 startende TV-Serie Daredevil vorgenommen wurde - doch da der Neustart der Reihe beschlossen war, dürfte hier eher das Bestreben, einen runden Schluss für den Handlungsbogen zu finden, im Vordergrund gestanden haben.

I 27 Foggy erklärt schliesslich, dass Matts Freunde statt auf Geheimhaltung auf sein Heldentum vertrauen: «You get up every morning and you fight an unjust universe because you think you can make a dent. That is exactly the level of arrogance Kirsten and I will always trust to protect us.» Interessanterweise vermag diese Aussage das Heldentum zugleich mit einem kritischen Unterton zu kommentieren und zu zementieren. (Man Without Fear (Mark Waid, Chris Samnee et al.), in: $D D$ v4 I 8, 2015.) 

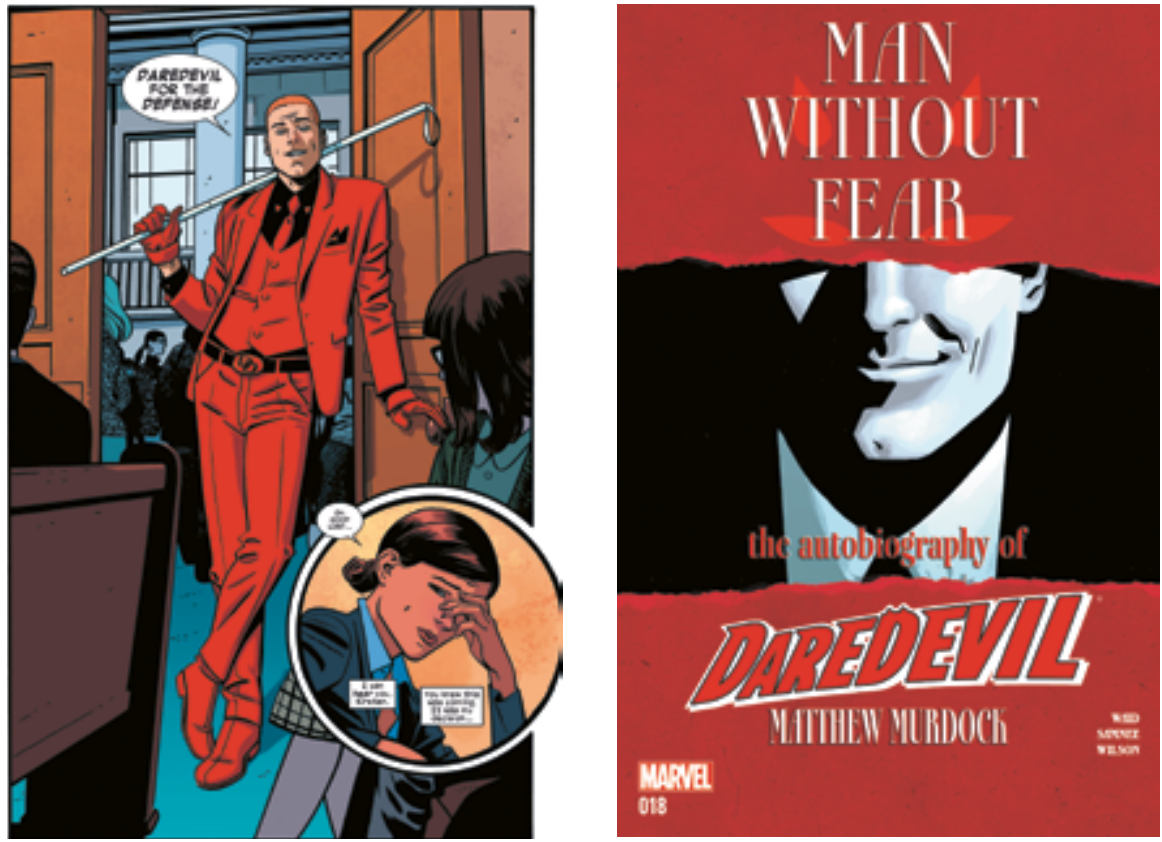

Abb. 47a und 47b: Matt Murdock auf einer splash page im zivilen 〈Daredevil-Anzug〉 und das Titelbild seiner Autobiografie, das einerseits mit den roten Streifen seine Maske nachbildet, aber auch die Assoziation einer zerrissenen Maske, hinter der ihr Träger durchscheint, ermöglicht. Beide Illustrationen präsentieren Matts neue Selbstdarstellung, in der er jedoch trotz offenbartem Geheimnis die Zweiheit seiner Gestalt betont. [Ohne Titel] (Mark Waid, Chris Samnee et al.), in: Daredevil (Volume 4) I4, Mai 2015, und Cover von Daredevil (Volume 4) I 8, November 201 5. (C) Marvel Comics

Als Nachsatz ist hier noch festzuhalten, dass Daredevil/Matt Murdock mit Volume s seiner Heftreihe einen Reboot erhielt - sein Outing und der Verlust seines Anwaltspatents sind nie geschehen, sodass er (mit teils neuen festen $\mathrm{Ne}$ benfiguren) wieder in New York arbeiten kann, und zwar als Staatsanwalt. Das wiederum scheint für Simmels Beobachtung zu sprechen, dass das Geheimnis ein «Individualisierungsmoment ersten Ranges ${ }^{128}$ ist, dass sich also das Verbergen von Wissen als Differenzierung von andern und somit als identitätssteigernd verstehen lässt. Das zurückgehaltene Wissen wird laut Simmel zum persönlichsten Eigentum - so definiert sich die Persönlichkeit des Helden nicht zuletzt über 

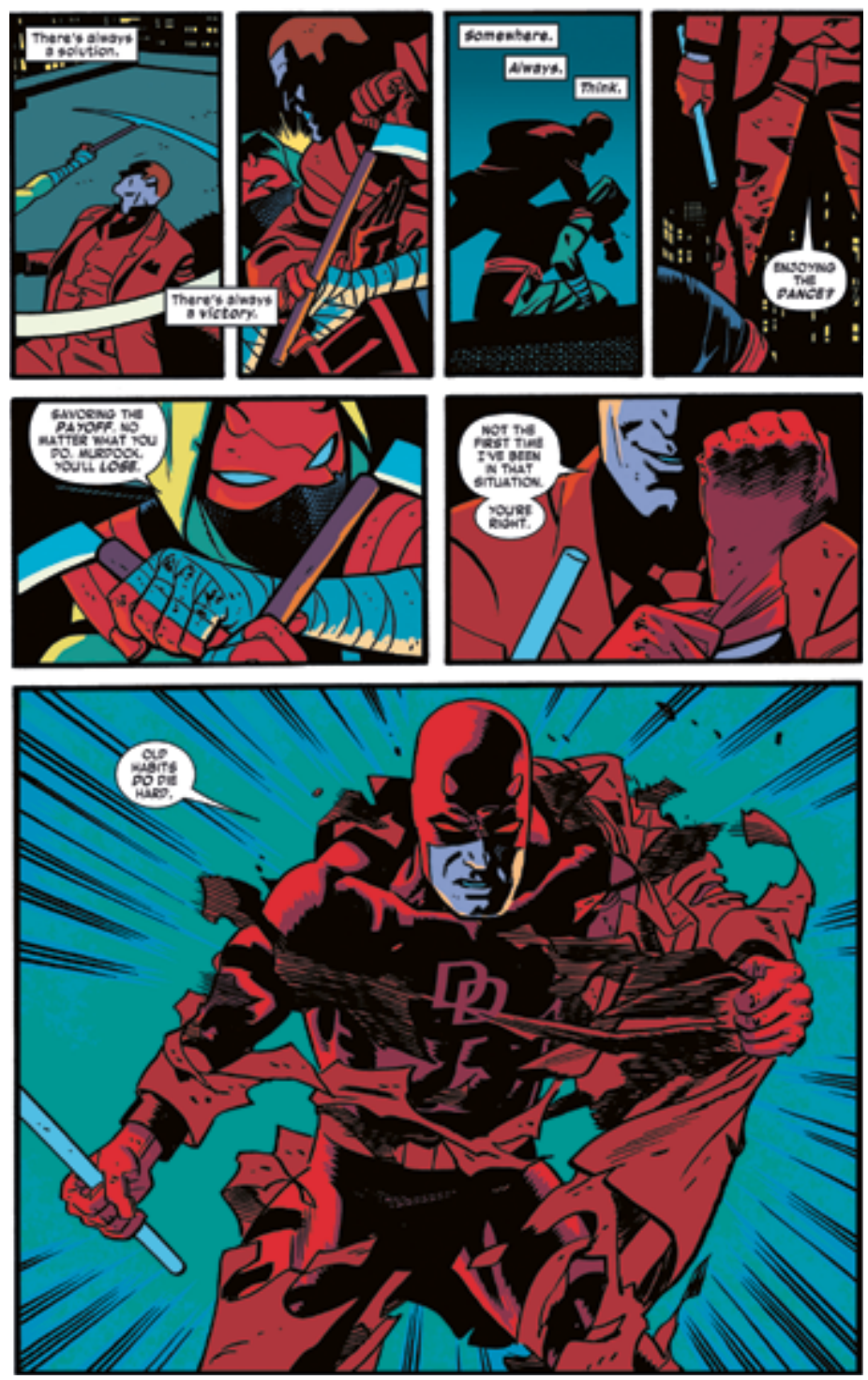

Abb. 48: Nicht ohne meine Maske! Daredevil greift auf seine alte Gewohnheit zurück, um doch noch zu gewinnen - wobei die «Hemd auf>-Ikonografie 〈durchschlägt>, sodass gewissermassen die alte Maske wieder aus ihm hervorbricht. [Ohne Titel] (Mark Waid, Chris Samnee et al.), in: Daredevil (Volume 4) I7, September 201 5. (C) Marvel Comics 
ebendieses Geheimnis. Unter diesem Aspekt wäre dieser Reboot, der zuerst vor allem ein narrativer Rückschritt scheint, keine unlogische Entwicklung.

Matt Murdocks/Daredevils erneut etablierte Doppelidentität scheint jedoch auch ein Hinweis darauf zu sein, dass die in den letzten Jahren aufgekommenen Vermutungen, die Doppelidentität sei im 2r. Jahrhundert schlicht überholt, wohl etwas zu kurzsichtig waren. ${ }^{129}$ Gerade im Hinblick darauf, dass die Superhelden mit der Weiterentwicklung der digitalen filmischen Spezialeffekte in den letzten Jahren geradezu eine Welle von Adaptionen in verschiedenen Medien (neben Filmen und Serien etwa auch Videogames und Romane) erlebt haben, erweist sich die Doppelidentität als zwar nicht mehr so unhinterfragbare und schon gar nicht mehr unumstössliche Bedingung für die Heldenexistenz, aber doch als noch lange nicht auserzählt.

I29 Vgl. Harrison in Easton/Harrison 2010, 275-307 und 335-349. 


\title{
Thunderbolts: \\ Mögliche Selbste zwischen Gut und Böse
}

\author{
Be careful what you pretend to be, you might \\ become it. \\ Lois McMaster Bujold, Mirror Dance, 1994
}

I 996 beschloss Marvel nach fast vierzig Jahren Continuity und wirtschaftlichen Turbulenzen eine Generalüberholung seines erzählten Universums wie der verlegten Palette an Comic-Heften. ${ }^{.}$Um diesen zugleich erzählerischen und publizistischen Neustart zu ermöglichen, ohne aber die Continuity aufzugeben, liess Marvel in einer grossen Schlacht gegen ein Wesen namens Onslaught die mächtigsten Helden sterben, namentlich die Fantastic Four und die Avengers inklusive Captain America und Iron Man. ${ }^{2}$ Wie zu erwarten, erwiesen sich diese später als doch nicht tot - sie waren vielmehr in einem pocket universe auf einem anderen Planeten, der Counter Earth, gelandet, von wo sie nach einem Jahr zurückkehrten. Direkt nach dem Onslaught-Event jedoch war in der erzählten Welt der Verlust der grössten Helden zu beklagen. An diesem Punkt setzt die Geschichte der Thunderbolts ein. Während die Einzelgänger wie Spider-Man und Daredevil sowie kleinere Heldengruppen wie die New Warriors (unter anderen mit Nova) oder die Heroes for Hire (mit Luke Cage und Iron Fist) der unzähligen Superschurken nicht Herr zu werden vermögen, ist die Stunde für ein neues Superhelden-Team gekommen. Scheinbar aus dem Nichts kommen die Thunderbolts: Neben dem Anführer Citizen V (V für victory) waren dies fünf weitere Superhelden namens Techno, Atlas, Mach-I, Songbird und Meteorite. Das erste Heft soll wie eine sprichwörtliche Bombe eingeschlagen haben, ${ }^{3}$ war es doch gelungen, die grosse Überraschung bis zur Publikation weitgehend geheim zu halten - erst am Schluss dieses Heftes wurden die «wahren> Identitäten dieser Heldentruppe offenbart. Es handelt sich keineswegs um neue Helden, sondern um eine alte Schurkentruppe im neuen Gewand: die Masters of Evil mit Baron Helmut Zemo und seinen Untergebenen, dem Fixer, Goliath, dem Beetle, Screa-

I Vgl. etwa Costello (2009, I98): «[...] forty years of continuity had begun to take its toll, with characters being written into corners from which they seemingly could not emerge.» Vgl. Easton in Easton/Harrison 2010, 78-83.

2 Vgl. Costello 2009, 198-201, Kahan/Stewart 2010, I 82.

3 So erzählt es Thunderbolts-Erfinder Kurt Busiek im Vorwort der Sammelausgabe (Busiek 20 I I (200I)). 
ming Mimi und Moonstone. Allerdings wird bald klar, dass zumindest einigen von ihnen das Heldenleben mehr zusagt als ihr bisheriges Schurkendasein. Ihr Ringen darum, ihren Standort als Helden oder Schurken zu wählen bzw. wählen zu können, bietet sich für eine Interpretation anhand der Theorie der possible selves an, die zunächst kurz vorgestellt wird. Die anschliessenden Ausführungen beziehen sich auf die Thunderbolts-Hefte I bis 75 (1997-2003)4, wobei der Fokus auf den Heften I bis 50 liegt, denn Heft 50 stellt eine erste Zäsur dar, nach der - wenn auch temporär - keines der ursprünglichen Mitglieder mehr Teil des Teams war.

\section{Possible Selves}

Das Konzept der possible selves wurde von den Sozialpsychologinnen Hazel Markus und Paula Nurius entworfen. Sie bezeichnen damit Vorstellungen seiner selbst: «Possible selves represent individuals' ideas of what they might become, what they would like to become, and what they are afraid of becoming [...].»5 Das Repertoire möglicher Selbste eines Individuums umfasst also nicht nur Idealvorstellungen von erhofften oder erstrebten Versionen seiner selbst, sondern auch befürchtete oder zu vermeidende Aspekte - jeder imaginiert sich selbst wohl manchmal als bereits befördert und manchmal als beruflich gescheitert. Nach Markus/Nurius denkt man mögliche ¿Ziele> und Szenarien im Kopf nicht abstrakt, sondern stellt sich diese konkret vor. Beispielsweise sieht sich jemand, der studiert, vielleicht mit dem Abschlussdiplom in der Hand. Bei den möglichen Selbsten handelt es sich nicht um x-beliebige Selbstvorstellungen, sondern sie verkörpern die individuellen Hoffnungen, Ängste und Fantasien einer Person; sie lassen sich als «the cognitive manifestation of enduring goals, aspirations, motives, fears, and threats» verstehen. ${ }^{6}$

4 Ab Heft 76 erfolgten einige Sondereditionen unter dem Etikett «Real Men», die inhaltlich kaum mit dem bisherigen Geschehen verknüpft waren, bevor der Handlungsfaden dann mit Avengers Thunderbolts (2003) und New Thunderbolts (2004-2006) weitergesponnen wurde, wonach wieder der Originaltitel verwendet wurde.

5 Markus/Nurius 1986, 954. Die folgenden Aussagen basieren auf diesem Aufsatz. Vgl. zu den possible selves und ähnlichen Konzepten Baumeister 1987, I73, Harter 1996, McAdams 1997, 68.

6 Markus/Nurius 1986, 954, 955. Markus/Nurius (ebd.) verorten die möglichen Selbste dabei als Elemente des self-concept, das sich kurz umschreiben lässt als Organisationsstruktur (genauer: System von Strukturen) der Identität. Auf die verästelte Identitätsstruktur der psychologischen und soziologischen Studien, in die Markus/Nurius ihre possible selves einbetten, kann hier nicht eingegangen werden (vgl. dazu Hoyle/Sherrill 2006, I675; Comello 2009, 34I); am Rande setzen sie implizit self und self-conception mit identity gleich (ebd., 956, 958). 
Obwohl sie also äusserst individuell sind, sind die möglichen Selbste ebenso stark im Sozialen verhaftet. So konstruiert ein Individuum diese oft in direkten Vergleichen mit andern. Auch ist das Spektrum der für ein Individuum in Frage kommenden möglichen Selbste stets in dessen soziokulturellen und historischen Kontext eingebunden.7 Dabei können sich mögliche Selbste aufgrund individueller Erfahrung gestalten oder sich mitunter an medial vermittelten (positiven wie negativen) Vorbildern orientieren. ${ }^{8}$

Mögliche Selbste lassen sich sozusagen im Ausschlussverfahren definieren: Sie umfassen alle Selbstkonzepte, die nicht «current» oder «now selves» darstellen. ${ }^{9}$ Possible selves sind dabei nicht ausschliesslich «representations of self in the future», vielmehr werden sie von «representations of self in the past» gespiesen, die ebenso mögliche Selbste sind. ${ }^{10}$ Obwohl past selves das Individuum nicht mehr definieren, können sie erneut relevant werden, das heisst, sie können als mögliche (oder sogar aktuelle) Selbste wieder aktualisiert werden. ${ }^{\text {II }}$

Possible selves sind dennoch eng mit current selves verknüpft, da sie diese stark beeinflussen können. Sie liefern Motivationen für Handlungen und steuern Verhaltensweisen und Gefühle mit. ${ }^{12}$ Zudem dienen sie als Wertmassstab, mit welchem das Individuum sein aktuelles Selbst reflektiert und interpretiert: "Possible selves furnish criteria against which outcomes are evaluated.» ${ }^{13}$ Zum Beispiel ist einem angehenden Arzt eine Biologie-Prüfungsnote vielleicht wichtiger als einem zukünftigen Programmierer. Laut Markus/Nurius liegt die Wichtigkeit der möglichen Selbste in dieser Funktion und weniger darin, ob und wie sie umgesetzt werden (können). ${ }^{14}$

7 Die möglichen Selbste erinnern in diesem Punkt unter anderem an Goffman (2002, $27 f$., engl. I990, 26f.): Auch er geht ja davon aus, dass man in der Regel nur Rollen übernehmen kann, die in der gegebenen Gesellschaft verfügbar sind (vgl. die Ausführungen zu Goffman im Kapitel zu Masken, Rollen, Identitäten).

8 Markus/Nurius 1986, $954 \mathrm{f}$.

9 Ebd. und 957.

Io Ebd., 954, 956.

I I Markus/Nurius (ebd., 955) erwähnen als Beispiel, dass man als Erwachsener zwar nie wieder ein achtjähriges Kind ist, dass aber Aspekte der kindlichen Identität einen als mögliches Selbst weiterbegleiten können und dieses etwa bei einem Besuch im Elternhaus durchaus das Verhalten beeinflussen kann.

I 2 Ebd., 960. Sie sehen in den possible selves denn auch den «essential link between the self-concept [Identität] and motivation» (ebd., 954), vgl. dazu z. B. auch Quinlan/Jaccard/Blanton 2006.

I 3 Markus/Nurius 1986, 956, vgl. 960, 963.

I 4 Markus/Nurius (ebd.) betonen, dass now selves jeweils den verschiedensten sozialen Beschränkungen unterliegen - bei den possible selves jedoch bleibt nur das Individuum Richtinstanz über deren Validität, zumal es deren Inhalt oft verborgen hält bzw. vor Bewertung durch andere schützt. 
Diskrepanzen zwischen actual selves und angestrebten possible selves, wie dem ideal selfis, können dabei zu inneren Konflikten und Spannungen mit den Mitmenschen führen. ${ }^{16}$ Wie Markus/Nurius erläutern: «When a possible self is active in the working self-concept, we may often appear to be behaving in ways that are inconsistent, crazy, or seriously at odds with what others perceive to be our 〈true〉 selves.» ${ }^{17}$ Hier lässt sich eine Brücke zu Goffmans Begriff der Kategorisierung schlagen. Sobald eine Darstellung nicht mehr mit den Zuschreibungen des Publikums übereinstimmt, kommt es zu einer Störungsempfindung. ${ }^{18}$ Markus/Nurius führen die possible selves auf William James ${ }^{19}$ (1910) zurück, sehen sie aber auch als Fortschreibung einiger Gedanken der Interaktionisten, etwa von G. H. Mead. In dessen Ausführungen ist bereits das Verständnis angedeutet, dass das Selbst als 〈Organisator des Verhaltens〉 stets zukunftsorientiert ist und sein Handeln aufgrund ständigen Antizipierens situationsgerecht anpasst (worauf Goffmans Beschreibung des Individuums in Interaktion ebenfalls aufbaut). ${ }^{20}$ Dieses gedankliche role-taking, so Markus/Nurius, führt zur Schaffung von possible selves, die sie entsprechend einmal als «imagined roles or states of being» umschreiben. ${ }^{21}$ Es sind Selbstvorstellungen, die üblicherweise nicht durch soziale Erfahrung bestätigt wurden. ${ }^{22}$ Gerade deswegen, argumentieren Markus/Nurius, sind die möglichen Selbste besonders empfindlich auf Veränderungen in der sozialen Umgebung: «They are the first elements of the self-concept to absorb and reveal such change.»23

Ihr Konzept der möglichen Selbste diskutieren Markus/Nurius auch im Kontext der die Identitätsdiskussion mitprägenden Frage: «Gibt es ein ein-

Is Mit dem ideal self wird Bezug genommen auf eine oft alternativ zu Markus/Nurius genannte Theorie über self-discrepancy von E. T. Higgins (1987), der von actual, ideal und ought self sprach (vgl. dazu Comello 2009, 342). Es gibt mehrere vergleichbare Konzepte, die sich mehr oder weniger nahtlos mit den Rollentheorien verknüpfen bzw. als eine Erweiterung von diesen sehen lassen. Vgl. Mischel/Mendoza-Denton 200I, Reid/Deaux 1996.

I6 Markus/Nurius I986, 958; vgl. Comello 2009, 342.

I7 Markus/Nurius 1986, 963.

I 8 Goffman I990 (1959), 26 (dt. 2002, 27).

I9 James sprach u. a. vom «potential social Me», das er vom «immediate present Me» und dem «Me of the past» unterschied (William James: Psychology. The Briefer Course, New York 1910, zit. n. Markus/Nurius 1986, 956). Zur Relation der possible selves zu James vgl. Comello 2009.

20 Ein Selbst zu haben, bedeutet für Mead «the ability to rehearse possible courses of action depending on a reading of the other person's reactions and then being able to calibrate one's subsequent actions accordingly", so Markus/Nurius (1986, 956).

2 I Ebd. und 954.

22 Ebd., 955 .

23 Ebd., 956. Vgl. Comello 2009, 342: «One reason possible selves are thought to be so influential in effecting change is that they provide the self-relevant form of an idea, changing it from the vague to the personal and concrete.» 
ziges, darunterliegendes, authentisches Selbst als Essenz der Person oder ist das Selbst eine Sammlung von Masken im Rahmen bestimmter sozialer Umstände?» ${ }^{24}$ Damit eng zusammen hängt, ob das Selbst als stabil oder wandelbar (malleable) gedacht wird. Die Forschungsergebnisse zu diesen Fragen sind, wie auch Markus/Nurius darlegen, höchst unterschiedlich. ${ }^{25}$ Markus/ Nurius sehen in ihren possible selves einen Ansatz, einige dieser Diskrepanzen zu verbinden. Das now self, das «very much a part of the public domain» ist, kann über lange Zeit sehr stabil sein, während mögliche Selbste «instruments of the intense temporary changes in self-evaluation» sein können. ${ }^{26}$ Mögliche Selbste tragen zur Fluidität und Wandelbarkeit des Selbst bei, «because they are differentially activated by the social situation and determine the nature of the working self-concept» ${ }^{27}$. Die möglichen Selbste deuten auf eine komplexe und variable Identität hin, die aber dennoch «authentisch» ist, insofern sie die langlebigen Hoffnungen und Ängste eines Individuums repräsentieren, die Markus/Nurius als bedeutendes Indiz für die Kontinuität der Identität über die Zeit werten. ${ }^{28}$

\section{Vom Schein zum Sein}

Die Geschichte der Thunderbolts beginnt mit einem schurkischen Plan - Baron Zemos Vorhaben, sich und seine Mitstreiter so lange als Helden auszugeben, bis ihnen Staat und Öffentlichkeit uneingeschränkt vertrauen und ihnen Zugriff auf geheime Akten und Computersysteme gewähren. Damit wäre die Weltherrschaft in wenigen Schritten zu erreichen. Zemo selbst posiert als Citizen V, der Fixer nennt sich neu Techno, der Beetle (dessen neue Rüstung einen Ein-MannKampfjet darstellt) Mach-I, aus Screaming Mimi wird Songbird, aus Goliath Atlas und aus Moonstone Meteorite. Wie erwähnt werden die Protagonisten als Helden eingeführt, bevor ihre Schurkenidentitäten in Heft I als 〈Schlussknüller〉 für die Leser aufgedeckt werden (Abb. 49). ${ }^{29}$

24 Markus/Nurius I986, 965 (meine Übersetzung). Vgl. dazu auch Gergen 1972.

25 Markus/Nurius 1986, 964.

26 Ebd., 965. Mit den possible selves lässt sich ein core self erklären als «[s]ome conceptions of the self», die so wichtig sind, dass sie konstant «abrufbar» sein müssen (ebd., 957).

27 Ebd., 965.

28 Die Idee einer einzigen wahren Identität verwerfen Markus/Nurius (ebd.) allerdings explizit, eine solche zu behaupten, «is to deny the rich network of potential that surrounds individuals [...]».

29 Justice Like Lightning (Kurt Busiek, Mark Bagley, Vince Russell et al.), in: Thunderbolts I, April 1997. 
Die Thunderbolts unterscheiden sich bezüglich Doppelidentität von den bisher besprochenen maskierten Helden. Zwar sprechen sie sich untereinander mit ihren zivilen Namen an, doch davon abgesehen verfügen die 〈T-Bolts〉 in ihren zivilen Identitäten über keinerlei soziale Einbindung. Als die beiden Seiten ihrer Doppelidentität werden die Helden- und die Schurkenidentität präsentiert; zu enthüllen gäbe es also weniger eine zivile, sondern vielmehr die schurkische Identität. Bemerkenswerterweise verzichtet die Hälfte der Thunderbolts auf eine das Gesicht verbergende Heldenmaske ${ }^{30}$ (obwohl auch sie offenbar nicht in ihrer zivilen Identität ins Rampenlicht gelangen wollen $\left.{ }^{31}\right)$. Die ThunderboltsComics lassen sich als eine ständige Auseinandersetzung der Hauptfiguren mit ihren (möglichen) Identitäten lesen. Diese erfolgt allerdings sozusagen zugespitzt auf Gut und Böse; Held und Schurke bilden die stilisierten zwei Pole der possible selves der Protagonisten, die immer wieder ins Schwanken geraten.

Damit Zemos Plan funktioniert, bedarf es der disziplinierten Aufrechterhaltung des Scheins. So will der luxusverwöhnte Techno in Thunderbolts 2 (I997) das etwas baufällige Haus, in welchem die Thunderbolts ihr Quartier aufgeschlagen haben, mit seinen Robotern etwas dekadenter machen. Dies untersagt ihm Meteorite, die als rechte Hand von Citizen V amtet, strikt, denn sie müssten wie Idealisten (und nicht technisch und finanziell hochausgestattet) wirken, wenn sie staatliche Hilfe bekommen wollten. In Goffmans Begriffen gesprochen, zeigt Meteorite Techno auf, dass ihr Wohnort keine Hinterbühne sein darf, sondern jederzeit als Vorderbühne genutzt werden können muss.

Tatsächlich geht der Plan auf, überlässt ihnen die Stadt New York doch bald die verwaiste Zentrale der Fantastic Four, das Four Freedoms Plaza. Die Psychologin Meteorite/Karla Sofen erkennt jedoch bald die Gefahr, die der Plan birgt. Angesichts von Songbird, die erfreut den Dank von Polizisten entgegennimmt, und von Atlas, der mit Dallas Riordan schäkert, die vom Bürgermeister

30 Obwohl sie als Schurken verdeckende Masken trugen, wird zusätzlich erklärt, warum dies möglich ist: Techno hat Atlas und Mach-I neue Gesichtszüge verliehen; er selbst trägt eine «bio-plasmic disguise» (The Origin of the Thunderbolts (Kurt Busiek et al.) in: Thunderbolts Annual, 1997, Kap. 8), die ihm auf Knopfdruck fremde Gesichtzüge verleiht. Songbird dagegen verzichtet hauptsächlich auf Screaming Mimis Perücke und weisse Schminke.

3 I So beruft sich Atlas bei der ersten Pressekonferenz gegenüber den Journalisten auf die Heldenkonvention: «We've got to keep our identities and backgrounds a secret, to give us more of an edge on the bad guys. You know how it is» (Justice Like Lightning (Kurt Busiek, Mark Bagley, Vince Russell et al.), in: Thunderbolts I, April I997). Ferner sind Meteorite und Jolt, ein neues Mitglied, einige Hefte später in Zivil in der Stadt unterwegs und drohen von Fans erkannt zu werden - sie ziehen rasch ihre Kostüme über, damit sie niemand erkennt (Thunderbolts 5, August 1997). 


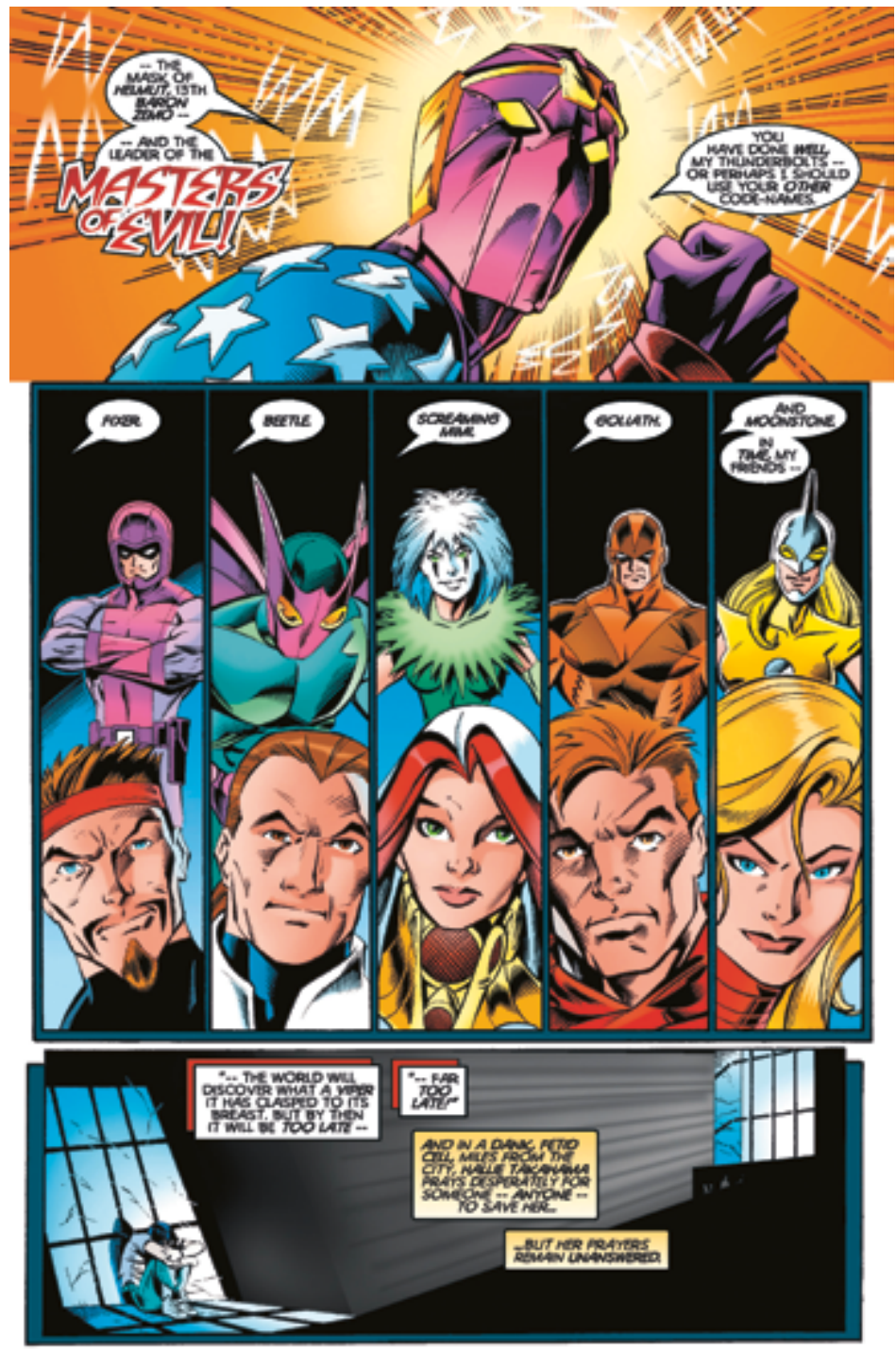

Abb. 49: Als die neuen Helden am Schluss des ersten ThunderboltsHefts für die Leser als Schurken enthüllt werden, stehen die SchurkenIchs visuell in Analogie zum heldischen Ich im Bildmuster des «Doppelidentitäts-Schattens; die maskenlosen Heldenidentitäten nehmen entsprechend den üblichen Platz der zivilen Ichs ein. Im untersten Panel steht Hallie am Beginn ihrer Origin Story als Jolt. Justice ... Like Lightning! (Kurt Busiek, Mark Bagley, Vince Russell et al.), in: Thunderbolts I, April r997. (C) Marvel Comics 
zur Amtskontaktperson für die Thunderbolts delegiert worden ist, formuliert die personale Erzählstimme Meteorites Gedanken:

The plan is working, Meteorite thinks. Better and faster than any of them had guessed. And yet ... something still bothers her. [...] And she's not sure she likes what she sees. It's a heady feeling to have reporters vying for your attention - to have policemen speak to you respectfully. It's a heady feeling to play hero - and to be accepted. She felt it herself - in the heat of battle, she forgot the role she was playing, forgot everything but the need to save the boy [Franklin Richards] - and the rush that came with victory. It feels good, that rush. Maybe too good. ${ }^{32}$

Hier wird das Überhandnehmen der vorgetäuschten Rolle zwar erst als potenzielles Problem angesprochen. Den von Meteorite erwähnten «rush» werten Jeffrey Kahan und Stanley Stewart als klares Indiz dafür, dass die Protagonisten allerdings nicht wirklich zum Heldentum «konvertieren»: «[...] they are simply getting hooked on emotional highs.»33

Der Sinneswandel zumindest eines Mitglieds wird in einer Episode offensichtlich, in der die Thunderbolts auf Spider-Man treffen. Als zwei Nachtwächter einen mörderischen und höchst athletischen Roboter überraschen, halten sie diesen in der Dunkelheit für Spider-Man, der wieder einmal sofort in Verruf gerät. Die Thunderbolts sollen ihn verhaften. Zu Beginn freut sich Mach-I, ehemals als der Beetle ein altbekannter Widersacher Spider-Mans, diesem endlich einmal etwas heimzahlen zu können: «And the chance to give some of that back to him - to be the hero who brings him in - I just want that so bad I can taste it.»34 Die Vorstellung wird dadurch versüsst, dies in der Rolle des Helden tun zu können. Damit aber impliziert Mach-I/Abe Jenkins wohl unbewusst auch den Wunsch, tatsächlich ein Held zu sein.

Wie erwartet kommt es zu einem Scharmützel, doch als Meteorite und Techno den Roboter an einem anderen Ort sichten, wissen zumindest die Thunderbolts um Spider-Mans Unschuld, weshalb sie ihn entkommen lassen. Mach-I sieht allerdings nicht ein, warum sie Spider-Man nicht trotzdem gefasst oder gleich getötet haben, wenn sie ihn schon in ihrer Gewalt hatten. Auch ihm muss Me-

32 Deceiving Appearances (Kurt Busiek, Mark Bagley, Vince Russell et al.), in: Thunderbolts 2, Mai 1997.

33 Kahan/Stewart 2010, I83. Sie sprechen den Thunderbolts das Heldentum denn auch klar ab (ebd.): «Good and evil aren't the issue: feeding the ego and enjoying the rush are. The Thunderbolts make no personal sacrifices but think they're heroes all the same. They're not.»

34 Old Scores (Kurt Busiek, Sal Buscema, Dick Giordano et al.), in: Spider-Man Team-up 7, Juni I 997, I I. Allerdings kennt Mach-i Spider-Man nur zu gut, daher ist er sicher, dass dieser am Tatort auftauchen wird (ebd.): «Because he's innocent. Funny, isn't it - I'm one of [his] greatest enemies, and I'm one of the few people absolutely sure he's innocent. He'd never do anything like this. He'll want to clear his name [...].» 
teorite die Risiken einer solchen Handlungsweise erklären (solange der Roboter nicht gefasst ist, können sie Spider-Man nicht verhaften, ohne wie Idioten dazustehen, wenn der Roboter dennoch entdeckt würde).

Im anschliessenden Kampf gegen den Roboter und seine Erfinder üben diese durch Signale ihres sogenannten «Bio-Modems» Gedankenkontrolle über die Thunderbolts aus. Nur Spider-Man, der ihnen gefolgt ist, und Mach-I entgehen den Signalen. So steht Mach-I plötzlich im Kampf mit seinen Teamkameraden. Als er schon seinen Tod fürchten muss, schwingt ihn Spider-Man aus der Gefahr, und es gelingt den beiden, den Rest des Teams zu befreien. Doch da die Wissenschaftler samt Robotor durch ein Portal spurlos verschwinden, hat Spider-Man keinen Beweis für seine Unschuld. Zum Erstaunen des Teams ist es Mach-I, der Spider-Man aus der Patsche hilft, indem er ihm eine entlastende Filmaufnahme (Techno hatte den Roboter gefilmt) überlässt (Abb. 5oa). Seinem Team gegenüber erklärt Mach-ı dies als Notwendigkeit, um die Täuschung nicht zu gefährden. ${ }^{35}$ Später aber gesteht Mach-I/Abe Jenkins gegenüber Meteorite nachdenklich, dass er ein anderes Motiv hatte:

All that stuff I told Citizen V [...] - it was all garbage. I'd planned to leave him [Spider-Man] hanging - I was looking forward to it, even. But I couldn't. I gave him the disc because he deserved it. Because it was the right thing to do. After we'd fought back to back like that ... well, maybe the Beetle could've stabbed him in the back but Mach-I couldn't. I've got to tell you, Meteorite, this hero thing - I'm starting to think - well, I'm starting to think it's contagious ... ${ }^{36}$

Den Helden zu spielen, färbt auf Abe Jenkins ab, ohne dass er dies bewusst wollen würde (Abb. sob). Mit dieser Erkenntnis führt er - umgemünzt auf die Dialektik von Held und Schurke - Kants Vorstellung vor, dass eine Rolle des Anstands zu spielen idealerweise eine charakterliche Verbesserung des Darstellers zur Folge habe, indem die gekünstelte Tugend schliesslich in die Gesinnung übergehe (wie im Kapitel zu Masken, Rollen, Identitäen erläutert). Ohne damit zu rechnen, kommen die Thunderbolts durch ihr Rollenspiel, das blosse Täuschung sein soll, zu neuen möglichen Selbsten - namentlich der Vorstellung von sich selbst als Held. Diese bleibt allerdings keine kognitive Erscheinung, vielmehr können sie diese mögliche neue Identität gleich ausprobieren, da sie auch eine veränderte soziale Umgebung erfahren. Implizit wird dann das schurkische

35 Mach-I antizipiert dabei ein Szenario der Verdächtigung (ebd., 37): «We knew Spider-Man was innocent - and he knew we knew it. So if we'd smeared him, he'd know we were up to something $[\ldots] . »$

36 Ebd., 38 . 

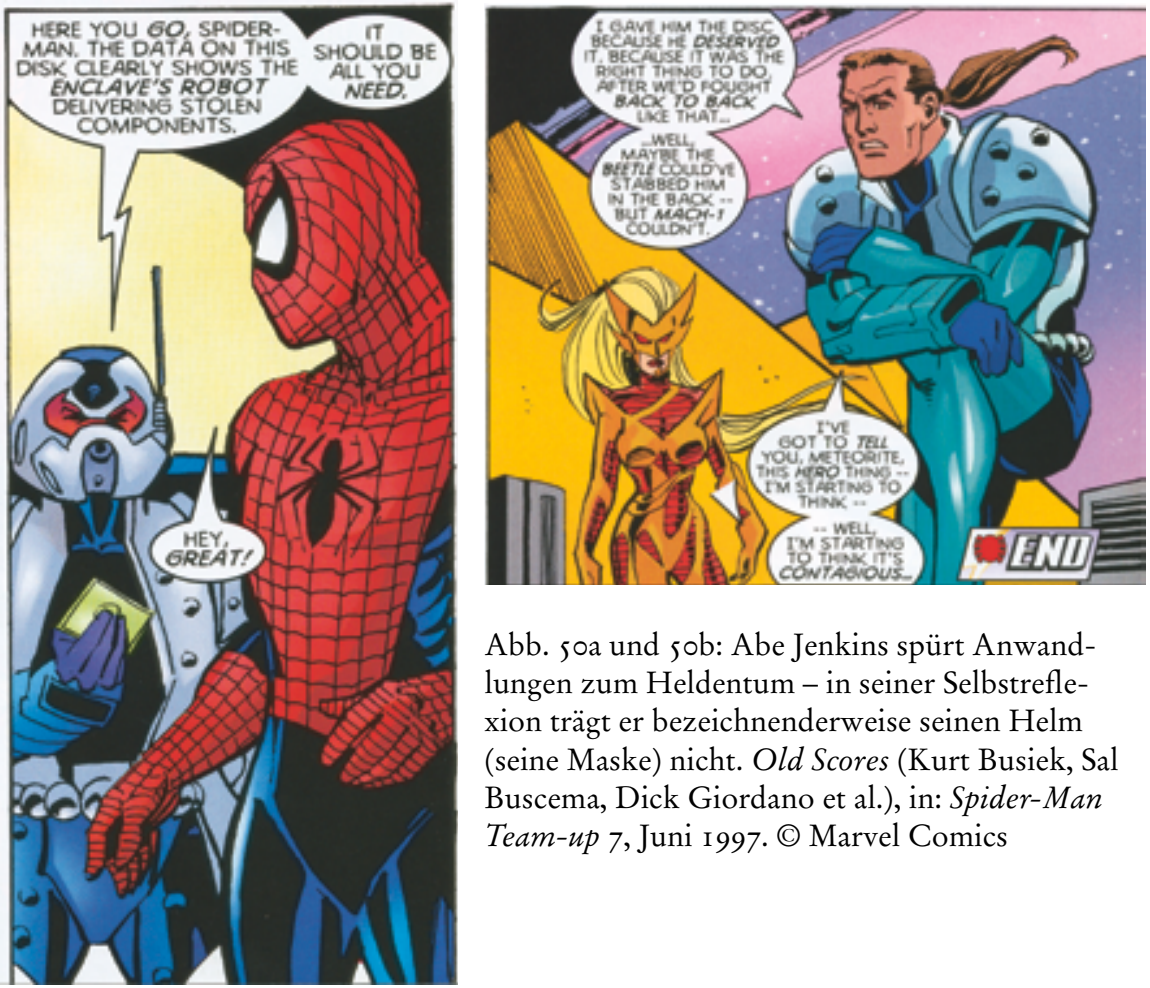

Abb. soa und sob: Abe Jenkins spürt Anwandlungen zum Heldentum - in seiner Selbstreflexion trägt er bezeichnenderweise seinen Helm (seine Maske) nicht. Old Scores (Kurt Busiek, Sal Buscema, Dick Giordano et al.), in: Spider-Man Team-up 7, Juni i997. (C) Marvel Comics

Ich ein past self, dessen erneute Aktualisierung jedoch immer wieder möglich scheint. ${ }^{37}$

Dass gerade Abe Jenkins am klarsten vom «Heldenvirus` ergriffen wird, ist dabei kein Zufall. Denn es wird - psychologisch glaubhaft - klar, dass er in der Heldenrolle das Ziel besser erreicht, welches ihm im zivilen Leben sowie als Schurke stets verwehrt geblieben ist. Als innovativer Mechaniker, dessen Vorschläge in seiner Firma bloss belächelt wurden, war schon immer der Wunsch nach Anerkennung seine Motivation, und dieser Geltungsdrang wird durch den Hel-

37 In der Entwicklung der Protagonisten sehen Kahan/Stewart (2010, I 84) eine Art <umgekehrtes Entzugsprogramm: «If the Thunderbolts get high by doing good, then we can say that their rehabilitation is akin to a twelve-step program, albeit in reverse. The point is not to get off addiction, but to get off on addiction. Their occasional petty crimes are relapses, normal and natural enough in any sobriety program.» 
denstatus erfüllt. Die vorgespielte Rolle ermöglicht ihm die Umsetzung eines lange erhofften möglichen idealen Selbst. Erst durch seine Darstellung aber wird Abe Jenkins klar, dass die heldische Identität für ihn eine mögliche sein kann. Hinzu kommt, dass er und Songbird/Melissa Gold sich verlieben ${ }^{38}$ wie auch Atlas durch seine Hoffnung auf eine Beziehung mit Dallas Riordan neue Identitätsfacetten in Betracht zieht.

Während die Heldenanwandlungen der Thunderbolts noch recht zart sind, ${ }^{39}$ verlangt die Aufrechterhaltung ihrer Darstellung ihnen bald noch mehr ab. Die fünfzehnjährige Waise Hallie Takahama alias Jolt stösst zu ihnen und gewinnt mit ihrem tragischen Schicksal ${ }^{40}$ schnell das Mitgefühl einiger Teammitglieder. Meteorite beobachtet, wie die vorgetäuschte Darstellung gegenüber Jolt immer mehr in eine authentische rutscht: «It was interesting, the way they were moved by her [Jolts] story, by her appeal for help. The roles they were playing were taking over - and they were forgetting that it was supposed to be nothing more than a ruse. Yes, it was interesting to watch, but this wasn't the first example of it - and it posed a grave danger to our overall plan.»4${ }^{41}$ Obwohl sie die Gefahr erkennt und Citizen V sogar (vergebens) warnt, überzeugt Meteorite - die ihre eigenen Ziele verfolgt - ihren Anführer, Jolt als Teammitglied aufzunehmen, um die Glaubwürdigkeit und die positive Publicity des Teams zu stärken. Denn Jolt ist beseelt von jugendlichem Idealismus und nach ihrem ersten Exploit (einer Mission gegen den Superschurken Arnim Zola) bereits ein Publikumsliebling; sie soll sozusagen als Requisit der Darstellung dienen. Da Jolt von den finsteren Plänen der ehemaligen Masters of Evil nichts erfahren soll, müssen die Thunderbolts ihre Darstellung, dass sie heldisch-integre Charaktere seien, rund um die Uhr aufrechterhalten ${ }^{42}$ was Citizen V bald ein Dorn im Auge ist. Durch Jolt entwickelt die von Zemo angestrebte Präsentation sozusagen ein Eigenleben.

38 Vgl. ebd., I83.

39 So lässt Mach-I, der einen Dieb schnappt, in Thunderbolts 3 (1997) dessen Beute in seiner eigenen Tasche verschwinden, wofür er dann vom Rest des Teams kritisiert wird (dazu auch Kahan/Stewart 2010, I83).

40 Hallies Familie starb bei dem Onslaught-Chaos, wonach sie in der zertrümmerten Stadt als Anführerin einer Kindergruppe auf der Strasse lebte. Die Kinder wurden dann nach Latveria entführt, wo der verrückte Wissenschaftler und Superschurke Arnim Zola an ihnen Versuche durchführte, denen Hallie - als einzige Überlebende - ihre Superkräfte verdankt. Schliesslich kann sie sich befreien und sucht Hilfe bei den Fantastic Four, wo sie aber nur die Thunderbolts vorfindet, die ihr auch helfen und sie trösten. Atlas empört sich: «What kind of monster would experiment on kids?!» (A Shock to the System (Kurt Busiek, Mark Bagley, Vince Russell et al.), in: Thunderbolts 4, Juli 1997.)

$4 \mathrm{I}$ Ebd.

42 Im ersten Annual-Heft (1997) muss Citizen V Hallie die Origin-Storys der einzelnen Mitglieder erzählen - allerdings so verändert bzw. geschönt, dass sie nicht merkt, dass ihre Kollegen 
Zemo beobachtet sein Team (wie Atlas ein ver- und geliebtes possible self hegt oder wie Songbird und Mach-I sich über die Berge von Fanpost freuen) und ist angewidert: $«[\ldots]$ his men are enjoying their roles too much, enjoying their $p u b-$ lic approval, and it's softening them - making them more buman. [...] It's disgusting, he thinks. Only months ago, they were brutal, callous career criminals. And now look at them.»43 So verlangt er von Meteorite, Jolt bei nächster Gelegenheit zu Tode kommen zu lassen. Zwar wendet sie ein, dass dies schlecht für das Helden-Image wäre, was Citizen V aber nicht beeindruckt.

Zur Ausführung kommt es allerdings nicht, da der nächste Einsatz ruft, der zu einem ersten Riss im Zusammenhalt des Teams führt. Da er den Zugriff auf die Akten der Avengers noch immer nicht erhalten hat, verbietet Citizen V seinem Team in Thunderbolts 7 (1997), etwas gegen die sogenannten Elementals, die gerade ihr Unwesen treiben, zu unternehmen. Doch auf die Fürsprache Jolts hin, die diese Entscheidung - ohne Kenntnis der schurkischen Hintergründe überhaupt nicht verstehen kann, und weil die notorisch manipulative Meteorite darin eine gute Möglichkeit sieht, einen Keil zwischen Zemo und sein Team zu treiben, legen sie trotzdem los. Die Entscheidung fällt weniger um ihres offiziellen Ansehens willen, als weil sie Jolt recht geben und es falsch fänden, untätig zu bleiben. Da Citizen V durch diese Aktion endlich die Akten erhält, vergibt er ihnen nochmals. ${ }^{44}$

Als die Thunderbolts in einem offiziellen Festakt endlich die «paragon level security clearage»45 des National Security Council und der Vereinten Nationen erhalten - kaum dass die vermeintlich verstorbenen Helden von der Counter Earth zurück sind -, stürmen Shield-Agenten heran, um die Thunderbolts zu verhaften; ihr Geheimnis ist entdeckt. Wie sich zeigt, hatte Zemo genug von der Täuschung und mit Techno alles vorbereitet. Die Thunderbolts müssen fliehen eben noch gefeierte Helden, trifft sie nun der Zorn der Öffentlichkeit umso härter.

Nur Zemo verspürt Genugtuung: «And I must say, it feels good to cast off that annoyingly-idealistic facade, and return to my true self! [...] I am Zemo. [...] You were thinking of abandoning the plan - of playing the role of heroes forever, since

eigentlich Superschurken sind; er steht hier vor einem «klassischen〉 Doppelidentitätsproblem, denn die Erzählung verweigern kann er erst recht nicht, weil das noch verdächtiger wäre.

Unstable Elements (Kurt Busiek, Mark Bagley, Vince Russell et al.), in: Thunderbolts 6, September 1997 .

44 Zudem hat Techno dabei sein Leben bzw. seinen Körper verloren; da er sein Gehirn virtuell gesichert hatte, wird er zum <lebenden Computer), der einen unendlich wandelbaren Roboterkörper besitzt - für ihn eher ein Gewinn.

45 Heroes' Reward (Kurt Busiek, Mark Bagley, Vince Russell et al.), in: Thunderbolts ıo, Januar 1998. 
you've enjoyed it so much.» ${ }^{46}$ Die Stelle zeigt deutlich, dass Zemo nach wie vor klar zwischen seinem schurkischen true self und der vorgetäuschten Rolle unterscheidet und ebenso unbedingt <er selbst > bleibt. Ein Identitätswandel scheint für ihn gar nicht denkbar; explizit benennt er die Schurkenidentitäten der anderen Thunderbolts als deren «true identities» ${ }^{47}$. Dazu ist zu bemerken, dass Zemos Gesicht unter seiner Ganzmaske völlig entstellt ist, sodass es für ihn eine <einfache> zivile Identität auch nicht mehr ohne Weiteres geben kann. ${ }^{8}$ Zudem geht es ihm um die Fortführung der Familientradition, war doch schon sein Vater einer der grossen Nazischurken des Marvel-Universums. Während die anderen Thunderbolts keine nennenswerten Bindungen oder Vermögen haben, sind Zemos pekuniäre Reserven zwar nicht immens, aber etwa mit einer geheimen Dschungelfestung nicht unerheblich. ${ }^{49}$ Die anderen Thunderbolts haben sich ganz neue Identitäten für ihre Heldenrolle ausgedacht, Zemo dagegen hat sich mit dem Mantel von Citizen V als Enkel eines Helden ausgegeben, den sein Vater im Zweiten Weltkrieg getötet hatte. ${ }^{5 \circ}$ Sein ideales mögliches Selbst ist, sogar seinen Vater zu übertrumpfen, und nun sieht er sich am Ziel. Er fliegt sein Team auf einen Satelliten, um von dort via Computer mehrere Militäreinheiten gedanklich zu kontrollieren, sodass sich ihm Dutzende Nationen ergeben.

Die fassungslose Jolt ist ungesehen mitgeflogen und belauscht Zemos Pläne, die er mit Technos Hilfe ausführt, hört aber auch, wie sich bei den restlichen Thunderbolts Zweifel regen. Besonders Abe hadert nun mit dem Weltbeherrschungsplan: «I don't like this. [...] We were fine the way we were!» Als Meteorite ihn als Beetle anspricht und erklärt, dass er bald zu den Masters of the World gehöre, wiegelt er ab: «Look, don't call me that, okay? And yeah, maybe I'll be in charge, and people will fear me and bow to me, and all. But, well, I guess I liked it better - when they just liked me.» ${ }^{\text {I }}$ Auch für Abe selbst etwas überraschend ist die Vorstellung, ein Weltbeherrscher zu sein, statt ein wünschenswertes ein abzulehnendes mögliches Selbst geworden.

46 Ebd.

47 Unstable Elements (Kurt Busiek, Mark Bagley, Vince Russell et al.), in: Thunderbolts 6, September 1997.

48 Bei den Thunderbolts ist das Ändern von Gesichtszügen allerdings kein Problem; tatsächlich bietet Techno Zemo später denn einmal an, sein Gesicht wieder herzustellen, was dieser aber ablehnt, da es ihn daran erinnere, wer er sei (Thunderbolts I4, I998).

49 Wie Costello (2009, 212) bemerkt, sind es vor allem die als Schurken wenig erfolgreichen Figuren, die Gefallen am Heldentum finden.

50 Zur Verbindung zum originalen Citizen V vgl. Costello 2009, 2 Io.

II The High Ground (Kurt Busiek, Mark Bagley, Vince Russell et al.), in: Thunderbolts I I, Januar 1998. 
Jolt gelingt es, ihnen Mut zu machen, indem sie an ihre besseren Identitäten appelliert: «I know you - I know you're not the cold-hearted killers you're made out to be. I've lived with you - fought alongside you - and I know you liked being heroes. I know it felt good for you to do the right thing, and that you don't want this.» ${ }^{22}$ Obwohl Zemos Plan zunächst geradezu reibungslos funktioniert, geht er nun gründlich schief - hauptsächlich, weil seine Mitstreiter ihre alten Schurkenidentitäten zwar noch als past und damit possible selves empfinden, diese aber nicht mehr sein wollen. Die neu geschaffenen heldischen possible selves beeinflussen die Entscheidung gewaltig; nicht zuletzt deshalb, weil Jolt ihnen zuerkennt, dass sie diese umsetzen können und nicht mehr an die Verhaltensweisen ihrer alten Identitäten gebunden sind.

Als Zemo die Szene mitbekommt, befiehlt er Techno und Atlas, die andern zu töten. Kaum ist der Kampf im Gange, erscheinen die Avengers und die Fantastic Four. Doch auch sie unterliegen Zemos Bio-Modem-Gehirnkontrolle (die Techno nachgebaut hatte). Atlas, der Zemos Befehle zunächst treu befolgen wollte, fällt Zemo in den Arm, als dieser Jolt erschiessen will (denn sie erinnert ihn an seine jung verstorbene Schwester). Den 〈guten> Thunderbolts bleibt erneut nur die Flucht auf eine verlassene Wetterstation im All - zusammen mit Iron Man, der von der Gedankenkontrolle verschont blieb. Derweil Iron Man und Abe die nötigen Hilfsmittel für eine Gegenaktion zusammenschrauben, haben die Protagonisten Zeit für Selbstreflexion.

In diesem Moment in Thunderbolts I 2 (I998) schwanken die Figuren explizit zwischen altem und neuem Ich, jeweils mit anderen Akzenten. Abe fragt sich, ob er überhaupt wieder der Beetle sein könnte: «I was a hero. I was respected. Looked up to. Applauded. [...] And now look at me. So if I make it through this, do I go back to being the Beetle? To being a crook and a loser? Even if I wanted to, could I bring myself to do that?»53 Songbird denkt an ihre Zeit als Screaming Mimi bei den Grapplers, einem Frauen-Wrestlingteam, zurück, in der ihr Unsicherheit und Angst fremd waren, allerdings auch Hoffnungen und Träume. Atlas, der als Soldat am liebsten Befehle befolgt, hadert damit, dass er Zemo, dem er Gehorsam geschworen hatte, «verraten〉 hat - zugleich weiss er, dass er Jolt nicht hätte sterben lassen können. Für ihn führt das Ausprobieren des heldischen possible self zu einem inneren Konflikt, da seine current und past selves nicht mehr mit einem ideal self übereinstimmen. In diesem Moment der Unsicherheit hinterfragt sogar Jolt ihre Motive: Wie viel ihres Handelns zielt darauf, eine Heldin zu sein, und wie viel ist davon bestimmt, dass sie sonst keine Fami-

52 Ebd.

53 Endgame (Kurt Busiek, Mark Bagley, Vince Russell et al.), in: Thunderbolts I2, März 1998. 
lie und keinen Ort mehr hat, wo sie hingehen könnte? Mit andern Worten: Wie sehr ist ihr Engagement davon motiviert, ein mögliches alone self zu vermeiden? Nur Meteorite sind solche Gefühle fremd: Sie gestaltet durch ihre Gedankenkraft ihr Kostüm um, um einen Neustart zu symbolisieren und versichert sich ihrer Identität: «If I know the others, they're wallowing in the past, in regrets, trying to figure out who they are, what they want to do. But I know who I am, I've always known. And I know that if I'm going to salvage something from this mess, I need to think it all through coldly, and decide on my best move.» ${ }^{4}$ Interessanterweise ist Meteorite, obwohl sie hier ihre Selbstsicherheit betont und zudem am häufigsten die Erzählstimme übernimmt, von allen Thunderbolts der am wenigsten greifbare Charakter. Zwar sucht sie bei anderen Personen ständig Schwachpunkte, um diese dann manipulieren zu können, aber sie hat nie ein klares Ziel, ss ausser eben andere zu beeinflussen und sich zu diesem Zweck eine möglichst gute Ausgangslage zu verschaffen.

Schliesslich können Iron Man und die Thunderbolts die anderen Helden befreien und Zemo und Techno besiegen, wobei diese beiden dennoch - mit Atlas' heimlicher Hilfe - entkommen. Da die Avengers und die Fantastic Four die Thunderbolts immer noch als Kriminelle sehen, wollen sie sie verhaften; Meteorite stimmt im Namen des Teams zu, sich einem Prozess zu stellen. Ob sie dies nur sagt, um von dem Satelliten wieder auf die Erde zu kommen, bleibt unklar, denn im nämlichen Moment werden die Thunderbolts plötzlich auf einen anderen Planeten «gesaugt); es folgt ein Intermezzo auf dem Planeten Kosmos (Thunderbolts $\mathrm{I}_{3}$ und $\left.\mathrm{I}_{4}, \mathrm{I} 998\right)$.

Auf Kosmos wird die soeben durchgemachte Entwicklung des Teams nochmals herausgefordert und bestätigt. Auch hier hält Jolt das Team inmitten chaotischer Umstände (wie einer drohenden Exekution) zusammen. Um wieder nach Hause zu kommen, geht Meteorite mit einem der Machthaber einen Handel ein, den alten König zu töten. Während Jolt und Atlas anderswo kämpfen, stehen Meteorite, Mach-I und Songbird vor ihrem designierten Opfer. Aber in Mach-I sträubt sich alles gegen die Tat: «I can't $d o$ it. [...] Maybe I just played hero too long, but - but this is just wrong. This guy didn't do anything he deserves to die for.» ${ }^{6}$ Spätestens hier ist sein schurkisches Ich Vergangenheit, und er kommt seinem als ein mögliches Selbst erfahrenem heldischen Ich näher. Da es Songbird ähnlich geht, begeht Meteorite die schändliche Tat selbst, und so kommen die Thunderbolts wieder auf die Erde. Bis zu dieser Stelle sind die Thunderbolts

54 Ebd.

55 Vgl. Costello 2009, 209f.

56 Casualties of War (Kurt Busiek, Mark Bagley, Scott Hanna et al.), in: Thunderbolts I4, Mai 1998. 
eher nolens volens zu ihren Heldenaspirationen gekommen. Ein gewollter Läuterungsprozess war dies nicht - von Reue für vergangene Schurkentaten ist nie die Rede. Nun aber suchen sie trotz ihres beschädigten Rufs die Rehabilitation, was sich als steiniger Weg erweisen wird.

\section{Die fortwährende Auseinandersetzung mit möglichen Identitäten}

Zurück auf der Erde, bleibt den Thunderbolts - die nach wie vor als Verbrecher gesucht sind - nichts anderes übrig, als im Wald (in Colorado) zu campen. Sie beschliessen aber, sich nicht zu stellen, sondern zu versuchen, ihren demolierten Heldenruf zu rehabilitieren, indem sie «for real» als Helden agieren. ${ }^{77}$ Abe wirft die Frage auf, ob sie sich nicht besser nochmals neue Heldenidentitäten schaffen sollen - was jedoch zu verdächtig wäre: Sollte eine weitere Täuschung auffliegen, wären ihre angestrebten Heldenkarrieren definitiv vorbei. Dies gilt indes nicht für ihre zivilen Identitäten - weil sie erst etwas Geld verdienen müssen, besorgen sie sich falsche Papiere, um eine Arbeit zu finden. Dies gelingt allerdings nur kurzzeitig, da Shield (im Marvel-Universum der für Superhelden/-schurken zuständige US-Geheimdienst) die Thunderbolts aufspürt und diese wieder fliehen müssen. Auch wenn die Identitätstäuschung somit vorbei ist, müssen sich die Thunderbolts immer wieder mit Identitätsoptionen beschäftigen, wobei sich diese Prozesse in der Regel über mehrere Abenteuer hinziehen..$^{8}$

Ein Faktor dabei ist stets auch, wie die Thunderbolts von anderen wahrgenommen werden. Besonders zu Beginn hadern sie mit der medialen Berichterstattung über ihre Taten, die über ihre Motive rätselt und nicht weiss, ob sie nun als Helden oder als Schurken zu sehen sind. ${ }^{99}$ Auf einige eher demoralisierende

57 Obwohl alle anwesenden Thunderbolts dafür sind, zeigt sich auch hier der Wille zum Wandel am stärksten bei Abe Jenkins, wenn er erklärt: «I'm in. I loved being Mach-I - and if I never play the Beetle again, it'll be too soon.» Damit deutet er eine Verschiebung in der Wertung seiner Identitäten an: Den Beetle hat er «nur` gespielt (Wanted Dead or Alive! (Kurt Busiek, Mark Bagley, Scott Hanna et al.), in: Thunderbolts i s, Juni i998).

58 Übrigens bleiben die Thunderbolts-Storys dem Motiv der vorgetäuschten Identitäten (inklusive überraschender Anagnorisis-Momente) treu, nachdem die Thunderbolts ihr HeldenTäuschmanöver beendet haben. Beispielsweise stecken unter den Kostümen von Citizen V und Crimson Cowl verschiedene Träger; ein weiterer Gegner trägt unter der gegenständlichen Maske noch eine Gesichtsmaske; das 〈Karussell der vorgespielten Identitäten〉 dreht sich teils in Nebenhandlungen, ist teils aber auch in umfassende Verschwörungsplots eingebunden.

59 Dies gilt zwar für viele andere Superhelden ebenfalls, doch scheint mir meist die Intention zum Heldsein klarer bzw. die Zweifel sind häufiger solche am Heldentum per se oder entstehen aufgrund gegensätzlicher Meinungen des 〈Publikums〉 (oft sind klar unfaire Medienkampagnen oder Missverständnisse die Auslöser). 
Ereignisse folgen jeweils erhebende Begegnungen, etwa als drei Jugendliche die abgelegene Hütte der Thunderbolts aufsuchen, weil sie Hilfe brauchen. Für alle jene Personen aber, bei welchen die Thunderbolts ihre Glaubwürdigkeit komplett verloren haben, spricht besonders Dallas Riordan, die Atlas/Erik Josten schwerste Vorwürfe macht, weil er sie angelogen hat, und nichts mehr von ihm hören will.

Der zurückgestossene Atlas fällt noch mehr in Selbstzweifel nach seinem <Verrat> an Baron Zemo - er interpretiert nun sein gesamtes bisheriges Leben in dieser Linie des Scheiterns und zweifelt sehr, ob er eine Rehabilitation und das Vertrauen des Teams überhaupt verdient. Weil ihm dieses Selbstbild gar nicht behagt, will er sich bei seiner Familie dafür entschuldigen, dass er sie damals verund damit im Stich gelassen hat. Doch kommt er zu spät, um seinen Bruder zu retten; dieser stirbt in seinem Beisein. Atlas nimmt sich nun vor, nie mehr davonzulaufen - als er erfährt, dass die Thunderbolts gegen den Bösewicht Graviton kämpfen, kehrt er rechtzeitig zurück, um das Kampfesglück zu wenden. Damit sind seine Zweifel an sich selbst jedoch nicht beseitigt. Wie er Jolt gesteht, hat er Angst, wieder jene Version seiner selbst zu werden, die er als durch seltsame Präparate halb verrückter Goliath einmal war, da er im Kampf gegen Graviton «the same thrill» gespürt hat. Jolt versucht, ihn damit aufzubauen: «You know what you're scared of, Erik - you can guard against it - fight it. And you're taking steps to change your life, we all are. Maybe you guys were all villains - and I'm some sort of accessory, but we're making our own choices - we're going to win back the public's trust, prove we can be heroes. ${ }^{60}$ Auch wenn Atlas/Erik nicht ganz überzeugt ist, tröstet ihn Jolts Überzeugung, dass er eine Wahl hat und sozusagen jenes possible self, das er zu werden fürchtet, verhindern kann, wenn er darum weiss. ${ }^{61}$

Durch das Leben auf der Flucht (in einer Blockhütte) wird Songbird/Melissa Gold immer gereizter und nähert sich ihrer alten Schurkenidentität wieder an: Sie scheint immer öfter auf sich als Screaming Mimi zu referieren und driftet immer stärker in die eher rüden Verhaltensweisen, die «attitude», von Screaming Mimi ab. Als Melissa/Songbird in Thunderbolts i 8 (I998) wütend erklärt, wenn sie schon so leben müssten, sollte es wenigstens etwas abwerfen, fürchten die anderen, dass sie eine Rückkehr in die Kriminalität in Betracht zieht und der Zerfall des Teams bevorsteht (was aber keiner anspricht). Tatsächlich besteht diese Versuchung für alle, als ihnen Crimson Cowl, die Anführerin der neuen

60 Career Opportunities (Kurt Busiek, Mark Bagley, Scott Hanna et al.), in: Thunderbolts i 8, September 1998.

6I Auf die weitere Entwicklung von Atlas kann hier nicht eingegangen werden, aber sie ist damit keineswegs abgeschlossen. 
(selbst ernannten) Masters of Evil, anbietet, sich ihr anzuschliessen. Doch als deren Handlanger den Thunderbolts noch während der zugestandenen Bedenkzeit verbieten wollen, einigen Menschen zu helfen, beschliessen sie einmütig, dass sie sich nichts mehr befehlen lassen wollen (Heft I9).

Nach einem emotionalen Ausbruch erklärt Songbird Abe schliesslich ihren Rückfall ins «Mimi-Gebaren〉. Für sie stehen Mimi und Melissa für zwei verschiedene mögliche Selbste, die einander jedoch auszuschliessen scheinen. Mimi ist sozusagen ihr 〈survival self〉 (charakterisiert durch emotionale Distanz), das sie lange Zeit umgesetzt hat, seit sie als Jugendliche auf der Strasse überleben musste: «You have to be cold and hard and tough to survive. But I found a way to do that. Mimi could be though - Mimi could be cold - and she protected Melissa. Like a Mom should. She's not a split personality or anything, just a way of thinking. A way to get by.» ${ }^{62}$ Bei den Thunderbolts hat sich Melissa trotz aller negativen Erfahrungen - ihr vorheriger Geliebter und Verbrechenspartner Ansgar the Screamer starb nach einem Überfall in ihren Armen - auf neue Beziehungen eingelassen, und zwar als Melissa, weil sie als Thunderbolt und mit Abe so glücklich war, dass sie ihre Mimi-Seite nicht mehr brauchte, bevor Zemo die Illusion zerschlug. Für Songbird/Melissa ist die Frage nach gut oder böse in hohem Masse von der Möglichkeit sozialer Zugehörigkeit abhängig, und so will sie trotz ihren Verlustängsten Teammitglied bleiben.

Inzwischen haben die Thunderbolts mit dem Avenger Hawkeye/Cliff Barton einen neuen Anführer bekommen. Da er selbst als Schurke begonnen hat, möchte er, dass die Thunderbolts eine Chance zur Rehabilitation bekommen. Ein erster Meilenstein unter seiner Führung ist die Verhaftung der Masters of Evil, die gerade eine grosse Verschwörung planten; dadurch steht deren grosszügig eingerichtete Basis in den Bergen von Colorado leer, die die Thunderbolts nun übernehmen. Hawkeye verspricht den Thunderbolts, dass, wenn sie sich als Helden bewähren, eine Begnadigung für sie möglich ist. ${ }^{63}$ Allerdings geht dies nur unter einer Bedingung: Da Abe Jenkins als Beetle einen Mann ermordet hat, soll er sich nun - medienwirksam - stellen, damit das Vertrauen in die neue Rechtschaffenheit der Thunderbolts eine solide Basis erhält.

Bevor Abe sich zu diesem Schritt durchringt, reflektiert er nochmals sein früheres Schurken-Ich, das vor allem seine Unsicherheit verbergen wollte und ihm rückblickend wenig erstrebenswert erscheint. Um seinen Teammitgliedern die

62 Decisions Part 2: Trust (Kurt Busiek, Mark Bagley, Scott Hanna et al.), in: Thunderbolts 2 I, Dezember 1998.

63 Dabei lügt Hawkeye aber: Er erzählt, er habe die Zusage vom entsprechenden Rat bekommen, tatsächlich war dieser dazu aber nicht bereit (ebd.). 
Chance auf Rehabilitation nicht zu ruinieren, geht er ins Gefängnis. ${ }^{64}$ Nach einigen Verwicklungen kommt er schliesslich frei und darf als Mach-2 bei den Thunderbolts bleiben, wenn auch nicht offiziell. Dazu erhält er einen neuen zivilen Namen (Matt Davis), und Techno verdunkelt ihm die Haut so stark, dass er wie ein Afroamerikaner aussieht. Obschon in Nebensträngen erzählt wird, dass Songbird sich erst an das neue Aussehen gewöhnen muss und wie er rassistische Vorurteile von anderen erlebt, stört Abe seine neue Hautfarbe gar nicht, nachdem er sich seiner Identität als Held einigermassen gewiss ist.

Während Abe im Gefängnis ist, erhält das Team mit Charcoal ${ }^{6 s}$ und dem alten Mechaniker Ogre ${ }^{66}$ zwei neue Mitglieder und erleidet einen schweren Schock, als Jolt von einem Scharfschützen heimtückisch ermordet wird (Thunderbolts 34/35, 2000). In der Folge dieses Schocks zeigt sich bei Moonstone/Karla Sofen eine Identitätskrise, die ins Fantastische verlagert ist. ${ }^{67}$ Diese beginnt damit, dass sich Karla Sofen in gewissen Verhaltensweisen nicht mehr wiederzuerkennen scheint - wenn es ein Scharfschütze auf das Team abgesehen hat, sollte sie nicht fliehen, statt Hawkeye schöne Augen zu machen? Dabei ist sie selbst überrascht, dass sie - die personifizierte kühle Berechnung - sich tatsächlich verliebt hat. Zugleich fragt sie sich, warum sie zugunsten der Rehabilitation plötzlich ihr Leben riskiert, um die Welt zu retten, statt etwa 〈bloss> Bankräuber aufzuhalten. ${ }^{68}$ Moonstone wächst in ihrer Heldenrolle sozusagen über sich hinaus, und zugleich hat sie immer stärker das Gefühl, dass sie eine fremde Person in ihrem Inneren hat. Ihre Identitätsverwirrung analysiert Karla Sofen vor dem Spiegel gleich selbst sehr ausführlich:

64 Dabei bekommt Abe auch im Gefängnis verschiedene Identitätsmöglichkeiten, bestätigt sich aber als Held, indem er heimlich einen Ausbruchsversuch verhindert (Thunderbolts 26, I 999).

65 Der Teenager Charlie Burlingame/Charcoal erscheint bei seinem ersten Auftritt in Thunderbolts I9 (I998) zwar als Schurke - er kämpft für eine paramilitärische, sektenähnliche Organisation -, folgt dann jedoch den Thunderbolts und bittet sie um Aufnahme. Im Gegensatz zu den anderen Thunderbolts machen er und Jolt keine Identitätsschwankungen durch.

66 Ogre hat versteckt in der Basis gelebt und will dann für die T-Bolts tätig sein (Thunderbolts 33). Kurz darauf übernimmt jedoch Techno, der sich von Zemo getrennt hat, dessen Rolle (sein Roboterkörper kann jede Form annehmen).

67 Wie sich in Thunderbolts 46 (200I) herausstellt, ist der Moonstone, der ihr ihre Kräfte verleiht, auch eine Art Informationsspeicher für die Erinnerungen von dessen früheren Trägerinnen; aufgrund ihrer eigenen Identitätsunsicherheit bzw. ihrer Anpassungsschwierigkeiten an neue Identitäten (als Verliebte und Heldin) hat Moonstone unbewusst auf diese Erinnerungen zurückgegriffen (die frühere Trägerin war vor Tausenden von Jahren eine Kree, eine Ausserirdische, die zu den damaligen Guardians of the Galaxy gehörte).

68 Für Karla entspricht dies nicht der Identität, die ihrem bisherigen Lebenslauf entspricht, wie sie zu Beginn einer Retrospektive über ihr Leben denkt: «But putting our lives on the line to save the world? That's not me. It never has been [...]» (Saving The World! (Kurt Busiek, Mark Bagley et al.), in: Thunderbolts 25, April 1999). 
[...] who am I?! [...] This is not me! These are not my thoughts, my feelings! All of this [...] has always been nothing more than a means to an end! I became Meteorite as part of Baron Zemo's plan [...]. When that fell apart, I led the Thunderbolts [...]. But through it all ... and especially since Hawkeye volunteered to lead us ... something was growing inside of me ... and I can't deny the truth of what I have been feeling any longer ... a sense of belonging. Of family. Of purpose. Of ... hope. But instead of embracing the (yuch!) warmth of those feelings, I have ignored them - submerged them - for fear ... of what, Karla? [...] that they are not my own! No, too simple. For fear that I can't aspire to them ... or worse - for fear that I don't deserve them! Or is it something more? Something I have buried so deep that confronting it would shatter my entire view of who I am. What if I've refused to embrace all those concepts, because I'm really just afraid of becoming ... a better person?69

Mit den möglichen Selbsten vor Augen lassen sich Karla Sofens Nöte so erklären, dass sie zaghaft ein neues mögliches Selbst aufgebaut hat, dessen Umsetzung sie sich vielleicht wünscht, vor allem aber fürchtet (Abb. 51). ${ }^{70}$ Denn dazu gehören auch Gefühle von Zugehörigkeit und Verantwortung, mit denen sie bisher eher auf Kriegsfuss stand. ${ }^{\text {II }}$ In einem Schlüsselmoment in Moonstones Kampf gegen ihre inneren Dämonen (die im Superheldengenre etwas greifbarer scheinen als ausserhalb der Comicwelt), als sie wieder ihr Schurkenkostüm trägt, steht sie vor der Wahl, ihr Team zu retten oder ihre Mitwisser sterben zu lassenzwischen den widerstreitenden Motiven gibt schliesslich das Vertrauen in das Thunderbolts-Team den Ausschlag. Gleich darauf bringt Hawkeye Moonstones Problem auf den Punkt: "This whole thing with you has been nothin' more than you decidin' who you want to be. [...] you haven't figured out yet - what every Thunderbolt has figured out for themselves - what I saw in all of you ... why I'm fighting for you ... You can be whatever kind of person you choose to be!» ${ }^{22}$ Nicht nur die jeweiligen Schurken- und Helden-Ichs erscheinen so als mögliche Selbste (die mit einem Namen versehen sind), sondern auch die Zugehörigkeit zum Team, also ein Thunderbolt zu sein. Deutlicher noch als Moonstone illust-

69 Physician, Heal Thyself? (Fabian Nicieza, Mark Bagley, Al Vey et al.), in: Thunderbolts Annual 2000.

70 Entsprechend können possible selves sowohl befreiend als auch einengend wirken, je nachdem, ob durch sie Hoffnung auf Wandlung gegeben wird oder Wandlungsversuche unterminiert werden (Markus/Nurius 1986, 963 ).

7I Explizit formuliert wird dies, als sie bei den Fantastic Four einbricht, um diese um Rat zu fragen, was sie sich dann doch nicht traut. Die Erzählstimme erläutert: «Her power is ... incredible ... but ... the one thing she can't do ... is figure out why. Why she even has it. Why she is in such conflict. Why she feels trapped between who she was and who she is expected to be» (Chasing Your Own Tail (Fabian Nicieza, Mark Bagley, Greg Adams et al.), in: Thunderbolts 43, Oktober 2000).

72 Heroic Tendencies Part I: The Inside Job (Fabien Nicieza, Patrick Zircher, Walden Wong et al.), in: Thunderbolts 45, Dezember 2000. 

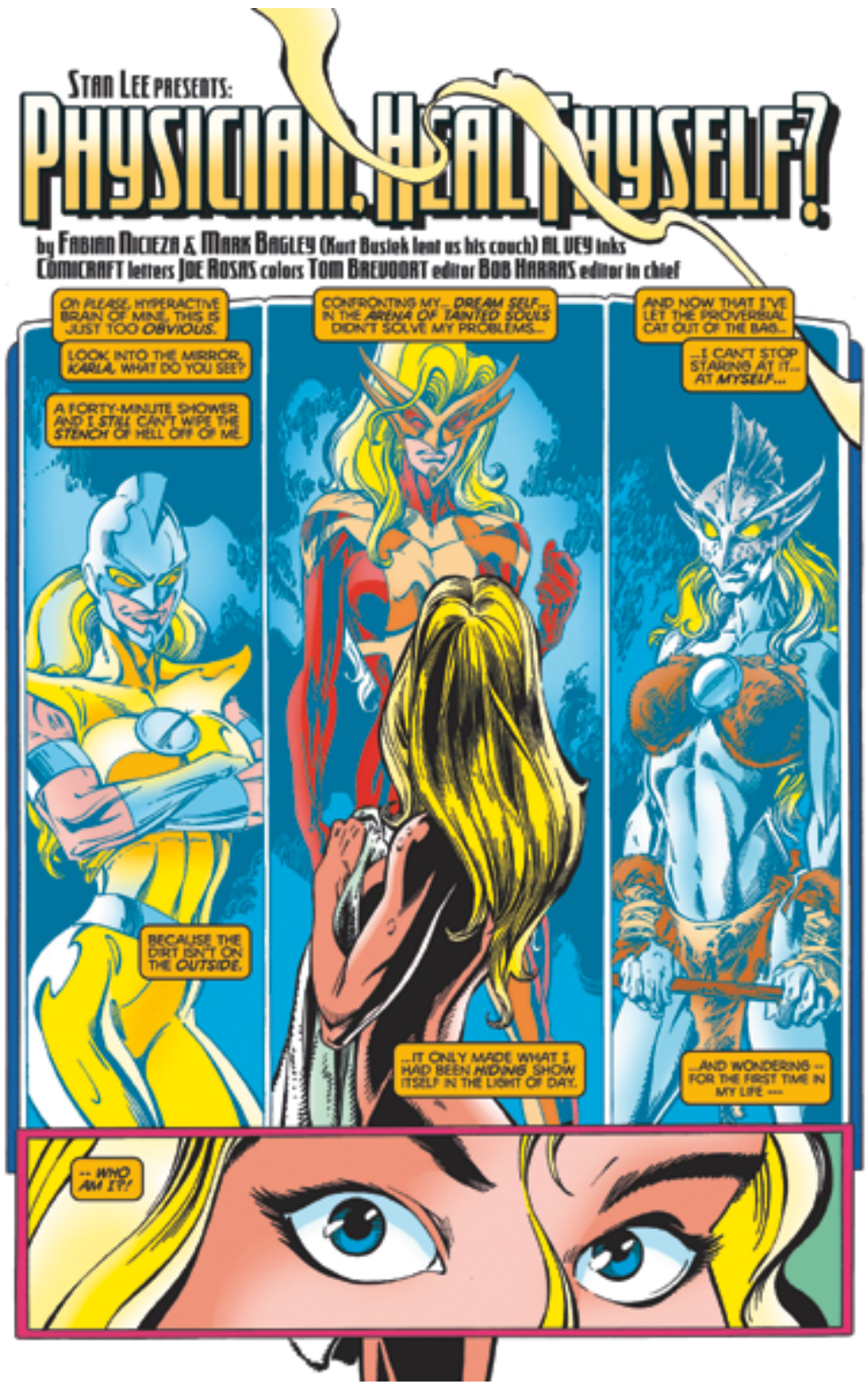

Abb. 5 r: Im Clinch mit sich selbst, sieht Karla Sofen in ihrem Spiegelbild drei mögliche Identitäten mit klar distinkten äusserlichen Erscheinungen: Schurkin, Heldin und rätselhafte fremde Kämpferin. Physician, Heal Thyself! (Fabian Nicieza, Mark Bagley, Al Vey et al.), in: Thunderbolts Annual 2000. (C) Marvel Comics. 
riert dies wohl das Beispiel von Techno. Nachdem sich die Wege von Zemo und Techno getrennt haben, gelingt es Techno, sich in die Thunderbolts-Festung einzuschleichen und den Körper des alten Mechanikers Ogre zu übernehmen, ohne dass die anderen Thunderbolts dies bemerken. Dabei hält er nicht nur den Mechaniker, sondern auch Jolts Körper in sogenannten Kryokammern am Leben. Schliesslich gelingt es Scourge, dem mysteriösen Killer Jolts, auch Techno tödlich zu verletzen - dieser könnte seinen netzwerkartigen Metallkörper zwar retten, müsste dafür aber die Energie der Kryokammer restlos aufbrauchen. Nur hat er kurz davor ein Lebenszeichen von Jolt gesehen, und so steckt er nun im Dilemma. Im Sterben liegend, reflektiert er, warum er zu den Thunderbolts zurückgekehrt ist, und analysiert seine Handlungsmöglichkeiten mit verschiedenen possible selves bzw. welche Option welcher Identität entspricht. Je nachdem, wie er handelt, würde er ein anderes mögliches Selbst umsetzen:

Ever since I replaced Ogre, this has been more than a game to me. I can readily admit I missed the daily challenges of being a member of the Thunderbolts. [...] When Scourge killed Hallie Takahama, a part of me was ... unsettled. While another part of me saw it merely as an opportunity for engaging scientific research. [...] What kind of a fool am I? I know what Zemo would do were he in my place. Even what Techno would do. But what would Paul Norbert Ebersol do ...? What would ... a Thunderbolt do ...? Systems dysfunction! Systems dysfunction! A Thunderbolt ... would choose to die ... like a hero ... Systems dysfunction! Systems dys-KLIK.73

Ausgerechnet Techno, von Beginn an neben Zemo der am wenigsten an einem Heldendasein interessierte und selbstzentrierteste Charakter, entscheidet sich hier für das ultimative Heldenopfer, um Jolt zu retten. Dies bedeutet eine Entscheidung für sein Thunderbolt-Selbst, während er seine anderen möglichen Selbste - den Fixer, seine zivile Identität und sogar Techno - verwirft (Abb. 52). Er leitet die letzte Energie noch in Jolts Kryokammer, der sie einen Moment später mit gesteigerten Kräften entsteigt.

Schliesslich gelingt es den Thunderbolts, Jolts Mörder zu finden (der ebenfalls nicht Herr seines Willens war) und zugleich eine weite Kreise ziehende Verschwörung aufzudecken bzw. zu verhindern. Da auch wichtige staatliche Stellen involviert waren, gelingt es Hawkeye in Heft 50 , für die Thunderbolts eine Begnadigung auszuhandeln. Dies bringt aber zwei Nachteile mit sich: Erstens muss Hawkeye als Bauernopfer selbst ins Gefängnis, und zweitens müssen die Thunderbolts ihr Heldentum aufgeben und sich in ein ziviles Leben zurückzie-

73 Heroic Tendencies Part 2: Heart and Soul (Fabian Nicieza, Mark Bagley, Greg Adams et al.), in: Thunderbolts 46, Januar 200I (im Impressum des Heftes wird als Erscheinungsjahr irrtümlich 2000 aufgeführt). 


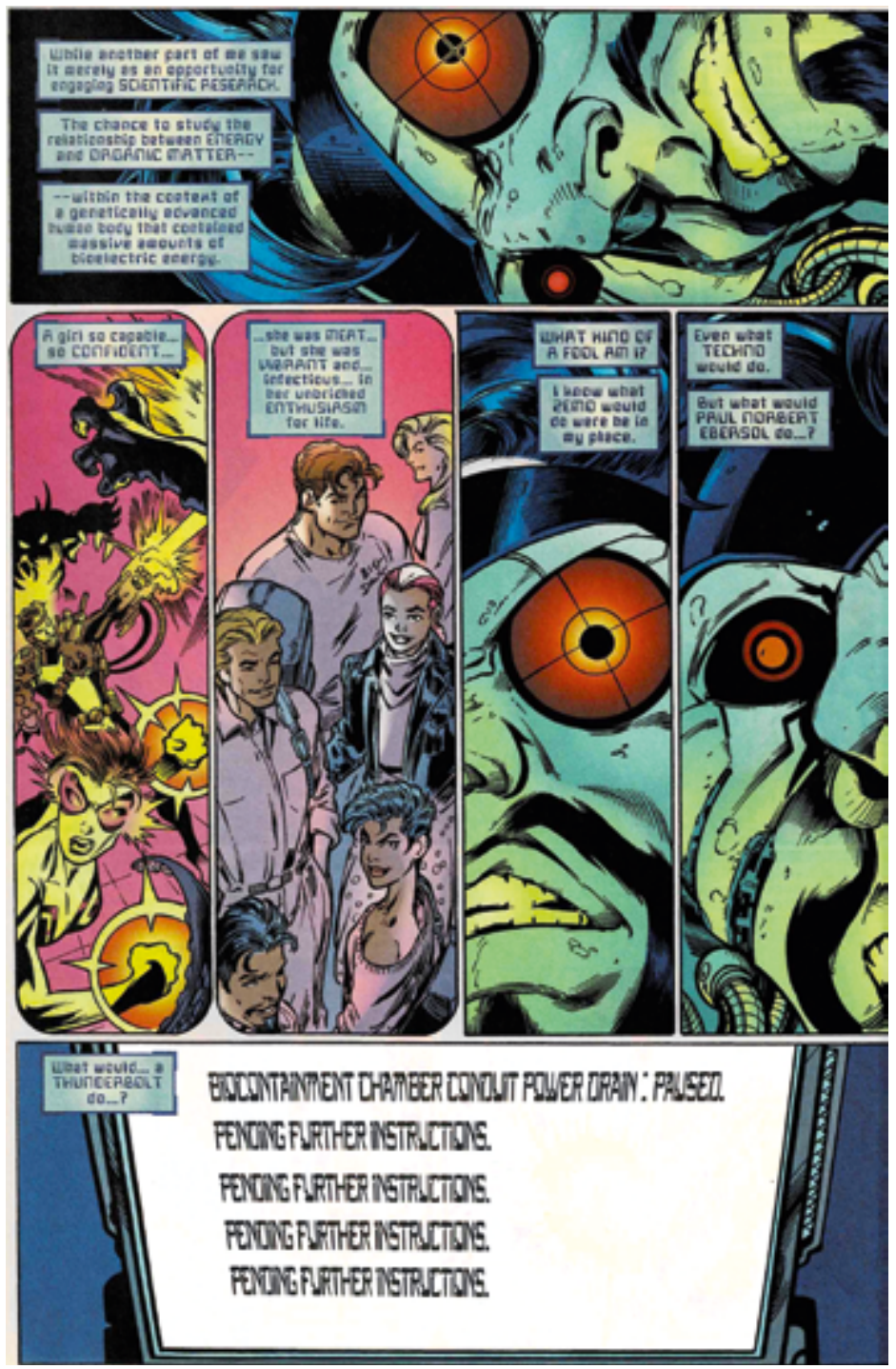

Abb. 52: Technos Tod: Obwohl nur heimlich Teil des Teams, bestimmt seine Entscheidung, sich schliesslich doch als Thunderbolt zu fühlen - nicht zuletzt aus Bewunderung für das jüngste Teammitglied Jolt -, seine Handlungsweise zum Heldenopfer. Heroic Tendencies Part 2: Heart and Soul (Fabian Nicieza, Mark Bagley, Greg Adams et al.), in: Thunderbolts 46, Januar 2000. (C) Marvel Comics 
hen. Kahan/Stewart erläutern das Problem dabei: «Their punishment is inaction and non-involvement. This goes against the very nature of both hero and villain, since both believe that an individual, for better or worse, can make a difference in the world.» ${ }^{74}$ So ist klar, dass die Thunderbolts nicht endgültig geläutert und rehabiliert sind.

Interessant sind dazu die Schlüsse von Matthew J. Costello, der überzeugend darlegt, wie eng die Geschehnisse im Marvel Universe mit den jeweiligen Befindlichkeiten der nationalen Identität der USA verbunden sind. Im nach der Onslaught-Katastrophe neu aufgesetzten Marvel-Universum sieht Costello den Versuch, auch inhaltlich an die Erfolge der I960er-Jahre anzuknüpfen, ${ }^{75}$ was aufgrund des ganz unterschiedlichen Zeitgeistes aber im Grunde gar nicht möglich sei. ${ }^{6}$ Die neue politische Ökonomie im Marvel-Universum reflektierte namentlich das steigende Misstrauen gegenüber der Staatsgewalt. In den Thunderbolts sieht Costello einen Beleg für das Scheitern der versuchten Wiederherstellung des «american consensus» aus den I950er-Jahren (die Vorstellung einer «unitary national identity»), denn «the Thunderbolts [...] reiterate the tropes of the I960s but with neither conviction nor certainty ${ }^{77}$. Die Anknüpfung an 1965 geschieht explizit durch Hawkeye, der ebenfalls einen geläuterten Charakter darstellt. ${ }^{8}$ Doch während bei den damaligen reformierten Avengers (neben Hawkeye etwa Black Widow, Scarlet Witch und Quicksilver) das Bestreben nach Wiedergutmachung nie im Zweifel stand («the issue was primarily one of public perception and willingness to follow orders» ${ }^{9}$ ), stellt sich bei den Thunderbolts immer wieder neu die Frage, auf welche Seite die Protagonisten kippen werden - wobei anzufügen ist, dass der Kern der reformwilligen Thunderbolts sich in der Regel jeweils für das Gute entscheidet. ${ }^{80}$ Costello betont dennoch zu Recht, dass die

74 Kahan/Stewart 2010, I 84.

75 Wie Costello (2009, 20I) ausführt, ist dies übrigens auch im Visuellen ablesbar: Im Vergleich zu den I980er- und frühen 1990er-Jahren, als eher impressionistischere, auf Ambivalenzen zielende Tendenzen herrschten, kamen nun wieder kräftige, helle Farben, klare Kontraste und Linien zum Zug, es gab mehr Splash-Pages, Rinnsteine wurden häufiger eingesetzt, und die Figuren hoben sich klar vom Hintergrund ab.

76 Costello erklärt dies mit der veränderten Wahrnehmung des eigenen Staates: «The very rhetoric of American identity - the language of virtue, progress, and freedom - had lost its power [...].» Dies war namentlich eine Folge des Kalten Krieges, der auch sinkendes Vertrauen in die Staatsmacht mit sich brachte, wobei vor allem auch «international adventurism» sogar die Sprache suspekt gemacht hatte, sodass diese nur noch ironisch gebrochen wieder aufgenommen werden konnte (Costello 2009, I99).

77 Costello 2009, 200.

78 Wie Costello (ebd., 2 I I) bemerkt, spielte die Läuterungsgeschichte (redemption tale) in der einen oder anderen Form bei den meisten Marvel-Helden der 1960er-Jahre eine Rolle.

79 Ebd., 2 Iо.

80 Wie bereits erwähnt, wenden sich die Thunderbolts nicht aus Reue über ihre Taten dem Hel- 
Dinge immer wieder hinterfragt werden. Mehr noch: «[...] the possibility of redemption is never assured», sodass Costello sogar von einer Unmöglichkeit der Läuterung bzw. Wiedergutmachung spricht, da die Figuren den Prozess aufgrund stets neuer Herausforderungen nie definitiv abschliessen können ${ }^{81}$

Entsprechend sind die Abenteuer der Thunderbolts mit der offiziellen Begnadigung keineswegs beendet, wobei hier nur die eine oder andere erwähnenswerte Entwicklung noch kurz angesprochen werden soll. Im Thunderbolts-Team bleiben die minderjährigen Jolt und Charcoal sowie einige neue Rekrutierte, darunter eine neue Inkarnation des Fixers (Norbert P. Ebersols originaler Körper wurde wiederbelebt). Karla, Melissa und Abe dagegen müssen sich in einem zivilen Leben zurechtfinden; Hawkeye muss sich im Gefängnis durchschlagen. Mit dem Sonderheft Life Sentences (200I) wird diesen Prozessen ein eigenes Heft gewidmet, und auch hier kreisen die Herausforderungen, denen sich die Figuren stellen müssen, nicht zuletzt um die Wahl zwischen verschiedenen möglichen Selbsten. So wird Moonstone wie folgt eingeführt:

Dr. Karla Sofen: Moonstone. A psychologist who manipulated a former patient into giving her an alien gemstone of immeasurable power - her role as a Thunderbolt had forced her into behavioral extremes. Self-preservationist or altruistic hero? Clinical manipulator or marionette to an alien conscience? Indifferent to Hawkeye's plight ... or honestly in love with him? ? $^{28}$

Hier werden für einmal nicht nur die namentragenden possible selves aufgezählt, sondern auch weitere Aspekte ausgesprochen. Je nachdem, was Moonstone für ein Bild von sich hat, ändert sie die Bewertung ihrer Taten. Ohne Team fehlt ihr die Orientierung; durch ihren Wandel ist ihr ihr individueller moralischer (bzw. unmoralischer) Kompass abhanden gekommen. Aus Ratlosigkeit, was sie mit sich und ihren Kräften anfangen soll, nimmt sie daher Gravitons Jobangebot an, ihm als seine persönliche Psychologin zu einer Vision, die seiner Grösse respektive seinem Grössenwahn entspricht, zu verhelfen. Wie zu erwarten, passt sich Abe Jenkins am schnellsten an. Er bekommt rasch einen Job in einem Elektronikgeschäft, wobei er dem nine-to-five job nun viel mehr abgewinnen kann als noch vor seinen Beetle-Jahren: «Now, that same existence feels like a carpet of unlimited opportunity spread before him.» ${ }^{{ }^{8}}$ Melissa hingegen weiss nicht so

dentum zu, sondern vor allem, weil sie sich so ein besseres und erfolgreicheres Leben erhoffen (dies gilt insbesondere für Moonstone, aber auch für Atlas, Songbird und zu Beginn auch Mach-I).

8 I Costello 2009, 2 I 2.

82 Thunderbolts - Life Sentences (Fabian Nicieza, Charlie Adlard et al.), Juli 200r. Das Heft ist chronologisch nach Heft 52 einzuordnen.

83 Ebd. 
recht, was sie will - auch weil sie nicht weiss, was sie alles tun könnte, ausser eben sich wieder dem Verbrechen zuzuwenden. ${ }^{84}$ Man könnte dies als Mangel an möglichen (zivilen) Selbsten interpretieren. Mit etwas Hilfe von Captain Marvel findet sie aber ihren Weg und findet eine Stelle, in der sie subtil ihre Kräfte einsetzen kann.

Die Zeit des ausschliesslich zivilen Lebens kann für Helden jedoch nur beschränkt sein. So können auch Abe und Melissa nicht nur zusehen, als Graviton (mit Moonstone und dem Fixer unter seinen Adlaten) die Erde nach seinem Gesicht formen will - obwohl Abe seine letzte Chance auf ein normales Leben nur widerstrebend aufgibt. Gravitons Aktionen öffnen in Thunderbolts 58 (2002) eine Art Korridor zwischen der Erde und Counter Earth, der die Erde zu verschlingen droht. In letzter Minute raufen sich die Thunderbolts zusammen und bringen das heldische Opfer: Da der Korridor grob gesagt nur <von innen> geschlossen werden kann, muss Songbird das Ganze von aussen mit einem ihrer Konstrukte aus solid sound festhalten, während die restlichen Thunderbolts auf der Counter Earth landen. Auf diesem von Katastrophen gebeutelten Planeten stehen sie erneut vor der Frage, welche Rolle sie spielen bzw. wer sie sein wollen. Songbird wird derweil von Shield angeheuert, um den mittlerweile mit drei Superschurken aus der Haft geflohenen Hawkeye zu finden. Auf Hawkeyes Spur greift Melissa wieder auf Aspekte ihres Mimi-Ichs zurück und setzt sich erneut damit auseinander, wer sie war, ist, sein soll und sein will. Sie reflektiert ausführlich, welche Identitätsmöglichkeiten ihre past selves ihr bieten. Es wird so dargestellt, als ob auf der Kippe stünde, welches ihr present self werden soll, wenn sie sich, die Flüchtigen schon in Sichtweite, fragt: «Okay, now what do I do? Bust 'em? Work with 'em? Take whatever they got going and bolt? Until now, it's just been an excuse to strut. Now ... what I do depends on ... who I want to be. Mimi? Melissa Gold? Songbird? Am I a con? A Shield agent? A super bero?» ${ }^{85}$ In dem Moment aber, wo sie Hawkeye findet, gibt es keinen Zweifel mehr. Bezeichnenderweise nicht ihr eigenes, sondern Hawkeyes Kostüm (das sie ihm mitgebracht hat) hat für sie dabei eine besondere Bedeutung bekommen (Abb. 53): «A reminder ... of who I am.» ${ }^{86}$ Obwohl die Thunderbolts sich immer wieder mit ihren Identitäten beschäftigen müssen, ist festzuhalten, dass sie im Vergleich etwa zu Spider-Man oder Daredevil insgesamt deutlich weniger Zweifel an sich selbst kultivieren - was auch damit zusammenhängen mag, dass sie über keine klassische Doppelidentität verfügen.

84 So sinniert sie einmal (ebd.): «Been playing wannabe hero for so long - I’ve forgotten what it’s like to be a criminal.»

85 Criminal Intent (Fabian Nicieza, Patrick Zircher, Al Vey et al.), in: Thunderbolts 63, Juni 2002.

86 Ebd. 

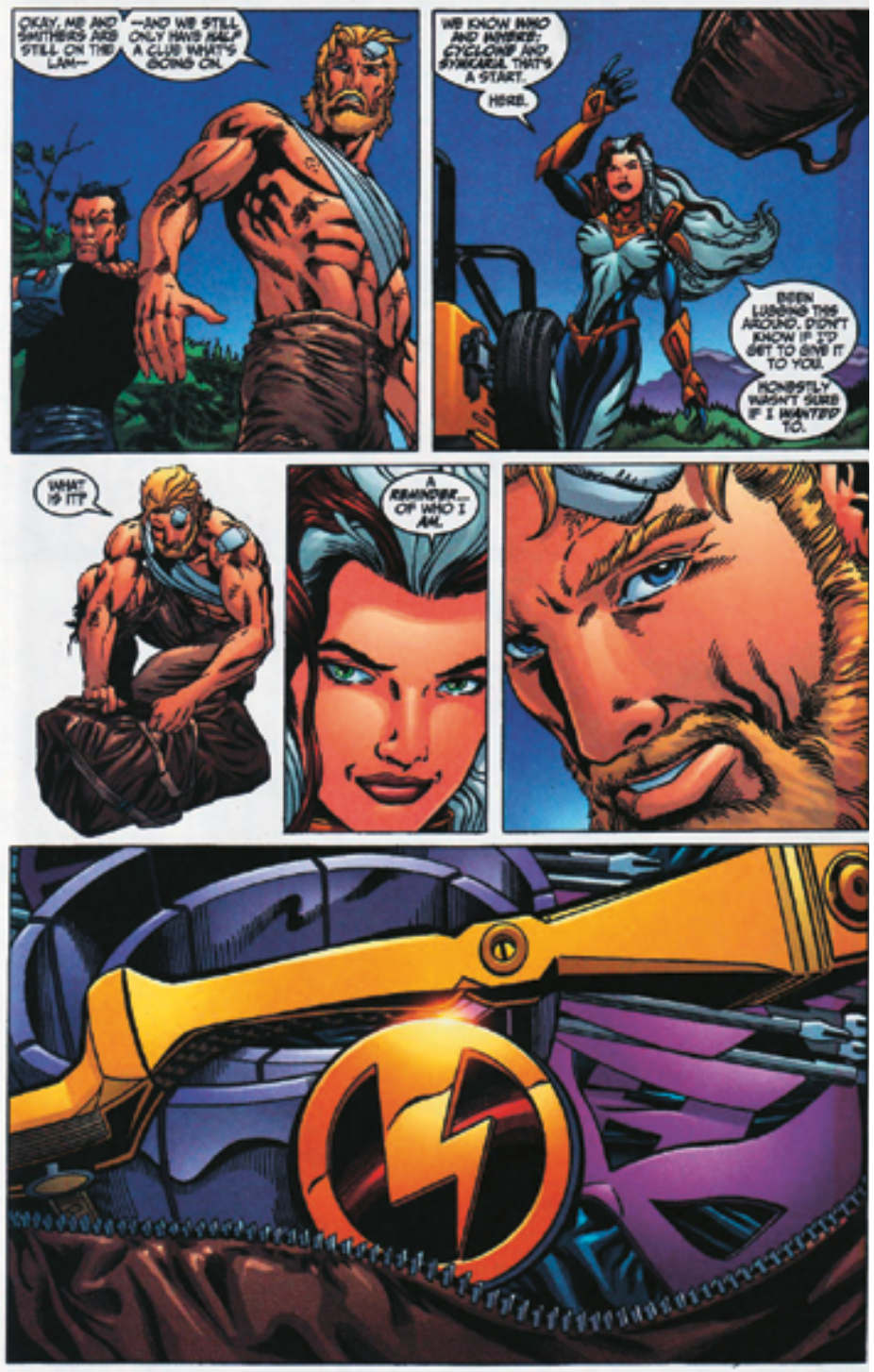

Abb. 53: Songbird und Hawkeye wieder vereint - das ThunderboltsSignet (mit Hawkeyes Bogen und Maske) repräsentiert dabei für beide ihr angestrebtes heldisches possible self. Criminal Intent (Fabian Nicieza, Patrick Zircher, Al Vey et al.), in: Thunderbolts 63, Juni 2002. (C) Marvel Comics 
Schliesslich gelingt es mit Bemühungen von beiden Planeten aus, die auf Counter Earth gestrandeten Thunderbolts wieder zurückzubringen (bis auf Jolt, die dort bleibt). Die Rückkehr wird zu einem Neuanfang: Hawkeye verlässt das Team, weil seine Anführerposition inzwischen von einem anderen ausgefüllt wird (einer neuen Version von Baron Zemo, der sich tatsächlich dem Guten zuzuwenden scheint). Zudem beschliesst Abe, seine Gefängnisstrafe abzusitzen alles andere würde mit seinem Selbstbild nicht mehr übereinstimmen. Selbstverständlich ist die Geschichte der Thunderbolts damit nicht zu Ende. Dass sich ihr Schwanken zwischen Helden- und Schurkentum weiter hinziehen wird, bekräftigt nur schon, dass der neue Anführer - der soeben wieder die alte Zemo-Maske übergestreift hat - am Ende seinen verbliebenen Teammitgliedern erklärt: «That in order to save this planet ... the Thunderbolts will have to rule it! ${ }^{87}$

Die Thunderbolts werden sich, salopp gesagt, also wohl nie auf einer festen Identität ausruhen können. Indem sie immer wieder als zwischen verschiedenen Möglichkeiten ihrer Identitäten stehend gezeichnet werden und zum Teil ihre Position zwischen den Polen von Gut und Böse mehrfach wechseln, zeigen die Thunderbolts Identität als wandelbar und flexibel - wenn auch nicht als beliebig. Denn meistens schwanken die Figuren zwischen nicht allzu vielen Möglichkeiten, sondern es geht in der Regel darum, welches von zwei, allenfalls drei (noch dazu mit einem Namen versehenen) möglichen Selbsten im Moment und in der Zukunft umgesetzt werden soll. Ein tragendes soziales Umfeld spielt dabei eine besonders wichtige Rolle, denn nicht selten ist dieses ausschlaggebend dafür, um ein Thunderbolt zu bleiben.

87 «Didn't See That Coming» (Fabian Nicieza, Manuel Garcia, Scott Hanna et al.), in: Thunderbolts 75 , Februar 2003. 


\title{
Wie aus Bruce Wayne immer wieder Batman wird - der multiple Dunkle Ritter und die narrative Identität
}

\author{
My favorite mask is myself. \\ Orson Welles, 1982
}

Bei seinem allerersten Auftritt im Mai 1939 in Detective Comics 27 wurde «The 〈Bat-Man`» noch vor dem Beginn der Geschichte mit folgenden Worten angekündigt: «a mysterious and adventurous figure fighting for righteousness and apprehending the wrong doer, in his lone battle against the evil forces of society ... His identity remains unknown.» ${ }^{\perp}$ Im Hintergrund prangte die schwarze Silhouette einer Figur, die mit ausgebreitetem Fledermausumhang vor einem überdimensionierten Vollmond stand. Zumindest für die Leser blieb die Identität dieses Verbrechensbekämpfers gerade mal acht Seiten lang im Dunkeln. ${ }^{2}$ Denn die letzten beiden Panels bestätigten in einem «If he only knew>-Moment, dass der Träger des Fledermauskostüms ein gewisser Bruce Wayne ist. Dieser «bored young socialite» hatte in der Geschichte Commissioner Gordon bei Ermittlungen zu einem Fall begleitet, den er als Batman löste.

Obwohl Batman Superman imitieren und zugleich einen Gegenentwurf zu diesem darstellen sollte, steht an seinem Anfang keine Origin-Story. Da Batman keine Superkräfte besitzt, müssen diese nicht erklärt werden. Bezüglich der Doppelidentität folgte die Geschichte daher der 〈Zorro-Erzählstruktur〉; der Plot dagegen war die schlankere Version einer früheren Shadow-Geschichte, womit die beiden offensichtlichsten Inspirationsquellen ${ }^{3}$ von Batmans Schöp-

I The «Bat-Man». The Case of the Chemical Syndicate (Bill Finger, Bob Kane), in: Detective Comics 27, Mai 1939, I.

2 Der Einstiegs-Erläuterungstext der zweiten Batman-Geschichte (Frenchy Blake's Jewel Gang (Bill Finger, Bob Kane), in: Detective Comics 28, Juni 1939, I) schreckte nicht davor zurück, nach «His identity remains unknown» kurzerhand noch in Klammern nachzuschieben: «(He’s one Bruce Wayne, bored young socialite.)»

3 Kane selbst führte zusätzlich einen weiteren Film - The Bat Whispers von 1930 mit einem Mörder in Fledermausmontur - sowie Leonardo da Vincis berühmte Zeichnung eines Flugapparats an. Motivgeschichtlich Interessierte haben darüber hinaus mögliche weitere Vorbilder ausgemacht. Dazu zählen Spring-Heeled-Jack-Illustrationen, Fledermauskostüme für Maskenbälle (Brownie/Graydon 2016, 86) und Fallschirmspringer, die sich mit Flügelanzügen bei Air Shows, die in den I930er-Jahren offenbar beliebte Spektakel waren, vom Himmel fallen liessen und in der Presse als Bird Men oder Bat Men bezeichnet wurden - wobei es vereinzelt schwarze Flügelkonstruktionen gab (Hagen 20I4). 
fern Bob Kane (Zeichner, I9I 5-I998) und Bill Finger4 (Autor, I9I4-1974) genannt sind.

Wie es intradiegetisch zu Bruce Waynes Heldenidentität kam, wurde erst ein halbes Jahr später in Detective Comics 33 nacherzählt, wie damals typisch recht bündig auf nur gerade anderthalb Seiten.5 Der Titel des Segments, wie er beim (übrigens anders kolorierten) Nachdruck in Batman I (Frühling 1940) erschien The Legend of the Batman - Who He Is and How He Came to Be--, offenbarte bereits, dass die Origin-Story die Identität bzw. den Charakter eines Superhelden in wesentlicher Weise ausdrückt. Bruce Waynes Werdegang umfasst vier Stationen: I. Bruce' Eltern werden vor den Augen ihres Sohnes bei einem Überfall auf offener Strasse erschossen. 2. Kurz darauf legt Bruce einen Eid ab, sich dem Kampf gegen das Verbrechen zu widmen. ${ }^{6} 3$. Darauf folgt eine jahrelange Lernphase, in der Bruce unermüdlich sowohl an seinen körperlichen wie auch an seinen geistigen Fähigkeiten feilt. 4. Schliesslich fehlt ihm als letztes Puzzleteil für sein Vorhaben nur noch eine wirkungsvolle Verkleidung; als er gerade darüber sinniert, dient ihm eine zufällig durchs Fenster fliegende Fledermaus als Omen ${ }^{7}$ (vgl. Abb. 8).

Seither hat Bruce Wayne/Batman ein Abenteuer nach dem anderen erlebt, gehört er doch zu den seltenen populären Gestalten, bei welchen die Publikation von neuen Geschichten in ihrem Stammmedium seit ihrer Erfindung nie ausgesetzt wurde. ${ }^{8}$ Vielmehr hat er weitere Medien erobert. Mit der Zeit wurde er aber auch $\mathrm{zu}$ einer Figur mit Vergangenheit, und so werden die Momente, die seine Karri-

4 In den Comics selbst wurde jahrzehntelang nur Zeichner Bob Kane als Urheber genannt, inzwischen ist man sich allerdings einig, dass Autor Bill Finger massgeblich an der Figurenkonzeption beteiligt war (Darowski 2009, 46, Harrison in Easton/Harrison 2010, 3 I). Zur Autorkonzeption und den verschiedenen Umgangsweisen mit Autorschaft bei DC und Marvel vgl. Kelleter/Stein 2012, 265-268, Brooker 2013.

5 Legend of the Batman and How He Came to Be (Bill Finger, Bob Kane), in: Detective Comics 33, November 1939, I-II (der Story The Batman Wars Against The Dirigible of Doom von Kane und Gardner Fox vorangestellt).

6 Bruce schwört zwar, den Tod seiner Eltern durch den Kampf gegen das Verbrechen zu rächen, von individueller Rache gegen den eigentlichen Täter ist auffälligerweise aber keine Rede.

7 Auch hier fand Batmans Geschichte einen erwähnenswerten Paten: Das Vorbild für die Fledermausszene bietet die Pulp-Novel The Bat Strikes! aus dem Jahr 1934 (McCulley 2009, I6), wobei sich «Bat` Dawson Clade vor der Fledermaus fürchtet, was bei der ersten Batman-Version nicht vorkommt, später aber prominent wieder aufgenommen wurde (vgl. Murray 2007).

8 Damit zählen die Hefte zu Superman, Batman, Green Arrow und Wonder Woman zu den wohl ältesten noch immer laufenden Serien überhaupt (wobei es bei Wonder Woman geplante kleine Unterbrüche gab). Deutlich älter sind freilich gewisse Zeitungscomicstrips, z. B. laufen seit 1919 Gasoline Alley und Popeye (zuerst als The Thimble Theater, Popeye kam erst 1929 dazu), Blondie seit 1930 oder Flash Gordon seit 1934. 
ere geprägt haben, immer wieder nacherzählt, um neue Leser damit vertraut zu machen - dies gilt insbesondere für die Origin-Story.

Zwischen Batman und dem Konzept der narrativen Identität lassen sich einige frappante Parallelen ziehen, wie dieses Kapitel aufzeigen soll. Der bisher auf intradiegetische Welten gerichtete Blick wird dazu auf das Netzwerk von Erzählungen, das die Superheldencomics prägt, ausgeweitet. Im Fokus stehen dabei verschiedene Batman-Origin-Versionen und Rekapitulationen von Batmans Anfangsjahren. Im Einzelnen sind dies: The Untold Legend of the Batman aus dem Jahr I980, dann die gross angelegte Origin-Revision aus dem Jahr 1987 - mit Batman: Year One (zuerst in Batman 404-407, Februar-Mai 1987), «... My Beginning ... and My Probable End.» (Detective Comics 574, Mai i 987) sowie Batman: Year Two (Detective Comics 575-578, Juni-September 1987) und nach 2000 die im Anschluss an den Story-Arc Batman RIP erschienenen Batman-Hefte 282 und 283 (The Butler Did It und What The Butler Saw, 2009) und schliesslich die Graphic Novels Batman: Earth One sowie Batman: Earth One Volume Two von 2012 bzw. $2015 .^{9}$

\section{Multiplizität durch Serialität: Batmen}

Die Vorstellung einer narrativen Identität hat in der Sozialpsychologie spätestens seit den I980er-Jahren immer mehr Fuss gefasst, sodass sogar schon von einem «narrative turn» gesprochen wurde und sich inzwischen ein eigener Zweig der Psychologie bzw. Psychotherapie mit Narration beschäftigt. ${ }^{10}$ Dahinter steht die Ansicht, dass Erzählungen für menschliche Erfahrung und Handlungsweisen in der Welt zentral sind und sogar der Schlüssel zum Verständnis von Identität und Persönlichkeit sein könnten, wie Amia Lieblich und Ruthellen Josselson erläutern. ${ }^{\text {II }}$ Gewisse Psychologen sehen in der Narration das Potenzial zu einer sogenannten root metaphor der psychologischen Theoriebildung. ${ }^{12}$ Die narrative Psychologie fokussiert dabei auf lebensgeschichtliches Erzählen, teils

9 Diese Titel werden im Folgenden abgekürzt als Legend, Year One, My Beginning, Year Two, The Butler und Earth One sowie Earth One 2.

Io Lieblich/Josselson 2013, 209. Sie bemerken, dass Vorstellungen narrativer Identität schon im Lauf des 20. Jahrhunderts verschiedentlich in der Philosophie (und, wie anzumerken ist, der Erzählforschung) zu finden sind.

I I Ebd., 209f.; Lucius-Hoene/Deppermann (2004, I67) formulieren dies wie folgt: «[Der Begriff] entspringt der wachsenden Erkenntnis über die Besonderheiten der Narrativität als wirklichkeitskonstruktives und sinnstiftendes Handeln auch jenseits der Literaturwissenschaft und Volkskunde.»

I 2 Lieblich/Josselson 20I3, 2 I 4. 
eher in Autobiografien, teils eher in Alltagskonversationen. ${ }^{13}$ Hier wird davon ausgegangen, dass der Akt des Erzählens über sich selbst das Selbst formt bzw. das Individuum dadurch seine Identität konstruiert. ${ }^{14}$ Freilich gibt es unter den einzelnen Ansätzen Unterschiede, die nicht zuletzt davon abhängen, ob und wie Identität, Selbst und Ich als Grundgerüst aufeinander bezogen werden; auch variiert der Grad, in welchem Identität sozusagen ohne Umschweife als reine Narration bestimmt wird (diese Unterscheidungen würden hier indes zu weit führen).

Wie die Erzählforschung mehrfach gezeigt hat, bedeutet Erzählen stets auch Interaktion und (Re-)Konstruktion des Erzählten und des Erinnerten. Da im Erzählen unweigerlich eine Gestaltung des Erzählten erfolgt, lässt sich Erzählen als Form der Arbeit an der eigenen Identität auffassen. ${ }^{15}$ Dies erläutern Gabriele Lucius-Hoene und Arnulf Deppermann:

In der Art und Weise, wie der Erzähler also seine vergangene Person in der Geschichte aufscheinen lässt und an die imaginierten oder tatsächlichen Reaktionen der Hörer anpasst, werden Facetten und Strategien von Identitätsarbeit sichtbar, in denen personale und soziale Aspekte des erzählten wie des erzählenden Ich in der Situation selbst verhandelt werden [...]. Das Erzählen von Selbsterlebtem ist somit sowohl eine Selbstdarstellung als auch interaktionell mitbestimmte und emergente Selbstherstellung, mit dem das aktuell erzählende Ich «Identitätsarbeit in Aktion> betreibt und für sich selbst einen bestimmten Geltungsrahmen und Konsequenzen beansprucht. ${ }^{16}$

Wie hier deutlich wird, ist die narrative Identität ebenfalls eine soziale Konstruktion. Mit dem Stichwort der Selbstdarstellung liegt die Verbindung zur Theatermetapher Goffmans auf der Hand (wie bei Goffmans Darsteller kann auch beim Erzählen das Publikum ein imaginäres sein ${ }^{17}$ ). Das Selbst als eine sich fortwährend entfaltende Geschichte aufzufassen, bedeutet auch, dieses Selbst als dynamischen Prozess zu verstehen. ${ }^{18}$ Dabei wird - und hier ist wiederum auf Kant zurückzuverweisen (vgl. das Kapitel zu Masken, Rollen, Identitäten) - davon

I 3 Vgl. Lucius-Hoene/Deppermann 2004, I67.

I4 Lieblich/Josselson 20I3, 207.

Is Gemeint ist hier in erster Linie autobiografisches Erzählen - «life stories» oder «self narratives» -, doch kann Identitätsarbeit in anderen Erzählungen wohl auch über Wertungen, Gewichtungen oder jedenfalls Arbeit an der eigenen Identität/Rolle als Erzähler geschehen. Lieblich/Josselson (ebd., 2 I 2) halten fest, dass eine Person ihre Einzigartigkeit nicht nur über den Erzählinhalt, sondern auch über die Erzählweise vermitteln kann.

I6 Lucius-Hoene/Deppermann 2004, I68 (Hervorhebung im Original).

17 Ebd.

I 8 Cox/Lyddon I997, 2 I I; vgl. Lieblich/Josselson 201 3, 204-206. Bei der narrativen Identität wird Identität explizit nicht als Zustand oder Substanz definiert, sondern als eine «Art und Weise» (Lucius-Hoene/Deppermann 2004, I68). 
ausgegangen, dass der Erzählvorgang auf das Individuum zurückwirkt. ${ }^{19}$ Erzählen und Identitätskonstruktion stehen also in einer Wechselwirkung: Ändert der Erzähler seine Geschichte, so halten Lieblich/Josselson fest, ändert sich auch die Erinnerung an das erzählte Ereignis und dadurch die damit zusammenhängende Erfahrung und so die Identität. ${ }^{\circ}$ Ein ähnlicher Prozess lässt sich bei Superhelden, die in seriellen Erzählformen zuhause sind, beobachten. So betont Terrence R. Wandtke: «[A]s long as the superhero has been in existence, [he] has been sin the making>, working through a series of revisions.» ${ }^{21}$

Narrative Identität - ein Konzept, das sich auf lebensgeschichtliches Erzählen bezieht und mit dem dieses auf ähnliche Strukturen wie fiktionale Geschichten hin untersucht wird - mit einer fiktionalen Figur wie Batman zu verknüpfen, mag zunächst etwas seltsam erscheinen. Tatsächlich stösst die Übertragbarkeit in gewissen Punkten schnell an Grenzen: Unter anderem wird der zentrale Punkt der Rückwirkung des Erzählten auf den Autor/Erzähler hinfällig. Auch kommt es bei fiktionalen, also fingierten Lebenserzählungen nicht zu einem Referenzpakt zwischen Erzähler und Rezipient (den Philippe Lejeune für lebensgeschichtliches Erzählen als autobiografischen Pakt benannt hat); ${ }^{22}$ dieser wird sozusagen a priori durch die willing suspension of disbelief ausgehebelt. Doch weisen die (Re-)Konstruktion der eigenen Lebensgeschichte und die Konstruktion der Biografie einer fiktionalen Figur durchaus Parallelen auf, die trotz der unterschiedlichen Fundamente eine Analogiesetzung rechtfertigen. ${ }^{23}$ Gerade weil Batman eine massen- und multimediale Figur serieller Formate ist, lassen sich in ihm Aspekte narrativer Identität wiedererkennen. Die Grundlage dafür liegt in der Serialität als Erzählform im Allgemeinen, Batman erweist sich mit seiner langen Geschichte und der daraus resultierenden riesigen Publikationsliste allerdings als herausragendes Beispiel.

I9 In den Worten von Lieblich/Josselson (2013, 2 I2): «We become the stories we tell each other or ourselves.»

20 Ebd. Laut Lieblich/Josselson (ebd., 205f.) kann Identität so auch als «innerer Dialog» aufgefasst werden - sozusagen als ständiges Frage-Antwort-Spiel «Wer bin ich?»-, der jedoch auch Teil der «interpersonal negotiations and social relations» ist.

2I Wandtke 2007, 5 .

22 Lejeune 1994 (1975), 27-45.

23 So beschreiben Lucius-Hoene/Deppermann (2004, 173) in Bezug auf lebensgeschichtliches Erzählen die sogenannte Positionierung, die als Positionierungsakte nicht nur jene von Erzähler und Zuhörer(n) in der Erzählsituation, sondern auch von «erzählten Figuren» im Erzählten beinhaltet. Über den 〈Umweg〉 der Zuhörer-/Leserperspektive kann zudem jede fiktionale Figurenbiografie potenziell als lebensgeschichtliche Erzählung gelten (dem widersprechen sogar fantastische Elemente nicht, wenn diese unter die willing suspension of disbelief fallen), vgl. Lieblich/Josselson 2013, 2 I3, sowie Lejeune I994 (1975), 29 und 4 of. 
Eine Person kann nach Dan McAdams mehr als eine «life story» haben, oder diese kann aus kleineren, auch unzusammenhängenden Storys bestehen. ${ }^{24}$ Bei den «self narratives» oder «life stories» wiederum handelt es sich um Konstrukte, die aus verschiedenen Erfahrungen, Gedanken und Gefühlen - die gewöhnlich auf Fragment- und Momenthaftigkeit beruhen - zusammengefügt werden. ${ }^{25}$ Analog dazu lässt sich die Serie als bewusst gestaltete zeitliche Klammer für aufeinanderfolgende Fragmente betrachten: Nicht nur besteht eine Serie aus Folgen, sondern eine Folge lässt sich wiederum als Aneinanderreihung einzelner Szenen betrachten, die sich nochmals aus kleineren Einheiten wie Panels, Kameraeinstellungen oder Abschnitten zusammensetzen. Man könnte sogar so weit gehen und die Identität bzw. das Selbst als serielles Konstrukt auffassen, in welchem das jeweils aktuelle Ich (etwa als von den possible selves unterscheidbares actual self, ${ }^{26}$ wie im Kapitel zu den Thunderbolts erläutert) einer Episode gleichkommt.

Über die Doppelidentität hinaus kann man bei Batman auf mehreren Ebenen von einer Vervielfachung seiner Figur sprechen, deren Grundlage wie erwähnt in der Serialität der Batman-Publikationen liegt. Nur schon in den Comics tritt Batman seit 1940 ohne Unterbruch in mindestens zwei Heftreihen, Detective Comics und Batman, gleichzeitig auf, wobei diese üblicherweise nebeneinander laufen, manchmal aufeinanderfolgen und zuweilen Teil von noch übergreifenderen Handlungssträngen sind, die das ganze DC-Universum umfassen können. Hinzu kommen zeitweise weitere Reihen, Sonderhefte, Auftritte von Batman in Titeln anderer Helden oder Teams (wie Justice Society of America, Justice League of America oder Superman/Batman). ${ }^{27}$ Damit ist Batmans Welt keineswegs komplett: Zahlreiche weitere Medienprodukte - Hörspiele, Filmreihen, TV-Serien, Spiele, Romanadaptionen - sind dem Dunklen Ritter gewidmet. Batman ist nicht «nur literarische Figur, sondern ein ganzes Franchise. Die zahlreichen Batman-

24 McAdams 1996, 307.

25 Lieblich/Josselson 2013, 204. McAdams (1996, 307) formuliert dies noch genauer, unter «life story» versteht er «an internalized and evolving narrative of the self that incorporates the reconstructed past, perceived present and anticipated future».

26 Eine Verbindung der possible selves mit narrativer Identität (und zudem mit der self-control theory) bietet Granberg 2006.

27 In vielen Fällen sind Comicleser darauf angewiesen, dass Verlag, Autoren oder andere Leser bzw. Fans Listen mit Lese-Reihenfolgen erstellen, die einen bestimmten Story-Arc chronologisch verfolgen (was sich von der Publikationsreihenfolge unterscheiden kann). In den I990er-Jahren führte DC für die Superman- und Batman-Publikationen zeitweilig sogar eine zusätzliche inhaltschronologische Heftnummerierung (pro Held) ein. Zum Wandel der seriellen Form der Comic-Hefte, von der series zum serial, vgl. Meteling 2013, 94. 
Umsetzungen stellen entsprechend ein Beispiel für transmedial konstruierte Erzählwelten dar, wie sie Henry Jenkins beschreibt. ${ }^{28}$

Bezeichnenderweise charakterisieren Shane Denson und Ruth Mayer «die materielle Dimension seriellen Erzählens» als "Prozess der Selbstentfaltung». ${ }^{29}$ In diesem Zusammenhang sind denn auch Mayers und Densons «serielle Figuren» interessant, die sie idealtypisch vom «Seriencharakter» unterscheiden. Wie Mayer anmerkt, sind Superman und Batman zwar «nur mit signifikanten Einschränkungen» ${ }^{\circ}$ als serielle Figuren zu verstehen. Einige Charakteristika sind aber, wenn auch gewiss nicht für einzelne Batman-Werke, so doch für die Gesamtheit aller (teils kooperierenden, teils konkurrierenden) Batman-Publikationen zutreffend. So erklären Mayer/Denson, dass serielle Figuren einerseits «in der jeweiligen Annäherung völlig linear präsentiert werden» können, aber andererseits - übergreifend über die unzähligen einzelnen Varianten - «palimpsest-ähnliche Biografien [aufweisen], die sich diegetischer Kohärenz [und Geschlossenheit] widersetzen». ${ }^{31}$ Denn in idealtypischer Form präsentieren sich serielle Figuren «als eine Reihe von variierenden Wiederholungen, die sich nicht innerhalb eines homogenen medialen und diegetischen Raumes, sondern zwischen und quer zu solchen Erzäblräumen entfalten» ${ }^{32}$.

28 Transmediale Erzählwelten zeichnen sich insbesondere dadurch aus, dass in verschiedenen Medien unterschiedliche Geschichten erzählt werden und so für den einzelnen Leser unüberschaubare narrative Konstrukte entstehen, da jeder Text zum einen gewisse Informationen enthält, die in anderen nicht zu finden sind, und zum andern eine je eigene Interpretation z. B. von Charakteren bietet. Im Idealfall ist für den Leser jede verfügbare Story ein möglicher Einstiegspunkt ins erzählte Universum; der Leser (bzw. Fan) wird sozusagen zum Lektürejäger und -sammler, wie Jenkins (2006a, 93-130) erläutert. Zu Comics vgl. Jenkins 2006b und 2006c, wo er u. a. darauf verweist, dass Comics - seit den frühen Superhelden-Medienverbünden mit transmedialen Strategien vertraut - heute oft als Erprobungsfeld für die weitere mediale Vermarktung einer narrativen Welt gelten; DC als Teil von Time Warner zählt dabei zu den «major transmedia companies», was inzwischen für Marvel (das heute zum Disney-Konzern gehört) ebenso gilt.

29 Damit ist der Eindruck gemeint, dass sich serielle Figuren «offenbar selbst (fort)schreiben»; mit Michael Chabon erscheinen solche Figuren als «storytelling engines» (Denson/Mayer 20I 2, I 866 .).

30 Mayer 20I 2, I44. Insbesondere beschreiben Denson/Mayer $20 \mathrm{I} 2$ sowie Mayer $20 \mathrm{I} 2$ serielle Figuren, für die sie als weitere Beispielen etwa Tarzan, Fantômas oder Sherlock Holmes nennen, als «flach», wobei sie aber betonen, dass es sich um eine idealtypische Unterscheidung handelt, bei welcher die Grenzen fliessend sind (auch sehen sie serielle Figuren als Phänomen vor allem zwischen etwa i 880 und 1960).

3 I Denson/Mayer 2012, I88. So bemerkt etwa Harrison, dass der Versuch, die Biografie eines Superhelden nachzuzeichnen, heute unweigerlich in der Aufzählung diverser Versionen ende (Easton/Harrison 2010, 25f.).

32 Denson/Mayer 201 2, I9I (meine Hervorhebung). 
Dies erinnert deutlich an postmoderne Verständnisse von Identität, wie sie etwa McAdams zusammenfasst, in welchen Personen angesichts der Globalisierungsphänomene, die unter anderem als dauernder Wandel und heraus- oder sogar überfordernde Multiplizität des Lebens empfunden werden, als «locations» of intersecting forces and interacting voices situated within a particular social community and linked $[\ldots]$ to many other communities around the globe» verstanden werden. ${ }^{33}$ Die Parallelen werden noch offensichtlicher, wenn McAdams weiter schreibt: «[...] the postmodern person seems to reside amid the stories, that surround and define him or her on a moment by moment basis.»34

Lebensgeschichtliches Erzählen ist per Definition individuell und subjektiv. Zugleich aber ist es stets vom soziokulturellen, historischen und situativen Kontext abhängig, in welchem die Erzählung stattfindet. ${ }^{35}$ Dazu gehört nur schon, dass eine «life story» in der westlichen Welt einem bestimmten Muster folgt etwa entlang der Altersstufen (Kindheit, Berufswahl, Familiengründung etc.) -, in welches die Erinnerungen eingefügt werden..$^{36}$ Ein solches Muster prägt ein Stück weit auch intradiegetisch die Biografie von Bruce (Kindheit, Studienjahre, Karriere, Mentor für Robins als Ziehsöhne/Juniorpartner, Vater von Damian etc.). Als weitere Muster bzw. Kontexte auf der Ebene der Handlung kann für die Batman-Storys das grundlegende Handlungsschema - Batman löst einen Fall (meist inklusive Sieg gegen den jeweiligen Schurken) oder eine Heldenaufgabe gelten.

Im Rahmen dieser kontextbedingten Muster verlangt Erinnern/Erzählen eine andauernde Aktualisierung, wie Lieblich/Josselson ausführen: «We have to revise our stories constantly, reshuffle the memories of the past and perform new selections of events and characters, in accordance with new current experiences of live development, and with the changing expectations regarding our future.»37 Im Lauf der Zeit wird Erzählgut, das immer wieder aufgegriffen wird - seien es lebensgeschichtliche Erfahrungen oder Batman-Geschichten -, unterschiedlich inszeniert und damit jeweils dem (vermuteten) Zeitgeschmack angepasst. Diese Anpassungen mögen zuweilen eher formaler Natur sein. Wenn zum Beispiel eine Neuerzählung von Batmans Origin-Story als klares Zitat der ersten Version,

33 Mc Adams 1996, 298 (McAdams bezieht sich hier u. a. auf das saturated self von Kenneth J. Gergen, der diesbezüglich auch von multiphrenia sprach.)

34 Ebd. (meine Hervorhebung). Zur Kritik an diesen Ansätzen vgl. ebd., 299.

35 Lieblich/Josselson 2013, 204. Oder wie Cox/Lyddon (1997, 2 I I) formulieren: «Lives are played out within the larger framework of an overarching «cultural tale» or story.»

36 Nur schon weil Erzähler nicht wissen können, wie ihre Lebensgeschichte weitergehen wird, muss die Geschichte immer wieder neu eingepasst werden, so Lieblich/Josselson (2013, 2 I 5 ), die hierzu auch von «emplotment» (ebd., 207) sprechen.

37 Ebd., 21 5. 
aber mit aktualisiertem Zeichenstil umgesetzt wird, mag dies zwar leichte Verschiebungen inhaltlicher Akzente beinhalten, bedeutet aber keine eigentlichen inhaltlichen Änderungen. ${ }^{3}$ Die Neuerzählungen sind stets auch Anpassungen an veränderte Erzählgewohnheiten: Während die Schlüsselszenen des Mordes und des Fledermaus-Omens in den ersten Origin-Versionen mit Erläuterungstext versehen waren, wurden daraus mit der Zeit Szenen ohne Worte: Einerseits wohl weil man davon ausgehen kann, dass den meisten Lesern das Geschehen inzwischen in Grundzügen bekannt ist, andererseits steigert dies insbesondere die Intensität der Mordszene, wird doch impliziert, dass der von ihr ausgehende Schrecken und die Fassungslosigkeit des jungen Bruce nicht in Worte gefasst werden können. Während die älteren Versionen der Szene auch visuell aus der Sicht eines allwissenden Erzählers (bzw. unsichtbaren Beobachters) gezeichnet waren, bieten die neueren Versionen meist ein oder mehrere Panels aus Bruce' Perspektive; My Beginning verwendet diese Perspektive in der Mordszene sogar konsequent über mehrere Panels.

Je nach Situation kann ein Geschehen beim Erzählen eher komisch oder eher tragisch eingefärbt oder im Lauf der Zeit umgewertet werden. ${ }^{39}$ So hat sich, kaum überraschend, im Lauf der Jahrzehnte auch Batman sehr gewandelt. Zwischen den Polen vom lachenden Wagehals bis zum brütenden Getriebenen hat Batman zahlreiche Schattierungen seiner Identität souverän ausgefüllt..$^{\circ}$ Doch betreffen Veränderungen nicht nur ihn allein: Wird Batman modifiziert, wandelt sich sein Umfeld mit. Dies belegt die Entwicklung Gothams geradezu idealtypisch:41 Vom Golden Age bis in die 1960er-Jahre präsentierte sich die Stadt als eine Art bunter Abenteuerspielplatz, auf dem sich allerlei karnevaleske Figuren tummelten. Einhergehend mit der vielzitierten Verdüsterung von Batmans Figur ab den I 970er-Jahren wurde Gotham City schliesslich zu einem Hexenkessel der Hoffnungslosigkeit stilisiert, in welchem sich (sichtbar und unsichtbar) Stigmatisierte zu einem Jahrmarkt der Eitelkeiten treffen und unter anderen die Exponenten von Batmans Schurkenkabinett mit dem Ausleben schriller Perversionen nur zu oft die Grenze zu gemeingefährlichen Psychopathen überschreiten.

38 So zum Beispiel im Prolog des Story-Arcs Hush (Jeph Loeb, Jim Lee et al.), in: Batman 608, Dezember 2002.

39 Vgl. McAdams 1996, 301, 307, 3 I 3.

$4 \circ \mathrm{Zu}$ Batmans Entwicklung vgl. z. B. Darowski 2009, 64f., Easton in Easton/Harrison 2010, 55; ferner beschreibt DiPaolo (201 I, 30-32) verschiedene Phasen für langlaufende Serien.

4I Zur Relation zwischen der Charakterzeichnung Batmans und Gothams vgl. Stemmann 20I4 (die sich auf zwei Filmadaptionen bezieht, ihre Schlüsse gelten aber sinngemäss für die Comics) sowie Uricchio 2010. 
Nicht zuletzt gibt es inhaltliche Änderungen: So werden die vier Stationen, in welche sich die erste Origin-Story einteilen lässt, auf zwei reduziert ${ }^{42}$, seit in Year One der Mord und die Fledermausszene dramaturgisch geschickt auf zwei aufeinanderfolgenden Seiten platziert waren, Bruce' Schwur jedoch weggelassen und seine Ausbildung/sein Training im Ausland nur angedeutet wurde. ${ }^{43}$ Eine ikonische Veränderung erfuhr das Fledermaus-Omen: Die Fledermaus fliegt nicht mehr durch das offene Fenster, sondern kracht durch die Scheibe und landet auf einer Büste seines Vaters Thomas Wayne, vor deren starrem Antlitz der schwer verletzte Bruce sehnsüchtig auf ein Zeichen hofft, bevor er nach Alfred (und damit nach Rettung) klingelt (Abb. 54).

Auch das Figurenumfeld ändert sich mehrfach, sowohl in der jeweiligen Erzählgegenwart - wenn etwa Alfred Bruce' Diener wird oder wenn Robin/Dick Grayson als Nightwing selbstständig wird (worauf Robin/Jason Todd und nach dessen Tod Robin/Tim Drake seine Rolle übernehmen) - als auch für Bruce' Jugendzeit: So wächst Bruce einmal bei seinem Onkel Philipp und dessen Haushälterin Mrs. Chilton auf (die sich später wiederum als Mutter von Joe Chill, dem inzwischen identifizierten Mörder der Waynes, entpuppt, Legends), ein andermal wird Leslie Thompson seine Ziehmutter (My Beginning/Year Two, wo sie entgegen früherer Versionen auch in seine Doppelidentität eingeweiht ist), während in Earth One Alfred per testamentarischer Verfügung Bruce' Vormund wird.

Für die Superhelden fasst Wandtke die ständige Neuschreibung der Figuren mit den Bezeichnungen revisions und revisionism. ${ }^{44}$ Es zeichnet die Serie allgemein aus, dass sie im Prinzip niemals endet, da jedes Ende von einer allfälligen Fortsetzung retrospektiv als vorläufiges umgedeutet werden kann. ${ }^{45}$ In den Superhelden-Heftreihen kann es entsprechend keinen ¿Zustand geben, vielmehr sind die erzählten Ereignisse einem ständigen Transformationsprozess unterworfen: «Everything is open to revision, and every revision is open to further rewriting»,

42 Entsprechend sieht auch Meteling (2013, I03) nur zwei «Urszenen` für Batman (Mord und Fledermaus).

43 Year One, Chapter One: Who I Am, How I Came To Be (Frank Miller, David Mazzucchelli et al.), in: Batman 404, Februar 1987. Zur Ikonografie der Fledermausszene in Year One vgl. Meteling 2013, 103-105.

44 Wandtke 2007,6 . Revisionism wird hier nach Wandtke (ebd.) allgemein gebraucht und nicht als Bezeichnung einer bestimmten Strömung in den Comics aus den I980er-/frühen I990erJahren, als deren Gegenbewegung dann der Reconstructionism (etwa ab Mitte der I990er-Jahre) dazukam. Mit diesen beiden Begriffen werden nun aber auch zwei verschiedene Erzählmodi bezeichnet, welchen sich neuere Comicwerke zuordnen lassen (vgl. dazu Darius 20 I I).

45 Vgl. Denson/Mayer 201 2, I 89. 
Abb. 54: Das Fledermausomen in der <brachialen> Version von Year One - die Büste von Thomas Wayne scheint dabei die für Bruce' Batman-Identität zentrale Präsenz der Absenz seines Vaters zu verkörpern. Year One, Chapter One: Who I Am, How I Came To Be (Frank Miller, David Mazzucchelli et al.), in: Batman 404, Februar 1987, 22. (C) DC Comics

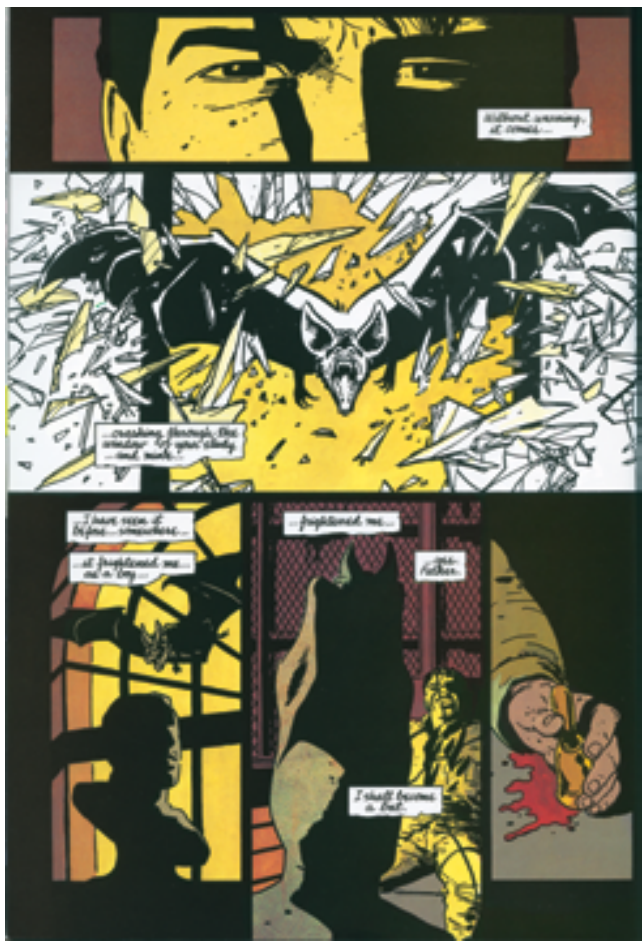

konstatiert Harrison. ${ }^{46}$ Ein besonders 〈lebhaftes〉 Beispiel dafür ist die schon zum Stereotyp geronnene Erfahrung, dass Superhelden niemals unwiederbringlich tot sind. Bis auf sehr wenige Ausnahmen werden verstorbene Figuren zuverlässig ins Leben zurückgeholt. Insofern ist in Superheldencomics selbst der Tod kein Zustand mehr, sondern Teil eines Wiederauferstehungs- oder Entwicklungsprozesses der jeweiligen Figur.

Angesicht der Vielfalt verschiedener Batman-Geschichten, in denen sich im Lauf der Jahre auch Widersprüche ansammelten,47 griff man im Comic-Universum $\mathrm{zu}$ einer bestimmten Strategie der Revision: dem Retconning (retcon steht für retroactive continuity). Wie Arno Meteling definiert, werden beim Retconning «Ereignisse, die in der Vergangenheit passiert sind, im Nachhinein mit Effekt auf

46 Easton/Harrison 2010, 24.

47 Zum Beispiel wurde in einer Version in der Mordszene der Vater erschossen, worauf die an einer Herzschwäche leidende Mutter am davon verursachten Schock starb (The Origin of the Batman (Bill Finger, Bob Kane et al.), in: Batman 47, Juni-Juli 1948). 
diese Vergangenheit verändert, umgedeutet oder aus dem Kanon gestrichen» ${ }^{4}$. Retcons stellen bewusste Umgestaltungen bisheriger Erzählinhalte dar, die diese ändern oder auch ersetzen sollen. Dabei tragen sie jedoch Referenzen ${ }^{49}$ auf frühere Versionen mit bzw. stehen stets in einem Dialog mit früheren Versionen auch wenn diese abgelehnt werden, bleiben sie als Hintergrundfolie präsent. ${ }^{5 \circ}$ Als ein erster, das gesamte Universum betreffender Retcon ${ }^{51}$ ist bei DC jener Moment zu bezeichnen, als nach dem Start des Silver Age propagiert wurde, dass die Golden-Age-Helden nicht mit den aktuellen Protagonisten identisch seien vielmehr handle es sich dabei um deren Doppelgänger von einer Parallelwelt, Earth-2 (erstmals in The Flash I23, 196I). Damit schuf DC auf einen Streich eine Verdoppelung seiner Protagonisten (respektive eine Vervielfachung, indem noch weitere Erden hinzukamen). ${ }^{52}$ Der Golden-Age-Batman ist also nicht identisch mit dem Batman des jetzigen Universums, was jedoch üblicherweise übergangen wird. In Crisis on Infinite Earths (1985-86) wurde das aus allen Nähten platzende Erzähluniversum wieder auf nur eine Welt, Earth-I, zusammengeschmolzen. Danach wurden die Origin-Storys mehrerer Superhelden bewusst neu aufgesetzt. ${ }^{53}$ Als umfassender Retcon des gesamten DC-Universums hatte dieser Event weitreichende Folgen: «It changed the way everything written from then on had to refer to the entire published history of DC's past. The way things were from Crisis had to be considered the way things had always been.» ${ }^{4}$ In den Worten von Kelleter/Stein verleiht der Retcon «Autorität über Zukunft und Vergan-

48 Meteling 20I3, I00.

49 Im Unterschied zum Retcon bleiben bei lebensgeschichtlichem Erzählen in der Regel frühere Versionen vergessen, während man bei den Superhelden die verschiedenen Versionen nebeneinander betrachten kann.

50 Beispielsweise wird dies in Batman RIP (Grant Morrison, Tony S. Daniel et al., in: Batman 676-68 I, Mai-November 2008) clever ausgenutzt, indem eine Episode mit einem ausserirdischen Batman aus den I950er-Jahren zu einer psychischen Grenzerfahrung wird, die schliesslich Batmans Rettung bedeutet: Der Batman von Zurr-en-Arrh ist kein Ausserirdischer, vielmehr hat Batman diesen - als Notfallmanöver gegenüber psychologischen Angriffen - als psychische ¿Ersatzidentität〉 geschaffen.

5 I Natürlich existierte der Begriff Retcon damals noch nicht; er wurde wohl erstmals 1983 von Comic-Autor Roy Thomas benutzt (Meteling 2013, I00).

52 So erhielt der Batman von Earth 2 in der Folge eine abweichende Biografie: Er heiratete die geläuterte Catwoman, und nach dem Tod der beiden führte ihre Tochter Helena Wayne, von Beruf Anwältin, als Huntress (ab 1977) das Erbe ihrer Eltern weiter; Batmans Original-Origin von 1939 wurde in einer ausführlichen Version neben dem «neuen> Anfang in Year One und My Beginning explizit als Ursprung des Earth-2-Batman im Sonderheft Secret Origins 6 (1986) nacherzählt.

53 Gerade für Batman wurde aber beschlossen, dass seine Origin-Story so gut sei, dass sie keiner Änderung, sondern bloss einiger Verbesserungen bedürfe, so der damalige Redaktor Denny O’Neil im Vorwort der Graphic-Novel-Ausgabe von Year One (O’Neil 2005 (1988)).

54 Harrison in Easton/Harrison 2010, 25. 
genheit einer Serie»'s. Retcons haben häufig einen gewissen revolutionären Anspruch gegenüber früheren Versionen bzw. dem Kanon, sind jedoch selbst dem Duktus der Kanonisierung verpflichtet. Nach Meteling sind Retcons für OriginStorys geradezu «konstitutiv». ${ }^{6}$

Legends von 1980 war noch klar dem Ziel verpflichtet, die verschiedenen Versionen - welche die prägenden Erlebnisse von Bruce Wayne immer weiter ausgebaut hatten, um der altbekannten Story neue Facetten abzugewinnen (zum Beispiel mit Leslie Thompson, einer Anwohnerin, die sich in der Mordnacht um Bruce gekümmert hatte) - unter einen Hut zu bringen. Dagegen hatten die beiden Adaptionen von 1986 - insbesondere Year One und in etwas weniger starkem Ausmass My Beginning/Year Two - klar den Anspruch, etwas Neues zu schaffen. Als konkretes Beispiel soll mit der Geschichte von Joe Chill ein selten besprochener Retcon, das (frühere) «späte Ende` von Batmans Origin-Story, näher beleuchtet werden.

So wurde Batmans Origin-Story 1948 zunächst damit erweitert, dass Batman den Mörder seiner Eltern findet. ${ }^{57}$ Nachdem er diesen Joe Chill zufällig auf einem Foto erkannt und ausfindig gemacht hat, konfrontiert Batman ihn. Er demaskiert sich und verspricht/droht Chill, beim nächsten kriminellen Fehltritt zur Stelle zu sein. Dies erweist sich indes als unnötig, denn Chill erfährt daraufhin die volle Wucht poetischer Gerechtigkeit: Als er hilfesuchend zu seinen Kumpanen rennt, schiessen ihn diese unverzüglich über den Haufen, weil er für Batmans Existenz verantwortlich ist. Damit war auch das Problem der enthüllten Doppelidentität gleich wieder aus der Welt, und der Fall des Wayne-Mords schien gelöst. Einige Jahre später wurde Chill zu einer Zwischenstation in der Mordursache umgewertet. Der Gangster Lew Moxon ${ }^{58}$ wurde als Chills Auftraggeber enthüllt, dessen Motiv Rache dafür war, dass ihn bereits Bruce' Vater in einem Fledermauskostüm von einem Maskenball - einmal der Justiz zugeführt hatte. Damit war der Wayne-Mord keine Zufallstat mit zufälligen Opfern mehr, sondern ein geplanter Racheakt für die Tat des ersten Batman〉 Thomas Wayne. (Auch Moxon ereilt per Autounfall die poetische Gerechtigkeit.) Batman demaskiert sich gegenüber beiden Verbrechern, und in der Version von $L e-$

55 Kelleter/Stein 201 2, 280 (Hervorhebung im Original).

56 Meteling 2013, ror.

57 Die eigentliche Origin-Story war dabei zwar fast täuschend ähnlich dargestellt wie die erste Version, es gab aber dennoch visuelle und inhaltliche Verschiebungen: Unter anderem schwört Bruce seinen Eid nicht mehr profan in seinem Zimmer, sondern vor der ungleich dramatischeren Kulisse des nächtlichen Friedhofs (The Origin of the Batman (Bill Finger, Bob Kane et al.), in: Batman 47, Juni-Juli 1948.

58 Moxon trat erstmals in 1956 in Detective Comics 235 auf. 


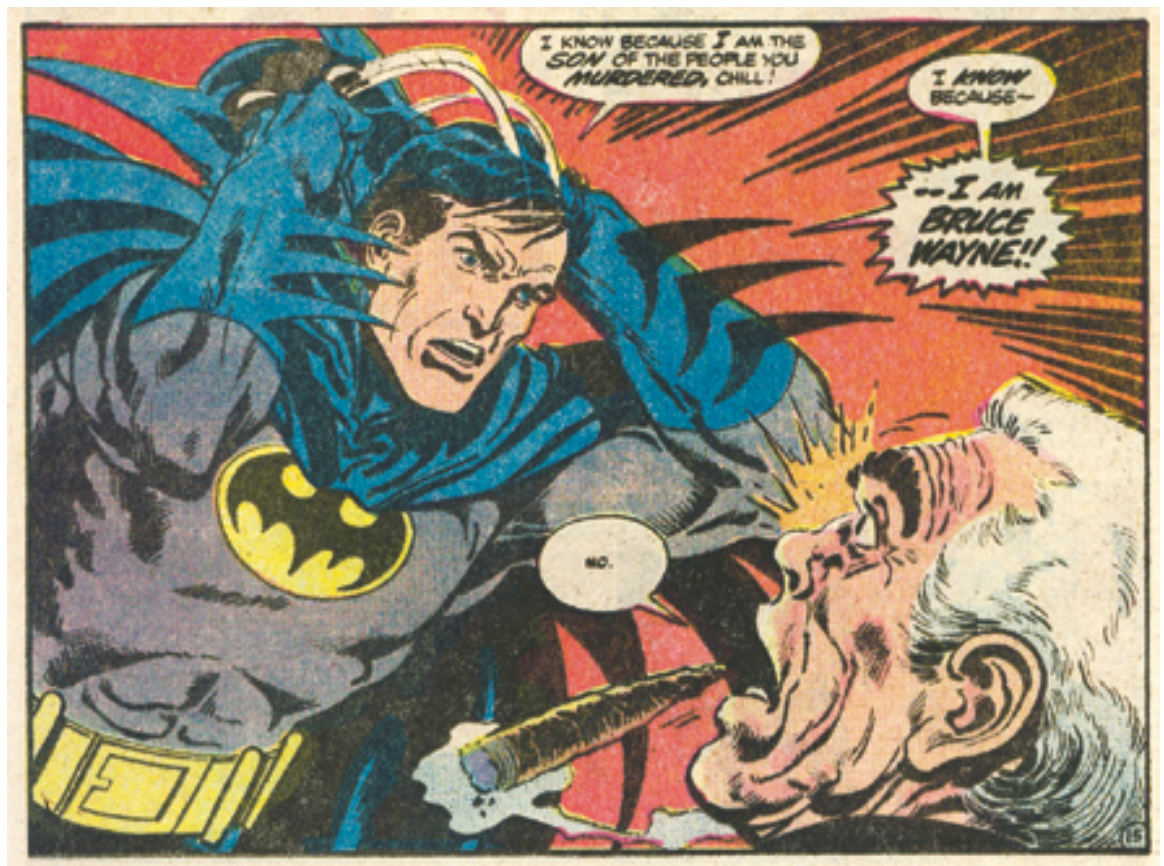

Abb. 55: Der dramatische Höhepunkt bei Batmans erneuter Begegnung mit Joe Chill ist nicht etwa eine Kampfszene, sondern dass sich Batman als Bruce Wayne demaskiert seine Doppelidentität ist dabei die Erklärung für sein Wissen um Chills Verbrechen, was diesen entsprechend überrascht. In the Beginning (Len Wein, John Byrne, Jim Aparo et al.), in: The Untold Legend of the Batman I, Juli I980, I 5. (C) DC Comics

gend erweist sich der Höhepunkt der Begegnung mit Joe Chill als ein besonderer Doppelidentitäts-Moment (Abb. 55). Als dieser sterbend meint, Batman hätte ihn nun doch gekriegt, erklärt dieser: «No, Chill - The Batman didn't finish you ... It was Bruce Wayne!»?9

Während Legend diese Ereignisse noch weitgehend entlang dieser Bahnen erzählt, ändert sich Joe Chills Story in Year Two. Um einen anderen Selbstjustizler, den Reaper, zu fassen, muss Batman mit den lokalen Verbrechern kooperieren und erhält als deren Vertreter einen zeitweiligen Partner: Joe Chill. Im vollen Bewusstsein, dass er den Mörder seiner Eltern vor sich hat, muss Bruce/

59 In the Beginning (Len Wein, John Byrne, Jim Aparo et al.), in: The Untold Legend of the Batman I, Juli I980, 17. 
Abb. 56: Als Joe Chill nach einer Explosion buchstäblich über dem Abgrund baumelt, scheinen die schräg dargestellten Gebäude der mitgenommenen Stadtstruktur anzudeuten, dass auch Batmans moralischer Kompass für einen Moment in Schieflage ist. Year Two (Mike W. Barr, Todd McFarlane, Alfredo Alcala et al.), in: Detective Comics 577, August I987, 21. (C) DC Comics

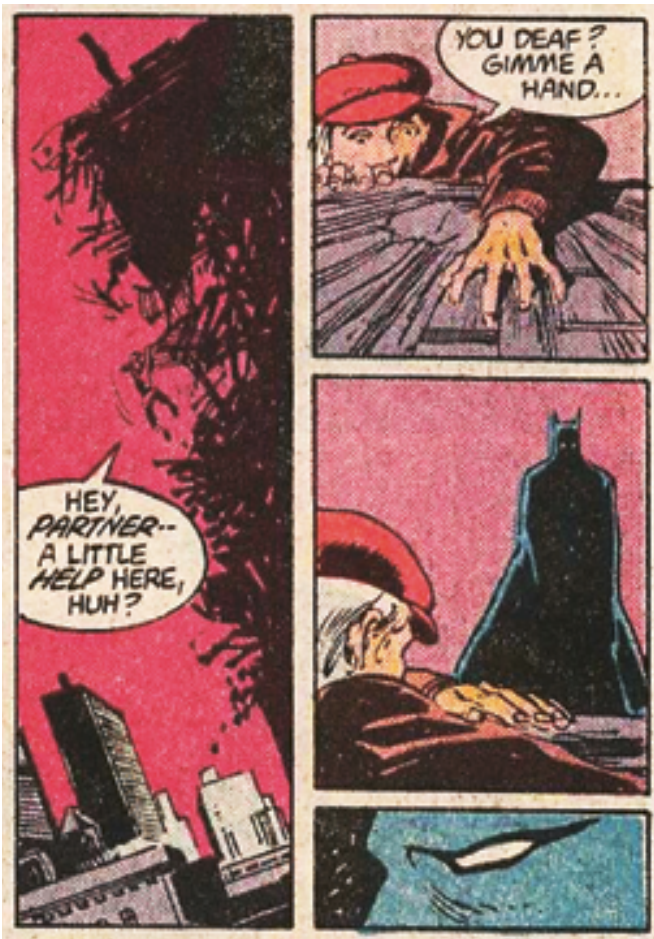

Batman gute Miene dazu machen. Dabei kommt es zu einem hochdramatischen Moment, als Chill - der wider Batmans Anweisung soeben einen anderen Kriminellen getötet hat - fast vom Dach fällt. Tatsächlich durchlebt Batman einen Moment des Zweifels, bevor er Chill hochzieht (Abb. 56). Am Ende will er Chill (der zudem den Auftrag hatte, Batman zu töten, aber nach dem Tod seiner Auftraggeber keinen Grund mehr dafür sieht) doch erschiessen - bevor er aber abdrücken kann, erledigt dies der (von der anderen Seite zur Szene tretende) Reaper für ihn, der im anschliessenden Kampf dann aus Wolkenkratzerhöhen in die Tiefe stürzt. Year Trwo bietet so eine völlig andere Reaktion von Batman - die Begegnung mit Joe Chill stellt ihn nun vor grösste moralische Herausforderungen. In beiden Versionen aber konnte Batman mit dem Tod des Mörders den Fall seiner Eltern abschliessen.

Demgegenüber entwirft Earth One - bei der es sich nicht um einen eigentlichen Retcon handelt, da die Geschichte in einer alternativen Welt situiert ist ${ }^{60}-$

60 Bei Earth One handelt es sich um einen bewussten Neuansatz ausserhalb der Continuity, der gerade neuen oder Serienkonnex-müden Lesern eine frische Batman-Lektüre ermöglichen 
eine nochmals andere Version des Mordes an den Waynes, die interessanterweise zwischen den verschiedenen früheren Implikationen schwankt: Hier ist es der ungestüme kleine Bruce, der den Unbekannten mit seiner kindlichen Arroganz herausfordert, sodass dieser ihn, den Millionenerben, als Geisel nimmt und in der Eskalation der Situation die Waynes erschiesst. Obwohl man nun erwarten würde, einen erwachsenen Bruce zu sehen, der sich die Schuld am Tod seiner Eltern gibt, verweigert dies der Text: Vielmehr wird Bruce zu Batman, um den Bürgermeister Oswald Cobblepot (sonst als Superschurke Penguin bekannt) als Auftraggeber des Mordes zu überführen, da Thomas Wayne seinerzeit der aussichtsreichere Kandidat für jenes Amt gewesen war. Die ganze Batman-Unternehmung basiert so rein auf persönlichem Rachebestreben, und entsprechend plant Bruce, sein Kostüm nach vollbrachter Tat an den Nagel zu hängen. Dies schlägt jedoch fehl, da der Penguin es doch nicht war. ${ }^{61}$ So bleibt der Täter letztlich eine Leerstelle ${ }^{62}$, und Bruce <muss> Batman bleiben. Dass der Fall ungelöst bleibt, korreliert auch mit der eher ungewöhnlichen Darstellung Batmans - dieser wird noch stärker, als dies bereits in Year One der Fall war, als blutiger Anfänger gezeigt, der das Ermitteln erst noch lernen muss, in Schlägereien übel vermöbelt wird und bei seinen waghalsigen Sprüngen zwischen Hochhäusern schon mal unsanft zu Boden plumpst. Earth One dürfte die erste zeichnerische Batman-Umsetzung sein, in welcher seine Augen durch die Masken-Augenlöcher zu sehen sind (Abb. 57).

Die verschiedenen Ausgestaltungen ziehen je eigene Implikationen nach sich. Wie Meteling zusammenfasst: «Das Bild einer einzelnen Origin-Story fällt dabei zugunsten eines seriellen Imaginären zurück, das aus mehreren Schichten besteht, die in verschiedenen Episoden, zu verschiedenen Zeiten und mit verschie-

sollte (trotz des Titels ist diese Earth One nicht jene des «Standard-DC-Universums`) und von Anfang an als Graphic Novel konzipiert war und so freier mit dem Stoff umgehen konnte - die Fledermausszene etwa wurde völlig umgestaltet und in Bruce' Kindheit verlegt (Earth One (Geoff Johns, Gary Frank et al.), New York: DC Comics 2012).

6I Schliesslich konfrontiert Batman Cobblepot, der ihn jedoch demaskiert. Bevor Alfred (der hier eine Variante als höchst unzimperlicher Kriegsveteran erhält) Cobblepot erschiesst, gesteht dieser zwar, den Mord für jenen Abend geplant zu haben, doch da Bruce aus dem Hinter- statt dem Vordereingang des Kinos stürmte, blieb Cobblepots Plan unausgeführt. Vgl. zur Variation der Schuld in Batmans Origin-Story Harrison in Easton/Harrison 2010, 35.

62 Noch diffuser gehalten wird der Mord übrigens in Batman RIP, wo auf der letzten Seite des Story-Arcs zwar dargestellt ist, wie Bruce mit seinen Eltern ins Kino geht (Batman 68 I, 2008), der eigentliche Mord aber ausgespart wird, bevor The Butler an späterer Stelle wieder einsetzt. Einerseits belegt dies, dass das Wissen um diese ‘Urszene> vorausgesetzt wird, andererseits erhält der Mord so auch eine <unwirkliche> Qualität, wie es ja beim Erleben tragischer Ereignisse nicht ungewöhnlich ist. 
Abb. 57: Als Neuumsetzung von Batmans Anfängen kratzen die Earth One-Bände an seinem Bild als Meisterdetektiv: Zwar besitzt er schon den spezifischen Look, doch gerade die Augen hinter der Maske statt der Batman-typischen weissen Schlitze zeigen eine Vermenschlichung des Helden an. Batman: Earth One 2 (Geoff Johns, Gary Frank, Jon Sibal et al.), New York: DC Comics 20I 5. (C) DC Comics
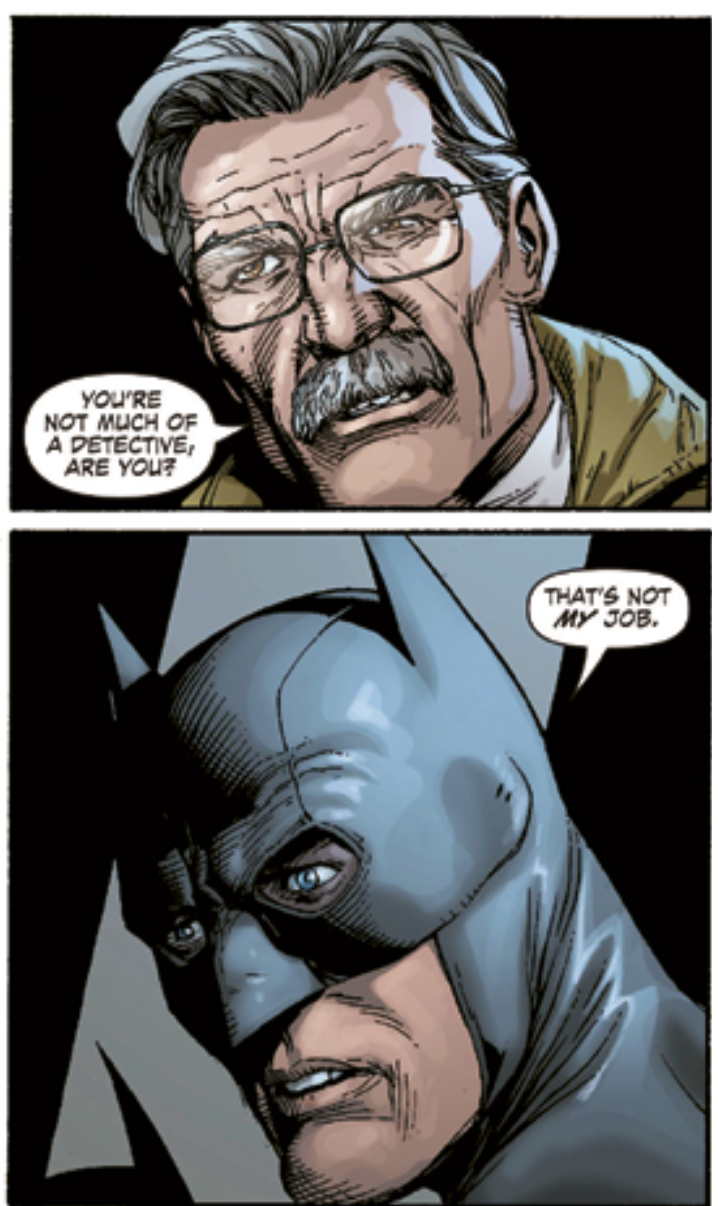

denen Intentionen entstanden sind. $\gg^{63}$ Entsprechend drücken life stories multiple Aspekte eines Selbst aus, die bruchstückhaft, vielschichtig und sogar widersprüchlich sein können, so Lieblich/Josselson, die hier den Vergleich zu einem polyphonen Roman ziehen. ${ }^{64}$

So konsumieren Batman-Rezipienten heute, wie auch Henry Jenkins festhält, verschiedene Versionen eines Franchise (das mehrere Medien umfasst), «each

63 Für die Superhelden im Allgemeinen schreibt Wandtke (2007, I2) vergleichbar: «[...] classic superheroes exist simultaneously in multiple forms in different contexts that do not logically cohere with one another.»

64 Lieblich/Josselson 2013, 219. 
with different conceptions of the character, different understandings of their relationship with the secondary figures, different moral perspectives, exploring different moments in their lives, and so forth». ${ }^{65}$ Angesichts dieser Vielzahl konstatiert Easton für Batman zusammenfassend:

Despite the generic and graphic similarities that have marked Batman as a superhero for the past seventy years, it might be more accurate to say that there has not been a single Batman, who has «developed over the years. Rather, there has been a proliferation of Batmen, all of whom have inhabited the costumed figure but each of whom differed at any given historical moment from the other Batmen of the past or the future. ${ }^{66}$

Wandtke beobachtet dabei eine Tendenz, dass jeweils die aktuellste Version auch als «relevanteste» gewertet wird. Allerdings kommt bei Fan- und Kritikerkreisen nicht jede Revision gleich gut an. ${ }^{67}$ In einem Umfeld, in welchem «the idea of origin and canon ${ }^{68}$ bestenfalls nebulös sei, so Wandtke, führt dies paradoxerweise erst recht zu einer Kanonbildung bei den Lesern bzw. Fans (und über den Kanon lässt sich ja immer streiten). Denn jeder Leser und jeder Künstler hegt so im Grunde eine eigene Vorstellung des jeweiligen Helden - hat seinen <persönlichen> Batman. ${ }^{69}$ Dazu sei ein Leserbrief zitiert, der diese Multiplizität des Helden explizit anpreist - angesichts der fast gleichzeitig erschienenen OriginNeuerzählungen in Batman (Year One) und Detective Comics (My Beginning und Year Two):

The two books [Batman and Detective Comics] offer distinct, contrasting versions of the Batman, both valid in their interpretation. There's plenty of room for both. Miller and Mazzuchelli are doing superb work on BATMAN: the perfect counterpoint to the DARK KNIGHT series. Barr, Davies and Neary continue to deliver fine entertainment $[\ldots]$ in DETECTIVE. There are moments of pure magic in this book $[\ldots] .^{70}$

Der Kommentar illustriert insbesondere das problemlose Nebeneinander verschiedener Batman-Varianten - ohne dass dies implizit dem Verständnis Batmans als einer Figur Abbruch täte, vielmehr wird das Lesevergnügen dadurch

65 Jenkins 2009, $2 \mathrm{I}$.

66 Easton in Easton/Harrison 2010, 56 (Hervorhebung im Original). Mit damals noch kritischerem Blick sahen 1991 Pearson und Uricchio die «Batmen» als «Gefahr» für die Integrität und Kohärenz der Fan-Erfahrung während der Lektüre (Pearson, Roberta E.; Uricchio, William (Hg.): The Many Lives of the Batman, New York I991, hier i 84, zit. n. Jenkins 2009, 22).

67 Wandtke 2007,7 .

68 Ebd., 5 .

69 Beispielsweise kann man diese nach Epochen oder Künstlern unterscheiden, etwa den GoldenAge-Batman von «Frank Millers Batman〉 etc. Vgl. z. B. Harrison (für Wonder Woman) in Easton/Harrison 2010, 27.

70 Leserbrief von Paul Fricke in Detective Comics 577, August 1987, 24. 
noch gesteigert. In Bezug auf postmoderne Persönlichkeitsvorstellungen, so halten Lieblich/Josselson fest, ist denn auch Gegensätzlichkeit ein «normales Phänomen ${ }^{71}$.

\section{Das Streben nach Einheit und Einzigartigkeit: Es kann nur einen geben}

Einerseits ist die narrative Identität mit der Betonung von Multiplizität und Prozesshaftigkeit ein klar postmodernen Vorstellungen verpflichtetes Konzept. Doch wie McAdams betont, bedeutet dies andererseits nicht automatisch eine Absage an den Gedanken von Einheit und Einzigartigkeit des Individuums. ${ }^{72}$ Vielmehr leistet der Prozess der Erzählung bzw. des Erzählens die «Herstellung von Kontinuität und Kohärenz» und dient so der Stiftung einer einheitlichen - oder vielleicht besser: nach Einheit strebenden ${ }^{73}$ - Identität. ${ }^{74}$ Entsprechend ist nach McAdams die Hauptfunktion einer life story die Integration: «By binding together disparate elements [...], the selfing process can make a patterned identity out of what may appear, at first blush, to be a random and scattered life. The I can provide an integrated telling of the self as a more or less followable and believable story.» ${ }^{5}$ Dieses Zusammenbringen disparater Elemente erfährt wiederum im protean self (das im Kapitel zu Spider-Man thematisiert wurde) eine Parallele.

Zweifellos werden beim Erzählen je nach Situation jeweils modifizierte Versionen von autobiografischen Geschichten kreiert. Zugleich ist zu erwarten, dass gewisse grundlegende Elemente in allen Versionen mehr oder weniger gleich bleiben. ${ }^{6}$ Dies gilt nur schon für das allgemeine Lebensumfeld, aber auch soge-

7I Lieblich/Josselson 2013, 219.

72 McAdams 1996, 297-299. Ein grundsätzliches Problem der Bezeichnung «postmodern» ist (ebd.), dass umstritten ist, ob die Postmoderne nun als Gegensatz der Moderne zu verstehen ist (vgl. z. B. Cox/Lyddon 1997) oder nicht eher deren Weiterentwicklung bzw. Überhöhung darstellt - so sprach etwa Anthony Giddens von high modernity statt von postmodernity (McAdams 1996, 299).

73 So bemerken Lieblich/Josselson (2013, 219), dass es vielleicht keine komplette Kohärenz der verschiedenen Teile einer (narrativen) Identität geben mag, dass diese aber immerhin in einem fortwährenden Dialog stehen.

74 McAdams 1996, 306, und Lucius-Hoene/Deppermann 2004, I67.

75 McAdams 1996, 309. McAdams unterscheidet dabei in Anlehnung an William James zwischen I und $\mathrm{Me}$ - das I ist für ihn sozusagen die Erzähl- bzw. Organisationsinstanz, während das Me das Erzählprodukt darstellt; Identität ist bei ihm spezifisch «a quality of the Me [...], the Me's overall storyness» (ebd., 308; 3 I 0 ). McAdams fügt an (309): «To the extent that the I is successful in doing this, it meets the modern challenge to create a self-reflexive project that is unified and purposeful although defying the centrifugal forces of the modern (and postmodern) world that threatens to undermine the person's identity work.»

76 Lieblich/Josselson 2013, $22 \mathrm{I}$. 
nannte Kernepisoden (nuclear episodes) können zumindest eine gewisse Stabilität über die Zeit bieten. Als Kernepisoden bezeichnet McAdams die \Schlagzeilen> eines Lebens: Höhe-, Tief-, Anfangs-, End- und Wendepunkte. ${ }^{77}$ Indem diese immer wieder rekonstruiert werden, fördern und stehen sie für die Kontinuität der Identität (bzw. bei McAdams des 〈Me〉), wobei sie natürlich als Wendepunkte auch eine Änderung deklarieren können. McAdams’ Beschreibung solcher Kernepisoden ist zweifellos für Batmans Origin-Story treffend: «[...] a particular event from the past that encapsules in a narrative nutshell an essential and enduring 〈truth> about the Me. Thus, the event may be symbolic 〈proof> from my past that $\left\langle\mathrm{I}\right.$ am what I am».» ${ }^{78}$ In Bezug auf die Superhelden sieht Harrison klar in der Origin-Story den Grund für eine <dauerhafte> Identität der Charaktere: "Yet Batman and Superman remain who they are despite these variations because each variation expresses, in the language of the time, their perpetual relationship to their traumatic beginnings.»79

Die häufige Reiteration der Origin-Story eines Superhelden (wobei es je nach Held recht unterschiedliche Frequenzen gibt) lässt sich vor dem Hintergrund der narrativen Identität damit begründen, dass nicht nur neue Leser eingeweiht werden müssen, sondern dass damit - für Künstler wie für Leser - eine Identitätsvergewisserung oder -bestätigung erzielt wird. Dazu reicht die Tatsache, dass die Origin-Story aufgegriffen wird, auch wenn sie Änderungen beinhaltet. ${ }^{80}$

Gerade bei Batman erweist sich neben der definierenden Fledermausikonogra$f_{i} e^{8 r}$ die Doppelidentität als eine die Jahre überdauernde Konstante. Dies ist nicht a priori zu erwarten, ${ }^{82}$ da spätestens seit den i980er-Jahren als Konsens gilt, dass

77 McAdams 1996, 308.

78 Ebd., $308 \mathrm{f}$.

79 Harrison in Easton/Harrison 2010, 54.

80 Metelings (20I3, IOI) Aussage, dass die Origin-Story mindestens einmal im Jahr nacherzählt würde, scheint dennoch etwas übertrieben (ab den I 990er-Jahren gab es oft einen kleinen Hintergrundtext zu den auftretenden Figuren in paratextueller Form, etwa auf der Cover-Innenseite eines Heftes). Meteling (ebd.) stellt hier zudem einen interessanten Bezug zur Psychoanalyse her: Da die meisten Origin-Storys Traumageschichten sind, erfülle sich im «Wiederholungszwang» ein Element, das «jedes Trauma als Traumaarbeit begleitet».

8I In The Butler (Grant Morrison, Lee Garbett, Trevor Scott et al., in: Batman 682, Januar 2009), stellt Alfred in Bruce' Traum die Frage, wie sein Kostüm ausgesehen hätte, wenn besagte Fledermaus nicht ins Zimmer gesegelt wäre - die hypothetischen Vorschläge reichen von «Owlman» bis zu «The Curtain». - Zu Beginn von The Butler kommt es zu einer weiteren poetologischen Anspielung: Wie in Year One sitzt Bruce im Traum blutend vor der Büste seines Vaters, als die Fledermaus durchs Fenster kracht, doch Bruce bemerkt, das stimme doch nicht, das Fenster habe offen gestanden - wie in seinen Origin-Storys vor Year One.

82 So erhielten andere Masken «definitiv neue Träger, beispielsweise wurde nach Barry Allens Tod in Crisis on Infinite Earths (1985/86) der bisherige Kid Flash Wally West der neue Flash und verzichtete auf eine Doppelidentität. Und nach Oliver Queens Tod übernahm sein Sohn 
Batman die swahre> Identität und Bruce nurmehr eine Fassade ist (wiewohl sein Heldentum ohne Frage von der Erfahrung und dem Reichtum von Bruce abhängig ist), und da ein persönliches soziales Umfeld von Bruce oft wenig bis gar nicht gezeigt wird - bezeichnenderweise erscheint Bruce Wayne so gut wie nie auf den Batman-Titelbildern. In all den Jahren wurde Batman nie auf eine Weise demaskiert, die sein Doppelleben längerfristig beendet hätte. Gerade im neusten hier betrachteten Beispiel für einen (alternativen) Batman-Reboot, Earth One, wird dabei der 〈klassischen> Doppelidentität wieder mehr Raum gewährt, als es etwa in Year One der Fall war, wo es nur gerade eine Szene gibt, in welcher Bruce Wayne für Jim Gordon, der ihn verdächtigt, Batman zu sein, den Playboy spielt (auch dort nämlich ist es Bruce wichtig, dass seine Identität geheim bleibt). In Earth One 2 gibt es mit Bruce Waynes Jugendfreundin Jennifer Dent eine Figur, die sein Geheimnis errät, weil er sich unbewusst verrät.

Das soziale Umfeld ist ebenfalls eine der Konstanten in den Batman-Narrativen: Unverzichtbar erscheinen Gotham City als Schauplatz und zumindest eine Auswahl der wichtigsten Nebenfiguren. Die Auswahl kann durchaus variieren, spätestens seit Legend aber erzählen Neufassungen von Batmans Origin-Story stets auch die Anfänge anderer Figuren, die für Batmans Universum prägend wurden, oder spielen zumindest klar auf diese an und entfalten so bereits Schritt für Schritt die Koordinaten von Batmans Welt. ${ }^{8_{3}}$

Angesichts der Zufälligkeit und Widersprüchlichkeit von Ereignissen im menschlichen Leben (die zwar aufeinanderfolgend geschehen) beschreiben Linda M. Cox und William J. Lyddon die narrative Identität als Teil einer Sinnsuche: «[Y]et humans attempt to make sense out of life's happenings within the larger context of their constructed life stories. Thus, one constructs meaning of temporal events by framing them within a narrative structure. ${ }^{84}$ Aus einzelnen Erlebnissen/Erfahrungen einen Plot zu konstruieren, bedeutet, (meist) unzusammenhängende Elemente so zu ordnen, dass sie eine vereinheitlichte Geschichte mit thematischen

Connor die Green-Arrow-Rolle - zwar mit Maske, aber schon seit den I $980 e r-J a h r e n$ kam die Doppelidentität bei Green Arrow narrativ kaum zum Tragen.

83 So umfasst Legends nicht nur Batmans Origin-Story, sondern das Aufeinandertreffen der (damals) wichtigsten Teile aus dem Batman-Figureninventar (Robin/Dick Grayson, Butler Alfred, Commissioner Gordon, Erfinder Lucius Fox sowie einige der Schurken); in Year One liegt der Fokus auf Gordon, während in einer Nebenhandlung Catwoman ihr Kostüm findet und ganz am Schluss der Joker angekündigt wird; Earth One I und 2 versammeln Alfred, Gordon und dessen hier noch jungen Partner Harvey Bullock, Lucius Fox und Killer Croc, als Gegner den Penguin und den Riddler, während Batgirl/Barbara Gordon, Catwoman und Two-Face (in einer weiblichen Version) als zukünftige Handlungsträger angedeutet werden.

84 Cox/Lyddon I997, 2 I 2. 
Schwerpunkten bilden: ${ }^{8}{ }^{5}$ «Every single episode or character in the story finds its meaning through its place or contribution to the narrative as a whole. ${ }^{86}$ So sieht denn McAdams in der narrativen Identität eine mögliche Antwort auf die «Identitätsherausforderung» der (Post-)Moderne, die vom Individuum verlange, eine Kohärenzen schaffende «Selbsterzählung» auf eine Weise zu kreieren, die trotz der vielfältigen Facetten des «Me» nahelegt, dass dieses selbst bei allen Veränderungen einheitlich ist: «[...] the Me of the past led up to or set the stage for the Me of the present, which in turn will lead up to [...] the Me of the future.» ${ }^{87} \mathrm{Be}-$ merkenswerterweise erkennt der Medienwissenschaftler Werner Faulstich in der Serie etwas Ähnliches, wenn er diese als «Wahrnehmungs- und Ordnungsprinzip» beschreibt und darin die Erfüllung eines elementaren menschlichen Bedürfnisses sieht: «Wenn es Serialität nicht gibt, erfinden wir sie, projizieren sie, denn Sinn entsteht für uns nur durch Verknüpfung von Singulärem zu Serien, zu Zusammenhängen. Die Serie schafft Ordnung, Vertrautheit, bildet das Koordinatensystem unseres Lebens. ${ }^{88}$

Wie bereits erwähnt, sammeln sich im Lauf der Jahre bei so intensiv genutzten Figuren wie Batman ebenfalls inhaltliche Widersprüche an. Diese zu glätten, ist auch einer der Hauptzwecke von sogenannten character reboots, ${ }^{89}$ bei welchen eine neue Version Elemente alter Versionen vereinigen (und allenfalls ausbauen) oder diese ersetzen soll - dies entspricht bemerkenswerterweise einem Grundgedanken der narrativen Therapie in der Psychologie ${ }^{90}$. So war bei Legend klar das Ziel, die vorher losen Geschichten zu vereinigen, indem sie als Erinnerungen der einzelnen Figuren in eine Geschichte eingebettet werden. Auch The Butler bietet sozusagen ein Best-of an prägenden Batman-Szenen, die bereits das Titelbild von Batman 683 visualisiert (Abb. 58).

Ein weiteres Beispiel dafür bieten My Beginning und Year Two: Hier wird bei Bruce' nächtlichem Friedhofsschwur in My Beginning hinzugedichtet, dass er nochmals zum Tatort zurückkehrte und die Mordwaffe aus dem Gebüsch

85 Man könnte hier wohl mit Albrecht Lehmann (1982) auch von den «Leitlinien» des lebensgeschichtlichen Erzählens sprechen.

86 Lieblich/Josselson 2013, 2 I 5 . Sie erklären dazu weiter (ebd.): «It is important to note that the narrative of one's life is not a list or a chronicle [...], but a chain of happenings manifesting some values or directions which characterize the individual narrator in his time and culture.»

87 McAdams 1996, 306.

88 Faulstich 1994, 51. Faulstich bezieht sich auf TV-Serien und spricht mehr von der Seite der Rezeption als von der Produktion aus gesehen. Vgl. dazu auch Denson/Mayer 201 2, I 98.

89 Harrison in Easton/Harrison 20I0, 26. Dies gilt natürlich auch für andere Retcons: So umschreibt Harrison (ebd., 24) das Ziel von Crisis on Infinite Earths (1985/86) wie folgt: «They turned a grab bag of inconsistent and ad hoc superhero fables [...] into a coherent whole along the lines of the largely self-consistent and commercially more successful Marvel Universe.»

90 McAdams 1996, 300. 
Abb. 58: Das Cover von Batman 683 versammelt Figuren, die mit wichtigen Stationen in Batmans Leben verknüpft sind: In der Mitte ist der Tod von Jason Todd (dem zweiten Robin) platziert, dahinter steht Nightwing/Dick Grayson, der Batman zugleich den Rücken zukehrt und ihm Rückendeckung gibt. Als eine Art graue Eminenz erscheint der Kopf des Schurken R'as al Ghul, dessen Tochter Talia die Mutter von Batmans Sohn Damian ist (die visuell fast unter Batmans Fittichen stehen). Eingerahmt wird das Ganze von der Spannung zwischen Batman und seinem Erzfeind, dem Joker, als deren irreparabler «Kollateralschaden> das ehemalige Batgirl Barbara Gordon im Rollstuhl sitzt. Titelbild von Alex Ross zu What The Butler Saw, Januar 2009.

(C) DC Comics

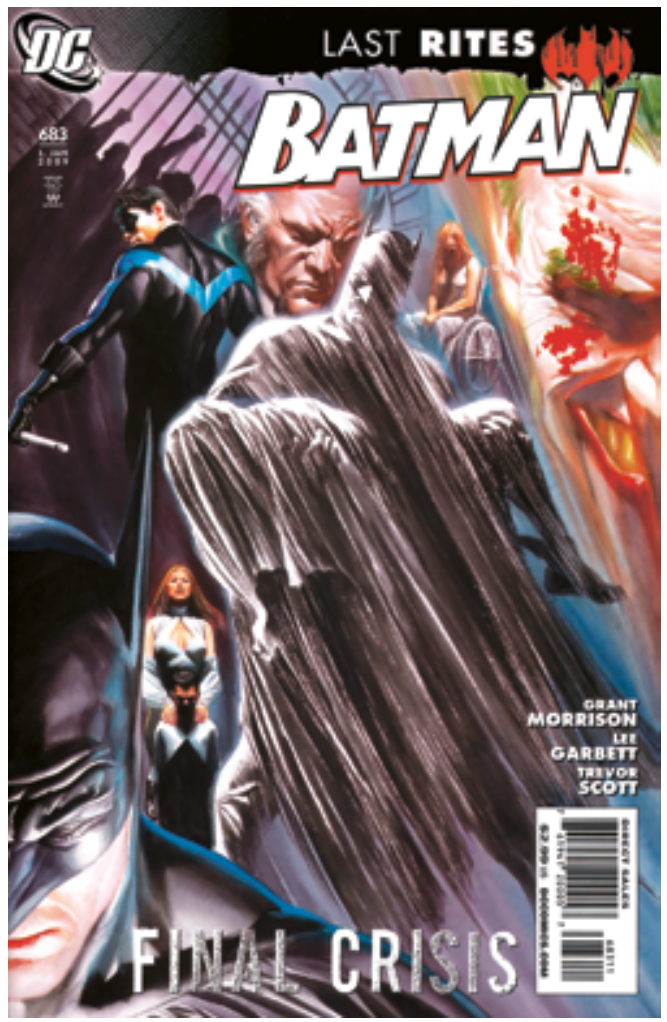

fischte. In Year Two wird daraus ein veritabler Subplot: Als Bruce denkt, der zwei tödliche Sicheln schwingende Reaper sei ihm überlegen, greift er zu dieser Waffe - trotz der Skepsis und Kritik von Alfred und Leslie (Abb. 59). Die Frage, ob er sie tatsächlich einsetzen wird, verstärkt die Spannung der Handlung, denn bekanntlich benutzt Batman nie und nimmer eine Schusswaffe. Tatsächlich feuerte er in den ganz frühen Comics sporadisch eine Waffe ab (um etwa einen im Sarg schlafenden Vampir/Werwolf ohne Federlesens zu erschiessen ${ }^{91}$ ), was die Herausgeber dann strikt verboten, damit Batman kindgerecht war. Selbstverständlich geschieht dies auch bei Year Tro im allerletzten Moment nicht, da der Reaper ihm den Schuss und damit die Entscheidung abnimmt. Doch indem die

9I [Batman Versus The Vampire, Part Two] (Gardner Fox, Bob Kane u. a.), in: Detective Comics 32, Oktober 1939 . 


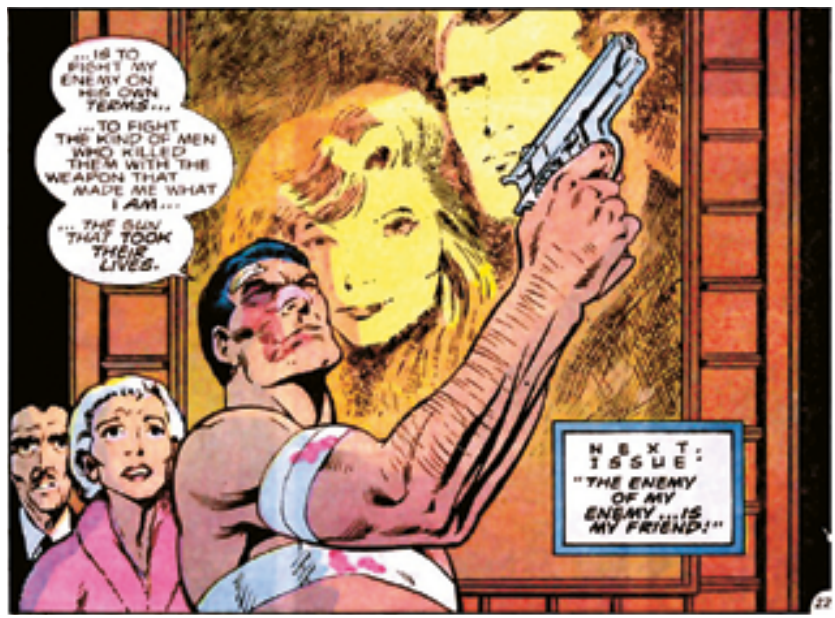

Abb. 59: Bruce greift im Gedenken an seine Eltern - auf dem Porträt im Hintergrund zu sehen - zur Schusswaffe; das damalige Mordinstrument soll ihm als Rachewerkzeug dienen. Betont wird mit der Darstellung von Verletzungen auch der körperliche Schaden aufgrund der eskalierenden Gewalt. Batman: Year Two. Part I (Mike W. Barr, Alan Davis, Paul Neary et al.), in: Detective Comics 575, Juni 1987, 22. (C) DC Comics

Waffenfrage als Anfängerunsicherheit interpretiert wird, werden diesbezügliche Inkonsistenzen zwischen den ersten Geschichten und der späteren Konvention durch eine poetologische Anspielung geglättet.

Im Hinblick auf die Stiftung von Kohäsion und Kohärenz in Batmans Schicksal hat die Origin-Story im Lauf der Zeit eine bemerkenswerte Entwicklung erfahren. So ist es in der allerersten Version von 1939 im Prinzip Bruce' freie Entscheidung, Batman zu werden (und in Legend zieht Bruce zunächst noch in Betracht, Polizist zu werden, erkennt aber in klassischer Pulp-Helden-Manier, dass dem Verbrechen mit den beschränkten Mitteln der Justiz nicht beizukommen ist). Die Origin-Neuerzählungen zeigen dagegen eine auffällige Tendenz: Batmans Origin-Story wird so mit verschiedenen Arten von Vorausdeutungen geschmückt, dass seine Batman-Existenz als bereits früher vorgespurt inszeniert wird. Denn obwohl für diese der Mord an seinen Eltern das auslösende Ereignis darstellt, beginnt Batmans Karriere nicht, bevor er als Erwachsener den Fledermausumhang trägt. 


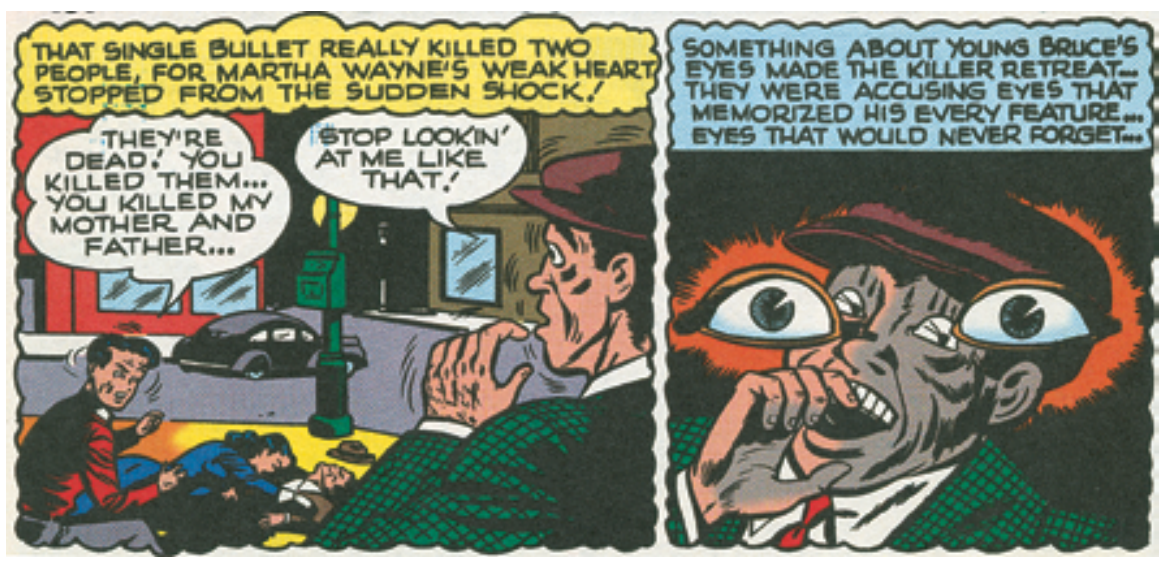

Abb. 6o: Der furchteinflössende Blick des kleinen Bruce schlägt den Mörder seiner Eltern in die Flucht. The Origin of the Batman (Bill Finger, Bob Kane, Charles Paris et al.), in: Batman 47, 1948, 4. (C) DC Comics

Ein erstes Mittel dazu stellt die <Verlängerung> der Origin-Story zu Ereignissen in der Vergangenheit dar, die bereits vor den Kernepisoden auf Bruce' Existenz als Batman vorauszudeuten scheinen. Dies beginnt schon in der erwähnten ersten Geschichte mit Joe Chill: Diese Version nämlich betont Bruce' anklagende Augen, die den Täter in die Flucht schlagen: «They were accusing eyes that me-

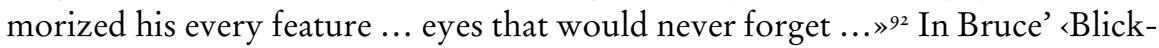
kraft> lässt sich nicht nur ein Widerschein des Shadow ${ }^{93}$ erkennen, sondern die Szene bedeutet auch eine 〈Umdrehung des Schreckens〉 und weist so auf die spätere Rolle als Batman voraus (Abb. 60). Diesen $\mathrm{Zweck}$ erfüllen überdies visuelle 〈Foreshadowings〉 wie in My Beginning, als beim Friedhofsschwur die Flügel einer Engelstatue den typischen Batman-Schatten um den kleinen Bruce werfen (Abb. 6I).94

92 The Origin of the Batman (Bill Finger, Bob Kane, Charles Paris et al.), in: Batman 47, JuniJuli 1948 .

93 Dieser Kreis schliesst sich übrigens damit, dass die letzte fiktionale Geschichte aus Walt Gibsons Feder die Batman-Prosageschichte The Batman Encounters The Gray Face (in: Detective Comics 500, März I98 I, 43-50) ist (Murray 2007, 7I). Auch gibt es diverse in Batmans früher Karriere angesiedelte Storys, in welchen The Shadow auftritt (z. B. Batman 259, 1974).

94 «... My Beginning ... and My Probable End.» (Mike W. Barr, Alan Davis, Paul Neary et al.), in: Detective Comics 574, Mai 1987, I 3. 


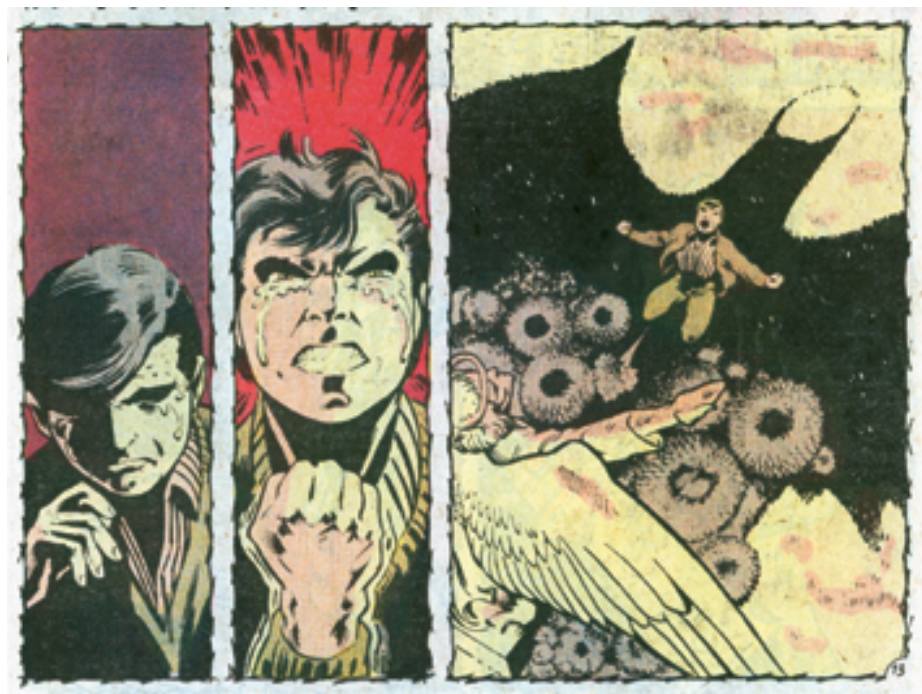

Abb. 6r: Schwur ohne Worte - doch visuell ist der Weg von Bruce klar vorgezeichnet, wirft doch der Schatten der Engelsstatue bereits einen vorausdeutenden Batman-Schatten um den Jungen. «... My Beginnings ... and My Probable End.» (Mike W. Barr, Alan Davis, Paul Neary et al.), in: Detective Comics 574, Mai i987, I3. (C) DC Comics

My Beginning beinhaltet dabei im Rahmen von Bruce' Schüler-/Studentenzeit das Element, dass Bruce seine Doppelidentität schon in der Schulzeit vorgebildet hat. Bereits fest zur Karriere als Verbrechensbekämpfer entschlossen, beginnt er schon hier, als gelangweilter Taugenichts aufzutreten, damit ihn später niemand identifizieren kann. Hingegen büffelt und trainiert er im Geheimen so viel wie möglich. Mehr noch: Um den Lehrern unauffällig Fragen stellen zu können, geht er verkleidet in die Kurse und bricht nachts in ihre Büros ein, um zusätzliches Wissen zu erlangen.95

Noch weiter zurück in die Vergangenheit verlängert wird die «Batman-Bestimmung, wenn sich in Bruce' Stammbaum schon Batman-Vorläufer finden. Neben zahlreichen Ahnen in verschiedenen Epochen (sozusagen Proto-Batmen) spinnt etwa Legend eine Geschichte um das Fledermauskostüm von Bruce' Vater, mit welchem dieser in einer Episode wie erwähnt als «erster Batman` wirkte. ${ }^{96}$ Ein

95 Ebd., I6-18.

96 In Legend (Heft I), wo zunächst Batman Alfred seine Geschichte erzählt (bevor weitere Figuren 
Ahnen-Foreshadowing anderer Art findet sich in Earth One: Hier stammt Bruce' Mutter Martha aus der Familie Arkham, die als Wahnsinnige stadtbekannt sind. Ohne dass es explizit formuliert würde, ist klar: Die seit Jahren leerstehende Arkham-Villa, seit einem brutalen Verbrechen verlassen, wird zum berüchtigten Arkham Asylum werden, wo die psychisch gestörten Batman-Schurken (im «normalen〉 Universum seit I974) inhaftiert werden. Implizit wird Bruce so bedenklicherweise eine genetische Affinität zum Wahnsinn zugeschrieben - was allerdings der verbreiteten Interpretation entspricht, dass Bruce/Batman bezüglich Wahnsinn im Grunde nur ein schmaler Grat von seinen Schurken trennt.97 Als Erbe sowohl der Waynes wie der Arkhams repräsentiert er ebenso das ‘helle> wie das 〈dunkle〉 Gotham. Tatsächlich glaubt er zuerst, als Batman ein Hoffnungssymbol zu sein, erkennt aber am Ende des zweiten Bandes, dass er dies wohl als Bruce Wayne, der sozusagen als «Prinz von Gotham» seine gesellschaftlichen (karitativen) Pflichten übernimmt, besser erfüllen kann..$^{8}$

Um Bruce’ Batman-Werdung als unentrinnbares Schicksal zu implizieren, besteht eine weitere Strategie darin, zu zeigen, dass seine Geschichte sich anders hätte entwickeln können (bzw. eben nicht). So verliebt er sich in Batman: Year Two in eine junge Frau namens Rachel Caspian, der er sogar einen Heiratsantrag macht und für die er das Batcape nach Abschluss des aktuellen Falles aufgeben will.99 In einem klassischen Doppelidentitätsmotiv entpuppt sich ihr Vater jedoch als Reaper, als Bösewicht der Geschichte (Abb. 62). ${ }^{100}$ Als Sühne für die Taten ihres Vaters beschliesst Rachel, ins Kloster zu gehen - und so bleibt Bruce Batman. Die Szene hätte potenziell eine neue Kernszene werden können, durch fehlende Renarration blieb sie jedoch weitgehend vergessen.

wie Robin oder Gordon sich an ihre Anfänge mit Batman erinnern), kommt noch die Episode von 1955 (Detective Comics 226) hinzu, in welcher Bruce als Junge sich vom berühmten Detektiv Harvey Harris unterrichten lassen wollte. Damit dieser ihn nicht erkannte, schuf er sich ein Kostüm, und zwar das Robin-Kostüm, das Dick Grayson dann übernahm (so wird Bruce zum ersten Robin, und Dick wird noch etwas mehr an Batman «angesippt ). Die Episode nimmt also nicht nur Batmans zukünftige Detektivkarriere vorweg, sondern auch seine Doppelidentität.

$97 \mathrm{Vgl}$. McCue/Bloom i 993, i i (Aussage von Autor und DC-Redaktor Dick Giordano).

98 Earth One 2 (Geoff Johns, Gary Frank, Jon Sibal et al.), New York: DC Comics 2015.

99 Beim Heiratsantrag steckt Bruce den Ring in einen chinesischen Glückskeks - den darin enthaltenen Spruch bemerken die Verliebten nicht, wohl aber wird er den Lesern präsentiert: «You may avoid your fate, but never escape it» (Batman Year Two. Chapter Four: "... So Shall Ye Rear..." (Mike W. Barr, Todd McFarlane et al.), in: Detective Comics 578, September 1987, 5).

ı०० Der Reaper erscheint dabei als ein Vorläufer von Batman, der schon zwanzig Jahre zuvor einmal aktiv war. Caspian erlitt ein ähnliches Schicksal wie Bruce: Seine Frau wurde (auf dem Rückweg vom Zirkus) auf offener Strasse erschossen, er und seine Tochter überlebten. Insofern erscheint der Reaper als dunkler Spiegel von Batmans Schicksal bzw. als Gegenentwurf, wie Batman auch hätte werden können/werden könnte, wenn er sich nicht gegen tödliche Waffen entscheiden würde. 
The Butler zeigt als Traumszenen eine ganze Reihe von Möglichkeiten, was wohl passiert wäre, wenn die Waynes den Überfall überlebt hätten (unter anderem wäre der arglose Bruce von Catwoman über den Tisch gezogen worden). Dennoch wäre Bruce Wayne schliesslich Batman geworden. Durch die recht komplizierte Handlung, in der zwei verrückte Wissenschaftler mithilfe von Bruce' Erinnerungen eine ganze Batman-Armee erschaffen wollen, wird schliesslich die Erkenntnis durchgesetzt, dass eben nur Bruce Wayne Batman sein kann - nur er ist in der Lage, all dem erlittenen Leid gegenüber - unter anderem auch Jasons Tod und als ihm Bane den Rücken brach - nicht wahnsinnig zu werden und sein Schicksal tragen zu können.

Dies ist in Bezug auf The Butler (wie den vorangegangenen Story-Arc Batman $R I P)$ umso bemerkenswerter, als diese Geschichten durch eine fragmentierte Erzählweise gekennzeichnet sind, die bewusst Leerstellen offen und Widersprüche bestehen lässt. Demgegenüber ist Batman derjenige, welcher das Puzzle einer riesigen Verschwörung gegen ihn löst und für jede Eventualität gerüstet ist, ja sogar eine alternative psychische Identität aus dem Hut zaubert, als seine Gegner ihn mit psychischen Manipulationen zerstören wollen (wobei die Geschichte vor intertextuellen Bezügen zu früheren Batman-Geschichten strotzt, die zum Teil ein Retconning erfahren). Die Inszenierung von Bruce als einzig möglichem Batman wird dabei von The Butler nochmals unterstrichen. ${ }^{\text {I0r }}$

Aus den ursprünglich wohl eher als narrative Spielerei gedachten Vorausdeutungen auf Batmans Karriere und der Verweigerung anderer Möglichkeiten entsteht das doch ziemlich kohärente Bild, dass Batman zwar Bruce' Willen entsprang, die Weichen dafür jedoch schon lange zuvor gestellt waren. In My Beginning erzählt Bruce selbst rückblickend (im Wechsel mit Leslie Thompson) einen Teil seiner Geschichte und resümiert schliesslich - untermalt von der Erinnerung an die wie in Year One durchs Fenster krachende Fledermaus: «[...] I was chosen ... to do the work I was born to ... my life's work ... work that became my life.» ${ }^{\mathrm{102}}$ Interessanterweise hat Leslie ein etwas anderes Bild von Bruce/Batman als er selbst, für sie ist nämlich Bruce das «real you» ihres Freundes, aber Batman

IOI Da Batman am Schluss von RIP (bzw. dem das DC-Universum umfassenden Story-Arc Final Crisis) als tot gilt, übernimmt in der Folge (weil Gotham wenn nicht den, dann einen Batman braucht) Dick Grayson/Nightwing den Fledermausmantel. Dabei ist für die Leser früh klar, dass Bruce Wayne nicht tot ist und folglich zurückkehren wird. Und wie aus Bruce immer Batman wird, ist klar, dass als sein Nachfolger - wiewohl es zu einer Battle of the Cowl kam (Sonderserie, März-Mai 2009) - letztlich nur Dick Grayson infrage kommt (oder später Bruce' Sohn Damian, der aber noch ein Kind ist und entsprechend Dicks Robin wird).

I02 «... My Beginning ... and My Probable End.» (Mike W. Barr, Alan Davis, Paul Neary et al.), in: Detective Comics 574, Mai 1987, I I. 


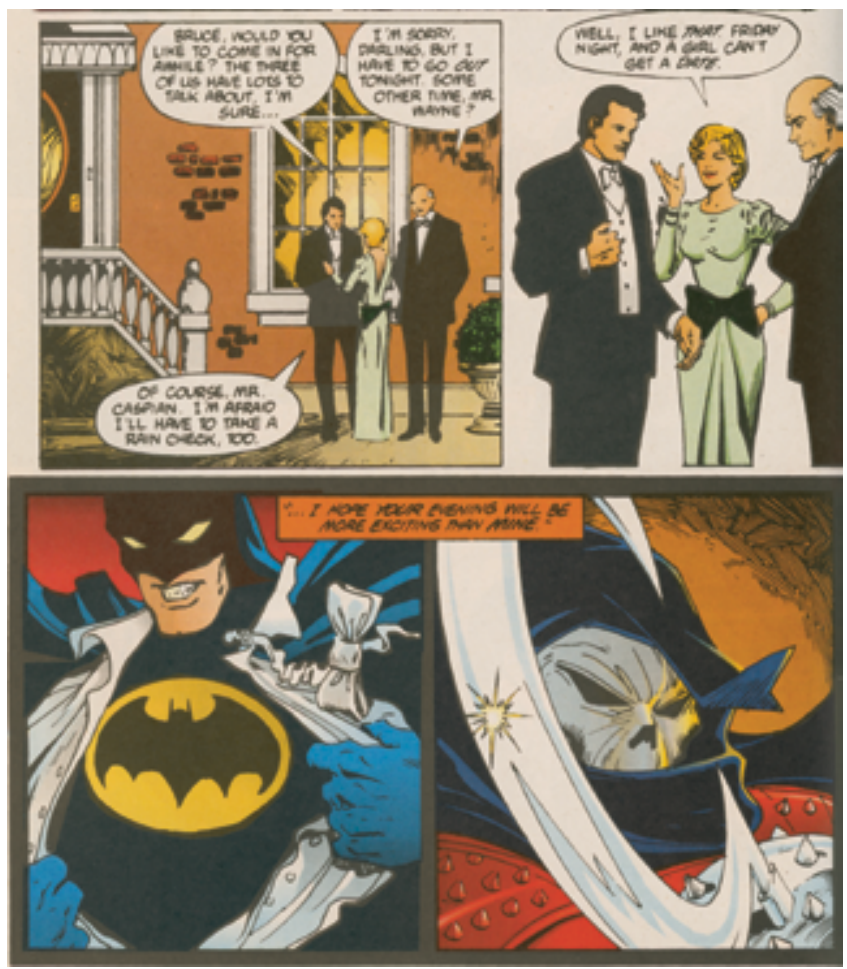

Abb. 62: In einem 〈klassischen〉 Doppelidentitätsmoment stehen sich in Zivil Bruce Wayne und Caspian gegenüber - unwissend, dass sie am nämlichen Abend als Batman und Reaper maskiert den Kampf miteinander suchen werden. Year Two (Mike W. Barr, Todd McFarlane, Alfredo Alcala et al.), in: Detective Comics 577, 1987, 14. (C) DC Comics

gibt $\mathrm{zu}$, dass er nicht mehr weiss, ob Bruce überhaupt noch existiert oder nur noch eine Fassade/Verkleidung (disguise) ist. ${ }^{103}$

In dieser Frage kommt auch Batmans enge Verknüpfung mit Gotham City zum Tragen, wird doch oft implizit oder explizit gesagt, dass Gotham City als Stadt voller Korruption und Kriminalität Batman 〈hervorgebracht> hat. ${ }^{104}$ So findet

I03 Ebd., 20. Nur in Legend und in My Beginnings (im Wechsel mit Leslie) erzählt Bruce sein Schicksal selbst, stellt also einen (fiktionalen) lebensgeschichtlichen Erzähler dar - allerdings gilt dies in den meisten Panels nur für die Wortebene, die dazugehörigen Bilder sind bis auf wenige Ausnahmen meist dennoch aus der Perspektive eines «allwissenden Beobachters` gezeichnet.

I04 Explizit findet sich dies etwa in Dark Knight, Dark City (Peter Milligan, Kieron Dwyer, Dennis Jake et al., in: Batman 452-454, August-September 1990), wo ein jahrhundertelang gefangener 
Batmans Existenz ihre Begründung nicht mehr nur in einer persönlichen, oft dem Zufall geschuldeten Tragödie, sondern in einer Notwendigkeit des Schicksals, wobei die Stadt Batman nicht nur einmal hervorbrachte, sondern ihn auch immer wieder neu hervorbringt, wenn er einmal versucht sein sollte, seinen Heldenmantel nicht mehr anzuziehen. Inszeniert wird ein ewiges Seilziehen: Da sich das Verbrechen in dieser Stadt niemals ausmerzen lassen wird, kommt Gotham nie ohne Batman aus, als Gegenkräfte sind Batman und die Schurken in ihrer Existenz aufeinander angewiesen.

Letztlich verleiten alle revidierten Versionen der Origin-Story zur Schlussfolgerung, dass Batman nicht zu vermeiden war. ${ }^{105}$ Während die hohe Anzahl von Origin-Versionen die Vielheit von Batman mitkomponiert, wird in den einzelnen Versionen Bruce Wayne als der eine und einzig mögliche/wahre Batman präsentiert. Wie sein oben zitiertes «I was chosen» aus My Beginning zum Ausdruck bringt, ist er damit nichts weniger als der auserwählte Held, dessen Schicksal ihm bestimmt ist und welches er auf sich nehmen muss. Damit wird der Griff zur Maske, der stets eine Wahl ist und damit die aktive Entscheidung, als Held zu agieren (wie im Kapitel zu Maskerade und Geheimnis erläutert wurde), für Batman letztlich im Grunde zu einer nur scheinbaren Wahlmöglichkeit - jedenfalls in jenen Geschichten, welche diese Vorherbestimmtheit betonen, was in unzähligen anderen notabene gerade nicht der Fall ist.

Die (vermeintliche) Klarheit, dass (nur) aus Bruce Wayne immer Batman werden wird, wird kontrastiert durch die Tatsache, dass Batman in vielen Inszenierungen - in den letzten Jahrzehnten, weniger im Golden Age - dennoch stets etwas Rätselhaftes auszeichnet, sodass seine Figur von einer gewissen Ungreifbarkeit geprägt bleibt. ${ }^{106}$ In Gotham ist es daher gerade Batman, der «kontrollierte` Wahnsinn, der in gewisser Weise die Unwahrscheinlichkeit in Person darstellt. Besonders bei Gastaufritten in anderen Reihen reicht als Erklärung für seine <unglaublichen> Taten nicht selten die Nennung seiner Identität: «It’s Batman» oder «I am Batman» wird dabei zum Gütesiegel seiner «Unwahrscheinlichkeit».

Während diese Mystifizierung in den frühen Jahren hauptsächlich in den Erzählerkommentaren zu finden war, griff man in den I970er-Jahren (als man wieder

Dämon sozusagen über die Stadt die Existenz von Batman eingefädelt hat, damit ihn dieser eines Tages befreien können würde.

I05 Dies wird mitunter sogar von Geschichten unterstrichen, in denen der Mord verhindert werden kann - als Batman in To Kill A Legend (Alan Brennert, Dick Giordano et al., in: Detective Comics 500, März 1988, 5-19) den Mord an den Waynes auf einer anderen Erde verhindern kann, wird der dortige Bruce aus Verehrung für Batman selbst zu einem Batman.

I06 Zugleich zeigen die Origins aber zunehmend, dass Batman alles andere als ein einzelgängerischer Held ist, und wenn er noch so stark als ein solcher inszeniert wird (Darowski 2009, 56). 
vom Camp-Image ${ }^{\mathrm{I07}}$ wegkommen wollte, welches die beliebte, komödiantisch erzählte TV-Serie der I960er-Jahre geprägt hatte) diese Facette wieder auf - ausgerechnet unter dem Leitgedanken eines magic realism, wo man sich fragte, wie Batman wäre, wenn er in der tatsächlichen, realen Welt existieren würde. ${ }^{108}$ Dies führte im doppelten Sinn zu einer Verdunkelung des Charakters, wobei die neue Düsterheit zunächst als (vermeintlich) realistische, erwachsene Darstellung gefeiert wurde, was aber inzwischen auch kritisiert wird. ${ }^{\circ 09}$ Batman ist zweifellos der wohl am stärksten mystifizierte Held der grossen DC-Namen - und darin liegt wohl ein weiterer Grund, warum Batmans Origin-Story auffallend of $\mathrm{t}^{110}$ nach- und neu erzählt wird, scheint sich doch darin die Suche nach einer kklaren> Herkunft als Gegengewicht zum Unwahrscheinlichkeitsnimbus der Figur zu spiegeln.

Einerseits betonen die einzelnen Geschichten unermüdlich die Einzigartigkeit von Bruce' Waynes Charakter als Batman, andererseits kann durch die unzähligen Batman-Inkarnationen jeder Leser und jeder Künstler «seinen〉 Batman hegen. Über die Doppelidentität des maskierten Helden hinaus erscheint Bruce Wayne/Batman in seiner seriellen und medialen Vervielfachung als Paradebeispiel dafür, ständigen Wandel mit Dauerhaftigkeit zu vereinen. Damit lässt er sich geradezu als Verkörperung der Formel «multiplicity in unity, unity in multiplicity» ${ }^{11}$, die die paradoxale dialektische Natur der narrativen Identität auf den Punkt bringt, verstehen.

Schliesslich sei noch eine der jüngsten Origin-Versionen erwähnt, die eine vergleichsweise massive Änderung beinhaltet - nach dem universumsweiten DC-

I07 Zu Batman und Camp vgl. z. B. Medhurst 2013.

I08 Darowski 2009, 64. Inwiefern der Begriff magic realism bei Darowski damit übereinstimmt, wie dieser in den letzten Jahrzehnten in Bezug auf postkoloniale Literatur verwendet wird, oder ob er diesem gerade zuwiderläuft, wäre freilich abzuklären.

I09 Vgl. Darius 201 I, 54-56, Wandtke 2007, 6. Auch ist anzufügen, dass gerade Origin-Neuerzählungen wie Year One und Earth One auch eine gewisse Dekonstruierung dieser Mystifizierung beinhalten, indem sie Bruce als bei Weitem noch nicht perfekten Anfänger in seinem Metier zeigen (was nicht ausschliesst, dass die Mystifizierung nicht zugleich dennoch, gerade auf der Bildebene, weitergeführt würde).

I I 0 Beispielsweise wird die Origin-Story von Green Arrow - der sich à la Robinson Crusoe allein auf einer einsamen Insel wiederfand und dort das Bogenschiessen entdeckte - in den Comics weit weniger häufig neu thematisiert als etwa Batmans Herkunft, wobei in jüngerer Vergangenheit aber namentlich die TV-Serie Arrow (USA, ab 20I2) die Origin-Story massiv ausbaute (Rückblenden zu Oliver Queens fünf Jahren als Verschollenem bilden hier konstant einen zweiten Erzählstrang, wobei bezeichnenderweise immer wieder neue Verstrickungen, die in seiner Zeit auf der Insel gründen, zum Vorschein kommen).

I I Dan McAdams und R. L. Logan: Creative Work, Love and the Dialectic in Selected Life Stories of Academics, in: McAdams/Josselson/Lieblich (Hg): Identity and Story. Creating Self in Narrative, Washington 2006, zit. n. Lieblich/Josselson 20I 2, 220. 
Reboot New 52 im Jahr 20 I I schienen die Autoren verstärkte Ansprüche an Novität zu hegen. 2017 nun erzählt Batman seine Geschichte in einem Brief an die inhaftierte Catwoman; er enthüllt, dass er sich nach dem Tod seiner Eltern (im Kindesalter) umbringen wollte und die Rasierklinge schon angesetzt hatte. Seine Batman-Aktivitäten erklärt er daher als «Suizid» (der Brief enthält seine Selbstdeklaration «I am suicide», den Titel der Geschichte). ${ }^{112} \mathrm{Ob}$ diese Version in den Kanon populärer Batman-Vorstellungen eingeht, bleibt abzuwarten, sicher ist jedenfalls, dass Batman bis zu seinem hundertsten Geburtstag 2039 noch diverse weitere Umerzählungen erfahren und immer wieder in anderen Facetten seiner Identität bzw. seiner Identitäten schillern wird. 


\section{Fazit}

Ich bin nämlich eigentlich ganz anders, aber ich komme nur so selten dazu.

Ada in Ödön von Horváths Zur schönen Aussicht, 1926

Um das Geheimnis seiner Doppelidentität als Held und Zivilperson zu wahren, muss der maskierte Held eine zweifache Maskerade vollbringen: Die gegenständliche Maske entbindet ihn äusserlich von jeglichen persönlichen sozialen Bindungen, wobei er in Zivil gegenüber den Menschen in seinem sozialen Umfeld eine metaphorische Maske trägt, indem er sich als Nicht-Helden inszeniert. Die Leitthese dieser Arbeit, dass sich in der Figur des maskierten Helden aufgrund dieser besonderen Konstruktion Identitätsvorstellungen des 20. und beginnenden 2I. Jahrhunderts offenbaren, hat sich anhand der ausgewählten Beispiele bestätigt. Bei einem Figurentypus, dessen Geschichten in erster Linie durch Actionsequenzen (Verfolgung, Kampf) bekannt sind, ist dies einerseits vielleicht nicht unbedingt zu erwarten, doch erstaunt es andererseits nicht, da die Maskerade im Allgemeinen Identitätskategorien und -kategorisierungen hinterfragt und herausfordert.

Maskerade und Geheimnis fallen in zentralen Aspekten in eins: Beides lässt sich als Kommunikationsform bzw. als Form von Informationsmanagement in Interaktion verstehen, beides ist auf ein Gegenüber, ein Publikum, angewiesen, um sich konstituieren zu können. Die Maskerade entwirft dabei stets ein Spiel um Identität(en). Die gegenständliche und die metaphorische Maske unterscheiden sich allerdings in ihren Konnotationen. Das Schlüsselrequisit dieser Figurenkonstruktion, die gegenständliche Maske, dient zunächst der Verhüllung (so klein sie auch sein mag): Indem sie das Gesicht ihres Trägers verdeckt, verwehrt sie dessen Identifizierbarkeit. Sie verbirgt seine zivile Identität und übernimmt damit nicht zuletzt eine Schutzfunktion (namentlich vermeidet der Protagonist so, durch Bedrohung seines persönlichen Umfelds erpressbar zu werden). Als Werkzeug des Verbergens wie des Irreführens gilt die Maske im Allgemeinen als Inbegriff von Täuschung und Falschheit. ${ }^{1}$

I Weihe 2004, 70, Wimmer/Schäfer 2009, 9f., Brownie/Graydon 2016, $38 \mathrm{f}$. 
Doch ist dieser Verhüllung paradoxerweise die Enthüllung eingeschrieben: Nicht nur offenbart die gegenständliche Maske, dass sie etwas verbirgt ${ }^{2}$ (womit sie in vielen Fällen eine Mystifizierung des Helden unterstützt und einem <einfachen ${ }^{3}$ Geheimnis entspricht), sie kennzeichnet vielmehr auch den handlungsbereiten 〈Helden im Dienst `. Die bei den Superhelden zu einem ganzen Kostüm erweiterte Maske wirkt so als einzigartige, individuelle Uniform und proklamiert die Selbstermächtigung ihres Trägers, der in Selbstjustiz Aufgaben übernimmt, die üblicherweise staatlichen Instanzen vorbehalten sind.' Die Maske schafft für ihren Träger erweiterte Handlungsmöglichkeiten (dazu zählt auch, dass der maskierte Held stets über ihm eigene, anderen verwehrt bleibende Bewegungsarten oder -räume verfügt). Gerade in diesem alternativen Handlungsraum jenseits der alltäglichen gesellschaftlichen Eingebundenheit scheint die Maske in der Verhüllung gerade die Enthüllung zu bergen: Unter dem Schutz der Maske traut sich das Individuum, sein ‘wahres> Ich zu zeigen. In der Tradition des Christentums oszilliert die Maske somit zwischen einer Reihe von Dichotomien wie etwa Schein und Sein oder Täuschung und Wahrheit. ${ }^{6}$ Entsprechend wird für den maskierten Helden das Anziehen der Maske gewissermassen zur Demaskierung.

Diese Umkehrung der Maskerade impliziert die Annahme, dass die Menschen im alltäglichen Leben eine metaphorische Maske tragen, um den gesellschaftlichen Ansprüchen zu genügen. Während die gegenständliche Maske für den Ausbruch aus dem Alltag steht, leistet die metaphorische Maske in der Regel eine Anpassung an Erwartungen, denen gemäss man sich verhalten will oder muss. Da diese Maske aber nicht als solche erkennbar sein soll, lässt sie sich für den maskierten Helden als 〈reflexives ${ }^{>}$Geheimnis klassifizieren.

Die Metapher des Menschen als Schauspieler ist dem abendländischen Denken seit Jahrhunderten vertraut und wurde im Lauf der Zeit mit unterschiedlichen Werthaltungen verknüpft. Als ein Kristallisationspunkt zwischen dieser althergebrachten Theatermetapher und verschiedenen nachfolgenden Identitätstheorien hat Erving Goffman die Selbstdarstellung des Individuums als Grundbestandteil jeder zwischenmenschlichen Interaktion beobachtet. ${ }^{8}$ Eine gelingende Darstellung darf dabei keine Störfaktoren aufweisen, sie muss rund und authentisch wirken, was der Darsteller/Akteur unter anderem durch eine möglichst

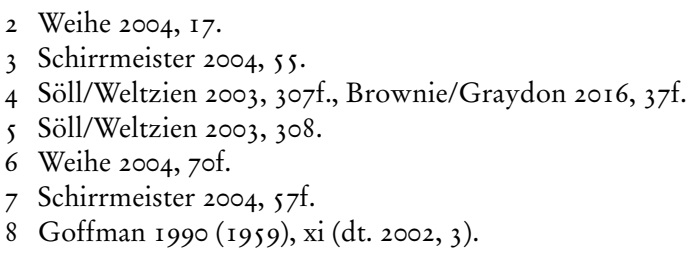


umfassende dramaturgische Disziplin und Ausdruckskontrolle zu erreichen sucht. Zu erkennen, was für die Zuschauer ein Störfaktor sein könnte, erfordert das Hineindenken in andere Rollen (was schon George Herbert Mead als roletaking benannt hat ${ }^{9}$ ).

Diese «Antizipation fremder Erwartungserwartungen ${ }^{10}$ akzentuiert sich freilich noch, wenn der Darsteller ein Geheimnisträger ist: Handlungen, die für andere bedeutungslos sind oder scheinen, können für ihn eine besondere Signifikanz erhalten. In den Geschichten um maskierte Helden bildet das Geheimnis zudem die Grundlage für den Plot der Intrige, ${ }^{\text {II }}$ die sich als literarisches Motiv leicht mit der Doppelidentität des Helden verknüpfen lässt. So steuert die Handlung im Prinzip auf das Fernziel der öffentlichen Entlarvung bzw. der Anagnorisis zu, selbst wenn diese in seriellen Geschichten (wie den hier betrachteten) oft in unerreichbare Ferne zu rücken scheint. ${ }^{12}$ Sie kann zwar als Gefahr präsent sein und immer wieder umspielt werden, doch bedeutet ihre Existenz als unwiderrufliche Tatsache einen massiven Einschnitt in das Schema des typischen Narrativs (als Entlarvter ist der maskierte Held keiner mehr). Zumindest in den hier untersuchten Superheldencomics und Pulp-Novels kann es zwar zu solchen Einschnitten kommen - aufgrund ihrer Serialität, die ein gewisses «Erzählkorsett〉 verlangt, handelt es sich dabei jedoch eher um Ausnahmen, die die Regel bestätigen. Geschichten um maskierte Helden können somit nicht nur die Spannung, ob und wie der Protagonist seine Abenteuer besteht, enthalten, sondern auch, ob und wie er dies schafft, ohne seine Doppelidentität zu kompromittieren.

Nichts anderes als eine besondere Art des Geheimnisses ist dabei das ebenfalls von Goffman beschriebene, potenziell diskreditierende Stigma, wenn es sich verbergen lässt. Eine stigmatisierte Identität zu verheimlichen, erfordert vom Stigmaträger ein passing. ${ }^{13}$ Bei Daredevil/Matt Murdock als Blindem ist diese Deutung besonders naheliegend, doch lässt sich dies im Grunde auf jede Doppelidentität übertragen, wenn man Heldenfähigkeiten bzw. Superkräfte als eine Art Stigma betrachtet - wobei der maskierte Held in seinen beiden Identitätshälften passingStrategien anwendet. Denn komplementär gehört zum passing auch die Taktik,

9 Mead I973 (1934), 196.

IO Schirrmeister 2004, 59.

I I von Matt 2006.

I 2 Die Anagnorisis muss nicht öffentlich sein - wenn ein Freund die Doppelidentität entdeckt, gewinnt der Protagonist in der Regel einen Mitwisser, oft einen Mitstreiter; interessanterweise finden dabei auch Schurken, die im Lauf der Jahre hinter das Geheimnis ihres Gegners kommen, in der Regel gute Gründe, um die zivile Identität des Helden zwar allenfalls zu bedrohen, aber doch weiter zu verschweigen.

I3 Goffman 1963, 42 (dt. 1975, 57). 
die Tobin Siebers als «disability as masquerade» ${ }^{14}$ bezeichnet: In Zivil spielt der Protagonist möglichst den Heldenuntauglichen, um einen allenfalls aufkommenden 〈Heldenverdacht〉 gegen ihn a priori zu entschärfen. Die Doppelidentität des maskierten Helden zieht nicht selten ein stattliches Lügengebilde nach sich (nur schon in den zahlreichen Ausreden, um Abwesenheit wegen Heldenpflichten zu erklären) - und da eine einmal erzählte Lüge oft weitere Stützlügen benötigt, damit sie nicht auffliegt, ist bei gewissen Helden immer wieder ein Sich-Hineinreiten (in-deeperism) ${ }^{\text {Is }}$ möglich, das wiederum teils elaborierte Intrigen erfordert, um wieder heil aus der Verstrickung herauszukommen. Ein zweifellos etwas groteske Ausmasse annehmendes Beispiel dafür ist Matt Murdocks Konstruktion eines inexistenten Zwillingsbruders namens Mike und damit die Schaffung einer dritten Identität, um das Doppelidentitätsgeheimnis zu wahren.

Das grundlegendste Mittel, um einen 〈Heldenverdacht〉 gar nicht erst aufkommen zu lassen, ist der Kontrast zwischen den beiden Identitäten des Protagonisten. Tatsächlich würde die Maske ohne diesen Kontrast ihren Sinn verlieren, und die willing suspension of disbelief, dass der Held nur wegen eines Stücks Stoff nicht einmal von seinen nächsten Angehörigen identifiziert werde, leidet merklich, wenn dieser Kontrast zu klein wird (wie es teilweise bei den Pulp-Protagonisten The Phantom Detective/Richard Curtis Van Loan und The Spider/ Richard Wentworth der Fall ist). Der Kontrast zwischen Helden- und Zivilidentität besteht dabei aber vor allem im Grad der zugeschriebenen Heldenuntauglichkeit, da der Protagonist in beiden Identitäten denselben Werten folgt und (fast) immer Herr über seine Identitäten und seine Identitätswechsel ist - im Gegensatz zu gewissen wahnsinnigen Superschurken.

Während das Individuum in einer Gesellschaft nach Goffman seine Rolle nur in Ausnahmefällen selbst schafft, sondern meist eine zur Verfügung stehende Rolle und eine dafür bestehende Fassade einnimmt (die es individuell modifizieren kann), unterziehen die Zuschauer ihre Erwartungen üblicherweise der Kategorisierung bzw. Stereotypisierung. ${ }^{16}$ Dies machen sich die maskierten Helden mit ihren vermeintlich heldenuntauglichen zivilen Identitäten zunutze. In ausgeprägter Weise zeigen dies bereits The Scarlet Pimpernel/Percy Blakeney und Zorro/Diego Vega, die als maskierte Helden einen prägenden Einfluss auf den Figurentypus hatten: Beide kalkulieren und manipulieren bewusst den Eindruck, den sie auf andere machen, um ihre Kategorisierung in der Wahrnehmung der anderen zu steuern, wiewohl beiden offensichtlich die Voraussetzungen zum Heldentum in die Wiege ge-

I4 Siebers 2012, IO2.

I5 Goffman 1963, 83 (dt. 1975, 107).

I6 Goffman I990 (I959), 26 (dt. 2002, 27). 
legt worden sind. Sowohl der Pulp-Held The Black Bat/Tony Quinn als auch der Superheld Daredevil/Matt Murdock verlassen sich für diesen Kontrast auf eine körperliche Behinderung, die sie von vornherein aus dem allerdings doch erstaunlich häufig von anderen Figuren geäusserten Heldenverdacht zu nehmen scheint. Die Maske bedeutet für den Protagonisten auch die Möglichkeit und manchmal den Zwang zu einem heimlichen Heldentum, wenn er Dritte über sein jeweils anderes Ich urteilen hört. Nimmt der Protagonist an einem Gespräch über sich selbst teil, muss er sich jeweils überlegen, welche Relation zu sich selbst er präsentiert, um möglichst wenig Verdacht zu erregen. (Allerdings schwankt dies bei den meisten Helden im Lauf der Zeit oder auch von Situation zu Situation.) Das heimliche Heldentum wird dabei oft in sIf they only knew>-Momenten akzentuiert, die in den Superheldencomics vorzugsweise am Ende einer Story für einen komischen oder melodramatischen Moment eingesetzt werden. Diese Momente vermitteln manchmal kleine Triumphe, deuten aber häufig auch auf einen Verzicht, ein Opfer, das der Protagonist für seine Doppelidentität bringen und still erdulden muss.

In der Thematisierung dieses Verzichts finden sich dabei je nach Quellengruppe signifikante Unterschiede: Während die Pulp-Helden dies zwar mit Bedauern, aber unhinterfragter Heldendeterminiertheit auf sich nehmen, anerkennen die Golden-Age-Comic-Helden, denen Krisenmomente im Allgemeinen kaum bekannt sind, auch hier keinen inneren Konflikt. Den im Silver Age geschaffenen Superhelden, wie Spider-Man und Daredevil, ist hingegen oft sehr bewusst, auf was sie alles verzichten, und entsprechend stellen sie diesen Verzicht - und damit ihr Heldentum bzw. ihre Doppelidentität - immer wieder in Frage. Gerade Spider-Man und Daredevil, deren Karriere von Selbstzweifeln begleitet wird, ziehen immer wieder in Betracht, eine ihrer beiden Identitäten aufzugeben. Manchmal verzweifeln sie dabei ob ihres inneren «Heldenzwangs`, manchmal erscheint ihnen die zivile Identität als «leere> Maske.

Spider-Man und Daredevil haben dabei in groben Zügen eine ähnliche Entwicklung: In den Anfangsjahren erhält das Dilemma, sich entweder für die eine oder für die andere Identität entscheiden zu müssen, mehr Aufmerksamkeit. Und doch kommen beide Helden - was in den letzten Jahrzehnten auffallend weniger häufig bestritten wird - jeweils zum Schluss, dass sie beides sind, sowohl der Held im Kostüm als auch die zivile Identität. Insofern ist es nicht verwunderlich, dass die Geschichten beider Helden nach ihrem Outing bzw. Coming-out mit wieder intakter Doppelidentität neu gestartet wurden. Dies widerspricht auch allen Annahmen der letzten Jahre, die Doppelidentität als Motiv sei überholt. ${ }^{17}$

I7 $\mathrm{Zu}$ beobachten ist zudem der Trend, dass kaum noch ein Held ein wirklich einsamer Wolf 
Die Schwierigkeit, die Balance zwischen Anpassung und Auffälligkeit zu halten, führt zu einem Leitthema des Indiviuums in Gesellschaft - den gegensätzlichen Ansprüchen von Individualität und von Konformität. Danny Fingeroth sieht diese Balance als Wunsch jedes Menschen in der Massengesellschaft: «[...] living in mass societies[,] [w] we want both to stand out and blend in. We want to be accepted by the group - or various groups - yet still be appreciated for the unique and wonderful individuals we (hope) we [sic] are.» ${ }^{18}$ Diese Balance zu halten, ist dabei nicht immer einfach, wie die maskierten Helden mit ihrer Doppelidentität plakativ zeigen. So fasst Robert Inchausti zusammen: «Secret identities establish a tension within superhero narratives that represent the antinomy each of us finds within ourselves between the finite and infinite poles of existence, between the world of quotidian reality and the pure possibility of our existentially free selves. The hero never resolves this tensions, he lives within them.» ${ }^{19}$ Balance erscheint denn auch als Zauberwort der hier näher betrachteten Identitätstheorien.

Vor allem (aber nicht nur) in Momenten des Zweifelns liegt bei maskierten Helden die Frage auf der Hand, welches denn nun die 'wahre), die authentische Identität des Maskenträgers ist, die Maske oder das Darunter. Doch bietet die Maske ebenso die Lesart multipler Identität(en): Jede Rolle ist eine authentische Manifestation der Identität, die keinen festen Kern aufweist und keine fixe Einheit darstellt (das ‘wahre> Ich ist hier nicht eine Instanz hinter allen Masken, eine solche existiert nicht). Mit der Maskerade lassen sich so die beiden grundsätzlich verschiedenen Identitätsmodelle des 20. und beginnenden 2 I. Jahrhunderts koppeln: Oft entwerfen Identitätstheorien, die als postmodern zu bezeichnen sind, einen geschichtlichen Wandel bzw. einen Bruch mit der <früher> dominanten Identitätsvorstellung eines stabilen, einheitlichen Selbst. Abgelöst worden sei diese inzwischen durch Vorstellungen einer multiplen, prozesshaften Identität, die entsprechend nurmehr im Plural existieren kann. ${ }^{20}$

Mit ihrer Doppelidentität scheinen die maskierten Helden zunächst klar die letztere Vorstellung aufzunehmen, zumal sich ihre ¿Zweiheit〉 als Ausgangspunkt für Vielheit entpuppen kann, nur schon weil die separaten Rollen die Notwendigkeit einer kongruenten Selbstpräsentation aufheben. Doch auch wenn der Held äusserlich in zwei Personen getrennt ist, bleiben diese für den jeweiligen Prot-

ist - ähnlich, wie es schon die meisten Pulp-Helden praktiziert haben, sind sie im Lauf der Zeit (abgesehen von der 〈Superheldencommunitys) zu einer kleinen Gruppe von Eingeweihten gekommen, die oft das «Unternehmen maskierter Held entscheidend unterstützen.

I 8 Fingeroth 2008, 98 .

I9 Inchausti $1983,66$.

20 Vgl. dazu z. B. McAdams I996, 297-299, Cox/Lyddon 1997, Tracy/Trethewey 2006. 
agonisten wie für die (eingeweihten) Leser eine Einheit. ${ }^{21}$ So oft der Held seine Doppelidentität auch verlassen möchte, wird doch - wie es die Serialität gebietet - die einmal etablierte Doppelidentität immer wieder installiert. So ist vielmehr festzuhalten, dass der maskierte Held zwischen Einheit und Vielheit changiert. Gerade mit den Superhelden zusammen gelesen, offenbaren auch die hier zur näheren Betrachtung gewählten Identitätstheorien ein Oszillieren zwischen diesen Polen.

Robert Jay Liftons Konzept des protean self, das sich etwa in Spider-Man verkörpert findet, zeichnet sich zwar durch Vielseitigkeit und Wandlungsfähigkeit aus. Auch ist es von einer gewissen Verlorenheit in der Welt gekennzeichnet jener Vater- und Heimatlosigkeit, die viele maskierte Helden, die als Waisen aufgewachsen sind, prägt -, wozu ein oft ironischer, distanzierender Blick auf die Geschehnisse gerechnet werden mag. ${ }^{22}$ Ebenso erscheint die narrative Identität - die sich im Erzählvorgang konstruiert und die hier weniger in einzelnen Storys als im Netzwerk verschiedener Batman-Geschichten wiederzufinden ist - als ständiger Transformationsprozess, der auf vielschichtigen und nicht selten widersprüchlichen Identitätsfragmenten beruht. ${ }^{23}$ Erzählen wird zur Identitätsarbeit, was ein dynamisches Selbst impliziert. Und auch die possible selves postulieren auf den ersten Blick eher Variabilität und Vielheit statt Einheit der Identität(en). ${ }^{24}$

Und dennoch gibt es in den ausgewählten Identitätskonzepten - wie es die maskierten Helden auch zum Ausdruck bringen - Bestrebungen zu Beständigkeit. So ist die zentrale Fähigkeit des protean self, disparate Elemente («odd combinations», etwa beim maskierten Helden zwei in der öffentlichen Wahrnehmung inkompatible Rollenbilder) zusammenzubringen. Obwohl dies meist nur als prekäre Kohärenz möglich ist, stellt das protean self einen Balanceakt zwischen «responsive shapeshifting» und «efforts to consolidate and cohere» dar. ${ }^{25}$ Es umfasst auch die Suche nach neuen Zugehörigkeiten (zum Beispiel dauerhaften Beziehungen) und als Teil des survivorpattern Bemühungen um eine Sinnhaftigkeit

2I So besehen erweist sich die Benennung als Doppelidentität - als Balance zwischen Einheit und Zweiheit, die die Vielheit beinhaltet, wie sie im Objekt der Maske angelegt ist - rückblickend dennoch als wohl angemessenste Bezeichnungsvariante, obschon sich im Verlauf dieses Buches stellenweise eine Bennenung als Dreifach- oder Mehrfachidentität aufgedrängt haben mag.

22 Lifton 1993.

23 McAdams 1996, 307, Lieblich/Josselson 2013, 204. Freilich lässt sich dieser Transformationsprozess auch auf die Produktionstraditionen von Superheldencomics zurückführen, da diese meist in Teamarbeit entstehen und im Lauf der Zeit auch immer wieder andere Kreativteams am Werk sind.

24 Markus/Nurius 1986.

25 Lifton 1993,9 und 50. 
des eigenen Lebens, was sich in der Heldentätigkeit, die oft in einer Tragödie wurzelt, zweifellos erkennen lässt.

Ebenso sucht die narrative Identität oft aus dem Fragmentarischen ein sinnhaftes Ganzes zusammenzufügen, wie es Batmans Origin-Geschichten tun, die im Lauf der Jahre angesammelte Widersprüche zu glätten versuchen. So weisen Origin-Retcons in der Regel Referenzen (die zugleich Reverenzen sein können) auf frühere Texte auf, selbst wenn sie der Abgrenzung von früheren Versionen dienen. Nur schon der Erzählprozess als solcher dient der Herstellung von Kontinuität. Bezeichnenderweise gibt es besonders bei Batman eine auffällige Tendenz, Bruce Waynes Batman-Werdung als unausweichliches Schicksal zu inszenieren, was doch in einem gewissen Gegensatz zu all jenen Batman-Storys steht, die eher die innere Spaltung des Charakters betonen. Vielleicht ist es gerade seine Zweiheit, sei es als Doppelung oder als Spaltung, die ihn in seinem Erzähluniversum zu einer einzigartigen Person macht.

Die Thunderbolts, deren Identitätsdilemma nicht zwischen zivil und heldisch, sondern zwischen gut und böse situiert ist, kommen durch die Darstellung einer neuen Identität tatsächlich zu einem neuen Selbstgefühl. Obwohl es sich dabei nicht um einen gewollten Läuterungsprozess handelt, findet sich hier Immanuel Kants Gedanke wieder, dass die metaphorische Maske auf ihren Träger zurückwirkt. ${ }^{26}$ Mit der möglichen Umsetzung verschiedener possible selves ${ }^{27}$ konfrontiert, schwanken die Mitglieder der Thunderbolts immer wieder, in welche Richtung sie sich entwickeln wollen. Die Thunderbolts echoen dabei wohl auch einen gewissen Zeitgeist: In ihren Geschichten kommt deutlich zum Ausdruck, dass Identität auch eine Wahl ist. Freilich erscheint dieser Wahlprozess als niemals abschliessbar, da die Thunderbolts ihre Entscheidungen immer wieder aufs Neue bestätigen müssen - wie der Griff zur Maskerade, der Schritt zur Heldenaktivität, eine Entscheidung ist, die stets neu zu treffen ist.

Aus der Analyse, wie die maskierten Helden mit Identitätsvorstellungen korrespondieren, lässt sich schliessen, dass die beiden zuerst oft als einander ausschliessende Gegensätze erscheinenden Identitätsverständnisse wohl eher als zwei Pole einer breiten Skala zu verstehen sind, wobei sich spekulieren lässt, dass selbst in einem Pol jeweils noch ein Quentchen des andern Pols mitschwingt. Die maskierten Superhelden aber wären wohl (je nach Held und Zeitraum mehr oder weniger) in der Mitte dieser Skala zu positionieren.

Das Verständnis der Maske als Symbol für Täuschung (bzw. Umkehrung der Täuschung) lässt sich nach Weihe mit einer weiteren Lesart der Maske ergänzen.

26 Kant I798, i 5 I.

27 Markus/Nurius 1986. 
In Anlehnung an den antiken Maskenbegriff spricht er hier von der Maske als Verkörperung einer Denkfigur der «prosopischen Einheit» ${ }^{28}$, in der sich Gegensätze paradoxerweise zugleich als Kombination denken lassen. Im Hinblick auf die Thematisierung von Identität in den Geschichten um maskierte Helden, die narrativ sowohl das «Wahr-falsch-Paradigma als auch das «Einheit-in-VielheitParadigma bespielen, lässt sich somit folgern: Die maskierten Helden verkörpern diese paradoxe prosopische Einheit, in der das Entweder-oder das Sowohlals-auch nicht ausschliesst. 


\section{Danksagung}

Als Teil des Projekts «Übergänge und Entgrenzungen. Welt, Wissen und Identität in fantastischer (Kinder- und Jugend-)Literatur und ihren Verfilmungen» wurde diese Arbeit finanziell unterstützt durch den SNF, den Schweizerischen Nationalfonds zur Förderung wissenschaftlicher Forschung, der auch die OpenAccess-Publikation ermöglicht hat.

Prof. Dr. Ingrid Tomkowiak hat diese Arbeit mit Rat und Tat und in der Überzeugung, dass dieses Thema die Mühe wert sein würde, begleitet und gefördert. Ich hätte keine bessere Doktormutter finden können.

Prof. Dr. Klaus Müller-Wille ist mir mit zeitlicher Flexibilität und seiner Bereitschaft, sich in mein Thema zu vertiefen, grosszügig entgegengekommen.

Die Liebe und das Verständnis meiner Familie sowie das Interesse und die Hilfe meiner guten und besten Freundinnen und Freunde haben mich über so manche Durststrecke und so manchen Stolperstein getragen.

Eine Vielzahl oft anonymer Comic- und Pulp-Fans hat ihre Schätze und ihr Wissen online oder in gedruckter Form zugänglich gemacht - ohne sie wäre die breite Materialbasis dieser Arbeit kaum möglich gewesen.

Von Herzen danke ich allen Menschen und Institutionen, die auf irgendeine Weise dazu beigetragen haben, dass diese Arbeit entstehen konnte. 


\section{Bibliografie}

\section{Primärliteratur (Korpus)}

\section{Comics}

Batman. In: Detective Comics 27-37 (1939-1940); Batman I (1940). Sammelband: Batman Chronicles. Bd. I. New York: DC Comics 2005.

Batman. The Origin of the Batman. In: Batman 47, Juni-Juli 1948.

Batman in the Forties. Introduction by Bill Schelly. New York: DC Comics 2004.

Batman: Year One. In: Batman 404-407, Februar-Mai 1987.

Batman: «... My Beginning ... and My Probable End.» In: Detective Comics 574, Mai 1987.

Batman: Year Two. In: Detective Comics 575-578, Juni-September 1987.

Batman: Batman RIP. In: Batman 676-68 I, Mai-November 2008.

Batman: The Butler Did It. In: Batman 682, Januar 2009.

Batman: What The Butler Saw. In: Batman 683, Januar 2009.

Batman: Earth One. New York: DC Comics $20 \mathrm{I} 2$.

Batman: Earth One Volume Two. New York: DC Comics 2015.

Daredevil I-380 (vi), April i964-Oktober 1998.

Daredevil I-I 9 (v2), November I998-August 2009.

Daredevil I-36 (v3), Mai 20I I-Februar 20I4.

Daredevil I-I 8 (v4), September 20I4-April 2015.

In The Beginning. In: The Untold Legend of the Batman I-3, Juli-September 1980.

Life Sentences (Thunderbolts Special). [Annual] $200 \mathrm{I}$.

Sensational Spider-Man 27-28, Mai-Juni 1998.

Spectacular Spider-Man 257-258, Mai I998-Juni 1998.

Peter Parker Spider-Man 91-92, Mai I 998-Juni 1998.

Spider-Man! In: Amazing Fantasy is, August 1962.

Superman. In: Action Comics I-I 3 (Juni I938-Juni 1939), Superman I (Juli I939). Sammelband: Superman Chronicles. Bd. I. New York: DC Comics 2006.

Superman I-230, Juli I939-August 1970.

The Amazing Spider-Man I-44 I (vi), März I 963-November 1998.

The Black Hood. In: Top Notch Comics / Top Notch Laugh Comics 9-35, Oktober I940-April I944.

The Black Hood. In: Jackpot Comics I-9, Frühling I 94 I-Frühling 1943.

The Black Hood. In: Black Hood Comics 9-19, Winter 1943-Sommer 1946.

The Black Terror. In: Exciting Comics 9-69, Mai I94 I-September 1949.

The Black Terror. In: America's Best Comics I-3 I, Februar I942-Juli 1949.

The Black Terror. In: The Black Terror Comics I-27, Februar I943-Juni I 949.

The Owl. In: Crackajack Funnies 25-43, Juli i 940-Januar I 942.

The Owl. In: Popular Comics 75-8 5, Mai I 942-März I943.

Thunderbolts I-75, April I997-Februar 2003. 


\section{Pulp-Novels und Romane}

Chance, George (d. i. G. T. Fleming-Roberts): The Ghost Strikes Back. 2003. E-Text, URL: http://www.pulpgen.com/pulp/downloads/getpdf.php?id=I76, Abruf I 2. 7 . 20I0. [EA in: The Ghost, Frühling I940.]

Daniels, Norman A.: The Black Bat. Omnibus Volume r. The First Three Adventures of Tony Quinn. Boston: Altus Press 2010. [EA in: Black Book Detective, Juli/Sept./ Nov. 1939.]

Fleming-Roberts, G. T.: The Green Ghost Detective. O. O.: Pulp Tales Press 20 i I (Pulp Tales Presents I9). [Enthält vier Green-Ghost-Storys, EA in: Thrilling Mystery, Sept. I942, Nov. I942, Juni I943, Herbst I943.]

Fleming-Roberts, G. T.: The Case of the Clumsy Cat [The Green Ghost]. In: High Adventure 77 (2004), 4-45. [EA in: Thrilling Mystery, März I943.]

Gibson, Walter B. (writing as Maxwell Grant): The Shadow 3. Two Classic Adventures of The Shadow. «The Voodoo Master» and «The Red Blot». Encinitas: Nostalgia Ventures, I I. 2006, 67-I 27. [EA in: The Shadow, I. 6. I 933 und I. 3. I936.]

Gibson, Walter B. (writing as Maxwell Grant): Lingo. In: Ders.; Tinsley, Theodore: The Shadow 9. Two Classic Adventures of The Shadow. «Lingo» and «Partners of Peril». Encinitas: Nostalgia Ventures, 7. 2007, 5-69. [EA in: The Shadow, I. 4. 1935.]

Gibson, Walter B. (writing as Maxwell Grant): The Shadow I4. Two Classic Adventures of The Shadow. «The Grove of Doom» and «The Masked Lady». Encinitas: Nostalgia Ventures, I. 2008a. [EA in: The Shadow, I. 9. 1933 und I 5. 9. 1939.]

Gibson, Walter B. (writing as Maxwell Grant): The Shadow i 5. Two Classic Adventures of The Shadow. «The Shadow Unmasks» and «The Yellow Band». Encinitas: Nostalgia Ventures, 2. 2008b. [EA in: The Shadow, I. 8. 1937 und I 5. 8. I937.]

Gibson, Walter B. (writing as Maxwell Grant): The Shadow i 8. Two Classic Adventures of The Shadow. «The Golden Masks» and «The Unseen Killer». Encinitas: Nostalgia Ventures, 5. 2008c. [EA in: The Shadow, I. 9. 1936 und I. I 2. I934.]

Grant, Maxwell (d. i. Walter B. Gibson): The Living Shadow. London: New English Library / NEL Paperback I9 1976 (I974). [EA in: The Shadow, I. 4. I93 I.]

Jones, G. Wayman (d. i. Norman A. Daniels): The Crime to Come. In: Black Book Detective, Vol. XXII, No. I., Februar 1947, I I-60.

Jones, G. Wayman (d. i. Norman A. Daniels): The Dennison Documents. In: Black Book Detective, Vol. XXVII, No. I. Herbst I 949, I I-88.

Jones, G. Wayman (d. i. Norman A. Daniels): The Black Bat and the Red Menace. In: High Adventure 69 (2003), 4-86. [EA in: The Black Book Detective, Mai I94I.]

Jones, G. Wayman (d. i. D. L. Champion): The Emperor of Death. O. O.: Wildside Press 2005 (Pulp Classics 7), 8-ıo5. [Faks., EA in: The Phantom Detective, Februar I933, Vol. I, Nr. I.]

Jones, G. Wayman (d. i. Norman A. Daniels): Brand of the Black Bat. In: High Adventure 90 (2006), 4-84. [EA in: Black Book Detective, Juli I939.]

Jones, G. Wayman (d. i. D. L. Champion/Anatole Feldman): The Yellow Murders. Silver Spring: Adventure House 2007, 9-9I. [Faks., EA: The Phantom Detective, Dezember I933.] 
Jones, G. Wayman (d. i. Norman A. Daniels): The Blackout Murders. In: High Adventure 96 (2007), 4-79. [EA in: Black Book Detective, März 1942.]

Jones, G. Wayman (d. i. Norman A. Daniels): The Murder Prophet. Athen: Hanos Reprint o. J. [ca. I980]. URL: https://archive.org/details/black_book_detective_ v22n3_47.06_-_hanos_reprint, Abruf 30. I0. 2018. [EA in: Black Book Detective, Vol. XXII, No. 3, Juni 1947, 3-56.]

McCulley, Johnston: The Crimson Clown. London, Toronto, Melbourne, Sidney: Cassell 1929 (1927). [Enthält die ersten vier Crimson-Clown-Storys, EA in: Detective Story Magazine, 3I. 7., 21. 8., 4. 9. und I8. 9. I926.]

McCulley, Johnston: The Mark of Zorro. New York: Doherty 1998. [EA I919/1924.]

McCulley, Johnston: The Man in Purple. Boston: Altus Press 2010. [Enthält alle drei Man-in-Purple-Storys, EA in: Detective Story Magazine, I. Iо., 5. I I. und Io. I 2. I92I.]

McCulley, Johnston: Alias The Whirlwind. Boston: Altus Press 20r ra. [Enthält alle sieben Whirlwind-Storys, EA in: Thrilling Adventures, Dez. 1933, Feb. I934, April 1934, Juli 1934, Sept. 1934, Nov. 1934, Jan. 1935.]

Orczy, Emmuska: The Scarlet Pimpernel. New York: Bantam 2007. [EA 1905.]

Packard, Frank L.: The Adventures of Jimmie Dale. Project Gutenberg, E-Book I 2 I 8 (1998). [EA 1914/1917.]

Stockbridge, Grant: Slaves of the Laughing Death. [Rockville:] Wildside Press/Argosy Communications, Inc. 2005, 6-84. [Faks., EA: The Spider. Gotham Hound, März I942.]

Scott, R. T. M.: The Spider. Mississauga: Girasol Collectables 2006, 8-ı06. [Faks., EA: The Spider. Master of Men!, Oktober I933.]

Stockbridge, Grant: The Wheel of Death. E-Text, URL: http://www.munseys.com/ book/20739/WHEEL_OF_DEATH,_THE, Abruf I 3. 7. 201 5. [EA in: The Spider, November 1933.]

Stockbridge, Grant: Wings of the Black Death. E-Text, URL: http://www.munseys. com/book/I9564/WINGS_OF_THE_BLACK_DEATH, Abruf I 3. 7. 201 s. [EA in: The Spider, Dezember I933.]

Tinsley, Theodore (writing as Maxwell Grant): Partners of Peril. In: Gibson, Walter B.; Tinsley, Theodore: The Shadow 9. Two Classic Adventures of The Shadow. «Lingo» and «Partners of Peril». Encinitas: Nostalgia Ventures, 7. 2007, 72-I 3 I. [EA in: The Shadow, I. I I. I936.]

Wallace, Robert: Diamonds of Death. Silver Spring: Adventure House 2008, I I-6.

[Faks., EA: The Phantom Detective, Juni i 934.]

Wallace, Robert: Grim Shadow of Hate. In: High Adventure 74 (2004), 5-8 I. [EA in: The Phantom Detective, Juni I94I.] 


\section{Weitere Primärliteratur (erweitertes Korpus)}

\section{Comics}

Ant-Man/Giant-Man. In: Tales to Astonish 27, 35-52, Januar 1962-Februar 1964. Sammelband: Marvel Masterworks: Ant-Man/Giant-Man. Bd. I. New York: Marvel Comics 2013.

Batman in the Fifties. Introduction by Michael Uslan. New York: DC Comics 2002.

Batman in the Sixties. Introduction by Adam West. New York: DC Comics 1999.

Batman in the Eighties. Introduction by John Wells. New York: DC Comics 2004.

Batman: Masque. New York: DC Comics I 997.

Captain America. In: Captain America I-4, I94I. Sammelband: Marvel Masterworks: Golden Age Captain America Comics. Bd. I. New York: Marvel Comics 2005.

Firebrand. In: Police Comics I-I 3. August I94 I-November 1942.

Green Arrow (v2) I-I 37, August 1987-Oktober 1998.

Green Arrow (v3) I-75, April 200I-August 2007.

Green Arrow - Black Canary I-32, Dezember 2007-April 2010.

Green Arrow (v4) I-I 5, August 2010-Oktober 20I I.

Green Lantern. In: All-American Comics 3 I-38, Oktober I94I-Mai I942, Green Lantern Quarterly 2 (1942), Green Lantern 3 (1942). Sammelband: Green Lantern Archives. Bd. 2. DC Archive Editions. New York: DC Comics 2002.

Green Lantern. In: Showcase 22-24, I959-1960; Green Lantern I-3, I960. Sammelband: The Green Lantern Chronicles. Bd. I. (John Broome, Gil Kane et al.). New York: DC Comics 2009.

Huntress. In: Batman Family i7-20, April/Mai-Oktober/November 1978, und Wonder Woman 271-32 I, September i 980-November 1984.

Iron Man. In: Tales of Suspense 39-72 (März 1963-Dezember 1966). Sammelband: Essential Iron Man. Bd. I. New York: Marvel Comics 2005.

Lady Luck. In: Smash Comics 42-47; 80-85, April I943-Oktober I943; Dezember I $948-O k$ tober 1949.

Masquerade I-4. Sammelband: Runnemede: Dynamite Entertainment 2009.

Miss Masque. In: Exciting Comics 5 I-54, September 1946-März 1947; America's Best Comics 23-3 I, September I947-Juli i 949.

Nightwing I-I00, Oktober I $996-$ Februar 2005.

Plastic Man. In: Police Comics I-9. August I94 I-Mai I 942.

Project Superpowers 0-7. Sammelband: Runnemede: Dynamite Entertainment 2008.

Secret Identities I-7. Sammelband: Berkeley: Image Comics 2015.

Superman: The Dailies I939-1942 (Strips I-966). New York: Sterling [2006] (1998). Superman in the Fifties. Introduction by Mark Waid. New York: DC Comics 2002. Superman in the Sixties. Introduction by Mark Waid. New York: DC Comics I 999. Superman in the Seventies. Introduction by Christopher Reeve. New York: DC Comics 2000.

Superman in the Eighties. Introduction by Jerry Ordway. New York: DC Comics 2006. Superman: Earth One. New York: DC Comics 2010.

Superman: Earth One Volume Two. New York: DC Comics 2012. 
The Black Terror I-4. Sammelband: Runnemede: Dynamite Entertainment 2008. Bd. I.

The Black Terror 5-9. Sammelband: Runnemede: Dynamite Entertainment 2010. Bd. 2. The Black Terror I0-I4. Sammelband: Runnemede: Dynamite Entertainment 20 I I. Bd. 3 .

The Flash. In: Showcase 4, 8, I 3, I 4, Oktober I956, Juni 1957, April I958, Juni I958; Flash 105-106, März 1959, Mai 1959. Sammelband: The Flash Chronicles. Bd. I. New York: DC Comics 2009.

The Green Arrow. In: Adventure Comics 250-269, Juli I958-Februar i960; World's Finest Comics 95-I40, Juli I958-März I964. Sammelband: Showcase presents Green Arrow I, New York: DC Comics 2006.

The Human Bomb. In: Police Comics I-58, August I94 I-September 1946.

The Jester. In: Smash Comics 23-85, Juni i 94 I-August 1948.

The Lone Ranger. 9. I 2. I938-I4. 3. 1942. Sammelband: Comic Strip Showcase I. Greenfield: Arcadia Publications I990.

The Lone Ranger I: Für immer und ewig. Ludwigsburg: Amigo Grafik (Cross-Cult) 2009. [Engl. EA 2009, Dynamite, Lone Ranger I-6.]

The Mask. In: Exciting Comics I-20, April I940-Juli I942.

The Ray. In: Smash Comics I4-18, September 1940-Januar I94I.

The Shield. In: Pep Comics I-s ( I940), Shield-Wizard Comics I (I 940). Sammelband:

New York: Archie Comic Publications 2002.

The Sphinx. In: Exciting Comics 2-I4, Mai I940-November I94I.

The Woman in Red. In: Thrilling Comics I-2, I940; America's Best Comics 2, I 942.

Watchmen I-I 2 (September I986-Oktober 1987). Sammelband: New York: DC Comics 2008.

Wildfire. In: Smash Comics 25-37, August I94 I-November 1942.

Wonder Woman. In: All-Star Comics 8, Dezember I 94 I-Januar 1942; Sensation Comics I-I 2, Januar 1942-Dezember 1942; Wonder Woman I, Sommer I 942. Sammelband: Wonder Woman Archives. Bd. I. DC Archive Editions. New York: DC Comics 1998.

\section{Pulp-Novels und Romane}

Anderson, Lars: Emeralds Aboard. Another Sophisticated Domino Lady Story. Silver Spring: Adventure House 2005, 43-62 [Faks., EA in: Saucy Romantic Adventures Vol. I, Nr. 4, August I 936.]

Champion, D. L.; Eliot, George Fielding; Ward, Harold: Alias Mr. Death. The Complete Series. Boston: Altus Press 2009. [EA in: Thrilling Detective, I932-1939.]

Féval, Paul: Le Loup Blanc. Edition définitive. Paris: Albin Michel 1977.

Féval, Paul: Le Bossu ou Le Petit Parisien Lagardère. Paris: Librairie Générale Française I 997 (Le Livre de Poche Classiques).

Féval, Paul: Gentlemen of the Night. Captain Phantom. Adapted by Frank J. Morlock. Encino: Black Coat Press 2007.

Fleming-Roberts, George: The Whispering Eye. O. O.: Wildside Press 2006 (Pulp Classics I 5). [Faks., EA: Hooded Detective. Januar I942, 8-4 I.] 
Fleming-Roberts, G. T.: The Pulp Adventures of the Hooded Detective. Boston: Altus Press 2008. [Enthält alle drei Black-Hood-Storys, EA in: Black Hood Detective, Sept. I94 I, Hooded Detective, Nov. I94 I, Jan. I942.]

Johnson, Frank: The Crimson Mask and the Vanishing Men. In: High Adventure 98 (2008a), 4-4I. [EA in: Detective Novels Magazine, Juni I94I.]

Johnson, Frank: The Money Trail. [Crimson Mask.] In: High Adventure 98 (2008b), 74-109. [EA in: Detective Novels Magazine, April 1942.]

Leinster, Murray (d. i. Will Jenkins): The Coney Island Murder. In: High Adventure 67 (2002), 4-23. [EA in: Black Bat Detective Mysteries, November I933.]

McCulley, Johnston: Trap of the Mongoose. A Novelette. In: Detective Fiction Weekly, 27. 5. 1933 (Vol. LXXVI), 70-93.

McCulley, Johnston: The Masked Woman. O. O.: Wildside Pulp Classics 2006. [EA in: The Washington Post, 2. I. I92 I.]

McCulley, Johnston [?, orig. publiziert unter C. K. M. Scanlon]: The Bat Strikes Again and Again! Boston: Altus Press 2009. [Enthält alle vier The-Bat-Storys, EA in: Popular Detective, Nov. 1934, Dez. 1934, Jan. 1935, Feb. 1935.]

McCulley, Johnston: Murder Note. A Green Ghost Novelette. E-Text, URL: http:// www.pulpgen.com/pulp/downloads/getpdf.php?id=863, Abruf I 2. 7. 2010. [EA in: Thrilling Detective, Januar I935.]

McCulley, Johnston: The Black Star. A Detective Story. New York: Chelsea House I 92 I. Project Gutenberg, E-Book Nr. 35833 (20I I b). [EA in: Detective Story Magazine, 5. 3. I9I6.]

McCulley: The Spider Strain. E-Book: www.manybooks.net, Abruf I 5. 3. 201 5. [EA in: Detective Story Magazine, 8. 4. I919.]

Orczy, Emmuska: I Will Repay. Further Adventures of The Scarlet Pimpernel. Leipzig: Tauchnitz I924 (I906).

Richards, Stanley: Brain of the Octopus. Silver Spring: Adventure House 2005, 6-45. [Faks., EA: Red Mask Detective Stories, März i94 I, Vol. I, Nr. I.]

Whitehouse, Arch: Guns of the Griffon. E-Text: http://www.pulpgen.com/pulp/downloads/getpdf.php?id=49, Abruf I 2. 7. 2010. [EA in: Flying Aces, Juni I935.]

Whitehouse, Arch: The Griffon’s Gamble. E-Text: http://www.pulpgen.com/pulp/ downloads/getpdf.php?id=50, Abruf I 2. 7. 2010. [EA in: Flying Aces, August 1935.]

Zschokke, Johann Heinrich Daniel: Abaellino der grosse Bandit. Mit einem Nachwort hg. v. Josef Morlo. St. Ingbert: Röhrig I 994 (Kleines Archiv des achtzehnten Jahrhunderts $2 \mathrm{I}$ ).

\section{Hörspiele / Hörspielskripte}

Bierstadt, Edward Hale: Danger in the Dark. Radiohörspiel, Erstausstrahlung Iо. I0. 1937. Skript in: Grant, Maxwell (Pseud. Walter B. Gibson): The Shadow I4. Two Classic Adventures of The Shadow. «The Grove of Doom» and «The Masked Lady». Encinitas: Nostalgia Ventures, I. 2008, I I6-I 27. 
Black Hood. The Emerald Ring. Erstausstrahlung 5. 7. I943. URL: https://ia600409. us.archive.org/29/items/otr_blackhood/BlackHoodEmeraldRing.mp3, Abruf i 5 . 4 . 2017.

Green Hornet. Spies \& Rackets. Classic Radio. 20 Episodes. Little Falls: Radio Spirits 2009. ISBN 978-I-57019-889-2. [ Iо Hörspiele von I 944 (inklusive D-Day-Folge).]

Slon, Sidney: The Laughing Corpse. Radiohörspiel, Erstausstrahlung I0. 4. I940. Skript in: Grant, Maxwell (Pseud. Walter B. Gibson): The Shadow i9. Two Classic Adventures of The Shadow. «Voodoo Trail« and «Death's Harlequin». Encinitas: Nostalgia Ventures, 6. 2008, I I 8-I 28.

The Adventures of Superman. The Baby from Krypton. Erstausstrahlung I 2. 2. I940. URL: https://archive.org/details/superman_otr, Abruf I 5. I०. 2018.

The Blue Beetle. Drug Ring. Part I and 2. Erstausstrahlung I 5. 4. I940. URL: https://archive.org/details/OTRR_Blue_Beetle_Singles, Abruf. I7. 2. 20 I 8.

The Green Hornet. Cedar Knolls: Radio Spirits/Media Bay 2003. ISBN I-57019-637-0.

[6 Hörspiele von I946.]

\section{Sekundärliteratur}

Abels, Heinz: Identität. Über die Entstehung des Gedankens, dass der Mensch ein Individuum ist, den nicht leicht zu verwirklichenden Anspruch auf Individualität und die Tatsache, dass Identität in Zeiten der Individualisierung von der Hand in den Mund lebt. Wiesbaden: VS Verlag für Sozialwissenschaften 2006.

Abels, Heinz: Interaktion, Identität, Präsentation. Kleine Einführung in interpretative Theorien der Soziologie. 4. Aufl. Wiesbaden: VS Verlag für Sozialwissenschaften 2007 (Hagener Studientexte zur Soziologie).

Alaniz, José: «What Can We Ever Have to Fear From a Blind Man?!!» or Spoiled (Secret) Identities: Disability, Daredevil and Passing. In: IJOCA I 4: I (Frühling 20 I2), $36 \mathrm{I}-375$.

Andrae, Thomas: From Menace to Messiah: the Prehistory of the Superman in Science Fiction Literature. In: Discourse 2 (Summer I980), 84-I I 2.

Anz, Thomas: Textwelten. In: Ders. (Hg.): Handbuch Literaturwissenschaft. Bd. I: Gegenstände und Grundbegriffe. Stuttgart/Weimar: Metzler 2007, I I I-I 30.

Arnett Jensen, Lene: The Culture Wars and Psychology. Robert Jay Lifton's The Protean Self. In: Culture \& Psychology I (1995), 393-40I.

Ashmore, Richard D.; Jussim, Lee: Introduction. Toward a Second Century of the Scientific Analysis of Self and Identity. / Conclusion. Fundamental Issues in the Study of Self and Identity - Contrasts, Contexts, and Conflicts. In: Dies. (Hg.): Self and Identity. Fundamental Issues. New York: Oxford UP 1997 (Rutgers Series on Self and Social Identities I), 3-19/2 10-230.

Backer, Ron: The Shadow. The Caped Avenger. In: Ders.: Mystery Movie Series of I 940 s Hollywood. Jefferson, London: McFarland 2010, 86-96.

Bails, Jerry: Foreword. In: The Golden Age Green Lantern Archives. Bd. 2. New York: DC Comics 2002, $5-8$. 
Bainbridge, Jason: «Worlds Within Worlds»: The Role of Superheroes in the Marvel and DC Universes. In: Ndalianis, Angela (Hg.): The Contemporary Comic Book Superhero. New York, Abingdon: Routledge 2009, 64-85.

Bainbridge, Jason: «I Am New York» - Spider-Man, New York City and the Marvel Universe. In: Ahrens, Jörn; Meteling, Arno (Hg.): Comics and the City. Urban Space in Print, Picture and Sequence. New York, London: Continuum 2010, 163-179.

Baumbach, Gerda: Maschera, ve saludo! - Maske, seid gegrüsst! Anmerkungen zu Maske, Theater-Maske und Masken-Theater in der europäischen Neuzeit. In: Schäfer, Alfred; Wimmer, Michael (Hg.): Masken und Maskierungen. Opladen: Leske und Budrich 2000 (Grenzüberschreitungen 3), I 37-1 59.

Baumeister, Roy F.: How the Self Became a Problem. A Psychological Review of Historical Research. In: Journal of Personality and Social Psychology 52:I (I987), I63-I76.

Baumeister, Roy F.: The Self and Society. Changes, Problems, and Opportunities. In: Ashmore, Richard D.; Jussim, Lee (Hg.): Self and Identity. Fundamental Issues. New York: Oxford UP I 997 (Rutgers Series on Self and Social Identities I), I9I-2 I7.

Baumeister, Roy F.: Self and Identity: A Brief Overview of What They Are, What They Do, and How They Work. In: Annals of the New York Academy of Sciences I 234 (20I I), 48-55. DOI: I0.I I I /j.I749-6632.20I I.06224.x.

Baumeister, Roy F.; Vohs, Kathleen D.: Editor's Introduction. What Do We Know about Self and Identity? In: Dies. (Hg.): Self and Identity. Bd. I: Self-Concept and Self-Esteem. Los Angeles et al.: Sage 20r 2, xvii-xxxiv.

Benthien, Claudia: Das Maskerade-Konzept in der psychoanalytischen und kulturwissenschaftlichen Theoriebildung. In: Stephan, Inge; Benthien, Claudia (Hg.): Männlichkeit als Maskerade. Kulturelle Inszenierungen vom Mittelalter bis zur Gegenwart. Köln: Böhlau 2003 (Literatur - Kultur - Geschlecht, Kleine Reihe I 8), 36-59.

Beritela, Gerard F.: Super-Girls and Mild Mannered Men: Gender Trouble in Metropolis. In: Wandtke, Terrence R. (Hg.): The Amazing Transforming Superhero! Essays on the Revision of Characters in Comic Books, Film and Television. Jefferson, London: McFarland 2007, 52-69.

Bettinger, Elfi; Funk, Julika: Vorwort: In: Dies. (Hg.): Maskeraden: Geschlechterdifferenz in der literarischen Inszenierung. Berlin: Schmidt I 995, 7-I4.

Blackbeard, Bill: The Pulps. In: Inge, Thomas M. (Hg.): American Popular Culture. Bd. I. Westport, London: Greenwood Press 1978, I95-223.

Blythe, Hal; Sweet, Charlie: Superhero: The Six Step Progression. In: Browne, Ray B.; Fishwick, Marshall W. (Hg.): The Hero in Transition. Bowling Green: Bowling Green University Popular Press 1983, I 80-1 87.

Brooker, Will: Fandom and Authorship. In: Hatfield, Charles; Heer, Jeet; Worcester, Kent (Hg.): The Superhero Reader. Jackson: UP of Mississippi 20I 3, 6I-7I. [Auszug aus Brookers Batman Unmasked, 2000, 250-279, mit einem Nachtrag.]

Brownie, Barbara; Graydon, Danny: The Superhero Costume. Identity and Disguise in Fact and Fiction. London, Neu-Delhi, New York, Sydney: Bloomsbury Academic 2016.

Bukatman, Scott: Matters of Gravity. Special Effects and Supermen in the 2oth Century. Durham, London: Duke UP 2003. 
Busiek, Kurt: Introduction: «The Trickiest Part of the Whole Thing Was Maintaining the Surprise». In: Thunderbolts Classic. Bd. I: Justice Like Lightning. New York: Marvel Comics 20I I (200I), unpag.

Caillois, Roger: Die Spiele und die Menschen. Maske und Rausch. Frankfurt a. M., Berlin, Wien: Ullstein 1982 [frz. EA 1958].

Callero, Peter L.: Role Theory. In: International Encyclopedia of the Social Sciences. Hg. v. William A. Darity. Bd. 7. 2. Aufl. Detroit: Macmillan Press 2007, 275f. URL: http:// link.galegroup.com/apps/doc/CX $3045302300 / G V R L ? u=u n i z u r \& s i d=G V R L \& x i d=90$ ca6ice (is. I0. 2018).

Carr, Nick: The Western Pulp Hero. An Investigation into the Psyche of an American Legend. Mercer Island: Starmont House 1989 (Starmont Popular Culture Studies 3).

Casey, Jim; Silver Age Comics. In: Bould, Mark; Butler, Andrew M.; Roberts Adam; Vint, Sherryl (Hg.): The Routledge Companion to Science Fiction. London, New York: Routledge 2009, I 23-I 33.

Castiglione, Baldesar: Das Buch vom Hofmann. Übersetzt, eingeleitet und erläutert von Fritz Baumgart. Bremen: Schünemann o.J. [1960?] (Sammlung Dieterich 78). [Ital. EA I 528.$]$

Castle, Terry: Masquerade and Civilization. The Carnivalesque in Eighteenth-Century English Culture and Fiction. Stanford: Stanford UP 1986.

Chambers, Samuel A.: Telepistemology of the Closet; or, The Queer Politics of Six Feet Under. In: The Journal of American Culture 26: I (März 2003), 24-4I.

Comello, Maria Leonore G.: William James on «Possible Selves»: Implications for Studying Identity in Communication Contexts. In: Communication Theory I9 (2009), 337-350. DOI: 0.I I I I/j.I 468-2885.2009.01346.x.

Coogan, Peter: Superhero. The Secret Origin of a Genre. Austin: MonkeyBrainBooks 2006.

Costello, Matthew J.: Secret Identity Crisis. Comic Books and the Unmasking of Cold War America. New York, London: Continuum 2009.

Coughlan, David: The Naked Hero and Model Man: Costumed Identity in Comic Book Narratives. In: De Tora, Lisa (Hg.): Heroes of Film, Comics, and American Culture. Essays on Real and Fictional Defenders of the Home. Jefferson, London: McFarland 2009, 234-25I.

Cox, Linda M.; Lyddon, William J.: Constructivist Conceptions of Self: A Discussion of Emerging Identity Constructs. In: Journal of Constructivist Psychology I0:3 (I997), 20I-2 I9. DOI: 10.1080/10720539708404623.

Curtis, Sandra R.: Zorro Unmasked. The Official History. New York: Zorro Productions Inc. I998a.

Curtis, Sandra R.: Preface. In: McCulley, Johnston: The Mark of Zorro. New York: Tor I 998 b, vii-xx.

D’Ammassa, Don: Encyclopedia of Adventure Fiction. New York: Facts on File 2009.

Daemmrich, Horst S.; Daemmrich, Ingrid G.: Täuschung. In: Dies.: Themen und Motive in der Literatur. Ein Handbuch. Tübingen: Francke 1987, 303-304.

Dallmann, Antje: ConspiraCity New York: Stadtbetrachtung zwischen Paranoia und Selbstermächtigung. Heidelberg: Winter 2009 (American Studies I76). 
Danziger, Kurt: The Historical Formation of Selves. In: Ashmore, Richard D.; Jussim, Lee (Hg.): Self and Identity. Fundamental Issues. New York: Oxford UP I 997 (Rutgers Series on Self and Social Identities I), I 37-I 59.

Darius, Julian: «The Hidden Wonders of the World»: Planetary and Reconstructionism. In: Walker, Cody (Hg.): Keeping the World Strange. A Planetary Guide. Edwardsville: Sequart Research \& Literacy Organization 20 I I, 54-79.

Darowski, Joseph J.: The American Way. What Superman, Batman, Spider-Man, and The X-Men Reveal About America. Köln: Lambert 2009.

Deaux, Kay: Identity. In: Kazdin, Alan E. (Hg.): Encyclopedia of Psychology. Bd. 4. Washington: American Psychological Association 2000, 222-225.

DeForest, Tim: Storytelling in the Pulps, Comics, and Radio. How Technology Changed Popular Fiction in America. Jefferson, London: McFarland 2004.

Deger, Petra: Masken der Normalität. In: Schäfer, Alfred; Wimmer, Michael (Hg.): Masken und Maskierungen. Opladen: Leske und Budrich 2000 (Grenzüberschreitungen 3), I 87-207.

Denson, Shane; Mayer, Ruth: Grenzgänger. Serielle Figuren im Medienwechsel. In: Kelleter, Frank (Hg.): Populäre Serialität: Narration - Evolution - Distinktion. Zum seriellen Erzählen seit dem I9. Jahrhundert. Bielefeld: Transcript 201 2, I 8 5-203.

Dinan, John A.: The Pulp Western. A Popular History of the Western Fiction Magazine in America. San Bernardino (California): R. Reginald The Borgo Press I983 (I. O. Evans Studies in the Philosophy \& Criticism of Literature 2).

DiPaolo, Marc Edward: Wonder Woman as World War II Veteran, Camp Feminist Icon and Male Sex Fantasy. In: Wandtke, Terrence R. (Hg.): The Amazing Transforming Superhero! Essays on the Revision of Characters in Comic Books, Film and Television. Jefferson, London: McFarland 2007, I 5 I-I73. [Auch in: DiPaolo 201 I.]

DiPaolo, Marc Edward (Hg.): War, Politics \& Superheroes. Ethics and Propaganda in Comics and Film. Jefferson, London: McFarland $20 \mathrm{I}$.

Ditschke, Stephan; Anhut, Anjin: Menschliches, Übermenschliches. Zur narrativen Struktur von Superheldencomics. In: Ditschke, Stephan; Kroucheva, Katerina; Stein, Daniel (Hg.): Comics. Zur Geschichte und Theorie eines populärkulturellen Mediums. Bielefeld: Transcript 2009, I 3 I-I 78. [Auch in: Etter, Lukas; Nehrlich, Thomas; Nowotny, Joanna (Hg.): Reader Superhelden. Theorie - Geschichte - Medien. Bielefeld: Transcript 2018 (Edition Kulturwissenschaft I33), i I 7-1 56.]

Dittmar, Jakob F.: Comic-Analyse. 2., überarb. Aufl. Konstanz: UVK 20I I (2008).

Dittmer, Jason: Retconning America: Captain America in the Wake of World War II and the McCarthy Hearings. In: Wandtke, Terrence R. (Hg.): The Amazing Transforming Superhero! Essays on the Revision of Characters in Comic Books, Film and Television. Jefferson, London: McFarland 2007, 35-5 I.

Dittmer, Jason: Fighting for Home: Masculinity and the Constitution of the Domestic in Tales of Suspense and Captain America. In: De Tora, Lisa (Hg.): Heroes of Film, Comics, and American Culture. Essays on Real and Fictional Defenders of the Home. Jefferson, London: McFarland 2009, 96-i i6.

Doering, Sabine: Motiv. In: Metzler Lexikon Literatur. 3., völlig neu bearb. Aufl. Hg. v. Dieter Burdorf, Christoph Fasbender, Burkhard Moennighoff. Stuttgart, Weimar: Metzler 2007, 514. 
Dooley, Dennis: The Man of Tomorrow and the Boys of Yesterday. In: Ders.; Engle, Gary (Hg.): Superman at Fifty. The Persistence of a Legend. Cleveland: Octavia 1987, I9-34.

Drechsel, Wiltrud Ulrike; Funhoff, Jörg; Hoffmann, Michael: Massenzeichenware. Die gesellschaftliche und ideologische Funktion der Comics. Frankfurt a. M.: Suhrkamp I975.

Drucker, Aaron: Spider-Man: MENACE!!! Stan Lee, Censorship and the roo-Issue Revolution. In: Peaslee, Robert Moses; Weiner, Robert G. (Hg.): Web-Spinning Heroics. Critical Essays in the History and Meaning of Spider-Man. Jefferson (North Carolina), London: McFarland 201 2, 90-100.

Dubiel, H.: Identität, Ich-Identität. In: Historisches Wörterbuch der Philosophie. Hg. v. Joachim Ritter und Karlfried Gründer. Bd. 4. Darmstadt: Wissenschaftliche Buchgesellschaft I976, I48-i 5 I.

Duncan, Randy; Smith, Matthew J.: The Power of Comics. History, Form, Culture. New York: Continuum International 2009.

Durkheim, Émile: Les dualisme de la nature humaine et ses conditions sociales. In: Scientia (Rivista di Scienza) Is (I9I4), 206-22 I. URL: http://amshistorica.unibo.it/7, Abruf: I5. 3. 2017.

Dusi, Nicola: Zorro. Ein transmedialer Held. Übertragung, Neudeutung und Remake einer Figur. In: montage/av I 6: I (2007), I 2 I-I 39. URL: http://www.montage-av.de/ pdf/r6I_2007/I6I_2007_Nicola_Dusi_Zorro-Ein-transmedialer-Held.pdf, Abruf i 5 . IO. 2018.

Earle, David M.: Pulp Magazines and the Popular Press. In: Brooker, Peter; Thacker, Andrew (Hg.): The Oxford Critical and Cultural History of Modernist Magazines. Bd. II, North America I 894-I960. Oxford: Oxford UP 201 2, I97-2 I 5 .

Easton, Lee; Harrison, Richard: Secret Identity Reader. Essays on Sex, Death and the Superhero. Hamilton: Wolsak and Wynn 2010.

Ebeling, Ingelore: Masken und Maskierung. Kult, Kunst und Kosmetik. Von den Naturvölkern bis zur Gegenwart. 2. Aufl. Köln: DuMont i 987 (1984).

Eco, Umberto: Der Mythos von Superman. In: Ders.: Apokalyptiker und Integrierte. Zur kritischen Kritik der Massenkultur. Frankfurt a. M.: Fischer 1992 (1986), I 87-222. [Ital. EA i 964. Auch in: Etter, Lukas, Nehrlich, Thomas, Nowotny, Joanna (Hg.): Reader Superhelden. Theorie - Geschichte - Medien. Bielefeld: Transcript 20 I 8 (Edition Kulturwissenschaft I 33), 275-300.]

Edgar, Andrew; Sedgwick, Peter: Identity. / Self. In: Dies. (Hg.): Key Concepts in Cultural Theory. London: Routledge I999, I 83-187, 346-350.

Eisgruber, Frank Jr.: Gangland's Doom. The Shadow of the Pulps. Revised Edition. Boston: Altus Press 2007 (I974).

Eisner, Will: Comics and Sequential Art. Principles \& Practice of the World's Most Popular Art Form. Tamarac: Poor House Press 2004 (1985).

Elliott, Anthony: Concepts of the Self. Cambridge (UK), Malden: Polity Press 2007.

Ellis, Doug; Locke, John; Gunnison, John: The Adventure House Guide to the Pulps. The Checklist of the Pulp Magazines. Silver Spring: Adventure House 2000.

Engle, Gary: What Makes Superman So Darned American? In: Dooley, Dennis; Engle, Gary (Hg.): Superman at Fifty. The Persistence of a Legend. Cleveland: Octavia I987, 79-87. 
Evans, Heather Dawn: Un/covering: Making Disability Identity Legible. In: Disability Studies Quarterly 37:I (2017). URL: http://dsq-sds.org/article/view/5556/4550, Abruf i 5. IO. 2018.

Faulstich, Werner: Serialität aus kulturwissenschaftlicher Sicht. In: Giesenfeld, Günter (Hg.): Endlose Geschichten. Serialität in den Medien. Hildesheim, Zürich, New York: Olms-Weidmann I 994, 46-54.

Ferry, Anne: Anonymity: The Literary History of a Word. In: New Literary History 33:2 (Frühling 2002), I93-2 I4. DOI: I0.1353/nlh.2002.0015.

Fingeroth, Danny: Disguised as Clark Kent. Jews, Comics, and the Creation of the Superhero. New York, London: Continuum 2007.

Fingeroth, Danny: Superman on the Couch. What Superheroes Really Tell Us about Ourselves and Our Society. New York, London: Continuum 2008 (2004).

Flanagan, Martin: «Continually in the Making»: Spider-Man's New York. In: Peaslee, Robert Moses; Weiner, Robert G. (Hg.): Web-Spinning Heroics. Critical Essays in the History and Meaning of Spider-Man. Jefferson (North Carolina), London: McFarland 201 2, 40-52.

Fludernik, Monika: Identity/Alterity. In: Herman, David (Hg.): The Cambridge Companion to Narrative. Cambridge: Cambridge UP 2007, 260-273.

Fossati, Franco: Die maskierten Helden. In: Ders.: Das grosse illustrierte Ehapa Comic Lexikon. Stuttgart: Ehapa 1993, 234.

Frahm, Ole: Wer ist Superman? Mythos und Materialität einer populären Figur. In: Diekmann, Stefanie; Schneider, Matthias (Hg.): Szenarien des Comic-Helden und Historien im Medium der Schriftbildlichkeit. Berlin: Sukultur 2005, 35-49. [Unter dem Titel Der Mythos vom Mythos von Superman auch in: Etter, Lukas; Nehrlich, Thomas; Nowotny, Joanna (Hg.): Reader Superhelden. Theorie - Geschichte - Medien. Bielefeld: Transcript 2018 (Edition Kulturwissenschaft I33), 468-483.]

Frenzel, Elisabeth: Stoff-, Motiv- und Symbolforschung. 4., durchges. u. erg. Aufl. Stuttgart: Metzler 1978 (1963) (Sammlung Metzler, Abt. E: Poetik 28).

Friedrich, Andreas; Rauscher, Andreas (Hg.): Film-Konzepte 6. Superhelden zwischen Comic und Film. Edition text+kritik 2007/4.

Fuchs, Wolfgang J.; Reitberger, Reinhold C.: Comics. Anatomie eines Massenmediums. Gekürzte Ausgabe. Reinbek b. Hamburg: Rowohlt I973 (I97I).

Funk, Julika: Die schillernde Schönheit der Maskerade - Einleitende Überlegungen zu einer Debatte. In: Bettinger, Elfi; Funk Julika (Hg.): Maskeraden: Geschlechterdifferenz in der literarischen Inszenierung. Berlin: Schmidt I995, I 5-28.

Gavaler, Chris: On the Origin of Superheroes. From the Big Bang to Action Comics No. I. Iowa City: University of Iowa Press 2015.

Gergen, Kenneth J.: The Healthy, Happy Human Being Wears Many Masks. In: Psychology Today. Mai i 972, 3 I-34, 64, 66.

Gerigk, Horst-Jürgen: Die Maske des Zorro und was damit zusammenhängt. In: Harress, Birgit; Herlth, Jens; Lauhus, Angelika (Hg.): Die Lust an der Maske. Festschrift für Bodo Zelinsky. Frankfurt a. M. et al.: Peter Lang 2007 (Heidelberger Publikationen zur Slavistik B, Literaturwissenschaftliche Reihe 32), 199-203.

Gibson, Walter B.: Introduction. In: Ders.: The Shadow: A Quarter of Eight and The Freak Show Murders. Garden City: Doubleday I978, xi-xv. 
Gibson, Walter [B.]: Introduction. In: Ders.: The Shadow. Crime Over Casco and The Mother Goose Murders. Garden City: Doubleday 1979, ix-xiii.

Gleason, Philip: Identifying Identity: A Semantic History. In: The Journal of American History 69:4 (März I983), 9I0-93 I. URL: http://www.jstor.org/stable/I 90 I I 96, Abruf: 30. 9. 2018.

Goffman, Erving: Stigma. Notes on the Management of Spoiled Identity. EnglewoodCliffs: Prentice-Hall 1963.

Goffman, Erving: Stigma. Über Techniken der Bewältigung beschädigter Identität. Frankfurt a- M.: Suhrkamp i975 (1967) (Suhrkamp Taschenbuch Wissenschaft I40). [Engl. EA i 963.]

Goffman, Erving: The Presentation of Self in Everyday Life. New York: Anchor 1990 (1959).

Goffman, Erving: Wir alle spielen Theater. Die Selbstdarstellung im Alltag. München, Zürich: Piper 2002 (1969). [Engl. EA 1959.]

Goldberg, Chad Alan: Robert Park's Marginal Man. The Career of a Concept in American Sociology. In: Laboratorium - Russian Review of Social Research 2 (20I2). URL: http://www.soclabo.org/index.php/laboratorium/article/view/4/I i 9, Abruf I 8. I 2. 2017.

Goodstone, Tony: The Pulps. Fifty Years of American Pop Culture. Compiled and edited by Tony Goodstone. New York: Chelsea House I970.

Goulart, Ron: Cheap Thrills. An Informal History of the Pulp Magazines. New Rochelle (N. Y.): Arlington House 1972.

Goulart, Ron: The Dime Detectives: New York, London, Tokio: The Mysterious Press I988.

Grams, Martin, Jr.; Salomonson, Terry: The Green Hornet. A History of Radio, Motion Pictures, Comics, and Television. Churchville: OTR 2010.

Granberg, Ellen: «Is That All There Is?» Possible Selves, Self-Change, and Weight Loss. In: Social Psychology Quarterly 69:2 (2006), I09-I 26.

Grue, Jan: The Social Meaning of Disability: A Reflection on Categorisation, Stigma, and Identity. In: Sociology of Health \& Illness 38:6 (2016), 957-964. DOI IO.I I I I/I 467-9566.I 24 I 7 .

Grünewald, Dietrich: Fluss und Bäche. «Zeit» in der Bildergeschichte. In: Bachmann, Christian A.; Sina, Véronique; Banhold, Lars (Hg.): Comics intermedial. Beiträge zu einem interdisziplinären Forschungsfeld. Essen: Bachmann 20 2, 23-53.

Gunning, Tom: From the Kaleidoscope to the X-Ray: Urban Spectatorship, Poe, Benjamin, and Traffic in Souls (1913). In: Wide Angle 19:4 (1997), 25-61. DOI: 10.1353/ wan.1997.0019.

Günthart, Romy: The Batman and How He Came To Be. In: Michel, Paul (Hg.): Spinnenfuss und Krötenbauch. Genese und Symbolik von Kompositwesen. Zürich: Pano 20I 3 (Schriften zur Symbolforschung I6), 429-443.

Hagen, Carrie: The Bat Men Before Batman. In: The Atlantic, 4. Juni 20I4. URL: https://www.theatlantic.com/entertainment/archive/2014/06/the-original-batman/372100, Abruf 23. I0. 2016.

Harrison, Kelby: Sexual Deceit. The Ethics of Passing. Lanham et al.: Lexington 2013. 
Harter, Susan: Chapter I. Historical Roots of Contemporary Issues Involving Self-Concept. In: Bracken, Bruce A. (Hg.): Handbook of Self-Concept. Developmental, Social, and Clinical Considerations. New York u. a.: Wiley \& Sons 1996, I-37.

Harter, Susan: The Personal Self in Social Context. Barriers to Authenticity. In: Ashmore, Richard D.; Jussim, Lee (Hg.): Self and Identity. Fundamental Issues. New York: Oxford UP 1997 (Rutgers Series on Self and Social Identities I), 8I-I05.

Harvey, Robert C.: The Art of the Comic Book. An Aesthetic History. Jackson: UP of Mississippi 1996.

Helvie, Forrest C.: The Loss of the Father: Trauma Theory and the Birth of Spider-Man. In: Peaslee, Robert Moses; Weiner, Robert G. (Hg.): Web-Spinning Heroics. Critical Essays on the History and Meaning of Spider-Man. Jefferson, London: McFarland 20I2, I46-I 53 .

Henrich, Dieter: «Identität» - Begriffe, Probleme, Grenzen. In: Marquard, Odo; Stierle, Karlheinz (Hg.): Identität. München: Fink 1979 (Poetik und Hermeneutik 8), I33-I 86.

Hettlage, Robert: Masken der Kommunikation. Goffmans Hermeneutik des Selbst zwischen Nähe und Distanz. In: Schäfer, Alfred; Wimmer, Michael (Hg.): Masken und Maskierungen. Opladen: Leske und Budrich 2000 (Grenzüberschreitungen 3), I6I-I 86.

Hillmann, Karl-Heinz: Wörterbuch der Soziologie. 5., vollst. überarb. u. erw. Aufl. Stuttgart: Kröner 2007.

Holzmann, Gabriela: Schaulust und Verbrechen. Eine Geschichte des Krimis als Mediengeschichte. Stuttgart: Metzler $200 \mathrm{I}$.

Holzmann, Gabriela: Von Morden und Medien. Wie neue Medien ein altes Genre immer wieder neu erfinden. In: Vogt, Jochen (Hg.): MedienMorde. Krimis intermedial. München: Wilhelm Fink 2005, I 3-32.

Hoppeler, Stefanie; Rippl, Gabriele: Continuity, Fandom und Serialität in anglo-amerikanischen Comic Books. In: Kelleter, Frank (Hg.): Populäre Serialität: Narration Evolution - Distinktion. Zum seriellen Erzählen seit dem i9. Jahrhundert. Bielefeld: Transcript 201 2, 367-379.

Hoppenstand, Gary: Pulp Vigilante Heroes, the Moral Majority and the Apocalypse. In: Browne, Ray B.; Fishwick, Marshall W. (Hg.): The Hero in Transition. Bowling Green: Bowling Green University Popular Press I983, I4 I-I 50.

Hoyle, Rick H.; Sherrill, Michelle R.: Future Orientation in the Self-System: Possible Selves, Self-Regulation, and Behavior. In: Journal of Personality 74:6 (Dezember 2006), I673-I696. DOI: I0. I I I /j. I 467-6494.2006.00424.x.

Hügel, Hans-Otto: Einführung./Abenteurer. In: Ders. (Hg.): Handbuch Populäre Kultur. Begriffe, Theorien und Diskussionen. Stuttgart, Weimar: Metzler 2003, I-22, 9I-98.

Inchausti, Robert: The Superhero's Two Worlds. In: Browne, Ray B.; Fishwick, Marshall W. (Hg.): The Hero in Transition. Bowling Green: Bowling Green University Popular Press $1983,66-73$.

Irving, Christopher: The Blue Beetle Companion. His Many Lives from 1939 to Today. Raleigh: TwoMorrows Publishing 2007.

Jenkins, Henry: Convergence Culture. Where Old and New Media Collide. New York, London: New York UP 2006a. 
Jenkins, Henry: Comics and Convergence Part I. 17. 8. 2006b. In: Confessions of an ACA-Fan. The Official Weblog of Henry Jenkins. URL: http://henryjenkins.org/ blog/2006/08/comics_and_convergence.html, Abruf 30. 8. 2018.

Jenkins, Henry: Comics and Convergence Part 2. 22. 8. 2006c. In: Confessions of an ACA-Fan. The Official Weblog of Henry Jenkins. URL: http://henryjenkins.org/ blog/2006/08/comics_and_convergence.html, Abruf 30. 8. 20 I 8.

Jenkins, Henry: «Just Men in Tights»: Rewriting Silver Age Comics in an Era of Multiplicity. In: Ndalianis, Angela (Hg.): The Contemporary Comic Book Superhero. New York, Abingdon: Routledge 2009, I6-43.

Johnson, Tom et al.: The Phantom Detective Companion. Boston: Altus Press 2009. Johnson, Tom: Introduction. In: Daniels, Norman A.: The Black Bat Omnibus I. Boston: Altus Press 2010, I-III.

Jörissen, Benjamin: George Herbert Mead: Geist, Identität und Gesellschaft aus der Perspektive des Sozialbehaviorismus. In: Ders.; Zirfas, Jörg (Hg.): Schlüsselwerke der Identitätsforschung. Wiesbaden: VS Verlag für Sozialwissenschaften 2010, 87-108.

Jung, Carl Gustav: Bewusstsein, Unbewusstes und Individuation. In: Gesammelte Werke. Bd. 9/r. Olten, Freiburg i. Br.: Walter i 989a (I976), 291-307. [EA I 934/I 950.]

Jung, Carl Gustav: Über die Archetypen des kollektiven Unbewussten. In: Gesammelte Werke. Bd. 9/I. Olten, Freiburg i. Br.: Walter I989b (I976), I I-5 I. [EA I935/1954].

Jung, Carl Gustav: Über Wiedergeburt. In: Gesammelte Werke. Bd. 9/ı. Olten, Freiburg i. Br.: Walter I989c (1976), I 27-I6r. [EA I940/1950].

Jung, Carl Gustav: Zur Psychologie der Trickster-Figur. In: Gesammelte Werke. Bd. 9/ı. Olten, Freiburg i. Br.: Walter I989d (1976), 27I-290. [EA I954.]

Kahan, Jeffrey; Stewart, Stanley: Caped Crusaders ıо . Composition Through Comic Books. Jefferson, London: McFarland 2010.

Kant, Immanuel: Anthropologie in pragmatischer Hinsicht. In: Ders.: Der Streit der Fakultäten. I798. URL: https://korpora.zim.uni-duisburg-essen.de/kant/aao7/Inhalt7. html, Abruf 30. 5. 2017.

Karrer, Wolfgang: Pulp Magazines: Zu ihrer Geschichte, Struktur und Funktion. In: Diller, Hans-Jürgen et al. (Hg.): American Popular Culture. Heidelberg: Winter I985 (Anglistik \& Englischunterricht 25), 8 I-96.

Kaufmann, Jean-Claude: Die Erfindung des Ich. Eine Theorie der Identität. Konstanz: UVK 2005 (2004).

Kawa, Abraham: Comics Since the Silver Age. In: Bould, Mark; Butler, Andrew M.; Roberts Adam; Vint, Sherryl (Hg.): The Routledge Companion to Science Fiction. London, New York: Routledge 2009, I63-173.

Kelleter, Frank; Stein, Daniel: Autorisierungspraktiken seriellen Erzählens. Zur Gattungsentwicklung von Superheldencomics. In: Kelleter, Frank (Hg.): Populäre Serialität: Narration - Evolution - Distinktion. Zum seriellen Erzählen seit dem I9. Jahrhundert. Bielefeld: Transcript 201 2, 259-290.

Keupp, Heiner: Identität. In: Grubitzsch, Siegfried; Weber, Klaus (Hg.): Psychologische Grundbegriffe. Ein Handbuch. Reinbek bei Hamburg: Rowohlt I 998, 239-245.

Kim, Tae-Won: G. Simmel, G. H. Mead und der Symbolische Interaktionismus: Geistesgeschichtliche Zusammenhänge, soziologische Semantik. Diss. Würzburg: Ergon I 999. 
Klein, Alan M.: Comic-Book Masculinity and Cultural Fiction. In: Ders.: Little Big Men. Bodybuilding Subculture and Gender Construction. Albany: State University of New York Press I993, 234-280.

Kleine, Inge: Der Mann, die Frau, ihre Maske und seine Wahrheit: Zur Maske bei JeanJacques Rousseau. In: Bettinger, Elfi; Funk Julika (Hg.): Maskeraden: Geschlechterdifferenz in der literarischen Inszenierung. Berlin: Schmidt I995, I 54-I68.

Kniep, Matthias: Einmal lebt' ich, wie Götter. Die «Zeitalter» des Superhelden-Comics und ihre Heldenkonzeptionen. In: Krah, Hans (Hg.): All-Gemeinwissen. Kulturelle Kommunikation in populären Medien. Kiel: Ludwig 200I (Literatur- und medienwissenschaftliche Studien - Kiel 2), I38-168.

Kniep, Matthias: Die drei «Zeitalter» des Superhelden-Comics (Gold, Silber und Bronze). Von der Geburt, Demontage und Wiederbelebung eines amerikanischen Mythos. Diss. Kiel: Ludwig 2009 (Geist \& Wissen 6).

Knigge, Andreas C.: Alles über Comics. Eine Entdeckungsreise von den Höhlenbildern bis zum Manga. Hamburg: Europa 2004.

Krappmann, Lothar: Neuere Rollenkonzepte als Erklärungsmöglichkeit für Sozialisationsprozesse. In: Auwärter, Manfred; Kirsch, Edit; Schröter, Klaus (Hg.): Seminar: Kommunikation, Interaktion, Identität. Frankfurt a. M.: Suhrkamp I976 (Suhrkamp Taschenbuch Wissenschaft I 56), 307-33 I. [EA I97I.]

Krueger, Rex: Abstraction, Trauma, and the Orphan in Brian Michael Bendis and David Mack's Daredevil: Wake up. In: ImageText. Interdisciplinary Comic Studies 4:2 (2008), I-I 8. URL: http://www.english.ufl.edu/imagetext/archives/v4_2/krueger/, Abruf 3. 8. 2018.

Kukkonen, Karin: Neue Perspektiven auf die Superhelden. Polyphonie in Alan Moores «Watchmen». Marburg: Tectum 2008.

Lai, Rick: Chronology of Shadows. A Timeline of The Shadow's Exploit. Revised Edition. Boston: Altus Press 2007 (I995).

Lee, Peter: Have Great Power, Greatly Irresponsible: Intergenerational Conflict in I960's Amazing Spider-Man. In: Peaslee, Robert Moses; Weiner, Robert G. (Hg.): Web-Spinning Heroics. Critical Essays in the History and Meaning of Spider-Man. Jefferson (North Carolina), London: McFarland 201 2, 29-39.

Lehmann, Albrecht: Leitlinien des lebensgeschichtlichen Erzählens. In: Brednich, Rolf Wilhelm et al. (Hg.): Lebenslauf und Lebenszusammenhang. Autobiographische Materialien in der volkskundlichen Forschung. Freiburg i. Br. I982, 7 I-87.

Lejeune, Philippe. Der autobiographische Pakt. Frankfurt: Suhrkamp i 994 (Edition Suhrkamp Neue Folge Bd. 896). [Frz. EA 1975.]

Lie, Nadia: Free Trade in Images? Zorro as Cultural Signifier in the Contemporary Global/Local System. In: Nepantla: Views from the South 2:3 (200I), 489-508. Project MUSE, URL: muse.jhu.edu/article/23930.

Lieblich, Amia; Josselson, Ruthellen: Identity and Narrative as Root Metaphors of Personhood. In: Martin, Jack; Bickhard, Mark H. (Hg.): The Psychology of Personhood. Philosophical, Historical, Social-Developmental and Narrative Perspectives. Cambridge et al.: Cambridge UP 2013, 203-222.

Liebsch, Katharina: Identität und Habitus. In: Korte, Hermann; Schäfers, Bernhard (Hg.): Einführung in die Hauptbegriffe der Soziologie. 7., grundleg. überarb. Ausg. Wiesbaden: VS Verlag für Sozialwissenschaften 2008, 69-86. 
Lifton, Robert Jay: The Protean Self. Human Resilience in an Age of Fragmentation. New York: BasicBooks i993.

Lindner, Christoph: Imagining New York City: Literature, Urbanism, and the Visual Arts, I 890-1940 (Teil I: Skylines). Oxford: 2015. DOI: 10.1093/acprof: oso/9780195375 I 45.001 .0001 .

Linton, Ralph: The Study of Man. An Introduction. Student's Edition. O. O.: AppletonCentury-Crofts 1964 (1936) (The Century Social Science Series).

Lucius-Hoene, Gabriele; Deppermann, Arnulf: Narrative Identität und Positionierung. In: Gesprächsforschung - Online-Zeitschrift zur verbalen Interaktion 5 (2004), I66-I 83. URL: http://www.gespraechsforschung-online.de/heft2004/heft 2004 .html, Abruf I0. Iо. 2018.

Ludwig, Heinz: Zur Handlungsstruktur von Comics und Märchen. In: Fabula I9:3 (1978), 262-286.

Lund, Martin: Re-Constructiong The Man of Steel. Superman I938-r94I, Jewish American History, and the Invention of the Jewish-Comics Connection. Cham: Palgrave Macmillan 2016 (Contemporary Religion and Popular Culture).

Mackie, C. J.: Men of Darkness. In: Haslem, Wendy; Ndalianis, Angela; Mackie, Chris (Hg.): Super/Heroes. From Hercules to Superman. Washington: New Academia Publishing 2007, 83-96.

Mahler, Andreas: Maske und Erkenntnis - Funktionen karnevalesker Identität bei Shakespeare. In: Bettinger, Elf; Funk Julika (Hg.): Maskeraden: Geschlechterdifferenz in der literarischen Inszenierung. Berlin: Schmidt I995, I I7-I 34 .

Markus, Hazel; Nurius, Paula: Possible Selves. In: American Psychologist, 9. 1986, $954-$ 969. DOI: 10.1037/0003-066X.41.9.954.

Marotta, Vince P.: Civilisation, Culture and the Hybrid Self in the Work of Robert Ezra Park. In: Journal of Intercultural Studies 27:4 (2006), 4I3-433. DOI: I0.1080/072568606009369I I.

Marotta, Vince P.: The hybrid self and the ambivalence of boundaries. In: Social Identities I4:3 (Mai 2008), 295-3I 2. DOI: I0.1080/I 3504630802088052.

Mayer, Ruth: Die Logik der Serie. Fu Manchu, Fantômas und die serielle Produktion ideologischen Wissens. In: Pop. Kultur \& Kritik I (Herbst 201 2), I $36-$ I 54.

McAdams, Dan P.: Personality, Modernity, and the Storied Self: A Contemporary Framework for Studying Persons. In: Psychological Inquiry 7:4 (I996), 295-32 I. URL: http://www.jstor.org/stable/I4488I3, Abruf I 5. I०. 20 I 8.

McAdams, Dan: The Case for Unity in the (Post)Modern Self. A Modest Proposal. In: Ashmore, Richard D.; Jussim, Lee (Hg.): Self and Identity. Fundamental Issues. New York: Oxford UP I 997 (Rutgers Series on Self and Social Identities I), 46-77.

McCloud, Scott: Understanding Comics. New York: Kitchen Sink (Harper Perennial) I994 (I993).

McCue, Greg; Bloom, Clive: Dark Knights. The New Comics in Context. London, Boulder (Colorado): Pluto Press I 993.

McWilliams, Ora C.: The Incorrigible Aunt May. In: Peaslee, Robert Moses; Weiner, Robert G. (Hg.): Web-Spinning Heroics. Critical Essays in the History and Meaning of Spider-Man. Jefferson (North Carolina), London: McFarland 201 2, I 87-I 94.

Mead, George Herbert: Geist, Identität und Gesellschaft. Mit einer Einleitung hg. v. Charles W. Morris. Frankfurt am Main: Suhrkamp i973. [Engl. EA 1934.] 
Medhurst, Anthony: Batman, Deviance and Camp. In: Hatfield, Charles; Heer, Jeet; Worcester, Kent (Hg.): The Superhero Reader. Jackson: UP of Mississippi 201 3, 23725 I. [EA: Pearson, Roberta; Uricchio, William (Hg.): The Many Lives of Batman, I99I, I49-I63.]

Meier, Stefan: Superman transmedial. Eine Pop-Ikone im Spannungsfeld von Medienwandel und Serialität. Bielefeld: Transcript 2015.

Meißner, Jill: Rezept für einen Superhelden. In: dérive. Zeitschrift für Stadtforschung 35, April-Juni 2009, 7-II.

Meteling, Arno: To be continued ... Zum seriellen Erzählen im Superhelden-Comic. In: Brunken, Otto; Giesa, Felix (Hg.): Erzählen im Comic. Beiträge zur Comicforschung. Essen: Bachmann 2013, 89-I I 2.

Meyer, Michaela D. E.: Utilizing Mythic Criticism in Contemporary Narrative Culture: Examining the «Present-Absence» of Shadow Archetypes in Spider-Man. In: Communication Quarterly 51:4 (2003), 5 I8-529. DOI: I0.1080/0I46337030927017I.

Meyer, Roland: Im leeren Zentrum der Netze. Ein Versuch über Superschurken und kriminelle Genies. In: (Super) Kritische Berichte. Zeitschrift für Kunst- und Kulturwissenschaften I (20I I, 39. Jg.): Superhelden. Zur Ästhetisierung und Politisierung menschlicher Ausserordentlichkeit, I35-I 22.

Mezger, Werner: Masken an Fastnacht, Fasching und Karneval. Zur Geschichte und Funktion von Vermummung und Verkleidung während der närrischen Tage. In: Schäfer, Alfred; Wimmer, Michael (Hg.): Masken und Maskierungen. Opladen: Leske und Budrich 2000 (Grenzüberschreitungen 3), г09-1 36.

Mischel, W.; Mendoza-Denton, R.: Personality Theories. In: International Encyclopedia of the Social \& Behavioral Sciences. Hg. v. Neil J. Smelser and Paul B. Baltes. O. O.: Pergamon/Elsevier 200I, I I 320-I I 326. URL: https://doi.org/I0. I016/Bo-o8-0430767/01647-8, Abruf iо. 10. 2018.

Montandon, Alain: Zur Galanterie im Frankreich des 17. Jahrhunderts. In: Florack, Ruth; Singer, Rüdiger (Hg.): Die Kunst der Galanterie. Facetten eines Verhaltensmodells in der Literatur der Frühen Neuzeit. Berlin, Boston: de Gruyter 20 I 2, I9-48.

Moraldo, Sandro M.: Wandlungen des Doppelgängers. Shakespeare - E. T. A. Hoffmann - Pirandello. Von der Zwillingskomödie (Comedy of Errors) zur Identitätsgefährdung (Prinzession Brambilla, Il fu Mattia Pascal). Diss. Frankfurt a. M. et al.: Lang I 996.

Morris, Tom: What's Behind the Mask? The Secret of Secret Identities. In: Ders.; Morris, Matt (Hg.): Superheroes and Philosophy. Truth, Justice, and the Socratic Way. Chicago, LaSalle: Open Court 2008 (2005) (Popular Culture and Philosophy I 3), 250-265.

Müller, Eggo: Genre. In: Hügel, Hans-Otto (Hg.): Handbuch Populäre Kultur. Begriffe, Theorien und Diskussionen. Stuttgart, Weimar: Metzler 2003, 2 I 2-2 I 5 .

Murray, Chris: Popaganda: Superhero Comics and Propaganda in World War Two. In: Magnussen, Anne; Christiansen, Hans-Christian (Hg.): Comics \& Culture. Analytical and Theoretical Approaches to Comics. Kopenhagen: Museum Tusculanum Press 2000, I4I-I 55 .

Murray, Will: Man of Magic and Mystery. In: Gibson, Walter B. (writing as Maxwell Grant): The Shadow i 8. Two Classic Adventures of the Shadow. «The Golden Masks» and «The Unseen Killer». Encinitas: Nostalgia Ventures, I I. 2006, I 28. 
Murray, Will: The Shadowy Origins of Batman. In: Gibson, Walter B.; Tinsley, Theodore: The Shadow 9. Two Classic Adventures of The Shadow. «Lingo» and «Partners of Peril». Encinitas: Nostalgia Ventures, 7. 2007, 70-7I.

Murray, Will: Introduction. / Afterword: The Strange Saga of the Skull. In: FlemingRoberts, G. T. (d. i. George Thomas Roberts): The Pulp Adventures of the Hooded Detective. Boston, Altus Press 2008a, i-iii/2 17-228.

Murray, Will: Out of the Shadows. / Writing The Shadow. In: Gibson, Walter B. (writing as Maxwell Grant): The Shadow i s. Two Classic Adventures of The Shadow. «The Shadow Unmasks» and «The Yellow Band». Encinitas: Nostalgia Ventures, 2. 2008b, $6 \mathrm{I}-63$ / I 26-I 28.

Murray, Will: Pulp Superhero Index. Introduction. 2009. URL: http://www.altuspress. com/the-ultimate-pulp-superhero-index/, Abruf 5. I0. 2018.

Naficy, Siamak Tundra: Coming to Terms with Bizarro. In: Rosenberg, Robin S.; Canzoneri, Jennifer (Hg.): The Psychology of Superheroes. An Unauthorized Exploration. Dallas: BenBella 2008, I75-186.

Nagl, Manfred: Zukunft. In: Hügel, Hans-Otto (Hg.): Handbuch Populäre Kulturen. Begriffe, Theorien und Diskussionen. Stuttgart, Weimar: Metzler 2003, 530-539.

Napier, A. David: Masks, Transformation, and Paradox. Berkeley, Los Angeles, London: University of California Press 1986.

Nedelmann, Birgitta: Geheimhaltung, Verheimlichung, Geheimnis - einige soziologische Vorüberlegungen. In: Kippenberg, Hans G.; Stroumsa, Guy G. (Hg.): Secrecy \& Concealment. Studies in the History of Mediterranean \& Near Eastern Religions. Leiden, New York, Köln: Brill i995, I-I6.

Nehrlich, Thomas: Wenn Identität mittels einer Maske sichtbar wird. Zu Geschichte, Wesen und Ästhetik von Superhelden. In: Immerk, Nikolas; van Marwyck, Mareen (Hg.): Ästhetischer Heroismus. Konzeptionelle und figurative Paradigmen des Helden. Bielefeld: Transcript 2013, I07-I 28.

Nicholls, Peter: Pulp Magazines. In: Encyclopedia of Science Fiction. Hg. v. John Clute und Peter Nicholls. London: Orbit 1999, 978-980.

Nowotny, Joanna: The Human Shell: The Iron Man Armour as an Agent of Heroism. In: helden. heroes. héros. 4: I (2016), 65-78. DOI: 10.6094/helden.heroes. heros./2016/0I/07.

Nunner-Winkler, Gertrud: Personal Identity: Philosophical Aspects. In: International Encyclopedia of the Social \& Behavioral Sciences. 2. Aufl. Hg. v. James D. Wright. O. O.: Elsevier 201 5, I I 247-I I 250. URL: https://doi.org/I0.1016/B978-0-08-0970868.63057-X, Abruf 25. 10. 2018.

Nyberg, Amy Kiste: Seal of Approval. The History of the Comics Code. Jackson: UP of Mississippi 1998 (Studies in Popular Culture).

O’Connell, Shaun: Remarkable, Unspeakable New York. A Literary History. Boston: Beacon i995.

O’Neil, Denny: Introduction. In: Miller, Frank; Mazzuchelli, David et al.: Batman: Year One. New York: DC Comics 2005 (1988), unpag.

Olschanski, Reinhard: Maske und Person. Zur Wirklichkeit des Darstellens und Verhüllens. Göttingen: Vandenhoeck und Ruprecht $200 \mathrm{I}$. 
Oropeza, B. J.: Introduction: Superhero Myth and the Restoration of Paradise. In: Ders. (Hg.): The Gospel According to Superheroes: Religion and Popular Culture. New York: Lang 2005a, I-24.

Oropeza, B. J.: «Behold! The Hero Has Become Like One of Us.» The Perfectly Imperfect Spider-Man. In: Ders. (Hg.): The Gospel According to Superheroes: Religion and Popular Culture. New York: Lang 2005b, I 27-I44.

Packer, Sharon: Superheroes and Superegos. Analyzing the Minds Behind the Masks. Santa Barbara, Denver, Oxford: Praeger (ABC-Clio) 2010.

Park, Robert Ezra: Behind Our Masks. In: Ders.: Race and Culture. Glencoe: The Free Press 1950 (The Collected Papers of Robert Ezra Park I), 244-255. [EA 1926.]

Park, Robert Ezra: Human Migration and the Marginal Man. In: Ders.: Race and Culture. Glencoe: The Free Press i950 (The Collected Papers of Robert Ezra Park I), 345-356. [EA 1928.]

Park, Robert Ezra: Personality and Cultural Conflict. In: Ders.: Race and Culture. Glencoe: The Free Press I950 (The Collected Papers of Robert Ezra Park I), 35737I. [EA 1930.]

Park, Robert Ezra: Cultural Conflict and the Marginal Man. In: Ders.: Race and Culture. Glencoe: The Free Press 1950 (The Collected Papers of Robert Ezra Park I), 372-376. [EA I937.]

Peltz, Rachael: Learning from History: An Interview with Robert Jay Lifton. In: Psychoanalytic Dialogues i 8:5 (2008), 710-734. DOI: I0.1080/1048 I 8808022977 I 5.

Pepetone, Gregory: Pulp Heroes in the Shadow of God. In: Oropeza, B. J. (Hg.): The Gospel According to Superheroes: Religion and Popular Culture. New York: Lang 2005, $215-227$.

Petrie, Edward «Josh»: Prowling in Poulaines - An Introduction. In: The Owl. The Frank Thomas Archives. Bd. 3: The Dell Years. Hg. v. Chris Beneke, Yocitrus. O. O.: DCM Archives and Collections 20I8, 7-I I. URL: http://digitalcomicmuseum.com/ index.php?dlid=29480, Abruf: 30. I0. 2018).

Pitkethly, Clare: The Pursuit of Identity in the Face of Paradox: Indeterminacy, Structure and Repetition in Superman, Batman and Wonder Woman. In: Journal of Graphic Novels and Comics 3:2 (20I 2), 2 I 5-22 I. URL: http://dx.doi.org/I0.1080/2 I 5048 57.201 I.5599847, Abruf I 5. 5. 2016.

Platt, G. M.: Status and Role, Social Psychology of. In: International Encyclopedia of the Social \& Behavioral Sciences. Hg. v. Neil J. Smelser and Paul B. Baltes. O. O.: Pergamon/Elsevier 200I, I 5090-I 5095. ScienceDirect, URL: https://doi.org/I0.1016/ Bo-08-043076-7/01973-2, Abruf 25. 10. 2018.

Plessner, Helmuth: Soziale Rolle und menschliche Natur. In Ders.: Diesseits der Utopie. Ausgewählte Texte zur Kultursoziologie. Düsseldorf, Köln: Diederichs I966, 23-35. [EA i 960.]

Plessner, Helmuth: Zur Anthropologie des Schauspielers. In: Helmuth Plessner. Gesammelte Schriften. Bd. VII: Ausdruck und menschliche Natur. Hg. v. Dux, Günter; Marquard, Odo; Ströker, Elisabeth. Frankfurt a. M.: Suhrkamp 1982, 399-4 I8. [EA I948.]

Quinlan, Shannon L.; Jaccard, James; Blanton, Hart: A Decision Theoretic and Prototype Conceptualization of Possible Selves: Implications for the Prediction of Risk 
Behavior. In: Journal of Personality 74:2 (April 2006), 599-630. DOI: I0.I I I I/j.I 4676494.2006.00386.x.

Reid, Anne; Deaux, Kay: Relationship Between Social and Personal Identities: Segregation or Integration? In: Journal of Personality and Social Psychology 7 I:6 (I 996), I084-I091. DOI: 10.1037/0022-3514.71.6.1084.

Reynolds, Richard: Super Heroes. A Modern Mythology. Jackson: UP of Mississippi I994 (I992).

Rhoades, Shirrel: A Complete History of American Comic Books. New York et al.: Lang 2008.

Rosenberg, Robin S.: Superman's Personality. In: Dies.; Canzoneri, Jennifer (Hg.): The Psychology of Superheroes. An Unauthorized Exploration. Dallas: BenBella 2008, 29-49.

Roth, Klaus: Rolle. In: Enzyklopädie des Märchens. Handwörterbuch zur historischen und vergleichenden Erzählforschung. Hg. v. Rolf Wilhelm Brednich. Bd. I I. Berlin, New York: de Gruyter 2004, Sp. 778-780.

Sampson, Robert: Yesterday's Faces. A Study of Series Characters in the Early Pulp Magazines. Bd. I: Glory Figures. Bowling Green (Ohio): Bowling Green University Popular Press 1983.

Sampson Robert: Yesterday's Faces. A Study of Series Characters in the Early Pulp Magazines. Bd. 3: From The Dark Side. Bowling Green (Ohio): Bowling Green State University 1987.

Sampson, Robert: Deadly Excitements. Shadows and Phantoms. Bowling Green (Ohio): Bowling Green State University Popular Press 1989.

Sampson, Robert: Yesterday's Faces. A Study of Series Characters in the Early Pulp Magazines. Bd. 6: Violent Lives. Bowling Green (Ohio): Bowling Green University Popular Press i 993.

Scheibe, Karl E.: Historical Perspectives on the Presented Self. In: Schlenker, Barry R. (Hg.): The Self and Social Life. New York et al.: McGraw-Hill i 985, 33-64.

Schenck, Ken: Superman: A Popular Culture Messiah. In: Oropeza, B. J. (Hg.): The Gospel According to Superheroes: Religion and Popular Culture. New York: Lang $2005,33-48$.

Schikowski, Klaus: Der Comic. Geschichte, Stile, Künstler. Stuttgart: Reclam 20 I4.

Schirrmeister, Claudia: Geheimnisse. Über die Ambivalenz von Wissen und Nicht-Wissen. Wiesbaden: Deutscher Universitätsverlag 2004.

Schrader, W. H.; Schönpflug, U. et al.: Selbst. In: Historisches Wörterbuch der Philosophie. Hg. v. Joachim Ritter und Karlfried Gründer. Bd. 9. Darmstadt: Wissenschaftliche Buchgesellschaft 1995, 292-3 I3.

Schulte, Bill: The Man Without Fear, a Time of Fear: A Review of Countercultural Themes in the First roo Issues of Daredevil. In: IJOCA I 4: I, Frühling 201 2, 339-359.

Schüwer, Martin: Erzählen in Comics: Bausteine einer plurimedialen Erzähltheorie. In: Nünning, Ansgar; Nünning, Vera (Hg.): Erzähltheorie transgenerisch, intermedial, interdisziplinär. Trier: Wissenschaftlicher Verlag Trier 2002, I 8 5-2 I6.

Schüwer, Martin: Wie Comics erzählen. Grundriss einer intermedialen Erzähltheorie der grafischen Literatur. Diss. Trier: Wissenschaftlicher Verlag Trier 2008 (Handbücher und Studien zur Medienkulturwissenschaft I). 
Schweizer, Reinhard: Ideologie und Propaganda in den Marvel-Superhelden-Comics. Vom Kalten Krieg zur Entspannungspolitik. Diss. Frankfurt a. M., Bern, New York, Paris: Lang 1992 (Neue Studien zur Anglistik und Amerikanistik 54).

Seesslen, Georg: En garde! Der Mantel \& Degen-Film [sic]. In: (Ders.): Abenteuer. Geschichte und Mythologie des Abenteuerfilms. 3.; überarb. u. akt. Neuaufl. Marburg 1996 (Grundlagen des populären Films), I I 7-I 49.

Seidl, Claudius: Absolut unmöglich und zugleich sehr lebensecht. Warum wir SpiderMan so gern ins Netz gehen. In: Klassiker der Comic-Literatur i 5: Spider-Man. (Ausgewählt vom F.A.Z.-Feuilleton.) Frankfurt a. M.: FAZ/Panini 2005 , 3-I 2.

Seidman, Steven; Meeks, Chet; Traschen, Francie: Beyond the Closet? The Changing Social Meaning of Homosexuality in the United States. In: Sexualities 2:9 (1999), 9-32. DOI: $10.1177 / \mathrm{I} 36346099002001002$.

Server, Lee: Danger Is My Business. Illustrated History of the Fabulous Pulp Magazines, I 896-1953. San Francisco: Chronicle Books I993.

Sheldrick Ross, Catherine: Dime Novels and Series Books. In: Handbook of Research on Children's and Young Adult Literature. Hg. v. Wolf, Shelby A.; Coats, Karen; Enciso, Patricia; Jenkins, Christine A. New York, London: Routledge 20 I I, I $95-206$.

Siebers, Tobin: Disability Theory. Ann Arbor: University of Michigan 201 I (2008).

Sieck, Thomas: Der Zeitgeist der Superhelden. Das Gesellschaftsbild amerikanischer Superheldencomics von 1938 bis 1988. Meitingen: Corian-Verlag Heinrich Wimmer I999.

Sievers, Burkard: Geheimnis und Geheimhaltung in sozialen Systemen. Opladen: Westdeutscher Verlag 1974 .

Simmel, Georg: Das Geheimnis und die geheime Gesellschaft. In: Ders.: Soziologie. Untersuchungen über die Formen der Vergesellschaftung. Berlin: Duncker \& Humblot I908, 256-305. Georg Simmel Online, URL: http://socio.ch/sim/soziologie/index.htm, Abruf I 5. 8. 2018.

Sitz, Verena: Die Heldenfigur als Erzählstrategie im populären Spielfilm. Sind Comic-Superhelden «mythische» Erzählfiguren? Diss. Stuttgart: Ibidem 20 I 5.

Smith, Andrew A.: J. Jonah Jameson - Hero or Villain? Spider-Man's Nemesis Hard to Pigeonhole. In: Peaslee, Robert Moses; Weiner, Robert G. (Hg.): Web-Spinning Heroics. Critical Essays in the History and Meaning of Spider-Man. Jefferson (North Carolina), London: McFarland 20I 2a, IOI-I I 2.

Smith, Erin A.: Pulp Sensations. In: Glover, David; McCracken, Scott (Hg.): Cambridge Companion to Popular Fiction. Cambridge et al.: Cambridge UP 20 I 2 b, I 4 I-I 58.

Smith, Greg M.: The Superhero as Labor: The Corporate Identity. In: Ndalianis, Angela (Hg.): The Contemporary Comic Book Superhero. New York, Abingdon: Routledge 2009, I 26-I 43 .

Smith, Matthew J.: Die Tyrannei der Schmelztiegel-Metapher. Wonder Woman als amerikanisierte Immigrantin. In: Eder, Barbara; Klar, Elisabeth; Reichert, Ramón (Hg.): Theorien des Comics. Ein Reader. Bielefeld: Transcript 201 I, 263-28 I. [Engl. EA 200I.]

Söll, Änne; Weltzien, Friedrich: Spider-Mans Heldenmaske. Kampf um Männlichkeit im Superhelden-Genre. In: Stephan, Inge; Benthien, Claudia (Hg.): Männlichkeit als Maskerade. Kulturelle Inszenierungen vom Mittelalter bis zur Gegenwart. Köln: Böh- 
lau 2003 (Literatur - Kultur - Geschlecht, Kleine Reihe i 8), 297-3 I 5. [Auch in: Etter, Lukas; Nehrlich, Thomas; Nowotny, Joanna (Hg.): Reader Superhelden. Theorie Geschichte - Medien. Bielefeld: Transcript 20 I 8 (Edition Kulturwissenschaft I33), I $57-189$.

Spiegel, Simon: Die Konstitution des Wunderbaren. Zu einer Poetik des Science-FictionFilms. Marburg: Schüren 2007 (Zürcher Filmstudien I6).

Spitznagel, Albert: Einleitung. In: Ders. (Hg.): Geheimnis und Geheimhaltung: Erscheinungsformen - Funktionen - Konsequenzen. Göttingen, Bern, Toronto, Seattle: Hogrefe I998, I9-5I.

Stemmann, Anna: Der Held und sein Raum: Batmans Metamorphosen im Spiegel von Gotham City. In: Muth, Laura; Simonis, Annette (Hrsg.): Weltentwürfe des Fantastischen: Erzählen - Schreiben - Spielen. Essen: Bachmann 20I4, I48-I 57.

Stryker, Sheldon: Die Theorie des Symbolischen Interaktionismus. In: Auwärter, Manfred; Kirsch, Edit; Schröter, Klaus (Hg.): Seminar: Kommunikation, Interaktion, Identität. Frankfurt a. M.: Suhrkamp I 976 (Suhrkamp Taschenbuch Wissenschaft I 56), 257-274. [EA 1970.]

Stryker, Sheldon; Burke, Peter J.: The Past, Present and Future of an Identity Theory. In: Social Psychology Quarterly 63:4 (2000), 284-297. URL: https://www.jstor.org/ stable/2695840, Abruf i 5. I0. 2018.

Terrill, Robert E.: Put on a Happy Face. Batman as Schizophrenic Savior. In: Quarterly Journal of Speech 79:3 (1993), 3 19-335. URL: http://dx.doi. org/I0.1080/I 52950300093884I5, Abruf 23.9. 2017.

Thoits, Peggy A.; Virshup, Lauren K.: Me's and We's. Forms and Function of Social Identities. In: Ashmore, Richard D.; Jussim, Lee (Hg.): Self and Identity. Fundamental Issues. New York: Oxford UP I 997 (Rutgers Series on Self and Social Identities I), I06-I 33 .

Thomas, Ronald C.: Hero of the Military-Industrial Complex. Reading Iron Man through Burke's Dramatism. In: De Tora, Lisa (Hg.): Heroes of Film, Comics, and American Culture. Essays on Real and Fictional Defenders of the Home. Jefferson, London: McFarland 2009, I 52-I66.

Thurtle, Phillip; Mitchell, Robert: The Acme Novelty Library: Comic Books, Repetition, and the Return of the New. In: Configurations I 5:3 (Herbst 2007), 267-297. DOI: $10.1353 /$ con. 0.0038 .

Tollin, Anthony: Spotlight on The Shadow. Foreshadowing The Batman. In: Gibson, Walter B.; Tinsley, Theodore: The Shadow 9. Two Classic Adventures of The Shadow. «Lingo» and «Partners of Peril». Encinitas: Nostalgia Ventures, 7. 2007a, I $32-$ I33.

Tollin, Anthony: Spotlight on The Shadow. The Dark Master of Magic. In: Grant, Maxwell (d. i. Gibson, Walter B.): The Shadow I2. Two Classic Adventures of The Shadow. «The Magigals Mystery» and «Serpents of Siva». Encinitas: Nostalgia Ventures, I0. 2007 b, 57-59.

Tracy, Sarah J.; Trethewey, Angela: Fracturing the Real-Self $\leftrightarrow$ Fake-Self Dichotomy: Moving Toward «Crystallized» Organizational Discourses and Identities. In: Communication Theory I 5:2 (Mai 2005), I68-I95. URL: https://doi-org.ezproxy.uzh. ch/I0.I I I /j.I468-2885.2005.tbo033 I.x, Abruf i 8. I0. 20 I 8. 
Treat, Shaun; Grano, Daniel; Croghan, Jon: The Shadow Knows: The Counter-Fantasy of the American Antihero and Symbolic Divergence in Golden Age Radio. In: Journal of Radio \& Audio Media I6: I, Mai 2009, 30-49. DOI: I0.1080/I 9376520902847949 .

Tseëlon, Efrat: Is the Presented Self Sincere? Goffman, Impression Management and the Postmodern Self. In: Theory, Culture \& Society. Explorations in Critical Social Science 9:2 (Mai I992), i I 5-I 28.

Tseëlon, Efrat: Introduction: Masquerade and Identities. / Reflections on Mask and Carnival. In: Dies. (Hg.): Masquerade and Identities. Essays on Gender, Sexuality and Marginality. London, New York 200I, I-I7/I 8-37.

Turner, Ralph H.: Rollenübernahme: Prozess versus Konformität. In: Auwärter, Manfred; Kirsch, Edit; Schröter, Klaus (Hg.): Seminar: Kommunikation, Interaktion, Identität. Frankfurt a. M.: Suhrkamp I 976 (Suhrkamp Taschenbuch Wissenschaft I 56), I I 5-I 39. [EA I962.]

Uricchio, William: The Batman's Gotham City ${ }^{\mathrm{TM}}$ : Story, Ideology, Performance. In: Ahrens, Jörn; Meteling, Arno (Hg.): Comics and the City. Urban Space in Print, Picture and Sequence. New York, London: Continuum 2010, I I9-1 32.

Vance, James: A Job for Superman. In: Superman: The Dailies I939-I942 (Strips I-966). New York: Sterling [2006] (1998), 6-I I.

Veith, Hermann: Das Konzept der balancierenden Identität von Lothar Krappmann. In: Jörissen, Benjamin; Zirfas, Jörg (Hg.): Schlüsselwerke der Identitätsforschung. Wiesbaden: VS Verlag für Sozialwissenschaften 2010, I79-202.

von Engelhardt, Michael: Erving Goffman: Stigma. Über Techniken der Bewältigung beschädigter Identität. In: Jörissen, Benjamin; Zirfas, Jörg (Hg.): Schlüsselwerke der Identitätsforschung. Wiesbaden: VS Verlag für Sozialwissenschaften 2010, I $23-$ I 40.

von Holzen, Aleta-Amirée: «A Pirate’s Life for Me!» Von «The Black Pirate» bis «Pirates of the Caribbean» - Abenteuerkonzepte im Piratenfilm. Zürich: SSI 2007 (Populäre Literaturen und Medien I).

von Holzen, Aleta-Amirée: Der maskierte Held im Spannungsfeld von Maskerade und Identität. In: Tomkowiak, Ingrid (Hg.): Perspektiven der Kinder- und JugendmedienForschung. Zürich: Chronos 20I I (Beiträge zur Kinder- und Jugendmedienforschung I), 205-225.

von Holzen, Aleta-Amirée: Marvel-lous Masked Men. Doppelidentitäten in Superheldenfilmen. In: Schmeink, Lars; Müller, Hans-Harald (Hg.): Fremde Welten. Wege und Räume der Fantastik im 2 I. Jahrhundert. Berlin, Boston: de Gruyter 20 I 2a, I 87-202. [Auch in: Etter, Lukas; Nehrlich, Thomas; Nowotny, Joanna (Hg.): Reader Superhelden. Theorie - Geschichte - Medien. Bielefeld: Transcript 20 I 8 (Edition Kulturwissenschaft I33), I9I-204.]

von Holzen, Aleta-Amirée: «Danger in the Dark». Grossstadt-Räume in der Pulp-Novel-Reihe The Shadow. In: Schweizerisches Archiv für Volkskunde I08 (201 2b) 2, 243-252.

von Holzen, Aleta-Amirée: Schneller als das menschliche Auge. Zur Sichtbarmachung von Superspeed in Fotografie, Comic und Film. In: Tomkowiak, Ingrid; Frizzoni, Brigitte; Trummer, Manuel (Hg.): Action! Artefakt, Ereignis, Erlebnis. Würzburg: 
Königshausen \& Neumann 20 17a (Kulturen populärer Unterhaltung und Vergnügung 4), 43-60.

von Holzen, Aleta-Amirée: Von Helden und Masken. In: Tausendundein Buch 4/20 I 7 , I $5-16$.

von Matt, Peter: Die Intrige. Theorie und Praxis der Hinterlist. München, Wien: Hanser 2006.

Wagner, Peter: Fest-Stellungen. Beobachtungen zur sozialwissenschaftlichen Diskussion über Identität. In: Assmann, Aleida; Friese, Heidrun (Hg.): Identitäten. Frankfurt a. M.: Suhrkamp 1998 (Erinnerung, Geschichte, Identität 3), 44-72.

Wagner, Peter: Self, History of the Concept. In: International Encyclopedia of the Social \& Behavioral Sciences. Hg. v. Neil J. Smelser and Paul B. Baltes. O.O.: Pergamon/ Elsevier 200I, I3833-I3837. URL: https://doi.org/I0.1016/Bo-08-043076-7/00I46-7, Abruf 30. I0. 2018.

Wandtke, Terrence R.: Introduction: Once Upon A Time Once Again. In: Ders. (Hg.): The Amazing Transforming Superhero! Essays on the Revision of Characters in Comic Books, Film and Television. Jefferson, North Carolina, and London: McFarland $2007,5-32$.

Wasielewski, Marek: Golden Age Comics. In: Bould, Mark; Butler, Andrew M.; Roberts Adam; Vint, Sherryl (Hg.): The Routledge Companion to Science Fiction. London, New York: Routledge 2009, 62-70.

Weihe, Richard. Die Paradoxie der Maske: Geschichte einer Form. München: Fink 2004.

Weiner, Robert G.: Three Stories, Three Movies and the Romances of Mary Jane and Spider-Man. In: Peaslee, Robert Moses; Weiner, Robert G. (Hg): Web-Spinning Heroics. Critical Essays in the History and Meaning of Spider-Man. Jefferson (North Carolina), London: McFarland 201 2, I66-176.

Weltzien, Friedrich: Masque-ulinities. Changing Dress as a Display of Masculinity in the Superhero Genre. In: Fashion Theory 9:2 (2005), 229-250.

Westfahl, Gary: Masked Avenger. In: The Encyclopedia of Fantasy. Hg. v. John Clute, John Grant. New York: St. Martin’s Press 1997, 629.

Wiener, Oswald: der geist der super-helden [sic]. In: Zimmermann, Hans-Dieter (Hg.): Comic Strips. Vom Geist der Superhelden. Berlin: Gebrüder Mann Verlag I970 (Schriftenreihe der Akademie der Künste 8), 93-I0ı. [Auch in: Etter, Lukas; Nehrlich, Thomas; Nowotny, Joanna (Hg.): Reader Superhelden. Theorie - Geschichte - Medien. Bielefeld: Transcript 20 I 8 (Edition Kulturwissenschaft I 33), 30I-309.]

Wimmer, Michael; Schäfer, Alfred: Einleitung. Zwischen Maskierung und Obszonität. Bemerkungen zur Spur der Masken in der Moderne. In: Schäfer, Alfred; Wimmer, Michael (Hg.): Masken und Maskierungen. Opladen: Leske und Budrich 2000 (Grenzüberschreitungen 3), 9-3 I.

Wright, Bradford W.: Comic Book Nation. The Transformation of Youth Culture in America. Baltimore, London: John Hopkins UP $200 \mathrm{I}$.

Wulff, Hans J.: Konzepte des Motivs und der Motivforschung in der Filmwissenschaft. In: Brinckmann, Christine N.; Hartmann, Britta; Kaczmarek, Ludger (Hg.): Motive des Films. Ein kasuistischer Fischzug. Marburg: Schüren 2012, I3-32.

Wulff, Hans J.: Mehrfachidentitäten, Maskierungen und Verkleidungen als empathisches Spiel. In: Maske und Kothurn 53:2 (2007), I 49-I6I. 
Zirfas, Jörg; Jörissen, Benjamin: Phänomenologien der Identität. Human-, sozial- und kulturwissenschaftliche Analysen. Wiesbaden: VS Verlag für Sozialwissenschaften 2007.

Zirfas, Jörg: Identität in der Moderne. Eine Einleitung. In: Jörissen, Benjamin; Zirfas, Jörg (Hg.): Schlüsselwerke der Identitätsforschung. Wiesbaden: VS Verlag für Sozialwissenschaften 2010, 9-17.

\section{Internetressourcen}

Altus Press, The Pulp Fiction Superstore. URL: https://www.altuspress.com/, Abruf 30. 9. 2018.

Bails, Jerry: Who's Who of American Comic Books I928-I999. 2006. URL: http:// www.bailsprojects.com/whoswho.aspx, Abruf 28. I0. 2018.

Bonner Online-Bibliographie zur Comicforschung. URL: http://www.comicforschung. uni-bonn.de/index.php, Abruf: I 5. I0. 2018.

cbr.com [Comic Book Resources. The World's Top Destination for Comic, Movie \& TV News]. URL: https://www.cbr.com/, Abruf 8. 5. 2018.

ComicVine. URL: https://comicvine.gamespot.com/, Abruf: 29. I0. 20 I 8.

DC Comics. URL: https://www.dccomics.com/, Abruf: 29. I0. 2018.

DC Entertainment. URL: https://www.dcentertainment.com/, Abruf: 29. I0. 20 I 8.

Digital Comic Museum (DCM). URL: http://digitalcomicmuseum.com/, Abruf: з०. ı०. 2018.

Estep, Larry: Online Pulps. URL: https://pulpgen.com/pulp/ Copyright 1998., Abruf 3. 2. 2018.

Grand Comics Database (GCD). URL: https://www.comics.org/, Abruf: ı 8. I०. 20 I 8.

Kannenberg, Gene, Jr.: ComicsResearch.org. Comics Scholarship Annotated Bibliographies. 2000-2010. URL: http://www.comicsresearch.org/, Abruf: 25. I0. 2018.

Lambiek Comix-Strips: Comiclopedia - Illustrated Artist Compendium. I999-. URL: https://www.lambiek.net/comiclopedia.html, Abruf 25. I0. 2018.

Lampkin, William P.: The PulpNet. I996-2018. URL: http://www.thepulp.net/, Abruf 3. 2. 2018.

Markstein, Don: Toonopedia. A Vast Repository of Toonological Knowledge. I99920I I. URL: http://www.toonopedia.com/, Abruf I 5. I०. 20 I 8.

Marvel Comics. URL: https://www.marvel.com/, Abruf 29. I0. 2018.

Murray, Will: Pulp Superhero Index. URL: https://www.altuspress.com/the-ultimatepulp-superhero-index/, Abruf 25. I0. 2018.

Norman Rockwell Museum: Pulp Illustration: Pulp Magazines. In: Illustration History. An Educational Resource and Archive. URL: https://www.illustrationhistory.org/ genres/pulp-illustration-pulp-magazines, Abruf 25. I0. 2018.

Saunders, David: David Saunder's Field Guide to Wild American Pulp Artists. URL: https://www.pulpartists.com/index.html, Abruf: 25. I0. 2018.

Stephensen-Payne, Philip: Galactic Central. URL: http://www.philsp.com/, Abruf 30. IO. 2018.

The Pulp Magazines Project. An Archive of All-Fiction Pulpwood Magazines from I 896-I946. 2010-201 8. URL: https://pulpmags.org/, Abruf 30. I0. 20 I8. 
Tollin, Anthony: The Shadow's Sanctum. URL: http://www.shadowsanctum.com/, Abruf 30. 10. 2018.

Wikipedia - The Free Encyclopedia. URL: https://en.wikipedia.org/wiki/Main_Page, Abruf 30. I0. 2018. 